TE WHARE WĀNANGA O TE ŪPOKO O TE IKA A MĀUI

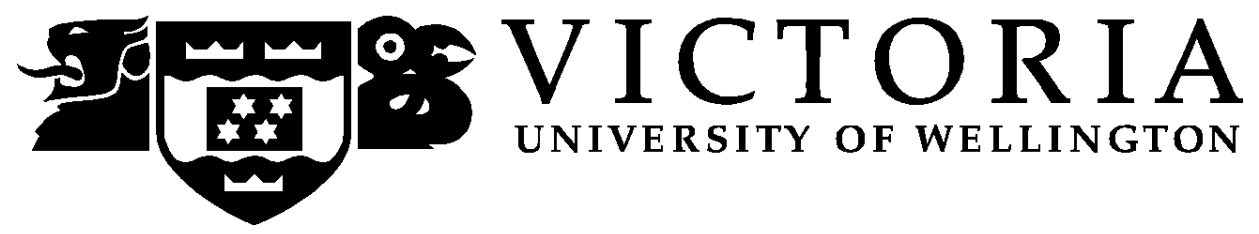

\title{
The Last Glacial Maximum and Deglaciation in Southern New Zealand: New Pollen-climate Reconstructions
}

\section{Sarah Louise Callard}

\author{
A thesis submitted to \\ Victoria University of Wellington \\ in fulfilment of the requirements for the degree of Doctor of Philosophy \\ School of Geography, Environment and Earth Sciences, \\ Victoria University of Wellington, \\ New Zealand
}

July 2011 


\section{Abstract}

The project builds upon existing knowledge of late Quaternary palaeoenvironmental change and tests the recently developed New Zealand INTIMATE (Integration of Ice Marine and Terrestrial archive) climate event stratigraphy (NZ-I CES; 30-8 ka). Four pollen and sediment records from three climatically contrasting regions in the South Island provide a vegetation and climate history for this area between 38-4 ka. In this study, the Last Glacial Cold Period (LGCP; c. 31.4-18.9 ka) is characterised by a two step cooling, with the coldest conditions, reaching possibly $>5.3^{\circ} \mathrm{C}$ cooling, occurring between 21-19 ka, marking the Last Glacial Maximum. A new precipitation proxy using macrophyte pollen concentrations at an eastern South Island site suggests dominantly dry conditions prevailed during the LGCP except for two periods of wetter climate around 26-24 ka and $21 \mathrm{ka}$. The dry periods correspond with evidence of glacial advance, colder environments and possibly increased intensity of the southern westerlies. Conversely, the wet periods coincide with reduced glacial activity, milder climates and decreased westerly wind intensity. Deglaciation began between 18.9-18.4 ka followed by rapid climate amelioration culminating with Dacrydium cuppressinum-dominant lowland forest at western sites as early as $11.9 \mathrm{ka}$, indicative of the start of the Holocene. A disturbance in forest development occurs between 13.4-11.9 ka in one record and may be indicative of a minor cooling within the timeframe of a late glacial climate reversal recognised in the NZI-CES.

Overall the project results (timing and pattern of climate change) broadly align with the NZ-I CES. However, there are some disparities, in particular during the LGCP, which this study suggests began at least 3-4 ka earlier than concluded in the NZ-I CES. The NZ-I CES oversimplifies the complexity of the LGCP which contains evidence of significant climate variability that may be important for an understanding of the possible forcing factors on climate change. The chronology derived from the current study supports recent evidence that points towards a younger, refined age of 25.4 ka for the Kawakawa/Oruanui Tephra, a key chronostratigraphic marker for the LGCP. Pollen-climate models and 
Environmental Lapse Rates were used to quantify changes in mean annual temperatures with sometimes conflicting results. This research reveals some limitations of the current New Zealand pollen-climate transfer function when applied to reconstruction of cold climate periods in particular. These include a lack of limitations with modern analogues and a number of wide-ranging pollen taxa that encompass a broad climate envelope. The current research also highlights the potential of regional climate regimes and spatial differences in vegetation and inferred climate reconstructions. These differences pose a major limitation for a New Zealand-wide composite. While the NZ-I CES provides a valuable framework of climate change during a period of large climate variability, results of this study highlight aspects that need further consideration and revision. 


\section{Acknowledgements}

So many people have helped me throughout my PhD and I would like to thanks them all, but certain individuals deserve special mention. First and foremost, I express my deepest gratitude to Professor Rewi Newnham and Dr Marcus Vandergoes, my two supervisors, for their constant guidance, discussions, patience and encouragement throughout the thesis. I also want to thank Rewi for allowing me to join him at Victoria University of Wellington and to his family's kindness when I first arrive. Advice given from Professor Roland Gehrels and Dr. Ralph Fyfe from the University of Plymouth was most useful during the early stages of the project. Thanks go to the University of Plymouth and Victoria University of Wellington for the support and PhD scholarships. Also to NERC for funding the radiocarbon ages of two cores.

I am grateful to Dr Maureen Marra from the University of Waikato, for inviting to Howard Valley and the opportunity to jointly work on this site. Thanks also go to Matt Ryan, Sam Kelly and Dr Brent Alloway for help in the field. A number of people have been integral for the completion of the lab work. Recognition goes to the University of Plymouth geography technical staff, Richard Hartley, Debbie Bauckham, and Kev Solman for all their help. Special thanks go to Dr. Katie Price for her expert knowledge of the pollen preparation process. I am also appreciative to Dr. Mark Garnett for his advice and help with the radiocarbon dating. I am indebted to $\mathrm{Dr}$ Janet Wilmshurst from Landcare Research whose expertise in the pollen-climate reconstruction was integral for this project. Also my appreciation extends to Matt McGlone and Neville Moar for their help in pollen identification and informative discussions during my brief visits at Landcare Research, and to Andrew Mackintosh for his advance on ELR. I would also like to thank Charlotte Moll, who carried out Loss on Ignition and Particle Size Analysis on the Lake Mudgie record for her BSc (hons) dissertation.

My appreciated extends to the postgraduate community at both the University of Plymouth and Victoria University of Wellington. In particularly I want to thank Katrin Sattler, Nick Mulcahy, Beth Risdon and my office buddies for their support and friendship and for proofing my work. I am also grateful to Mary and Jamie Mulcahy who made sure I was well fed during the final months. Finally, I wish to thank my family for their constant support. They have been a steady rock under my feet throughout and without their love and guidance the completion of this thesis would not have been possible. 


\section{Contents}

$\begin{array}{lr}\text { Abstract } & \text { i } \\ \text { Acknowledgements } & \text { iii } \\ \text { Contents } & \text { iv } \\ \text { List of Figures } & \text { ix } \\ \text { List } \text { of Tables } & \text { xii } \\ \text { List } \text { of Abbreviations } & \text { xiv }\end{array}$

1 Introduction and Rationale 1

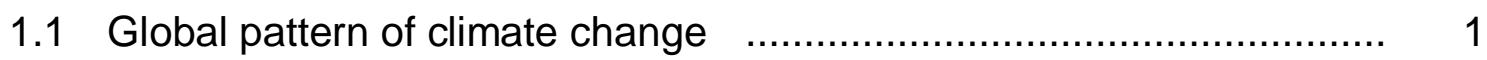

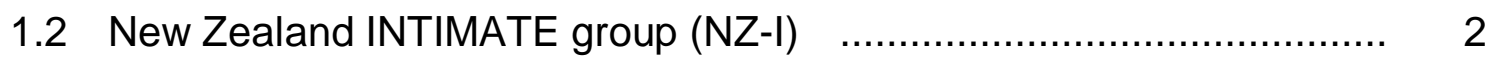

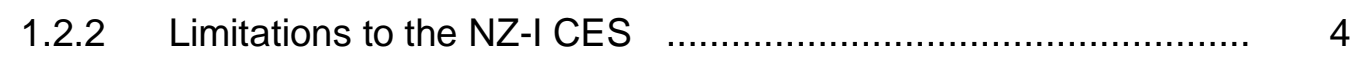

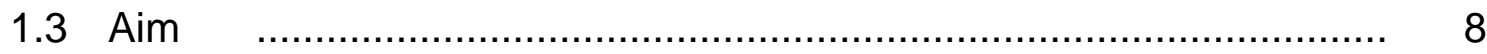

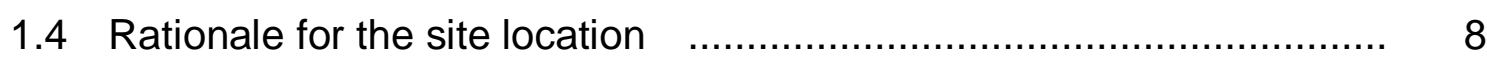

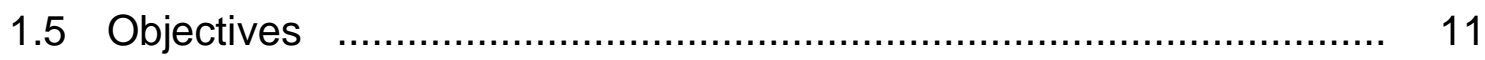

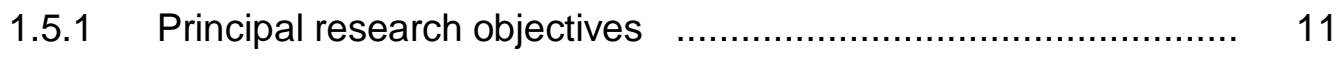

2 Background 13

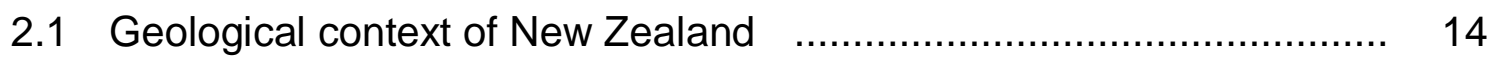

2.2 Late Cenozoic history of New Zealand f....................................... 17

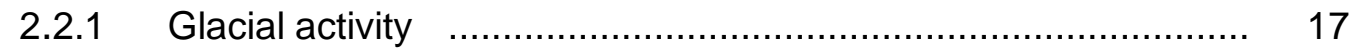

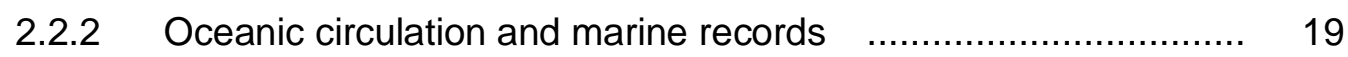

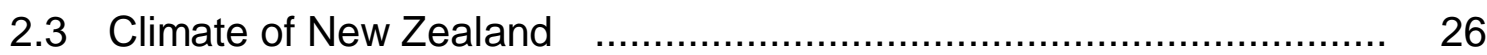

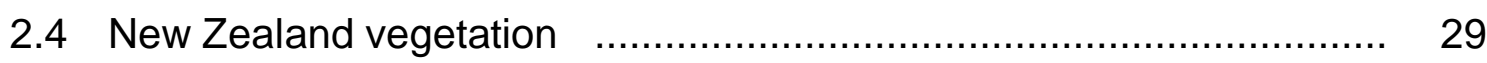

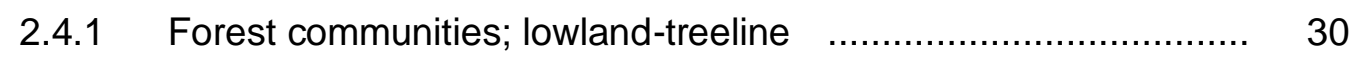

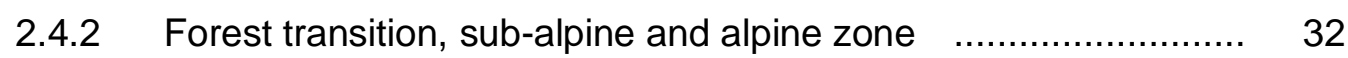

2.5 Cenozoic vegetation history of New Zealand: overview $\quad$................. 32

2.5.1 Palaeogene/Neogene …................................................. 33

2.5.2 Quaternary (past 2.58 Ma) …........................................ 34

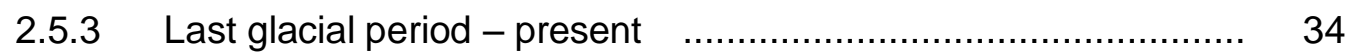

2.6 South Island proxy records spanning the late Quaternary

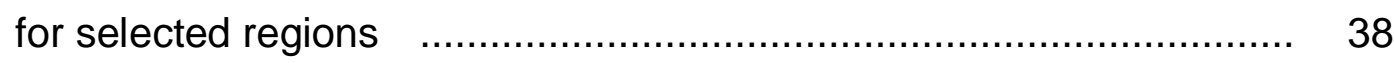


2.6.1 Westland ......................................................................... 38

2.6.2 Nelson and Malborough regions of northern South Island f....... 44

2.6.3 Central Canterbury - Mackenzie Basin ……...................... 49

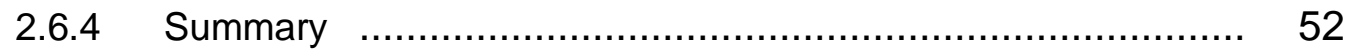

3 Methodology $\quad 54$

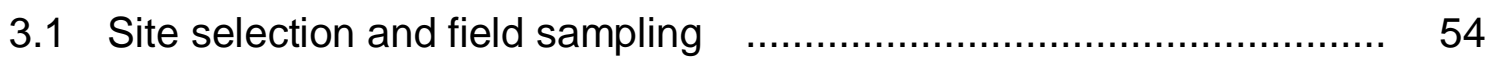

3.2 Pollen procedure …................................................................ 56

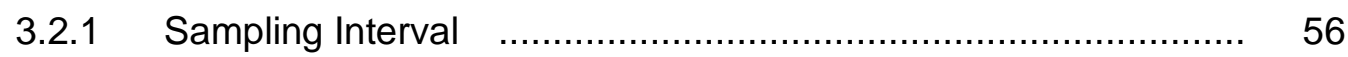

3.2.2 Pollen preparation .............................................................. 56

3.2.3 Pollen counting and identification .......................................... 58

3.3 Pollen analysis ...................................................................... 59

3.3.1 Pollen percentages and concentrations …………………..... 59

3.3.2 Pollen diagram and cluster analysis …………....................... 60

3.3.3 Principle Component Analysis.................................................. 61

3.3.4 Environmental Lapse Rate …………………………....... 63

3.3.5 Quantitative pollen-climate modelling ……………................. 64

3.4 LOI and Particle Size Analysis ...................................................... 73

3.5 Chronological method ............................................................. 75

3.5.1 Radiocarbon Dating ....................................................... $\quad 75$

3.5.2 Tephrochronology methodology …………………………... 77

4 Lake Mudgie $\quad 80$

4.1 Regional setting …........................................................... $\quad 80$

4.1.1 Geological setting ………………………………....... 81

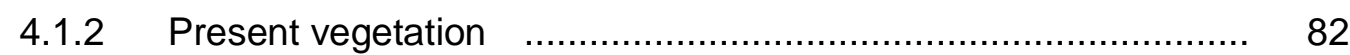

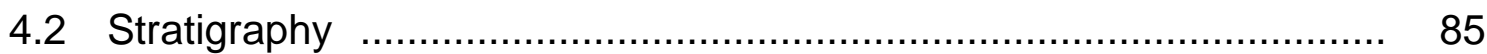

4.3 Chronology .................................................................... 88

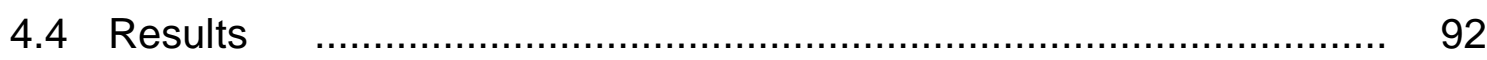

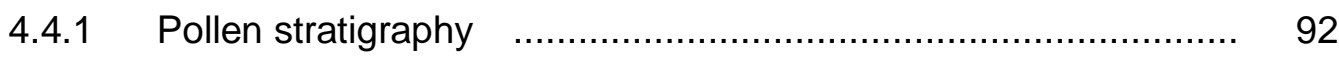

4.4.2 Particle Size Analysis ………………………………......... 99

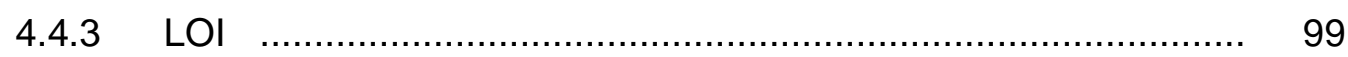

4.4.4 Temperature reconstructions ……………………................. 100

4.4.5 Principal Component Analysis ............................................. 101

4.5 Discussion ...................................................................... 110 


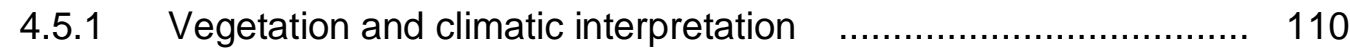

4.5.2 Summary Discussion f............................................... 123

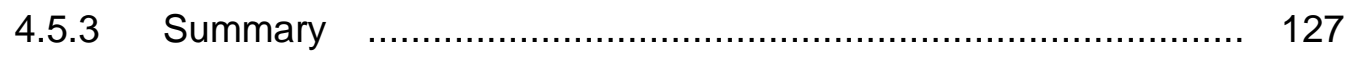

5 Manks Tarn $\quad 129$

5.1 Manks Tarn site description $\quad$................................................... 129

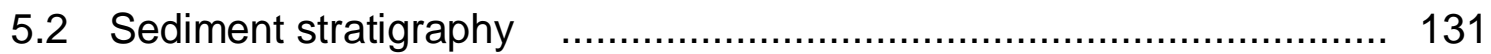

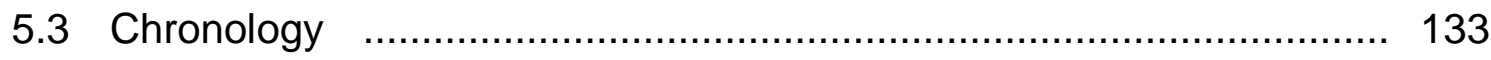

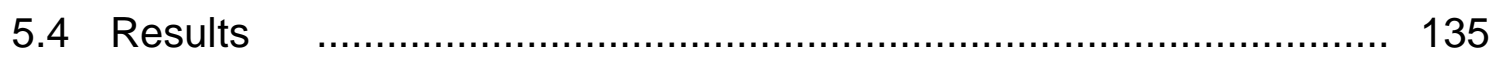

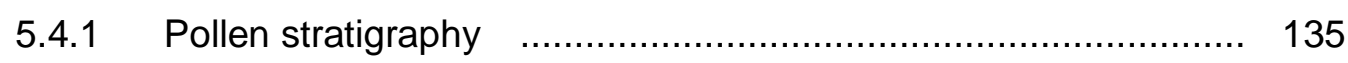

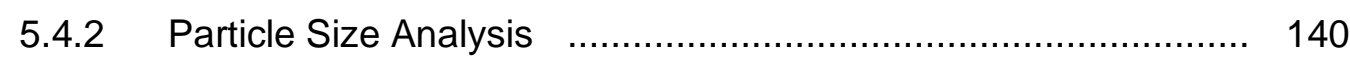

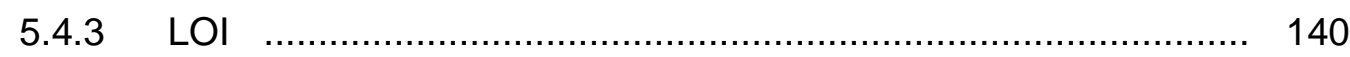

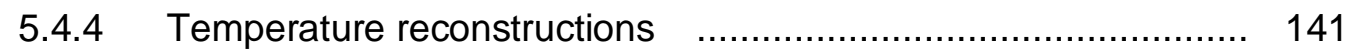

5.4.5 Principle Component Analysis ......................................... 141

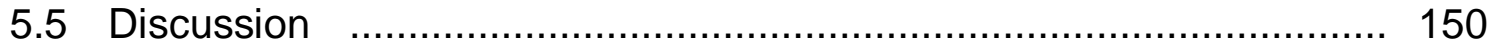

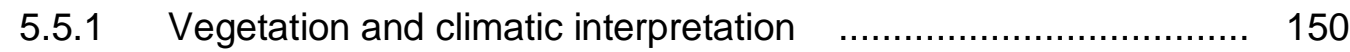

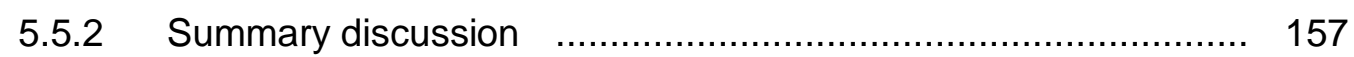

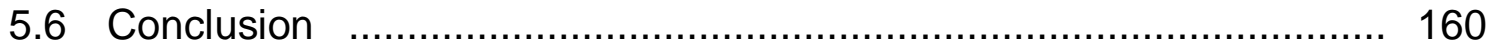

6 Howard Valley 162

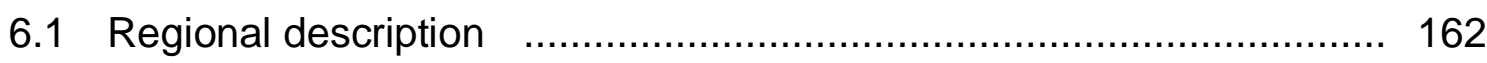

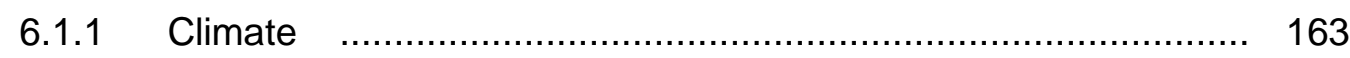

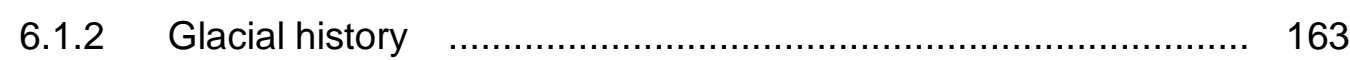

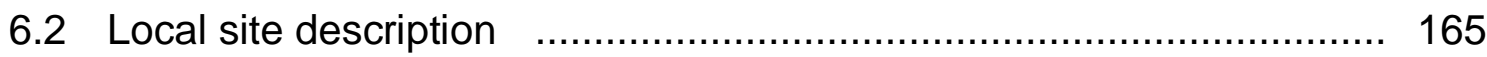

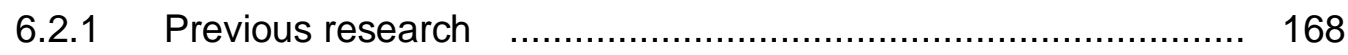

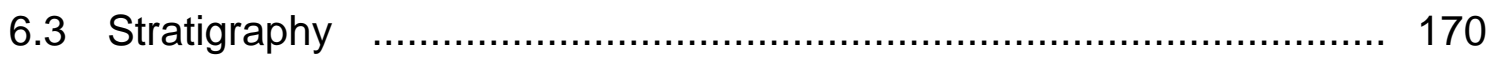

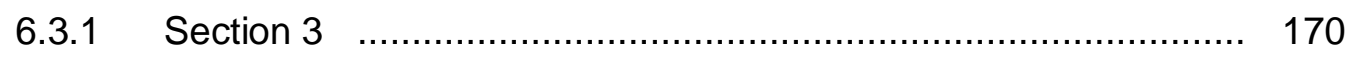

6.3.2 Section 2 …........................................................... 173

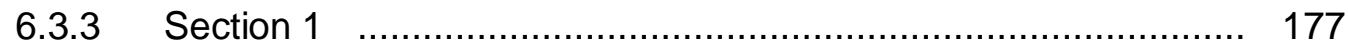

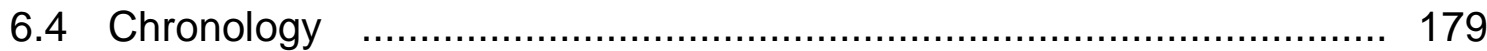

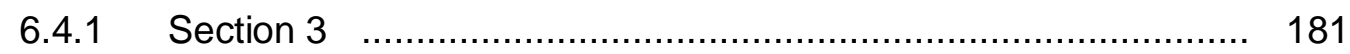

6.4.2 Section 2 .................................................................. 182

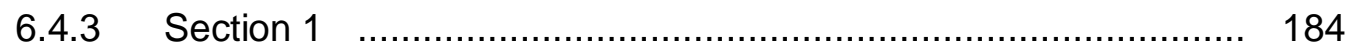

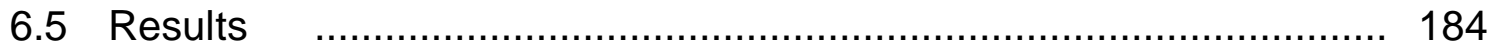

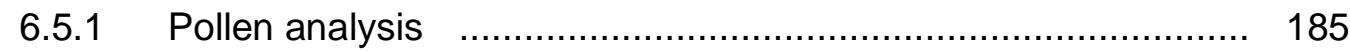




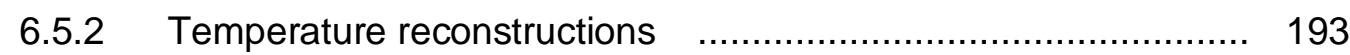

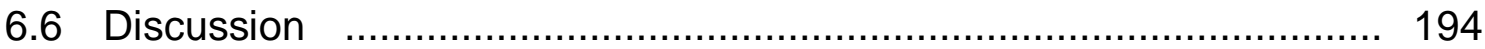

6.6.1 Pre-LGCP: Section 3 (37.7- 28.5 ka) ............................... 194

6.6.2 Pre-LGCP: Climate reconstruction f................................... 196

6.6.3 LGCP: Section 2 and 1 vegetation interpretation (25.6- $18.9 \mathrm{ka}) .197$

6.6.4 LGCP: Climate reconstruction f........................................ 199

6.6.5 Quantitative pollen/climate reconstructions f....................... 199

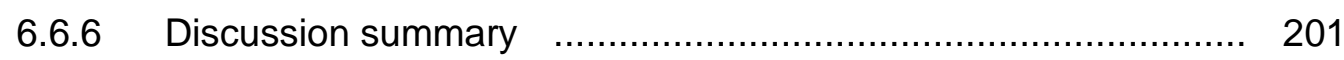

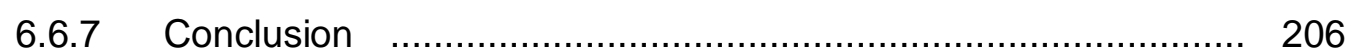

7 Forks Lagoon $\quad 208$

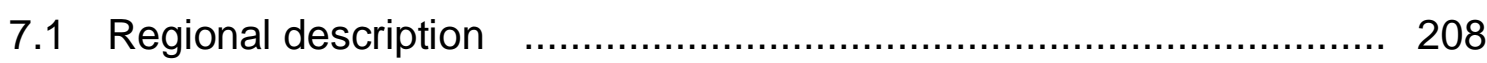

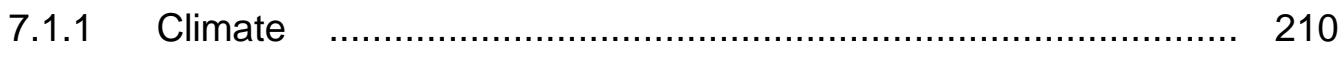

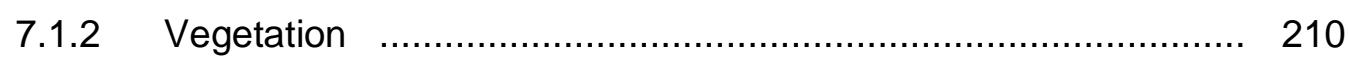

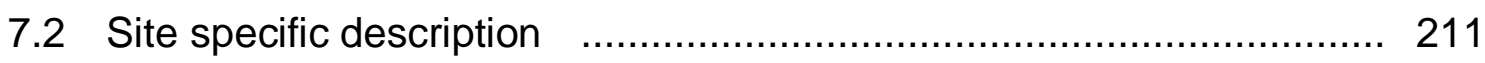

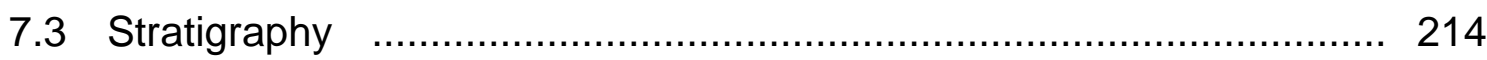

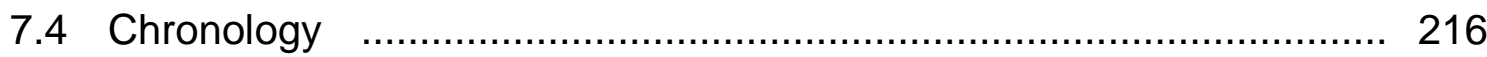

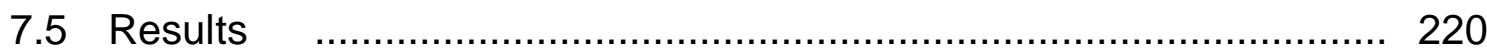

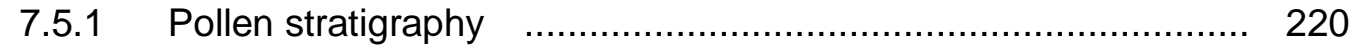

7.5.2 Particle Size Analysis f................................................... 225

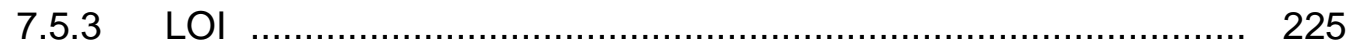

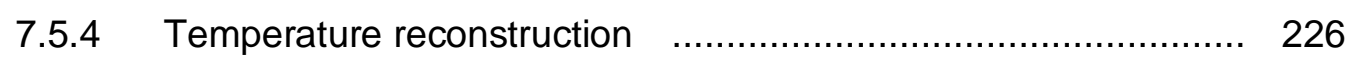

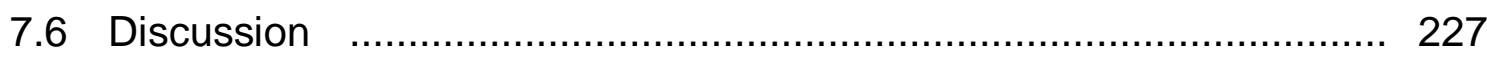

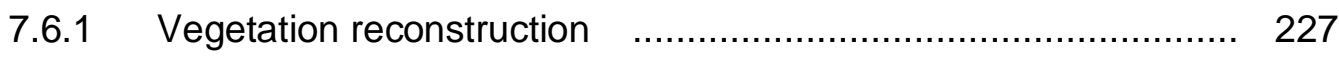

7.6.2 Aquatic macrophyte and sediment records f........................ 228

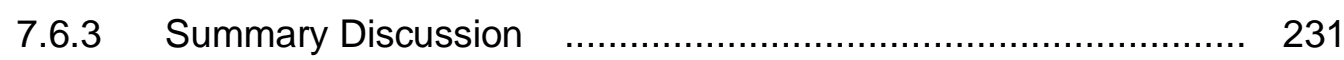

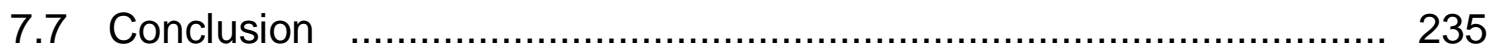

8 Discussion 236

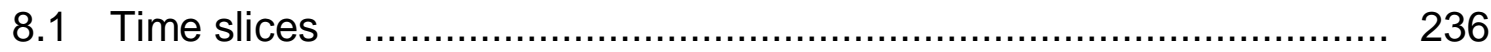

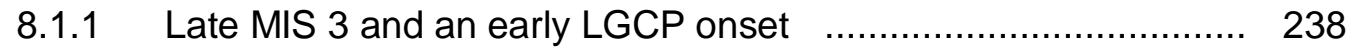

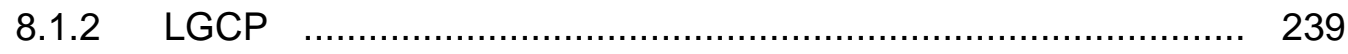

8.1.3 Termination I f......................................................... 246

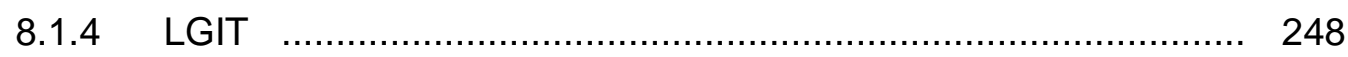

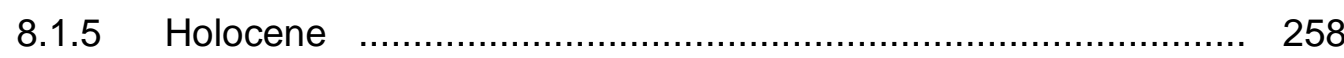




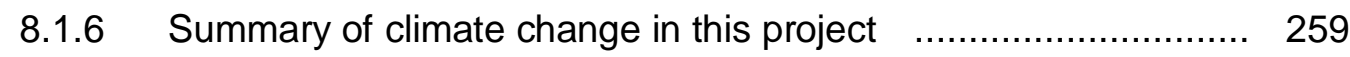

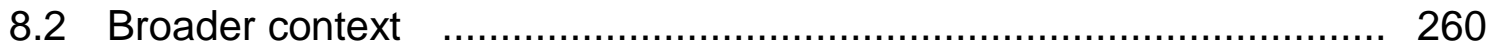

8.2.1 Chronology and age models ............................................. 261

8.2.2 The age of the KOT layer f................................................. 263

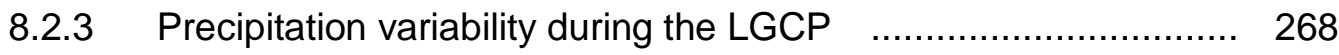

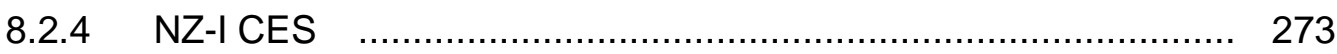

8.2.5 Quantitative pollen-climate reconstruction $\ldots \ldots \ldots \ldots \ldots \ldots \ldots \ldots \ldots . . . . \ldots \ldots$

9 Conclusion and future work 288

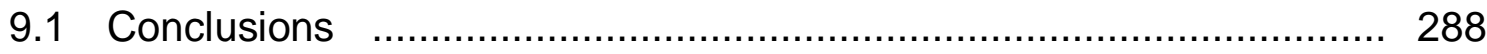

9.2 Future work f................................................................ 291

9.2.1 Project specific recommendations f..................................... 291

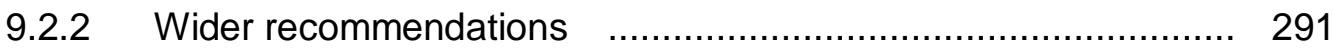

References 293

Appendices 323 


\section{List of Figures}

1.1 A collation of simplified summary palaeoclimate diagrams from sites around New Zealand.

1.2 South Island New Zealand showing the location of the four sites.

2.1 A simplified location map of the major tectonic activity in New Zealand.

2.2 The current location of the different surface water masses and their bounding and their bounding oceanic fronts.

2.3 Mean Annual Temperature (MAT) and precipitation (MAP) maps of the South Island.

2.4 The different rainfall anomalies during different climate regimes for each rainfall region.

2.5 Summary diagram of LGM vegetation in New Zealand. 36

2.6 Location map of the Westland sites. 39

2.7 Location map of the north South Island sites.

2.8 Location map of the pollen sites used in the description of past vegetation change.

3.1 Examples of the coring technique. 55

3.2 Methodological flowchart for pollen sample preparation. 57

3.3 Location map of the current modern sites used in Wilmshurst et al (2007). .... 72

3.4 Sieving separation methodology used to extract pollen for radiocarbon dating.

4.1 Location map of Lake Mudgie.

4.2 Coring on the surface of Lake Mudgie.

4.3 Stratigraphic illustration of the three thrusts analysed with the core images beside each corresponding illustration.

4.4 Age depth model for Lake Mudgie using calibrated ages. ............................. 91

4.5 Lake Mudgie pollen percentage diagram. $\quad$................................................. 97

4.6 Lake Mudgie PCA results for selected taxa. ......................................... 103

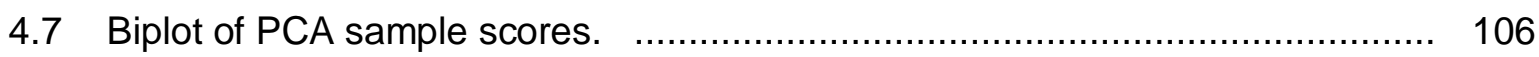

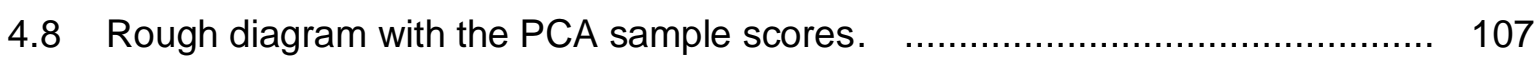

4.9 Lake Mudgie PCA results for selected taxa and sedimentology results. .......... 109

5.1 Location map of Manks Tarn. 
5.2 Image of Manks Tarn.

5.3 Core images from Manks Tarn. …............................................................ 132

5.4 An age-depth model for Manks Tarn. ............................................... 134

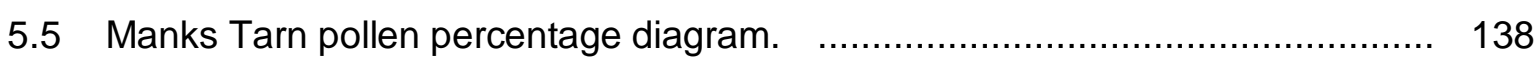

5.6 Manks Tarn PCA results for selected taxa. …............................................. 143

5.7 The PCA results for each Manks Tarn sample. …..................................... 145

5.8 Manks Tarn pollen and sediment results. ................................................ 148

5.9 Manks Tarn PCA results for selected taxa and sediment characteristics. ........ 149

6.1 Map showing the ice limits during glacial periods in the Lake Rotorua and Howard Valley region during the late Quaternary period. ....................... 164

6.2 Image of Howard Valley - section 1. ..................................................... 162

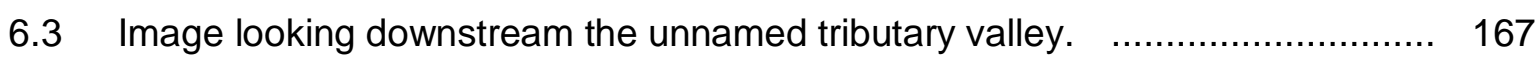

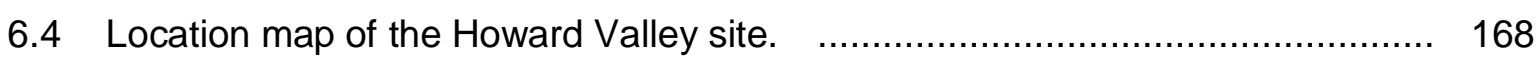

6.5 Detailed stratigraphy and photographic image of Howard Valley - section 3. 172

6.6 Detailed stratigraphy and photographic image of Howard Valley - section 2. 176

6.7 Detailed stratigraphy and photographic image of Howard Valley - section 1. 178

6.8 Age depth model for Howard Valley - section 3. ....................................... 182

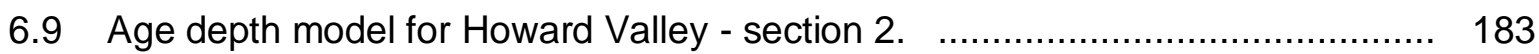

6.10 Age depth model for Howard Valley - section 1. ....................................... 184

6.11 Pollen percentage diagram for Howard Valley - section 3. ........................... 187

6.12 Pollen percentage diagram for Howard Valley - section 2. ........................... 190

6.13 Pollen percentage diagram for Howard Valley - section 1. ............................ 192

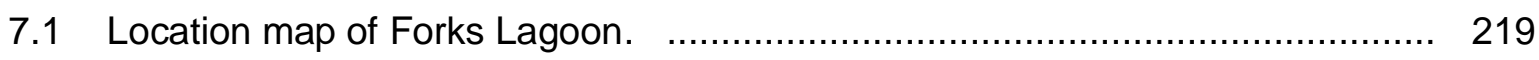

7.2 Map showing the location of moraines and their assumed ages around the site location.

7.3 Aerial photographic image of Forks Lagoon showing the location of the ephemeral stream at the southern end of the Lagoon. $\ldots \ldots \ldots \ldots \ldots \ldots \ldots \ldots . . . . . . . . . . . .213$

7.4 Image of Forks Lagoon taken from the south-west/ looking north-east. $\quad$.......... 213

7.5 Stratigraphy cores for this project with calibrated age and tie point. $\quad \ldots \ldots \ldots \ldots \ldots \ldots . . . . . .215$

7.6 Age-depth model using calibrated radiocarbon ages for Forks Lagoon. ......... 219

7.7 Relative percentage pollen diagram of Forks Lagoon with the core colour stratigraphy and sediment analysis added. …......................................... 222

7.8 Pollen concentrations of the two aquatic taxa and total dry land pollen. .......... 224

7.9 A simplified core description showing the location of the colour bands and their relationship with the LOI. 
8.1 An overview of the timing of climate change recorded in the four records of this project.

8.2 Comparison of Lake Mudgie and Manks Tarn LGIT vegetation pattern.

8.3 Calibrated radiocarbon ages for each site 265

8.4 Comparison of three Forks Lagoon age depth models.

8.5 Comparison of proxy records from around New Zealand and the macrophyte record of Forks Lagoon.

8.6 Onset of the LGCP at Okarito. 275

8.7 Comparison between the PLS-C3 MAT reconstruction and Phyllocladus alpinus and Fuscospora pollen abundance. 


\section{List of Tables}

1.1 A summary of the timing of the key climate events in New Zealand terrestrial and marine records.

2.1 Names and timing of the glacial and interglacial periods from terrestrial evidence in New Zealand related to the Marine Isotope Stages.

3.1 Model outputs for the different models used in the Transfer function and Modern Analogue Technique.

4.1 Radiocarbon age details for Lake Mudgie.

4.2 Taxon comprising the Lake Mudgie PCA groups with their represented vegetation communities.

4.3 A table comparing the depths of the pollen assemblage zones to the depths of the sample groups.

4.4 A summary table of the vegetation and climate reconstruction for the Lake Mudgie pollen assemblage zones.

5.1 Radiocarbon age details for Manks Tarn.

5.2 Species list for each Manks Tarn group recognised by the PCA results and split into different vegetative components.

5.3 A table comparing the depths of the pollen assemblage zones to the depths of the sample groups.

5.4 A summery table of the vegetation and climate reconstruction for the different pollen assemblage zones.

6.1 Radiocarbon age details for Howard Valley.

6.2 A summary table of the vegetation and climate reconstruction for Howard Valley pollen assemblage for section 1-3.

7.1 Radiocarbon age details for Forks Lagoon.

7.2 Summary table of the vegetation and climate reconstructions for Forks Lagoon. 
8.1 Summary table comparing the timing of climate transitions and millennial scale events between the four project records and the NZ-I CES.

8.2 Comparison of ELR and quantitative pollen/temperature model MAT estimates 281 


\section{List of Abbreviations}

\begin{tabular}{|c|c|}
\hline AAA & Acid-Alkali-Acid \\
\hline ACC & Antarctic Circumpolar Current \\
\hline ACR & Antarctic Cold Reversal \\
\hline AMS & Accelerated Mass Spectrometry \\
\hline $\mathrm{BP}$ & Before present \\
\hline $\mathrm{D}-\mathrm{O}$ & Dansgaard-Oeschger \\
\hline ELA & Equilibrium-Line Altitude \\
\hline ELR & Environmental Lapse Rate \\
\hline ENSO & El Niño-Southern Oscillation \\
\hline EPICA & European Project for Ice Coring in Antarctica \\
\hline ESI & East South Island \\
\hline GISP2 & Greenland Ice Sheet Project 2 \\
\hline GRIP & Greenland Ice Core Project \\
\hline INTIMATE & Integration of Ice Marine and Terrestrial archives \\
\hline IPO & Inter-decadal Pacific Oscillation \\
\hline ITCZ & Inter-Tropical Convergence Zone \\
\hline KOT & Kawakawa/Oruanui tephra \\
\hline LGCP & Last Glacial Cold Period \\
\hline LGIT & Last Glacial/Interglacial Transition \\
\hline LGM & Last Glacial Maximum \\
\hline LGR & Late Glacial Reversal \\
\hline LOI & Loss on Ignition \\
\hline MAP & Mean Annual Precipitation \\
\hline MAT & Mean Annual Temperature \\
\hline MIS & Marine Isotope Stage \\
\hline NGRIP & North Greenland Ice core Project \\
\hline $\mathrm{NNI}$ & Northern North Island \\
\hline NSI & Northern South Island \\
\hline NZ-I & New Zealand INTIMATE group \\
\hline NZ-I CES & New Zealand INTIMATE Climate Event Stratigraphy \\
\hline ODP & Ocean Drilling Project \\
\hline OSL & Optically Stimulated Luminescence \\
\hline PC & Principal Component Axes \\
\hline PCA & Principle Component Analysis \\
\hline PLS & Partial Least Squares Regression \\
\hline PSA & Particle Size Analysis \\
\hline RMSE & Root Mean Square Error \\
\hline RMSEP & Root Mean Square of Predictions Error \\
\hline SAW & Sub-Antarctic Surface Waters \\
\hline SNI & Southern North Island \\
\hline SSS & Sea Surface Salinity \\
\hline SST & Sea Surface Temperature \\
\hline STF & Sub-Tropical Front \\
\hline
\end{tabular}


STW

TDP

TVZ

W-MAT

WSI

YDC
Sub-Tropical Surface Waters

Total Dry Land Pollen

Taupo Volcanic Zone

Weighted Modern Analogue Technique

West South Island

Younger Dryas Chronozone 


\section{Chapter 1: Introduction and Rational}

\subsection{Global pattern of climate change}

It is now generally accepted that changes in the Earths orbital geometry are a major driver of climate change, and the glacial/interglacial cycles observed during the Quaternary (past c. $2.58 \mathrm{Ma}$, Gibbard et al, 2010; Imbrie and Imbrie, 1979). Since c. $700 \mathrm{ka}$ a $100 \mathrm{ka}$ eccentricity/precision dominated glacial/interglacial cycle is recorded globally (Imbrie and Imbrie, 1979; Huybers and Wunsch, 2005; Liu et al, 2008) with a major assumption that the global pattern of climate change occurs synchronously between the hemispheres. Indeed, this has been validated by ice core records (North Greenland Ice Core Project (NGRIP) members, 2004; EPICA community members, 2006) deep-sea records (Kitamura and Kanoto, 2007; Crundwell et al, 2008; Herbert et al, 2010) and terrestrial archives (Sun et al, 2005; Prokopenko et al, 2009). However, superimposed upon the astronomical global cycles are numerous millennial scale, abrupt climate oscillations which point towards a phasing of climate change between the poles (North Greenland Ice Core Project members, 2004; EPICA community members, 2006).

GRIP (Greenland Ice Core Project; Dansgaard et al, 1993; Johnsen et al, 2001) and GISP2 (Greenland Ice Sheet Project 2; Grootes et al, 1993) ice core records have shown the existence of numerous millennial-scale climate oscillations. Between 110-14 ka, 25 Dansgaard/Oeschger events (D-O events), periods of abrupt warming to interstadial conditions over a few centuries followed by gradual cooling to glacial temperatures, have been identified (Dansgaard et al, 1993; Grootes et al, 1993; Johnsen et al, 2001; NGRIP members, 2004). Likewise, similar warming events have been identified in Antarctic ice core records (EPICA community members, 2004). However, the pattern and timing of these events between the poles appear to be out of phase with each other. This elucidated that an asynchronous millennial scale pattern of climate change is controlled by variations in the oceanic hydrological circulations through the bipolar seesaw effect (EPICA community members, 2006). 
The precise link between the hemispheres is still uncertain with the idea of asynchronous phasing of millennial scale climate change remaining controversial (Alley et al, 2002; Schmittner et al, 2003; Huybers, 2004; Alley, 2007). The Last Glacial Maximum (LGM) and Last Glacial/Interglacial Transition (LGIT) provide a valuable testing point for assessing the pattern of global climate change. Modelling efforts for this period have helped to clarify the pattern as the outputs show the bipolar ice-core signals can be accurately reproduced using various modelling techniques (Stocker, 2000; Stocker and Johnsen, 2003; Schmittner et al, 2003; Knutti et al, 2004). This bipolar seesaw pattern is not restricted to ice core records with evidence suggesting the pattern extends into the mid-latitudinal regions as well. The Global mulitiproxy data set indicates a globally (near) synchronous ice age cycle with a superimposed north-south millennial bipolar see-saw pattern (Pahnke et al, 2003; Lamy et al, 2004 Pahnke and Zahn, 2005). However, there is uncertainty and conflicting evidence from mid-latitude sites with some records observing synchronous climatic oscillations to the Northern Hemispheric signal (e.g. Denton and Hendy, 1994; Ivy-Ochs et al, 1999) or slightly offset from the Northern Hemisphere signal (e.g. McCulloch et al, 2000). The paucity of results and controversial observations makes it difficult to assess the nature and extent of any asynchronous interhemispheric pattern of climate within the Southern Hemisphere mid-latitudes. There is, therefore, a need to increase the reliability and robustness of the proxy climatic reconstructions for the Southern Hemisphere and to produce regional climatic stratigraphies of the last glacial period before answers to the nature and pattern of interhemispheric pattern of climate change can be tackled with any certainty. The New Zealand INTIMATE (INTegration of Ice core Marine and Terrestrial archives) group was set up in 2003 to accomplish just that.

\subsection{New Zealand INTIMATE group (NZ-I)}

New Zealand is a temperate, sub-continental, oceanic island located in the south east Pacific Ocean. It lies in the path of the southern westerly zonal winds, the strongest mean oceanic winds in the world driving the deep Antarctic Circumpolar Current (ACC) eastwards around the Antarctic continent, and pushing surface waters away from Antarctica causing upwelling of intermediate water south of the 
ACC (Russell et al, 2006). The westerlies link climatic processes of New Zealand with those from the Antarctic domain. This provides potential to examine any Antarctic influence on New Zealand and therefore the Southern Hemispheric mid latitudes (Sugden et al, 2005). New Zealand's glaciers, vegetation and fauna have been observed to respond quickly to climate change. These responses have been preserved with palaeoenvironmental records capturing and ageing any climate transitions and millennial scale events (Vandergoes and Fitzsimons, 2003). New Zealand is also one of the few land masses located within the oceanic dominant Southern Hemisphere. Therefore terrestrial climate records can be compared and related to marine and ice-core records. New Zealand therefore holds an important strategic location for providing palaeoclimatical information and for assessing the pattern of climate change for the region. Even so there are still relatively few records that span the Last Glacial Maximum (LGM) and the Last Glacial/Interglacial Transition (LGIT). However, the NZ-INTIMATE (NZ-I) group identified key onshore and offshore proxy climate reconstructions, which were used to produce the NZ-INTIMATE climate event scheme (from now on known as NZ-I CES).

The NZ-I group focused on the period spanning 30-8 ka to encompass the onset of the coldest part of the last glacial up to the early Holocene epoch, a period of known large climate variability. (Alloway et al, 2007; Lowe et al, 2008). This project included seven high resolution continuous proxy records from Auckland Maars, Kaipo, Otamangakau wetlands, Okarito wetland, two speleothem records from northern Westland and the marine core MD97-2121 record (Figure 1.1). Numerous fragmentary records from glacial and fluvial sequences, loess deposits and aeolian quartz accumulations were used to aid the production of the NZ-I CES. Three distinct climate phases where recognised: the last glacial cold period (LGCP) spanning 28-18 ka and includes the Last Glacial Maximum (LGM, 21-18 ka); the Last Glacial/Interglacial Transition (LGIT, 18-11.5 ka) and the Holocene warm epoch (11.5 ka to present). However, superimposed upon these temporally long climate transitions are millennial scale climatic oscillations including the warm and variable climate interval during the LGCP $(27-21 \mathrm{ka})$, and the Late Glacial Reversal (LGR 15-11.5, Figure 1.1). The timing of these climatic changes appears to closely follow an Antarctic pattern and timing (EPICA Community Members, 
2006; Alloway et al, 2007). The timing of the onset of the LGCP and the LGR, as concluded by the NZ-I group, appear to occur asynchronously to their Northern Hemispheric counterparts. However, this is only a provisional scheme and the NZI group recognises the need to improve upon the results by the addition of more high resolution, chronologically robust records that incorporate new methodologies such as quantitative pollen-climate reconstructions and refinement to glacial records (Alloway et al, 2007).

\subsubsection{Limitations to the NZ-I CES}

The provisional NZ-I CES has produced a useful model of climate change in New Zealand for the past $30 \mathrm{ka}$. The process of synthesising multiple records to produce a single CES is not straightforward, however, the NZ-I CES has provided a useful CES that can be tested. Nevertheless, there are some limitations with the provisional NZ-I CES and areas that can be improved. These are discussed further below.

A limited number of high resolution, continuous records spanning the LGCP are available in New Zealand and therefore in the NZ-I CES. Of the continuous records used, only five extend beyond the LGM. As such the robustness of the hypothesised CED is restricted. The records used for this period also show some uncertainties regarding the timing of climate periods and millennial scale climate oscillations (Table 1.1). For instance the timing of the LGCP onset and the pattern or existence of the LGCP warmer variable period is not clear (refer to Table 1.1; Alloway et al, 2007). An increase to both the fragmentary and continuous records that span the LGCP would help produce a more accurate and robust conclusion of climate change during this period.

The Late Glacial Reversal (LGR) is a controversial climate event in New Zealand (refer to section 2.5.3). and as a consequence makes it a difficult event to constrain in the NZ-I CES. Nevertheless the NZ-I CES concluded that the LGR occurred between 13.5-11.6 ka. However, following closer inspection of the records used by the NZ-I group, both the continuous (Table 1.1) and fragmentary records do not so clearly constrain the timing of the LGR and an overall age range 
of this event spans $15-11 \mathrm{ka}$. This is significant as the concluded 13.5-11.6 ka age is suggestive of an asynchronous 'Antarctic' timing of climate change for New Zealand. However the 15-11 ka age would include both an Antarctic Cold Reversal (ACR) and Younger Dryas chronozone (YDC) timing (Alloway et al, 2007) making conclusions, as to whether New Zealand follows an Antarctic or Greenland pattern of change, difficult to elucidate convincingly. For this event, higher resolution records that have better age constraint is needed to aid the NZ-I CES and refine the timing of the LGR.

Recent research by Kidson (2000) and Lorrey et al (2007) have elucidated that New Zealand can be separated into modern climate regions. The AustralasianINTIMATE meeting in June 2008 (Vandergoes and Barrell, 2008) suggest that this could also be applied to the NZ-I CES. However, as already mentioned there is a paucity of sites used in the project, particularly in the South Island, which can be split into three climate regions, but currently only one climate region with continuous proxy records is used in the CES. Therefore, to achieve a more rounded regional picture of the different climate zones New Zealand an increase in reliable sites, for the South Island in particular, is required.

In summary, although the preliminary NZ-I CES has made the best of the available data, there are still some limitations with the CES. There is a paucity of high resolution terrestrial records used in the NZ-I CES, particularly from the South Island and during the LGCP. There is also uncertainty concerning some important climate transitions and oscillations including:

- Timing of the onset of the LGCP.

- Climate variability patterns during the LGCP.

- Timing and duration of the LGR.

It will also be useful to more robustly confirm the following:

- Timing of Termination 1.

- The timing of the Holocene.

- Pattern of climate change during the deglaciation. 


\begin{tabular}{|c|c|c|c|c|c|c|}
\hline Record & $\begin{array}{l}\text { LGCP } \\
\text { onset }\end{array}$ & $\begin{array}{c}\text { LGCP } \\
\text { 'warming } \\
\text { complex' }\end{array}$ & $\begin{array}{c}\text { Termination } \\
\text { I }\end{array}$ & LGR & $\begin{array}{c}\text { Early-Holocene } \\
\text { warm period }\end{array}$ & $\begin{array}{c}\text { Mid-Holocene } \\
\text { warm period }\end{array}$ \\
\hline $\begin{array}{l}\text { Auckland } \\
\text { Maars }\end{array}$ & $27-28$ & $21-27$ & $18-19$ & $11-14$ & $10-11$ & 6.2 \\
\hline Kaipo & - & - & 18 & $12.4-13.8$ & 11 & - \\
\hline Speleothem & 26 & $21-24$ & 17.9 & $11.6-13.5$ & $10.8-11.6$ & $6.5-6.8$ \\
\hline Okarito & $28-29$ & $21-27$ & 18 & $11-15$ & $11-12$ & - \\
\hline MD97-2121 & ca 27 & - & 18 & $\begin{array}{c}11.5-13.7 \\
\text { (surface water) } \\
12.5-14.1 \\
\text { (bottom waters) }\end{array}$ & $\begin{array}{l}\text { 7.9-9.0 SST- } \\
\text { alkenone }\end{array}$ & - \\
\hline
\end{tabular}

Table 1.1: A summary of the timing of the key climate events in New Zealand terrestrial and marine records. All ages are expressed as ka unless otherwise stated and SST = Sea Surface Temperatures (taken from Alloway et al, 2007). 


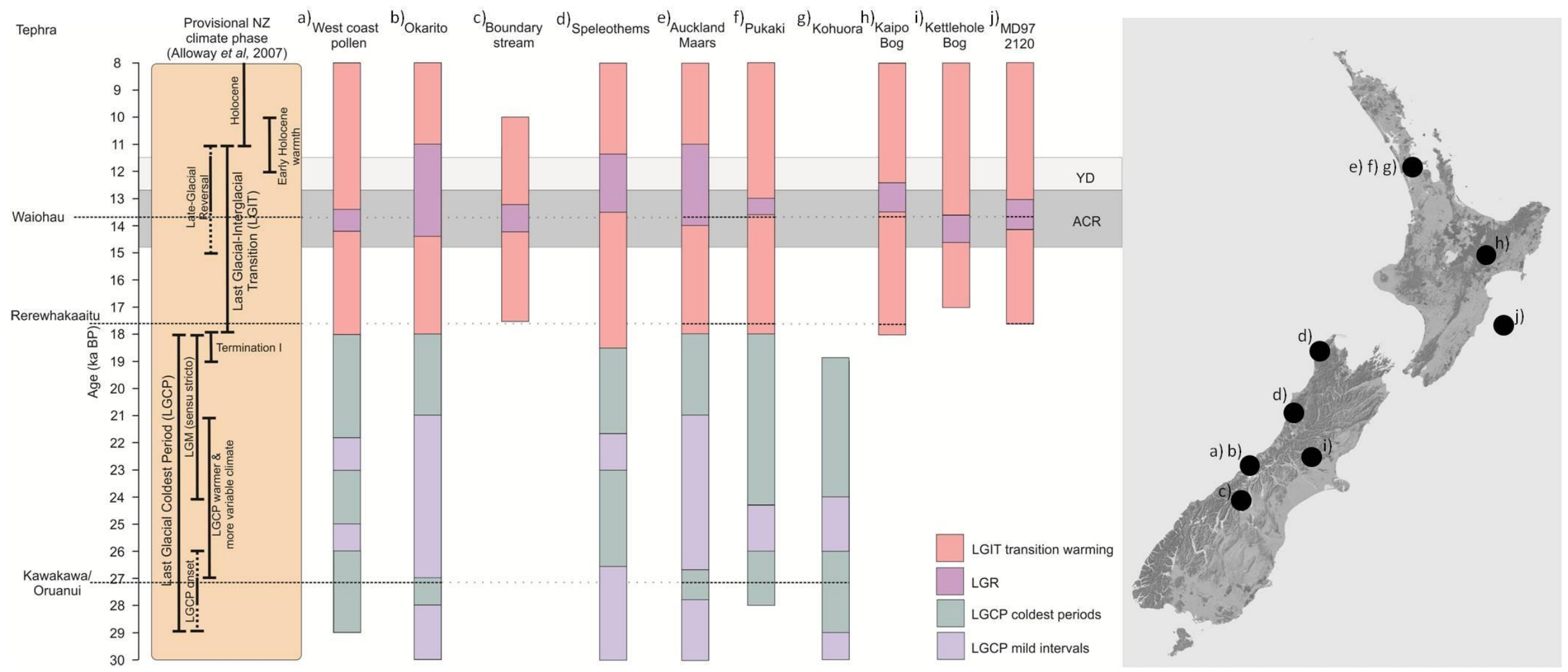

Figure 1.1: A collation of simplified summary diagrams from sites around New Zealand with b), d), e), f), h) and j) the main continuous records used in the NZ-I CES. a) Vandergoes and Fitzsimons, 2003; b) Newnham et al, 2007a; c) Vandergoes et al, 2008; d) Williams et al, 2005; e) Alloway et al, 2007; f) Sandiford et al, 2003; g) Newnham et al, 2007c; h) Newnham and Lowe, 2000; i) Turney et al, 2003; j) Carter et al, 2002. 


\subsection{Aim}

This thesis therefore aims to test the hypothesised NZ-I CES by producing continuous, high resolution, well-dated palaeoenvironmental reconstructions. Three new sites spread across the South Island will be used to produce continuous records with a fourth providing a fragmentary record formed by three river terrace risers. The four sites collectively span $>30-8 \mathrm{ka}$, but individually spanning part of this period. These sites represent altitudinal, north-south and west-east contrasts that today are characterised by strong contrasts in temperature and precipitation, and lie in the three different climate regions of the South Island as depicted by Kidson (2000) and Lorrey et al (2007). It is a secondary aim to investigate whether regional variations occur between the palaeoenvironmental record.

\subsection{Rationale for the site location}

NZ-I CES has highlighted the key areas in which improvement is required. Now that these limitations are recognised site selection targeting these limitations (increase the spatial resolution, increase the resolution of the palaeoenvironmental reconstructions or go back far enough to date the onset of the LGCP) can be chosen with more discretion. By using tarns, peat bogs or lakes constrained by moraines, geological age constraint can ensure a record can incorporate all, or some, of these events. The Kawakawa/Oruanui tephra (KOT) layer has a best age of ca $25.4 \mathrm{ka}$ (Vandergoeset al, 2011). If this layer is found then the deposit must predate the LGM and has the potential to go back beyond the onset of the LGCP. The sites predating the LGM are located near the ice margin during the LGCP and will therefore provide a sensitive record of climate change for this period.

Two of the four sites are located in the Westland region, South Island (Figure. 1.2). Lake Mudgie, is a glacially impounded lake constrained by a pre-LGM moraine complex. This is confirmed by the presence of the KOT layer at 593-595 cm depth in the core. Therefore, Lake Mudgie can provide a continuous record spanning from c. 30-8 ka. Manks Tarn, the second site, lies within a LGCP lateral moraine and provides a climate record spanning from the start of ice retreat to c. $8 \mathrm{ka}$. This site has an incredibly high sedimentation rate with $c .13 \mathrm{~m}$ of sediment 
accumulated over the past $18 \mathrm{ka}$ and has the potential to provide the highest resolution record for the LGIT and early Holocene period in the region.

Forks Lagoon is located east of the Southern Alps in the Mackenzie Basin, southwest Canterbury. This is a glacially impounded lake bounded by a moraine predating the LGCP. This is confirmed by the presence of the KOT layer located at $2.5 \mathrm{~m}$ in the core. This site's climate contrasts strongly with the Westland region and enables us to analyse the climatic changes for a region that is currently drier than present-day West Coast. The palaeoenvironmental record will concentrate on the LGCP, and will potentially date the onset of the LGCP, assess the climate variability during the LGCP, the timing of LGM and possibly the timing of Termination I. This is an important site as it is the only site which extends beyond the LGM in the region.

The Howard valley site is located in the Nelson lakes region and is composed of three river terrace risers with exposed sections. These risers have been previously dated and range from c. 34-18 ka (Marra and Thackray, 2010). A $10 \mathrm{~cm}$ thick KOT layer is located within cover-beds of the third terrace riser. This site will provide a climatic reconstruction beginning pre-LGCP and will hopefully provide a rough estimate for the onset of the LGCP, the pattern of climate during the LGCP including the LGM. Although a fragmentary record will be produced meaningful interpretations can still be made. 


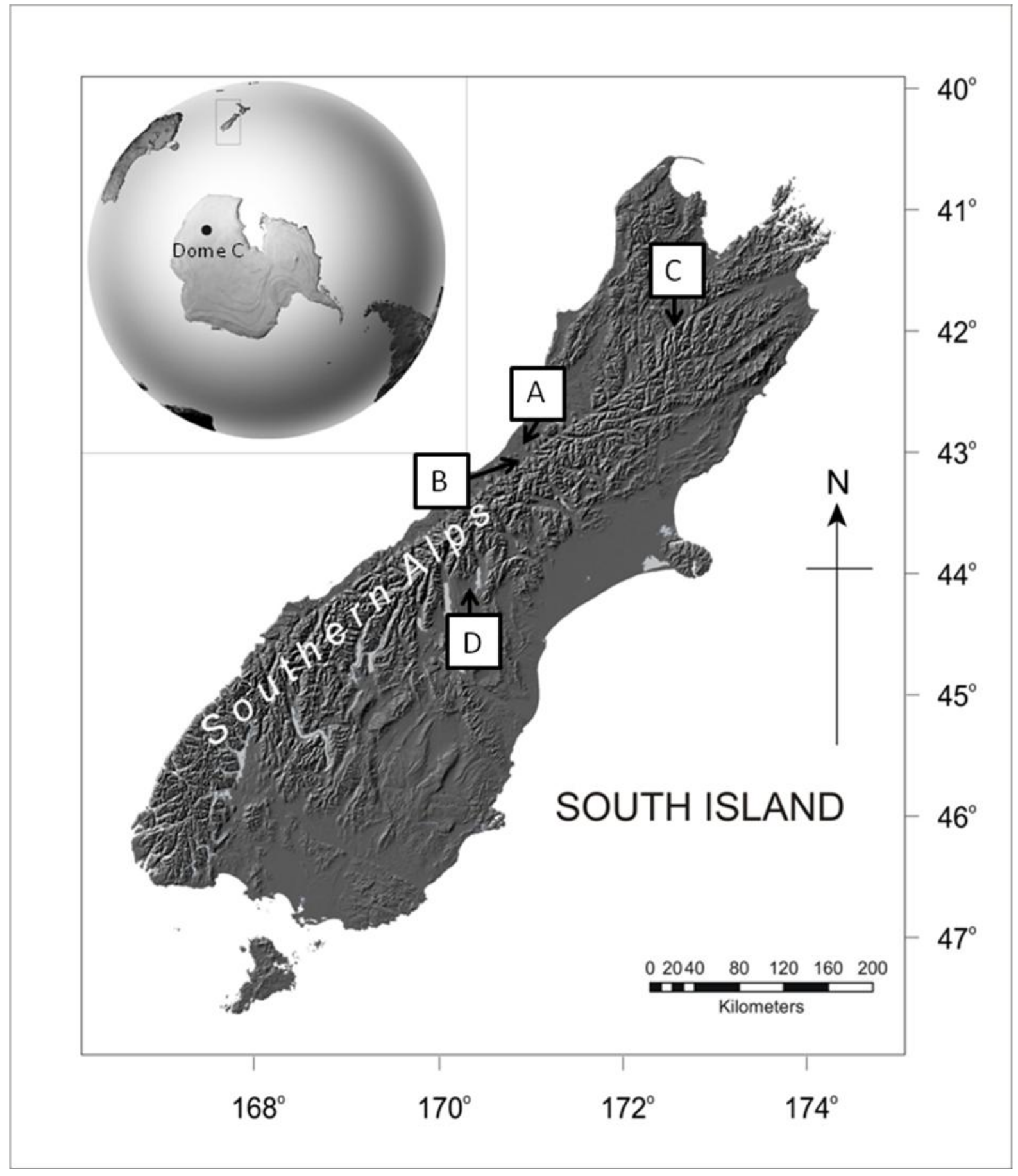

Figure 1.2: South Island New Zealand showing the location of the four sites: A. Lake Mudgie, B. Manks Tarn, C. Howard Valley and D. Forks Lagoon. Inset shows the South Island (boxed) in context of the Southern Hemisphere and the EPICA Dome C core site (EPICA Community Members, 2004). 


\subsection{Objectives}

Palynology, the study of pollen, will be the primary proxy used for palaeoenvironmental reconstructions. The pollen assemblage at a particular time and space relates to regional vegetation which, in turn, is controlled largely by climatic parameters. Therefore, pollen can be used to reconstruct past climates (Birks, 1981). This project will apply the recently developed pollen-based transfer function for New Zealand (Wilmshurst et al, 2007) to generate quantitative reconstructions of mean annual temperature at these sites. This method was not previously used in the NZ-I CES but was mentioned in the conclusion as a way to improve the results. Sedimentological analysis, including Loss on Ignition (LOI) and Particle Size Analysis (PSA), will aid the pollen interpretation. Dating of the sequences will rely primarily on radiocarbon dating along with one tephra layer of known age thereby aiding the chronology in three sites.

\subsubsection{Principal research objectives}

1. Produce high resolution palynological and sedimentological records from four sites of contrasting climates in the South Island, New Zealand (see map, Figure 1.2).

2. Apply the pollen transfer function to reconstruct Mean Annual Temperature (MAT) at the four sites between 30-8 ka.

3. Use multivariate analysis to enable objective comparisons of the pollen sequences from the four sites.

4. Develop reliable chronology for all four stratigraphies thereby enabling accurate determination of the key climatic transitions and millennial scale oscillations in New Zealand. This includes the following:

- Onset of the LGCP.

- The LGCP milder interval.

- Beginning and end of the LGM.

- Beginning and end of the LGR.

- Onset of the Holocene. 
5. Determine the pattern and extent of the climatic changes during the LGCP and LGIT for the South Island of New Zealand and assess whether any regional variation exists in these interpretations.

6. Assess the usefulness of the NZ-I CES at explaining the timing and pattern of South Island climate change between 30-8 ka.

This project will therefore provide further evidence and increase the reliability of the timing, magnitude and pattern of climate change in New Zealand by testing the hypothesised model created by the NZ-I group. By increasing the spatial resolution, the robustness of the scheme can be tested, with the data adding to the model to produce a more refined stratigraphy of New Zealand as a whole. An increase in temporal resolution, and records spanning beyond the LGCP will enable both the LGCP and LGR to be specifically targeted. With the known events targeted, more detailed dating can occur to produce a reliable chronology. The project will also expand the use of the existing New Zealand quantitative pollenclimate reconstruction models by attempting to use this methodology on samples predating $18 \mathrm{ka}$, the limit of use in the Wilmhurst et al, (2007) study. The use of this method was advised by the NZ-I group as a way to progress the provisional scheme to provide a more objective statistical interpretation of the pollen results.

Regarding the wider context, it would be unrealistic to produce conclusions on the causation and timing of global climate changes for the past $30 \mathrm{ka}$ based upon the results of this thesis. However, the results will add validity and argument to this debated topic and highlight any connections which exist between New Zealand and Antarctica by assessing and comparing the timing and pattern exhibited in both localities. It may also provide insights into the possible forcing factors of climate change in the Southern Hemisphere. These points will be highlighted later in the discussion chapter (Chapter 8). 


\section{Chapter 2: Background}

The previous chapter provides an introduction to the project by introducing late Quaternary climate change concepts and patterns both globally and in New Zealand, identifying current gaps and uncertainties in previous research and provides the aim, objectives and justification for the project. This chapter follows on from the previous chapter by providing geographical, geological and environmental context for the project. This chapter also provides a review of previous late-Quaternary research from New Zealand and the surrounding oceans, which are relevant to the discussion sections in Chapters 4-8.

This chapter begins with a geological background to New Zealand which has primary and secondary influences on the contemporary climate and vegetation of New Zealand. A summary of the late-Cenozoic history of New Zealand will follow, providing an understanding of the terrestrial, marine and climatic changes experienced in New Zealand. This leads onto the contemporary climate. An understanding of New Zealand's vegetative communities and ecological restriction is an important aspect for this project as ultimately the pollen record will be used to produce vegetation and inferred climatic interpretations at the four sites. Therefore, a section on the contemporary vegetation summarising the different floristic communities and factors that impede or promote certain species growth is discussed. An emphasis is placed on South Island communities, particularly those that are relevant for this project. Likewise, an understanding of past vegetative response to climatic change is also necessary and therefore a section on lateCenozoic vegetation follows the contemporary vegetation section. The final section of the chapter provides a summary of established South Island proxy records. This section is split into the three regions that are studied in this project and provide an overview of previous research from each region. The limitations of the available research at each site are reviewed. A summary section concludes this chapter. 


\subsection{Geological context of New Zealand}

The geological processes, both in the past and ongoing, experienced in New Zealand are significant to palaeoenvironmental reconstructions. The isolation of the New Zealand continent from other large landmasses has had a significant influence to its biogeography. Likewise, tectonic activity has controlled the morphology of New Zealand and significantly influences climate and vegetation patterns. The geological processes in New Zealand also directly influence the stratigraphy of the palaeorecords. Therefore it is important to summarise the geological history and the ongoing processes in New Zealand.

New Zealand is a relatively young archipelago dating from the Mesozoic onwards. Prior to $80 \mathrm{Ma}$ New Zealand was part of the super continent of Gondwana, formed by the continents of Australia, Antarctica, Africa and South America. During the Cretaceous period (60-80 Ma) New Zealand separated and drifted away from Australia and Antarctica (Molnar et al, 1975) and subsequently became isolated from both continents by the Tasman Sea, spanning nearly $2000 \mathrm{~km}$ (Pole, 1994). During the Oligocene the New Zealand continental plateau thinned reaching a thickness of 17-25 km thick (Adams, 1962). Continued thinning and progressive submergence of the landmass occurred between the Cretaceous and Oligocene (Waters and Craw, 2006). The geological nature of New Zealand has been dominated and controlled for the last $30 \mathrm{Ma}$ by the Pacific and Indian/Australian plate boundary upon which it lies. Movement along what is known today as the Alpine Fault began around 30-25 Ma and continued through the Miocene. Around $10 \mathrm{Ma}$ extension and thinning of the continent reduced and compression began along the alpine fault. During the Pleistocene (past $2.59 \mathrm{Ma}$ ) the compression significantly increased causing rapid uplift and mountain building in New Zealand (Carter and Norris, 1976).

The period of rapid mountain building coincides with a period of large climate variability during the late Pliocene and Pleistocene. The climatic variability is characterised by a succession of glacial/interglacial cycles (refer to Section 2.2.1). The large climate variability also induced glacio/eustatic sea-level changes. In turn, this affected the base level, which, combined with extensive glacial activity 
and large precipitation values, has resulted in high levels of erosion and weathering of the landscape. This activity has produced a youthful and heavily dissected landscape containing large Quaternary aged deposits and erosional features (see Sections 2.2.1 and 2.6). Tectonic activity continues to uplift the mountains and is responsible for the high relief of the country. Over $75 \%$ of New Zealand lies $\geq 250 \mathrm{~m}$ (McGlone, 1988; Soons and Selby, 1992).

Today only around $10 \%$ of the New Zealand continent is emergent (Waters and Craw, 2006) forming a collection of small temperate islands spanning the midlatitudes $\left(34-47^{\circ} \mathrm{S}\right)$ in the Pacific Ocean. It is a long (approximately $1500 \mathrm{~km}$ ) thin, north-east trending archipelago. New Zealand still straddles the Pacific and Indian/Australian Plate boundaries (Figure 2.1), forming a convergence zone causing both uplift and subduction throughout the country. The Alpine fault marks the boundary between the two plates and this is trended in a north-east - southwest direction throughout the country (Walcott, 1984; Figure 2.1). Immediately to the east of this fault lies the Southern Alps mountain range in the South Island, formed by the Pacific Plate rising over the Indian/Australian Plate (Adams, 1980). The Southern Alps dominate the South Island and have a profound influence on the climate (see Section 2.3).

Whilst the South Island is dominated by tectonic uplift and mountain building, the North Island is characterised by its recent volcanic activity which, during the Quaternary, has been an important geomorphic influence. Three major types of volcanism is experience in New Zealand and are classified as basaltic, andesitic and rhyolitic. These three types of volcanic activity act in different ways which influences the type, extent and chemical composition of a volcanic deposit (Houghton et al, 1995). The Taupo Volcanic Zone (TVZ) in central North Island spans an area $300 \mathrm{~km}$ long and $60 \mathrm{~km}$ wide (Figure 2.1) and is caused by the subduction of the Pacific Plate under the North Island. Earliest activity in this zone was andesitic beginning around $2 \mathrm{Ma}$. By $1.6 \mathrm{Ma}$ rhyolitic activity became dominant (Wilson et al, 1995, Carter et al, 2003; Alloway et al, 2005) with the TVZ being the most active and productive rhyolitic magmatic system in the world (Houghton et al, 1995). Since volcanic activity began in the area approximately 15$20,000 \mathrm{~km}^{3}$ of volcaniclastic deposits has been produced (Wilson et al, 1995). This 
material is dominated by gas- and water-supported mass flow deposits as well as airfall tephra which are widely distributed across the landscape and can also form secondary redeposited volcaniclastic materials. These tephra layers have become important stratigraphic and chronological markers which are useful for this project (refer to Section 3.5.2 for more information).

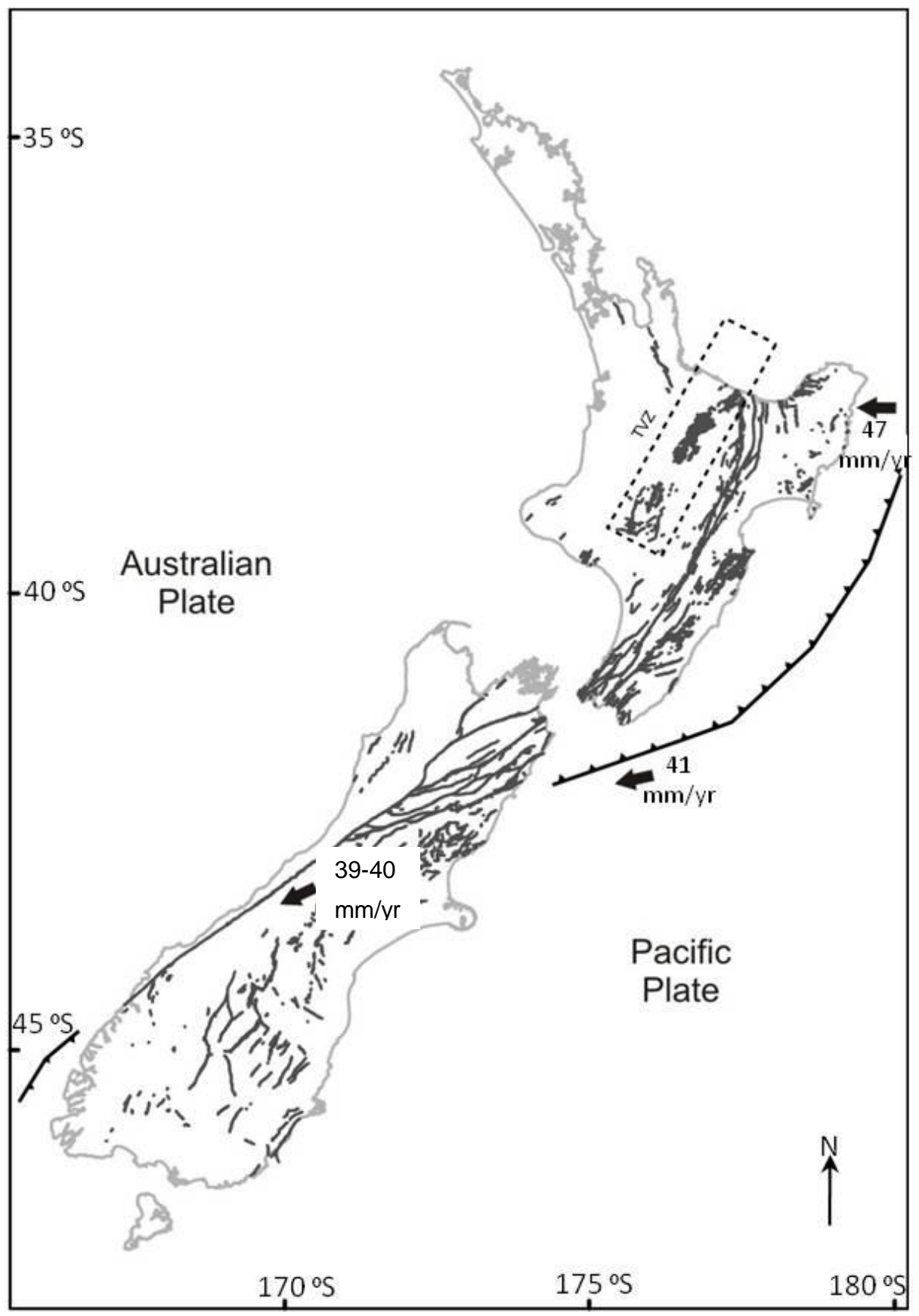

Figure 2.1: A simplified location map of the major tectonic activity in New Zealand. Taupo Volcanic Zone (TVZ) location is based upon Wilson et al (1995). Plate boundaries and rates of movement are from DeMets et al (1994) and Beavan et al (2001). 


\subsection{Late Cenozoic history of New Zealand}

\subsubsection{Glacial activity}

\subsubsection{Quaternary glaciations}

There are over 3000 glaciers exceeding $0.01 \mathrm{~km}^{2}$ in mainland New Zealand today containing a total ice volume of $55.3 \mathrm{~km}^{3}$ (Chinn, 1989). The largest of these is the Tasman Glacier extending $29 \mathrm{~km}$ from the main divide down the eastern side of the Southern Alps (Porter, 1975a). However, these existing glaciers are only small remnants of the extensive ice cover experienced during the last glacial. The sediment record from Wanganui Basin shows at least 58 unconformity bounded glacial and interglacial couplets on a 41 ka or 100 ka timescale spanning back 3.6 Ma (Naish and Kamp, 1997; Naish et al, 1998). In the terrestrial realm a fragmented and incomplete record of glacial/interglacial activity is preserved (Suggate, 1990). The most complete records are found in north Westland, South Island. Here, a pattern of glacial outwash aggradation surfaces, interbedded with coastal sediments that are interpreted as interglacial high sea-level high events (Suggate, 1965; 1990).

The oldest glacial deposits, found by Gage (1945) in north west South Island, are assigned to the Ross glaciation occurring approximately 2.62.4 Ma. Porika glacial occurred after this between $\sim 2.2-2.1 \mathrm{Ma}$ (Suggate, 1990). A combination of erosion and regional uplift produce a gap in the record until $0.35 \mathrm{Ma}$, after which evidence of a further four glacial are identified. These are known in New Zealand as the Nemona, Waimaunga, Waimea, and, the most recent glacial period, the Otira (Suggate, 1990; see Table 2.1). The marine and terrestrial proxy records can be correlated and appear to show good correspondence with the geomorphic evidence including vegetation change associated with warm and cold periods, and the $\delta^{18} \mathrm{O}$ marine isotope records (e.g. Mildenhall et al, 2004; see Section 2.2.2.3).

During the glacial periods the ice volume increased significantly in the South Island. The glacial complex in the Southern Alps widened by $100 \mathrm{~km}$ whilst the valley glaciers extended into the lowland areas forming piedmont ice lobes reaching up to $50 \mathrm{~km}$ wide in the Westland region (Porter, 1975b). Associated with the glacial advances is an increase in sediment source, transport and deposition 
leading to large gravel deposits and extensive outwash aggradation surfaces. These fluvioglacial derived material can be traced up valley to moraines particularly for younger glacial events. When excluding the Quaternary volcanic deposits around $10 \%$ of New Zealand is covered by glacial deposits with a concentration on the lowland areas, particularly in the South Island (Suggate, 1965). In contrast, the glacials had limited geological impact on the North Island where only Mt Ruapehu (McArthur and Shepherd, 1990) and the Tararua ranges (Brook and Brock, 2003) reach sufficient altitudes for permanent snow or ice accumulations. Permafrost did not occur in the North Island but periglacial activity, fluvial and wind erosion had notable impact on the geomorphology (Soons and Selby, 1992).

\begin{tabular}{lllll}
\hline MIS & Glacial & Interglacial & Westland & Mackenzie \\
& formations & Basin & Upper \\
& (New Zealand) & (New Zealand) & & $\begin{array}{l}\text { Buller } \\
\text { formations }\end{array}$ \\
& & & & \\
\hline 1 & & Aranui & &
\end{tabular}

Birch Hill

2 Otira

Moana Tekapo

Larrikins $\quad$ Mt John Speargrass

3

4

Loopline Balmoral $1 \quad$ Roundall

5

Kaihinu

$6 \quad$ Waimea

Waimea

Balmoral 2 Tophouse

7

Karoro

8 Waimaunga

Tansey

Wolds

Harry

Table 2.1: Names and timing of the glacial and interglacial periods from terrestrial evidence in New Zealand related to the Marine Isotope Stages (MIS) (Suggate, 1990; Challis et al, 1994; Suggate and Almond 2005). 
The last glacial period (the Otira Glacial) spans 70-12 ka and includes the Marine Isotope Stages (MIS) 4, 3, and 2 (Soons, 1979). The period of maximum ice extent occurred between 28-18 ka and is referred to as the LGCP by the NZ-I CES (Alloway et al, 2007; see also Section 1.2). This intensive cold period is followed by rapid deglacition and climatic amelioration in New Zealand. During the LGCP glaciers extended to within $2 \mathrm{~km}$ onshore from the current coastline, and in some instances extended beyond the coastline e.g. between Hokitika and Greymouth (Suggate, 1990; Suggate and Almond, 2005). During these cold periods and lower sea level outwash material was deposited far offshore (Suggate, 1990). Moraine, loess and other proxy records indicate the LGCP was climatically complex (Almond et al, 2001; Alloway et al, 2007). Suggate and Almond (2005) find evidence for 3 periods of ice advance occurring between 34-28 ka, 24-21.5 ka and 20.5-19 ka, with milder condition interrupting these cold periods. The period 21-18 $\mathrm{ka}$, the LGM sensu-stricto, marks the period of coldest climate conditions and most extensive period of ice advance (Alloway et al, 2007). The moraine records suggest glacial activity remained complex throughout the deglaciation with a number of halts and minor readvancements (Soons and Selby, 1992).

\subsubsection{Oceanic circulation and marine records}

New Zealand is an oceanic Island surrounded on all sides by water. Therefore, oceanic water masses, fronts and circulations influence New Zealands contemporary environment. Past changes in latitudinal location of the water masses and fronts and the intensity of the circulations have been shown to impact upon New Zealand climate. Therefore an understanding of these oceanic factors influences on New Zealand is important for climatic reconstructions. Marine sediments also produce valuable proxy reconstructions which can be linked to and complement terrestrial records. The following section provides a brief overview of ocean water masses and fronts in New Zealand followed by a review of the marine records. An emphasis will be placed upon late Quaternary records, particularly the last glacial/interglacial period, MIS 4-1. 


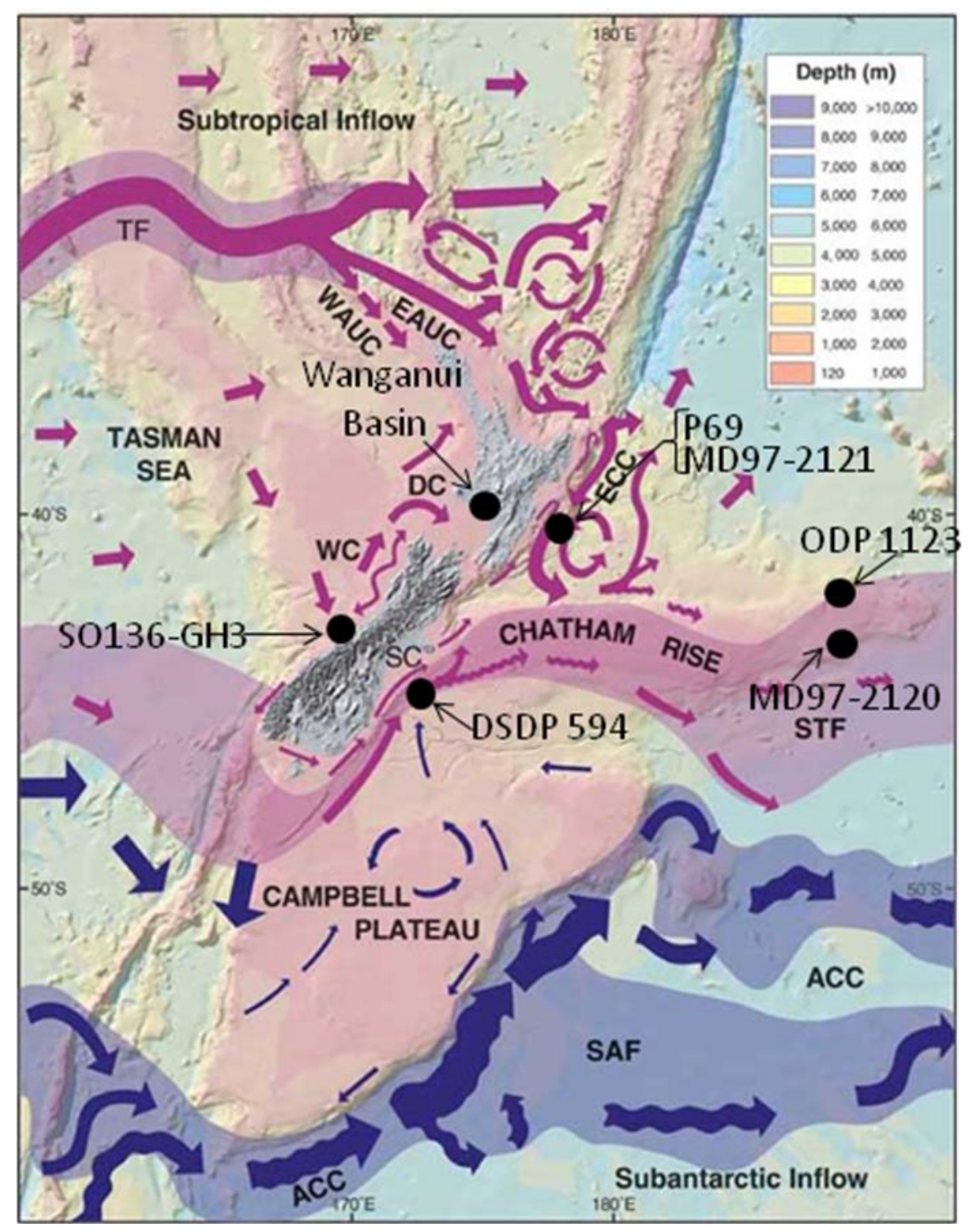

Figure 2.2: The current location of the different surface water masses and their bounding oceanic fronts from Carter (2001).

\subsubsection{Current and past oceanic fronts and water masses}

New Zealand straddles two water masses, the warm Sub-Tropical Surface Waters (STW) and the Sub-Antarctic Surface Waters (SAW; see Figure 2.2). These water masses are separated by the 150-400 km wide, globally circulating, Sub-Tropical Front (STF), which bends around the base of the South Island flowing northward and then eastwards along the crest of the Chatham Rise (Carter, 2001). The Tasman Front, marking the boundary between the warm Coral Sea and cold Tasman Sea, flows from Australia to northern North Island bringing warm water from the sub-tropical region to New Zealand. A continuation of this front, the East Auckland Current, flows south along the east coast of New Zealand forming large 
anticylconic eddies by the East Cape (Tomczak and Godfrey, 1994). South of both New Zealand and the STF is the globally circulating Antarctic Circumpolar Current (ACC) at $52^{\circ} \mathrm{S}$. This current is disrupted by the Campbell Plateau causing large eddies of cold water to flow northwards along the plateau margin until c. $48^{\circ} \mathrm{S}$ where the current continues to flow eastwards (Carter, 2001).

The development of New Zealand's oceanic fronts to current conditions occurred over a long time period. Between 65-35 Ma (Paleocene and Eocene) the New Zealand sector of the Southern Ocean (NZSSO) was mostly influence by subtropical waters. No detectable oceanic fronts are evident in the marine cores during this period. At $35 \mathrm{Ma}$ the SAW and subtropical waters are separated by a proto-STF at $\sim 65^{\circ} \mathrm{S}$. During the Oligocene the Antarctic polar front develops, pushing the STF northwards and marking a period of global cooling. At $\sim 31$ Ma the Tasman gateway fully opens and the proto AACP front develops. The Antarctic waters flowed northwards onto the New Zealand plateau. Since the opening of the Tasman gateway and three part division of the Antarctic, subantarctic and subtropical waters have persisted in the NZSSO. Between 21-15 Ma, the STW shifted southwards into the northern NZSSO area possibly associated with reduced ice volume or the redirection of warm surface flows southwards into the Tasman Sea from higher latitudes. From 15-5 Ma the STF and SAF became established into their relative contemporary positions (Nelson and Cooke, 2001)

During the climatically variable Quaternary period relative locations of the STF and SAF were probably in similar positions during interglacials as they are today. However, little is known about the movements of these fronts during glacial periods (Nelson and Cook, 2001). Evidence from ocean core sites around New Zealand show a considerable, but temporary, northward shift (5-10 $\left.{ }^{\circ}\right)$ of the ACC and STF during glacial episodes (Nelson et al, 1993; Weaver et al, 1998). The compression of SAW by this shift would have likely intensified oceanic flows which contributed to the increased westerly winds or vice versa and added to the harsh conditions experienced during these cold periods (Nelson et al, 1993). Carter (2001) suggests there was a northward migration of the ocean fronts and wind belts during the LGM. The Tasman Front migrated $600 \mathrm{~km}$ northward reducing the warm water transport to northern North Island and possibly aiding the temperature 
depression on land. The STF also moved northwards in the Tasman Sea, but a northward shift east of the South Island is impeded by the Chatham Rise. During the LGM the ACC also strengthened increasing the amount of cold water eddying northward reaching Chatham Rise and flowing into the STF (Carter, 2001). During this period it is believed the colder waters allowed northward drift of icebergs as far north as the Chatham Rise (Carter et al, 2002; Crundwell et al, 2008). The northward movement of colder water would have helped maintain low temperatures or reduced them further during the LGM (Carter, 2001).

\subsubsection{Marine records}

The longest "marine" record in New Zealand, and one of the most complete late Neogene records in the world, is from the Wanganui Basin and extends over the past 3.6 Ma, spanning MIS 1 to MG6. Wanganui Basin is a $200 \mathrm{~km}^{2}$ sedimentary basin location in western North Island. Tectonic activity has caused in upwarping of the basin's eastern margin resulting in onland exposures of the marine sediments spanning 58 cyclothems. Each 40 ka (MIS 100-18) and 100 ka (MG6G2 and MIS 17-2) cyclothem consists of a glacial/interglacial couplet. The sediment facies represent deposition during highstands and falling caused by glacio-eustatic sea-level change. This cyclothem record illustrates the New Zealand experience effects caused by major climate and sea-level changes on orbital timescales since 3.6 (Naish and Kamp, 1997; Naish et al, 1998). Other temporally shorter marine records from both the eastern and western sides of New Zealand also show a Milankovitch scale climatic change (Pahnke et al, 2003; Pahnke and Zahn, 2005; Pelejero et al, 2006; Barrows et al, 2007; Elderfield et al, 2010).

A 280 ka long alkenone sea surface temperature (SST) record from marine core S0136-GC3, from Challenger Rise, western New Zealand reveal a $7{ }^{\circ} \mathrm{C}$ temperature amplitude between glacial and interglacial periods. A maximum temperature of $19{ }^{\circ} \mathrm{C}$ and $19.5^{\circ} \mathrm{C}$ lasting 5 ka long was recorded for MIS $7 e$ and 5e respectively. The temperature subsequently reduced to $14.5{ }^{\circ} \mathrm{C}$ and $15.4{ }^{\circ} \mathrm{C}$ respectively. Holocene temperatures only reached a maximum $16.9{ }^{\circ} \mathrm{C}$, significantly lower than the previous interglacials and averaged $3{ }^{\circ} \mathrm{C}$ lower than MIS 5e (Barrows et al, 2007). A similar pattern is recorded in marine records from 
eastern New Zealand. A benthic $\mathrm{Mg} / \mathrm{Ca}$ palaeotemperature reconstruction and $\delta^{18} \mathrm{O}$ record from Ocean Drilling Project (ODP) site 1123, Chatham Rise, reconstruct higher temperatures during the interglacials MIS 11, 9, 7 and $5 \mathrm{e}$ compared to the Holocene (Crundwell et al, 2008; Elderfield et al, 2010). Pahnke et al (2003) and Pahnke and Zahn (2005) MD97-2120 marine core record, also from the Chatham Rise, again, records higher temperatures for MIS 9c, 7e, 5e than the Holocene, although a smaller range in temperature from glacial to interglacial periods compared to the S0136-GC3 (Barrows et al, 2007). The pattern of SST in SO136-GC3 during the glacial show a progressively colder minimum temperature with age whereby MIS $8,6,4$, and 2 experienced a minimum temperature of $11.9{ }^{\circ} \mathrm{C}, \quad 11.6{ }^{\circ} \mathrm{C}, 11.3^{\circ} \mathrm{C}$ and $9.8^{\circ} \mathrm{C}$ respectively. Also prior to maximum cooling each glacial experiences a small increase in SST (Pelejero et al, 2006). This occurs also in eastern New Zealand with The $\delta^{18} \mathrm{O}$ curve from ODP 1123 core becoming more positive, suggesting a slight warming, prior to maximum cooling (Elderfield et al, 2010).

Barrows et al (2007) SST record from SO163-GC3 using planktonic foraminifera found millennial scale climate scale fluctuations superimposed on the larger Milankovitch scale climate transitions. For instance during MIS 3 warming periods were recorded every 6-7 ka between 57.8-38.9 ka. The timing of these warmer intervals appeared to lead the equivalent Dansgaard-Oeschger (D-O) events recorded in the GISP2 ice core record suggesting an asynchronous pattern of climate change between the hemispheres on millennial timescales. Another noticeable discrepancy between the Northern Hemisphere ice core records and SST record of SO136-GC3 is the pattern and timing of deglaciation at the end of the LGM. SST reconstructions show rapid increases in temperature marking the end of the LGM with the majority of warming occurring by $15 \mathrm{ka}$. This precedes the Bølling Allerød warming chronozone, identified in the GISP2 ice core record, by 3$4 \mathrm{ka}$. The pattern of warming is not continuous but contains a series of minor reversals. After 15 ka there does not appear to be a strong cooling trend and it is difficult to distinguish an ACR cooling event. However, the period marked by the Younger Dryas Chronozone in the Northern Hemisphere is a period of warming in the eastern Tasman Sea, and again precedes a Northern Hemisphere warming. 
The core MD97-2120 lies south of the Inter-Tropical Convergence Zone (ITCZ) which separates the warm, saline rich subtropical surface waters and the fresher, cold sub-Antarctic water, a perfect location to assess movement in ocean circulations as well as temperature change. Sea Surface Salinity (SSS) measurements have also been calculated with the results providing insight to oceanic changes coinciding with climate change. SSS decreases during glacial and stadials and increases during interglacial. Pahnke et al (2003) noted that terrestrial records, such as vegetation reconstructions, indicate increased aridity during glacials. This would indicate less fresh water and higher evaporation rates and would therefore be assumed to cause an increase in ocean salinity. However, the opposite occurs and suggests a northward migration of fresher, colder subAntarctic surface waters during glacials causing the lower SSS. MD97-2120 also uniquely records a $1.1{ }^{\circ} \mathrm{C}$ cooling coinciding with an ACR timing of cooling (Pahnke and Zahn, 2005), which is not recorded in the other marine records.

\subsubsection{Marine records containing dominantly terrestrially derived material}

Sediment deposited in the marine realm in part can be derived from and contain terrestrial material providing an opportunity to link marine records and terrestrial signals of climate change. The oldest palynomorph record is from ODP1123 and extends back $5 \mathrm{Ma}$ (Mildenhall, 2003; Mildenhall et al, 2004). Chronology for this core is constrained using benthic foraminifera $\delta^{18} \mathrm{O}$ records produced by Hall et al (2001). Like the records already mentioned in the previous section a clear Milankovitch scale climate change is recorded in the core. The pattern of glacial/interglacial cycles changes from low amplitude, high frequency $40 \mathrm{ka}$ obliquity cycles to saw toothed high amplitude, low frequency 100 ka eccentricity cycles between 0.92-0.62 Ma (Raymo, 1997).

Marine core DSDP 594 from Chatham Rise produces a 750 ka long silt, carbonate and $\delta^{18} \mathrm{O}$ record (Nelson et al, 1985, 1986) and a $350 \mathrm{ka}$ long pollen record (Heusser and Van de Geer, 1994). The following patterns from these records are observed. Pollen assemblages during the interglacials (MIS 1, 3, 5, 7 and 9) are dominated by arboreal pollen, like the palynomorph records from ODP 1123 (Mildenhall, 2003; Mildenhall et al, 2004). This vegetation pattern corresponds with an increase in pollen concentrations and silt minima suggesting a large vegetation 
cover and low amounts of erosion. The pollen assemblage suggests MIS 7 was the coldest interglacial period caused by the dominance of sub-montane taxa, whilst MIS 1 and 5 were the warmest caused by the large abundance of temperate rainforest taxa. Conversely the glacials (MIS 2, 4, 6, 8, and 10) were dominated by herb and grassland taxa. Evidence of forest refugia, contributing up to $20 \%$ of the pollen assemblage, was recorded during all glacial periods. Unlike the interglacial periods the pollen assemblage remained the same suggesting similar conditions between glacial periods. During the glacials pollen concentration decreased significantly whilst silt abundance increased indicative of reduced vegetation cover and increased erosion (Heusser and Van de Geer, 1994).

On shorter timescales Wright et al (1995) and McGlone (2001a) produced a marine palynomorph record, offshore from the North Island, extending $59 \mathrm{ka}$ and 30.7 ka respectively. From 59-46 ka conifer-hardwood forest dominated the North Island indicating warm interglacial conditions prior to the glacial maximum. Abrupt and significant cooling occurred between 46-28.8 ka, characterised by increased $\delta^{18} \mathrm{O}$ and pronounced vegetation change to a grass, herb and shrub dominated vegetation community (Wright, et al, 1995). Coinciding with the vegetation change was an increase in aeolian derived quartz deposits indicative of windy glacial conditions (Stewart and Neall, 1984). Temperatures reach a minimum between 22.8-18.3 ka, representing the last glacial maximum. This period had the lowest representation of arboreal pollen in both records (Wright et al, 1995; McGlone, 2001a), however scattered patches of forest refugia are evident. The end of the glaciation is marked by an abrupt transition from full glacial open vegetation landscape to a dominance of podocarp/hardwood forest (McGlone, 2001a) and a decline in quartz, suggesting a reduced strength or a shift in westerlies (Stewart and Neall, 1984).

\subsubsection{Summary}

The proxy terrestrial evidence in the marine record contains a number of glacial/interglacial cycles occurring throughout the past $5 \mathrm{Ma}$ shifting from a dominant 40 ka cycle to 100 ka cycle. These cycles corresponds to Milankovitch timescale and synchronously with the Northern Hemisphere. However, on a millennial timescale there are disparities evident between the hemispheres. The 
marine records from both the eastern and western sides of New Zealand record a similar pattern of climate change and all recognise the Holocene to be colder than the previous interglacials. A northward migration of the Antarctic cold water during the glacials is also evident from the SSS record.

\subsection{Climate of New Zealand}

New Zealand is located in the south-eastern Pacific Ocean and lying within the Southern Hemisphere temperate zone. New Zealand also lies in the path of the Southern Hemisphere prevailing westerlies (Salinger and Mullan, 1999). The weather is dominantly controlled by the progression of eastward migrating anticyclones, depressions and fronts (Fowler et al, 2008). However, blocking of the eastward migration does occur generally during the winter months. New Zealand is an oceanic island and regional weather and climate variations are largely influenced by the humid, moisture laden maritime air masses flowing from the subtropical and sub-Antarctic latitudes (Salinger and Mullan, 1999).

Climate is largely influenced by New Zealand's topography. The north-east-southwest trending mountain ranges run the length of New Zealand and have been found, in both islands, to have had a profound effect on regional climate by forming a barrier obstructing the westerly circulations (Maunder, 1971). This produces a marked contrast in precipitation between the western and eastern side of the ranges (Close et al, 1978; Griffiths and McSaveney, 1983; Figure 2.3). Therefore, regional-scale climate, particularly precipitation, is extremely sensitive to changes in the direction of the prevailing wind and variations in circulation strength (Lorrey et al, 2007). During periods of strong westerly flow, rainfall increases in the west and south coast of the South Island and central North Island whilst decreasing on the east coast of the North Island (Salinger 1980a; Salinger 1980b). If these westerlies are sufficiently strong, föhn winds are experienced in the Canterbury region with associated high temperatures and low, if any rainfall (Maunder, 1971). Conversely, during periods of low westerly or high easterly flows, these same areas experience lower and high rainfalls respectively (Salinger 1980a; Salinger 1980b). The North Island axial mountain ranges receive the majority of rainfall during northerly or north-easterly cyclonic storms (Soons and 
Selby, 1992). The west to east precipitation gradient is accompanied by a north to south latitudinal gradient in temperature (Close et al, 1978; Figure 2.3). New Zealand's climate is also sensitive to global climate phenomena that originate outside the mid southern latitudes. This includes teleconnections to the EI Niño Southern Oscillation (ENSO) and Inter-decadal Pacific Oscillation (IPO) (Lorrey et al, 2007).

Kidson (2000) split New Zealand into eight rainfall regions and three temperature regions, resultants of the orographic effect. He also recognised 12 synoptic circulation types which have been divided into three basic regimes: trough, blocking and zonal types (see Figure 2.4). Trough regimes are dominated by frequent troughs moving over New Zealand. During these regimes precipitation and cloudiness increases in all regions and climates tend to be cooler. Blocking regimes are dominated by highs over the South Island which block the westerly wind flow. During these regimes New Zealand receives an increased easterly flow resulting in increased precipitation in east and north North Island and drier conditions in western regions and east South Island (ESI). Finally, zonal regimes are characterised by high pressure located over northern New Zealand and increase westerly wind flow. This is accompanied by increased precipitation in western South Island and drier conditions over the majority of the North Island and in the north and eastern South Island (Kidson, 2000; Lorrey et al, 2007; see Figure 2.4). Lorrey et al (2007) took this idea further and tested the hypothesis that regional climate regimes identified in the contemporary environment would have been similar pattern in the palaeoenvironment. Their research indicates that longterm spatial climate signals could be identified in the palaeorecords. This idea implies that palaeoclimate records may also contain regional differences due to changing wind directions and circulation strength. This is an important point as it can help explain 1. the processes involved in New Zealand's palaeoclimates and 2. why there are many disparities between records from different regions. Regional climate regimes in the South Island were an important factor for site selection in this study, but this will also be important when interpreting the palaeoenvironmental records and its relevance. 


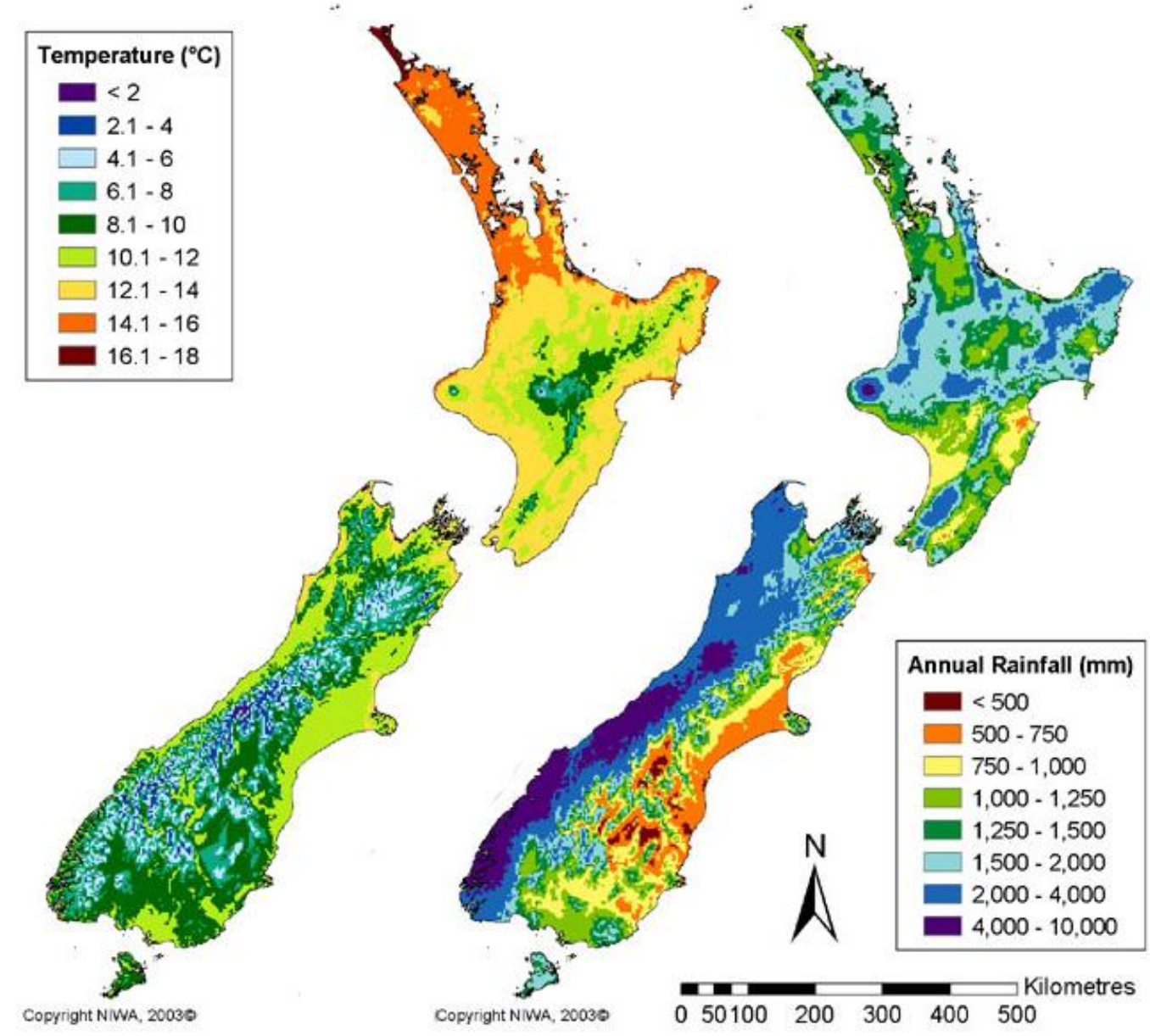

Figure 2.3: Mean Annual Temperature (MAT) and precipitation (MAP) maps of the South Island (adapted from NIWA, 2001). 


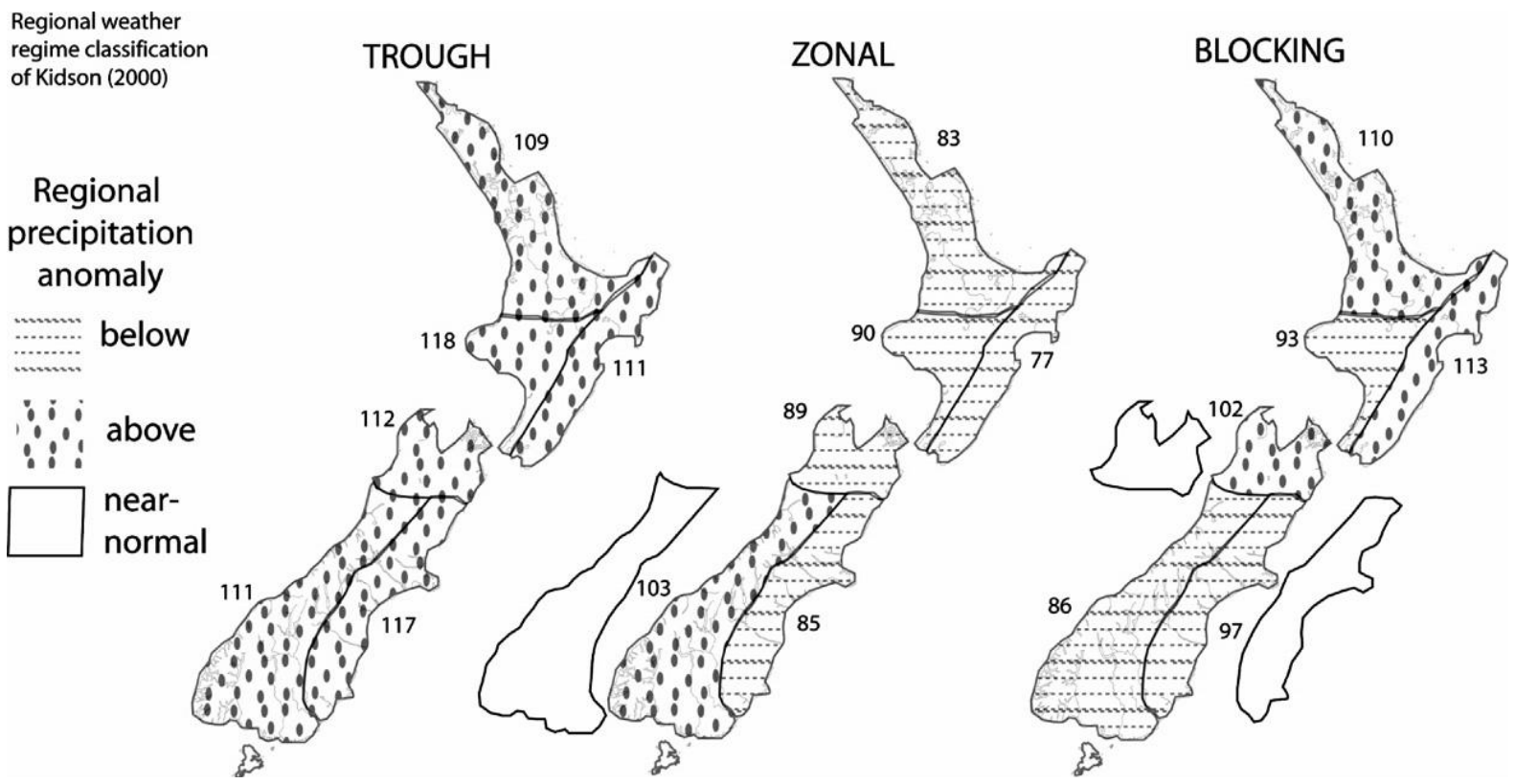

Figure 2.4: The different rainfall anomalies during different climate regimes for each rainfall region taken from Lorrey et al (2007, pp 413).

\subsection{New Zealand vegetation}

Before accurate vegetation, environmental and climatic reconstructions can be inferred from palaeopalynological records an understanding of vegetation in its contemporary environment is necessary. This includes; the different types of vegetation communities, plant assemblage in each community type, the way species interact with each other, specific niches and environmental limitations acting upon different species, altitudinal and latitudinal limits of species and the climatic factors which individual species and communities can tolerate. This section provides a summary of the points above for New Zealand's plant communities which will be used to reconstruct changing vegetation and infer climate. The section concentrates on the regions and vegetation communities that are representative of the plant assemblages in the pollen records and relevant to this project and excludes the North Island. The following is based primarily on Wardle (1991) and McGlone (1988) and the reader is directed to these sources for more information. Each site chapter contains a detailed vegetation description for the region (see Chapters 4-7 for more detail). 


\subsubsection{Forest communities; lowland-treeline}

Since human occupation, and in particular since European colonisation, New Zealand's forest cover has been severely reduced. This is especially the case in the lowland and easily accessible locations where only small, vulnerable remnants remain. Extensive native forest cover today is restricted to the remote, rugged areas. Only on the west coast of the South Island can unbroken forest exist from sea level to alpinal tree line limit (Wardle, 1991). The remaining native forests can be split into two sub-categories: conifer-broadleaved forest and Nothofagus (beech) forest.

\subsubsection{Conifer/hardwood forest}

These forests are highly diverse and species rich and occur throughout the whole of New Zealand and in all types of climate, although the complexity of a community can vary greatly with altitude, temperature and soil type/quality. This forest type includes the podocarp conifer species mostly belonging to the family Podocarpaceae and a selection of hardwood angiosperm (flowering plants; Godley, 1975). These forests are composed of a number of different vegetative tiers caused by the maximum growth limitation of each species. The tallest tier is formed from conifer species where the canopy ranges from being continuous to completely absent. The second tier is characterised by the shorter broadleaved trees with the density of cover varying greatly. A further tree tier is formed by the smaller trees and associated tree ferns. This can form the dominant canopy cover in localised regions but is suppressed if the canopy above is continuous. Beneath the tree cover, tall herb species are located with the ground level comprising mostly ferns, mosses and liverworts, although small angiosperms can also be present (Wardle, 1991).

Elevation has a significance influence on the conifer/hardwood forest community composition with clear elevation zones evident in the Westland region. The low land forest (0-400 m.a.s.l) is dominated by emergent podocarp species, including Dacrydium cupressinum and Prumnopitys. Hardwood taxa from the sub-canopy and shrubs (Coprosma, Pseudoponax and Myrsine) produce a diverse subcanopy. Tree ferns are also an important component of the sub-canopy whilst ground ferns cover the forest floor. In waterlogged/wetland areas Leptospermum 
and Halocarpus shrub tier grows. Between 400-800 m.a.s.I a montane hardwood forest dominates the vegetation community and many lowland podocarp taxa have limited growth. The sub-canopy is made up of low lying broadleaved trees, shrubs and tree ferns (Wardle, 1991). At 800-900 m.a.s.I the vegetation becomes dominated by sub-alpine shrubs and low forest up until 1200 m.a.s.l, marking the end of the treeline (Wardle, 1979). The distinct elevation zones are useful when estimating elevational vegetation depression to infer temperature depression using Environmental Lapse Rates (ELR) (see Section 3.2.6 for more detail).

\subsubsection{Beech forest}

New Zealand contains four species of beech: Nothofagus fusca, $N$. menziesii. $N$. truncata, and $N$. solandri (includes the var. solandri found in the lowland-montane elevations, and var. cliffortioides inhabiting the upland to sub-alpine zone) (McGlone, 1988; Wardle 1991). Ecologically, Nothofagus spp tend to flourish in regions climatically less favourable for other plant growth when compared to areas dominated by conifer-broadleaved forests (McGlone, 1988). Therefore, they are often located in the upland areas and form the majority of timberlines. Beech forests can extend from the sub-alpine zone to low altitudinal areas along river banks. They tend to inhabit recently disturbed areas where other species have not had the chance to dominate. With reduced altitude they become increasingly confined to shallow soils found on crests, ridges and spurs. Beech forest can mix with the conifer-broadleaved species although this tends to occur in the cooltemperate belt in areas with high-moderate rainfall. There are unexplained gaps in the beech distribution in some regions where the conditions are still favourable for beech growth. These major gaps include areas from Mt Taranaki, some areas of the Volcanic Plateau and Westland between the latitudes $42^{\circ} 40^{\prime} \mathrm{S}$ and $43^{\circ} 30^{\prime} \mathrm{S}$, and on Stewart Island (Wardle, 1991).

In comparison to conifer-broadleaved forest, beech forests structurally tend to be more simplistic. In the most extreme environments the canopy is solely made from Nothofagus with few shrubs and a very sparse understory. Each species has its own ecological preference. $N$. menziesii is generally found in wetter areas of south and central New Zealand and forms unbroken cover from sea level to treeline. In contrast, $N$. fusca and $N$. truncata are both less tolerant to colder environments. 
As a result $N$. fusca tends to be limited to the warm midslope locations and $N$. truncata is most common north of $38^{\circ} \mathrm{S}$. In areas of poorly drained, low fertility sites N. solandri var. cliffortiodes can be common (Wardle, 1991). The Howard Valley is located in the Nelson Lakes region which is dominated by mixed beech forest. A more detailed vegetation description is provided in Section 6.1.

\subsubsection{Forest transition, sub-alpine and alpine zone}

The character of forest transition into the alpine vegetation zone varies between beech and conifer-broadleaved forests. Beech forests tend to end abruptly with vegetation changing immediately into the tussock grasses. In contrast, the coniferbroadleaved tree line tends to be lower in altitude and has a more gradual transition into alpine vegetation with a highly diverse sub-alpine shrub zone. This zone includes: podocarp shrubs, composite shrubs, small leaved Coprosma spp, Dracophyllum, Hebe, Myrsine, Olearia Pseudopanax and others. This zone rarely exceeds $100 \mathrm{~m}$ higher than the tree line.

The alpine zone is dominated by tussock grasses such as Chionochloa spp. These grasslands have an abundance of herbs and shrubs including species from Apiaceae (Aciphylla, Anistotome, Hydrocotyle) Epacrideae (Drocophyllum, Cyathodes, Leucopogon), Compositae (Celmisia), Thymelaeaceae, Drapetes, Pimelia, Coprosma, Ephilobium, Geranium and Hebe (McGlone 1988). The alpine zone begins at 1200 m.a.s.I in the Westland region (Wardle, 1977), c. 1400 m.a.s.I in Nelson Lake National Park (Wardle, 1991), and at 1500 m.a.s.l at Mt Cook (Wardle, 1991).

\subsection{Cenozoic vegetation history of New Zealand: overview}

Since separating from the super continent Gondwana over c. 60 Ma the extent and length of New Zealand's isolation has led to a unique floristic community (Cooper and Millener, 1993). The traditional view is that origins of New Zealand's endemic flora are remnants from Gondwana times (e.g. Wardle, 1991). However, transoceanic dispersal from Australia, South America and Hawaii is the favoured contemporary view (McGlone et al, 2006; McDowell, 2008). The geological history 
of New Zealand (see Section 2.1) and past climatic changes have had a large influence on the vegetation composition in the past and therefore on the contemporary vegetation. The following section is a brief overview of the history of New Zealand's vegetation change during the Cenozoic. An emphasis is upon Quaternary vegetation change and the response of vegetation to climate changes during this period. These patterns of change are relevant to the discussion of the vegetation and inferred climate change for each site section in this project (Chapter 4-7) and the main discussion chapter (Chapter 8).

\subsubsection{Palaeogene/Neogene}

During the early to mid Cenozoic period New Zealand was a low lying archipelago located in the high latitudes $76-68^{\circ} \mathrm{S}$. The flora was dominated by temperate and sub-tropical species suggestive of an unseasonal and warm climatic regime (Mildenhall, 1980). The climate was very similar to that experienced by Australia and many floristic species were related (McGlone et al, 2006). This warm climate continued through the Miocene (Mildenhall, 1980).

Approximately $5 \mathrm{Ma}$ (late Miocene/Early Pliocene) the westerly circulation increased in intensity, coinciding with major polar ice sheet development in Antarctica (Kennett and Brunner, 1973; McGlone, 1985). During the Miocene/Pliocene, New Zealand moved into its current latitudinal position whilst contracting in length and entering a mountain building phase, which is continuing today (see Section 2.1). It was during this period that the beginnings of the rain shadow effect were felt in areas in the lee of the mountains. These alterations in latitude, altitude, climate and land area resulted in large floristic changes (Mildenhall and Pocknall, 1983), with conditions favouring the herbaceous and easily dispersible species. Consequently, these species increased in abundance (McGlone et al, 2006), with shrub and grassland dominating the vegetation (Mildenhall, 1980). Substantial plant extinction, due to climatic deterioration was experienced throughout New Zealand (McGlone, 1985; Lee et al, 2001). Warmtemperate flora, often associated with Australia, was most affected. These extinctions continued throughout the Quaternary glaciations (McDowell, 2008). 


\subsubsection{Quaternary (past 2.58 Ma)}

The Quaternary is characterised, around the world, by increased climatic variability than the Cenozoic. The climate was predominately cool which had a large impact on the vegetation. The last tropical/sub-tropical species disappeared from the fossil record by c. $1.7 \mathrm{Ma}$ (Mildenhall, 1980). Full interglacial conditions such as MIS stages $1,5 \mathrm{e}, 7 \mathrm{a}$ and $7 \mathrm{~b}$ are characterised by widespread development of conifer-angiosperm forests. By contrast, the glacial episodes experienced an expansion of grassland and shrub taxa. The most detailed and widely studied period of the Quaternary is the most recent glacial / interglacial cycle (Newnham et al, 1999) and is described below.

\subsubsection{Last glacial period - present (Figure 2.5)}

Recent evidence suggests an earlier onset of LGM cooling in New Zealand. Alloway et al (2007) renamed this period the LGCP to include the earlier cooling phase beginning at $28 \mathrm{ka}$ with the coldest period, 21-18 ka designated as the LGM. However, evidence from other studies suggest an even earlier onset of the LGCP e.g. 30.5 ka (Vandergoes et al, 2005; Newnham et al, 2007c). This section will produce an overview of New Zealand vegetation change from $30.5 \mathrm{ka}$ to the present. More detailed vegetation records concentrating on the regions studied in this project will follow in Section 2.6.

The onset of the LGCP is marked by a change from sub-alpine shrub dominated vegetation, and forest floristic element evident at some sites (Wright et al, 1995; Moar and Suggate, 1996; Vandergoes et al, 2005; Burge and Shulmeister, 2007a; Marra and Thackray, 2010) to an open grass dominated environment with alpine herb taxa (McLea, 1996; Moar and Suggate, 1996; Vandergoes et al, 2005; Marra and Thackray, 2010). There are only a limited number of vegetation records that cover the LGCP, with the evidence suggesting the onset, represented by a grass peak, began $30.5-28 \mathrm{ka}$. This is followed by a period of milder climate recognised in the pollen record by an increase in shrub taxa at the expense of grass. Nevertheless, grassland was still the dominant vegetation throughout the majority of New Zealand during this relatively milder interval (Wright et al, 1995; Moar and 
Suggate, 1996). A rise in grass abundance, and decrease shrub abundance, marks the LGM around 24-18 ka (Vandergoes et al 2005; Newnham et al, 2007a).

Pollen evidence for the LGM indicates forest cover throughout the period was sparse, with all trees, except Nothofagus, rare in many areas (McGlone, 1988; Sandiford et al, 2003). The exception is the Northland region of the North Island which remained fully forested throughout the LGM (Newnham, 1992: McGlone et al., 2010). McGlone et al (2010) note a regional pattern in vegetation composition during the LGM splitting New Zealand into four zones. A north to south decline in tree abundance was noted with east and west South Island containing only trace amounts of tree pollen. Conversely, east and west South Island contained the highest abundance of herb taxa. Sub-alpine taxa were characteristic of the majority of New Zealand with grassland and open herb fields dominating the landscape. Shrub species were particularly prolific in coastal areas and much of the North Island (Newnham et al, 1999; Horrocks et al, 2010; McGlone et al, 2010). Moar et al (2008) found an isolated site in northern Westland, located near the current coastline which contained persistent shrub and tree taxa throughout the last glacial period. This suggests lowland areas of the Westland region were capable of supporting forest growth during the LGM. 


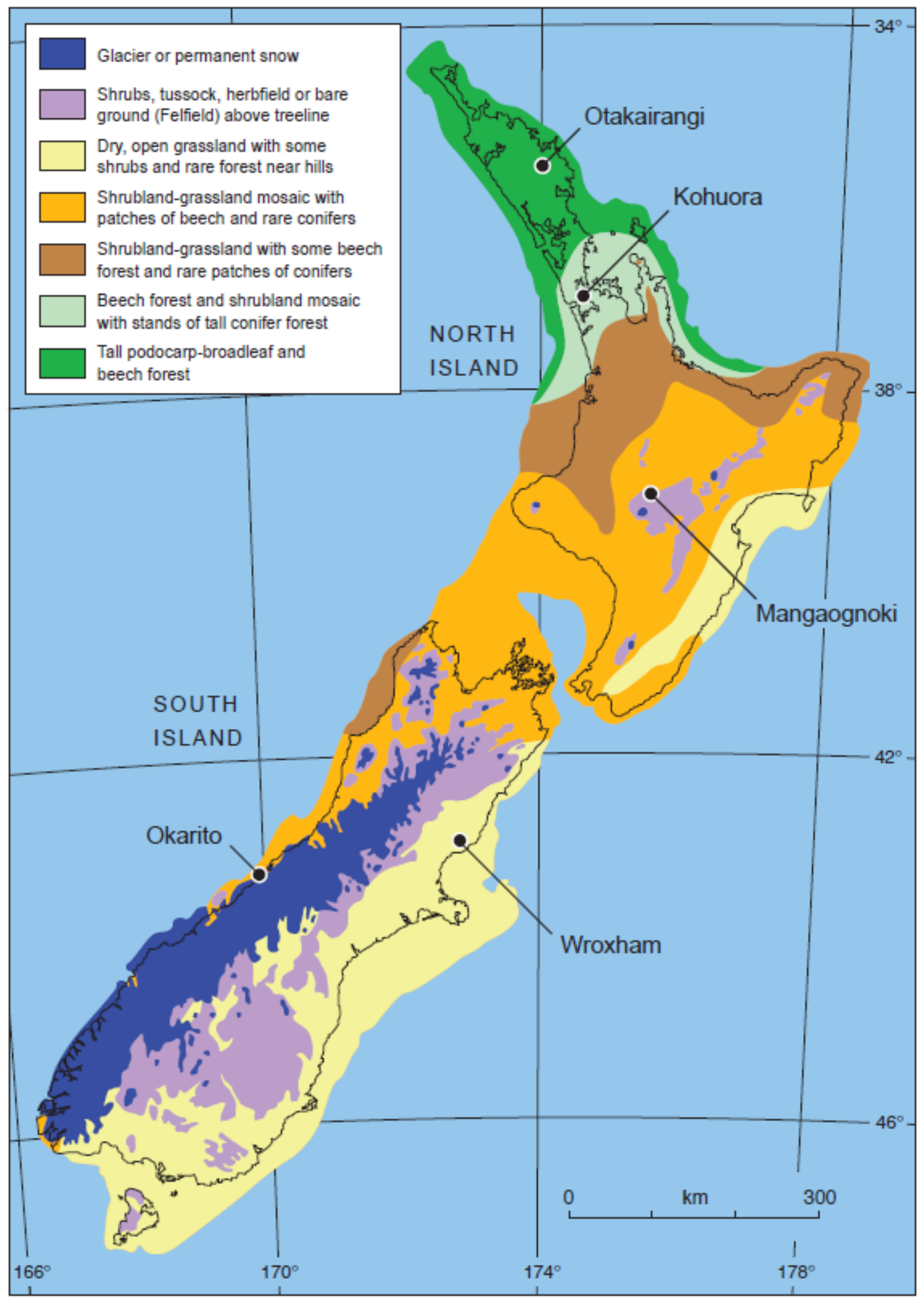

Figure 2.5: Summary diagram of LGM vegetation in New Zealand taken from McGlone et al (2010). 
The late glacial period was characterised by the rapid retreat of ice from its LGM position. This was accompanied by rapid southward afforestation beginning c. 18 ka in the Waikato Basin (Newnham et al, 1989) and in southern South Island around 10-9.5 ka (McGlone, 1988). This pattern does not represent a southward migration in vegetation but rather a stepwise southward amelioration of the climate. The increased temperature induced expansion of local forest refugia that had survived the cold conditions during the LGM. The generalised pattern of vegetation succession is: replacement of grassland by shrubs, colonisation by lowland forest, culminating in the growth of tall conifer/broadleaved or beech forests (McLea., 1996; Sandiford, et al, 2003; Vandergoes and Fitzsimons, 2003; McGlone et al, 2004; Newnham et al, 2007a). This transitional period of climatic amelioration is also known as the late glacial/interglacial transition (LGIT) and this term will be used throughout the rest of the text.

Recent evidence, from several records, indicates an interruption in the LGIT warming trend, although this is contested. Pollen reconstructions containing evidence of a climatic reversal are characterised by a stop or reversal in forest development combined with an increase in alpine shrub and herb species e.g. Coprosma, Phyllocladus and Poaceae. This is indicative of a cooling event (Vandergoes et al, 2005; Turney et al, 2003; McGlone et al, 2004; Newnham et al, 2007a; Vandergoes et al, 2008). However, other records spanning the same period show no evidence of a reversal with a continued increase in forest development (Singer et al, 1998; McGlone, 1995; Sandiford et al 2003; Vandergoes and Fitzsimons, 2003).

The Holocene epoch, c. 11.7 ka onwards (Walker et al, 2009), shows a continued vegetation change. The nature of change varied from region to region however all changes relate to an increase in biomass. The North Island experienced a generalised increase in the podocarp, Dacrydium cupressinum, which became the dominant species. In Wellington and the South Island, reoccupation by tall forest reached its vegetative climax by $9.5 \mathrm{ka}$ (McGlone, 1988). An exception to this is central Otago which remained unforested until $7.5 \mathrm{ka}$ (McGlone et al, 1995). From $7.5 \mathrm{ka}$ up to the time of initial human occupation the vegetative pattern was characterised by the spread of Nothofagus (beech) which quickly occupied areas 
of high rainfall especially in upland areas. However, beech was unable to colonise some isolated areas (McGlone, 1988, see Section 2.5.2). The driving force for vegetation changes during the early Holocene was consistent climatic amelioration. However, edaphic changes and in particular development of soils became a dominant influence on vegetation change from the mid-Holocene until human occupation of New Zealand (McGlone, 1988).

\subsection{South Island proxy records spanning the late Quaternary for selected regions}

This section will provide a review of previous research carried out in the three regions studied in this project. These regions include Westland, Nelson and the Mackenzie Basin. For each region the geological and proxy evidence spanning the LGCP to early Holocene will be concentrated upon.

\subsubsection{Westland}

This section will begin by exploring glacial sediment deposits, including successional outwash aggradational surfaces, loess and terminal moraines. Vegetation and inferred climate reconstructions based on pollen and beetle evidence will then be examined. Reconstructions from marine cores will also be discussed, although refer to Section 2.2.2 for more detail. A summary with points of divergence and/or convergence between the records will conclude this section. 


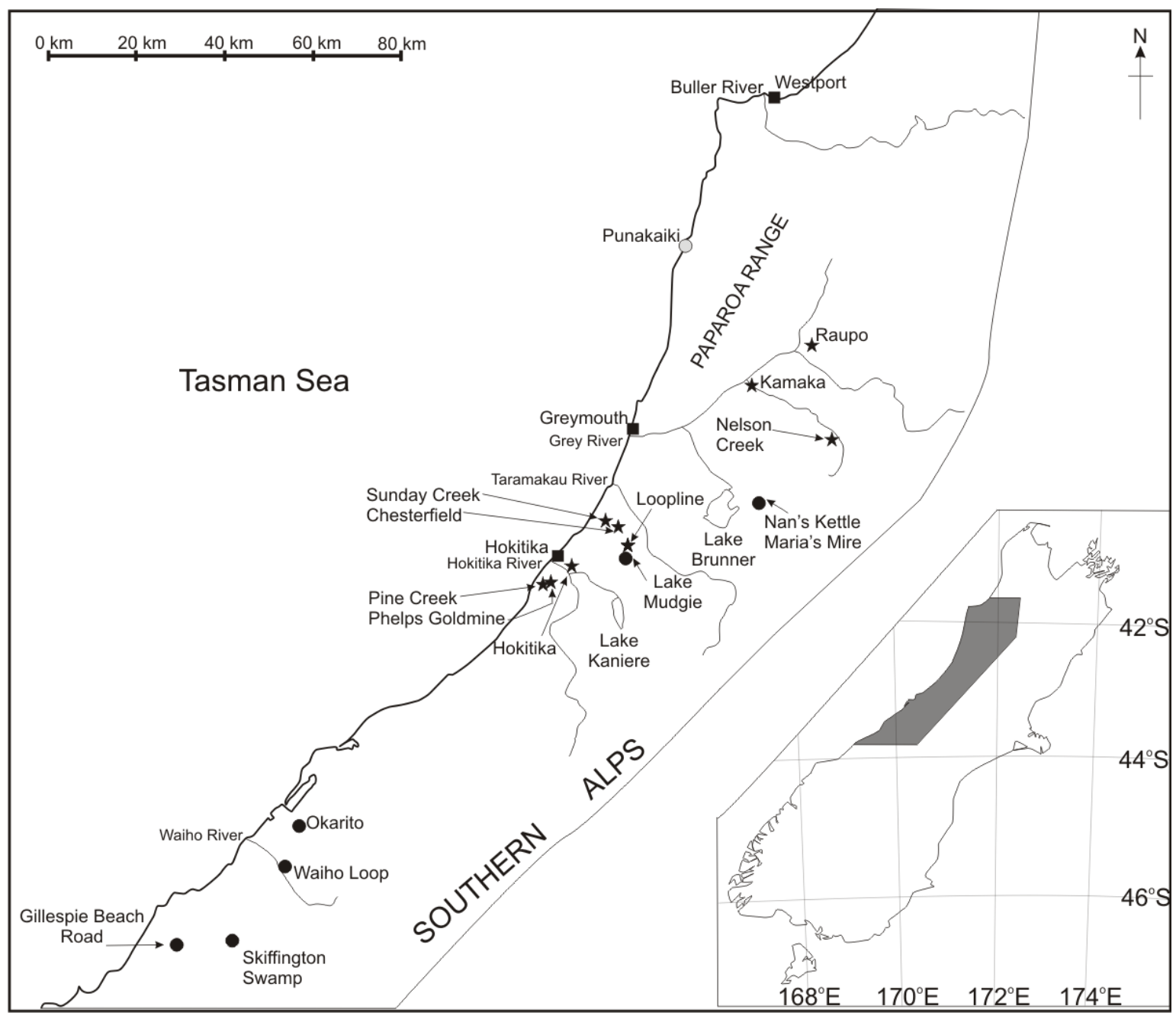

Figure 2.6: Location map of the Westland sites mentioned in the text. The light gray circle is a speleothems record site and black circles are pollen records used to produce an overview of the pattern of vegetation change The stars represent OSL dating of loess by Preusser et al (2005).

\subsubsection{Glacial deposits}

Suggate $(1965,1990)$ identifies three glacial advances during the last glacial period, each with an associated outwash surface formation (see Table 2.1). Since Suggate (1990) a number of studies in the region have been performed, improving upon the earlier glacial surface chronologies. Luminescence dating of river terraces at Raupo, south of the Grey River valley (see Figure 2.6) dates a sand layer lying directly below an outwash gravel associated with the Larrikins Formation. The sand deposit was dated twice, producing the ages $33.4 \pm 4 \mathrm{ka}$ and $31 \pm 2 \mathrm{ka}$. Overtopping the Larrikins formation is a fine-silt layer which was also dated and producing the following ages: $22.8 \pm 2.2 \mathrm{ka}$; $20.6 \pm 2.2 \mathrm{ka} ; 23.5 \pm 2.1$ ka. These ages bracket glacial derived material suggesting a glacial persisted from 
33.4 \pm 4 ka to $20.6 \pm 2.2$ ka based upon luminescence dating (Preusser et al, 2005). A change to fine silt overflow deposits, overlaying the Larrikins Formation, indicates a phase of reduced sediment source and river flow attributed to a period of glacial retreat between to the Larrikins glacial event and the beginning of the LGM (Hormes et al, 2003). This pattern is supported by loess deposits from two southern Westland loess sheets. The oldest was deposited after $36 \mathrm{ka}$ and before $24 \mathrm{ka}$, supporting an earlier LGCP onset. The second was deposited after $24 \mathrm{ka}$ but before $16 \mathrm{ka}$, deposited during the LGM. This indicates two periods of cooling during MIS 3 and 2 (Almond et al, 2001). Suggate and Almond (2005) date three periods of glacial advance in the Westland region the first between 34-28 ka, again suggesting an earlier LGCP, 24.5-21.5 ka and at 20.5-19 ka. The geological data points towards significant climate variability throughout the LGCP.

The Waiho Loop moraine is the most famous and controversial late glacial feature in New Zealand. Located $10 \mathrm{~km}$ below the terminal face of the Franz Josef glacier, it is a substantial terminal moraine and arguably represents a late glacial ice advance and associated climatic reversal (Denton and Hendy, 1994). Wardle (1978) initially dated wood which was directly overlain by glacial till from Canavan Knob, a rouche moutonneè located $1.6 \mathrm{~km}$ upstream from Waiho Loop. The wood was aged between 13.5-12.7 cal ka. Further dating by Denton and Hendy (1994) constrained the age to $12.9 \mathrm{ka}$. The timing of both studies indicates a glacial advance beginning synchronously with the beginning of the Northern Hemisphere YDC (12.9-11.5 ka, Alley, 2000), a period of sustained cooling. However, recent dating by Turney et al (2007) from the same site, provides an age of c. $13.1 \mathrm{ka}$, corresponding to a more Southern Hemispheric, ACR event (12.2-13.8 ka, EPICA Community Members, 2004). Cosmogenic nuclide ages collected from boulders forming the moraine, consistently age the feature 2300 years younger than Denton and Hendy (1994). Barrows et al (2007) conclude that this moraine is evidence of gradual glacial retreat opposed to a climate induced glacial advance. This conclusion was supported by a $\delta^{18} \mathrm{O}$ marine record (see Section 2.6.1.4.). Other conflicting arguments for the origins of the Waiho Loop add to the controversial nature of this feature. Recent research has attributed the moraine to have been caused by a rock avalanche inducing an ice advance and subsequently depositing the moraine in the existing location (Tovar et al, 2008; Shulmeister et al, 2009). 
However, modelling by Vacco et al (2010) disagrees with the rock avalanche theory above. Their models suggest rock avalanches and the debris covering the glacial does reduce glacial melt, but also causes the glacier to stagnate. Under such conditions, they argue a moraine morphologically similar to the Waiho Loop Moraine could not be formed. The foregoing discussion highlights the importance of clarifying the age and occurrence of a LGR in the Westland region

\subsubsection{Palynological records}

Compared with other regions of the South Island, pollen records from Westland are relatively abundant. Extensive research was initially carried out by Moar in the mid-late twentieth century (e.g. Moar, 1971; Moar and Suggate, 1996). However, records spanning back beyond the LGM are rare, and tend to come from river terrace risers, producing a fragmentary record of vegetation and inferred climate change. The few continuous records analysed have a limited resolution and are poorly dated in comparison to recent pollen records. Nevertheless, this initial work brings important and valuable insight of changing environmental conditions during the LGCP and LGIT. More recent work, e.g. Vandergoes and Fitzsimons (2003); Vandergoes et al (2005) and Newnham et al (2007a), have expanded upon Moar's earlier work, producing increased resolution and well dated continuous records spanning back to the LGM and even as far back as MIS 6 (Vandergoes et al, 2005). A summary of this earlier work combined with the recent studies will be discussed below.

Prior to the last glacial period, vegetation was dominated by shrub and sub-alpine taxa (Moar and Suggate, 1996; Vandergoes et al, 2005; Newnham et al, 2007a). At Okarito, initial LGM cooling, represented by an increase in grass, peaked between $30.5-28.5 \mathrm{ka}$. This was followed by a milder interval lasting 2-3 $\mathrm{ka}$ and straddling the KOT layer (c. $27 \mathrm{ka}$ ). This milder interval is characterised by a limited and temporary expansion of trees and shrubs. A second grass peak representing a return to colder climates and the LGM spanned 21-17.3 ka (Vandergoes et al, 2005; Newnham et al, 2007a). Lake Mudgie and Grahams terrace sites (Figure 2.6) also indicate full glacial conditions beginning prior to the KOT layer, and continuing until the end of the LGM, characterised by an open grassland dominated landscape (Moar and Suggate, 1996). 
Termination I (defined as the end of the LGM and, for this project, aged between 18-17 ka, Alloway et al, 2007) is marked by sustained decline of grass accompanied by an abrupt increase in shrubs. The timing of this climatic amelioration occurred between $18.3 \mathrm{ka}$ (Vandergoes and Fitzsimons, 2003) to 17.3 ka (Vandergoes et al, 2005), and is characterised by a succession of progressively larger peaks of shrub taxa culminating in podocarp/broadleaved forest with Dacrydium cuppressinum becoming the dominant species by $11.4 \mathrm{ka}$. Other sites from across the Westland region record a similar pattern of climate change (e.g. Gillespie Beach Road (Moar, 1973; Vandergoes and Fitzsimons, 2003), Maria's Mire, Nan's Kettle and Lake Mudgie (Moar and Suggate, 1996))

A possible climatic reversal spanning 14-11 ka was recognised in the Okarito pollen record (Vandergoes et al, 2005; Newnham et al, 2007a). A decline in tree taxa and coeval small increase in sub-alpine shrubs was concluded to represent a small and temporary cooling corresponding to both the ACR and YDC. No climatic reversal is reported from other records in the Westland region (Moar, 1971, 1973; Moar and Suggate, 1996; Vandergoes and Fitzsimons, 2003).

\subsubsection{Beetles}

A limited number of beetle studies have been undertaken in the Westland region (Burge and Shulmeister, 2007a, 2007b) with only one study by Burge and Shulmeister (2007b) representing the LGCP, producing a record spanning 37-21.3 ka from Wilson Lead Road. A pollen record was also taken from the same site (refer to Section 2.6.1.2). Similarly to the pollen evidence (Moar and Suggate, 1996), vegetation cover prior to the LGM, 37-34 ka, was dominated by closed canopy, forest vegetation. A transition to a more open landscape, with tussock grasses and alpine/scrubby taxa occurred after $34 \mathrm{ka}$ and continued until $21.3 \mathrm{ka}$. However, the dominant signal throughout this period is still closed canopy environment. It is therefore concluded by Burge and Shulmeister (2007b) that the LGM experienced milder conditions than evident in the pollen records. 


\subsubsection{Marine records}

There is limited marine core evidence taken from off shore Westland coastline. However, during the LGM the ice extent reached near to or beyond the current shoreline. Glacial outwash would have been deposited in the oceans within close proximity to the glaciers. Therefore, marine cores would provide a sensitive record of glacial activity in the region. Marine record SO163-GH3 (Figure 2.6) has two peaks in the sedimentation rate at $28-27 \mathrm{ka}$ and $18.4 \mathrm{ka}$, the latter representing the LGM. These pulses of sediment have been attributed to periods of glacial advance and associated increased erosion and sediment load in rivers that source this site. The $\delta^{18} \mathrm{O}$ record indicates Termination I began $19 \mathrm{ka}$ and was characterised by gradual, continuous warming, climaxing at $11.4 \mathrm{ka}$ and showing no evidence of a climatic reversal (Barrows et al, 2007). A pollen record from core site TAN0513-14 (Figure 2.6) corresponds closely to the Okarito record with the LGM dominated by grass and alpine herb and shrub species including a dominance of Asteraceae. Termination I is marked but an abrupt transition with a rapid decline in grass around $18 \mathrm{ka}$. Climate amelioration was consistent and culminated with Dacrydium and podocarp dominated forest by c. 11 ka (Ryan et al, 2009).

\subsubsection{Summary}

Overall, there is general consensus between the different records in the Westland region. The geological, pollen and marine evidence all suggest three glacial advances were experienced during the LGCP. The first advance began c. 30-28 $\mathrm{ka}$ and at $25 \mathrm{ka}$ (proxy record dependent), indicative of an extended LGM. The second occurred 24-18 ka, representing the LGM. Relatively milder conditions were experienced in the period between these two advances and straddle an important chronostratigraphic tie marker, the KOT layer (c. $25.4 \mathrm{ka}$; refer to Section 3.5.2). However, the limited number of continuous records covering this period prevents accurate conclusions of climate change. Inconsistencies between the beetle evidence, where milder conditions were experienced uniformly throughout this period, compared to the pollen results also adds to the uncertainties of this period. Also, the extent and timing of the LGCP warming interval is not clearly defined. 
The Westland records also provide general consensus on the timing of Termination I occurring between 18-17 ka. This is marked by sustained and abrupt warming and associated vegetation response. However, whether or not a LGR occurred in the region is debated. Geological interpretations, pollen evidence and chronology of records do not rule out the possibility of such an event. This period would therefore value from more high resolution, continuous records which are well dated and span back to $30 \mathrm{ka}$.

\subsubsection{Nelson and Marlborough regions of northern South Island}

This section provides a review of previous work carried out in the Nelson and northern South Island area with an emphasis upon the inland, south-eastern Nelson region. Figure 2.7 shows the location of the sites mentioned in the text. During the last glacial period Nelson and northern South Island were extensively glaciated. Glacial deposits laid down during this period provide evidence of the ice extent and nature of deglaciation. There are also numerous lakes, tarns and river terrace riser containing peat lenses and located outside the LGM ice extent. The deposits from these non-glacial sites have been utilised for pollen, beetle and other proxy reconstructions related to vegetation and climate change during the LGCP and LGIT. Speleothems, also provide useful information about climate change in the region during this period. All of these proxies will be discussed in this section. 


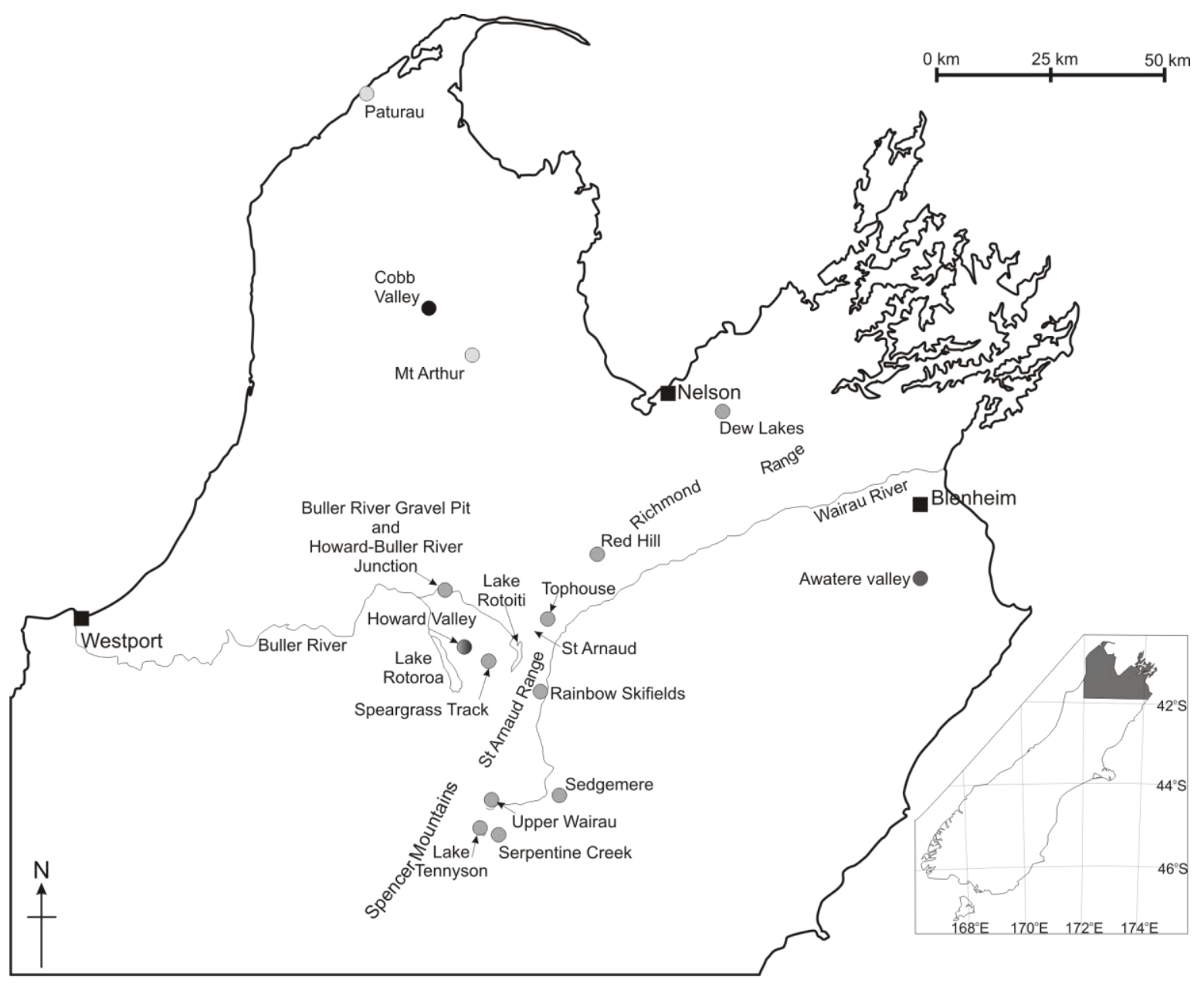

Figure 2.7: Location map of the north South Island sites mentioned in the text and the pollen record locations overviews in section 2.6.2.2. Light gray are speleothem records, medium/light grey are pollen records used to produce an overview of the pattern of vegetation change; medium/dark grey are the beetle records (Howard Valley contains both pollen and beetle records), and black circles locate the moraine exposure age sites.

\subsubsection{Geological evidence}

The Spencer and St Arnaud Mountain ranges, which extend the Southern Alps into this region, were extensively glaciated during the last glacial period. The ice extent is marked by numerous terminal moraines which have been mapped and described by Suggate (1965) (see Table 2.1). The LGM terminal moraines are found at the highest elevations on the eastern side of the ranges. For example at Lake Tennyson the terminal moraine is 1100 m.a.s.I (McCaplin, 1992a; Figure 2.7) and 1200 m.a.s.I in the upper Wairau Valley (McCaplin, 1992b; Figure 2.7). Whereas, on the western side of the ranges, in the Nelson Lakes National Park, the terminal moraines are limited to 600 m.a.s.I and 400 m.a.s.I at lake Rotoiti and Rotoroa, respectively (Suggate, 1965; Figure 2.7). Therefore, an east to west lowering of the ice extent was experienced during the LGM and was most likely caused by precipitation differences. In the north-west, the Cobb valley terminal 
moraine was restricted to 850 m.a.s.I (Shulmeister et al, 2005; Figure 2.7) indicating a latitudinal gradient in LGM ice limit as well.

The morainic evidence suggests rapid deglaciation at the end of the LGM, which started, at the earliest, $20 \mathrm{ka}$ with extensive ice wasting and retreat by $18 \mathrm{ka}$. This retreat was not constant, but stepwise with standstills and minor advances (Shulmeister et al, 2005). McCaplin (1992b) located a moraine which could potentially be evidence of a late glacial readvance in the upper Wairau Valley at the confluence of the Wairua River and Island Gully ( 1100 m.a.s.I).

\subsubsection{Palynological records}

LGCP pollen records from south-east Nelson are predominantly derived from peat and other organic units interbedded with fluvioglacial boulders, gravels and silt deposits in river terrace risers. The pollen evidence from these peat sections is indicative of an open landscape environment, dominated by grass and herb taxa (e.g. Apiaceae, Asteraceae). High abundances of Cyperaceae indicate low energy, marshy environments (Moar, 1971, 1980; McLea, 1996). Continuous pollen records also shared a similar vegetation composition during the LCGP (e.g. Mabin, 1983). Quantities of woody/shrub taxa were low, if at all present, with Phyllocladus the most consistently represented shrub from the sites in the region (Moar, 1971, 1980; Mabin, 1983; McLea, 1996). Tree species are represented in some pollen records, with Nothofagus representing 10\% at Howard Valley (McLea, 1996) and Moar (1980) also finding low percentages of Nothofagus from other LGCP sites. Therefore, during the LGCP the vegetation of the region was dominated by grassland with refugia of beech and podocarp/broadleaved trees, indicated by trace amounts of this tree pollen at various sites (see Figure 2.7 for the pollen site locations producing this overview).

Termination I is characterised by a rapid transition from grassland and herbland to shrubland dominated vegetation. McLea (1996) found shrub taxa, particularly Phyllocladus and Halocarpus, beginning to colonise grassland as early as c. 13.7 $\mathrm{ka}$ at Lake Tennyson with shrubs becoming the dominant vegetation by $10.4 \mathrm{ka}$ at Wairau. Overall in south-east Nelson, partial colonisation by shrubs occurred by $11.5 \mathrm{ka}$ and this element became dominant at all sites by $9.3 \mathrm{ka}$. Thus, the 
vegetation was becoming increasingly woody in nature (McLea, 1996). Climatecontrolled succession continued with the development of forest. Moar (1971) found beech forest already established at Tophouse by c. $8.7 \mathrm{ka}$ with beech forest expanding from Tophouse up the Wairau Valley (McLea, 1996). McLea's (1996) pollen records indicate that expansion of beech from refuges in Murchison and Moutere was initially slow. However, by 8.9 ka beech forest had developed in the upper Buller River after which the forest expanded quickly and by approximately $6.8 \mathrm{ka}$ beech was well established in the Nelson Lakes region. There was little change in vegetation composition until anthropogenic activity (Moar, 1971; McLea, 1996). In the Cobb valley, north-west Nelson (see Figure 2.7), Singer et al (1998) also found a similar transition from a dominant grassland environment during the LGCP, followed by rapid reforestation, starting c. $15.9 \mathrm{ka}$, by shrubs species and culminating in beech forest. Vegetation records from Dew Lakes, in the Bryant range, north-east Nelson (see Figure 2.7), show shrub taxa, including Coprosma, Myrsine and Phyllocladus, were already the dominant vegetation type by c. 12.5 ka with low abundance of podocarp and beech taxa. By c. 9.5 ka beech forest was dominant and remained so until European clearance (Dodson, 1978).

The evidence above shows close agreement between sites. LGCP was dominated by grassland and herb taxa, and a rapid deglaciation. An increase in shrub species, particularly Halocarpus and Phyllocladus, followed with vegetation culminating in beech forest. The timing of these events is not completely synchronous across the region with the north-eastern sites becoming fully forested prior to the southern sites. This is probably due to the latitudinal and altitudinal differences between these sites.

\subsubsection{Speleothem records}

Hellstrom et al (1998) produced $\delta^{18} \mathrm{O}$ and $\delta^{13} \mathrm{C}$ speleothem records spanning the past 31 ka from a cave site below Mt Arthur (Figure 2.7). Later work by Williams et al (2005) produced another $\delta^{18} \mathrm{O}$ records from cave sites in Paturau (Figure 2.7) and Punakaiki (Figure 2.6) also shown in Figure 2.7, spanning the past 23.4 ka and complementing Hellstrom et al (1998). The results from both are reviewed below. 
During the LGCP three negative $\delta^{18} \mathrm{O}$ excursions are recognisable and occurred between 27-25 ka, 24.5-22 ka and reaching minima between 22-18 ka. Each of these excursions can be associated with a glacial advance providing evidence of extended cold conditions. Attitudinal lowering of the treeline by $600-700 \mathrm{~m}$ was experienced at Mt Arthur during this period (Hellstrom et al, 1998). Both records indicate the coldest part of the LGCP. The LGM occurred between 23.4-18 ka. Rapid climatic amelioration marks the beginning of the deglaciation at $18 \mathrm{ka}$ (Williams et al, 2005), with decreased $\delta^{13} \mathrm{C}$, indicative of increased plant productivity and rapid reforestation in the region (Hellstrom et al, 1998). Another negative $\delta^{18} \mathrm{O}$ excursion, representing a cooling period, interrupted the LGIT warming trend between 13.8-11.1 ka. This cooling event spans the later part of the ACR and the YDC and therefore cannot be attributed to just one of these events (Hellstrom et al, 1998; Williams et al, 2005). There was not a similar response by the $\delta^{13} \mathrm{C}$ possibly due to a limited, if any, vegetation response (Hellstrom et al, 1998).

\subsubsection{Beetle records}

A fragmentary, river terrace record from Howard Valley, south-east Nelson (Figure 2.7), provides a beetle and macrofossil record spanning the LGCP (34-18.5 ka). Nothofagus menziesii leaves were found between 34.8-33 ka suggesting potentially more widespread forest occurring prior to the onset of the LGCP. Forest beetle species were still present, although in rare amounts, until $27 \mathrm{ka}$. Grassland taxa were dominant during this period. From 27-8 ka the area was dominated by an open grassland environment, with no evidence of lowland tree species. However beetle taxa suggest the site possibly represents an altitudinal tree line limit during the LGM (Marra and Thackray, 2010). Like the Howard Valley site, LGM beetle assemblages spanning 21-19 ka from Awatere Valley, Marlborough (Figure 2.7) were dominated by tussock grassland species. However, there was also a large forest influence and the record is interpreted as representing a forest refugia site (Marra and Leschen, 2004). Temperature reconstructions, inferred from the beetle evidence, suggests a maximum summer reduction range of 2.5-5 ${ }^{\circ} \mathrm{C}$ and a winter temperature reduction of $3.5-6{ }^{\circ} \mathrm{C}$ compared with current average summer temperatures in the same region (Marra et al, 2004). 


\subsubsection{Summary}

As with the Westland sites, there is good consensus between the different proxies. Both the vegetation and speleothem records provide evidence for the cold period extending beyond the LGM. However, there are few records which span the LGCP and the majority provide a fragmentary reconstruction of past climate and/or vegetation change. Therefore, there is limited insight of climate variability in the region during the LGCP.

Termination I is represented by rapid climatic amelioration and quick vegetation succession. Pollen evidence suggests a southward warming trend with climate amelioration starting in north Nelson region and spreading southwards. The speleothem records (Hellstrom et al, 1998; Williams et al, 2005) indicate a late glacial climate reversal interrupting the warming trend between 13.8-11.14 ka and McCaplin (1992b), found a moraine that may be attributed to this cooling. However, the pollen records show no evidence for a LGR. The Nelson region contains a variety of records but there is a paucity of sites extending beyond the LGM, limiting firm conclusions of the pattern of climate change during the LGCP. An increase in records spanning this period is necessary for an improved understanding of vegetation and climate change in the region.

\subsubsection{Central Canterbury - Mackenzie Basin}

This section will concentrate on last glacial evidence from the Mackenzie Basin and surrounding area. However, in comparison to the other regions, this area has considerably fewer records spanning the last glacial. Therefore, only two subsections will be included in this section, geological evidence and proxy records. 


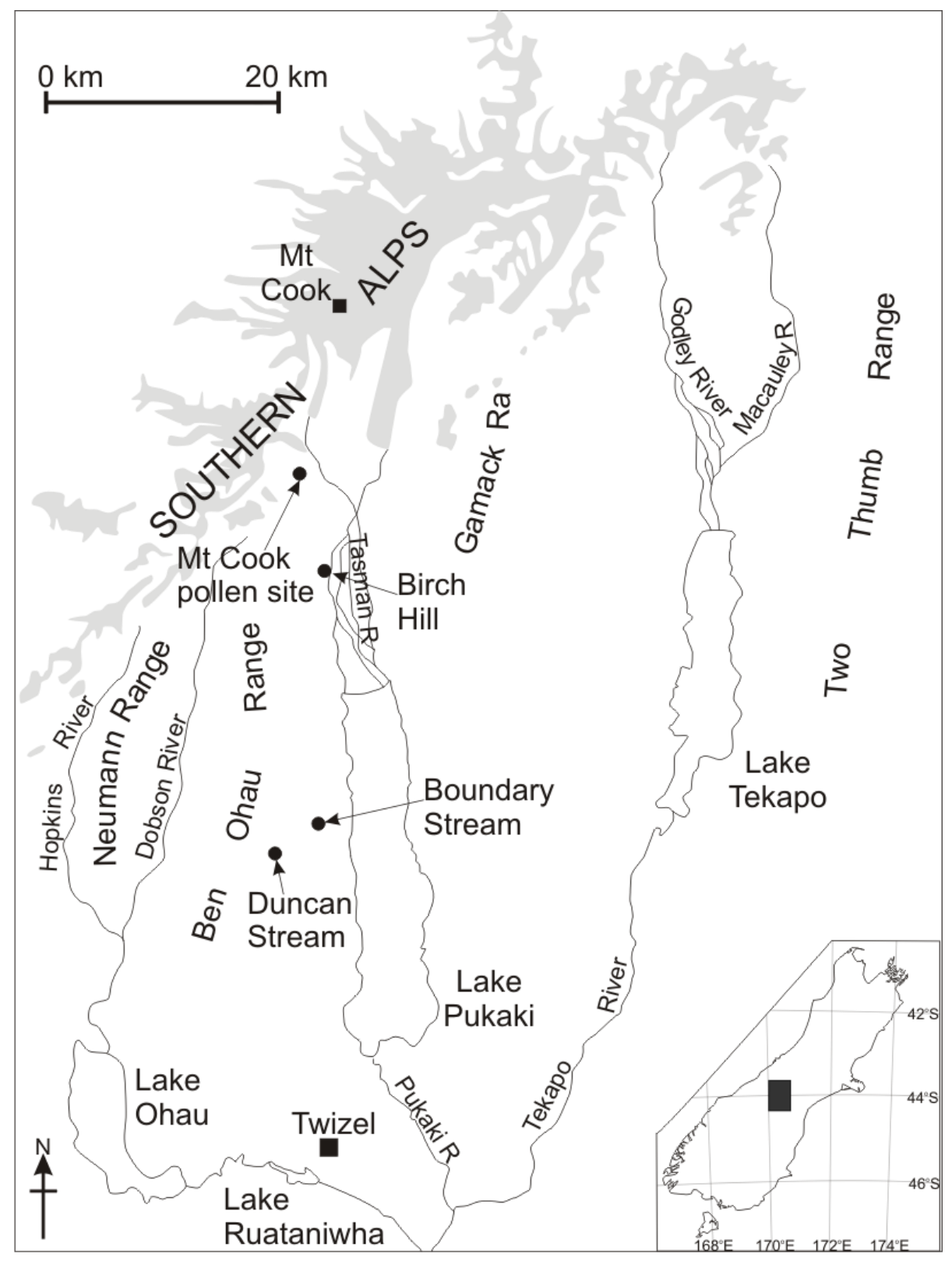

Figure 2.8: Location map of the pollen sites used in the description of past vegetation change. The shaded area is a rough location of ice in the region.

\subsubsection{Geological evidence}

The geomorphology of the Mackenzie Basin is dominated by Quaternary aged glacially derived deposition features, including late Quaternary moraines and extensive outwash aggradation surfaces. Gair's (1967) geological mapping of the region recognises five moraine formations evidence of at least five glacial advances; Wolds, Balmoral, Mt John, Tekapo and Birch Hill formations. Subsequently extensive research dating the moraines has been achieved producing a detailed chronology of glacial activity in the region. The Wold formation, the oldest glacial advance, is assigned to MIS 8 (Suggate, 1990) and 
both clast specific gravity research (McGregor, 1981) and geomorphological and loess coverbed distribution (Maizel, 1989) are consistent with this assignment. A period of glacial retreat activity separates the Wolds and Balmoral advance. Radiocarbon dates from wood fragments located in soil on the Balmoral moraine ages this advance at $40.2 \mathrm{ka}$ (Porter, 1975b). Another glacial retreat period follows until the Mt John, Tekapo and Birch Hill Formations (in chronological order) were deposited during the LGM (Porter, 1975b; Suggate, 1990; Table 2.1). EquilibriumLine Altitudes (ELAs) were estimated using the above formations which represent the former ice limits. ELAs were $1050 \mathrm{~m}$ lower during the Balmoral advance and $850 \mathrm{~m}$ lower during the LGM (Porter, 1975b).

Schaefer et al (2006) dated the inner terminal moraines from around Lake Pukaki's lake margin. The average age for the end of the LGM is $17.4 \mathrm{ka}$ and a maximum age of $19.3 \mathrm{ka}$. These ages correspond with other ages of the termination from sites spanning the whole of New Zealand (e.g. Alloway et al, 2007). Putnam et al (2010a) aged the LGM Boundary Stream moraines at $18 \mathrm{k}$, agreeing with Schaefer et al (2006). Numerous postglacial moraines have been deposited by the glacial still stands during glacial retreat. Putnam et al (2010b) age a glacial resurgence culminating at 13 ka corresponding with the $A C R$, and providing evidence of a LGR east of the main divide. Evidence of asynchronous timing of glacial advance in New Zealand, coinciding with Northern Hemispheric warming episodes continues throughout the Holocene (Schaefer et al, 2009).

\subsubsection{Proxy records}

Compared to the other regions, a limited number of vegetation reconstructions have been produced from the Mackenzie Basin and surrounding area. No record extends beyond the LGM. Boundary Stream Tarn is a kettle hole located on a LGM lateral moraine bounding Lake Pukaki. The site became ice free and sedimentation began by $17.5 \mathrm{ka}$, suggesting the onset of deglaciation occurred around this time. Between 17.5-15.5 ka the vegetation was dominated by mixed grassland and Coprosma dominated shrub, representative of an alpine environment and indicating the climate was colder and harsher than contemporary regimes. An expansion of tall tussock grass occurs at $14.1 \mathrm{ka}$ and is combined by an estimated mean summer temperature decline of $1.5-2{ }^{\circ} \mathrm{C}$ between 14.1-13.2 
ka. This late glacial cooling period corresponds with the timing of the $A C R$, and supports an Antarctica driven cooling and asynchronous interhemispheric pattern of climate change. This cold period is followed by warming and vegetation change from grassland/shrubland to Halocarpus podocarpus forest. After $11.5 \mathrm{ka}$ Phyllocladus rapidly becomes the dominant taxon in the record (Vandergoes et al, 2008).

Other evidence from the region shows a similar pattern of vegetation change from grassland and bare ground to a grassland-Myrsine-Coprosma shrubland followed by first Halocarpus and then Phllyocladus scrub or low lying forest (Moar, 1971). The early Holocene continued to be dominated by Phyllocladus. There is a lack of tall tree taxa in the pollen record and only trace amounts of Prumnopitys taxifolia suggest the source was either long distance dispersal or local small stands (McGlone and Moar, 1998). All the records suggest limited forest growth consisting of tall tree taxa during the LGIT and early Holocene.

\subsubsection{Summary}

A detailed morainic history of the region shows a complex glacial pattern of retreat and advance throughout the last glacial period also pointing towards a complex pattern in climate change. The available proxy data correspond with the geological data but the paucity of records extending into the LGCP makes it impossible to know how vegetation responded during this period. Only a handful or records span the LGIT. Moraine mapping indicates that a large proportion of this region was glaciated during the LGM (e.g. Suggate, 1990) limiting the areas where sediment records could have been preserved. Also, the regions climate is very dry, which is not the ideal conditions for proxy record preservation, again making it difficult to find any sites which could preserve a record extending back into the LGCP.

\subsubsection{Summary}

Section 2.6 has examined broadly equivalent-age records from a number of regions across New Zealand which are relevant to this project and also highlights some issues within the existing records. These include the paucity of records extending into the LGCP from all three regions, different climate reconstructions 
produced by different proxy records and whether or not a LGR registered in New Zealand. The results from this project aim to build upon the existing knowledge and tackle some of these issues in a bid to enhance the understanding of climate change in New Zealand. 


\section{Chapter 3: Methodology}

This chapter will describe each method used in this project and provide a rationale, and if necessary, a literature review of the method. Site selection and field sampling will be described first, followed by palynological methods, including the preparation process, pollen identification and statistical analysis. The other laboratory based methodologies (Loss on Ignition (LOI) and Particle Size Analysis (PSA)) will then be described. Finally the methods used to produce the chronology at each site will be explained.

\subsection{Site selection and field sampling}

Four new sites that collectively span the interval $30-8$ ka have been identified (Figure 1.2). The four sites represent locations that today are characterised by strong contrasts in temperature and precipitation. The rationale for site selection is explained in more detail in Section 1.4.

Three sites are moraine-impounded lakes or tarns with associated peat deposits. The moraine complex provides geological time constraint on the age of the deposits. Lake Mudgie and Manks Tarn were sampled in 2002 by Prof. Rewi Newnham, Dr Marcus Vandergoes, Dr Chris Hendy and Prof. Tom Lowell. The sites were cored using a Livingstone piston corer directly on the peat surface (Figure 3.1). In February 2008 the author participated in preliminary coring at Forks Lagoon. Further coring continued in February 2009 with a further two overlapping cores collected. This site was cored from a small boat platform (Figure 3.1) using a Livingston piston corer. At each of the above sites an $8 \mathrm{~cm}$ diameter barrel, collecting $1 \mathrm{~m}$ long sections, was used cored. Coring continued until either the substrate was too difficult to penetrate or the base of the deposit was reached. Whilst on site, each $1 \mathrm{~m}$ section was extruded into half cut PVC piping, logged and wrapped in cling-film. All the cores collected were refrigerated at $4{ }^{\circ} \mathrm{C}$ until used for analysis. 
Howard valley, the fourth site, has a number of river terrace risers with exposed section, three of which were sampled for this project (in February 2008, January 2009). In 2008 the organic bands were sampled at a $1 \mathrm{~cm}$ resolution for pollen analysis. Samples were cut directly from the riser face and placed in labelled, sealable bags. In 2009 monoliths were collected from the thickest terrace riser. These were logged then wrapped in foil and boxed for transport. Two cores were collected from the base of two terrace risers using the Livingstone Piston corer with the $8 \mathrm{~cm}$ barrel. The cores were extruded into half cut PVC piping, logged and wrapped in cellophane. All the samples collected from Howard Valley were refrigerated at $4{ }^{\circ} \mathrm{C}$ until used for analysis.

Prior to subsampling in the laboratory, the cores and monoliths were split in two and one half was kept as an archive. These samples where then photographed, logged and finally subsampled.

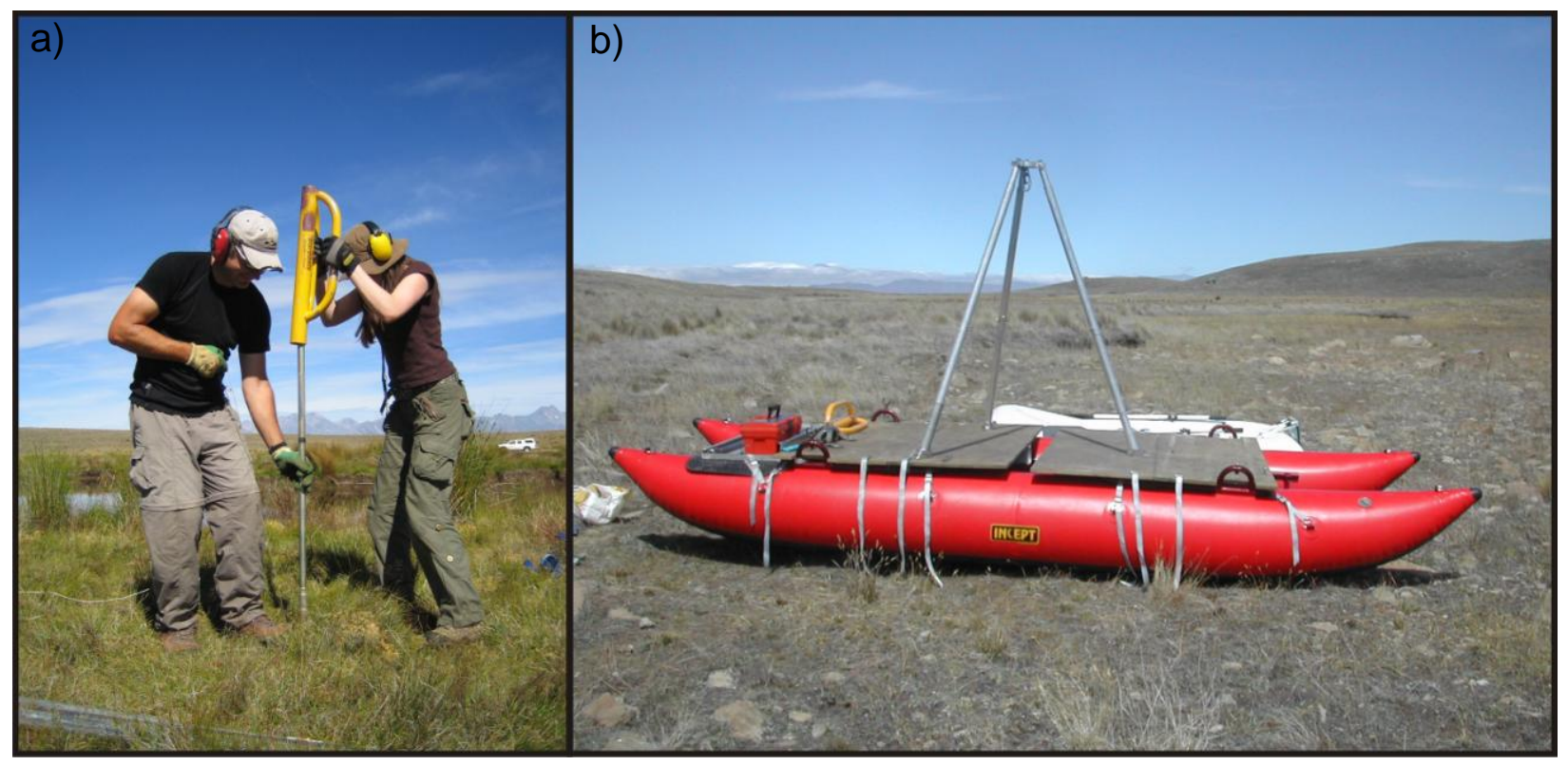

Figure 3.1: Examples of the coring technique used on a) the peat surface and b) the boat setup used for the lake coring. 


\subsection{Pollen procedure}

\subsubsection{Sampling Interval}

The sampling interval used varied between sites and within sequences depending upon core length and extent of change between pollen assemblages. Initially a skeleton technique, i.e. a coarse sampling interval, was used to sample down the cores. Subsequent higher resolution sampling was carried out for the sections of interest. For all pollen samples $0.5 \mathrm{~cm}^{3}$ of material spanning $0.5-1 \mathrm{~cm}$ depth (depending upon site) was taken.

\subsubsection{Pollen preparation}

The methodology for the laboratory pollen preparation followed the standard method outlined in Moore et al (1991) although modifications to procedures were needed depending on the sediment composition (Figure 3.2). To aid the estimation of pollen concentrations a known volume of sediment was used with exotic Lycopodium marker tablets added to each sample at the beginning of the preparation. The samples were soaked in $10 \%$ potassium hydroxide $(\mathrm{KOH})$ overnight then boiled in fresh $\mathrm{KOH}$ for 20 minutes. These were sieved through a $185 \mu \mathrm{m}$ sieve to separate the coarse material from the sample. Any macrofossils were collected and stored at $4^{\circ} \mathrm{C}$ for possible radiocarbon dating. If silicate minerals were present, the samples were soaked overnight in $60 \%$ hydrofluoric acid (HF) then heated for 20 minutes in 10\% hydrochloric acid $(\mathrm{HCl})$. If any silicate minerals were still present the samples were again heated in $60 \% \mathrm{HF}$ for 45 minutes then heated in $10 \% \mathrm{HCl}$ for 20 minutes. The peat samples did not undergo the HF stage. Glacial acetic acid dehydrated the samples which then underwent acetolysis for three minutes at $95-97{ }^{\circ} \mathrm{C}$. A 9:1 acetic anhydride $\left(\left[\mathrm{CH}_{3} \mathrm{CO}\right]_{2} \mathrm{O}\right)$ to concentrated sulphuric acid $\left(\mathrm{H}_{2} \mathrm{SO}_{4}\right)$ mixture was used for the acetolysis step. Glacial acetic acid was added to the samples and then washed with distilled water, and sieved through $5 \mu \mathrm{m}$ removing the fine material. If samples retained a high organic content then the acetolysis process was repeated. The samples were stained using aqueous safranine, washed in water then dehydrated using ethanol followed by tertiary-butanol. Finally the samples were mounted in silicon oil. 
Some experimentation with heavy liquid density separation was attempted but the large variation in the sediment matrix from sample to sample required considerable adjustments and so this methodology was not applied routinely.

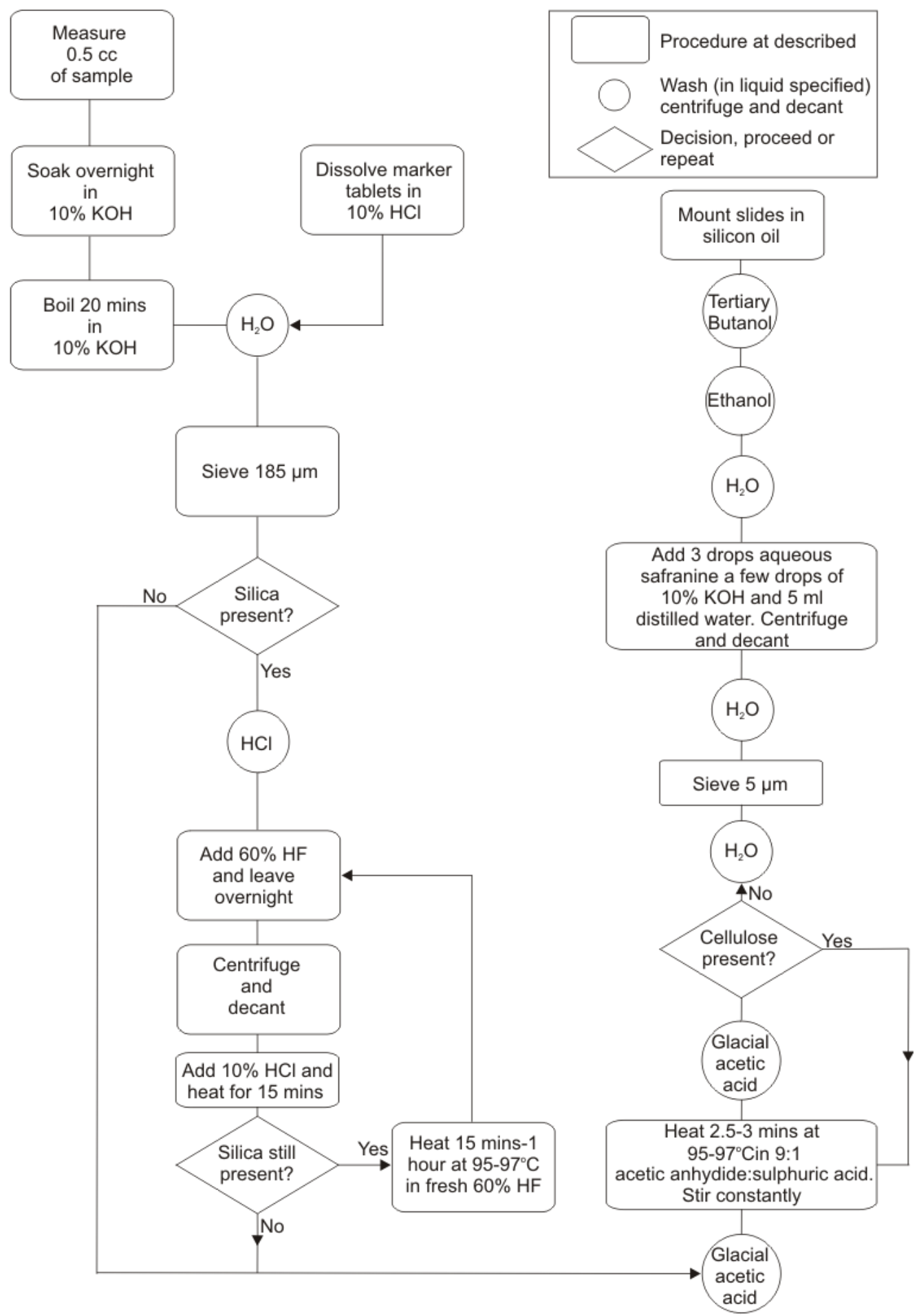

Figure 3.2: Methodological flowchart for pollen sample preparation. Modified from Moore et al (1991). 


\subsubsection{Pollen counting and identification}

Slides were analysed using a light microscope under $x 400$ magnification with x1000 oil immersion used on difficult grains. The identification of the pollen was aided by using New Zealand pollen type slide collections at the University of Plymouth and in Landcare Research from Lincoln, New Zealand. The dicotyledonous pollen types were identified using Moar (1993) and the ferns and fern allies were identified using Large and Biggins (1991). A sum of at least 250 dryland pollen grains was counted for each sample where possible.

Certain pollen types were difficult to identify due to deterioration or ambiguous affinities. The following are the procedures used to handle some of these difficulties:

Podocarpoid: This taxonomic term refers to the bi-saccate (recticulate) grains that have subsequently lost their sacs and only the main body of the grain has survived. These species include Prumnopitys taxifolla, $P$. ferruginea, Largarostrobos, Lepidothamnus, and Podocarpus. The taxon podocarpoid is still an important part of the pollen count as it represents the Podocarpaceae species, a tall tree family indicative of a forest environment. The deteriorated nature of these grains may be indicative of a high energy environment during grain deposition, or possible reworking of the grain, which in itself provides further insight of the environment these grains were deposited in.

Prumnopitys: This group was split into 3 headings during counting: Prumnopitys taxifolla, P. ferruginea and Prumnopitys for the grains which couldn't be differentiated between the two species. The counts where then adjusted with the ratio of $P$. taxifolla and $P$. ferruginea used to divide the Prumnopitys group between the two.

Spores: Species which represent a distinct environment, i.e. trees ferns (Cyathea and Disksonia species) where identified to species level. Those which were less significant or difficult to identify to species or even family level were placed in one of two groups: monolete spores and trilete spores. The monolete spore group includes the following: Psilotaceae, Marattia, Schizaea spp., Thelypteridaceae, 
Lindsea viridis, Davalliaceae, Dryopteridaceae, Blechnum spp., Anarthropteris lanceolata, Sticherus spp, Pyttosia eleagnifolia. The trilete spore group encompasses the following: Ophioglossaceae, Osmundaceae, Loxsoma cunninghamii, Ctenopteris spp, Pteridaceae, Lindsaea spp. (except L. viridis) Pillularia novae-zelandiae, Azolla rubra.

Poaceae: The pollen grains of this family are very similar and almost impossible to identify to species level or even genus. However, tall tussock grasses (Chionochloa) produce larger pollen grains than other grass species in New Zealand, tending to be greater than $40 \mu \mathrm{m}$. Based upon McGlone and Moar (1998) the taxon Poaceae was split into two groups: $>40 \mu \mathrm{m}$ and $<40 \mu \mathrm{m}$, the later including all other grass species.

Unidentifiable: This class includes any whole grain which was obscured or deteriorated to such an extent that it could not be identified. The number of unidentifiable grains gives an indication of the quality of the slide but also of the environment during deposition or whether possible reworking has occurred.

\subsection{Pollen analysis}

A number of calculations, statistical analyse and computer programs have be used to analyse the pollen data. The methods are explained below.

\subsubsection{Pollen percentages and concentrations}

Pollen data can be represented in a number of different ways. For this project both percentage data and pollen concentration are presented. Relative or percentage data are the most commonly used format for communicating pollen information in diagrams. Percentage data express a given pollen type in sample as a proportion of a specific pollen sum for that sample. This removes the effect of differing amounts of pollen grains in each sample, making comparisons between samples easier (Birks and Gordon, 1985). Pollen concentrations differ from percentage data as the concentrations are independent of changes in other pollen types. The percentage of pollen removes the effect of changing total grain amounts between 
samples, however this produces a constraint on the data. As one species increases in relatively frequency other species must decrease to preserve the $100 \%$ total. This statistical artefact could be interpreted as a negative relationship between the two species. In contrast, pollen concentrations can be used to distinguish between actual decline and relative decline in a species presence (Birks, 1985). However, pollen percentage data provide a good overview of the pollen assemblage and have been deemed a reliable format for showing the pollen results at all sites. In this project only Forks Lagoon uses pollen concentrations as well as percentage data due to the over dominance of one aquatic taxa; Isoetes. This is explained further in Chapter 7, Section 7.5.1.

Pollen concentrations can be calculated in a number of ways. Direct estimations occur when all pollen and spores are counted from a sub-sample from a known volume/weight of material. By knowing how much this fraction of subsample relates to the original sample, direct estimations of pollen concentration can occur (Jórgensen, 1967). Alternatively, indirect estimates can occur by adding a known amount of exotic marker pollen or spore, i.e. pollen or spore grains types which are not native to the region and morphologically different to the other pollen and spore that may be observed (Bonny, 1972). For this project a Lycopodium tablet with a known number of grains was added to each sample at the beginning of the pollen preparation. Once the preparation has been completed, both the pollen and exotic marker are counted. The indigenous pollen concentrations are then estimated through a simple proportional calculation (Maher, 1972; Birks and Birks, 1980). As mentioned above, only the Forks Lagoon chapter presents concentration results.

\subsubsection{Pollen diagram and cluster analysis}

The programs TILIA and C2 were used to produce the pollen diagrams (e.g. Figure 4.5). Stratigraphically constrained cluster analysis, a multivariate analysis technique for classifying stratigraphic zones, was used to group similar samples together in clusters. The program CONISS was used to perform the analysis and was used in conjunction with TG View. A dendrogram representing the entire set of amalgamations was sectioned, enabling objective zoning of the pollen 
diagrams. Stratigraphically constrained cluster analysis differs from ordinary cluster analysis, as only stratigraphically adjacent samples will be considered for grouping. Zoning the sequences helped with the description and correlation of the pollen assemblages. These zones are defined by the presence or absence of fossil taxa and variations in the abundance of selected taxa. Therefore zones of similar pollen assemblage associated with depth are objectively identified. For this project the dissimilarity coefficient using squared root transformation is the Edwards and Cavalli-Sforza's chord distance. This method up weights rare variables relative to abundant variables (Grimm, 1987).

\subsubsection{Principle Component Analysis (PCA)}

Principle Components Analysis (PCA) is a numerical ordination technique used to simplify multidimensional datasets, and thus enable relationships within the dataset to be objectively analysed in a low-dimensional space. Each pollen type is represented as a coordinate axis. If 40 pollen taxa were identified through a sequence then each would produce its own coordinate axis providing 40 coordinate axes. This is too highly multidimensional to assimilate and therefore PCA is used to reduce the data to a lower dimension. Factor reduction occurs by constructing new components that are linear combinations of existing variables by coalescing highly correlated variables. The first component lies along the axis of greatest variability within the dataset. Subsequent PCs are then chosen to account for the largest amount of residual variability, although this is restrained by the need to have all the principle axes orthogonal to each other. The purpose is to provide a number of linear relationships (PC) from a set of variables which preserve as much of the information from the original variables as possible. Reducing the dimensional complexity of the results aids the observer to analyse the relationships and communicate the results in an objective way. A disadvantage is that some data will be excluded in the process of reducing the output to only one or a few dimensions. However, if there is a strong structure within the dataset then the first few PCs tend to account for the majority of variability within the data set and the remaining PCs can be discarded with a minimal loss of information (Gauch, 1982; Birks and Gordon, 1985). 
Eigenvectors and eigenvalues are at the core of any PCA analysis. Eigenvectors represents the weighting of each individual taxon within each component. Eigenvector scores range from 1 to -1 . The more weighting a taxon has on the component the nearer to $1 /-1$ its score will be. Taxa with similar eigenvector scores would exhibit similar distributions down though the core, thus indicating which taxa occur together. Eigenvalues represent the relative contribution each component has in explaining the total variation in the data. This is calculated by summing the square root of each taxon eigenvectors in each component. In PCA analysis, the components are extracted in descending order of importance in regards to their contribution in explaining the total variation of the data. Therefore, component two will have a lower eigenvalue and represent less of the variance compared to component one, and so on. A dataset containing few variables needs only two-three components to represent the majority of the data whilst four-five components are needed for datasets containing a large number of variables. As a guideline, axes are extracted until the component's eigenvalue is less than 1. Eigenvalues are the exact measure of proportion of the total variation that the axis represents and are often expressed as a percentage.

In Sections 4.4.5.2 and 5.4.4.2 eigenvector scores of axis 1 and axis 2 are plotted. The species which plot together in the graph represent a relationship in their appearance in the stratigraphy. Component scores are calculated to enable relationships between samples to be seen. These are calculated by multiplying the original taxa counts in a sample by the eigenvector values for each variable (taxon abundance). These are then summed to produce a component score. This reduces the data down to each sample with orthogonal component scores for each axis. An ordination plot is used to display the data. Samples which plot close together in the graph have similar species composition.

The program CANOCO v 4.5 was used to for the PCA analysis, which was carried out on the pollen data from Forks Lagoon and the two Westland sites. The particle size analysis and loss on ignition results were also be added to the statistical analyses to assess objectively if there are between relationships these factors and the pollen assemblage. 


\subsubsection{Environmental Lapse Rate (ELR)}

Environmental Lapse Rate (ELR) is the rate at which temperature changes with altitude (Meyer, 1992). It is used frequently in paleoecology, in particular to infer MAT depression from elevation lowering of vegetation zones recorded in palaeovegetation records. For instance, if the pollen record is interpreted as showing a $300 \mathrm{~m}$ lowering of the alpine zone from its contemporary elevation, and an ELR of $0.5^{\circ} \mathrm{C} / 100 \mathrm{~m}$ is applied, then an estimated MAT depression at the time would be $1.5^{\circ} \mathrm{C}$. However, there are some limitations with this approach. ELRs are a semi-qualitative method which relies on analyst interpretation of the palaeovegetation community which can be more prone to bias. There are also limitations associated with the methodology used to calculate ELR which are discussed below.

Meyer (1992) identified a number of different factors associated with both temporal and spatial changes which can modify the ELR calculated. These factors include changing atmospheric conditions (although over long timescales these are assumed to average out), the surface albedo, moisture, local and regional topography, the time of day, and the nature and source of the dominant air mass to name a few. For example in areas of strong relief such as New Zealand, mountain barriers force air masses to rise causing a significant difference in precipitation and temperature between the leeward and windward sides of the mountains (see Section 2.3). Moisture levels, in particular, have a significant influence on the ELR with the drier leeward side of the mountain ranges experiencing a greater terrestrial lapse rate than the windward slopes. Dry adiabatic lapse rates are typically around $1{ }^{\circ} \mathrm{C} / 100 \mathrm{~m}$ whereas wet adiabatic lapse rates are around $0.5{ }^{\circ} \mathrm{C} / 100 \mathrm{~m}$ (Meyer, 1992). Research by Norton (1985) and Meyer (1992) also show large ELR changes on a number of timescales (e.g. daily, seasonally, and annually). Therefore an ELR based on a single temperature measure, from a limited number of sites and over a short time span would not produce a representative ELR for a region (Meyer, 1992). Meyer (1992) advised to use ELR calculated from a number of climate stations. 
ELR has been used widely in New Zealand, including estimating temperature depression (e.g. Burrows et al, 1977; Wardle, 1998; Hales and Roering, 2005). However, the rate applied has varied between and within studies. Mark et al (2000) used data loggers from three sites in the South Island and found a large difference in ELR during the warmest month of the year for different altitudes. Between $1200-1600$ m.a.s.I an ELR of $0.45^{\circ} \mathrm{C} / 100 \mathrm{~m}$ was recorded whilst the lapse rate between 1600-2000 m.a.s.l was larger at $0.65{ }^{\circ} \mathrm{C} / 100 \mathrm{~m}$. However, research by Norton et al (1985) suggests a large seasonal difference in ELR occurs and so a rate derived from only one month or one season would not be appropriate for reconstructing MAT. Using data from 301 temperature stations across New Zealand spanning the period 1950-1980, Norton (1985) calculated a mean annual ELR of $0.5^{\circ} \mathrm{C} / 100 \mathrm{~m}$ for New Zealand. Therefore, for this project the ELR calculated by Norton (1985) will be used to estimate MAT depressions from the pollen records. The same ELR has also been applied to a number of other records e.g. Soons (1979).

\subsubsection{Quantitative pollen-climate modelling}

Quantitative methods for reconstructing climate for a number of biological proxies have been developed over the past 30-40 years. Quantitative pollen-climate modelling aims to express the value of an environmental variable, such as mean annual temperature, as a function of biological data (e.g. pollen assemblages). Before a fossil assemblage can be converted into an environmental variable a modern training set is needed. A training set comprises taxa abundances from various sites with known associated modern environmental variables. The current relationship between taxa and their environment is statistically modelled producing a function. This function is then applied or transferred to the fossil data to infer estimates of past environmental variables (Birks, 1995). The function and process of applying it to reconstruct past environments is broadly referred to as a transfer function.

The use of quantitative pollen-climate reconstructions functions has been successfully applied around the world (Kay and Andrews, 2005; Finsinger et al, 2007). Traditionally, to produce a modern training set or analogue, modern moss pollsters and surface sediment sites are analysed. The relationship between the 
pollen assemblage and modern climate regime at each site is then statistically modelled. In New Zealand, Norton et al (1986) were the first to use modern pollen assemblages to infer the climate from the fossil pollen spectra. However, the study failed to produce a robust transfer function due to a number of factors. A variety of pollen site types were used to produce the modern training set and to perform the transfer function. These included an emphasis on sites from the wetter western regions of New Zealand, where remnants of native forest still remained. In contrast, representation of vegetative communities from other regions was inadequate. Also, frequent steep terrain aids the wide dispersal of pollen and spore grains, blurring relationships between climate and pollen taxa. Most significantly the transfer function based on modern surface samples produced an anthropogenic signal that masked climate influences (Norton et al, 1986). With these limitations in mind the pollen transfer function was further developed by Wilmshurst et al (2007).

Wilmshurst et al, (2007) used exclusively a pre-deforestation pollen database to produce a 'modern' training set. Cores from lakes, bogs and swamps were used with the pollen assemblage from the horizon directly underlying the first signal of human interference used in the training set. This signal includes a sustained upwards trend in amounts of large $(>50 \mu \mathrm{m})$ charcoal, a decrease in tree taxa and an increase in seral species (McGlone, 1989; McGlone and Basher, 1995; Ogden et al, 1998). For a few sites that have remained forested and/or lack evidence of Polynesian deforestation, the $750 \mathrm{cal}$ yrs BP horizon was used. The training set comprises a total of 135 sites (Figure 3.3) spanning the Polynesian deforestation period, 750-550 cal yrs BP. For each site climatic variables were applied from the modern climatic data. This introduces an important assumption and possible limitation of this method; that climate $750 \mathrm{cal}$. $\mathrm{yr} \mathrm{BP}$ was the same as it is today. Dendrochronological evidence by Cook et al (2006) indicates that the average temperature between $13^{\text {th }}-17^{\text {th }}$ centuries was not significantly different than during the mid-twentieth century. However, there are intervals of sustained warming and cooler excursions within the Polynesian deforestation period. The quantitative pollen-climate analysis performed on the training set indicate that mean annual temperature (MAT) can be quantitatively and objectively inferred from fossil records (Wilmshurst et al, 2007), although with comparatively broad 
errors. Additionally some limitations of the training set are recognised. These limitations may have a significant influence on the inferred climate reconstruction and therefore it is important that these are noted, as discussed below.

\subsubsection{The training set}

A major requirement for any quantitative climate reconstruction includes a large, high quality training set of modern pollen samples and associated climate data. The training set needs to span a wide climate gradient, but also cover the climate range expected to be represented by the fossil pollen record (Birks et al, 2010). Analyst consistency in identification of pollen, and nomenclature use combined with detailed taxonomy is a requirement for both the training set and fossil assemblages (Finklestein et al, 2006). It is also preferable that the training set samples should come from the same sedimentary environment as the fossil samples for comparable taphonomies (Goring et al, 2010). Although the above points are preferable it is not always possible to fully achieve them all with the limited resources and data available. The following highlights the established limitations of the current New Zealand pollen training set used by Wilmshurst et al (2007).

Spatial and climate range of the training set:

Currently 135 samples are included in the training set, providing large coverage of New Zealand and a wide range of environments (Figure 3.4). This training set is an improvement upon that of Norton et al (1986). However there are still some regions, e.g. central South Island east of the Southern Alps, which are poorly represented. Some important environments and vegetation communities are also lacking representation, in particular the alpine zone and treeless vegetation sites. During the last glacial period vegetation records suggest a large proportion of New Zealand was dominated by grass and herbland communities that contained few, if any, tree taxa. To achieve reliable climate reconstructions for this period a representative training set containing sufficient alpine and treeless sites is necessary. However, collecting representative samples of the alpine vegetation is difficult due the effects of wind transporting lowland pollen into the alpine zone. 
Level of taxonomic identification:

To produce a reliable training set for climate reconstruction, pollen and spore identification should be made at as low a taxonomic level as possible. Ideally identification to species level would produce the best training set, but some pollen types are difficult to distinguish, whilst the analyst may not consistently make a distinction with other types. In these cases pollen and spore types are combined into higher taxonomic groups. For the New Zealand pollen training set, around $40 \%$ of the pollen and spore types represent individual species and a number of these are major dominant species in the modern vegetation e.g. Dacrydium cuppressinum, Nothofagus menziesii. However, $55 \%$ of the pollen and spore types represent one or more species within a genus, and the remaining $5 \%$ consist of family groups containing two or more closely related genera or a large group representing a range of species from a number of families e.g. monolete spore grouping fern spores with similar morphologies together. This grouping can reduce the effectiveness of the training set to produce realistic climate reconstructions as some genera or groups may represent a wide range of growth forms and cover a broad environmental gradient e.g. Coprosma and Myrsine. When analysing the model reconstructions it is important to know the limitations of using certain pollen and spore types in the training set.

\section{Site selection:}

For an accurate reconstruction Birks et al (2010) suggest the sedimentary environment of the modern and fossil samples should be the same. Basin, lake or bog size, are potential sources of variation in pollen taphonomy associated with site types. However, to cover a broad climate gradient and to represent a large proportion of New Zealand it was necessary to use sites from a range of sedimentary environments with cores taken from bogs, swamps and lakes. Wilmshurst et al (2007) concede it would have been preferable to use only small lakes to produce the training set, but also noted that the sedimentology of a site may have changed over time e.g. terrestrialisation of a lake. Ideally, a sufficient number of samples which are fully representative of all major site types which would allow the segregation into site categories would be favourable. However, the limited dataset available does not permit this and may reduce the power of the models to reconstruct past climates. 


\section{Summary:}

The above points explain the limitations of the current training set used for quantitative pollen-climate reconstructions. However, as Wilmshurst et al (2007) has demonstrated, this new pre-deforestation database has significantly improved upon that of Norton et al (1986). Also, they have shown that meaningful quantitative MAT reconstructions can be produced for sites in New Zealand and the estimated pattern of MAT are consistent with previous qualitative reconstructions. Quantitative pollen-climate reconstructions also allow for a more objective climate reconstruction which should complement the qualitative results.

\subsubsection{Methodology}

The training set developed by Wilmshurst et al (2007) was used to infer MAT from the fossil pollen records produced in this project. Wilmshurst et al (2007) performed Detrended Correspondence Analysis (DCA) to the training set to assess the main gradient of the data and whether pollen and spore appearance have a linear or unimodel response to the environment. The calculated gradient was short suggesting linear methods of ordinations would perform better than unimodel methods (ter Braak, 1987). Two models were run with the performance of each compared: the linear response model Partial Least Squares regression (PLS) and the modern analogue technique. These statistical approaches are discussed below.

PLS is a multivariate calibration-function approach which contains the prior assumption that the data behave in a linear manner. This method uses the 'global' estimations of parametric functions for all the taxa present allowing some degree of extrapolation (ter Braak, 1995). Before the training set can be used to reconstruct past climates from the fossil data the relationship of individual species to climate is modelled using regression analysis. This initial stage produces the climate function which is then applied to transform the whole fossil assemblage into a quantitative estimate of past climate (Birks et al, 2010). This method successively selects a number of PLS components derived during the crossvalidation process of 1000 bootstrap cycles. The PLS component chosen to reconstruct past climates should be the model providing the best statistical results whilst being the lowest component possible (ter Braak, 1995). 
The modern analogue technique numerically identifies the closest modern analogues to the fossil assemblage using chi-squared distance of dissimilarity measure. Once the closest modern analogue samples are identified, the model takes a weighted mean of the modern environmental variables for the samples to infer the environmental conditions represented by the fossil assemblage. This process is repeated for each fossil sample. Climate reconstructions can be based on one modern sample which contains the closest pollen assemblage as the fossil assemblage. However, for greater reliability the climate reconstruction should be based on the mean or weighted mean of number of closest analogues. For this project a weighted mean of the 10 closest analogues for each fossil assemblage (Birks, 1995; Birks et al, 2010). Cross-validation of the dataset is necessary to assess whether enough analogues have been used to provide a reliable climate reconstruction and test the training set. The cross-validation method of bootstrapping on the modern samples using 1000 bootstrap cycles was used to provide sample-specific errors for each fossil sample.

The main difference between the two models is that the PLS model allows for extrapolation of climate for fossil assemblages which are lacking a close modern analogue. However, this method also incorporates species which represent a broad climate gradient and thus may reduce the climate signal produced by the model (see Section 8.2.4). In contrast, W-MAT can be very accurate when the fossil samples have closely matching modern analogues, but becomes inaccurate when a close match is not available (Birks et al, 2010). W-MAT is also more susceptible to autocorrelation, the tendency of sites located near each other to resemble one another compared to randomly selecting sites. Therefore variables from one site can be partially predicted from its neighbouring site. This can cause a lack of sample independence and cause spurious assumptions between environmental variables and species assemblage (Telford and Birks, 2005). To decide which model would be the most suitable the statistical parameters of each model needs to be assessed. The software $\mathrm{C} 2$ is used to perform the calibration and the outputs are presented in Table 3.1. 


\subsubsection{The model's performance (Table 3.1)}

For all the models a number of parameters were calculated to assess each models performance. Each model's parameter outputs are compared and the best performance is the model used to reconstruct MAT. These parameters are briefly explained in the following. The root mean square error (RMSE) estimates the accuracy of the training set to predict temperature (Birks, 1995) whilst the $r^{2}$ (coefficient of determination) represents the strength of the correlation between the observed and inferred MAT. The root mean square of predictions error (RMSEP) is a more robust measure of estimated precision of the predictability of the modern training set. This is calculated using a cross-validation method to test the training set and as mentioned already, 1000 bootstrapping cycles was used. The RMSEP is the square root of the sum of squares of the difference between the observed and predicted temperatures (ter Braak and Juggins, 1993; Birks, 1995). The $r^{2}$ (boot) is calculated for the RMSEP, and is thus a measure of the correlation between observed and inferred MAT after the cross-validation. Finally, max bias (boot) is a measure of the accuracy of the prediction (Birks, 1995). All these parameters are used to assess the robustness of the models. For the PSL model, which produces five components, the component chosen has the smallest number of useful components needed to produce a reliable calibration (Birks, 1995).

The parameter values for the models and components used to calibrate the New Zealand pre-deforestation dataset are displayed in table 3.1. The two models which performed the best and are the most suitable models to use for the MAT reconstruction is the weighted modern analogue technique (W-MAT) and PSL component 3 (PLS-C3). Both models performed similarly. PSL-C3 marginally outperforming W-MAT with the highest precision of $\pm 1.4{ }^{\circ} \mathrm{C}$ compared to $\pm 1.5^{\circ} \mathrm{C}$. However, W-MAT gives the highest $r^{2}$ (boot) of 0.82, (PSL-C3 is 0.81), and a significantly lower maximum bias (boot) of $1.95{ }^{\circ} \mathrm{C}$ compared to $2.53{ }^{\circ} \mathrm{C}$ for PSLC3. Statistically, the W-MAT produces the most robust model and therefore WMAT is the model favoured in this project and by Wilmshurst et al (2007). However, there are limitations with both models which are discussed in Section 8.2.4 and so both reconstructions are displayed in the pollen diagrams and compared in the results sections of the individual site chapters (Chapters 4-7). 


\begin{tabular}{|c|c|c|c|c|c|}
\hline Model & $\begin{array}{l}\text { RSME } \\
\left({ }^{\circ} \mathrm{C}\right)\end{array}$ & $\mathbf{r}^{2}$ & $\begin{array}{l}\text { RMESP } \\
\left({ }^{\circ} \mathrm{C}\right)\end{array}$ & $r^{2}$ (boot) & $\begin{array}{l}\text { Max bias (boot) } \\
\left({ }^{\circ} \mathrm{C}\right)\end{array}$ \\
\hline $\begin{array}{l}\text { Modern Analogue } \\
\text { Technique }\end{array}$ & 1.46 & 0.82 & 1.55 & 0.82 & 2.12 \\
\hline $\begin{array}{l}\text { Weighted Modern Analogue } \\
\text { Technique }\end{array}$ & 1.38 & 0.83 & 1.51 & 0.82 & 1.95 \\
\hline PSL component 1 & 1.77 & 0.66 & 1.85 & 0.65 & 3.6 \\
\hline PSL component 2 & 1.35 & 0.81 & 1.5 & 0.78 & 2.39 \\
\hline PSL component 3 & 1.2 & 0.85 & 1.4 & 0.81 & 2.53 \\
\hline PSL component 4 & 1.1 & 0.87 & 1.42 & 0.82 & 1.9 \\
\hline PSL component 5 & 1.1 & 0.88 & 1.46 & 0.81 & 1.84 \\
\hline
\end{tabular}

Table 3.1: Parameter values for the different models used to calibrate the pre-deforestation training set (source: Wilmshurst pers comm). 


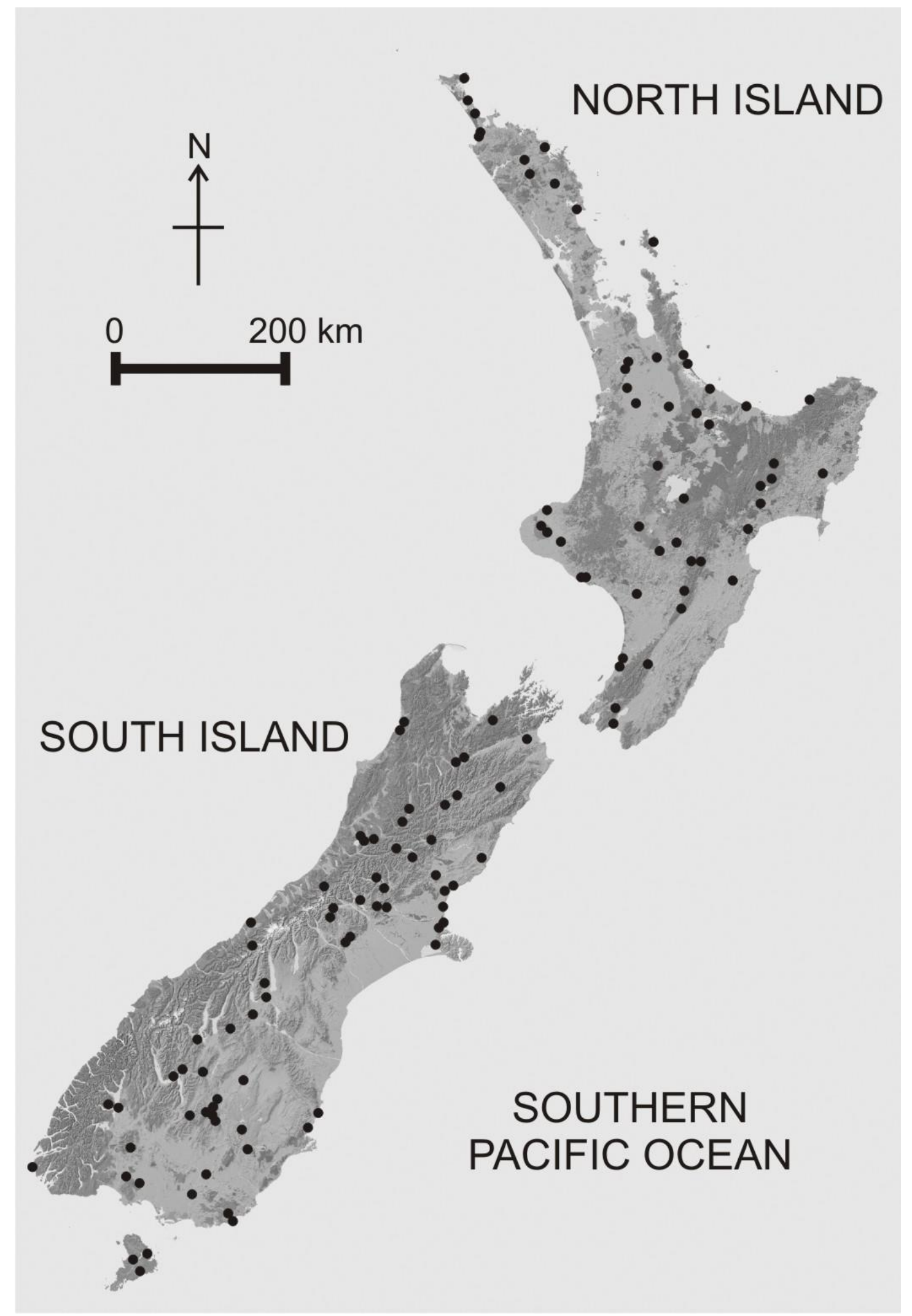

Figure 3.3: Location map of the current modern sites used in Wilmshurst et al (2007). 


\subsection{Loss on Ignition and particle size analysis (PSA)}

Sedimentological analyses of the sites consisted of Loss on Ignition (LOI) and particle size analysis (PSA). The content of organic carbon in a sample can be estimated by LOI. This provides a means of analysing the biological productivity and relative stability of the catchment. In previous research, high LOI has occurred during periods of forest expansion that is related to climate amelioration after glacial periods (Bos et al, 2007). In contrast, low total LOI typically occur during glacial periods where there was reduced productivity, vegetation cover and increased erosion rates. This indicates that climatic change can have a profound influence on carbon content (Beer et al 2007; Bos et al, 2007; Nesje et al, 2006). However, other factors can influence organic content and therefore the LOI results should be interpreted with the pollen results. The methodology for LOI was based upon Heiri et al (2001). Approximately $2 \mathrm{cc}$ of material for each sample was taken from the core. A crucible was weighed using analytical balance and weighed again with the sample added to the crucible. This was carried out for each sample and was then placed into a drying oven at $100{ }^{\circ} \mathrm{C}$ for 12 hours. The samples were left to cool in a dessicator and then reweighed. The samples were then transferred to a furnace at $550{ }^{\circ} \mathrm{C}$ for four hours after which the samples were again placed in the dessicator to cool. Finally the crucible and the now combusted sample was weighed for a final time.

The analytical balance was connected to a computer which automatically calculated the LOI. However, the formula used in the calculation is:

$\mathrm{LOI}=(\mathrm{W} 3-\mathrm{W} 4) /(\mathrm{W} 2-\mathrm{W} 1) \times 100$

Where:-

W1 $=$ Weight of empty crucible

W2 $=$ Weight crucible and sample

W3 $=$ Weight crucible and dried sample

W4 = Weight crucible and combusted sample

Particle size analysis measures the variations in the particle size of the sediment within different samples. Previous studies have suggest larger particle size is 
related to increased erosion and sediment transport caused by reduced vegetation cover producing bare slopes, increased freeze thaw activity, seasonal snow melt leading to high fluvial discharge, glacial erosion in the mountainous regions and a number of other factor (Digerfeldt et al, 2000). A reverse to the above may therefore result in smaller particle sizes, although this is not always the case (Digerfeldt et al, 2000; Lawson et al, 2004; Shichi et al, 2007) as changes in particle size can be influenced by a number of other factors and therefore the results will need careful interpretation.

Samples from the core were divided into three or five sub-samples and placed in vials. Hydrogen peroxide $\left(\mathrm{H}_{2} \mathrm{O}_{2}\right)$ treatment was used to remove the organics from the samples. The removal of the organics using $\mathrm{H}_{2} \mathrm{O}_{2}$ is common practice for particle size analysis (Gray et al, 2010), however the exact method used varies. In this project approximately $5 \mathrm{ml}$ of $3 \% \mathrm{H}_{2} \mathrm{O}_{2}$ was added to each vial and heated in a water bath at $95{ }^{\circ} \mathrm{C}$. After a few hours fresh $3 \% \mathrm{H}_{2} \mathrm{O}_{2}$ was again added to each sub-sample. Again, after a few hours $6 \% \mathrm{H}_{2} \mathrm{O}_{2}$ was added to each sample. The addition of $\mathrm{H}_{2} \mathrm{O}_{2}$ continued until there were no longer visible signs of a reaction (e.g. bubbling). When it appears that all the organic material has been removed the vials remained in the hot water bath until the majority of $\mathrm{H}_{2} \mathrm{O}_{2}$ has evaporated off. It is important throughout this process that the samples do not dry up entirely. Deionised water is added to each sample and any visible organics, which did not react with the $\mathrm{H}_{2} \mathrm{O}_{2}$ were removed. This part of the process should take roughly 1 to 2 days to complete it is important that fresh $\mathrm{H}_{2} \mathrm{O}_{2}$ is continually added until a reaction was no longer taking place.

Particle size analysis was carried out using a Malvern Mastersizer-2000 laser granulometer, with Hydro-G automated dispersal unit, and set for detecting grain size range from $0.02-2000 \mu \mathrm{m}$. The particles were passed through the particle sizer using the liquid suspension method. For each sample 3000 blue and red laser measurements were recorded. This was replicated five times for each subsample. The Mie theory is used to calculate the particle size distribution in each sample (Rawle, 2011) from which further measures of particle size distribution such as the proportion of sand, clay and silt is made. As mentioned earlier the 
PSA and carbon content will be combined with the pollen data and used in the PCA. Using a multiproxy approach should strengthen the vegetation interpretation.

\subsection{Chronological method}

\subsubsection{Radiocarbon Dating}

Since American chemistry professor, Willard Libby, thought up the application of radiocarbon dating, it has become one of the most popular methods for aging late Quaternary sediments (Walker, 2005). Subsequently, a multitude of ages have been published and the method for all parts of the process have evolved and refined e.g. Vandergoes and Prior (2003); Newnham et al (2007b). Accelerator Mass Spectrometry (AMS) is used to calculate the sample age throughout this project and radiocarbon ages will provide the majority of chronological control at the four sites.

\subsubsection{Sample preparation}

The sample strategy used for pollen and sediment analysis consisted of $1 \mathrm{~cm}$ and $0.5 \mathrm{~cm}$ thick samples taken at regular intervals down the core. In sections of interest, such as an apparent climatic oscillation or climatic transition, sampling was at a higher resolution. As a result, the number and location of dates for each site is dependent upon; 1) the temporal span of the core or section; 2) the amount of climatic transitions and millennial scale events evident in the core; and 3) the resolution and location of the pollen samples, which provide the climate signal. The aim of the project is to constrain the timing of the major climate transitions and also the beginning and end of any millennial scale climate events, e.g. LGR. However, the cost of dating and funding availability imposes limits on the amount of possible ages.

Macrofossils are the preferred medium of dating, when available, due to their general reliability compared to bulk sediment samples. The high rainfall Westland region, the location of Lake Mudgie and Manks Tarn, is known to potentially produce serious dating errors (Moar and Suggate, 1996) caused by younger carbon contamination by humic and fulvic acids. This is most notable with peats 
older than $10 \mathrm{ka} \mathrm{(Hammond} \mathrm{et} \mathrm{al,} \mathrm{1991).} \mathrm{Vandergoes} \mathrm{and} \mathrm{Prior} \mathrm{(2003)} \mathrm{established}$ that pollen concentrates consistently produced older ages compared to bulk sediment for dating. Newnham et al (2007b) further developed the pollen concentrate method but got slightly disappointing results. Contamination, believed to be sourced from the University of Plymouth, produced younger than expected ages. However, the results pointed to pollen concentrattes providing more reliable ages. Recent evidence suggests the source of contamination at the University of Plymouth was the sodium polytungstate liquid caused during factory processing (Vandergoes pers comm).

This project does not use heavy liquid separation. Instead numerous sieving steps, dividing the sample into size fractions, were used. After observing each size fraction under the microscope the most suitable sample fraction, believed to produce the least contamination, was used for dating. The preference was upon the smallest size fraction which contained the highest concentration of pollen. During the sieving process each sample and any standards underwent an acidalkali-acid (AAA) treatment (refer to Figure 3.4). Samples from Lake Mudgie and Manks Tarn were sent to NERC radiocarbon in East Kilbride for the final stages of the sample preparation and the dating. Forks Lagoon and Howard Valley samples were sent to Rafter Radiocarbon Facility in Lower Hutt.

\subsubsection{Age calibration and age-depth models}

The program OXCal was used to calibrate the ages using IntCal09 calibration dataset set (Reimer et al, 2009). This is coupled with simple linear interpolation to produce the age-depth models. Age-depth models are used to provide an age gradient up a stratigraphy allowing sediment deposition rates to be calculated and intermediate samples to have an interpolated age. The most commonly used agedepth models include linear regression, linear interpolation and splines (Bennett, 1994). Refer to Telford et al (2004) for an overview of the different age-depth models. For this project linear interpolation models is used. This method connects the age estimates to each other by a line of constant gradient (Bennett, 1994). This model is known to be incorrect as sediment accumulation does not change at the location chosen for radiocarbon dating. However, it is also considered to be the method that provides a reasonable general solution. As stated by Bennett and 
Fuller (2002) linear interpolation is "...never right but rarely unacceptably wrong" (Bennett and Fuller, 2002; pp427).

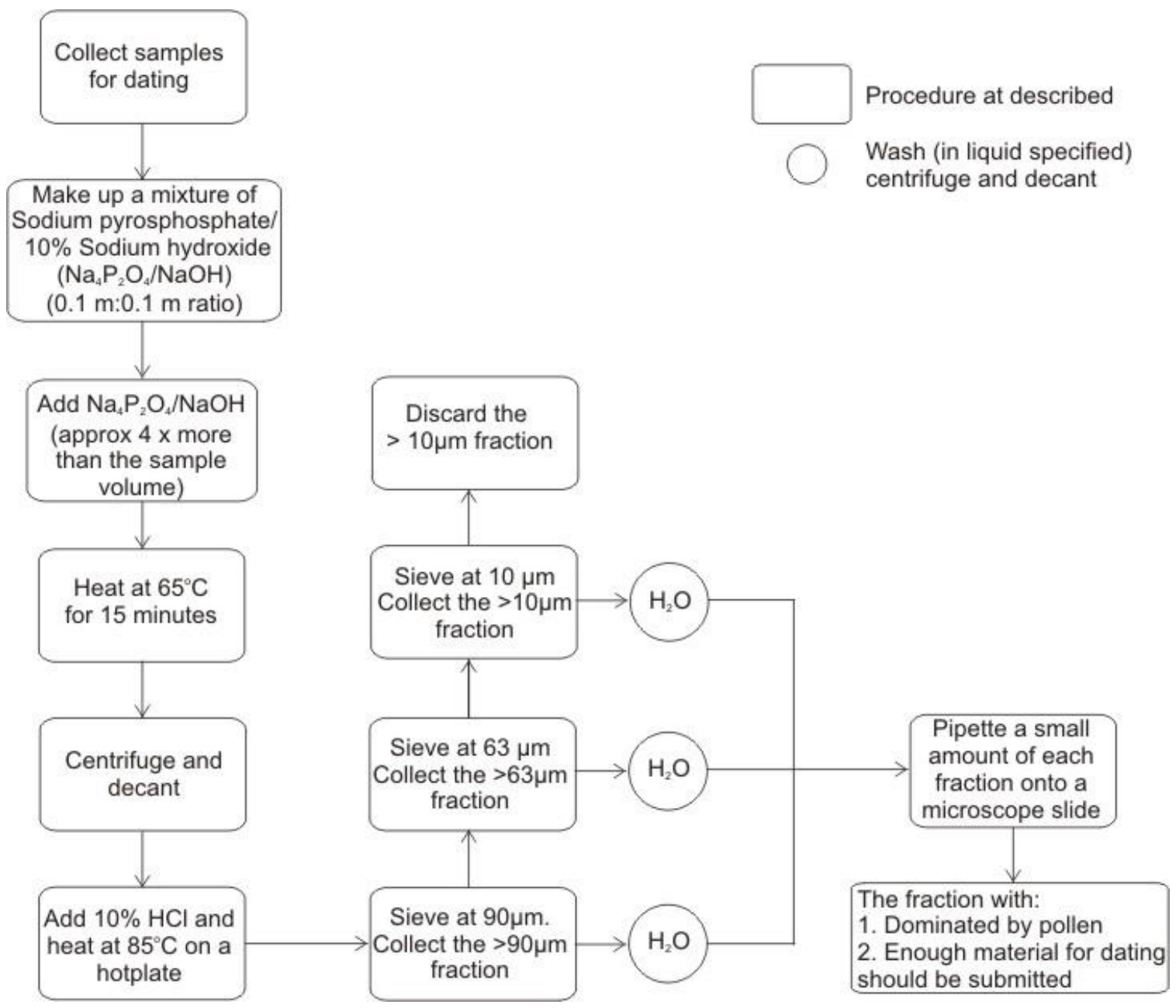

Fig 3.4: Sieving separation methodology used to extract pollen for radiocarbon dating.

\subsubsection{Tephrochronology methodology}

Tephra is the airborne, unconsolidated pyroclastic material of an explosive volcanic eruption (Lowe and Hunt, 2001). Tephrochronology is the identification of tephra (using geochemical and mineralogical properties) and the use of these tephra deposits/layers as chronostratigraphic markers. The assumption is that a tephra layer will have the same age wherever it is deposited, unless the material has been reworked, and therefore tephra layers are valuable for linking disparate terrestrial records and providing ages (Lowe et al, 2008). The KOT eruption is the 
largest known eruption from the Taupo Volcanic Zone (TVZ), located in central North Island, New Zealand (Self 1983; Figure 2.1) and ejected a ca $1200 \mathrm{~km}^{3}$ bulk volume of material from the volcano (Alloway et al, 2007). The KOT deposit is the most widespread late Quaternary tephra layer in New Zealand (Pillans et al, 1992) and is found throughout the South Island, which has no Quaternary volcanic centres (Mew et al, 1986; Nicol et al, 1994 McLea, 1996; Carter et al, 1995; Vandergoes et al, 2005). Mineralogical and geochemical analysis of the tephra layer confirms the source of the material and therefore the age. This analysis includes assessing the visual characteristics of the glass shard morphology and microprobing of the tephra to calculate whether the major and trace element glass shard chemistry matches the reference material (Lowe et al, 2008).

KOT samples from Howard Valley and Forks Lagoon were sent to Victoria University of Wellington for geochemical analysis. Electron probe microanalysis of the major elements was carried out using a JEOL 733 superprobe. The mean major element compositions for all samples are displayed in Appendix G. Comparison with reference samples confirm the tephra layer at both sites as the KOT. The Lake Mudgie tephra layer did not undergo geochemical analysis but is assumed also to be KOT. This seems reasonable from the stratigraphic position and because the KOT is the only late Quaternary tephra layer yet reported from this region. The KOT is believed to have been deposited prior to the LGM (Lowe et al, 2008) and therefore provides an important time-stratigraphic marker (Pillans et al, 1992). However, determining the age of the KOT has proved problematic. The inconsistent ages dating the KOT have been attributed to the variable abundance of carbonaceous material directly associated with the eruption (Froggatt and Lowe, 1990). A number of radiocarbon ages, ranging from $20-25{ }^{14} \mathrm{C}$ ka $\mathrm{BP}$, related to KOT deposition has been published (e.g. Wilson et al, 1988; Hammond et al, 1991; Pillans and Wright, 1992; Newnham et al, 2008b; Lowe et al, 2008). The recommended age by Lowe et al (2008), is $22,590 \pm 230{ }^{14} \mathrm{C}$ y BP (ca $27,097 \pm 957$ cal. yr BP; $95 \%$ probability). However, high rainfall regions of New Zealand have produced anomalously young ages, in comparison to the age of Lowe et al (2008), and these have been attributed to in situ contamination by younger carbon (e.g. Hammond et al, 1991; Gillespie et al, 1992; Moar and Suggate, 1996; Newnham et al 2007b). Other methods for dating the tephra have added to the debate. 
Optical luminescence dating has provided both consistent ages, e.g. Shepherd and Price (1990) and Lion et al (2002), and also conflicting younger ages, e.g. 19 ka by Grapes et al (2010), although the younger age has been considered unlikely (Lowe et al, 2009).

Thus the precise age of KOT remains somewhat problematic. The current adopted age of the KOT is $22,590 \pm 230{ }^{14} \mathrm{C}$ y BP (ca $27,097 \pm 957$ cal. yr BP; $95 \%$ probability) was produced by an activity-weighted pooled mean age derived from four small carbonised wood fragments embedded within an ignimbrite emplace during the eruption. (Lowe et al, 2008). The four fragments, from different sites, represent wood from short-lived plants killed during the eruption and their ages have narrow error ranges (Wilson et al, 1988), unlike other ages which are derived from airfall tephra sites and organic material less directly associated with the eruption and which have typically produced wider age ranges. However, recent research by Vandergoes et al (2011) has evaluated the age of the KOT in the context of recently obtained ages from pyrolised plant material within ignimbrites, intact and in-situ plant remains which were rapidly buried by distal airfall tephra, and organic material from undisturbed lake sediments bracketing the tephra deposits. Different preparation processes were also considered. On the basis of their evaluations, Vandergoes et al (2011) recommended a revised age of 25, 400 \pm 400 cal y BP $(2 \sigma$ age-range $)$ for the KOT.

The recommendation of this group, which included a number of New Zealand Quaternary specialists with considerable experience with this particular problem including Lowe \& Wilson, has been followed in this thesis. Nevertheless, the validity of both ages (Lowe et al, 2008; Vandergoes et al, 2011) in relation to the radiocarbon ages in this study will be discussed in chapter 8 . Also, comparisons between reconstructions from this project, which use the younger KOT age, and published records, that use the older age, will be based upon the stratigraphic location of the KOT layer, independent of age. See Section 8.2.1 for further discussion of the KOT age and the chronologies of the pollen records in this site. 


\section{Chapter 4: Lake Mudgie}

Lake Mudgie is the first of two pollen sites from central Westland. It is a shallow lake located inland, $17 \mathrm{~km}$ north-east of Hokitika. Geological mapping of the area indicates the region was extensively glaciated during the LGM (Figure 4.1). However Lake Mudgie appears to be outside this ice margin. It was therefore assumed, and later confirmed, that the sediment accumulation at the site began prior to the LGM. This provided a rare opportunity to produce a continuous pollen record extending beyond the LGM, spanning a large proportion of the LGCP. This chapter begins by providing background information for the region and the field site. The core stratigraphy, radiocarbon dates, pollen and sediment analysis are presented and then discussed. The chapter concludes with a summary section of the findings from Lake Mudgie. Chapter 8 will provide a summary discussion chapter combining the evidence gathered from all four sites investigated in this project.

\subsection{Regional setting}

In this project central Westland is defined as the narrow lowland coastal plain spanning $42^{\circ} 40^{\prime} \mathrm{S}$ to $43^{\circ} 40^{\prime} \mathrm{S}$. It is bordered by the Tasman Sea to the west and by the Southern Alps mountain range to the east, both of which heavily influence the climate of the region. The mountain ranges support the largest of New Zealand's glaciers, which are climatically sensitive and lie in close proximity to the lowland coastal area. Numerous glacial advances, occurring throughout the Pleistocene, extended out from the mountain ranges onto the coastal plains creating large piedmont glaciers. In most instances the glacial tongues reached close to, and even extending beyond, the present coastline (Suggate, 1990; Figure 4.1). For more information of Westland ice advances refer back to Section 2.6.1.1.

Central Westland lies within the Western South Island (WSI) regional climate zone (Kidson, 2000; Lorrey et al, 2007; see Section 2.3 for more information) and is dominated by the westerly airflows crossing the Tasman Sea. The region is therefore characterised by an oceanic/maritime climate, experiencing warm 
summers, mild winters and high precipitation. Mean annual rainfall in the coastal areas ranges from $2750 \mathrm{~mm}$ in south Westland to $2150 \mathrm{~mm}$ in north Westland. Mean annual temperature $11.7^{\circ} \mathrm{C}$ and ranges from $10-13{ }^{\circ} \mathrm{C}$ (New Zealand National Climate Centre, 2010). Average humidity is $80-90 \%$ with dry periods rare. However, the topography and distance from the coastline have a significant influence on the climate. The forcing of the moisture laden westerly winds over the axial ranges significantly increases precipitation levels with altitude. A level of $12000 \mathrm{~mm} / \mathrm{yr}$ has been recorded in the high altitudes west of the main divide (Figure 4.1; McSaveney and Griffiths, 1983). Altitude and aspect also affect temperature and inland areas experience considerably cooler winters than coastal sites (Moar and Suggate, 1996).

\subsubsection{Geological setting}

Tectonic uplift, caused by the collision of the oceanic Australian Plate into the continental Pacific Plate, has caused intense folding and faulting of the Alpine Fault, forming the Southern Alps (Katz, 1979). The Southern Alps are formed from a combination of Mesozoic and Palaeozoic quatz-feldspathic schist and Mesozoic greywacke. Quaternary deposits dominate the lowland plains and valleys comprising glacial outwash gravels and tills from the mid-late Pleistocene glacial advances. The main river valleys contain Holocene sand, silts and swamp deposits. Cenozoic sequence of folded greywacke, granite and marine siltstone form outcrops within the Quaternary deposits. (Warren, 1967).

Large moraines dominate the lowland areas, providing evidence of the successive ice advances of the mid-late Pleistocene. In the lowland areas, impeded drainage caused by the hummocky terrain and kettle hole depressions are commonly infilled by swampy deposits. Likewise, in the higher altitudes kettle holes and depressions located on top of terminal and lateral moraines contain small ponds, tarns and swamps which have subsequently been infilled since their creation (Moar and Suggate, 1996). 


\subsubsection{Present vegetation}

A number of vegetation studies in the region have described the floristic composition and plant communities (Wardle, 1975; 1977; 1991; Moar 1970; Reif and Allen, 1988). This section will provide a brief overview of the main native vegetative communities and their contemporary distribution including altitudinal restrictions (also refer to Section 2.4).

Central Westland is located in the beech gap (refer to Section 2.4.1.2), spanning $42^{\circ} 40^{\prime} \mathrm{S}$ to $43^{\circ} 40^{\prime} \mathrm{S}$, and therefore the lowland forest comprises podocarp/broadleaved species dominated by Dacrydium cupressinum. The forest canopy also contains a scattered presence of Prumnopitys ferruginea forming part of the overstory with Weinmannia racemosa, Podocarpus totara and Metrosideros umbellata typically. Trees ferns, including Cyathea smithii and Dicksonia squarrosa, are also often important in the small tree tier. Soil development has an important successional influence on the lowland vegetation composition in the Westland region. Dacrycarpus dacrydioides dominated communities typically grow on newly formed or frequently rejuvenated soils, such as river terraces that experiences episodic flooding and nutrient replenishment. $D$. dacrydioides performs well in high nutrient environments (Wardle, 1974). However, the high regional rainfall causes rapid leaching, nutrient loss and soil development. Within 1000 years nutrients which are important for $D$. dacrydioides, such as phosphorous, are no longer readily available and $D$. dacrydioides is replaced by Dacrydium cuppressinum and Prumnopitys ferruginea dominated vegetation (Norton and Leathwick, 1990).

Above 500 m.a.s.l, the montane forest zone begins characterised by a $W$. racemosa and $M$. umbellata dominated forest canopy and a significant decline in Dacrydium cupressinum and Prumnopitys ferruginea. Other important species include Cyathea smithii D. squarrosa, Coprosma, Griselinia litteralis, Pseudopanax and Schefflera. On soil experiencing leaching, Phyllocladus alpinus is also common. The $W$. racemosa/ $M$. umbellata montane forest remains present up to 850 m.a.s.l, where the vegetation develops into sub-alpine scrub dominated by the shrubs Coprosma, Myrsine, Pseudopanax, Hebe and Asteraceae. 
At c. 1200 m.a.s.I the alpine zone develops with grassland/herbfield dominating the vegetation community. This zone includes the herb varieties of Coprosma, Hebe and Asteraceae and the herbs Gentiana, Apiaceae and Kelleria. A variety of grasses grow in this zone including the tall tussock taxa Chionochloa and the small tussock grasses.

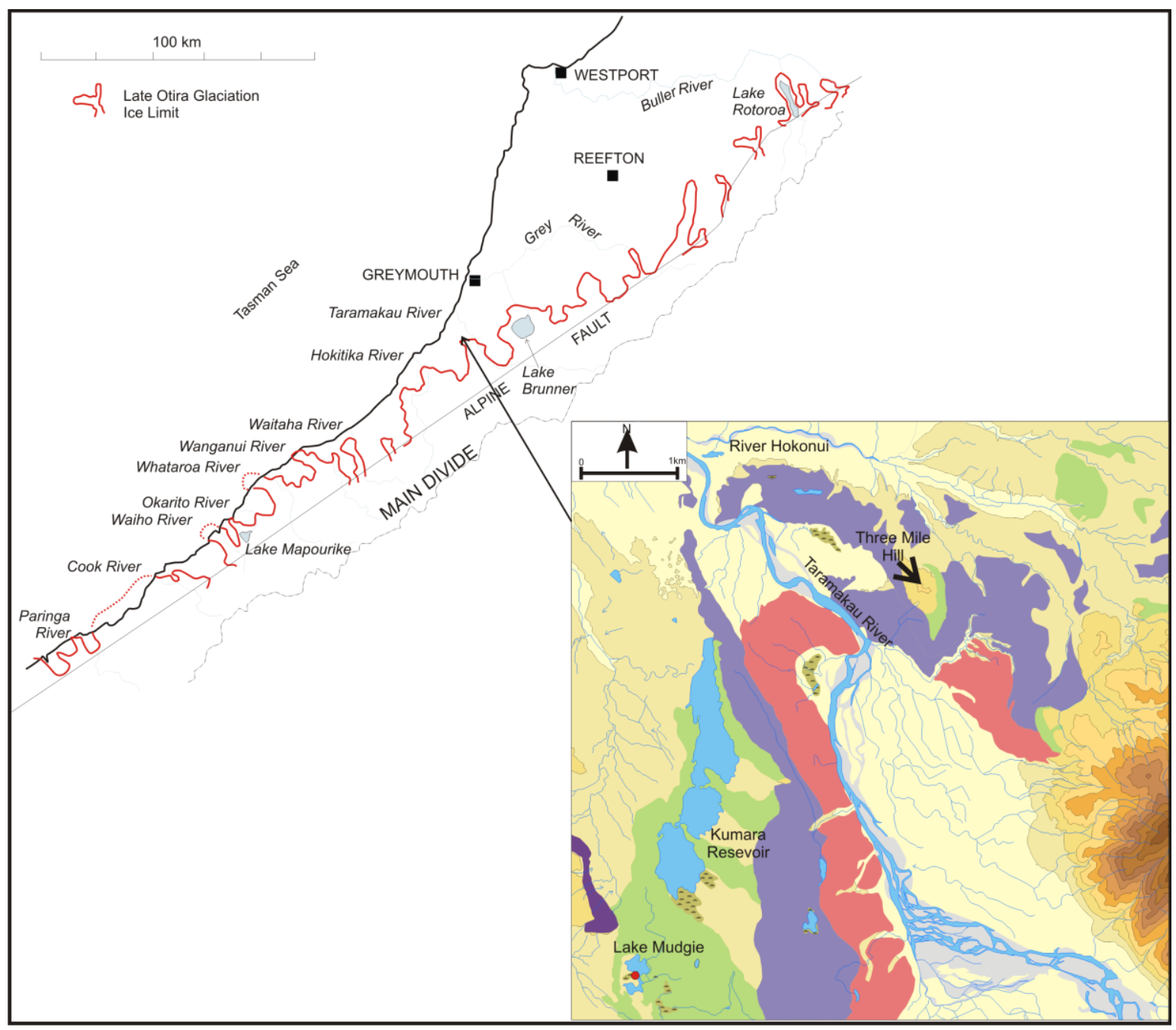

Figure 4.1: Location map of Lake Mudgie in central Westland with a) with Lake Mudgie site location in context of the LGM ice extent in the Westland region (redrawn from Suggate, 1990) and b) a zoom in site location with Lake Mudgie core site marked by a red dot. Moraine deposits are marked on the map and are colour coordinated relating to the glacial advance which deposited the features. Moraine location is based upon Barrell et al (unpublished). Red- Moana moraines; Purple; Larrikins moraines; Green - Loopline moraines; Deep purple - Waimea moraines

Lake Mudgie is a moraine-impounded lake bounded by a Loopline associated terminal moraine (Figure 4.1; refer to Section 2.2 for terminology definitions used in this section), and developed within Loopline formation terrace (Moar and Suggate, 1996). The terminal moraine and hummocky landscape has impeded drainage to form the wetland comprising the lake. Lying at 143 m.a.s.l, Lake 
Mudgie is elevated above the subsequent Larrikins ice extent and associated outwash deposits (Moar and Suggate, 1996), and is confirmed by the presence of the 25.4 ka old KOT layer.

East of Lake Mudgie the Taramakau River flows in a north-west direction (Figure 4.1) and enters the Tasman Sea south of the small settlement Camerons. Throughout the Quaternary the Taramakau River valley was extensively glaciated with glacial advances reaching within a few $\mathrm{km}$ of the current coastline. An LGM lateral moraine separates the Taramakau River and Lake Mudgie and the river flows through the terminal moraine north-east of the study site (Figure 4.1b). The area between the lateral moraine and Lake Mudgie consists of numerous hummocky moraines and depressions, deposited by the pre-LGM glaciers and in which Lake Mudgie is formed.

Lake Mudgie is a small lake with much of the area, including the core site, terrestrialised. The core was taken on the bog surface which was composed of wetland vegetation. The bog grades into a fringing scrub and then lowland podocarp forest (Figure 4.2). A pollen record from Lake Mudgie was previously produced by Moar and Suggate (1996; mentioned in Section 2.6.1.2). The core site of this early research was located in an infilled embayment to the east of the southern end of Lake Mudgie (Figure 4.1). It was initially connected to the lake by a small shallow channel, which has subsequently become blocked by peat. The pollen record produced had a comparatively low sample resolution and was not dated. However, it provides a good opportunity to compare the two records and confirm the main vegetation phases at the site. The pollen record by Moar and Suggate (1996) clearly shows a transition from Poaceae dominated vegetation, assumed in the paper to occur during the LGM, followed by a successive pattern of shrub then tree species culminating with Dacrydium cupressinum dominated forest marking the start of the Holocene. 


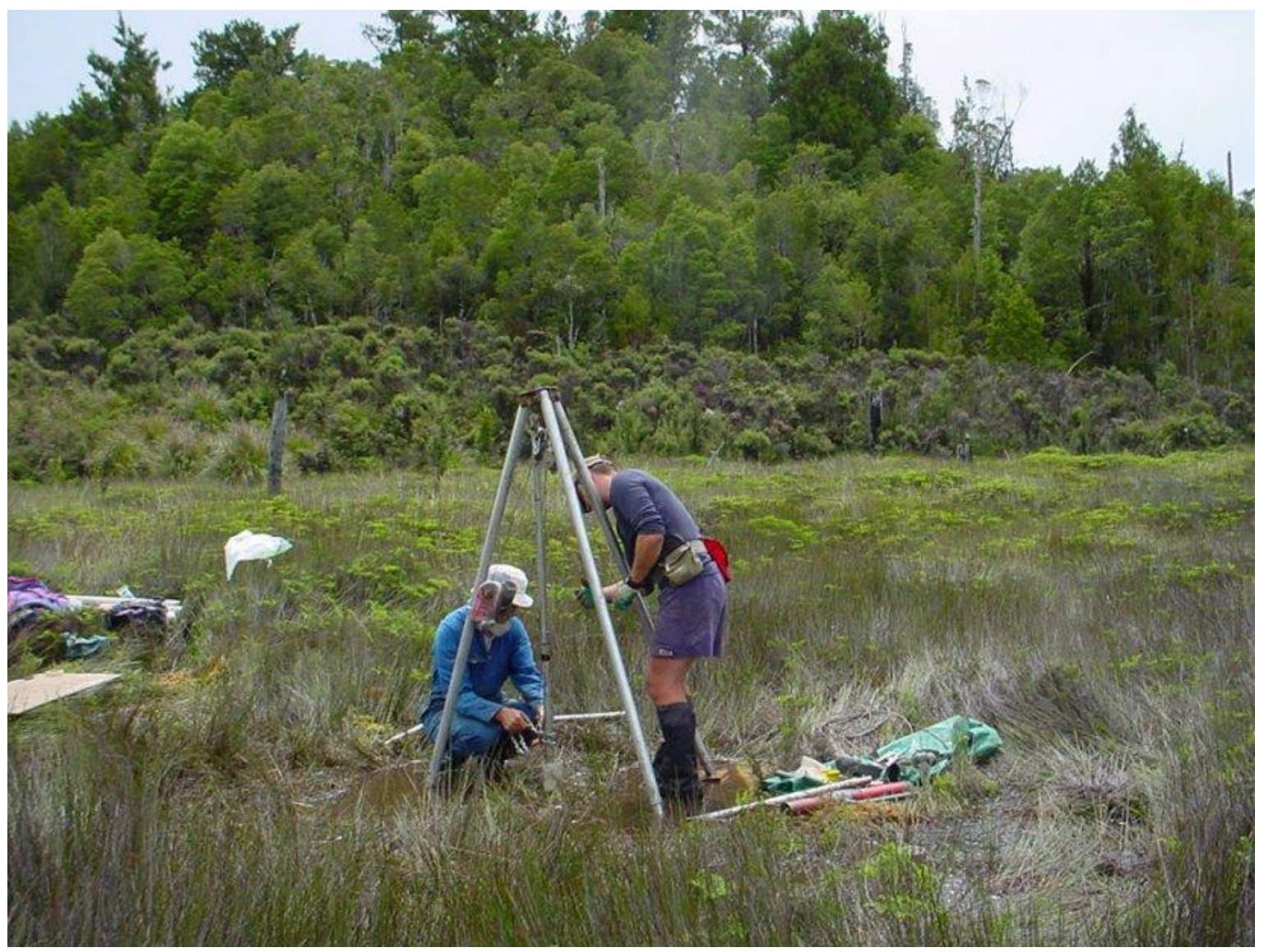

Figure 4.2: Coring on the surface of Lake Mudgie. In the background the higher vegetation marks the bounding moraine.

\subsection{Stratigraphy}

The core location was on the north-eastern bank of the Lake Mudgie, on top of a swampy, terrestrialised section of the site (Figure 4.2). The method used for coring is described in more detail in Section 3.1. The top $2.5 \mathrm{~m}$ of the core consisted of sloppy fibrous restiad peat and presumed to be late Holocene and was therefore not recovered. Coring began at $2.5 \mathrm{~m}$ down and seven $1 \mathrm{~m}$ sections were collected. The primary aim of this project, as stated in the introduction (Section 1.3), is to produce a palynological record spanning 8-30 ka. This interval is represented by the bottom three core sections as described in the section below and in Figure 4.3.

The lowermost section, $647.5-621 \mathrm{~cm}$, is dominated by blue/grey silts and sands which become laminated towards the base of the section. Between 621-559 cm the silts become greyer in colouration and a pebble layer is located at the top 
boundary of this section $(559-560 \mathrm{~cm})$. Within this section, a $2 \mathrm{~cm}$ thick orangebrown layer was deposited at $593-595 \mathrm{~cm}$. This is believed to be the KOT based upon the high abundance of volcanic glass shards in the matrix. However, this has not been confirmed by geochemical analysis, and is a best guess assumption. The silts become increasingly browner and darker up-sequence. The top $66 \mathrm{~cm}, 516$ $450 \mathrm{~cm}$, is composed of reddish brown fibrous peat. These changes in the stratigraphy are characteristic of gradual terrestrialisation and shallowing of a lake. The cores above the sections analysed in this project consist of reddish brown fibrous peat, containing visible plant macrofossils. This is of a similar composition as section $450-516 \mathrm{~cm}$. It is important to note that a possible earthquake crack beginning at $536 \mathrm{~cm}$ and ending c. $608 \mathrm{~cm}$ is visible in the core. This could be a cause of contamination and therefore during the sampling process any material associated with this crack was avoided.

When coring at the site, Moar and Suggate (1996) did not find, or record, the presence of the KOT layer. As it is present in the core used for this project, it seems likely that this record extends further in time than the previous record by Moar and Suggate (1996). 


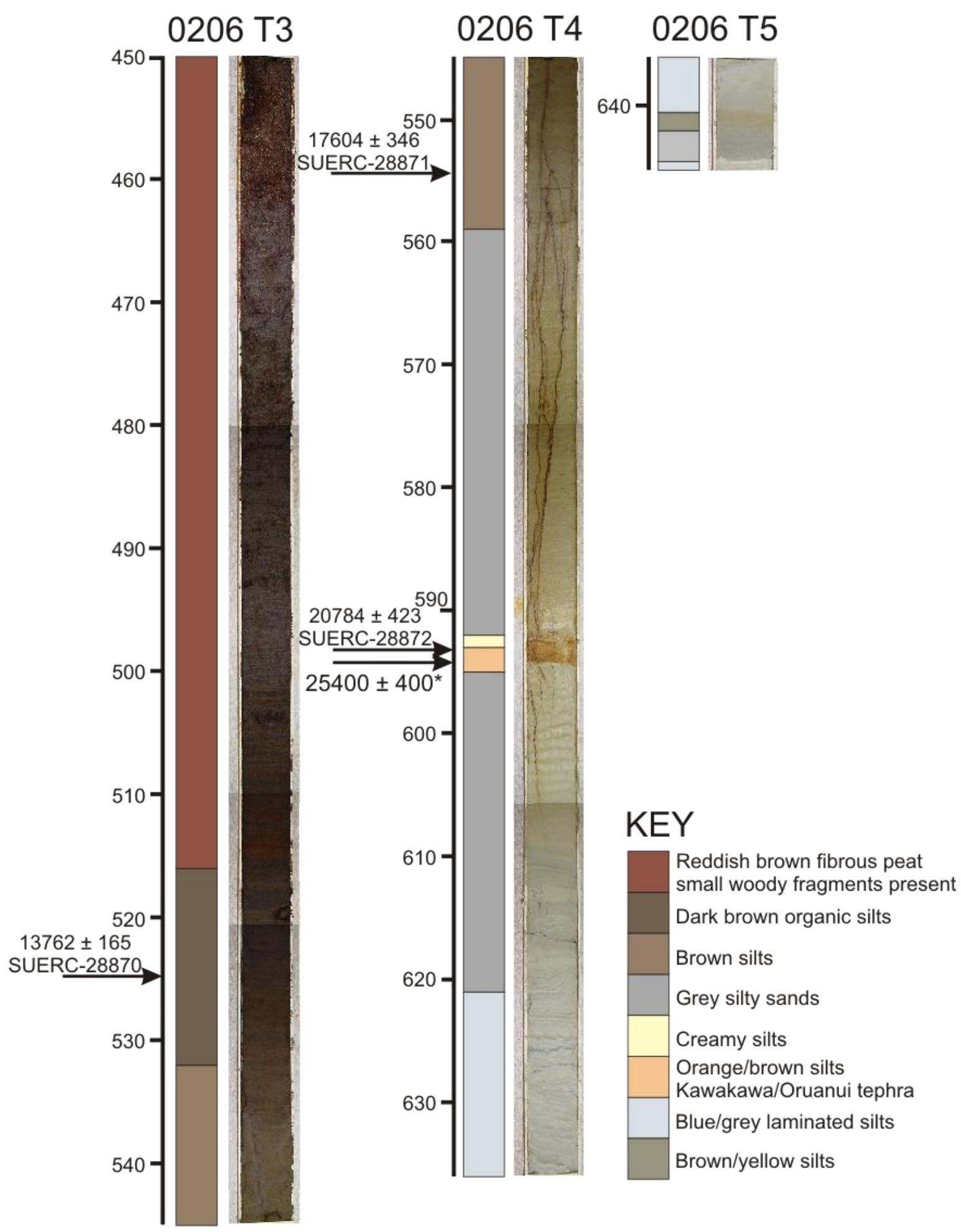

Figure 4.3: Stratigraphic illustration of the three thrusts analysed with the core images beside each corresponding illustration. Calibrated ages are added to the figure. *KOT age (Vandergoes et al, 2011). 


\subsection{Chronology}

Three samples provided three AMS ages to establish the chronology for this sequence (Table 4.1). All the ages were derived from pollen concentrates (the method is described in Section 3.5.1). A further age, produced by the chronostratigraphic marker the KOT, provides the age c. $25.4 \mathrm{ka}$ for the horizon 593-595 $\mathrm{cm}$, the same horizon as SUERC-28872.

\begin{tabular}{|c|c|c|c|c|c|c|}
\hline $\begin{array}{l}\text { Core } \\
\text { Depth }\end{array}$ & Fraction & $\begin{array}{ll}{ }^{14} \mathrm{C} & \text { age } \\
\mathrm{BP} & \end{array}$ & $\delta^{13} \mathrm{C} \%$ & $\begin{array}{l}\text { Reference } \\
\text { code }\end{array}$ & $\begin{array}{l}\% \text { carbon } \\
\text { yield }\end{array}$ & $\begin{array}{l}\text { Calibrated } \\
\text { age } \operatorname{BP}(2 \sigma)\end{array}$ \\
\hline $525-526$ & $<63 \mu \mathrm{m}$ & $11908 \pm 49$ & -29.1 & $\begin{array}{l}\text { SUERC- } \\
28870\end{array}$ & 13.2 & $13762 \pm 165$ \\
\hline $555-556$ & $<63 \mu \mathrm{m}$ & $14527 \pm 62$ & -26.4 & $\begin{array}{l}\text { SUERC- } \\
28871\end{array}$ & - & $17604 \pm 346$ \\
\hline 593-594 & $<63 \mu \mathrm{m}$ & $17418 \pm 85$ & -25.2 & $\begin{array}{l}\text { SUERC- } \\
28872\end{array}$ & 0.14 & $20784 \pm 423$ \\
\hline $\begin{array}{l}\text { *Wood } \\
\text { standard }\end{array}$ & & $\begin{array}{l}11727 \pm \\
50\end{array}$ & 25.0 & $\begin{array}{l}\text { SUERC- } \\
28880\end{array}$ & 51.9 & \\
\hline $\begin{array}{l}{ }^{*} \text { Coal bit } \\
\text { standard }\end{array}$ & & $\begin{array}{l}54160 \pm \\
350\end{array}$ & 23.2 & $\begin{array}{l}\text { SUERC- } \\
28881\end{array}$ & 88.6 & \\
\hline
\end{tabular}

Table 4.1: Radiocarbon age details for Lake Mudgie. Ages were calibrated using the online OXCal program *Standards used to assess if any contamination occurred during the preparation process.

The table above indicates the three AMS ages lie in stratigraphic order. However, when the established KOT age is added to the group, the oldest AMS age, SUERC-28872, is significantly younger than the tephra layer which this age dates. The two standards that underwent the same laboratory process as the other ages, reproduced ages that were expected, indicating that any contamination by both older and younger carbon introduced during the analytical procedure was minimal. The top uppermost ages, at $555-556 \mathrm{~cm}$ and $525-526 \mathrm{~cm}$, are consistent with the pollen stratigraphy (see Section 4.4.1 and Figure 4.5) and with the chronologies for the other pollen records in the Westland (Vandergoes and Fitzsimons, 2003; Vandergoes et al, 2005; Newnham et al, 2007a). However, the radiocarbon age for sample SUERC-28872 appears younger than expected, both in regards to its depth in the stratigraphy in relation with the KOT Layer and the pollen assemblage 
at the same horizon (see Section 4.4.1). The following section discusses this age in particular.

\subsubsection{Chronology discussion}

Sample SUERC-28872 was taken at $593-594 \mathrm{~cm}$ in the core, the horizon directly above the chronostratigraphic marker, the KOT layer. The recently refined age of c. 25.4 ka has been applied to the KOT and is currently regarded as a reliable age for this deposit (Vandergoes et al, 2011). Therefore, the date for SUERC-28872 is considerably younger than would be expected for a sample located directly above the tephra layer. The standards indicate that contamination during the preparation procedure was minimal and certainly not significant enough to produce such a young age. The remaining possibilities are that the "accepted" age of the KOT layer is wrong (refer to Section 3.5.2), or contamination from younger carbon occurred prior to the preparation process (see Section 3.5.1). The core stratigraphy (Figure 4.3) shows another potential source of contamination. A probable earthquake induce crack is visible from 536-608 cm. This crack could have opened a pathway for younger carbon to go down the sediment column, and thus causing contamination. Although every effort was made to prevent incorporating material associated with the crack with the dated sample, the low carbon content and the expected age of the sample means that even a small amount of contamination can have a large influence on the age. The $<90 \mu \mathrm{m}$ sediment fraction was used to produce a high pollen concentration sample for dating. It is possible that pollen travelled down the earthquake intrusion causing the contamination. However, this is unlikely as contamination from the younger sediment would contain different taxa and would be noticeable in the pollen assemblage. The most likely cause of contamination is from the more mobile humic and fulvic organic acids. It is therefore likely that contamination at the site is the cause for the young age. However, it is still important to ascertain whether the accepted age of the KOT age is a realistic age.

Figure 4.4 presents an age-depth model for Lake Mudgie. SUERC-28872 AMS is included in the figure but not in the model. If the KOT age is ignored and the SUERC-28872 age used, an initial sediment accumulation rate of $84 \mathrm{yrs} / \mathrm{cm}$ is calculated between SUERC-28872 and SUERC-28871. This is followed by a 
decrease in accumulation rate of $128 \mathrm{yrs} / \mathrm{cm}$ between samples SUERC-28871 and SUERC-28870. This would suggest higher rates of sediment accumulation occurred during the LGCP than the LGIT. When the KOT is used instead the sediment accumulation rate reduces to $205 \mathrm{yrs} / \mathrm{cm}$, over twice as slow. This rate is also an average $70 \mathrm{yrs}$ slower per $\mathrm{cm}$ deposited than the LGIT estimated sedimentation rate. Due to the significantly younger age produce by SUERC28872 compared to the established compared to the KOT age and possible contamination at the site it was decided to exclude SUERC-28872 from the age depth model. 


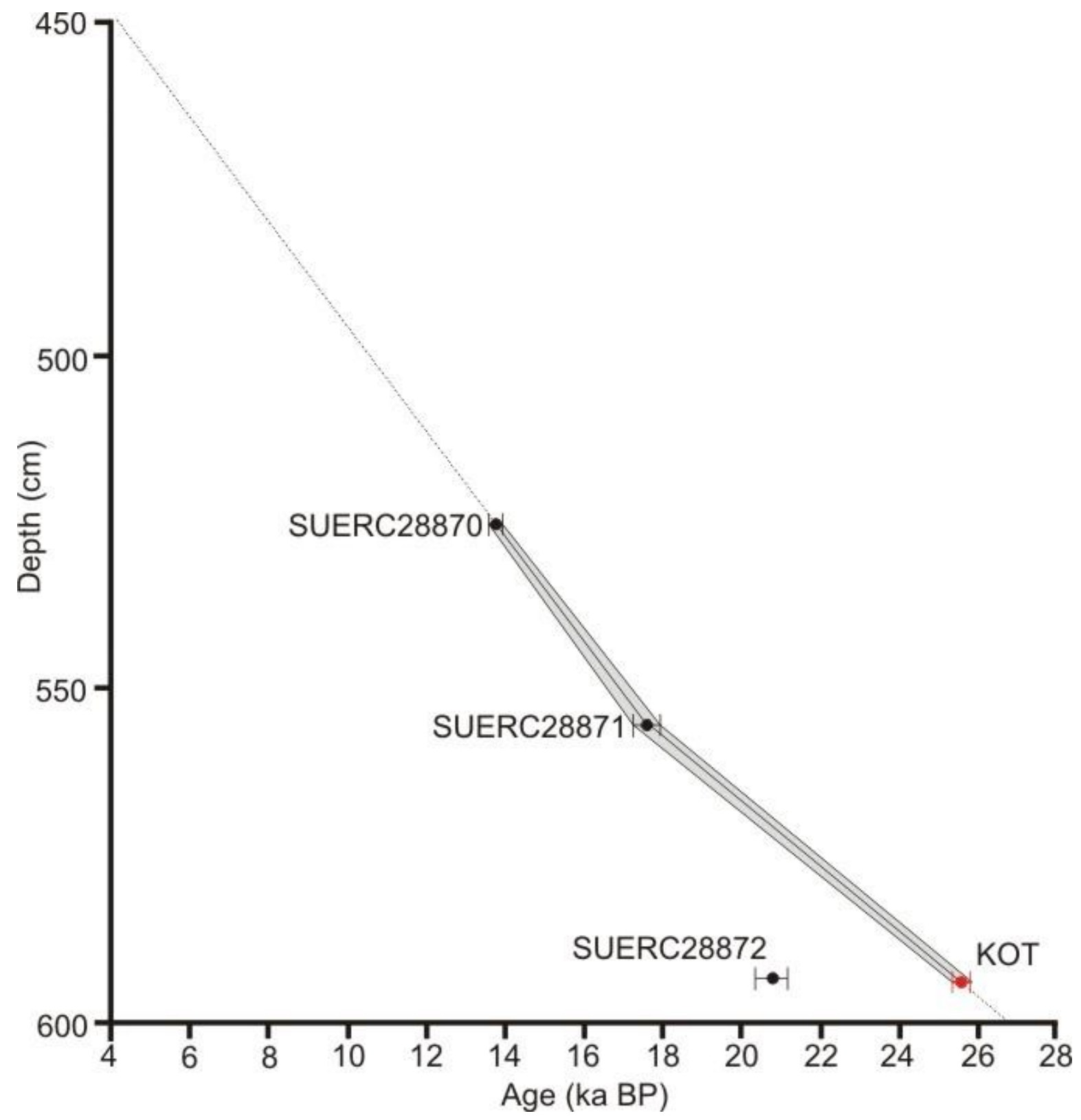

Figure 4.4: Age depth model for Lake Mudgie using the calibrated ages. The KOT age is in red. The dotted lines are extrapolated using the $129 \mathrm{yrs} / \mathrm{cm}$ sedimentation rate estimated between SUERC-28870 to SUERC28871. This provides and extrapolated age of $4130 \mathrm{yrs}$ BP for the top of the section analysed. 


\subsection{Results}

\subsubsection{Pollen stratigraphy}

The pollen diagram from the Lake Mudgie core is shown in Figure 4.5. This figure includes only the main pollen types, see appendix $C$ for the whole pollen data set. The core stratigraphy and radiocarbon dates are summarised alongside the diagram. The LOI and PSA results and temperature reconstructions are also shown next to the pollen diagram. The sedimentological results will be described later in sections 4.4.2 and 4.4.3. The temperature reconstructions are described in Section 4.4.4. As mentioned above, the time frame of 30-8 ka was chosen for this project and therefore only the bottom 3 cores of the site were analysed. Initially a $10 \mathrm{~cm}$ preliminary sample interval was used down the core. This produced a skeleton diagram which was used to decide areas where the higher resolution pollen analysis would take place. Below $600 \mathrm{~cm}$ there were insignificant amounts of pollen in the samples suggesting the site is of Larrikins I age, as if it were older then pollen would continue to have been deposited. Due to the low pollen concentrations the analysed was restricted to the depths $450-600 \mathrm{~cm}$.

CONISS stratigraphic cluster analysis, available in the TG View program, was used to group the pollen percentage data (see appendix $A$ for the cluster analysis results). The cluster analysis was only carried out on the total dryland pollen (TDP). The pollen assemblage zones for the Lake Mudgie sequence generally correspond to the biostratigaphic zones defined by the cluster analysis. However, the zones chosen were restricted to assemblage changes in the pollen composition that are considered to be of palaeoecological and palaeoclimatic significance. The main pollen zones are numbered LM1-LM4. Within these zones subsequent changes in pollen composition are defined as a sub-zone (Figure 4.5). 


\subsubsection{Pollen assemblage zones}

There are four main pollen assemblage zones splitting the stratigraphy with a number of sub-zones contained within these.

\section{Zone LM1: 600-555 cm (c. 26.6-17.6 ka):}

LM1 is dominated by non-arboreal pollen; in particular there are high percentages of Poaceae. There are also significant amounts of shrub species, including Hebe, Asteraceae, Coprosma and Myrsine, although the proportion of shrubs declines towards the top of this zone. Fuscospora tree pollen was consistently present throughout the zone averaging $5-10 \%$ abundance. The high resolution pollen analysis indicates a small, but significant, composition change with an increase in herb dominance and a reduction in the shrub component from $586-559 \mathrm{~cm}$. These changes are distinctive in the pollen record and the results of the cluster analysis support the chosen zones. This forms the basis for splitting the zone into three sub-zones (Figure 4.5)

Sub-zone LM1a (600-583 cm: c. 26.6- c. $23.2 \mathrm{ka})$ :

This sub-zone is dominated by grass species with a higher percentage of small Poaceae pollen grains in comparison to the Poaceae $>40 \mu \mathrm{m}$. Other herb species are also present, albeit in small percentages at the base of this zone, including Apiaceae, Brassicaeae and Kelleria. A significant amount of Hebe, reaching a maximum abundance of $25 \%$, is present throughout this sub-zone, although levels decrease towards the top of the boundary. Other shrub elements include Coprosma, Asteraceae and, to a lesser extent, Myrsine. These species contribute to a shrub abundance ranging $40-15 \%$ in this zone. Fuscospora is also present in low percentages of around 5\%. There is also a low amount of monolete spores, Lycopodium type and some wetland species (Gonocarpus, Empodisma and Cyperaceae).

Sub-zone LM1b (583-559 cm: c. 23.2- c. $18.4 \mathrm{ka})$ :

This zone is still dominated by Poaceae, with grains under $40 \mu \mathrm{m}$ consistently above $65 \%$ abundance and increased amounts of Poaceae $>40 \mu \mathrm{m}$ pollen averaging between $10-15 \%$. However, Poaceae peaks at the top of this sub zone with $29 \%$. The tall tree component, mostly Fuscospora remains at a similar 
abundance as in the previous sub-zone. However, the percentage of overall shrub composition decreases to $10-15 \%$. The most significant reduction is the abundance of Hebe, declining to $0 \%$. Coprosma and Myrsine also decline to negligible amounts, although Coprosma abundance starts to increase towards to the top of this sub-zone. The percentage and composition of fern spore and wetland species is similar to the previous sub-zone.

\section{Sub-zone LM1c (559-555 cm: c. 18.4-17.6 ka):}

Sub-zone LM1C marks the transition between the distinctive pollen compositions of zone LM1 and zone LM2. This zone is distinguished from sub-zone LM1b by the dramatic decrease in herb taxa, particularly Poaceae from $70 \%$ abundance down to only $10 \%$ towards the top of this zone. Fuscospora abundance also declines to trace levels. In contrast the proportions of Coprosma shift from $15 \%$ to $65 \%$ and Myrsine increases from $7 \%$ to $26 \%$ towards the top of this sub-zone. Asteraceae abundance remains the same. Coinciding with this increase in shrubs abundance is an increase in monolete spores from $5 \%$ to $18 \%$

\section{Zone LM2 (555-520 cm: 17.6 - c. $13.1 \mathrm{ka})$ :}

In zone LM2 the TDP is dominated by shrub species, in particular Coprosma and Myrsine especially in the lower to mid zone location. A pattern of successive introduction of other shrub species occurs up through the zone. The top of this zone begins to receive a large input of tall tree species; $W$. racemosa and to a lesser extent Prumnopitys ferruginea. This is the start of a transition from shrub to hardwood/podocarp vegetative communities. This zone also experiences a significant increase in fern, tree fern and wetland components.

Sub-zone LM2a (555-544 cm: 17.6 - c. $16.2 \mathrm{ka})$ :

This sub-zone is dominated by Coprosma and Myrsine with both genera reaching a maximum abundance of $50-60 \%$.Coprosma is the dominant species throughout the majority of this sub-zone, although Myrsine increases in abundance towards the top. Asteraceae remains at a similar abundance as in the previous zone. There is a small amount (10\%) of Poaceae at the bottom of this sub-zone, a remnant of the alpine dominated vegetation which was prevalent in LM1, but it quickly disappears from the record. The shrub Pseudopanax also begins to make an 
appearance in this sub-zone. The abundance of monolete spores continues from the previous sub-zone with a similar abundance of $15 \%$, but declines towards the top of this zone coinciding with an increase in Histiopteris.

Sub-zone LM2b (544-530 cm: c. 16.2 - c. $14.4 \mathrm{ka})$ :

The TDP abundance is very similar to the previous sub-zone with a high abundance of Coprosma which reduces up through the sub-zone, giving way to dominance of Myrsine. The presence of Pseudopanax continues with the addition of Pseudowintera and small amounts of Griselinia. The largest noticeable change in the sub-zone relates to the aquatic, tree fern and fern components. Cyathea smithii and Leptospermum type make an appearance at the base of this sub-zone. The C. smithii increase is more significant rising from $0-14 \%$ by the top of this zone. Similarly, Isoetes also make an appearance in this zone, and increases markedly from $0-86 \%$ at the top of this zone. A small peak in Dacrycarpus dacrydioides abundance occurs at the top of this sub-zone $(532-530 \mathrm{~cm})$ reaching a maximum $5 \%$ at $532 \mathrm{~cm}$ followed by a decrease to below $1 \%$ for the remainder of pollen zone LM2.

Sub-zone LM2c (530-520 cm: c. 14.4 - c. $13.1 \mathrm{ka})$ :

This zone shows the continuation of the upwards decrease in abundance of Coprosma, joined by reductions in Myrsine, Pseudopanax and Pseudowintera. However, this zone also marks a transition of new shrub/short tree species reaching either their maximum abundance (Griselinia) or first consistent appearance in the record (Elaeocarpus). This zone also marks a significant change via an increase in tall tree species. Libocedrus, present in the previous zone in small amounts, increases its abundance and is consistently between 5$10 \%$ and Weinmmania reaches its maximum abundance of $38 \%$ at $523 \mathrm{~cm}$, but decreases to $22 \%$ at the sub-zone boundary. Prumnopitys ferruginea also reaches a peak abundance of $20 \%$ at $522 \mathrm{~cm}$.

The wetland taxon, Leptospermum type, reaches a peak abundance of $26 \%$ and the macrophyte, Isoetes continues from the previous sub-zone, with a high abundance of $80 \%$, decreasing to $66 \%$ at $523 \mathrm{~cm}$. A dramatic decrease in Isoetes follows and by $520 \mathrm{~cm}$ it has an abundance of only $6 \%$. Cyathea smithii is 
persistent throughout the sub-zone, although at slightly lower amounts compared to the previous sub-zone.

\section{Zone LM3 (520-503 cm: c. 13.1 - c. $10.9 \mathrm{ka})$ :}

This zone represents a transition from shrub and early tree appearance to a dominance of the podocarp Dacrydium cupressinmum. Coprosma, Myrsine, Griselinia and Elaeocarpus all decrease in abundance to near $0 \%$ by the top of this zone. Likewise Libocedrus, W. racemosa and $P$. ferruginea also decrease significantly to $5 \%$. In contrast, $D$. cupressinum increases dramatically from near $0 \%$ to above $80 \%$ at the top of this zone. However there isn't a consistent or smooth increase in $D$. cupressinum, rather the pattern of increase is interrupted. Associated with this 'interrupted' $D$. cupressinum increase is a reoccurrence, albeit in small abundances, of Chenopodiaceae, Phyllocladus and Fuscospora, which were previously present together in Zone L1. This zone is marked by a decrease in Leptospermum type but an increase in Cyathea smithii and small abundances of Dicksonia squarrosa and Cyathea dealbata.

\section{Zone LM4 (503-450 cm: c. 10.9 - c. $4.2 \mathrm{ka})$ :}

The TDP is dominated by tall trees and in particular by the tree species Dacydium cupressinum that has an abundance ranging from $85 \%$ to above $90 \%$. W. racemosa and Prumnopitys ferruginea are present throughout this zone, albeit in low percentages (5-2\%). All the shrub species have very low abundance if present at all. The tree ferns are still present, although Cyathea smithii reduces in abundance. D. squarrosa and $C$. dealbata are also present in similar percentages as in the previous zone. There is a very small presence, if at all, of fern spores. 


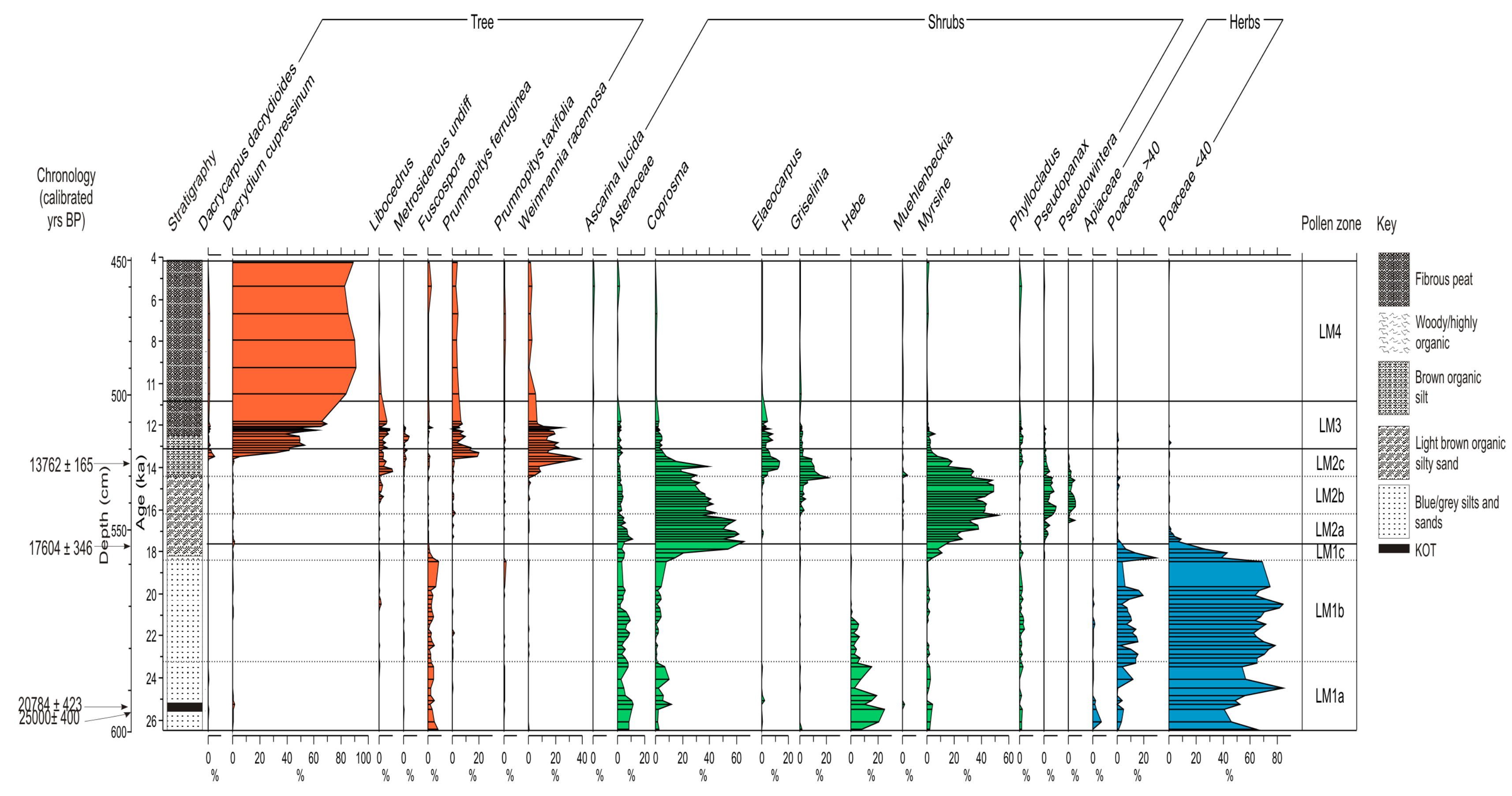

Figure 4.5: Lake Mudgie pollen percentage diagram, including core stratigraphy, summary diagram, total carbon content, particle size percentage and pollen-climate reconstructions. Radiocarbon dates are summarised in Table 4.1. 


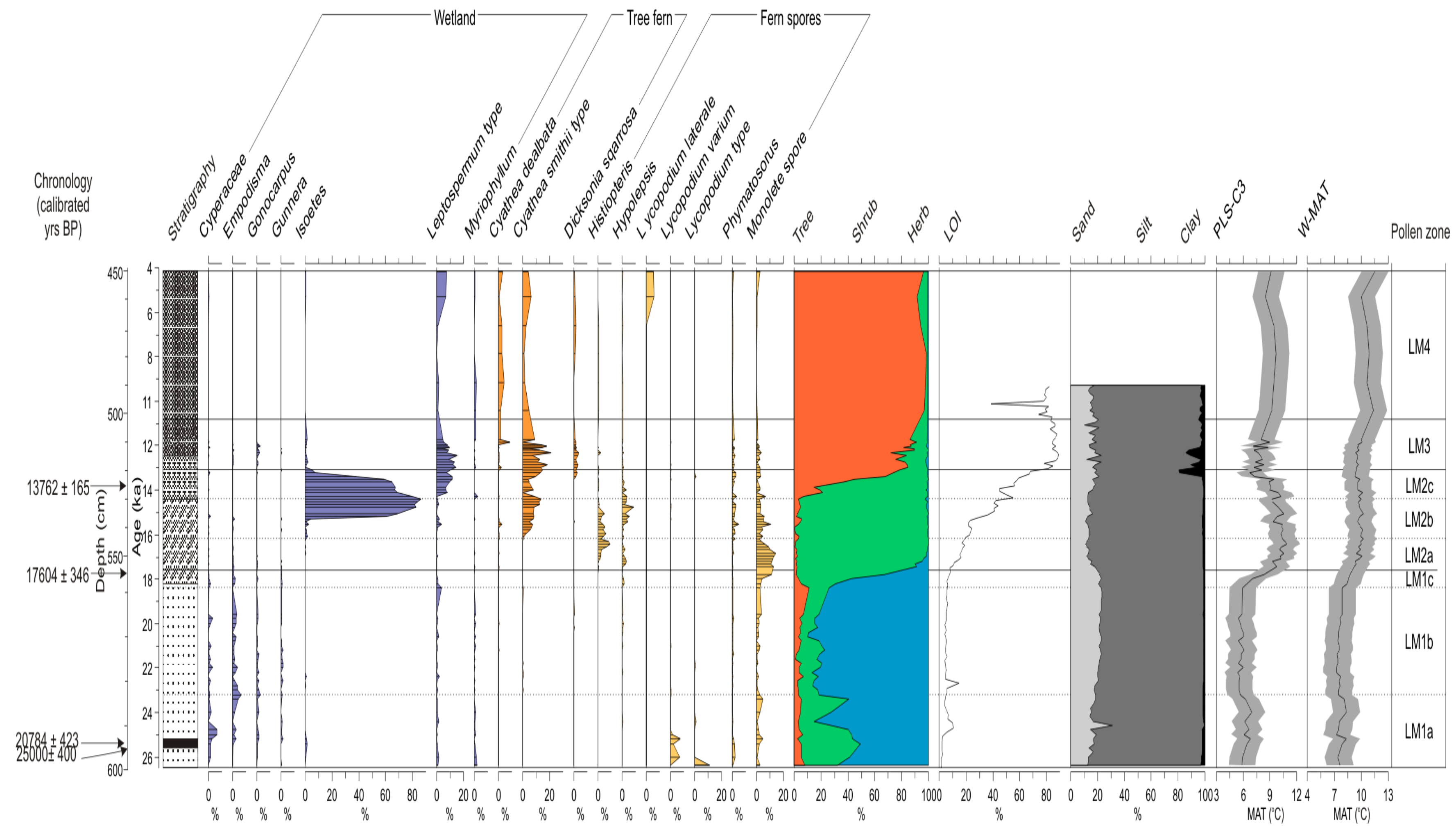

Figure 4.5: (continue) 


\subsubsection{Particle Size Analysis}

Sampling for the particle size analysis (PSA) occurred every other half $\mathrm{cm}$, producing a $1 \mathrm{~cm}$ resolution with a sample width of $0.5 \mathrm{~cm}$ thick. Sampling began at $490 \mathrm{~cm}$ and continued down through the core to $600 \mathrm{~cm}$, covering the section of detailed pollen analysis. Throughout this section the silt fraction was the most dominant particle size, mostly $70-80 \%$, however there are variations within the clay and sand component up the core and, of course, this influenced the percentage of silt in the sediment. The maximum sand abundance occurred, between 600-555 $\mathrm{cm}$ peaking at $592 \mathrm{~cm}$ (pollen assemblage zone LM 1a) and between 583-555 cm (pollen assemblage zone LM1b) and consistently ranging 17-22\%. Between 555$523 \mathrm{~cm}$ the abundance of sand decrease to $12-15 \%$. At $523 \mathrm{~cm}$ the abundance of sand again increases to near previous maximum levels of $20 \%$ although the pattern appears to be more erratic. The sand abundance then decreases back to $15 \%$ toward the top of the section analysed. In contrast the amount of clay throughout the core is relatively low, consistently having an abundance of $2 \%$ or lower from $600-523 \mathrm{~cm}$. However, between $523-510 \mathrm{~cm}$ the proportion of clay increases and has a bimodal peak in abundance. The first of the modes is at 521 $\mathrm{cm}$ reaching $20 \%$ abundance and then reducing to $8 \%$ then rising back up to $15 \%$ at $510 \mathrm{~cm}$ before again lowering back to $4 \%$ where it remains consistently around this abundance to the top of the section analysed. The abundance of silt therefore decreases to its lowest levels of $65-60 \%$ between $523-510 \mathrm{~cm}$.

\subsubsection{LOI}

As with the PSA, sampling for LOI analysis occurred every other half centimetre at a $1 \mathrm{~cm}$ resolution, from $600-490 \mathrm{~cm}$. Three main patterns in the record are evident, with minor variations superimposed upon this main pattern. The first noticeable pattern is the stable low LOI present in the sediment from 600-555 cm, corresponding to pollen assemblage zone LM1. The amount in this section increases from $2 \%$ up to a small peak of $10 \%(590 \mathrm{~cm})$ reducing back to $5 \%$ and followed by another peak to $15 \%$ at $580 \mathrm{~cm}$. After this second peak a consistent, $5-6 \%$ LOI is present sediment up to $555 \mathrm{~cm}$. Between $555-518 \mathrm{~cm}$ the LOI increases markedly from $8 \%$ to $84 \%$ (pollen assemblage zone LM2) with a few minor reversals. This section corresponds to LM2. From 518-490 cm the LOI 
reaches the maximum content of $87 \%$ and levels off after $520 \mathrm{~cm}$ with slight decreases in abundance to $80 \%$ towards the top of this record. This corresponds to pollen assemblage zones LM3 and LM4. One sample, at $496 \mathrm{~cm}$, has a carbon content of only $39 \%$ but the next samples increase in carbon content back to 80 $82 \%$ suggesting that this is an erroneous result.

\subsubsection{Temperature reconstructions}

Fig 4.5 displays the MAT reconstruction comparing the two models, PLS-C3 and W-MAT. Overall the pattern of temperature change is similar between models although W-MAT consistently produces higher temperature estimates than PLSC3 which exhibits greater variability. The initial predicted MAT in the PLS-C3 model is $5.6{ }^{\circ} \mathrm{C}$ increasing to $6.8{ }^{\circ} \mathrm{C}$ remaining around this level until the $583 \mathrm{~cm}$. Temperature decreases and ranges $5.4-6.3^{\circ} \mathrm{C}$ with an average of $5.7^{\circ} \mathrm{C}$ between $583-555 \mathrm{~cm}$. Temperatures increase rapidly after $555 \mathrm{~cm}$ reaching a maximum of $10.8{ }^{\circ} \mathrm{C}$ at $548 \mathrm{~cm}$. The temperature slowly declines down to $9.5^{\circ} \mathrm{C}$ at $523 \mathrm{~cm}$ followed by a rapid decline in temperature between $523-510 \mathrm{~cm}$ reaching a minimum $6.7^{\circ} \mathrm{C}$ and oscillating between $6.7-8.2^{\circ} \mathrm{C}$. At $510 \mathrm{~cm}$ temperatures reach $8.9^{\circ} \mathrm{C}$ and then rise consistently above $9^{\circ} \mathrm{C}$, the exception being at $459 \mathrm{~cm}$ where a temporary MAT dip to $8.5^{\circ} \mathrm{C}$ occurs.

W-MAT initially shows temperatures oscillating between 7.3-8.4 ${ }^{\circ} \mathrm{C}$ between 599 $583 \mathrm{~cm}$ followed by a period of consistently cooler temperatures ranging $7.2-7.8^{\circ} \mathrm{C}$ and averaging $7.5{ }^{\circ} \mathrm{C}$ between $583-559 \mathrm{~cm}$. Temperature begins to increase at $559 \mathrm{~cm}$ but less rapidly than in the PLS-C3 model, reaching a maximum $10.4{ }^{\circ} \mathrm{C}$ at $544 \mathrm{~cm}$ and plateaus until $523 \mathrm{~cm}$. A minor decline in temperature occurs between $532-510 \mathrm{~cm}$ declining to $9.3-9.7^{\circ} \mathrm{C}$. This is followed by an increase in temperature reaching $11.3^{\circ} \mathrm{C}$ at $500 \mathrm{~cm}$ and remaining above $10{ }^{\circ} \mathrm{C}$ for the majority of the top section of the core. However, the MAT changes reconstructed by both modelled lie within the error margin and indicating a limited temperature, if any, can be predicted for this site. 


\subsubsection{Principal Component Analysis (PCA)}

PCA, using CANOCCO version 2, was initially carried out on just the pollen data, with subsequent runs including the LOI and the \% of sand, silt and clay particle sizes in each sample to explore relationships between the pollen assemblages and changes in core sedimentology. Although pollen and PSA samples were at the same depths, LOI samples were consistently offset by $0.5 \mathrm{~cm}$, due to the sampling strategy. Therefore an average was taken of the two LOI samples which bordered the sampled depth of the PSA and pollen analysis.

The results are presented in two sections with and without the sedimentological data. The eigenvalues for each species are summarised (Figure 4.6 and Table 4.2) followed by a description of the sample eigenvalues (Figure 4.7 and Table 4.3). The results are then considered in context with the pollen diagram and pollen assemblage zones.

\subsubsection{Palynological PCA results}

Figure 4.6 is a biplot of species eigenvalues for axis 1 and axis 2, illustrating the relationships of different pollen types. Three groups are apparent, with one group sub-divided further into two sub groups.

Group 1 contains taxa with positive eigenvalue on axis 1 and negative to near 0 values on axis 2. Phyllocladus and Gonocarpus are the two exceptions having more positive values along axis 2 . This group represents vegetation present in zone LM1 including both the $>40 \mu \mathrm{m}$ and $<40 \mu \mathrm{m}$ Poaceae taxa and a further four herb taxa (see Table 4.2). The shrub taxa Asteraceae, Hebe, Phyllocladus and the tall tree species Fuscospora are included in this group as well as four wetland taxa (Table 4.2).

Taxa in group 2 have negative eigenvlaues along both axes. This group comprises seven shrub taxa, including Coprosma, Myrsine, Griselinia Pseudopanax and Pseudowintera, and four fern species. These taxa are more prevalent in pollen assemblage zone LM2. 
Group 3 contains taxa with negative eigenvalues on axis 1 and positive values on axis 2. This group can be further divided into $3 a$ and $3 b$, where sub-group $3 b$ have more positive eigenvalues on axis 2 . Sub group $3 a$ contains species which were prevalent in pollen assemblage zone LM2c and LM3. Four tall tree species $W$. racemosa, Libocedrus, Metrosideros and Elaeocarpus are included in this group along with the tree fern Cyathea smithii and wetland taxon Leptospermum type.

Sub-group $3 b$ is restricted to just five taxa including three tall tree species; Dacrycarpus dacrydiodes, Dacrydium cupressinum and Prumnopitys ferruginea, and two tree fern taxa. These taxa are restricted to the top of the core in pollen assemblage zone L3 and L4. These species are also representative of the lowland temperate forest that is prevalent in the contemporary Westland region.

\begin{tabular}{|c|c|c|c|c|c|c|}
\hline Group & Tall tree & $\begin{array}{ll}\text { Short } & \text { tree/ } \\
\text { shrub } & \end{array}$ & Herb & Wetland & Tree fern & Fern \\
\hline 1 & Fuscospora & $\begin{array}{l}\text { Hebe }^{*} \\
\text { Asteraceae* } \\
\text { Phyllocladus }\end{array}$ & $\begin{array}{l}\text { Poaceae } \\
\text { Kelleria } \\
\text { Chenopodiaceae } \\
\text { Brassicaceae } \\
\text { Gentiana }\end{array}$ & $\begin{array}{l}\text { Cyperaceae } \\
\text { Gonocarpus } \\
\text { Empodisma } \\
\text { Gunnera }\end{array}$ & & \\
\hline 2 & & $\begin{array}{l}\text { Coprosma } \\
\text { Myrsine } \\
\text { Griselinia } \\
\text { Muehlenbeckia } \\
\text { Pseudopanax } \\
\text { Pseudowintera } \\
\text { Schefflera }\end{array}$ & & & & $\begin{array}{l}\text { Histiopteris } \\
\text { Hypolepsis } \\
\text { Isoetes } \\
\text { Monolete spore }\end{array}$ \\
\hline $3 a$ & $\begin{array}{l}\text { W. racemosa } \\
\text { Libocedrus } \\
\text { Meterosideros }\end{array}$ & $\begin{array}{l}\text { Elaeocarpus } \\
\text { Rubus }\end{array}$ & & $\begin{array}{l}\text { Leptospermum } \\
\text { type }\end{array}$ & C.smithii & $\begin{array}{l}\text { Hymeonophyllum } \\
\text { Phymatosorus }\end{array}$ \\
\hline $3 b$ & $\begin{array}{l}\text { D.dacrydiodes } \\
\text { Dacrydium } \\
\text { cupressinum } \\
\text { P.ferruginea }\end{array}$ & & & & $\begin{array}{l}\text { C.dealbata } \\
\text { D.squarrosa }\end{array}$ & \\
\hline
\end{tabular}

Table 4.2: Taxa comprising the Lake Mudgie PCA groups with their represented vegetation communities. 


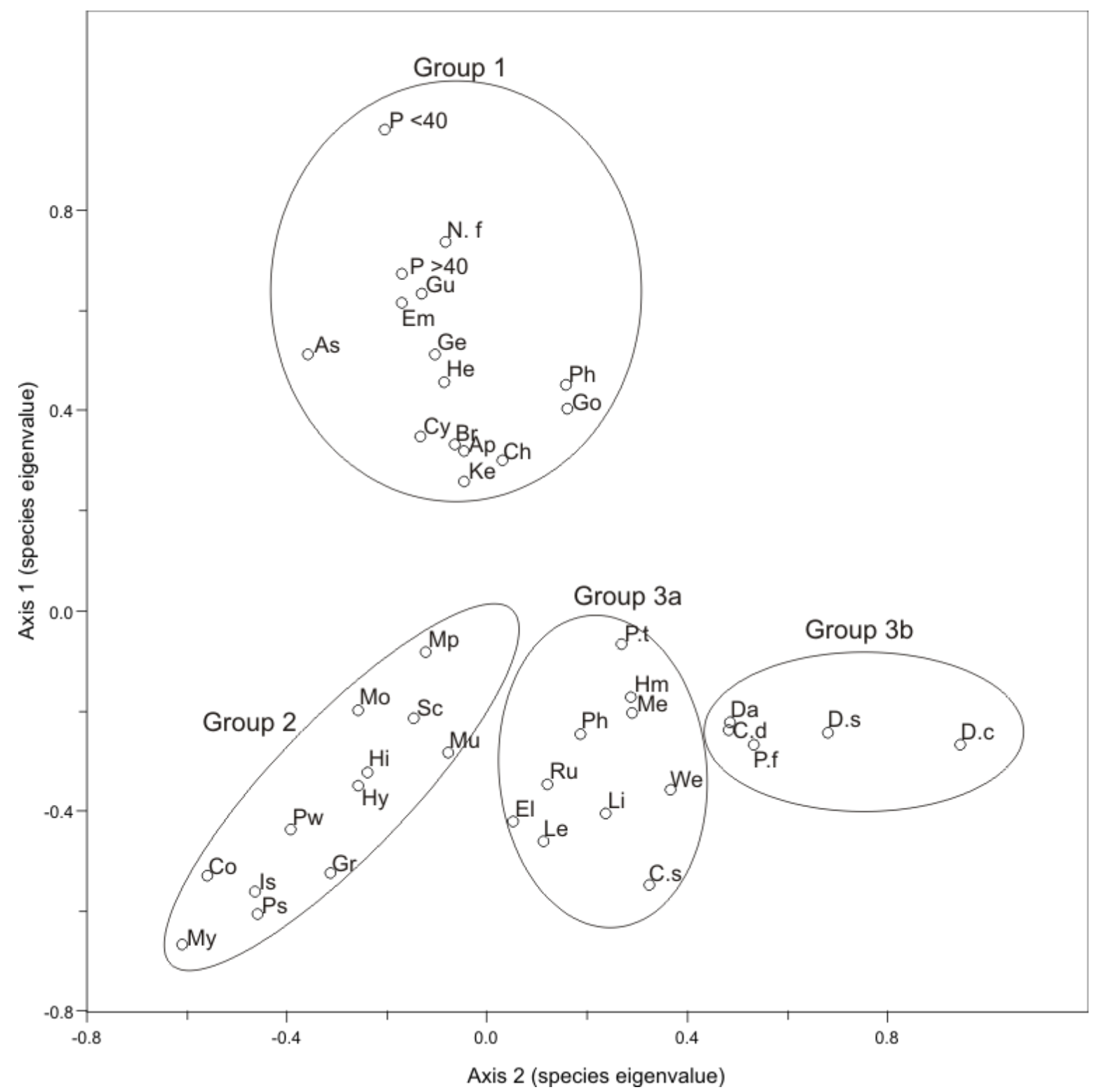

Figure 4.6: Lake Mudgie PCA results for selected taxa plotted for axis 1 and axis 2. Circles indicate arbitrary chosen group clusters. Group 1; P<40 - Poaceae $<40 \mu \mathrm{m}$, N.f - Fuscospora, P $>40$ - Poacaea $>40 \mu m$, Gu Gunnera, Em - Empodisma, As - Asteraceae, Ge - Gentiana, He - Hebe, Ph - Phyllocladus,Go Gonocarpus, Cy - Cyperaceae, Br - Brassicaeae, Ap - Apiacaeae, Ch - Chenopodiaceae, Ke - Kelleria. Group 2; Mp - Myriphyllum, Mo - monolete spore, Sc - Schefflera, Mu - Muehlenbeckia, Hi - Histiopteris, Hy - Hypolepsis, Pw - Pseudowintera, Gr - Griselinia, Is - Isoetes, Ps - Pseudopanax, My - Myrsine. Group 3a:Pt - P. taxifolia, Hm - Hymenophyllum, Me - Meterosideros, Ph - Phymatosorus, Ru - Rubus, El Elaeocarpus, Le - Leptospermum type, Li - Libocedrus, We - W. racemosa, C.s - C. smithii. Group 3b: Da Dacrycarpus dacrydiodes, C.d - C. dealbata, P.f - P. ferruginea, D.s - D. squarrosa, D.C - D. cupressinum.

\subsubsection{Sample PCA results}

Figure 4.7 is a biplot of sample PCA scores for axis 1 and axis 2. Lake Mudgie samples have been split into six sample groups with some samples appearing to be 'transitional' between groups. Arrows on the figure indicate the direction the 
results have been described in and indicate the linkage between the groups. The groups are described below.

Group 1 contains samples with positive eigenvalues on axis 1 and negative values on axis 2. These samples span the depth 597-585 cm and are located at the base of the core. The samples correspond to pollen assemblage zone LM1a.

Group 2 samples have a similar values to Group 1 on axis 2 and higher positive values on axis 1. The sample depths span $584-559 \mathrm{~cm}$ and correspond to pollen assemblage zone LM1b, although there is one anomalous sample which is the bottom most core sample at $600 \mathrm{~cm}$. Three transitional samples, 558-555 cm, join group 2 to group 3 . These samples occur in stratigraphic order and has the pattern were the shallower the sample is in core a lower PCA score on axis 1 it received. These transitional samples correspond to pollen assemblage zone LM1c.

Group 3 samples have negative eigenvalues ranging between -0.7 to -0.5 on both axes. This group of samples span the depths $554-527 \mathrm{~cm}$ and corresponds broadly to pollen assemblage zone LM2a.

Group 4 contains samples with the lowest eigenvalues (-1 to -1.5$)$ along both axes. The samples in this cluster range the depths $535-526 \mathrm{~cm}$ and closely match the pollen assemblage zone LM2b. Three transitional samples join group 4 to group 5, spanning the depths $524-522 \mathrm{~cm}$. As with the previous transitional samples, these lie in stratigraphic order receiving increasing PCA scores along both axes, particularly along axis 2 , with decreasing sample depth. These samples correspond to pollen assemblage zone LM2c.

Samples in group 5 have positive eigenvalues on axis 2 and negative values on axis 1 . The samples align in a horizontally linear cluster with similar axis 1 values and PCA scores spanning from $0.8-1.7$ on axis 2 . The samples included in this group range from $521-509 \mathrm{~cm}$ and match the pollen assemblage zone LM3.

The final group, group 6, comprises the top six samples of the core. This cluster has similar negative eigenvalues on axis 1 but larger positive axis 2 values. The 
cluster aligns in a horizontal linear fashion along axis 2 that appears to extend the trend established by group 5. The group covers the depths 499-450 and corresponds to pollen assemblage zone LM4. Comparisons between the CONISS and PCA (Table 4.3) show a close similarity between the depth of the groups and the pollen zones. This gives greater weight to the cluster analysis and justifies the placement of the chosen pollen zones.

\begin{tabular}{|ll|ll|}
\hline \multicolumn{2}{|c|}{ Cluster Analysis } & \multicolumn{2}{c|}{ PCA } \\
Pollen zone & Depth (cm) & Group & Depth (cm) \\
\hline LM1 & $600-555$ & & $597-585$ \\
LM1a & $600-583$ & 1 & $584-559(600)$ \\
LM1b & $583-559$ & 2 & $558-555$ \\
LM1c & $559-555$ & Transition & \\
LM2 & $555-520$ & & $554-537$ \\
LM2a & $555-544$ & 3 & $535-526$ \\
LM2b & $544-530$ & 4 & $524-522$ \\
LM2c & $530-520$ & Transition & $521-509$ \\
LM3 & $520-503$ & 5 & $499-450$ \\
\hline LM4 & $503-450$ & 6 & \\
\hline
\end{tabular}

Table 4.3: A table comparing the depths of the pollen assemblage zones, carried out by the CONISS stratigraphic cluster analysis, to the depths of the sample groups, identified using PCA statistical method. 


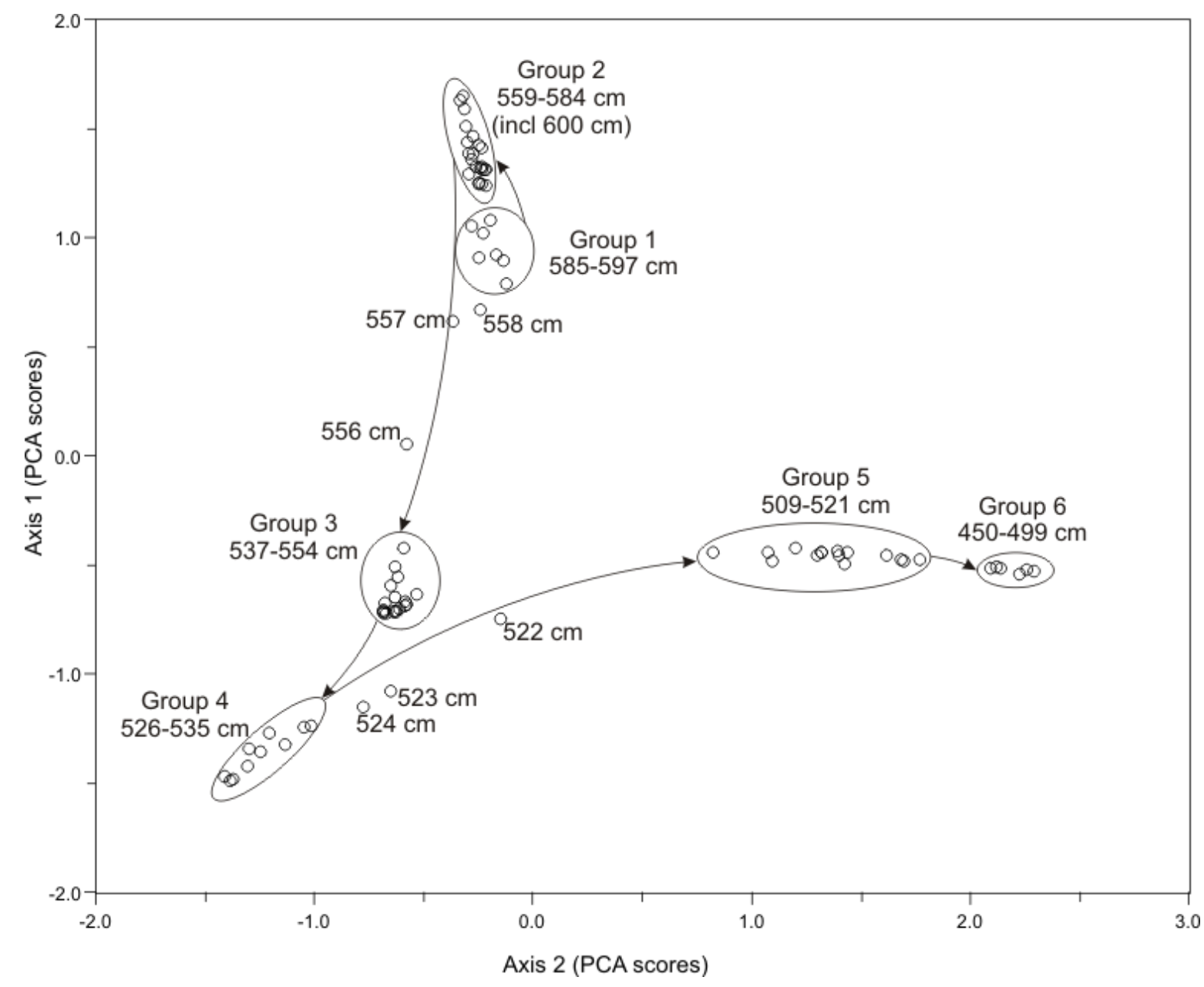

Figure 4.7: Biplot of PCA sample scores for axis 1 and axis 2. Each of the 6 groups has been labelled and the depths displayed indicate the depth range or core depth that each sample or group represents. These groups were chosen arbitrarily. The arrows indicate the stratigraphic order of the groups with the arrows pointing in the direction of decreased core depth.

Figure 4.8 plots the sample PCA score for axis 1 and axis 2 along a depth gradient. Unlike the biplot which plots the two axes scores for each sample (Figure 4.7), plotting the axis sample scores against depth can indicate what factors are influencing the individual axis over time, via comparisons with other results. The results are described below.

Axis 1 initially contains high PCA scores oscillating between 1.5-0.9 from the core base to $560 \mathrm{~cm}$. This is followed by a large decrease in eigenvalues to 0.5 at 552 $\mathrm{cm}$. A plateau of 0.5 values continues until $535.5 \mathrm{~cm}$, followed by a further decline in value to -1.5 to -1 between $535.5-525.5 \mathrm{~cm}$. A small increase in sample value to -0.5 occurs after $525.5 \mathrm{~cm}$ and this value remains constant to the top of the core. The pattern in the PCA score at the base of the core and the timing of the 
reduction in values is very similar to the Poaceae curve, however the similarities between the two records stop here.

Axis 2 initially has a consistent value of 0.5 from the core base until $558 \mathrm{~cm}$. The pattern in the PCA score is then a decrease to -1 until $536 \mathrm{~cm}$, followed by a further depression to a minimum of -1.5 at $530 \mathrm{~cm}$. The values slowly increase to 0.5 at $525 \mathrm{~cm}$. The pattern and values between $558-525.5 \mathrm{~cm}$ is the same as that recorded in axis 1 and is the section of the core dominated by shrub taxa. A dramatic increase in PCA score occurs above $525.5 \mathrm{~cm}$, reaching a value of 1 by $520.5 \mathrm{~cm}$. From $520.5 \mathrm{~cm}$ to the top of the core is a section of high PCA score which lie consistently between 1-2. The pattern in the upper section of the core (from $525-450 \mathrm{~cm}$ ) is similar to the pattern in total tree abundance, particularly the pattern of Dacrydium cupressinum abundance.

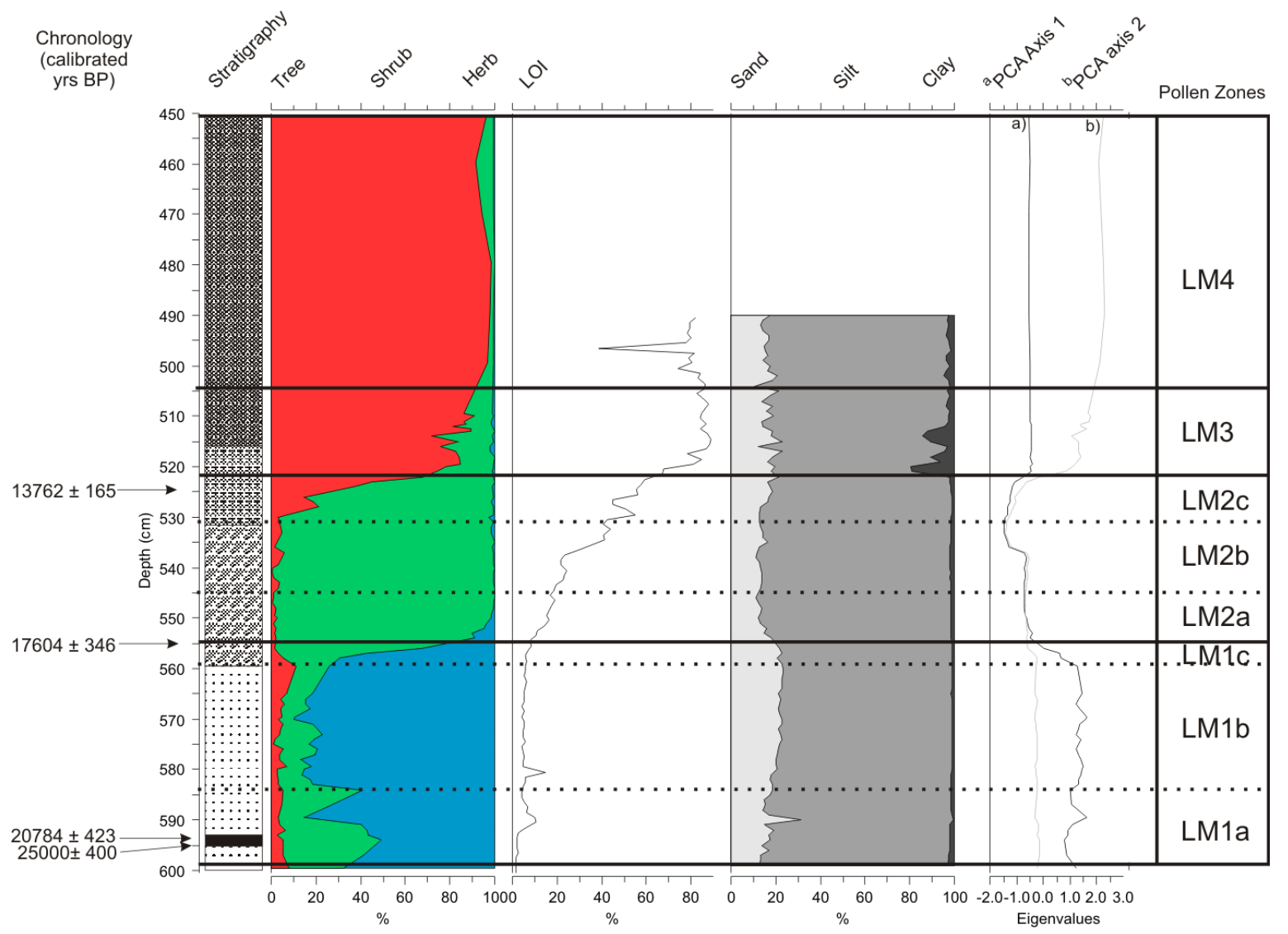

Figure 4.8: Rough diagram with the PCA sample scores of axis 1 and 2 plotting with depth. TDP, LOI and PSA have been added to show if there are any similarities between the records and the axes scores. 


\subsubsection{PCA results combining the pollen and sediment data}

The addition of the sedimentology to the PCA enables comparisons between species composition and sediment characteristics (Figure 4.9). Sand size particles lie in group 1 and are associated with alpine vegetation communities. Fine particle size and LOI have similar PCA score as the tall tree and tree fern species. In the contemporary environment these are species located in the lowland temperate rainforest. Silt size particle appear to be an anomaly and are ubiquitous, showing no particular association with any vegetation group. This is probably because silt levels remained between $70-80 \%$ throughout the section analysed and therefore do not relate to any vegetation groups in particular. 


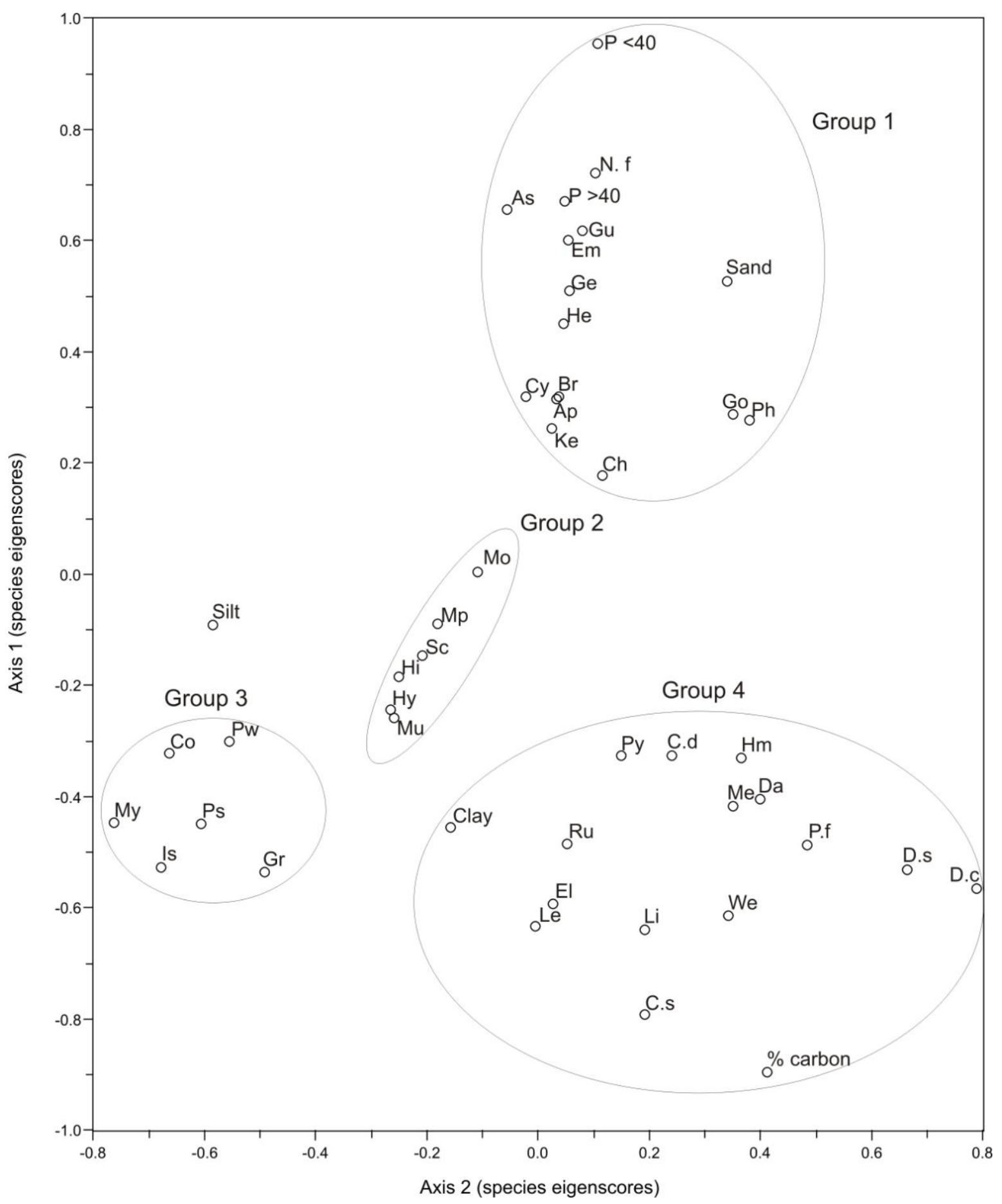

Figure 4.9: Lake Mudgie PCA results for selected taxa and sedimentology results plotted for axis 1 and axis 2. Circles indicate arbitrary chosen group clusters. Refer to Figure 4.6 for species names. 


\subsection{Discussion}

This section interprets the pollen and sedimentological results in terms of inferred vegetation communities and then climatic reconstruction. The chronology, derived from the three radiocarbon dates and the tephra layer, is discussed and then applied to the vegetation record. The discussion concludes with a summary of Lake Mudgie's results and interpretations where comparisons with other Westland and New Zealand records are made.

\subsubsection{Vegetation and climatic interpretation}

The vegetation and climatic reconstruction were inferred using contemporary vegetation ecological characteristics (Wardle 1975, 1977, 1991; Moar 1970), palaeoenvironmental interpretations of Westland pollen data (McGlone 1995, Moar and Suggate, 1996; Vandergoes and Fitzsimons, 2003; Newnham et al, 2007a), and the temperature reconstruction produced by the ELR. The transfer function results are also tentatively mentioned, but limitations in the method limits the interpretation (see Section 8.2.4). The reconstruction is dominantly based on the dryland flora and tree fern communities. However, some wetland and fern spores were included in the interpretations as these species can also provide insights into the climatic and ecological changes on a more local scale. The pollen transfer function also used a limited number of non-dryland pollen types (Wilmshurst et al, 2007), which are also included in the discussion to aid the interpretations. The inferred ages produced by the age-depth model have been applied to each pollen zone discussed.

The base of Lake Mudgie sequence records a change from grassland dominated flora with a mosaic of shrubs (LM1a), indicative of cold climates, to a further increase in grassland dominated vegetation community (LM1b). This suggests a cooling trend leading to a period of extreme cold. This is followed by sharp transition from alpine dominant to shrubland dominant taxa and a successional pattern from shrubs to mixed lowland broadleaved hardwood forest follows (LM1CLM4). These developments are inferred to represent a change to warmer, wetter conditions at the site although still cooler and drier than the contemporary climate. Finally, the top of the sequence indicates establishment of tall tree communities 
associated with warm, wet, temperate climate regimes, similar to that experienced on the west coast today.

The following provides a more detailed interpretation of the vegetation and climate interpretations made from the pollen assemblage and sedimentology of the sequence. The sample PCA result (Table 4.3) indicates a good correspondence between the two statistical methods and provides greater validity to the zonation of the pollen diagram (Figure 4.5).

\subsubsection{Zone LM1 vegetation reconstruction (c. 26.6 - c. $17.6 \mathrm{ka})$}

The vegetation in zone LM1 is dominated by grassland and herbfield communities indicating a persistence of alpine vegetation throughout. However, the base of this zone, sub-zone LM1a, has an increased abundance of shrub species including the frost tolerant Hebe, Asteraceae, and to a lesser extent Coprosma. However, it should be noted that these taxa include a wide range of plant forms including herb types. In the contemporary alpine landscape these plants occupy sheltered sites among the grassland-herb field and this seems a likely habitat in this zone as well (Wardle, 1991). In addition there are low amounts of Phyllocladus and Myrsine which were probably confined to favourable sites which in the contemporary environment tend to be north facing and areas with poor drainage (Wardle, 1977). The dominance of grass species is characteristic of the alpine area, which in the modern landscape is restricted to 1200 m.a.s.I and above (Moar, 1970; Wardle, 1977). However, the presence of the shrub species, occasional tree pollen suggests that a diverse vegetation community existed during this cold period.

A further increase in grassland vegetation composition occurs in subzone LM1b suggesting a further increase in alpine vegetation and a period of extreme cold. Coinciding with the increase of grassland is the decline of Coprosma, Myrsine and Hebe, indicating that local conditions were no longer suitable for extensive shrub growth. Asteraceae abundance remains at a similar level as in the previous subzone, and this taxon probably comprised herbs growing amongst the grassland as it does today (Wardle, 1991). The LOI is at its lowest abundance during this sub zone and indicates a lack of biomass and productivity of grassland communities. Likewise the maximum abundance of sand size particle during this sub-zone is 
indicative of reduced vegetative cover and an increase in erosion. An increase in inorganic material to the sites, linked to erosion and the transport of inorganic material to the site, can also dilute the organic carbon and thus producing low LOI results.

Towards the top of this zone, LM1c, a significant increase in Coprosma and Myrsine is accompanied by a sharp decline in grassland abundance. This indicates a transition in vegetation composition from an alpine dominated landscape to an abundant shrubland community and is suggestive of a warming in the climate. This vegetation transition is accompanied by an increase in total carbon content of the sediment suggestive of an increase in biomass contribution by the shrub taxa.

\subsubsection{Zone LM1 climate interpretation}

The vegetation composition of zone LM1 is characteristic of the high alpine zone in the contemporary landscape. The lack of any significant shrub or tall tree species indicates insufficient heat to enable these woody taxa to grow in this environment. In the south Westland region the contemporary lower limit of the alpine zone is at c.1200 m.a.s.I (Wardle, 1991), c.1050 m above the current Lake Mudgie core site located at 143 m.a.s.l. This implies the alpine zone descended to at least this altitude during the LGCP. Using the environmental lapse rate of $0.5{ }^{\circ} \mathrm{C} / 100 \mathrm{~m}$ estimated MAT depression during zone LM1 is $>5.4{ }^{\circ} \mathrm{C}$. However the higher abundance of shrub species, in particular Myrsine, which is prevalent in the contemporary sub-alpine/montane zone could represent a period of milder conditions in LM1a. Marine records from sites offshore from the Westland and estimations from other records suggest the maximum temperature depression around $5{ }^{\circ} \mathrm{C}$ and support the estimated MAT depression at Lake Mudgie (McGlone and Bathgate, 1994; Pelejero et al, 2006; Barrows et al, 2007).

The existing temperate rainforest and montane species in the Westland region are dependent upon high precipitation and are intolerant to water stress caused by drier periods (Wardle, 1991). The lack of species representing these vegetation communities may represent a reduction in precipitation at the timing of zone LM1. However, the modern alpine environment has high precipitation values, although a 
large proportion of this is received in the form of snow. It is probable that the alpine conditions experienced at the site, which today lies considerably below the modern alpine zone, during the much colder LGCP would have had a greater proportion of precipitation in the form of snowfall compared to modern conditions. The short growing season caused by the cold climates and greater snowfall as a proportion of total precipitation would have inhibited the growth of shrub and tree species (Wardle, 1991).

The increase in shrub species Coprosma and Myrsine in sub-zone LM1c combined with a significant decline in grassland abundance, point towards a sudden increase in temperature causing an expansion of shrub species into the site. Vegetation that is likely to respond to an increase in precipitation, such as Weinmannia or Dacrydium, made no appearance in this sub zone and implies that the main climatic change was an increase in temperature or reduction in frost severity.

The pattern of inferred temperature based on the quantitative pollen/climate modelled reconstructions suggests the LGCP can be split into two periods corroborating with the qualitative evidence. The initial period spanning 26.6-23.2 $\mathrm{ka}$ is characterised by 'milder' (approximately $1{ }^{\circ} \mathrm{C}$ warmer) temperatures compared to the period 23.2-18.4 ka which has consistently colder temperatures. The estimated MAT depression predicted by the models during the LGM range 6.1-5.5 ${ }^{\circ} \mathrm{C}$ in the PSL-C3 model and $4.2-3.8^{\circ} \mathrm{C}$ in W-MAT, the latter of which is less than the minimum estimated temperature reduction based upon the ELR. The predicted modelled results will be discussed further in Section 8.2.4. Climate warming begins at $18.4 \mathrm{ka}$ and is marked by a period of rapid warming in both records although the temperature increase is less in W-MAT model compared to PLS-C2 model (refer to Section 4.4.4 and Section 8.2.4). 


\subsubsection{Zone LM2 (c. 17.6 - c. $13.1 \mathrm{ka}$ )}

Zone LM2 is characterised by a continuously increasing shrub component and the disappearance of grassland leading to the evidential expansion of shrubland becoming the dominant vegetation community in the landscape. This is indicative of climate warming. A vegetation successional pattern occurs with the shrubland giving way to low lying broadleaved/hardwood forest and an expansion of tree ferns being an important component of the sub-canopy. This transitional zone experiences continued rise in LOI in the sediment indicating a consistent increase in plant productivity and biomass, confirming the changes from grassland to, eventually, a multi tiered forest community. The pattern of vegetation change in zone LM2 implies a continuous increase of temperature and the climate becoming warmer and wetter towards the top of this zone. However the continued lack of $D$. cupressinum in the assemblage suggests the climate was still not wet or warm enough for the presence of this species. However, towards the top of LM2 soil development also influenced some successional vegetation patterns. For instance, the appearance of Dacrycarpus dacrydioides suggests newly emerged, high nutrient, soils at the site were present. And possibly relates to the terrestrialisation of the lake. However it does not reach a high abundance and its peak appearance is short-lived, maybe representing a reduction in soil nutrients combined with climatic change which producing conditions more preferable to Dacrydium cuppressinum (refer back to section 4.1.2)

\subsubsection{LM2 vegetation reconstruction}

The high values of Myrsine and Coprosma in sub-zone LM2a and the small abundance of Poaceae implies that shrubland had taken over grassland as being the dominant vegetation community in the region by the start of this sub-zone. Grassland probably became restricted to higher altitude locations. The lack of any increase in Poaceae after zone LM1 indicates that once grassland disappeared from the landscape it was not a significant component in the local vegetation again and implies a continuous climate warming during this sub-zone.

Asteraceae remains at similar levels as it occurred in the previous zone suggesting that it was still a significant component in the vegetation. Like Coprosma and Hebe, Asteraceae includes both herb and shrub forms which are 
difficult to differentiate in the pollen diagram. However, its continued appearance during the shrub zone, when no other herb species are present including grass, suggest predominantly Asteraceae shrubs are represented in LM2a. During this zone a significant increase in Monolete spore abundance indicates ground ferns became more prevalent in the landscape and may indicate disturbance of the shrubland.

Sub-zone LM2b continues to be dominated by the shrub taxa Coprosma and Myrsine, however Coprosma abundance is declining and Myrsine increasing to become the overall dominant species. This change in composition may indicate an increase in temperature and/or precipitation. However, in the contemporary successional pattern of shrub development, Coprosma tends to be an important primary stage taxon with Myrsine developing and often becoming the dominant shrub after the shrubland has matured (Wardle 1991). Therefore the vegetation change recorded in LM2b may represent a successional vegetation pattern opposed to a climatically induced change.

Sub-zone LM2b assemblage also include Pseudopanax and Pseudowintera which are small tree/shrub taxa indicating a more diverse floristic composition. Concurrently, there is a sudden increase in Cyathea smithii abundance which remains persistent throughout the rest of this zone. The appearance of $C$. smithii in a shrubland environment rather than a forested landscape points towards its persistence as a pre-forest successional element. In the contemporary Westland landscape $C$. smithii occurs in gullies and grows around the bushland perimeter and these are likely to be the areas it inhabited during LM2b (McGlone and Bathgate, 1983). The appearance of Isoetes indicates the presence of open water, however, it also occurs during a stratigraphic transition in the core where an increase in organic material and a change from grey to brown silts occurs. This suggests the lake was becoming more terrestrialised with water level shallowing and eventually, in this zone, providing the optimum conditions for Isoetes growth. Therefore the occurrence of Isoetes here points to a shallowing of the lake (see Section 7.6.2 for more detail of the ecological limitations of Isoetes). 
Towards the top of zone LM2 (sub-zone LM2c) a significant decrease in Coprosma and Myrsine abundance occurs coincidently with a peak in the broadleaved, small tree taxa Griselinia and Elaeocarpus, and a rise in the tall tree taxa $W$. racemosa, Libocedrus and $P$. ferruginea. These changes indicate expansion of low lying broadleaved hardwood/podocarp forest in the area. Coprosma, Myrsine and the low abundance of Pseudopanax and Pseudowintera pollen in the record suggests these species were forming an understory to the main forest canopy. These inferred communities are similar to montane forest vegetative composition in the modern Westland environment today which lies between an observed altitude of 850-650 m.a.s.I (Wardle, 1977, 1991). The increase in $W$. racemosa, a drought and frost sensitive taxa, indicates that temperature and precipitation levels were high enough $(>1000 \mathrm{~mm} / \mathrm{yr})$ to allow this species to become established. The consistent presence of Cyathea smithii now probably part of the small tree tier is also indicative of moist environments. The small rise in Dacrycarpus dacrydioides reflects a successional pattern in reforestation of the site at the top of sub-zone LM2b.

The presence of Libocedrus, which has a high freezing tolerance of $-13^{\circ} \mathrm{C}$ and is often associated with cooler climates, may be indicative of cold air pooling which can occur in the valley basins along river banks. Libocedrus in the contemporary landscape is shade intolerant and unable to grow in dense canopy (Veblan and Stewart, 1982), and therefore needs to be in a canopy free zone. This may represent a catastrophic disruption in the landscape such as a landslide or earthquake in the area causing tree felling and leading to canopy gaps. However, and more likely, sinking cold air will inhibit the growth of the frost intolerant species, including the canopy producing trees species, thus allowing Libocedrus growth. Libocedrus is also found to be more prevalent on poorly drained surfaces in the lowland and montane environments. This indicates the site probably was poorly drained. The presence of Leptospermum type, that has peak abundance in sub-zone LM2b and c, is also indicative of poorly drained areas as it commonly forms a shrubby tier on boggy sites (Wardle, 1991).

The increase in Prumnopitys ferruginea is likely to represent the start of the development of tall podocarp forest in the area. However, the relatively low levels 
of this species suggest it was restricted in the landscape. This species was probably restricted to lowland terrace or hill slopes where it is commonly found today (Reif and Allen, 1988; Wardle, 1991). The disappearance of Isoetes indicates there is no longer open water at the site and coincides with a visual stratigraphic change from light brown silts, still probably representing lake deposits, to dark brown organic silts suggesting terrestrialistaion of the lake environment has occurred.

\subsubsection{Climatic interpretation}

Temperature increase is indicated at the base of this zone by the increased dominance of Coprosma-Myrsine shrubland and the introduction of other shrub species over the previously dominant alpine communities. The shrub communities are representative of the contemporary sub-alpine zone which lies between 800 1200 m.a.s.l (Moar, 1970; Wardle, 1977). The lack of tall podocarp or broadleaved trees and species characteristic of moist environments could represent a reduction in precipitation compared to the present. However, the lack of tall forest trees more likely represents a temperature control.

Towards the top of this zone, increases in tall forest and broadleaved taxa Griselinia, Elaeocarpus, Weinmannia racemosa and $P$. ferruginea indicate that temperatures and precipitation were now high enough (at least $1000 \mathrm{~mm} / \mathrm{yr}$ ) to support the development and expansion of a low hardwood-podocarp forest. The increase of species characteristic of mild moist equable climates such as Weinmannia racemosa, which demands high precipitation levels and is sensitive to both water stress and severe frost (McGlone et al, 1994), provides support for this interpretation. However the lack of abundance of Dacrydium, the species which is dominant in the contemporary forest, suggests that temperature and precipitation may not have been as high as at present. Therefore it is likely that this low hardwood-podocarp forest grew in wetter and warmer conditions than the previous sub-zones, but it was drier than present conditions in the region. The composition of sub-zone LM2b and $\mathrm{c}$ is representative of the montane vegetative zone, which in the contemporary landscape is restricted to 600-800 m.a.s.l (Moar, 1970; Wardle, 1977). Using the ELR of $0.5{ }^{\circ} \mathrm{C} / 100 \mathrm{~m}$, a minimum temperature depression of $2.3^{\circ} \mathrm{C}$ is implied. The average MAT depression predicted in the 
PLS-C2 model for the early LGIT is $1.8^{\circ} \mathrm{C}$ and in the W-MAT $1.5^{\circ} \mathrm{C}$. The two modelled temperatures are broadly similar to the ELR estimates when the temperature error of $\pm 1.5^{\circ} \mathrm{C}$ is taken into account. However, the PLS-C3 estimated MAT depression predicted during the early LGIT is less than predicted during the Holocene (see section 4.4.4), which is unexpected. The methods used to reconstruct past MAT are discussed in more detail in Section 8.2.4.

\subsubsection{Zone LM3 and LM4 (c. 13.1 - c. $4.2 \mathrm{ka}$ )}

This part of the discussion section interprets the results from both LM3 and LM4 together. The zone is characterised by the transition from shrub dominated vegetation communities to podocarp dominated lowland forest, primarily dominated by $D$. cupressinum, although $W$. racemosa, and to a lesser extent Prumnopitys ferruginea remain significant. This transition reflects the development of vegetation cover similar to contemporary vegetation in the lowland forest today (Wardle, 1977). However, the increase in D. cupressinum dominated forest is interrupted by a disruption in D. cupressinum expansion. A significant decrease in Isoetes in the previous zone and the increased organic content and brown colouration of the core indicates the near terrestrialisation of the lake and core site and the lack of an open water environment. This could also be illustrated by the decline in Leptospermum type, which in the contemporary environment inhabits wetter, boggy environments. The continued dominance of $D$. cupressinum in zone LM4 indicates the development of the temperate rainforest similar to that present in the contemporary lowland Westland environment (Moar, 1970; Norton et al, 1986; Wardle 1991).

\subsubsection{LM3 and LM4 vegetation reconstruction}

The abrupt increase of $D$. cupressinum in zone LM3 to become the most abundant species indicates the beginning of podocarp temperate rainforest development. It is likely that this species was more dominant in lowland areas on ridge slopes and terraces below 600 m.a.s.I where it is prevalent in the modern Westland landscape (Franklin, 1968; Wardle, 1977; 1991; McSweeny, 1982). However, the pattern of increasing $D$. cupressinum abundance is not continuous and minor reversals indicating a disruption in the development of the $D$. cupressinum forest. This occurs between 13.2-11.9 ka and is characterised by a reversal in $D$. cupressinum 
abundance coinciding with a small increased in W. racemosa, Elaeocarpus and Libocedrus. There is also a small increase in Fuscospora, Phyllocladus, Chenopodiaceae and the wetland taxon Gonocarpus, which were more prevalent in zone LM1. The PCA results indicate a close relationship between these species, which were also present in zone LM1 in conjunction with alpine species. A disturbance is also seen in the particle size analysis were a sharp influx of clays enters the lake environment although this begins earlier at $13.4 \mathrm{ka}$ and continues until $11.9 \mathrm{ka}$. The coincidence of these species with the increase in clay particle size and a disrupted increase in $D$. cupressinum abundance may illustrate a disturbance in the local environment, inhibiting the continued growth of $D$. cupressinum and enabling seral successional plants to colonise the area around the site. Although, it may not necessarily represent climatic cooling.

The low levels of tree ferns, Cyathea smithii, C. dealbata and Dicksonia squarrosa indicates these species form an important component of the small tree tier and persisted amongst the tall podocarp forest. However, C. smithii reaches maximum abundance between 13.4-11.9 ka, potentially indicating wetter conditions were experienced at the site coinciding with the disruption in forest expansion producing forest gaps again promoting $C$. smithii growth. This also corresponds with a rapid reduction in Isoetes indicating there is no longer a water body at the core site, which does not necessarily support increased precipitation. This is indicative of terrestrialisation of the lake and is combined with a change in stratigraphy to brown organic silts. The increased terrestrial are at the site would produced a larger area suitable for tree ferns allowing these species to locally expand into the site resulting in increased abundance of tree fern pollen in the pollen record. The LOI in zone LM3 reaches a maximum amount indicating the high biomass and plant productivity of the podocarp dominated forest. The core stratigraphy has an increased organic peat content again indicating the increase in biomass and the suitability of the climate for peat production and points towards the continued terrestrialisation of the site.

Zone LM4 experienced a continued increase in podocarp dominated lowland forest with $D$. cupressinum remaining the dominant species throughout this part of the sequence. $W$. racemosa and $P$. ferruginea are still persistently present in this 
zone albeit in small abundance suggesting they contribute significantly to the canopy vegetation. Small amounts of Coprosma and Myrsine towards the top of this zone indicates presence of these shrubs in the subcanopy or forest margins. Contemporary Westland forest has Myrsine autralis and Coprosma lucida which forms the main shrub tier under the forest canopy. This vegetation assemblage is very similar to contemporary forest communities in the Westland region. Together these assemblages represent a full development of interglacial temperate rainforest (Wardle, 1977). This idea is further supported by the high organic content of the sediment and further increase in visible organic material in the core representing greater biomass and productivity of the environment.

The consistent, low levels of tree ferns, $C$. smithii and $C$. dealbata suggest that these species formed an important component of the small tree tier and persisted amongst the tall podocarp forest. The relative abundance of tall forest and fern species represent a vegetation and pollen assemblage characteristic of the contemporary lowland forest zone that reaches a maximum altitude of c. 400 600 m.a.s.I (Wardle, 1977) and extends down to sea level.

\subsubsection{Climatic interpretation}

The dominance of Dacrydium and the presence of $P$. ferruginea and Weinmannia in the regional vegetation indicate the establishment of a stable climate during zone LM3. These species occupy the contemporary warm and wet montane and lowland forests in the area (Franklin, 1968; Wardle, 1977) which strongly suggest the climate at this time remained wet and warm. However, the presence of Dacrydium with alpine/sub-alpine zone taxa and the influx of clay particles in between 13.4-11.9 ka suggest some form of environmental disturbance to the progress of lowland podocarp forest growth. Whether or not this represents a period of climate cooling is hard to establish, however the timing of this event, 13.4-11.9 ka, coincides with a LGR timing (Alloway et al, 2007) and will be discussed further in sections 4.5.2 and 8.1.51. However, there are other possible scenarios for this disruption which is discussed below.

The rapid expansion of Dacrydium dominated forest towards the end of LM2 reflects a marked climatic amelioration. The dominance of Dacrydium suggests 
that precipitation was high enough to allow the species to expand into the area while temperature became consistently mild enough to enable the establishment of tall podocarp forest. However, it is not possible to interpret the vegetation change solely on the basis of temperature and precipitation rise. As previously stated, the area was suitable for the development of some podocarp forest and wet enough to support extensive tree fern groves since the middle of sub-zone LM2b. One explanation for the late appearance of podocarp forest is that the area may have experienced cold air ponding during LM3. This could be supported by the abundance of Libocedrus in LM2C and LM3 which would normally be representative of sub-alpine conditions unless there are cool frost prone areas in the lowland region (Wardle 1977). The presence of this tree, which in turn represents more frosty conditions, could also help explain the more disturbed development of Dacrydium in the area. Libocedrus is also shade intolerant and grows in recently disturbed areas where gaps in the canopy occur. Again this may be indicative of a disturbance in the substrate, limiting Dacrydium growth in these disrupted areas. Likewise the appearance in small abundance of species associated with sub-zone LM1b could also indicate opening of the canopy. Catastrophic events including landslides and earthquakes are likely in the Westland region due to the steep topography and fractured lithology in the presence of the active Alpine fault. Wells et al (2001) found evidence that large but infrequent earthquakes have a significant impact on forest vegetative composition causing large scale tree mortality and thus opening up the landscape for seral and shade intolerant species. However, the Westland region is prone to large earthquakes and similar pattern in vegetation would be recognisable throughout the pollen record. It is therefore unlikely that an earthquake was responsible for the disruption in forest development.

The continued dominance of Dacrydium and the presence of Prumnopitys ferruginea and Weinmannia in the regional vegetation indicate the establishment of stable climate during zone LM4. These species occupy the contemporary warm and wet montane and lowland forests in the area (Franklin, 1968; Wardle, 1977) which, along with peat development, strongly suggest the climate at this time remained wet and warm. The dominance of Dacrydium and reduction of Libocedrus may indicate an abatement of cold air ponding and increased stability 
of the substrate. The contemporary Dacrydium dominated temperate rainforests of Westland are prevalent up to $400-600$ m.a.s.I (MAT depression ranging $0-2.3{ }^{\circ} \mathrm{C}$ base on ELR) and experiences a mean annual temperature of c. $11{ }^{\circ} \mathrm{C}$ and precipitation c. $5000 \mathrm{~mm} / \mathrm{yr}$ (Wardle, 1977; 1991). It is likely that the climate experienced at the site during zone LM4 was similar to the contemporary Westland lowland climate and indicates that full climatic amelioration was reached.

The W-MAT MAT reconstruction indicates MAT remained relatively stable throughout the LGIT. The PLS-C3 model suggests MAT was getting cooler during the LGIT with MAT depression increasing up core. The PLS-C3 also predicts warmer climates during the early stages of the LGIT compared to the temperatures experienced during the Holocene. This is the opposite pattern implied by the vegetation record and explanations for this will be discussed in Section 8.2.4. The modelled results also suggest a period of cooling climate between 13.2-11.9 ka, however, the degree of cooling varied between the records. PLS-C3 predicts an average MAT depression of $3.6{ }^{\circ} \mathrm{C}$ whilst W-MAT predicts only $1.9^{\circ} \mathrm{C}$. This may suggest a period of cooling representing the LGR which is inconclusive in the pollen record alone (see above and Section 4.5.2). However, there are limitations of the modelled reconstructions which are discussed in Section 8.2.4. 


\subsubsection{Summary Discussion}

\begin{tabular}{|c|c|c|}
\hline Pollen assemblage zone & Vegetation reconstruction & Climatic reconstruction \\
\hline $\begin{array}{l}\text { LM4 } \\
(503-450 \mathrm{~cm}: \\
\text { c. } 10.8 \text { - c. } 4.1 \mathrm{ka})\end{array}$ & $\begin{array}{l}\text { D. } \text { cupressinum dominated } \\
\text { temperate rainforest }\end{array}$ & $\begin{array}{l}\text { Stable warm wet climates } \\
\text { with mean annual } \\
\text { temperatures c. } 11{ }^{\circ} \mathrm{C} \text { and } \\
\text { precipitation c. } 5000 \mathrm{~mm} / \mathrm{yr}\end{array}$ \\
\hline $\begin{array}{l}\text { LM3 } \\
(520-503 \mathrm{~cm}: \\
\text { c. } 13.1 \text { - c. } 10.8 \mathrm{ka})\end{array}$ & $\begin{array}{l}\text { Increase in podocarp dominated } \\
\text { lowland forest with episodes of } \\
\text { disturbance and poor drainage }\end{array}$ & $\begin{array}{l}\text { Warm, wet climate with the } \\
\text { site potentially experiencing } \\
\text { cool air ponding and } \\
\text { localised frost. }\end{array}$ \\
\hline $\begin{array}{l}\text { LM2c } \\
(530-520 \mathrm{~cm}: \\
\text { c. } 14.4-\text { c. } 13.1 \mathrm{ka})\end{array}$ & $\begin{array}{l}\text { Broadleaved hardwood } \\
\text { montane forest with tree fern } \\
\text { forming a significant part of the } \\
\text { sub-canopy Areas of open } \\
\text { water and poor drainage }\end{array}$ & $\begin{array}{l}\text { Warmer climate (a minimum } \\
2.3 \quad{ }^{\circ} \mathrm{C} \quad \text { temperature } \\
\text { depression) } \\
\text { precipitation }>1000 \mathrm{~mm} / \mathrm{yr}\end{array}$ \\
\hline $\begin{array}{l}\text { LM1c-LM2b }(559-530 \mathrm{~cm}: \\
\text { c. } 18.4-\mathrm{c} .14 .4 \mathrm{ka})\end{array}$ & $\begin{array}{l}\text { Sub-alpine shrub dominated } \\
\text { vegetation }\end{array}$ & $\begin{array}{l}\text { Climate amelioration } \\
\text { following glacial maximum }\end{array}$ \\
\hline $\begin{array}{l}\text { LM1b }(583-559 \mathrm{~cm}: \\
\text { c. } 23.2 \text { - c. } 18.4 \mathrm{ka})\end{array}$ & $\begin{array}{l}\text { Alpine vegetation dominated by } \\
\text { grassland and herb field } \\
\text { species }\end{array}$ & $\begin{array}{l}\text { Extreme cold (estimated up } \\
\text { to } 5.3{ }^{\circ} \mathrm{C} \text { temperature } \\
\text { depression) probably dry }\end{array}$ \\
\hline $\begin{array}{l}\text { LM1a }(600-583 \mathrm{~cm}: \\
\text { c. } 26.6 \text {-c. } 23.2 \mathrm{ka})\end{array}$ & $\begin{array}{l}\text { Alpine vegetation dominated by } \\
\text { grassland with low abundance } \\
\text { of shrubs }\end{array}$ & $\begin{array}{l}\text { Cold and probably dry } \\
\text { conditions }\end{array}$ \\
\hline
\end{tabular}

Table 4.4: A summary table of the vegetation and climate reconstruction for the Lake Mudgie pollen assemblage zones.

The vegetation and climatic changes identified in the Lake Mudgie record are summarised in Table 4.4. The base of this sequence represents cold and possibly drier conditions represented by alpine dominated vegetation, in particular grassland. The initial appearance of shrub species, a minor reduction in grain size and sand component and slight rise in LOI in the sediment suggest increased vegetation cover and milder conditions experienced at the site. The subsequent increase in herb taxa indicates an expansion of the high alpine zone and an associated decrease in MAT, relative to today, by a minimum of $5.3^{\circ} \mathrm{C}$ producing extremely cold conditions. A subsequent transition into shrub dominated vegetation indicates a cool but warming climate. An increase in warming and wetter conditions is indicated by the appearance of broadleaved, hardwood low- 
land forest. The vegetation composition is representative of the montane floristic zone and points towards MAT which were a minimum of c. $2.3^{\circ} \mathrm{C}$ lower than at the site today. The warmer and wetter conditions continue with the expansion of podocarp forest toward the top of the sequence, albeit with some minor disturbances. The presence of Libocedrus may indicate presence of cool frost hollows in the valley which may have slowed the expansion of $D$. cupressinum into the region and caused the apparent disruption of its growth in the record. However, by the top of the sequence $D$. cupressinum became persistently the dominant species indicating a stable climate regime had been reached and suggesting that warm and wet conditions prevailed at the site by $11.9 \mathrm{ka}$.

Zone LM1a contains the KOT layer near the core base with an extrapolated age of c. 26.6 ka dating the base of the sequence. The presence of the KOT confirms the record extends beyond the LGM and covers a large proportion of the LGCP as defined by Alloway et al (2007). At 26.6 ka the region was already dominated by alpine vegetation, therefore the onset of the LGCP could not be dated. The Okarito record (Vandergoes et al, 2005; Newnham et al, 2007a) suggest that the LGCP could have started around 30.5-30 ka with cold conditions already prevalent by the beginning of the Lake Mudgie record. Likewise, the NZ-I CES estimates the onset of the LGCP to have commenced c. 29 ka. The Lake Mudgie record doesn't extend back to $29 \mathrm{ka}$ but it does show that cold conditions were already prevalent in the Westland region by c. 26.6 ka and confirms an extended LGM occurred in southern New Zealand, beginning much earlier than the Northern Hemispheric equivalent (Mix et al, 2001).

The bottom $22 \mathrm{~cm}$, subzone LM1a, contains a larger shrub influence than subzone LM1b, potentially indicating milder but still cold climate at the site. This corresponds to other records spanning this period and the NZ-I CES which recognises a milder more variable period during the LGCP prior to the ice advance during the LGM. At Lake Mudgie, this milder cold period spans an estimated c. 26.6 - c. $23.2 \mathrm{ka}$ and corresponds to the NZ-I CES, which dates the milder and more variable climate phase between 27-21 ka (Alloway et al, 2007). The Okarito record shows a decline in grass abundance beginning just prior to the deposition of the KOT and continuing to decline afterwards coinciding with small revival of $D$. 
cuppressinum, indicative of lowland forest (Newnham et al (2007a). Stratigraphic comparison to the Lake Mudgie reconstruction shows the reconstruction does not extend far enough back to record a decline in grass abundance, marking the onset of the LGCP milder interval, however, the vegetation assemblage also indicates the site was experiencing milder conditions just prior and after the KOT deposition. This is represented by a large proportion of shrub taxa in the record, but does not include lowland tree taxa, suggesting the signal is more subtle at Lake Mudgie.

Following this milder period is a period of extreme cold represented in the pollen record by the increased abundance of grassland including the tussock grasses which reach a peak abundance at the top of sub-zone LM1b. LOI is at its lowest abundance, whilst sand size particle abundance is at its highest during zone LM1b. The low organic carbon content indicates that either there was low vegetation productivity at the site due to the type of vegetation and sparse vegetation cover or large transportation of inorganic material to the site diluting the organic content. However, it is likely a combination of the two occurred as the decreases vegetation cover would not only decrease organic content but lead to increased erosion and therefore inorganic sediment input. Therefore, evidence for the start of LGM at Lake Mudgie began at c. $23.2 \mathrm{ka}$. The continued sustained increase in grassland species up the zone indicates minimum MAT was reached by c. $18.4 \mathrm{ka}$. The onset of this cold period appears to be earlier than at other sites, particularly compared to the speleothem record by Williams et al (2010) that dates the start of the LGM at $21.7 \mathrm{ka}$. The NZ-I CES shows an overlap between the timing of the LGCP and the onset of the LGM (Figure 1.1), with the latter spanning 25-18 ka, and represent a large uncertainty in the NZ-I CES. The Lake Mudgie record supports an earlier onset of the LGM cold period.

Termination I and the start of deglaciation, began c. $18.4 \mathrm{ka}$. This period is characterised by an abrupt decrease in Poaceae coinciding with an increase in the shrubs Coprosma and Myrsine, indicative of milder but still cool climates. By 17.6 $\mathrm{ka}$, Poaceae has nearly been removed from the vegetation composition, emphasising the exceptionally rapid pace of vegetation response to climate amelioration. The timing of this event is similar to other pollen records from the Westland region e.g. Vandergoes and Fitzsimons, 2003 and Newnham et al, 
2007a. The NZ-I CES estimates the deglaciation occurred between 19-17.9 ka supporting the timing suggesting in the Lake Mudgie record (Alloway et al, 2007). The Lake Mudgie record thus indicates that Termination I was well underway by $17.6 \mathrm{ka}$ and the timing of deglaciation is broadly synchronous throughout New Zealand. The age of deglaciation in the South Island will be discussed further in Section 8.1 .4

The pattern of vegetation change following Termination $\mathrm{I}$ is indicative of continuous climatic amelioration and possibly increased precipitation. This period is characterised by successive peaks in vegetation evolving from sub-alpine shrubs to montane broadleaved hardwood forest and culminating in podocarp temperate rainforest, marking the start of the Holocene. This vegetation successional pattern identified at this site is similar to other Westland sites such as Gillespies Beach Road and Okarito (Moar, 1973; Vandergoes and Fitzsimons, 2003; Newnham et al, 2007a). After $13.8 \mathrm{ka}$ an abrupt increase in the lowland tree species, D. cupressinum, is apparent. However, this initial growth is not a smooth transition into dominance but contains minor reversals in $D$. cupressinum growth between 13.4-11.9 ka. At the same time a small abundance of species associated with the pollen assemblage zone LM1b return illustrating a potential disturbance in the vegetation growth at the site. This is further compounded by the sedimentology at the site which shows a small increase in sand size particles but more significantly two pulses of clay deposited as well. This indicates that there was possibly some disruption in the environment extending 13.4-11.9 ka although whether this was climate induced or a slow response to catastrophic event, such as an earthquake cannot be determined. The presence of $D$. cupressinum in ever increasing abundance suggests that any climatic deterioration could not have been severe.

The limited chronological control indicates this disturbance coincided with the LGR and corresponds closely with the timing of this event in the Williams et al (2005) speleothem record $(13.5-11.6 \mathrm{ka})$. Yet, this disturbance is very minor when compared to evidence of the LGR in other records, such as the Okarito vegetation reconstruction (Newnham et al, 2007a) and other causes, such as cold air ponding (see Section 4.5.1.8) cannot be ruled out. The increase in Cyathea smithii 
between 13.4-11.9 may indicate an increase in precipitation at the time which could also influence the vegetation composition. These disturbances aside, there is no unequivocal evidence in the Lake Mudgie pollen record for a LGR as has been reported in other regions of New Zealand (Alloway et al, 2007; Kaplan et al, 2010).

By $510 \mathrm{~cm}, 11.9 \mathrm{ka}$, stable $D$. cupressinum abundance dominated temperate rainforest, indicative of the lowland vegetation communities in the contemporary central Westland region. Likewise at $515 \mathrm{~cm}$ total soil carbon abundance reached its maximum amount, indicating peak vegetation productivity had been reached by c. $12.8 \mathrm{ka}$. This indicates that Holocene conditions where reached at the site by $11.9 \mathrm{ka}$ and represents early or pre-Holocene warmth that occurs during the YDC (12.9-11.5 ka; Alley, 2000), a period of cooling in the Northern Hemisphere. This early or pre-Holocene warming is also recorded at other sites in New Zealand including Okarito (Newnham et al, 2007a), Kaipo bog (Newnham and Lowe, 2000), Auckland Maars (Sandiford et al, 2003) and the speleothem record (Williams et al, 2005). Again Lake Mudgie supports the timing of main events set out in the preliminary NZ-I CES (Alloway et al, 2007).

\subsubsection{Summary}

The overall pattern of vegetation and climate change at Lake Mudgie is as follows. The LGCP began sometime before c. 26.6 ka. From c. 26.6 - c. 23.2 ka a milder period within the cold LGCP was recognised by the presence of shrub species. At c. $23.2 \mathrm{ka}$ an extreme cold period was felt at the site with the area dominated by alpine vegetation which today is limited to altitude above 1200 m.a.s.l (Wardle, 1991). This extreme cold period climaxed towards the top of pollen assemblage zone LM1b. An estimated MAT depression of $>6.1$ occurred at $18.4 \mathrm{ka}$ and deglaciation was evident by the transition of the alpine vegetation to shrubs. Climatic amelioration continued without significant interruption until a vegetation climax at c. 11.9 ka indicating the start of Holocene conditions. A possible minor climatic reversal occurred between 13.4-11.9 ka although this is tentative and the disruption in the vegetation and sediment record may be caused by some other environmental factor. The pattern and timing of change at Lake Mudgie are 
broadly consistent with other records from New Zealand and will be discussed further in Chapter 8. 


\section{Chapter 5: Manks Tarn}

Manks Tarn, the second site from the central Westland region, is located due south-east of Hokitika (see Figure 5.1) at 130 m.a.s.I. Manks Tarn is therefore altitudinally lower than Lake Mudgie and located further south. Geological mapping of the area suggest Manks Tarn is located within the LGM ice limit (Suggate, 1990). In planning the present study, it was therefore assumed that sediment assimilation commenced at the start of deglaciation and this was later confirmed by a radiocarbon age from the base of the sediment sequence. The site therefore provides a palaeoenvironmental record extending from Termination I to the Holocene. Whilst coring it became apparent that the sedimentation rate at the site was unusually high, allowing for a high resolution pollen record spanning the entire LGIT, producing a detailed palaeoenvironmental reconstruction from the site. As Manks Tarn is located in the same geographical region as Lake Mudgie, the reader is advised to refer to the regional setting description written in the previous chapter.

\subsection{Manks Tarn site description}

Manks Tarn is a small water body formed in a kettle hole nestled within a LGM lateral moraine (Figure 5.1 and 5.2). This moraine is one of many that step down and sweep along the western edge of Mt Upright, Mt Graham and Reef Knob. They were formed in the later stages of the LGM by a glacier extending down from the Southern Alps into the Kokatahi river valley and then northwards down the Hokitika River valley towards the coast. To the east of Manks Tarn lies the glacially formed Lake Kaniere which is dammed at the northern lake shore by a LGM terminal moraine. Lateral moraines also run along the eastern edge of $\mathrm{Mt}$ Graham and spill over the depression between Mt Graham and Mt Upright, eastwards, from the main Kokatahi River valley into Lake Kaniere. The Kokatahi River, today, flows north westwards around the base of Mt Graham and is a major tributary to the Hokitika River, joining it near the Kokatahi township. The Hokitika River continues to flow north westwards, entering the Tasman Sea at Hokitika Township. 
Manks Tarn is surrounded by native forest that is dominated by podocarp temperate rainforest and particularly the lowland podocarp Dacrydium cupressinum. The edge of the tarn is skirted by swamp and peat land vegetation. Coring took place on the peaty margin by the shoreline on the south-eastern end of the tarn.

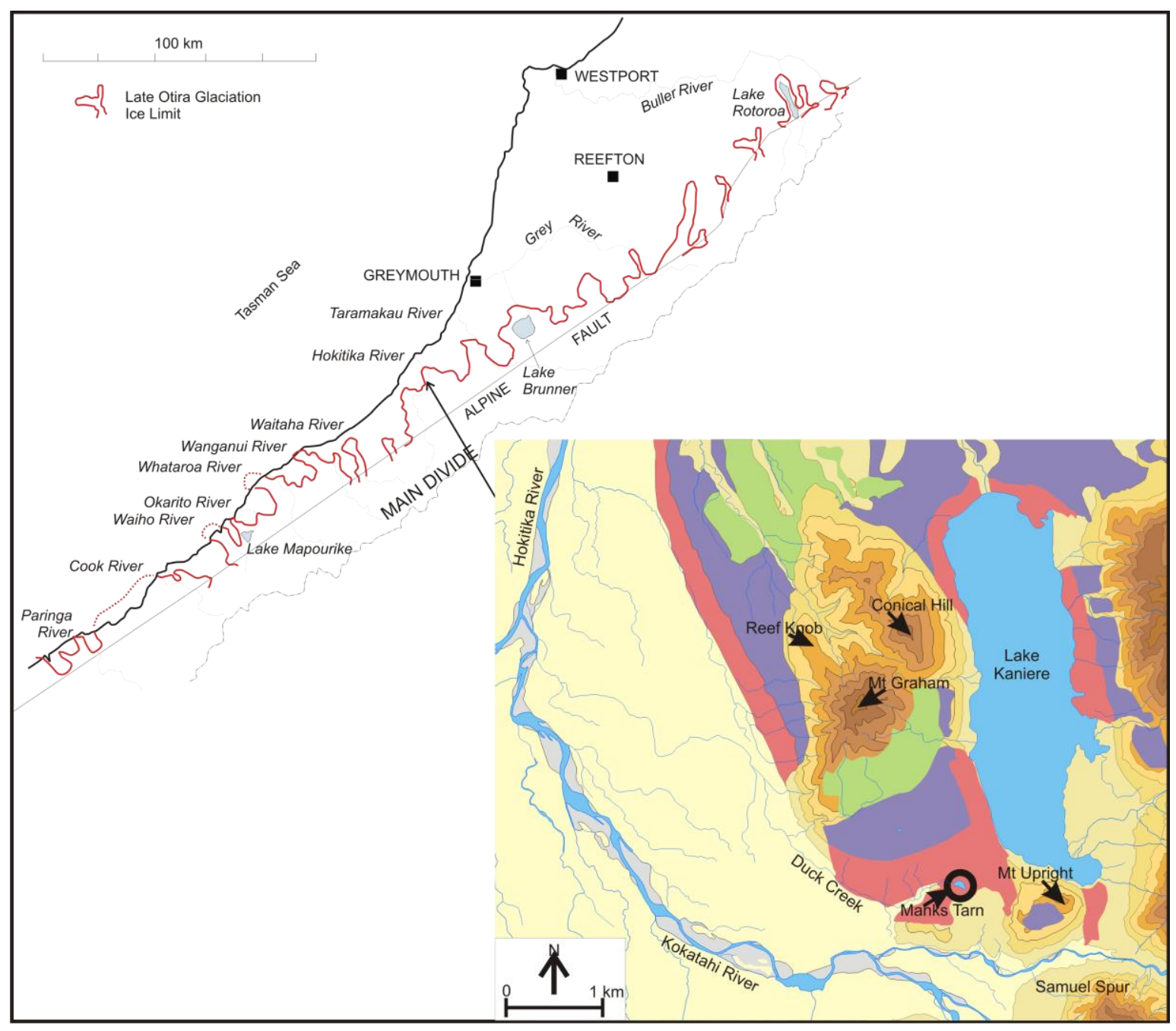

Figure 5.1: Location map of Manks Tarn in central Westland with a) with Manks Tarn site location in context of the LGM ice extent in the Westland region (redrawn from Suggate, 1990) and b) a zoom in site location with Manks Tarn circled in black. . Moraine deposits are marked on the map and are colour coordinated relating to the glacial advance which deposited the features. Moraine location is based upon Barrell et al (unpublished). Red- Moana moraines; Purple; Larrikins moraines; Green - Loopline moraines 


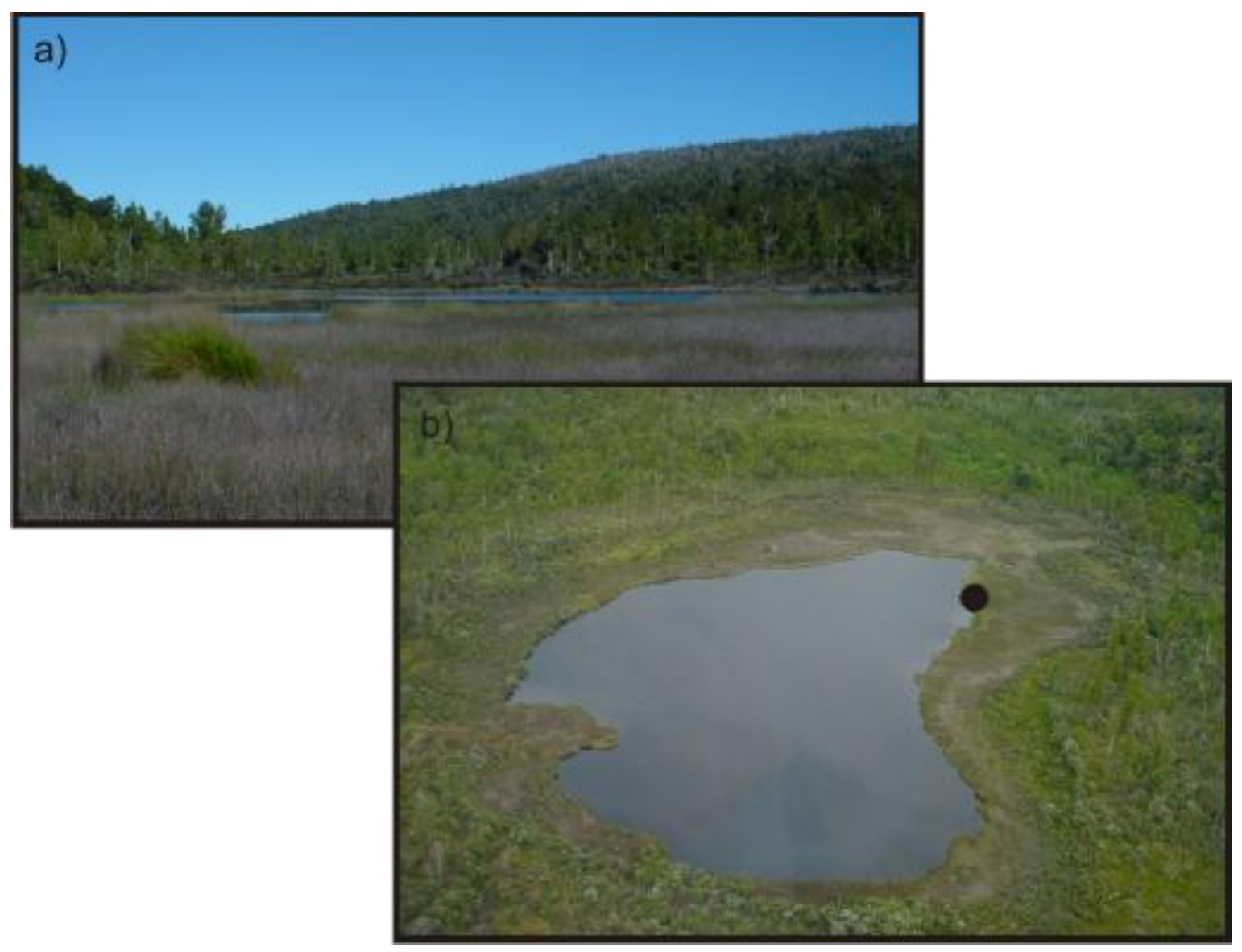

Figure 5.2: Image of Manks Tarn; a) Looking eastwards across the tarn. The foreground is dominated by wetland. The background, on the slopes, is native lowland podocarp forest; b) a bird's eye view of Manks Tarn, the black dot showing the core location.

\subsection{Sediment stratigraphy}

The method used for coring at this site is explained in Section 3.1. The core was taken in January 2002. The top $5 \mathrm{~m}$ of the sequence consisted of liquid detrital mud presumed to be late Holocene and was therefore not retained. Coring began at $5 \mathrm{~m}$ below the ground surface and a total of eight $1 \mathrm{~m}$ sections were collected. Due to the time frame of interest in this project only the bottom six sections starting at $7 \mathrm{~m}$ were analysed. The age period of study is $18-8 \mathrm{ka}$ (see Section 5.3) Figure 5.3 displays the core stratigraphy and description. A summary is described below.

The bottom $38 \mathrm{~cm}$ of the core was not analysed due to insufficient amounts of pollen for a statistically robust count. This section consists of blue-grey laminated sandy silts indicative of a lake environment. Pollen analysis began at $1170 \mathrm{~cm}$ and the stratigraphy between $1170-1160 \mathrm{~cm}$ consisted of grey-brown micaceaous silts 
changing to light brown organic silts between $1160-1118 \mathrm{~cm}$. The remainder of the core analysed was massive brown detrital mud which had limited visual changes. This section is highly organic, containing high abundance of partly decomposed, unidentifiable plant fragments. The texture of this section becomes increasingly siltier down the core whist becoming increasingly organic up core, indicative of lake shallowing and gradual terrestrialisation of the lake.

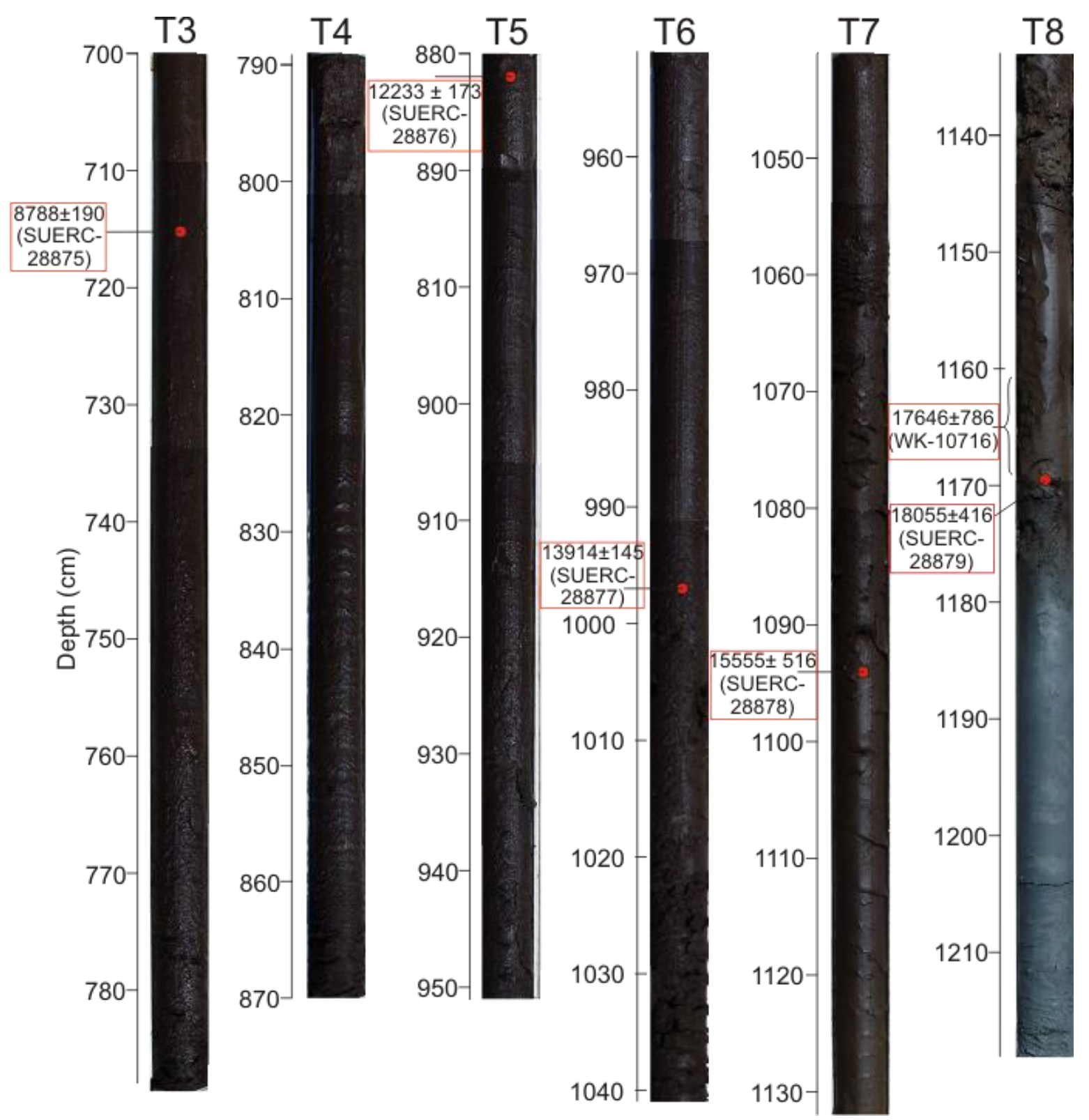

Figure 5.3: Core images from Manks Tarn in depth order and labelled with T representing each core section. Calibrated radiocarbon ages are added alongside the depth scale in the red block. The red dots represented sample location for radiocarbon dating. 


\subsection{Chronology}

Prior to this study a bulk sediment sample provided an age for the base of the core and was used to confirm that sediment accumulation in the tarn began soon after Termination I. Subsequently, in 2010, a further five ages, derived from pollen concentrates (method described in Section 3.5.1) where obtained. Thus, a total of six AMS ages were used to establish the overall chrono-stratigraphic framework. An age-depth model is shown in Figure 5.4.

\begin{tabular}{|c|c|c|c|c|c|c|}
\hline $\begin{array}{l}\text { Core } \\
\text { Depth }\end{array}$ & Fraction & $\begin{array}{ll}{ }^{14} \mathrm{C} & \text { age } \\
\mathrm{BP} & \end{array}$ & $\delta^{13} \mathrm{C} \%$ & $\begin{array}{l}\text { Reference } \\
\text { code }\end{array}$ & $\begin{array}{l}\% \text { carbon } \\
\text { yield }\end{array}$ & $\begin{array}{l}\text { Calibrated } \\
\text { date BP (2 } \\
\text { sigma) }\end{array}$ \\
\hline $714-715$ & $>63 \mu \mathrm{m}$ & $7908 \pm 38$ & -29.2 & $\begin{array}{l}\text { SUERC- } \\
28875\end{array}$ & 17.9 & $8788 \pm 190$ \\
\hline 883-884 & $>63 \mu \mathrm{m}$ & $10367 \pm 44$ & -29.1 & $\begin{array}{l}\text { SUERC- } \\
28876\end{array}$ & 13.1 & $\begin{array}{l}12233 \pm \\
173\end{array}$ \\
\hline 996-997 & $>63 \mu \mathrm{m}$ & $12068 \pm 50$ & -29.1 & $\begin{array}{l}\text { SUERC- } \\
28877\end{array}$ & 14.3 & $\begin{array}{l}13914 \pm \\
145\end{array}$ \\
\hline 1094-1095 & $>63$ & $12910 \pm 54$ & -29.2 & $\begin{array}{l}\text { SUERC- } \\
28878\end{array}$ & 10.8 & $\begin{array}{l}15555 \quad \pm \\
516\end{array}$ \\
\hline $1169-1170$ & $>63$ & $14746 \pm 64$ & -27.5 & $\begin{array}{l}\text { SUERC- } \\
28879\end{array}$ & 2.4 & $\begin{array}{l}18055 \pm \\
416\end{array}$ \\
\hline $1161-1169$ & $\begin{array}{l}\text { Bulk } \\
\text { sediment }\end{array}$ & $\begin{array}{l}14350 \quad \pm \\
270\end{array}$ & & WK10716 & & $\begin{array}{l}17646 \quad \pm \\
786\end{array}$ \\
\hline $\begin{array}{l}\text { *Wood } \\
\text { standard }\end{array}$ & & $\begin{array}{l}11727 \quad \pm \\
50\end{array}$ & 25.0 & $\begin{array}{l}\text { SUERC- } \\
28880\end{array}$ & 51.9 & \\
\hline $\begin{array}{l}{ }^{*} \text { Coal bit } \\
\text { standard }\end{array}$ & & $\begin{array}{l}54160 \quad \pm \\
350\end{array}$ & 23.2 & $\begin{array}{l}\text { SUERC- } \\
28881\end{array}$ & 88.6 & \\
\hline
\end{tabular}

Table 5.1: Radiocarbon age details for Manks Tarn. Ages were calibrated using OxCal program. *The standards used to assess possible contamination during the preparation process.

All six ages lie in stratigraphic order and there is no evidence of any age reversals in the sequence. The two standards, which were prepared at the same time and using the same methodology as the other samples, produced reliable and expected ages. This indicates that little contamination from modern carbon occurred during the preparation process. The chronology indicates that $455 \mathrm{~cm}$ of sediment accumulation occurred over a period of less than 10,000 years and 
confirms the high sedimentation rates at the site. This is important as it suggests the sequence will produce a high resolution and detailed palaeoenvironmental record of the LGIT and early Holocene period.

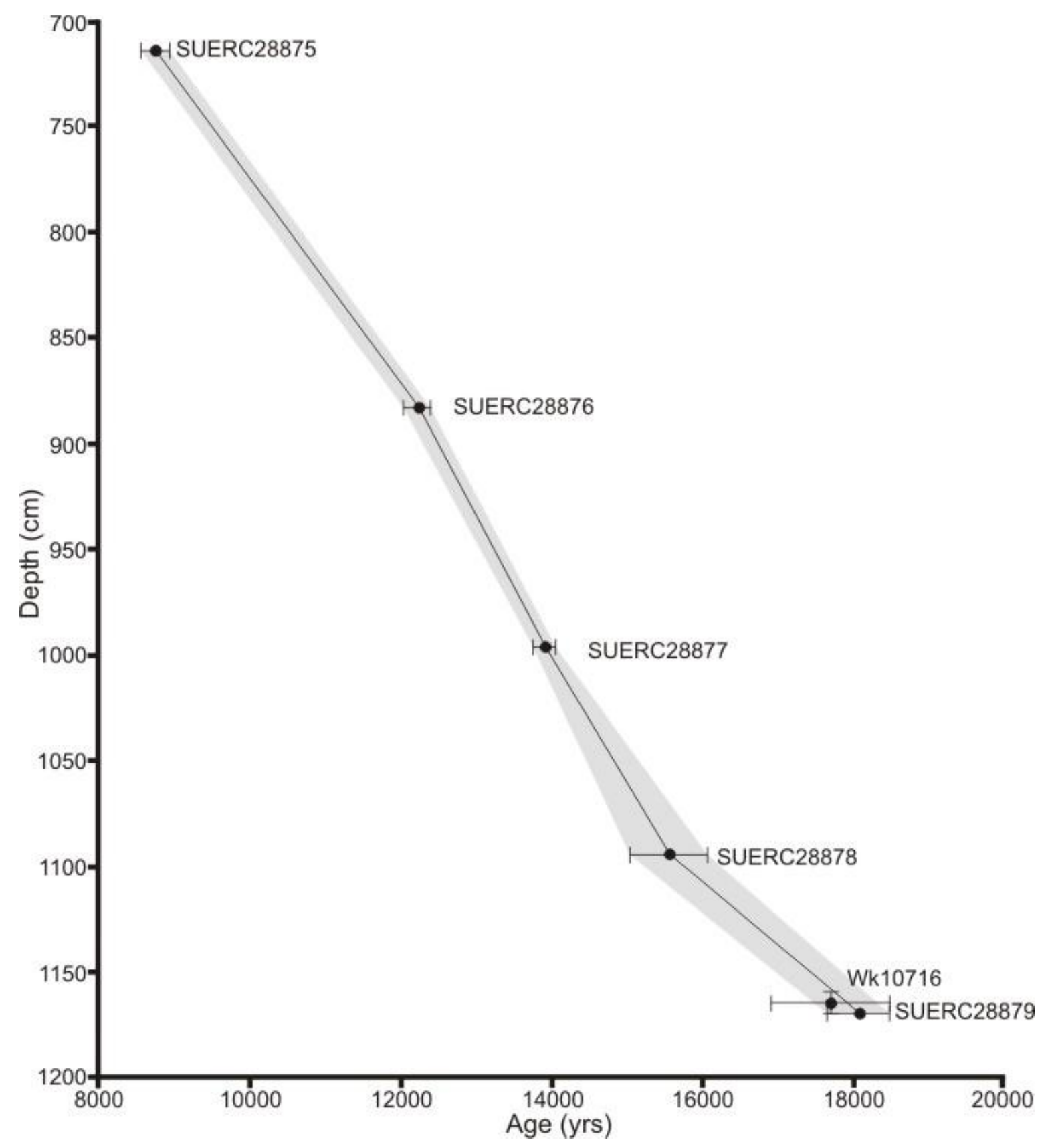

Figure 5.4: An age-depth model for Manks Tarn.

The age-depth model (Figure 5.4) shows that sediment accumulation remained high throughout the sequence, however, there are minor variations in the rate of accumulation through time. The slowest rates of deposition occur at the base of 
the sequence $(1170-1094 \mathrm{~cm})$ accumulating $1 \mathrm{~cm} / 33$ years. The rate of deposition nearly doubles between 1094-883 cm and averages $1 \mathrm{~cm} / 15-16$ years. Finally the rate of accumulation reduces towards the top of the section analysed, accumulating $1 \mathrm{~cm} / 20$ years. The slowest period of sediment accumulation occurred during the inorganic siltier section of the core.

\subsection{Results}

\subsubsection{Pollen stratigraphy}

The pollen diagram is represented in Figure 5.4 along with the core stratigraphy and radiocarbon ages. This figure includes only the main pollen types, see appendix D for the whole pollen data set. The LOI and PSA results are also shown next to the pollen diagram and will be described later in Sections 5.4.2 and 5.4.3. The quantitative MAT reconstructions are also presented in Figure 5.4 and will be described in Section 5.4.3. Initially a skeleton sampling technique was used down the core to produce a preliminary results diagram. This was used to decide where the higher resolution pollen analysis would occur in the sequence. Subsequently a $2 \mathrm{~cm}$ resolution was applied to the section spanning $882-1052 \mathrm{~cm}$. Based upon the age-depth model (Section 5.3) the section of detailed pollen analysis would have provided an average 30 year resolution.

CONISS cluster analysis, available in the Tilia program TGview, was used to group the total land pollen percentage data (see appendix B for the cluster analysis results). The pollen assemblage chosen for Manks Tarn tend to correspond to the biostratigraphic zones defined by the cluster analysis. The pollen assemblage zones used on the diagram were restricted to assemblage changes that represent palaeoecological and palaeoclimatic significance on a regional scale opposed to local scale variations. The main pollen zones are labelled MT1-4 (Figure 5.5). 


\subsubsection{Pollen assemblage zone}

Zone MT1: $1170-1140 \mathrm{~cm}(18.1-17.1 \mathrm{ka})$ :

The TDP is dominated by shrub taxa, in particular Coprosma, Myrsine, Elaeocarpus and Asteraceae and to a lesser extent Pseudopanax. This zone is the only section of the core where significant $(10 \%)$ Poaceae has been counted. There is high fern spore abundance with monolete spores initially receiving $50 \%$, reducing to $30 \%$ towards the top of this zone. Hypolepis also has a significant abundance, rising from $15 \%$ to a maximum of nearly $60 \%$ at the top of this zone. To a lesser extent Histiopteris and Phymatosorus are also present. The wetland taxon Cyperaceae also makes its only significant appearance in this zone reaching a peak abundance of $20 \%$ towards the top.

Zone M2: $1140-990 \mathrm{~cm}(17.1-13.8 \mathrm{ka})$ :

This zone is still dominated by the shrub component. Coprosma and Myrsine share co-dominance at the base of the zone, however both taxa decrease in percentage up the zone. Conversely, Griselinia has a low abundance at the base but increases and becomes the dominant taxon at the expense of Coprosma and Myrsine. Griselinia reaches a consistent 30-40\%. To a lesser extent Pseudowintera and Pseudopanax also increase in abundance. The tree taxa, Libocedrus and Weinmannia, are also present with consistent but low abundance of c. $5 \%$.

This zone contains a large transition in wetland, tree ferns and fern spore component. Cyperaceae decreases to near $0 \%$ coincidently with the rise in Leptospermum type, which steadily increases from $0 \%$ to $20 \%$. A large increase in tree fern abundance occurs with Cyathea smithii abundance increasing from $0 \%$ at $1140 \mathrm{~cm}$ to $50 \%$ at $1080 \mathrm{~cm}$ with its abundance remaining above $45 \%$ throughout the rest of the zone. A significant change in fern spore composition also occurs. The monolete spores consistently reduce in abundance concurrently with Histiopteris and Hypolepsis. Conversely the abundance of Phymatosorus and Hymenophyllum increase from near $0 \%$ to $5-8 \%$. More significantly, the aquatic taxon Isoetes increases from $0 \%$ to near $30 \%$ at $1180 \mathrm{~cm}$ and remains at a high percentage throughout. 
Zone MT3 990-885 cm (13.8-12.3 ka):

Zone MT3 is characterised by an increase of tall tree taxa at the expense of the shrubs. Coprosma, Griselinia and Myrsine, all decline in abundance and the overall shrub composition reduces from $80-90 \%$ down to only $20-30 \%$. Conversely, the abundance of Weinmannia racemosa increases abruptly from $5 \%$ at $990 \mathrm{~cm}$ to $70 \%$ by $965 \mathrm{~cm}$ and continues to increase to $80 \%$ remaining, consistently high for the rest of this zone. Cyathea smithii and Leptospermum type remain at a similar abundance as in the previous zone. The fern spore composition decreases in abundance with all species present in the previous zone decreasing. The aquatic Isoetes reduces to near $0 \%$ at the MT2-MT3 zone boundary.

Zone M4: 885-714 cm (12.3-8.8 ka):

Like the previous zone, the TDP is dominated by tall tree taxa, with the overall composition increasing to $80-85 \%$ at further expense to shrub species. $W$. racemosa is dominant at the zone base but decreases to only $30 \%$ at $818 \mathrm{~cm}$. Conversely the podocarps Prumnopitys ferruginea and P. taxifolia and more significantly Dacrydium cupressinum increase in abundance. D. cupressinum increases from $0 \%$ at $885 \mathrm{~cm}$ to $45 \%$ by $810 \mathrm{~cm}$ becoming the dominant taxon. It continues to increase reaching a maximum abundance of $70 \%$ at $760 \mathrm{~cm}$. The tree fern, Cyathea smithii abundance remains nearly consistently above 35\% throughout, except for one sample at $828 \mathrm{~cm}$. Dicksonia squarrosa is present at low abundance (2-3\%). Leptospermum type decreases to $10 \%$ and then $5 \%$. 


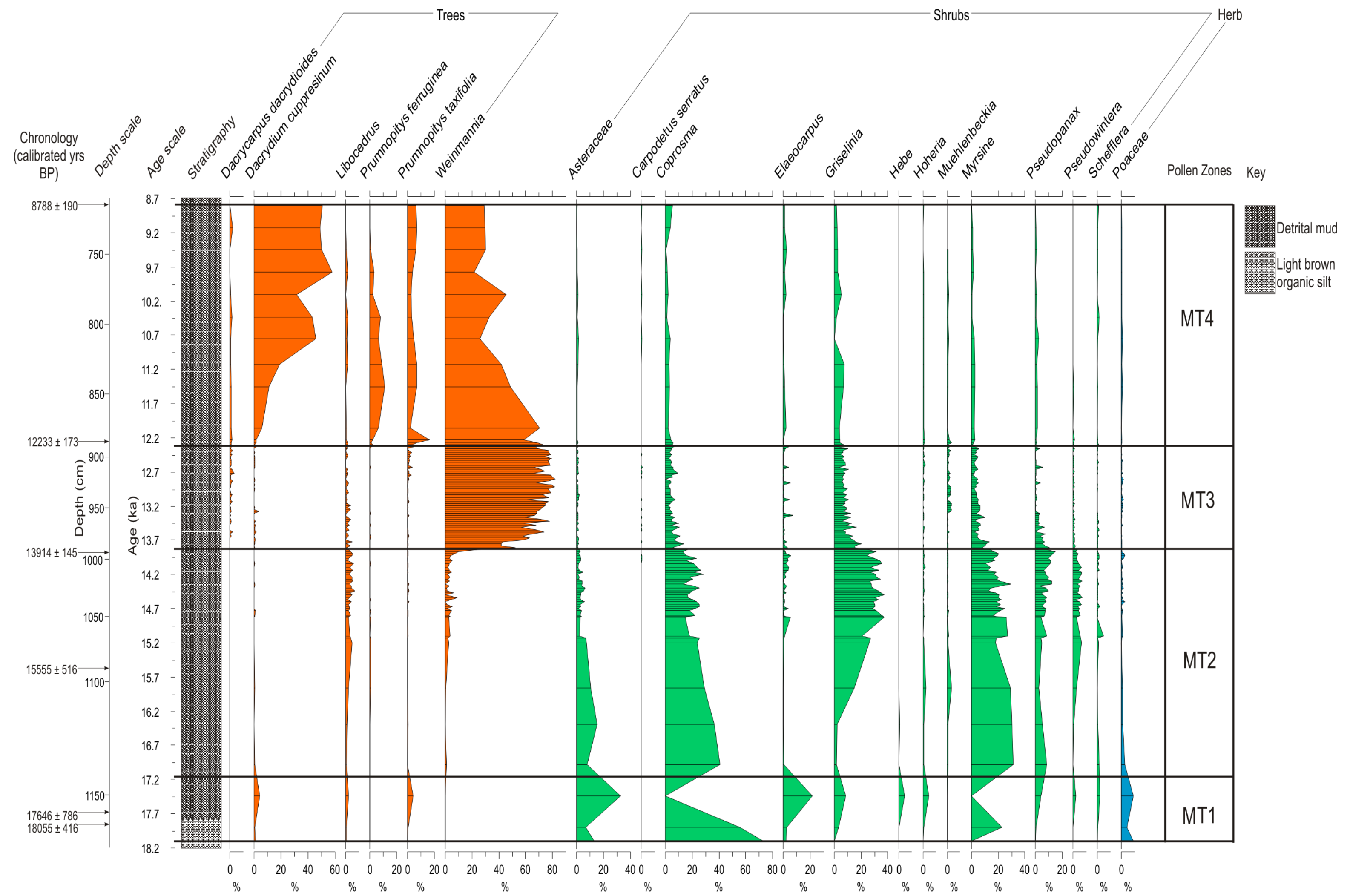

Figure 5.5: Manks Tarn pollen percentage diagram, including core stratigraphy, summary diagram, total carbon content, particle size percentage and pollen-climate reconstructions. Radiocarbon dates are summarised in Table 4.1. 


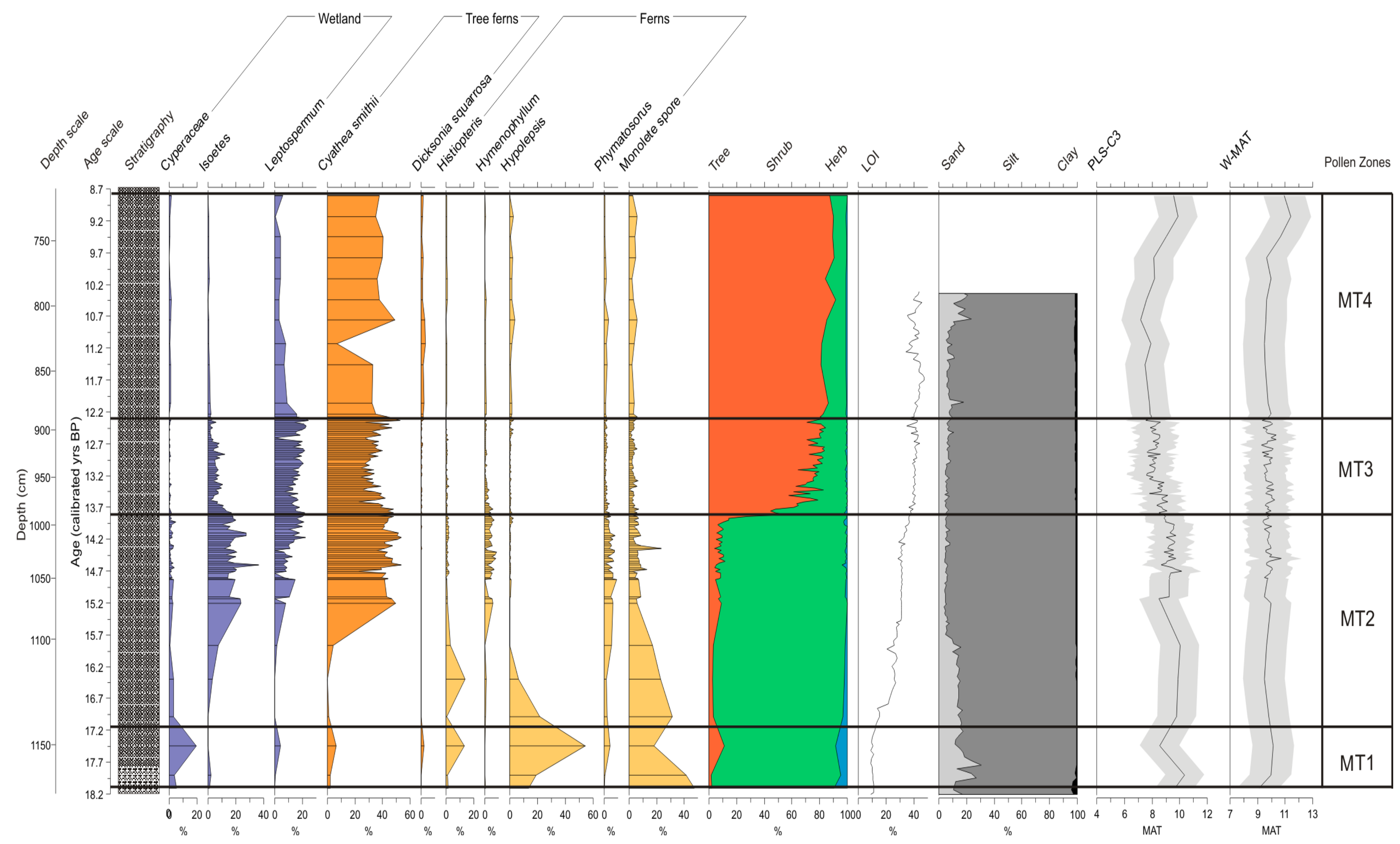

Figure 5.5: (continued) 


\subsubsection{Particle Size Analysis}

The core was sub-sampled at a $2 \mathrm{~cm}$ resolution spanning $790-1170 \mathrm{~cm}$. The results are presented in Figure 5.5. Throughout the section analysed the silt component is consistently dominant in the sequence, mostly between $70-80 \%$, and clay size particle abundance remains between $2-3 \%$. The pattern of the particle size composition can be split into three zones and is primarily based upon the changes in the sand abundance and associated silt variations. PSA results will be put into context with the pollen data. The section from 1170-1090 cm contains the highest abundance of sand in the sequence, decreasing from $25-30 \%$ at the base to around $17-20 \%$ for the majority of this zone. The silt component ranges from $70-80 \%$. A reduction in sand abundance begins at $1090 \mathrm{~cm}$ and remains consistently at c. $7 \%$ until $810 \mathrm{~cm}$ whilst the silt content increases to $90 \%$. At 810 $\mathrm{cm}$ the sand content increases to $20 \%$ and remains at that abundance for the remaining section.

\subsubsection{LOI}

As with the PSA, sampling for LOI analysis occurred at a $2 \mathrm{~cm}$ resolution spanning $791-1169 \mathrm{~cm}$. Four main patterns are evident in the core, with minor variations superimposed on the main patterns (see Figure 5.5). The base of the sequence contains $12-10 \%$ carbon between $1170-1145 \mathrm{~cm}$. This low carbon content corresponds with pollen assemblage zone MT1 and the section containing the highest amount of sand. After $1145 \mathrm{~cm}$ the LOI begins to consistently increase reaching $30 \%$ by $1082 \mathrm{~cm}$ and remains at this abundance until $1020 \mathrm{~cm}$. This is followed by a second, albeit more subtle increase in carbon content to $40 \%$. The carbon content remains stable at $40 \%$ until $900 \mathrm{~cm}$. The pattern of increased carbon content between $1145-900 \mathrm{~cm}$ corresponds closely to pollen assemblage zones MT2 and MT3 and the section contains relatively low amounts of sand. The LOI remains high between 900-791 cm, however, the abundance becomes more variable and oscillates between $35-42 \%$. This relatively variable section coincides with the rise in $D$. cupressinum and pollen assemblage zone MT4. This section also includes the rise in sand abundance towards the top of the sequence analysed. 


\subsubsection{Temperature reconstructions}

Figure 5.5 presents the pollen-temperature reconstructions for PLS-C3 and WMAT. Overall the W-MAT consistently gives higher temperature than the PLS-C3 model. Initially the PLS-C3 model predicts increasing temperature from $9.7^{\circ} \mathrm{C}$ to $10.4{ }^{\circ} \mathrm{C}$ followed by gradual and continuous cooling reaching a minimum $7.2^{\circ} \mathrm{C}$ at $10.8 \mathrm{ka}$. Temperature started to increase at 10.8 ka reaching $10{ }^{\circ} \mathrm{C}$ by 9.1 and decreasing slightly at $8.7 \mathrm{ka}$. The W-MAT model predicts a less varied pattern in temperature which initially increases from $9.1{ }^{\circ} \mathrm{C}$ to $10.1{ }^{\circ} \mathrm{C}$ and remains between 9.3-10.1 ${ }^{\circ} \mathrm{C}$ until $9.8 \mathrm{ka}$. Thereafter temperature increases significantly, reaching a maximum of $11.4^{\circ} \mathrm{C}$ at 9.1 ka then reducing to $10.9^{\circ} \mathrm{C}$ at the top of the core.

\subsubsection{Principle Component Analysis (PCA)}

PCA, using CANOCCO version 2, is first applied on the pollen data. Subsequent runs with the addition of $\mathrm{LOI}$ and the \% of sand, silt and clay particle sizes followed to explore the relationships between the pollen assemblage and changes in core sedimentology. Pollen and PSA samples were taken at the same depth horizon, but LOI was consistently $1 \mathrm{~cm}$ offset. Therefore an average was taken of the two $\%$ carbon samples which bordered the sample depth of the PSA and pollen analysis to enable more meaningful comparisons. At the top and the base of the core, pollen analysis occurred at a lower resolution and therefore the PSA and \% carbon sample lying between the pollen samples were excluded from the PCA dataset. The taxa included in the dataset are those with percentages over $1 \%$.

The results are presented in two sections; with and without the sedimentological data. The taxa eigenvalues are summarised in Figure 5.6 and Table 5.2, followed by a description of the sample eigenvalues presented in Figure 5.7 and Table 5.3. The results are considered in context with the pollen diagram and pollen assemblage zones (Figure 5.5). 


\subsubsection{Palynological PCA results}

Figure 5.6 is a biplot of taxa eigenvalues for axis 1 and axis 2, illustrating the stratigraphic affinities among the pollen taxa. Three groups are apparent with one group able to be divided into two sub-groups (Figure 5.6 and Table 5.2).

Group 1 contains species with high positive eigenvalues on axis 1 and negative values on axis 2, except for Coprosma, which has a positive eigenvalues on axis 2. This group represent taxa that are dominant in zone MT2 and include the shrubs Coprosma, Griselinia, Myrsine, Psuedopanax and Pseudowintera. This group also includes Isoetes, Hymenophyllum, and Phymatosorus.

Group 2 contains a large number of taxa and has subsequently been split into two sub-groups: $2 \mathrm{a}$ and $2 \mathrm{~b}$. Overall the group has positive eigenvalues on axis 1 and both positive and negative values on axis 2 . Sub-group 2a contains tall tree taxa Libocedrus, Meterosideros and Fuscospora and the shrub/short trees Elaeocarpus, Rubus and Schefflera. This group also contains the tree fern species Cyathea dealbata and wetland taxa Myriophyllum and Gunnera. Sub-group $2 \mathrm{~b}$ contains taxa with higher eigenvalues on axis 2 and comprises taxa which are most prominent in MT1. Group 2b includes Poaceae and Kelleria, and the shrub taxa Hebe and Asteraceae. The wetland taxa Cyperaceae, Gonocaropus and Empodisma and fern spores from Histiopteris, Hypolepsis, and monolete spores are also present in this group.

Group 3 contains taxa with positive scores on axis 2 and negative scores on axis 1. This group contains a large proportion of tall tree taxa when compared to the other group and includes Dacrycarpus dacrydioides, Dacrydium cupressium, Prumnopitys ferruginea and $P$. taxifolia. This group also includes the shrub Muehlenbeckia and the tree fern Dicksonia squarrosa. 
There are three outliers in this figure which do not appear to relate to any of these groups: Cyathea smithii, Leptospermum type and W. racemosa.

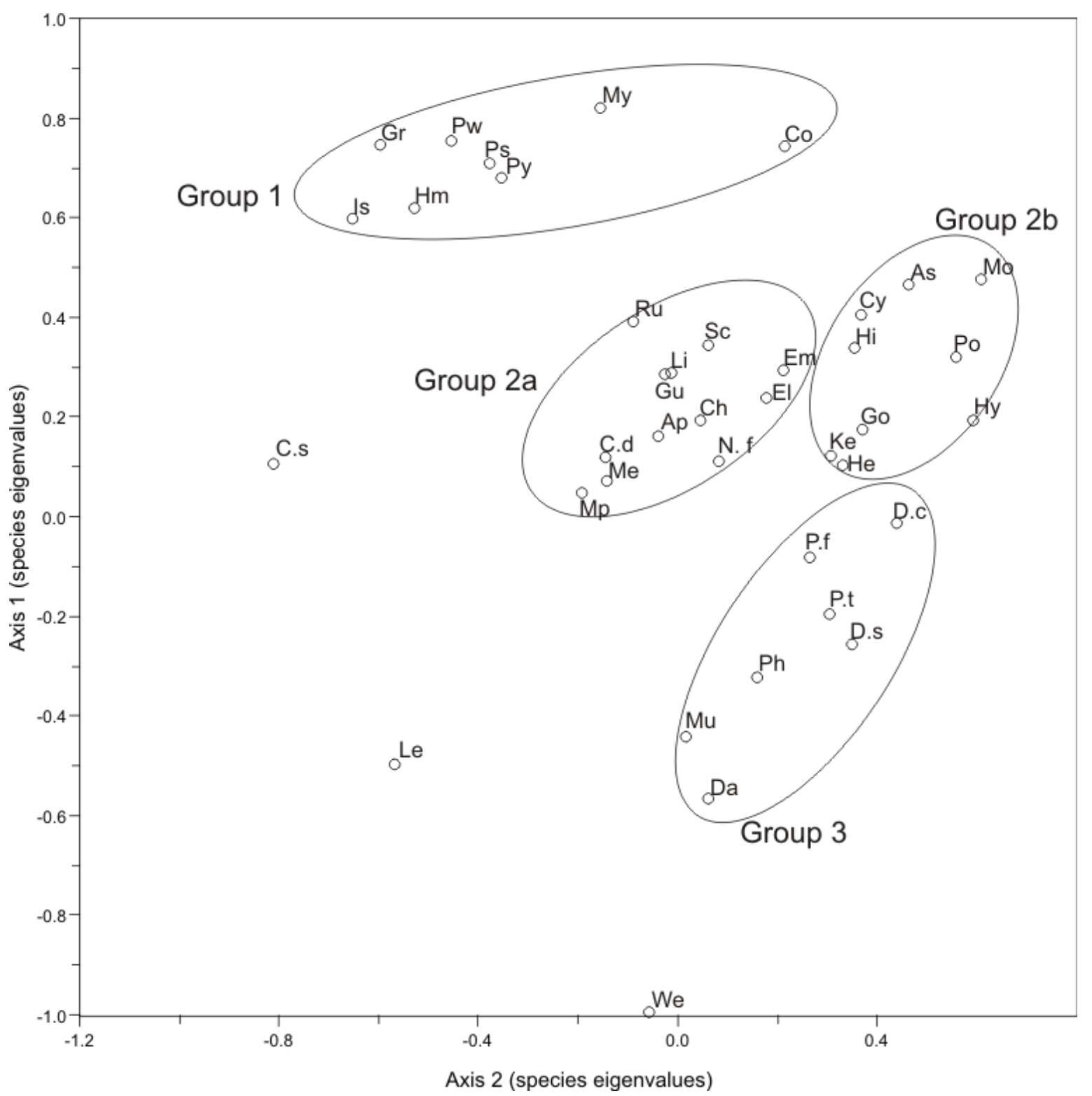

Figure 5.6: Manks Tarn PCA results for selected taxa plotted for axis 1 and axis 2. Circles indicate arbitrary chosen group clusters. Group 1; Co - Coprosma, Gr - Griselinia, My - Myrsine, Ps - Pseudopanax, Pw Pseudowintera, Py - Phymatosorus, Is - Isoetes, Hm - Hymenophyllum. Group 2a; Ap - Apiacaeae, C.d - C. dealbata, Ch - Chenopodiaceae, Em - Empodisma, El - Elaeocarpus, Gu - Gunnera, Li - Libocedrus, Me Meterosideros, Mp - Myriophyllum, N.f - Fuscospora, Ru - Rubus, Sc - Schefflera. Group 2b: As Asteraceae, Cy - Cyperaceae, Go - Gonocarpus, He - Hebe, Hi - Histiopteris, Hy - Hypolepsis, Ke Kelleria, Mo - monolete spore, Po - Poacaea. Group 3: Da - Dacrycarpus, D.c - D. cuppressinum, D.s - D. squarrosa, Mu - Muehlenbeckia Ph - Phyllocladus, P.f - P. ferruginea, Pt - P. taxifolia. Outliers: Le Leptospermum type, We $-W$. racemosa, C.s - C. smithii. 


\begin{tabular}{|c|c|c|c|c|c|c|}
\hline Group & Tall tree & $\begin{array}{ll}\text { Short } & \text { tree/ } \\
\text { shrub } & \end{array}$ & Herb & Wetland & Tree fern & Fern \\
\hline 1 & & $\begin{array}{l}\text { Coprosma } \\
\text { Myrsine } \\
\text { Griselinia } \\
\text { Pseudopanax } \\
\text { Pseudowintera }\end{array}$ & & & & $\begin{array}{l}\text { Isoetes } \\
\text { Hymenophyllum } \\
\text { Phymatosorus }\end{array}$ \\
\hline $2 a$ & $\begin{array}{l}\text { Libocedrus } \\
\text { Meterosideros } \\
\text { Fuscospora }\end{array}$ & $\begin{array}{l}\text { Elaeocarpus } \\
\text { Rubus } \\
\text { Schefflera }\end{array}$ & $\begin{array}{l}\text { Chenopodiaceae } \\
\text { Apiaceae }\end{array}$ & $\begin{array}{l}\text { Gunnera } \\
\text { Empodisma } \\
\text { Myriophyllum }\end{array}$ & C.dealbata & \\
\hline $2 b$ & & $\begin{array}{l}\text { Asteraceae } \\
\text { Hebe }\end{array}$ & $\begin{array}{l}\text { Poaceae } \\
\text { Kelleria }\end{array}$ & $\begin{array}{l}\text { Cyperaceae } \\
\text { Gonocarpus }\end{array}$ & 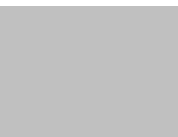 & $\begin{array}{l}\text { Hypolepsis } \\
\text { Monolete spore } \\
\text { Histiopteris }\end{array}$ \\
\hline 3 & $\begin{array}{l}\text { D.dacrydiodes } \\
\text { D.cupressinum } \\
\text { P.ferruginea } \\
\text { P.taxifolia }\end{array}$ & $\begin{array}{l}\text { Phyllocladus } \\
\text { Muehlenbeckia }\end{array}$ & & & D.squarrosa & \\
\hline Outliers & W. racemosa & & & $\begin{array}{l}\text { Leptospermum } \\
\text { type }\end{array}$ & C.smithii & \\
\hline
\end{tabular}

Table 5.2: Species list for each group recognised by the PCA results and split into different vegetative components.

Figure 5.7 is a biplot of sample eigenscores for axis 1 and axis 2. There are four sample groups identified with a few samples appearing to be transitional sample points between groups. Arrows on the figure show the stratigraphic order of groups beginning with the deeper samples and decreasing in depth. This is also the order the results are written in.

Group 1 contains the bottom 8 samples which lie in a horizontal linear pattern spanning eigenscores of 3.8-1.2 on axis 2, but only ranging 1.0-1.5 on axis 1 . Scores on both axes reduce with a decrease in sample depth with the samples lying in stratigraphic order and ranging 1170-1084 cm. However, sample $1004 \mathrm{~cm}$, lying at the end of the group, appears to be an outlier and is out of stratigraphic order. Group 2 comprises 32 samples clustered together again in a horizontal linear pattern, but not in stratigraphic order. These samples have negative scores on axis 2 . The sample cluster spans $1072-992 \mathrm{~cm}$. Four transitional samples join 
group 2 to group 3. A general stratigraphic pattern is followed with a decrease in eigenvalues on axis 1 corresponding with a decrease in core depth. Group 3 is the largest cluster containing 52 samples spanning $988-874 \mathrm{~cm}$. This group corresponds to pollen zone MT3. Another two transitional samples link group 3 and group 4. Group 4 contains the top 8 samples, excluding $78 \mathrm{~cm}$ which is a transitional sample. This group covers the top $828-714 \mathrm{~cm}$ of the core and corresponds to pollen zone M4.

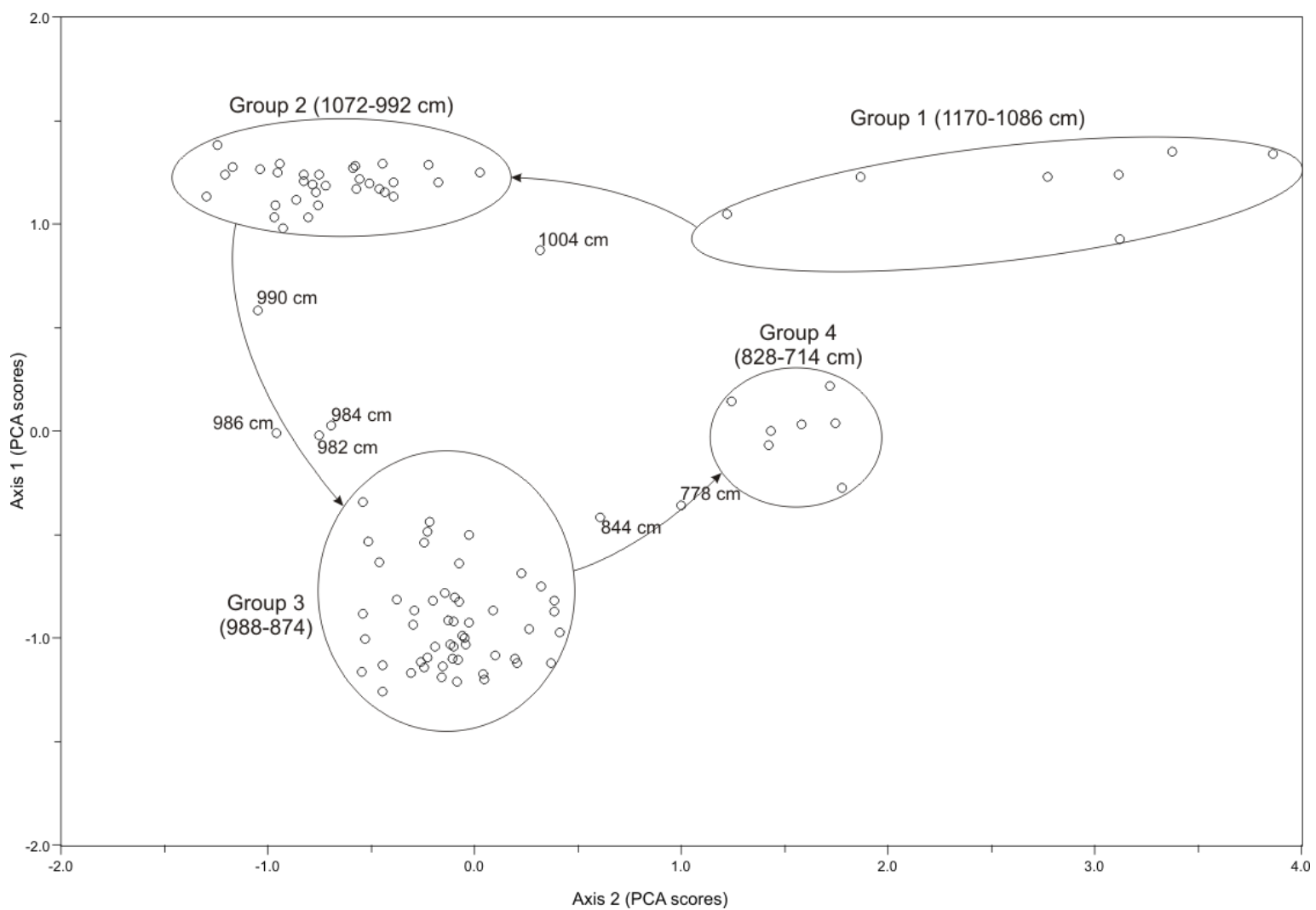

Figure 5.7: The PCA results for each sample plotted for axis 1 and axis 2. The circles around the sample clusters indicate which samples belong to a group and are chosen arbitrarily. Each of the 6 groups has been labelled and the depths displayed indicate the range of core depth that each group represents. The arrows indicate the stratigraphic order of the groups with the arrows pointing in the direction of decreased core depth. 


\begin{tabular}{|l|l|l|l|}
\hline CONISS & & PCA & \\
\hline Pollen zone & Depth & Group & Depth \\
\hline M1 & $1170-1140$ & 1 & $1170-1086$ \\
\hline M2 & $1140-990$ & 2 & $1072-992$ \\
\hline & & Transition & $990-982$ (excl 988) \\
\hline M3 & $990-874$ & 3 & $988-874$ \\
\hline & & Transition & 844,778 \\
\hline M4 & $874-714$ & 4 & $828-714$ \\
\hline
\end{tabular}

Table 5.3: A table comparing the depths of the pollen assemblage zones, carried out by the CONISS stratigraphic cluster analysis, to the depths of the sample groups, identified using PCA.

Comparison between the CONISS and PCA (Table 5.3) indicates a close similarity between the depth of the groups and pollen zones. Minor differences are mostly attributed to the different means of delineating boundaries: PCA recognises transitional values whereas cluster analysis does not. These differences are accentuated where a comparatively low sampling resolution coincides with a zone boundary, e.g MT4/3. A notable exception is pollen zone MT1, which only includes the bottom $30 \mathrm{~cm}$ of the section analysed, whereas PCA group 1 spans a large range on axis 2, more similar to the transitional samples, and could be representative of a continually changing pollen assemblage up core until $1086 \mathrm{~cm}$. However, the PCA groups were arbitrarily chosen which would also have an influence on the samples included in each group. The group classification method can also be used to explain the differences between the CONISS zones and PCA groups. Despite the minor discrepancies, overall the two methods produce similar results.

Figure 5.8 plots the sample PCA scores for axis 1 and axis 2 along a depth gradient. Unlike the biplot (Figure 5.7), which plots the position of each sample in a two dimensional space defined by the first two principles, plotting an axis individually shows the variation of PCA scores in a one dimensional, stratigraphic, space. This allows for stratigraphic comparisions between the PCA scores and 
pollen record and makes it easier to assess which species are influencing the PCA score at different depths. The results are described below.

Axis 1 PCA scores have a stable and high value ranging 1.4-0.9 from the core base until $1000 \mathrm{~cm}$. This is followed by a steep decline in values to -1.3 at $920 \mathrm{~cm}$. The values remain low but steadily increase up the core reaching a maximum 0.14 at $810 \mathrm{~cm}$. This is followed by a minor oscillation until $762 \mathrm{~cm}$ where the values become stable at 0.03 . The stratigraphic pattern of Axis 1 shows that samples with high scores contain high abundance of shrub taxa (pollen zones MT1 and MT2), which have high PCA scores (see fig 5.6.). Samples with low score on Axis 1, contain a high abundance of tree taxa, which have low PCA scores (MT4), and samples containing high abundance of Weinmannia racemosa, which has a very low PCA scores, also have a low axis score (MT3).

PCA scores PCA scores contain a much wider range in values and vary comparatively more up the core. Initially, axis 2 has a high value at the core base of 3.7 , followed by a large, steep decline to -0.8 at $1072 \mathrm{~cm}$. From $1072-892 \mathrm{~cm}$ is a period of low but oscillating values. This group can be split into two with the bottom section, 1072-978 cm, having an overall lower PCA scores compared to the upper section. The PCA scores steadily increase to 1.78 by $828 \mathrm{~cm}$ and oscillates with higher PCA scores between 1.78-1 up the remaining core section. Axis 2 scores appear to be sensitive to fern spores and tree fern loading scores. High axis scores, at the core base, coincide with high abundance of monolete spores and ferns which have high axis 2 loading scores. The decline in axis 2 scores is attributed to a decline in fern abundance, and an increase in the Cyathea smithii, which has a negative eigenvalue. Axis 2 values increase in MT3 and MT4 due to an increase in tree abundance, which contains positive eigenvalues on axis 2. However, the high abundance of $C$. smithii keeps the axis scores lower than at the base of the core. 


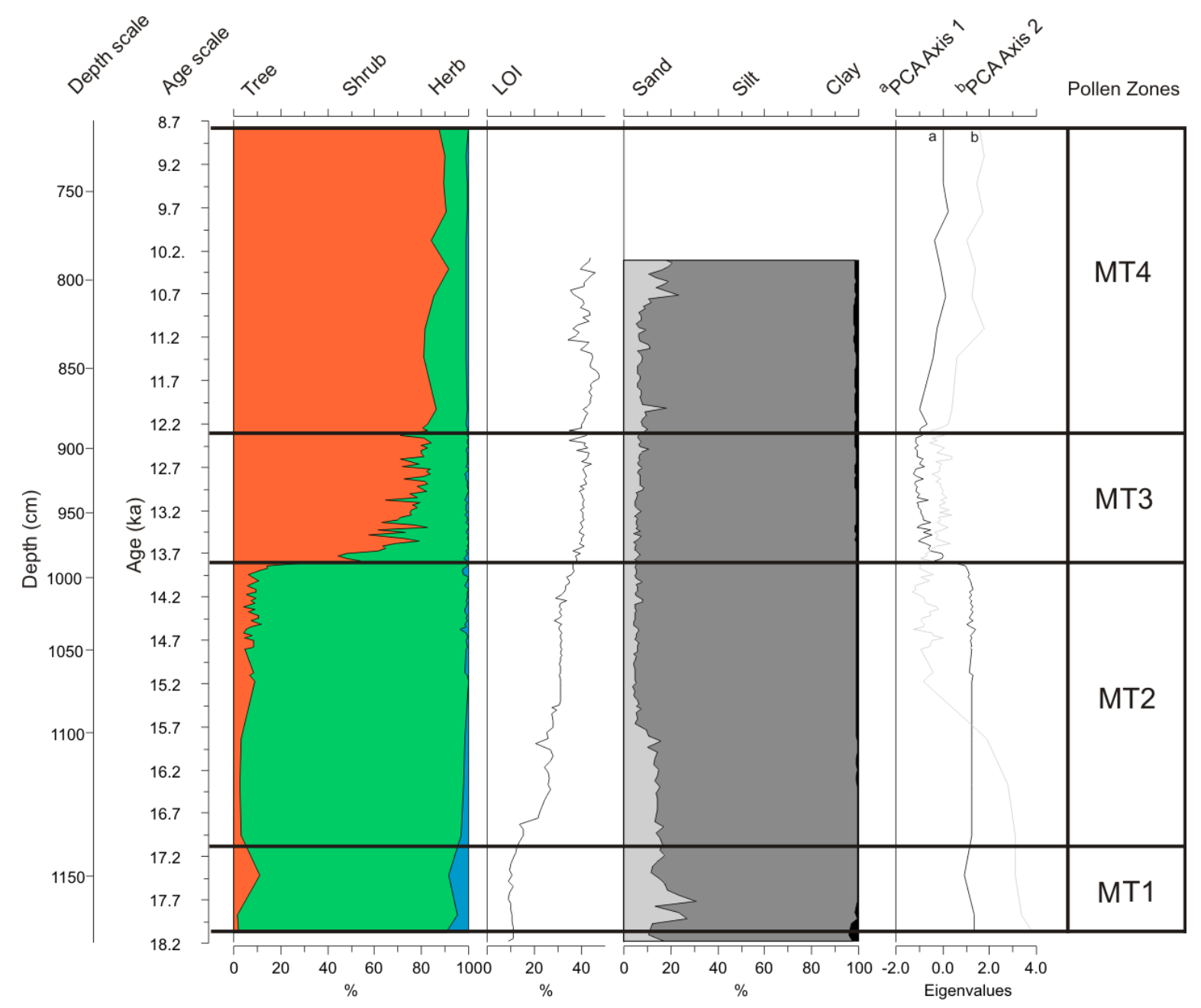

Figure 5.8: Manks Tarn pollen and sediment results with the addition of the sample eigenvalues for axis 1 and axis 2.

\subsubsection{Pollen and Sediment PCA results}

Figure 5.9 is a biplot of taxa and sediment eigenvalues of axis 1 and axis 2, illustrating the stratigraphic relationship of the pollen taxa and sediment characteristics. Sand size particles appear to relate to sub-group $2 \mathrm{~b}$, which are dominated by herb species, alpine flora and taxa represented in MT1. Silt size particles lie in subgroup $2 \mathrm{a}$ and are associated with tall tree species and tree ferns. Clay size particles lie in group 3 and are associated with podocarp forest and tree ferns. LOI is an outlier and is not associated with any taxa. W. racemosa remains an outlier but Cyathea smithii moves into group 2a and Leptospermum type into group 3 (refer back to Section 5.4.1.1 and Figure 5.6). 


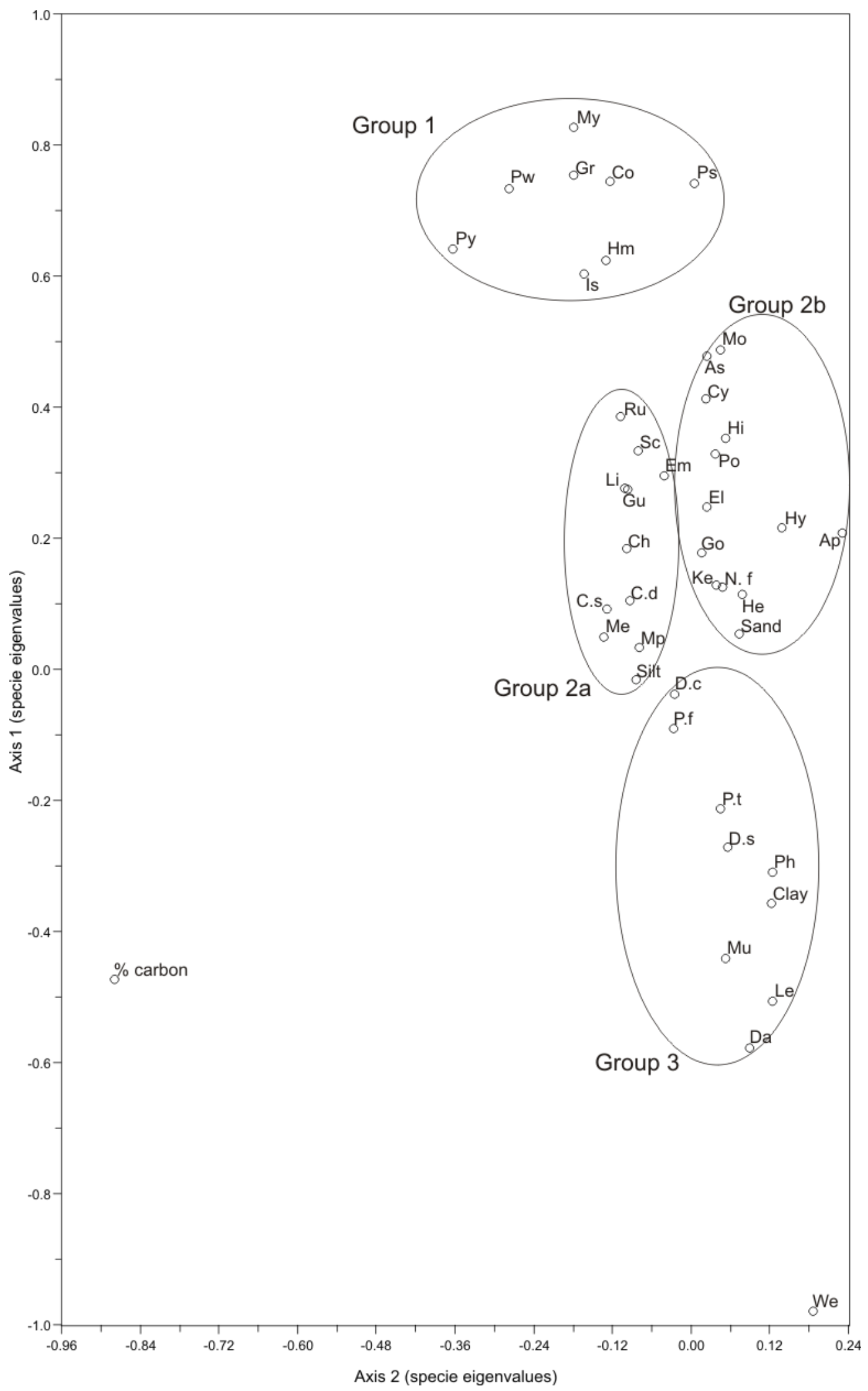

Figure 5.9: Manks Tarn PCA results for selected taxa and sediment characteristics plotted for axis 1 and axis 2. Circles indicate arbitrary chosen group clusters. (Refer to Figure 5.6 caption for sample codes). 


\subsection{Discussion}

This section interprets the pollen and sedimentological results in terms of inferred vegetation communities and then climatic reconstruction. The same principles and reference material used to interpret the Lake Mudgie results are used for Manks Tarn (refer to Section 4.5). The timing and pattern of vegetation and inferred climatic change will then be put in context with palaeoenvironmental records from other sites in New Zealand and from the Southern Hemisphere mid latitudes.

\subsubsection{Vegetation and climatic interpretation}

\subsubsection{Zone MT1 vegetation reconstruction (18.1-c. $17.1 \mathrm{ka}$ )}

Zone M1 is dominated by shrubland taxa with grassland and alpine associated flora including Hebe and Asteraceae present. The vegetation composition is very similar to that recorded in Lake Mudgie zone LM1c/LM2a. The presence of grassland taxa indicates a restricted alpine vegetation community that is possibly limited to the high altitude locations. Coprosma and Myrsine are the dominant shrubs in this zone, and are indicative of a sub-alpine/montane environment in the contemporary Westland environment (Wardle, 1977). Asteraceae, which contains both shrub and herb varieties, is also present, reflecting either shrubland or alpine herb environments, or both. The abundance of monolete spores and Hypolepis implies a prevalence of ground ferns and may be indicative of a disturbance in the shrubland or instability of the substrate limiting plant growth. The high sand component may also be indicative of instability and of an actively eroding landscape. The presence of Cyperaceae indicates a local environment that is either waterlogged or open water bodies skirted by sedgeland.

The LOI in this zone is at its lowest indicating that vegetation productivity and cover were limited. This is supported by the presence of high sand abundance suggestive of areas with limited vegetative cover and therefore increased erosion bringing larger particles into the tarn. Transport of sand size particles to the tarn basin would be limited due to the small catchment Manks Tarn and limited inflow to the site. 


\subsubsection{MT1 climate reconstruction}

The abundance of Coprosma and Myrsine contained in zone MT1 combined with a significant although low percentage of Poaceae, point towards a cool climate. The timing of deposition coincides with the start of deglaciation and a period of climatic amelioration as represented in other records (see Section 5.5.2). In the contemporary Westland environment, the plant assemblage represented in MT2 is indicative of the sub-alpine/alpine vegetation. This vegetation community is restricted to a minimum 800 m.a.s.I (Wardle 1991). This is $670 \mathrm{~m}$ above the Manks Tarn core site at 130 m.a.s.I. The pollen assemblage at $18.1 \mathrm{ka}$ implies the subalpine zone descended to at least this altitude. Using an environmental lapse rate of $0.5{ }^{\circ} \mathrm{C} / 100 \mathrm{~m}$, an estimated minimum temperature depression during MT1 is $\mathrm{c}$. $4.2^{\circ} \mathrm{C}$.

Palaeothermometer records from a site offshore of the Westland coastline and estimations from other records suggest a maximum sea surface temperature depression of c. $5{ }^{\circ} \mathrm{C}$ was experienced in New Zealand during the LGM (Barrows et al, 2007). The estimated temperature depression for MT1 is less than that during the LGM and implies temperature had already started to increase, although moderately, before the start of the record. This adds validity to the assumption that Manks Tarn was ice free soon after the LGM and the start of Termination I.

\subsubsection{MT2 vegetation reconstruction (17.1-13.8 $\mathrm{ka})$}

Zone MT2 is characterised by the disappearance of grassland and an expansion of shrubland community in the region. The disappearance of grassland and alpine taxa suggest climatic conditions became warmer and more suitable for shrub species, such as Coprosma and Myrsine. It is likely the alpine flora migrated and became restricted to the upland areas. Poaceae does not reappear with significant amounts after its disappearance in the record, indicating climate did not deteriorate, or if it did, was not great enough for regrowth of grassland in the region.

Coprosma and Myrsine remain the dominant taxa at the base of MT2 but begin to decline up the zone. A vegetational successional pattern occurs, similar to that recorded in Lake Mudgie, with a transition from cold sub-alpine dominated 
shrubland to montane Griselinia dominated forest. In the contemporary Westland environment Griselinia forest is restricted to $<800$ m.a.s.I and is characterised as montane. Myrsine divaricata, Pseudopanax simplex, P. colensio, and Coprosma wallii tend to form part of the sub canopy with $C$.astonii being part of the shrub tier. It is likely that a similar species composition was present in this pollen zone. At the site Griselinia probably dominated the lowland alluvial terraces and gullies, overtopping the Myrsine and Coprosma (Wardle, 1991). Coinciding with the Griselinia rise is an expansion of the tree fern Cyathea smithii which is likely to have been significant component in the sub-canopy. Pseudopanax and Pseudowintera, also a small tree/shrub taxon, is present in the regional vegetation suggesting an increase in plant diversity and a more complex vegetation structure. There is low abundance of Libocedrus, a shade intolerant species. Its presence may indicate there was not a dense forest canopy in the area enabling Libocedrus to grow. The LOI increases significantly from the previous zone, however, it is still limited to $30 \%$, suggesting that plant productivity and coverage had not reached its maximum potential at the site.

The abundance of Asteraceae remains at a similar level as in the previous zone suggesting it is still a significant component in the vegetation. Like Coprosma and Hebe, and as for MT1, Asteraceae includes both herb and shrub forms and it is difficult to differentiate these in the pollen diagram. However, its continued appearance during the shrub zone, when no other herb species are present, including grass, indicate that Asteraceae represents a shrub component in this zone.

Concurrent with the rise in Griselinia is an increase in the tree fern Cyathea smithii and Isoetes, a macrophyte. C. smithii abundance increases significantly and remain persists throughout the rest of this zone. The presence of $C$. smithii in a shrub community rather than a forested landscape points towards its persistence as a pre-forest successional element, although it also occurs in gullies and in the bushland perimeter in the contemporary landscape (McGlone and Bathgate, 1983) and these are likely to be the areas it inhabited during MT2. However, it could also be an important component in the small tree tier, dominated by Griselinia. Isoetes, representing open water in the local environment, was not present in the previous 
zone, which can either indicate the climate was unsuitable for its growth or the water level was not shallow enough to support Isoetes. Isoetes alpinus today grows in the alpine tarns and its presence in the Manks Tarn record suggests that temperature was not the limiting factor, but water level. This species has a limited water depth niche of 0.6-4.5 m (Brown, 1975) and would not be present in deeper water. It is likely Manks Tarn was becoming increasingly shallower due to continued sedimentation of the lake and leading to eventual terrestrialisation.

The base of MT2 continues to have a high abundance of sand indicating the Coprosma/Myrsine dominant shrubland had gaps in the canopy enabling erosion to persist at a similar rate as in the previous zone. The small tarn catchment and limited inflow into the tarn suggests the sand size material is most likely sourced from local hillslope erosion. However, coinciding with the rise in the broadleaved montane forest and increase diversity is a decrease in sand abundance and overall average particle size up core. This indicates an increase in plant density in the region protecting the soil surface from erosion. The \% carbon increases dramatically in this zone and corresponds with the disappearance of Poaceae and the increase in shrub dominance indicates an increase productivity and biomass input to the sediment. The carbon content maintains a plateau at $30 \%$ throughout the section dominated by Griselinia and only begins to increase towards the top of MT2, indicating plant productivity was stable throughout this section but had not reached its full potential. A climate interpretation for MT2 is presented along with that for MT3 in Section 5.5.1.5.

\subsubsection{MT3 vegetation reconstruction (13.8-12.3 ka)}

Pollen assemblages in zone MT3 shift from a low lying Griselinia-dominated broadleaved forest to a hardwood/podocarp forest dominated by tall tree species, in particular $W$. racemosa. The increase in $W$. racemosa, a drought and frost sensitive taxa, indicates that temperature and precipitation levels were high enough ( $>1000 \mathrm{~mm} / \mathrm{yr}$ ) to allow this taxon to become established. The presence of Griselinia, Myrsine and Coprosma, although in reduced abundance, indicates broadleaved forest was still widespread in the $W$. racemosa-dominated forest and was probably part of the shrub understory (Wardle, 1977). The consistent presence of Cyathea smithii, which is probably part of the small tree tier, is also 
indicative of moist environments. Griselinia may have also provided a nursery and cover for the podocarp taxa as it does in the contemporary landscape (Wardle, 1977). The increase in Prumnopitys ferruginea, P. taxifolia and Dacrydium cupressinum is likely to represent the start of the development of tall podocarp forest in the area. However, D. cupressinum abundance is low and was probably restricted to lowland terrace or hill slopes where it is commonly found today (Rief and Allen, 1988; Wardle, 1991). The disappearance of Isoetes is likely to indicate there is no longer open water at the site. However, unlike Lake Mudgie, the reduction in Isoetes is not combined with a visual stratigraphic change in the core. Libocedrus also reduces in abundance suggesting a denser canopy limiting its growth.

The LOI abundance increases to a stable $40 \%$ consistent with an increased biomass in the environment caused by the introduction of tall tree species. Grain size distribution remains similar to that recorded in the previous zone indicating the substrate was at a stable state as in pollen assemblage zone MT2.

\subsubsection{MT2 and MT3 climate interpretation (17.1-12.3 ka)}

Zone MT2 shows a shift from sub-alpine shrubland communities which today lie at 800-1200 m.a.s.l (Moar, 1970; Wardle, 1991) to montane broadleaved forest with a restricted upper altitudinal limit of 800 m.a.s.I. This indicates an increase in temperature that is characteristic of the LGIT.

The increase in $W$. racemosa and the pace of its rise to dominance suggest that temperature and increased precipitation was high enough to allow broadleaved/podocarp forest to grow at the site. W. racemosa in particular demands high precipitation levels and is sensitive to water stress and severe frost (McGlone et al, 1994). Furthermore, the expansion of Prumnopoitys ferruginea and P.taxifolia provide greater evidence to support an increase in precipitation and temperature during this zone. These species form an important component of the contemporary lowland forest. However, the lack or small abundance of $D$. cupressinum, which is dominant in the contemporary lowland forest suggest the temperature and precipitation may not have been as high as it is at present. Therefore it is likely that this low hardwood/podocarp forest grew in wetter and 
warmer conditions than in the previous zones, but the climate was cooler than present condition in the region. The species composition of zones MT2 and MT3 is representative of montane vegetative zone, which in the contemporary landscape is restricted to $600-800$ m.a.s.I (Moar 1970; Wardle, 1977). Using the ELR of $0.5^{\circ} \mathrm{C} / 100 \mathrm{~m}$, a minimum temperature depression of $2.4{ }^{\circ} \mathrm{C}$ is inferred.

\subsubsection{MT4 vegetation reconstruction (12.3-8.8 $\mathrm{ka})$}

This zone is characterised by the transition from $W$. racemosa dominated broadleaved/podocarp forest to a $D$. cupressinum dominated podocarp/hardwood lowland forest with $D$. Cupressinum being the dominant species throughout the zone and $W$. racemosa co-dominant. Prumnopitys taxifolia and to a lesser extent $P$. ferruginea are still persistent in this zone, albeit both in small abundance, suggesting they contribute significantly to the canopy vegetation. Small amounts of Coprosma and Myrsine occur towards the top of this zone and would be present in the shrub tier. Contemporary Westland forest has Myrsine australis and Coprosma lucida which forms the main shrub tier under the forest canopy. This vegetation assemblage is very similar to contemporary forest communities in the Westland region. Together these assemblages represent a full development of interglacial temperate rainforest (Wardle 1977). This idea is supported by the high organic carbon content of the sediment and further increase in visual organic material in the core representing an increase in biomass and productivity of the vegetation.

The high levels of tree ferns, in particular Cyathea smithii, but also Discksonia squarrosa, suggest that these species formed an important component of the small tree tier and persisted amongst the tall podocarp forest. The relative abundance of tall forest and fern species represent vegetation and pollen assemblage characteristic of the contemporary lowland forest zone that reaches a maximum altitude of c. 400-600 m.a.s.I and extending down to sea level (Wardle, 1977).

\subsubsection{MT4 climate reconstruction}

The dominance of Dacrydium cupressinum and the presence of Prumnopitys ferruginea, $P$. taxifolia and $W$. racemosa in the regional vegetation indicate the establishment of stable climate conditions during zone MT4. These species 
occupy the contemporary warm and wet montane and lowland forest in the area (Franklin, 1968; Wardle, 1977) which strongly suggests the climate at this time remained warm and wet. The contemporary $D$. cupressinum dominated temperate rainforests of the Westland region is prevalent up to 400-600 m.a.s.I and experiences MAT of c. $11{ }^{\circ} \mathrm{C}$ and precipitation c. $5000 \mathrm{~mm} / \mathrm{yr}$ (Wardle, 1977; 1991). It is likely that the climate experienced at the site during zone MT4 was similar to the contemporary lowland Westland climate and indicates that full climatic amelioration was reached. However, when compared to Lake Mudgie, the abundance of $W$. racemosa appears to be much higher during the early Holocene period, co-dominant with $D$. cupressinum. Other tall tree species are also present in high abundance suggesting greater forest diversity at this site than at Lake Mudgie. The establishment of full interglacial vegetation occurs between c. 11.2$10.8 \mathrm{ka}$.

\subsubsection{Quantitative pollen/climate reconstructions}

The climate changes described above are characterised by a consistent pattern of climate amelioration whereby MAT increases progressively. This pattern of amelioration is consistent with other late glacial records in New Zealand (e.g. Vandergoes et al, 2003; Newnham et al, 2007). However, the estimated temperature changes predicted by the two models do not follow with the above pattern. The PLS-C3 model suggests a continuous and gradual decline in MAT occurred between 17.2-10.8 ka followed by an increase in temperature to near contemporary conditions during the Holocene. The minimum MAT reached was $7.2{ }^{\circ} \mathrm{C}$, this is $4.3{ }^{\circ} \mathrm{C}$ colder than current conditions, and a similar temperature depression as expected to have occurred during the LGM (e.g. Barrows et al, 2007).

In contrast the W-MAT model does not show a cooling pattern during the LGIT. Instead this model suggests MAT remained stable between 18.1-10.8 ka with temperatures near to contemporary conditions. MAT increases after 10.8 ka to near contemporary levels during the Holocene. The patterns of predicted MAT change in both models do not correspond with the inferred pattern of climate change from the vegetation record and using ELR. The discrepancies between the patterns of MAT change inferred by the different methods may be attributed to the 
limitations with the quantitative methodology. This is discussed in more detail in Section8.2.4.

\subsubsection{Summary discussion}

\begin{tabular}{|c|c|c|}
\hline Pollen assemblage zone & Vegetation reconstruction & Climatic reconstruction \\
\hline $\begin{array}{l}\text { MT4; 874-714 cm } \\
(12.3-8.8 \mathrm{ka})\end{array}$ & $\begin{array}{l}\text { D. cupressinum dominated } \\
\text { temperate rainforest with } W \text {. } \\
\text { racemosa being the co- } \\
\text { dominant species. }\end{array}$ & $\begin{array}{l}\text { Stable warm wet climates with } \\
\text { mean annual temperatures } 11^{\circ} \mathrm{C} \\
\text { and precipitation } 5000 \mathrm{~mm} / \mathrm{yr} \text {. } \\
\text { Climate amelioration culminated at } \\
10.8 \text { ka representing the start of the } \\
\text { Holocene. }\end{array}$ \\
\hline $\begin{array}{l}\text { MT3; } 990-874 \mathrm{~cm} \\
(13.8-12.3 \mathrm{ka})\end{array}$ & $\begin{array}{l}\text { W. racemosa dominated } \\
\text { broadleaved/podocarp forest. }\end{array}$ & $\begin{array}{l}\text { Warm, wet climate with } \\
\text { precipitation at least } 1000 \mathrm{~mm} / \mathrm{yr} \text {, } \\
\text { probably much higher. }\end{array}$ \\
\hline $\begin{array}{l}\text { MT2; } 1140-990 \mathrm{~cm} \\
(17.1-13.8 \mathrm{ka})\end{array}$ & $\begin{array}{l}\text { Broadleaved hardwood } \\
\text { montane forest with tree } \\
\text { ferns forming a significant } \\
\text { part of the sub-canopy. } \\
\text { Areas of open water and } \\
\text { poor drainage. }\end{array}$ & $\begin{array}{l}\text { Warmer climates ( a minimum } \\
2.4^{\circ} \mathrm{C} \text { temperature depression). }\end{array}$ \\
\hline $\begin{array}{l}\text { MT1; } 1170-1140 \\
(18.1-17.1 \mathrm{ka})\end{array}$ & $\begin{array}{l}\text { Sub-alpine shrub dominated } \\
\text { vegetation. Alpine grassland } \\
\text { present in small abundance. } \\
\text { Vegetation cover was } \\
\text { sparse. }\end{array}$ & Climate is cooler than at present. \\
\hline
\end{tabular}

Table 5.4: A summary table of the vegetation and climate reconstruction for the different pollen assemblage zones.

Table 5.4 is a summary table of vegetation and inferred climate reconstructions. The climate reconstruction is based upon the assumption that vegetation change is climatically controlled. However, the pattern of vegetation transition in the core may not solely represent climatic change but could be factor of time lags associated with primary vegetation succession and will be discussed below. Wardle $(1980 ; 1991)$ documents the successional pattern of primary forest development in Westland forests and concluded that full succession takes a period ranging 500-1000 years. The initial seral stages are characterised by the occupation of Coprosma and Mrysine for the first 130 years. Tree ferns, Griselinia, 
Meterosideros umbellata and Weinmannia racemosa then overtop the shrubland and produce a tree canopy. The podocarp Prumnopoitys ferruginea and Dacrydium cupressinum may also be present in the environment but only as small seedlings and do not become canopy trees for another 400-450 years during which time the Metrosideros/ $W$. racemosa tree communities are collapsing. By 1000 years $D$. cupressinum becomes dominant.

The successional vegetation pattern described is very similar to the temporal changes in the pollen record which suggest that Coprosma and Myrsine shrubland was overtopped by Griselinia followed by tall tree species $W$. racemosa, $P$. ferruginea and $P$. taxifolia culminating in a $D$. cupressinum dominated forest. However, this process takes a period of 6000 years with a prolonged abundance of the shrubs and Griselinia combined with an abrupt increase in W. racemosa and $D$. cupressinum, which cannot be explained by successional pattern of vegetation change solely. The PCA sample eigenvalues confirm a rapid vegetation change as there are few transitional samples lining one group to another. This suggests the pollen assemblage changed significantly and abruptly from each zone/PCA group. The abrupt increase in these taxa from previously low representation in the previous pollen assemblage zone suggest increases in precipitation and temperature are important forcing factors for the pattern of vegetation recorded at this site.

The age of sediment accumulation and the first pollen assemblage analysed in the core indicates the minimum age of deglaciation at c. $18.1 \mathrm{ka}$. This indicates that deglacation must have begun prior to $18.1 \mathrm{ka}$. The pollen assemblage in MT1 is dominated by Coprosma/Myrsine shrub and a small abundance of Poaceae, providing a very similar assemblage as found in the top of section LM1c in Lake Mudgie (see Section 4.4.1). LM1c clearly marks the transition from alpine dominated grassland to sub-alpine shrubland and the end of the LGM. Before shrubland could grow at Manks Tarn the site needed to become ice free, lithologically stable and have soil development. This suggests deglaciation had begun sometime prior to $18.1 \mathrm{ka}$. Evidence from Lake Mudgie indicates that vegetation response to climate amelioration was rapid and the same process is 
likely at Manks Tarn too and suggests that deglaciation could have started not that long before $18.1 \mathrm{ka}$. This will be discussed further in Section 8.1.4.

Okarito pollen site, located in south Westland, has a similar pattern of deglacition characterised by a sustained decrease in grass and its replacement with shrub species. The age given at this site for the onset of deglaciation is $17.3 \mathrm{ka}$ and supports the age recorded at Manks Tarn (Newnham et al, 2007a). Furthermore, this age of glacial retreat from its LGM maximum extent is supported by Suggate (1990) and pollen proxy records from other sites in the Westland region (e.g. Vandergoes and Fitzsimons, 2003). Likewise the records used in the NZ-I CES, including the proxy records from the North Island, marine core MD97-2121 and the speleothem records, all consistently age the Termination I at occurring between 19-17.9 ka (refer to Section 1.2). Although there is evidence of large glaciers in the Westland region up until 19.5-19 ka (e.g. Abut Head; Moar, 1980; Denton et al, 1995; Suggate and Almond, 2005), the timing of deglaciation (between $19-17.9 \mathrm{ka}$ ) is broadly synchronous throughout New Zealand.

Deglaciation began before $18.1 \mathrm{ka}$, as discussed above, with climate amelioration culminating in the development of $D$. cupressinum dominated podocarp-hardwood forest around c. $10.8 \mathrm{ka}$. The pattern of vegetation change shows consistent climate amelioration characterised by a progression of successive peaks in firstly shrub taxa Coprosma and Myrsine, followed by Griselinia to tall tree taxa W. racemosa, Prumnopitys and finally $D$. cupressinum. The pattern of vegetation change is similar to that recorded at Okarito (Newnham et al, 2007a), Lake Mudgie (Chapter 4.6; Moar and Suggate, 1996), Gillespie Beach Road (Vandergoes and Fitzsimons, 2003) and other records from the region (refer to Section 2.6.1.2).

Unlike the Okarito record and the NZ-I CES there is no evidence for a LGR. Instead Manks Tarn shows progressive forest development, increased precipitation and continued climatic amelioration up until the Holocene. However, there is strong evidence of a glacial advance in the Westland region in the form of the Waiho Loop moraine. There is also evidence of a LGR in a number of other records from the South Island (e.g. Newnham et al, 2007a; Vandergoes et al, 2008; Kaplan et al, 2010). Vandergoes and Fitzsimons (2003) argue that in the high 
rainfall Westland region lowland vegetation may not provide the best proxy for short term and minor temperature cooling. Also, Vandergoes et al (2008) suggest that pollen sites which are not located at either high altitude or at ecotonal boundaries would most likely record only minor cooling, such as at Okarito (Newnham et al, 2007a) or no reversal at all (McGlone 1995; Vandergoes and Fitzsimmons, 2003). Manks Tarn is only 130 m.a.s.l and in a high precipitation region, away from any vegetation boundaries and was dominated by lowland forest taxa towards the end of the LGIT. The conditions at this site are therefore probably not conducive for recording a LGR. This event, or lack of, will be discussed further in Section 8.1.5.1.

The Manks Tarn record shows climatic amelioration, inferred by the rise in $D$. cupressinum beginning at c. $12.2 \mathrm{ka}$, culminating by $10.8 \mathrm{ka}$ after which a stable podocarp-hardwood forest persisted and is similar to that found in the contemporary landscape. This early Holocene warmth is not restricted to Manks Tarn but has also been recognised by the NZ-I CES. Records included in that project dated the onset of the early Holocene warmth occurring between 10.6-11.8 ka. This age is not only broadly synchronous regionally and nationally but also both hemispheric and interhemispheric suggesting global synchronicity for the onset of the Holocene warm period (refer to Section 8.1.6 for more detail).

\subsection{Conclusion}

The Manks Tarn record is consistent with other records in the region both in the timing of particular climate transitions and in the pattern of vegetation change. Deglaciation, marking the end of the LGM began $18.1 \mathrm{ka}$ and is characterised by reduction in grassland and an increase in sub-alpine shrubland. This is followed by vegetation successional pattern from sub-alpine to montane communities and culminating with podocarp-hardwood temperate rainforest. Climate is the primary forcing factor with these vegetation changes reflecting increase in precipitation and temperature at the site over time.

The record does not show a LGR occurring either at an ACR or YD timing. This may suggest the area did not experience a climatic reversal. Alternatively the site 
is situated in a climatically insensitive area due to its comparatively low altitudinal location away from an ecotonal boundary, high precipitation and insensitive vegetation. Holocene conditions were reached around 11.2-10.8 ka and are represented by the dominance of $D$. cupressinum and the stable podocarphardwood forest which occupies the lowland areas in Westland today. 


\section{Chapter 6: Howard Valley}

Howard Valley, the third site to be discussed, lies in the Nelson Lakes region, northern South Island. Located between two glacially formed lakes, Lake Rotorua and Lake Rotoiti (Figure 6.1) this site provides a fragmentary record constructed from three river terrace risers that cumulatively span c. 37.7-18.9 ka. Sediment accumulation beneath the oldest terrace began prior to the onset of the LGCP. This site provides a unique insight into the vegetation and climate spanning from pre LGCP and the entire LGCP including the LGM. As for the Westland region, geological mapping reveals this area was extensively glaciated during the LGM. A site where sediment accumulation that begins pre-LGM and is still preserved is therefore rare. However, due to the low elevation of the river terraces (500 m.a.s.l) sediment accumulation continued without interference by ice. As a result, the vegetation and inferred climate signal was captured. A recently published beetle and macrofossil proxy record from the same three terrace risers (Marra and Thackray, 2010) provides further scientific interest and opportunity to compare those proxies with the pollen record presented here.

\subsection{Regional description}

Howard Valley is located in the Nelson Lakes National Park, south-east Nelson region, at the northern limit of the Southern Alps mountain range. It is in an upland area with the mountain ranges reaching 2000 m.a.s.I and valley floors ranging 1200-600 m.a.s.l. The remaining native vegetation is restricted to the upland and steep mountain sides and is dominated by beech forest. Nothofagus fusca is the dominant tree species up to 900 m.a.s.l. N. menziesii then becomes dominant until 1100 m.a.s.l above which $N$. solandri var. cliffortiodes dominates up to a clearly defined treeline at 1400 m.a.s.I. The treeline is characterised by a sharp transition from forest to alpine tussock grassland (Wardle, 1985). The lowland and flat valley bottoms have been heavily modified by human activity, predominantly forest clearance for agriculture use. 


\subsubsection{Climate}

Howard Valley is located within the North South Island (NSI) climate zone (Kidson, 2000; Lorrey et al, 2007). The prevailing wind regime is from the north-west bringing moisture-laden air masses resulting in high annual precipitation, which averages $1600 \mathrm{~mm} / \mathrm{yr}$ at Lake Rotoiti. Precipitation falls evenly throughout the year. The region experiences a cool climate with mean annual temperatures of $9{ }^{\circ} \mathrm{C}$ at Lake Rotoiti and average summer temperatures of $14{ }^{\circ} \mathrm{C}$ and winter temperatures of $4{ }^{\circ} \mathrm{C}$ (New Zealand National Climate Centre, 2010).

\subsubsection{Glacial history}

The contemporary landscape is dominated both by depositional and erosional features; evidence of the glacial history in the region. Throughout the Quaternary, glaciers flowed down from the St Arnaud and Spencer Mountain ranges into the Rotoiti and Rotorua valleys (Suggate, 1965). Glaciers also spilled over a small divide at the southern end of Lake Rotoroa between Mt Cedric and the Muntz Range into the Howard Valley. During earlier glacial events glaciers extended down the Howard Valley into the Buller Valley and its two main tributary valleys (Maud and Maggie creek; see Figure 6.1). Large sections of the upper Howard Valley have been smoothed by the ice producing a valley oversized for the river it contains today. Successive lateral moraines step up the eastern and western sides of the valley representing the progressively shorter glacial tongues caused by incising of the valley via both glacial and interglacial erosion processes (Suggate, 1988; Challis et al, 1994).

The mid and lower sections of the Howard Valley were not glaciated during the last glacial period and contain extensive outwash aggradation surfaces known as the Speargrass formation (Challis et al, 1994). The origin of this material is from the small cirques and main valley glacier at the head of the Howard Valley. Multiple episodes of aggradation followed by incisions has produced a number of aggradation river terraces and exposed terrace risers, which flank both sides of the Howard River and up its tributaries. In the main Howard River Valley the risers reach up to $30 \mathrm{~m}$ high (Challis et al, 1994). Near the Howard Valley/ Buller River junction the deposits are described as poorly bedded coarse gravels (Suggate, 1988). 


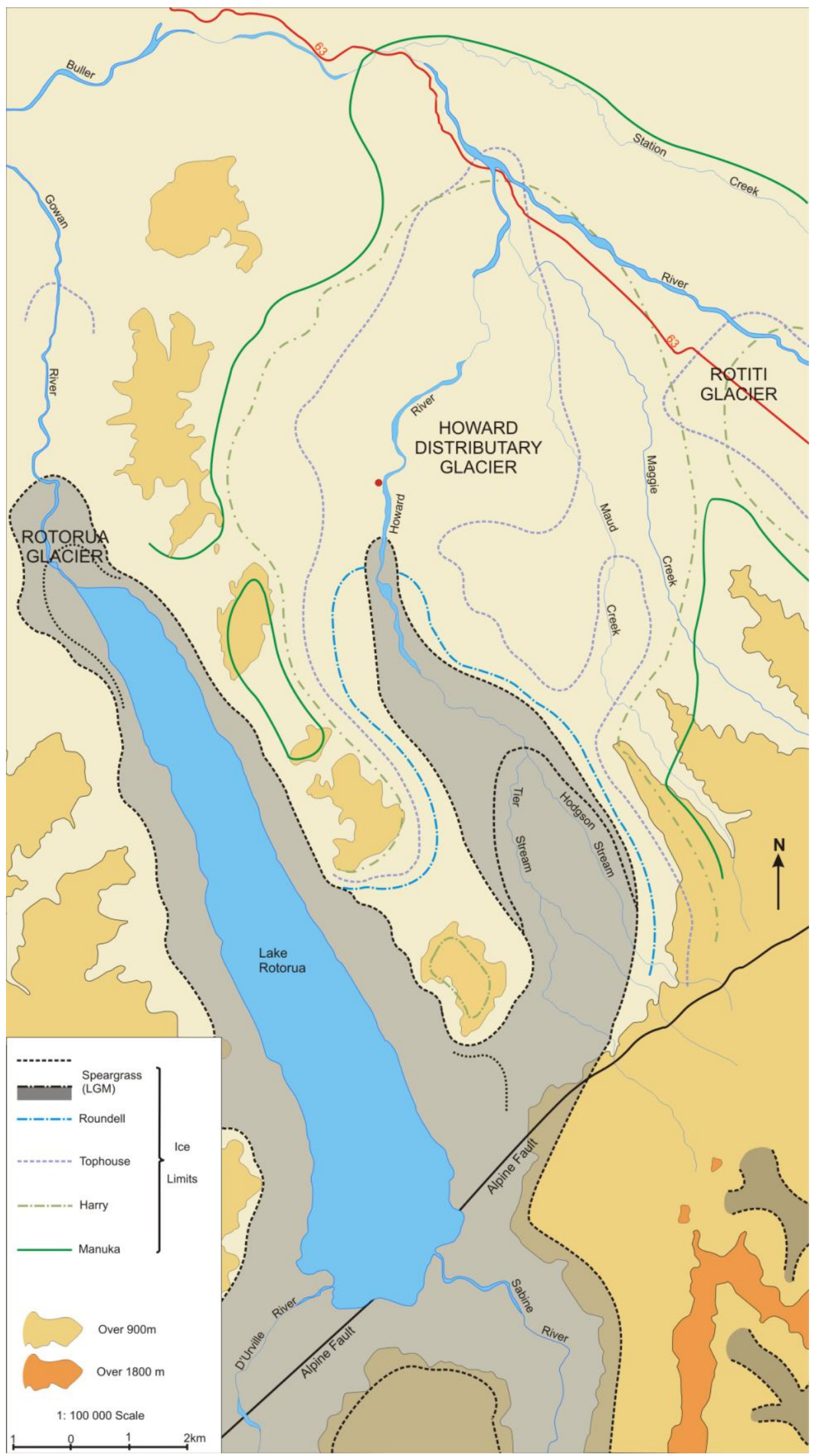

Figure 6.1: Map showing the ice limits during glacial periods in the Lake Rotorua and Howard Valley region during the late Quaternary period. Copied and adapted from Challis et al (1994). The red dot marks the location of the site area used for this project. The list of ice limits are in age order with the Speargrass limit being the youngest and Manuka the oldest (refer to Table 2.1). 


\subsection{Local site description}

The middle and lower sections of the Howard Valley and its tributaries contain a series of low river terrace risers, reaching $>30 \mathrm{~m}$ above the valley floor. These terraces have been incised by the river and streams resulting in exposed sequences (Figure 6.2) of gravels, sands and silt layers that also contain organicrich lenses. Three exposed sections from three different terraces were sampled. Two of these terraces are located up a small unnamed tributary of the Howard River, upstream from Coleman Creek (Figures 6.3, 6.4). The catchment of this tributary is small and restricted to the east by the Muntz Range. The upland area of this catchment is vegetated by native beech forest which is replaced by forestcleared grassland in the valley bottom. The tributary enters the western side of the Howard Valley (Figure 6.4).

The lower section of the unnamed tributary contains a complex system of terraces at varied heights which do not necessarily pair across the valley. A recent conifer plantation obscures and has potentially modified the surface of the largest terrace. The Howard Road has also been built on top of the largest terrace which may also have modified the terrace morphology. However, the two terraces sampled are smaller, located away from the road and pine plantations and free from human disturbance. The two terraces are adjacent to the small stream which is actively cutting the riser of the terraces to reveal these sections. The third terrace is located in the main Howard River Valley, set back from the active river channel today.

Sampling for pollen analysis used the same riser sections as analysed by Marra and Thackray (2010) for beetle and macrofossil analysis (refer to Section 6.2.1 for an overview of their findings). Section 1, the youngest deposit aged between 20.5$18.9 \mathrm{ka}$, is a large terrace riser located on the south-eastern bank of the unnamed tributary. Section 3, the oldest deposit (38.9- $28.5 \mathrm{ka}$; refer to chronology Section 6.4 ) is located $30 \mathrm{~m}$ across the valley from section 1 and the section base is only $0.72 \mathrm{~m}$ below the base of section 1 . Section 2 is located $200 \mathrm{~m}$ downstream from sections 1 and 3, in the main Howard River valley and is aged between 26.2-21.9 
$\mathrm{ka}$ (refer to the chronology Section 6.4). The base of section 2 lies c. $22 \mathrm{~m}$ below the base of section 1.

All three sections are capped by a coarse fluvially derived cobble layer. The contact between the cobble layer and underlying silts shows evidence of downcutting by stream activity above (Figure 6.3). This provides an explanation for the complex pattern in terrace deposition found in the area and how two terrace risers in the same valley at similar elevations can have such disparate ages. This will be discussed in greater detail in Section 6.4.

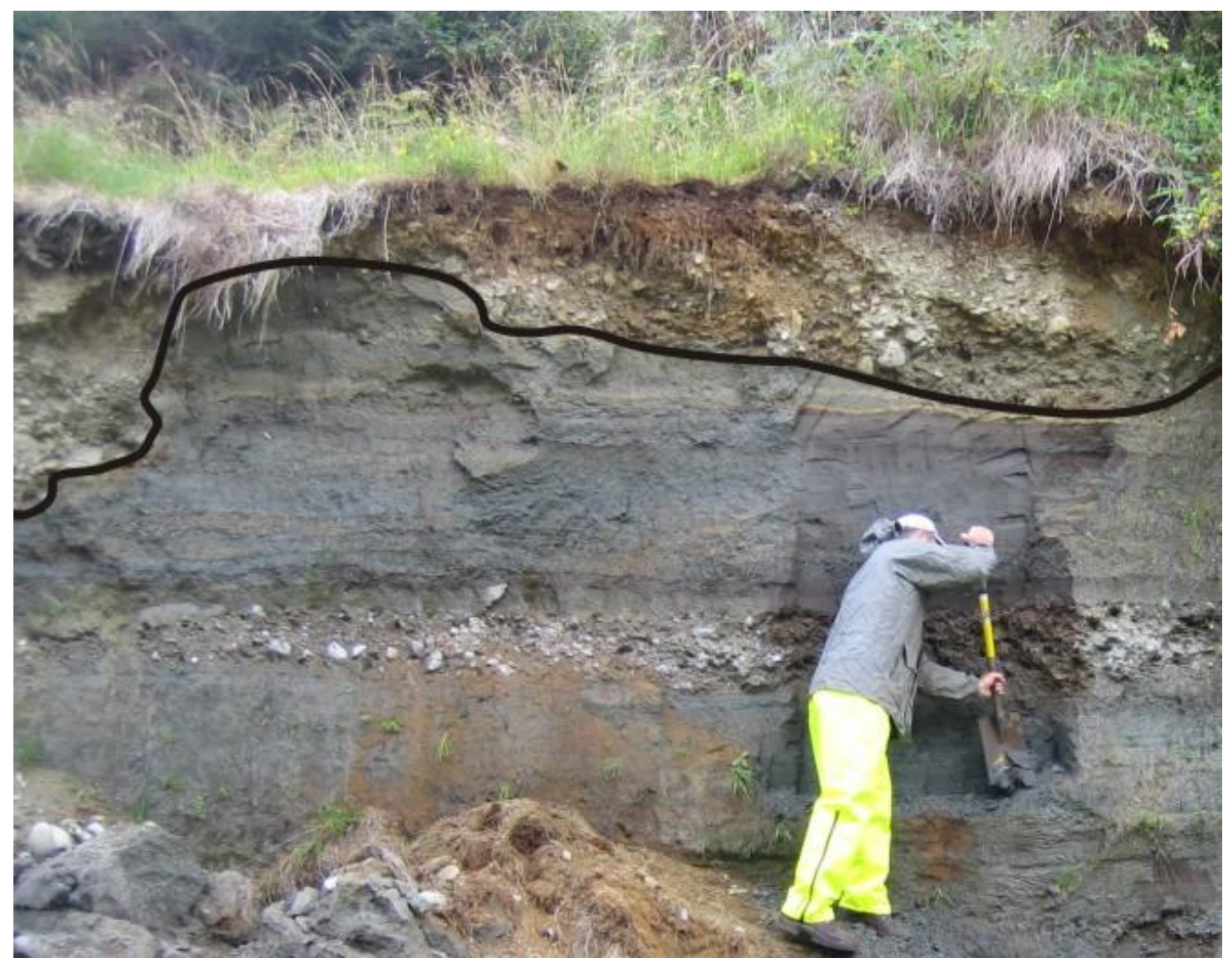

Figure 6.2: Image of section 1. The black line shows the erosion contact layer of the capping cobble/pebble and coarse sand layer which overlies the section analysed. 


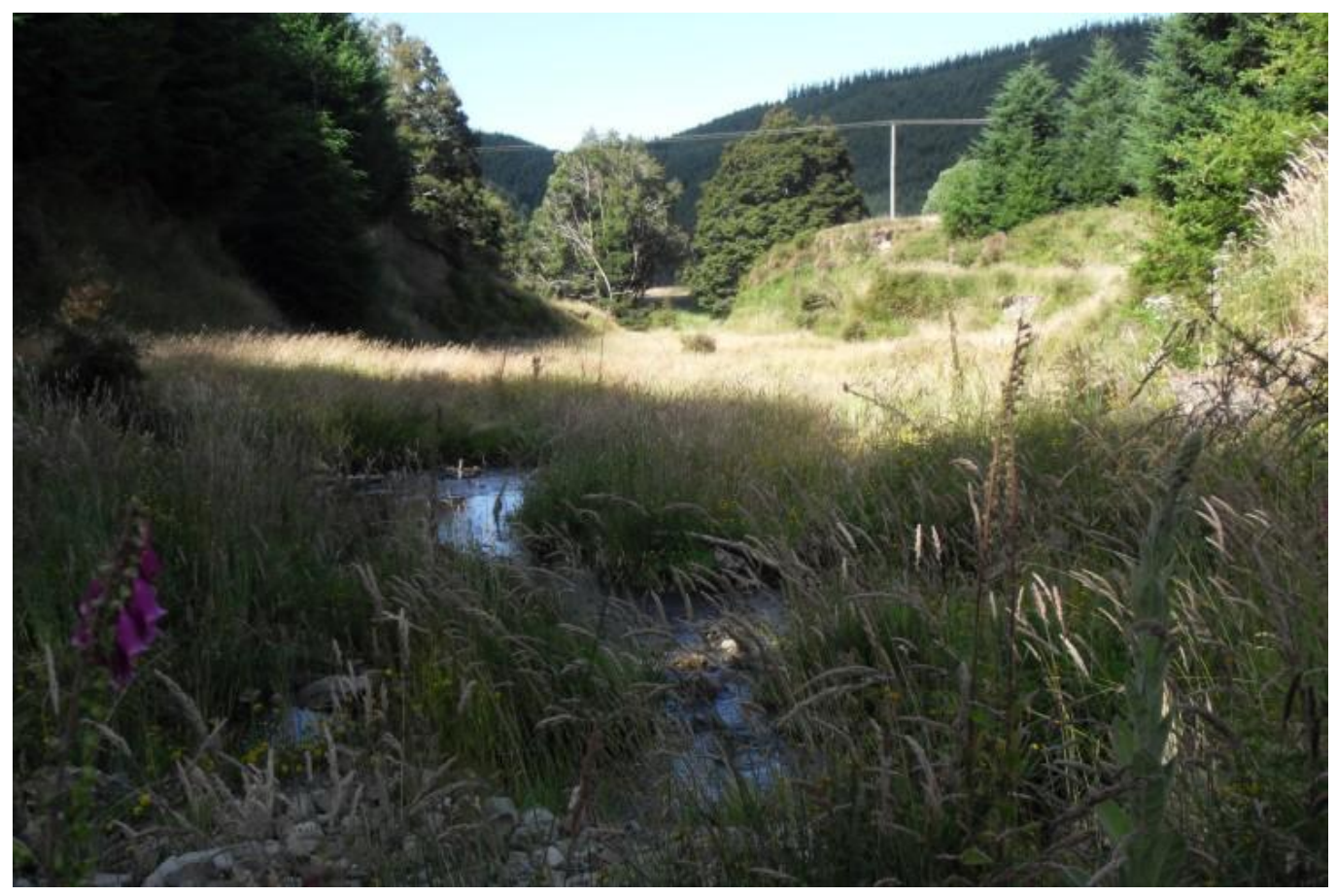

Figure 6.3: Image looking downstream the unnamed tributary valley. Terraces can be seen on both sides of the valley. Vegetation is primarily pastoral, although a Nothofagus menziesii tree is located in the middle ground. Pine plantations are located in the background and on both the larger terraces either side of the stream valley. 


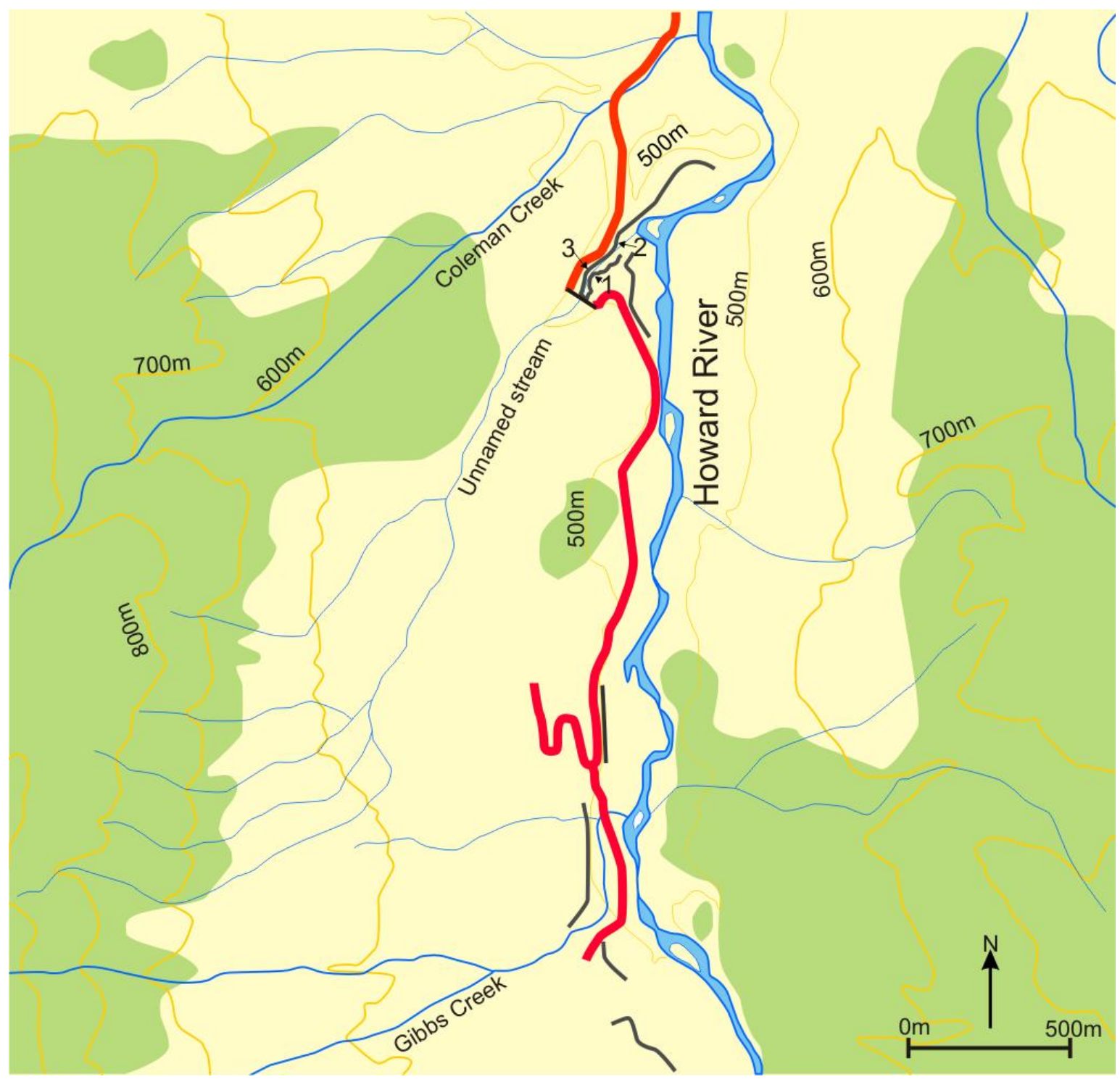

Figure 6.4: Location map of the Howard Valley site. Numbers 1-3 are the three terrace risers analysed. The dark lines represent the location of the river terraces in this valley.

\subsubsection{Previous research}

Previous research from the region has already been discussed in Section 2.6.2. This section will instead touch upon the research which has been carried out at the site itself rather than provide a regional overview. McLea (1996) produced a pollen record from two samples, one above and one below the KOT layer in the Howard Valley, either near to or at section 2 of this study (see Section 6.3). Grass taxa dominated the pollen assemblage along with Asteraceae, including a large proportion of Taraxacum, and Apiaceae. Fuscospora was the dominant tree taxon, providing only $10 \%$ of the pollen count whilst only trace levels of broadleaved forest and shrub taxa were counted. The pollen assemblage also contained trace 
levels of Nothofagus menziesii. The author concluded that during the period of KOT deposition the region was dominated by alpine grass and herbfields with forest refuges in sheltered locations in the region, which probably contained a significant presence of $N$. menziesii.

Subsequent research by Marra and Thackray (2010) expanded the temporal and spatial record at the site by producing a beetle and plant macrofossil record from three river terrace risers in the area. Their proxy record extends from 34.5-18.9 ka producing a fragmentary record during late MIS 3 and the entire LGCP. The stratigraphy at the site is complex indicating a dynamic depositional environment, changing from terrestrial organic accumulation in low energy environments to fluvial gravel deposits. Erosional contacts indicate there has been loss in the stratigraphy providing a discontinuous record. The record is summarised below:

Section 3, the oldest terrace riser, is aged between 34.4-28.5 ka. Grass and moss material dominate the macrofossils and woody fragments reaching $>10 \mathrm{~cm}$ diameter are also present. Abundant $N$. menziesii leaves, indicative of beech forest, are found in the lower riser section, and decreasing in abundance up the section. The beetle taxa are also indicative of a beech forest habitat with the assemblage representative of forest and forest floor habitats.

Section 2 contains the KOT layer which has an age of $25.4 \mathrm{ka}$. The macrofossil assemblage is dominated by grass material. Two $N$. menziesii and some podocarpus leaves, potentially $P$. hallii, are found below the tephra layer. The beetle assemblage is dominated by moss-habitat taxa with some forest and shrub species represented.

The youngest section is aged 20.5-18.9 ka spanning the LGM period (Alloway et al, 2007). The beetle assemblage represents a diverse habitat and includes forest, shrub, riparian and marshland taxa. The riser base is dominated by grass, marsh and moss taxa and one beetle which live in N. menziesii leaf litter habitats. Midway up the riser beetle taxa are indicative of stream environments above the treeline. These samples also contain Pimelea and Podocarpus seeds and mountain totara leaves and indicate the site was either at or just above the treeline. The upper part 
of the section contains a reduced beetle abundance and decline in diversity. The majority of the insects relate to marshland environments. Throughout the whole section Chenopodiaceae seeds indicative of marshland environments are present along with diving beetles which inhabit slow moving water or stagnant ponds.

Grass is the dominant plant macrofossil, indicating grass dominated the vegetation at the site. Fossil beetle evidence and leaves from N. menziesii suggest forest was present at the site from late MIS 3 to early stages of LGCP. No forest leaves were present in the younger sediment. The record shows the forest composition to change over time from Nothofagus, in the older samples, to Nothofagus/Podocarpus, commonly a sub-alpine shrub component at the altitudinal tree limit (Wardle, 1980), and is indicative of progressively cooling temperatures.

\subsection{Stratigraphy}

\subsubsection{Section 3 (Figure 6.5)}

Unit 1 (core: 262-193 cm): The core base is dominated by an unsorted coarse grey silty sand containing gravels reaching $5 \mathrm{~cm}$ diameter. A $6.5 \mathrm{~cm}$-thick organicrich sandy silt, containing wood pieces (aged $37.7 \mathrm{ka}$ ), lies between the base gravel section and another coarse sandy gravel section. There is a sharp transition between the underlying organic-rich deposits and an overtopping silty sand and coarse gravel layer with the gravels reaching up to $2 \mathrm{~cm}$ diameter. The top $6 \mathrm{~cm}$ returns to a dark brown organic-rich silt layer, which overlaps the base of the river terrace riser section.

Unit 2 (199-150 cm): Two dark brown organic-rich silt layers, located at the top and base of this unit, are interrupted by a $20 \mathrm{~cm}$-thick coarse gravel and sand layer. Both organic sections contain plant macrofossils, and the top section contains a piece of wood c. $6 \mathrm{~cm}$ long. This piece of wood produced two ages both dating c. $35.7 \mathrm{ka}$. The bottom organic layer produced an age of $34.4 \mathrm{ka}$. 
Unit $3(150-42 \mathrm{~cm})$ : This unit consists of grey silt containing gravels $<1 \mathrm{~cm}$. A single rounded cobble located in the centre of the unit measures $<15 \mathrm{~cm}$ diameter. The material becomes finer towards the top of the unit which has a sharp basal contact with the overlying organic unit.

Unit $4(42-37 \mathrm{~cm})$ : This unit is a $5 \mathrm{~cm}$-thick dark brown, organic-rich, silt which contains visual plant macrofossils, but no evidence of wood. This section was dated by Marra and Thackray (2010) and aged $28.5 \mathrm{ka}$.

Unit $5(37-0 \mathrm{~cm})$ : Section 3 appears to have slumped by c. $1 \mathrm{~m}$. Modern tree roots have disturbed the upper unit and destroyed some stratigraphic detail. The exposed part of this unit is $37 \mathrm{~cm}$-thick and consists of grey silts containing gravels and large cobbles reaching $<15 \mathrm{~cm}$. 


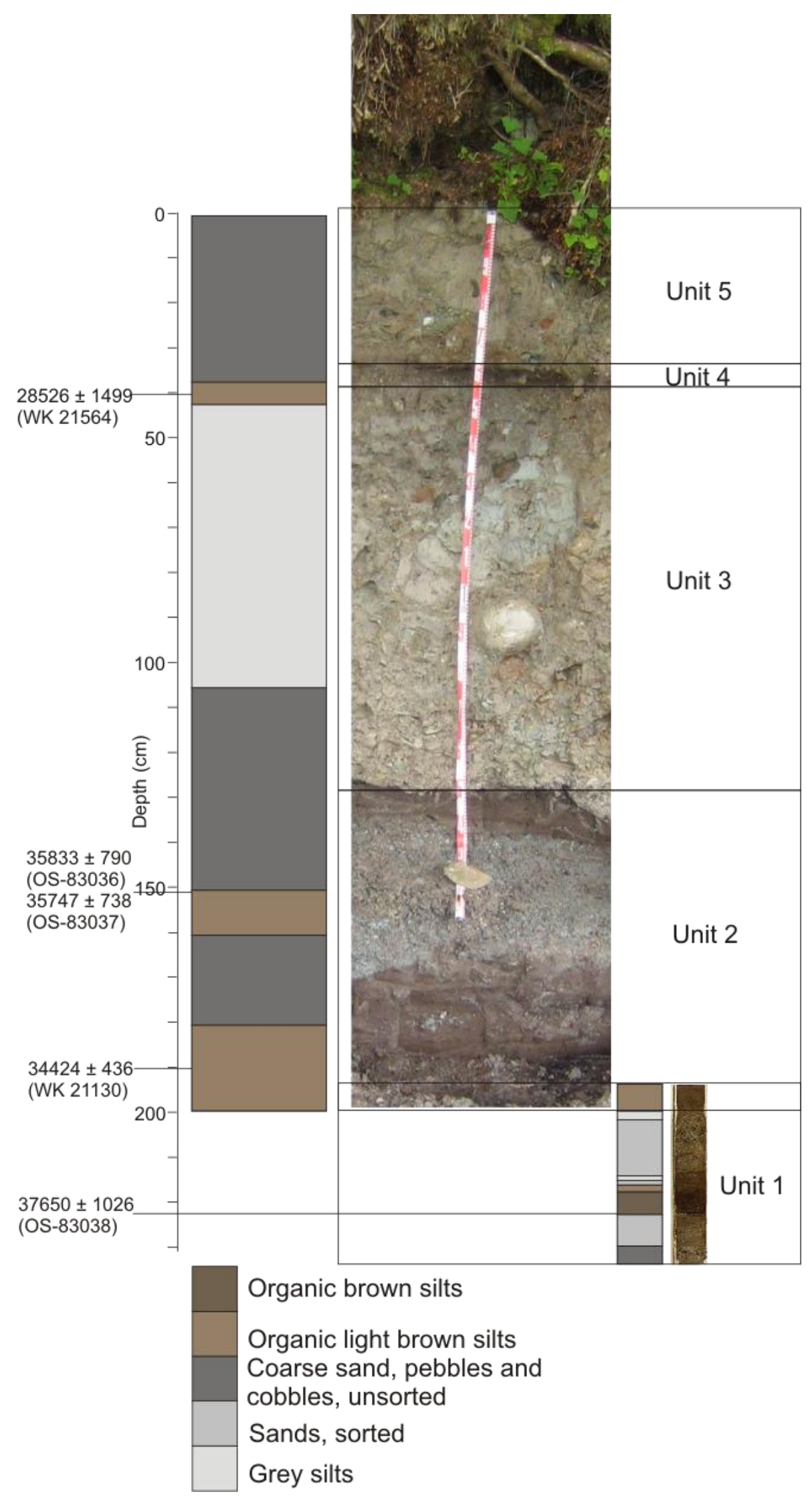

Figure 6.5: Detailed stratigraphy and photographic image of section 3. The units are described in the text. Calibrated ${ }^{14} \mathrm{C}$ ages are located next to the depth scale. The stratigraphy and image of this section does not match due to a step cut into the stratigraphy, marked by the stone, which distorts the true depth of the sequence 


\subsubsection{Section 2}

Section 2 forms part of the major terrace system in the main Howard Valley. A similar section has previously been described in Challis et al (1994). Marra and Thackeray (2010) have also described the same section, however their work was restricted to the base of the terrace riser which contains the KOT layer spanning only $160 \mathrm{~cm}$. The description below covers the whole exposed terrace riser and a core which was taken at the base of the riser (see Figure 6.6). This section will be described in four subsections. Refer to Figure (6.6) for each described section location in relation to each other and for a more detailed description.

\subsubsection{Subsection 2D - Core 1- 534-465 cm}

The core was taken directly from the base of the terrace riser, with the assumption that the top of the core lies directly at the base of the riser. During coring, the corer hit a solid, impermeable layer consisting of fluvial boulders which may indicate we had reached the base of the valley fill and the surface of the palaeo-channel.

Unit 1(534-465 cm): The core consists of brown, organic-rich silts from 534-478 $\mathrm{cm}$, interrupted by a $25 \mathrm{~cm}$-thick coarse grey sand layer containing pebble layers. Some pebbles reached $>2 \mathrm{~cm}$ diameter. A sharp, and potentially erosional contact occurs at the top of the first organic layer and the base of the interrupting coarse layer. The organic-rich silts stop at $478 \mathrm{~cm}$ and the top of the core consists of grey banded silts with a few pebble layers. This is consistent with the stratigraphy of the riser base.

\subsubsection{Subsection 2C: $465-325 \mathrm{~cm}$}

Unit $2(465-441 \mathrm{~cm})$ : This unit covers the bottom $24 \mathrm{~cm}$ of theriser. Alternating $\mathrm{mm}-\mathrm{cm}$ wide sand and gravel layers occur up through the stratigraphy. There is no organic material present in this unit.

Unit 3 (441-329 cm): This unit consist of alternating brown and grey silts which are interrupted by fine sands and a pebble layer between 399-391 cm. Plant macrofossils are evident in the organic brown sections but become notably less visible up section. The organic band at $373 \mathrm{~cm}$ is interrupted by a $10 \mathrm{~cm}$-thick fine, well sorted yellowy/brown silty sand. This has been ascribed as the KOT layer 
(KOT; Campbell, 1986; Challis et al, 1994; geochemical analysis in appendix g). The tephra layer is bordered above and below by organic-rich brown silts. Vegetative material directly below the tephra layer appears to have been flattened by the weight of the depositing tephra on top of the plants. Above the tephra is a continuation of alternating brown to grey silts with sediment becoming coarser towards the top of the section and the organic content reducing.

Unit $4(329-325 \mathrm{~cm})$ : The top $4 \mathrm{~cm}$ of this riser section is an unsorted pebbly silt layer which is assumed to be part of a slump.

\subsubsection{Subsection $2 B: 359-162 \mathrm{~cm}$.}

Unit 5: This coarse unit makes up the whole of section $B$. The base contains the top of the tephra layer, providing a stratigraphic overlap with Unit 3 of subsection 2C. Grey silts dominate the section above the tephra and become coarser upwards. At $317 \mathrm{~cm}$ the silt layer grades into a sand dominated zone, which also becomes coarser upwards. This is overtopped by a coarse sandy unit containing gravels and large boulders. The material is unsorted but becomes finer towards the top. The unit is capped by a $3 \mathrm{~cm}$-thick iron-stained sandy silt providing a stratigraphic link between subsections $2 \mathrm{~B}$ and $2 \mathrm{~A}$.

\subsubsection{Subsection $2 A$ - top section of terrace riser 2: $162-0 \mathrm{~cm}$}

Unit $6(162-113 \mathrm{~cm})$ : The base of subsection A lies on the contact of an underlying iron stained sandy silt and very likely to be equivalent to the top of subsection $B$. Unit 6 is dominated by dark brown sandy silts, containing fine banding. The unit is organic-rich and contains visible plant macrofossils. The contact between the organic-rich silts and the underlying iron-stained silty sand is separated by a $2 \mathrm{~cm}$ gleyed grey silt layer.

Unit $7(113-25 \mathrm{~cm})$ : This is an inorganic unit spanning $113-25 \mathrm{~cm}$ of subsection $2 \mathrm{~A}$. The base of unit seven is dominated by grey silts, containing 1-2 cm-thick sand bands. The sediment matrix becomes coarser upward with sands dominating at $93 \mathrm{~cm}$. This sand layer is well sorted and contains alternating coarse to fine bands. Further coarsening follows, with the top $49 \mathrm{~cm}$ of unit 2 composed of poorly sorted gravels, sands and large boulders. 
Unit $8(25-0 \mathrm{~cm})$ : This unit covers the top $25 \mathrm{~cm}$ of the section. Alternating $\mathrm{mm}$ tocm-thick silt and sand layers occur throughout. However, the base of the unit is dominated by grey silty sands fining to sandy silts towards the top of the unit. Contained throughout this unit are $\mathrm{cm}$-thick dark brown organic-rich silts containing visible plant macrofossils. The top of this section is capped by a section of large fluvial boulders and was not included in the description. 


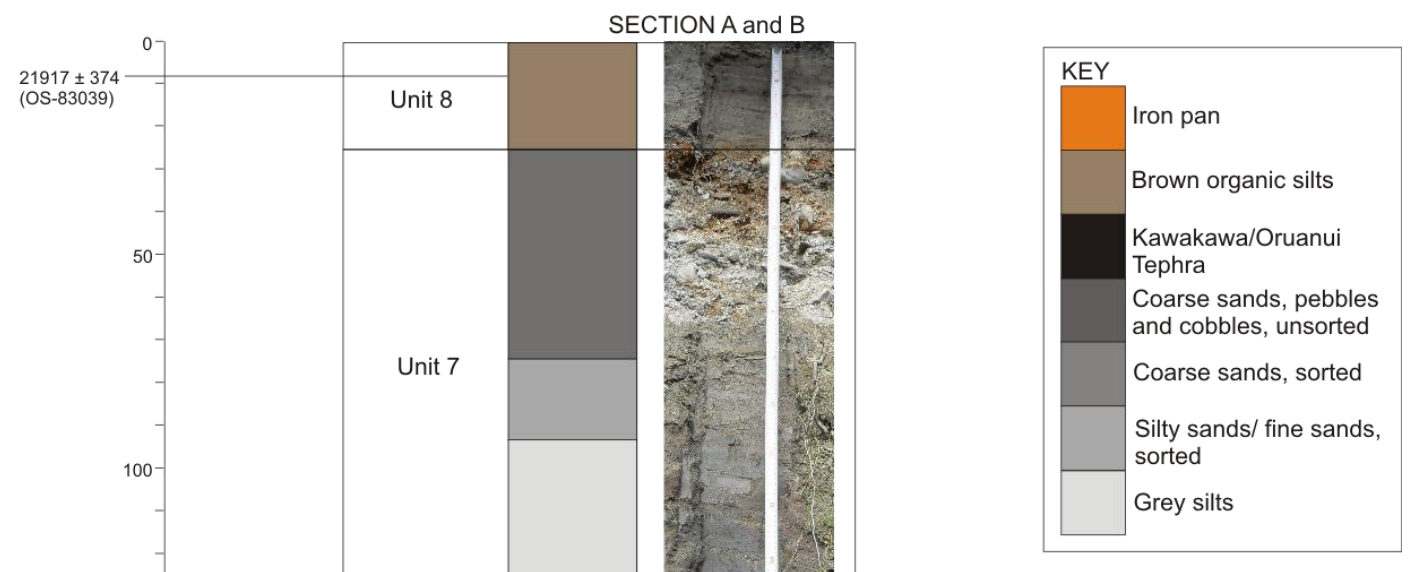
$26243 \pm 397$
(OS-83040)

Figure 6.6: Detailed stratigraphy and photographic image of section 2. The units are described in the text. Calibrated ${ }^{14} \mathrm{C}$ ages are located next to the depth scale. 


\subsubsection{Section 1}

Terrace 1 is the youngest terrace located on the south-eastern bank of the unnamed stream (Figures 6.2 and 6.7). The analysed section spans $2.80 \mathrm{~m}$ and is capped by a c. $1 \mathrm{~m}$ thick unsorted fluvially derived large boulder layer, containing sands and silts. This section has been previously described by Marra and Thackeray (2010).

Unit $1(325-215 \mathrm{~cm})$ : Unit 1 comprises the bottom $110 \mathrm{~cm}$. This unit consist of a 60 $\mathrm{cm}$-thick yellowy brown sandy silt section at the base interbedded with a $5 \mathrm{~cm}$ thick brown organic-rich organic-richsilt. This grades into a $50 \mathrm{~cm}$ coarser grey silty sand section, also interbedded with a $11 \mathrm{~cm}$-thick brown organic-rich layer. The bottom organic layer is dated at 20.7-20.3 ka.

Unit 2 (215-195 cm): Unit 2 consists of a $20 \mathrm{~cm}$-thick matrix of coarse sand and fine gravels up to $5 \mathrm{~cm}$ diameter.

Unit 3 (195-105 cm): Unit 3 consists of laminated sand and silts becoming coarser towards the top of the unit. The sands and silts are interbedded by $1-3 \mathrm{~cm}$-thick brown organic-rich silt layers

Unit $4(105-80 \mathrm{~cm})$ : Unit 4 consist of a $25 \mathrm{~cm}$-thick coarse gravel and sand layer containing rounded cobbles reaching $<12 \mathrm{~cm}$ diameter.

Unit $5(80-0 \mathrm{~cm})$ : The top $80 \mathrm{~cm}$ consist of grey silts interbedded with $\mathrm{cm}$-thick brown organic-rich silt layers. The bottom $10 \mathrm{~cm}$ consists of a continuous organic layer forming a sharp contact with the coarse gravels in unit 4. A large cobble layer caps unit 5 and forms an ersosional contact. At this point along the terrace the capping cobbles layer is c. $80 \mathrm{~cm}$-thick, however a little downstream this layer extends further into unit 5, being c. $150 \mathrm{~cm}$-thick. At this location it appears to gouge a channel-shaped incision (Figure 6.2). The top of Unit 5 is aged 19.3$18.5 \mathrm{ka}$. 

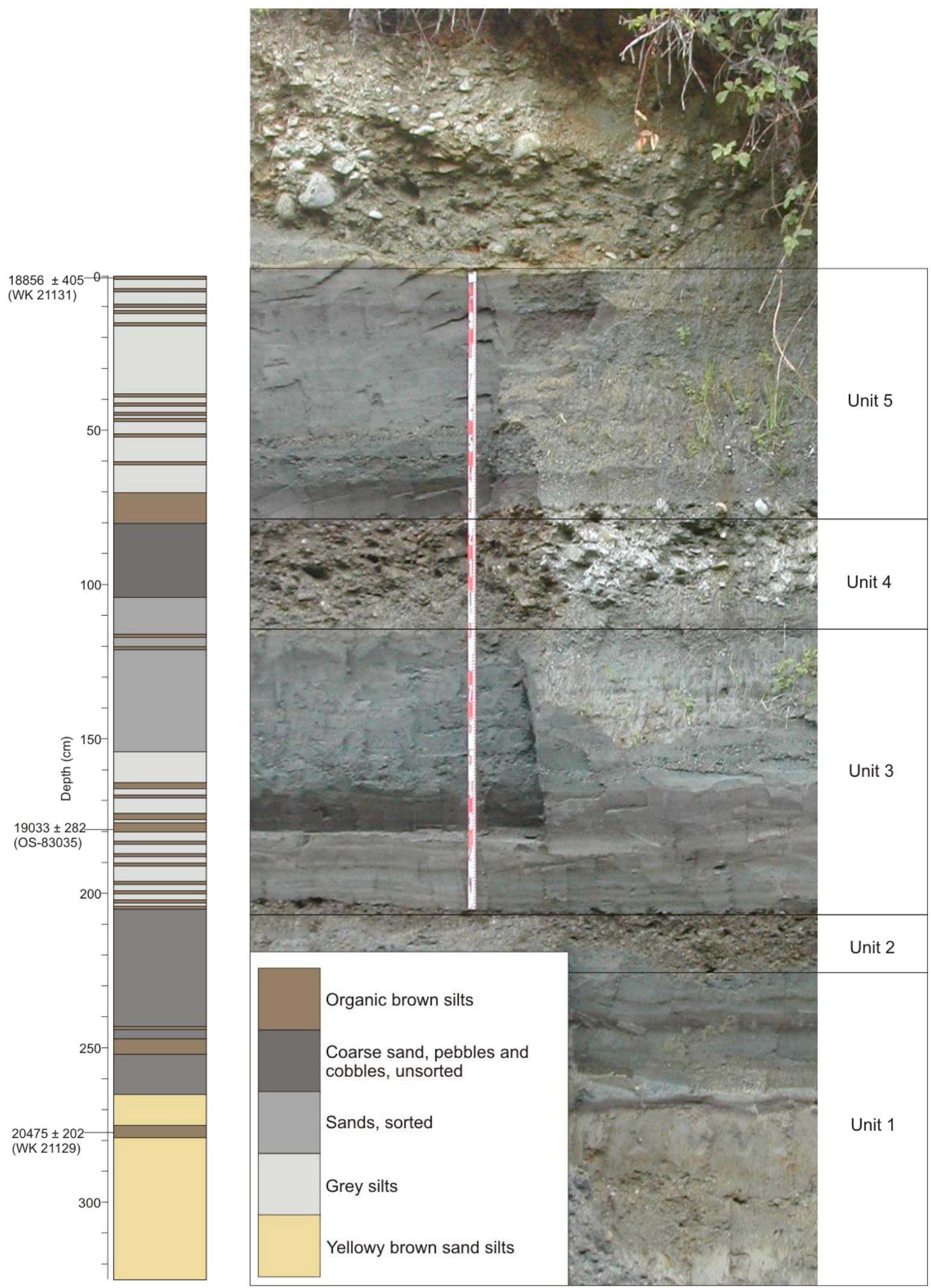

Figure 6.7: Detailed stratigraphy and photographic image of section 1. The units are described in the text. Calibrated ${ }^{i 4} \mathrm{C}$ ages are located next to the depth scale. 


\subsection{Chronology}

The chronology for the site was produced using bulk sediment and plant macrofossil samples. The pollen horizons sampled in this project are the same as that used by Marra and Thackray (2010). Therefore the ages reported in that paper can also be applied to the stratigraphy for this project. The terrace ages confirm the complex depositional and erosional environment of the site. As discussed earlier, the terraces are not topographically paired and apart from a few exceptions, units cannot be stratigraphically traced from one terrace riser to another. However, the records can be chronological related, with the site producing a record, albeit fragmentary, spanning 37.7-18.9 ka.

\begin{tabular}{|c|c|c|c|c|c|}
\hline Sample & Fraction & ${ }^{14} \mathrm{C}$ age $\mathrm{BP}$ & $\delta^{13} \mathrm{C} \%$ & $\begin{array}{l}\text { Reference } \\
\text { code }\end{array}$ & $\begin{array}{l}\text { Calibrated age } \\
\text { BP (2 sigma) }\end{array}$ \\
\hline HV1-179 & $>125 \mu \mathrm{m}$ & $15950 \pm 170$ & -28.6 & OS-83035 & $19033 \pm 282$ \\
\hline HV2-150 & Wood & $32800 \pm 1500$ & -24.8 & OS-83036 & $35833 \pm 790$ \\
\hline HV2-150 & Wood & $32500 \pm 1500$ & -26.27 & OS-83037 & $35747 \pm 738$ \\
\hline HV2-core1-28-29 & Wood & $34600 \pm 1900$ & -25.31 & OS-83038 & $37650 \pm 1026$ \\
\hline HV3-M3-8-9 & $>125 \mu \mathrm{m}$ & $18650 \pm 250$ & -23.67 & OS-83039 & $21917 \pm 374$ \\
\hline HV3-core1-68-69 & $125-63 \mu \mathrm{m}$ & $21900 \pm 380$ & -28.31 & OS-83040 & $26243 \pm 697$ \\
\hline *How 1-7 & Peat & $17586 \pm 133$ & -28.5 & WK-21131 & ${ }^{a} 18856 \pm 405$ \\
\hline *How 1-1 & Peat & $18902 \pm 106$ & -30.7 & WK-21129 & a $20475 \pm 202$ \\
\hline *How 3-3 & Peat & $24349 \pm 1393$ & -31.2 & WK-21564 & ${ }^{\mathrm{b}} 28526 \pm 1499$ \\
\hline${ }^{*}$ How 3-1 & Peat & $30004 \pm 433$ & -30.1 & WK-21130 & ${ }^{b} 34424 \pm 436$ \\
\hline${ }^{* *} \mathrm{H} 3 \mathrm{~B}-3-1$ & Plant/wood & $19050 \pm 270$ & -22.45 & OS-83041 & $22670 \pm 548$ \\
\hline **H3B-3-2 & Plant/wood & $21500 \pm 360$ & -22.44 & OS-83042 & $25237 \pm 420$ \\
\hline
\end{tabular}

Table 6.1: Radiocarbon age details for Howard Valley. The ages were calibrated using the online OXCal program. * Ages produced by Marra and Thackray (2010), calibrated using ${ }^{a}$ Calib Rev. 5.0.1. and ${ }^{b}$ converted to calendar years using GRIP calibration (Bard et al, 2004). ${ }^{* *}$ Unpublished ages by Vandergoes (pers comm). 
The oldest organic-rich layer in section 3 has an age of $37.7 \mathrm{ka}$ which is $19 \mathrm{ka}$ older than the base of section 1 but lies at a similar elevation. Both of these sections are adjacent to a small but active stream. It is therefore likely that section 1 represents a channel fill within the valley fill described in section 3 . Evidence from the cobble layer that caps the terrace risers also indicate that this process of infilling stream cuts has been ongoing in the area. Further evidence is shown by Challis et al (1994) who photographed the section containing the KOT layer. This image clearly shows the KOT bearing strata occupying a channel cut into a valley fill. The subsequent infilling of channel cuts into older sections can explain the complex chrono-stratigraphic pattern of the three terrace risers.

The KOT layer has contributed to the site chronology. Challis et al (1994) already identified the deposit as being the KOT. Recent geochemical analysis of both the major and minor elements of the deposit from this site confirms the original identification by Challis et al (1994) (see appendix g). As mentioned in the previous sections the age of the KOT used is currently estimated at $25.4 \mathrm{ka}$ (Vandergoes et al, 2011).

The stratigraphic description of the three terrace risers indicates that this was a dynamic setting during sediment deposition. The environment oscillated from a low energy terrestrial environment allowing the accumulation of organic-rich sediments to a high energy fluvial environment capable of carrying and depositing boulder size objects. The erosional contacts, evident in the stratigraphies, indicate a loss in stratigraphic record and thus a discontinuous record. The periods of organic accumulation, therefore represent periods where the site hydrology and geomorphology was such that back ponding could occur, producing the low energy environment needed for organic accumulation. The multiple episodes of aggradation and incision where driven by base level changes probably caused by bedrock constriction and episodic damming in either the Buller River Valley, Howard River valley, or a combination of both. The rate of sedimentation however cannot be assessed with certainty as the amount of deposit which has been lost through erosion is unknown and therefore a continuous age-depth model for each terrace riser cannot be produced. Figure 6.8-6.10 show the chronology in stratigraphic order for each terrace riser and will be discussed below 


\subsubsection{Section 3}

The chronology in section 3 is based upon five ages which date the terrace riser and the core. Marra and Thackray (2010) produced two ages (WK-21130 and WK21564) using bulk peat samples dating the top and bottom of the riser. A further three ages, sampled from wood and bark, date the top organic band in unit 2 (refer to Section 6.3) and the core. The chronology is discussed below.

The samples OS-83039, OS-83038 and OS-83037 and WK-21564 all lie in stratigraphic order. The samples OS-83038 and OS-83037 used wood and bark encasing the wood to date the same horizon and both samples provided a similar calibrated age of c. $35.7 \mathrm{ka}$ at $150 \mathrm{~cm}$ down the riser. However, there is an age inversion at $180 \mathrm{~cm}$ where sample WK-21565 produces an age 1300 yrs younger than the ages above. Bulk sediment was used to produce the age for WK21565 which is of greater risk of contamination than isolating a single macrofossil from the sediment. The wood and bark, used to date the $150 \mathrm{~cm}$ horizon, were both carefully cleaned and inspected under a microscope to remove any organic or inorganic material which was not part of the wood and thus reducing the potential contamination. The age cannot be ruled out entirely but the probability that the 180 $\mathrm{cm}$ organic horizon could be deposited 1400 years after the overtopping organic horizon is unlikely. It was therefore decided to exclude WK-21130 from the record and thus to apply age-depth model 2 to this section (Figure 6.8).

WK-21130 dates the top organic layer of the terrace riser. This age is considerably younger compared to the underlying organic horizon and suggests only $100 \mathrm{~cm}$ of sediment accumulated over 6000 years. This appears to be quite a low sediment accumulation rate, especially when comparisons are made to the youngest terrace, located on the opposite bank which accumulated $270 \mathrm{~cm}$ over only 1000 years. This could suggest contamination to the sample occurred resulting in a younger age. However, the younger age may also represent cut and fill of the terrace, whereby the older material was eroded away followed by aggradation of younger material. This would explain the large age difference over $100 \mathrm{~cm}$ of deposit. Evidence of stream cut erosion followed by aggradation is visible throughout the other terrace risers and is the likely cause of the large age difference. 


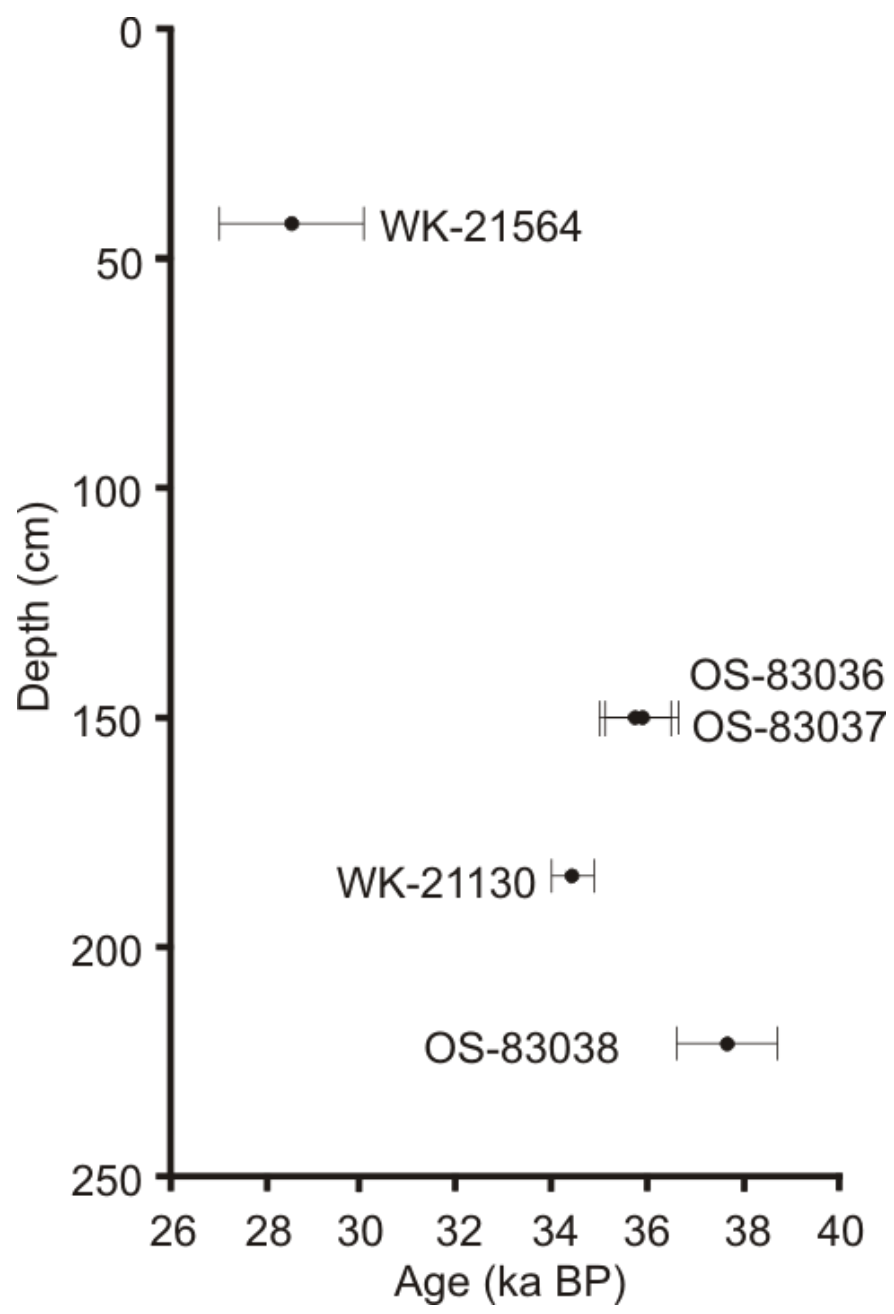

Figure 6.8: Age model for section 3, including the error bars for each AMS age. The model use two AMS ages produced by Marra and Thackray (2010).

\subsubsection{Section 2}

The chronology for section 2 is based upon four AMS ages taken from the riser and the core and one tephra marker. The AMS ages are derived from either bulk sediment samples or plant macrofossils (see table 6.1).The AMS dates however do not all lie in stratigraphic order and the two ages from the same sediment horizon directly underlying the KOT layer, are different. OS-83041 is younger than the established KOT age (Vandergoes et al, 2011) whilst OS-83042 provides a very similar age to the KOT. Two age model is discussed further below(Figure $6.9)$.

Sample OS- 83041 is 3000 years younger than OS- 83042 which dates the same horizon and the established KOT, which immediately overlies the sample. A 
discussion on the age of the KOT has been presented in Section 3.5.2. Sample OS83041 appears to be considerably younger than the KOT established age, suggesting that the sample may have been contaminated by younger carbon. This age has been excluded from the record.

The second AMS sample, OS-83042, is within error range of KOT (Vandergoes et al, 2011). The age is also similar to those from other sites around New Zealand which date the tephra deposit (refer to Section 3.5.2). For these reasons it was decided to apply the calibrated OS-83042 age of 25.4 ka to the age model of this section.

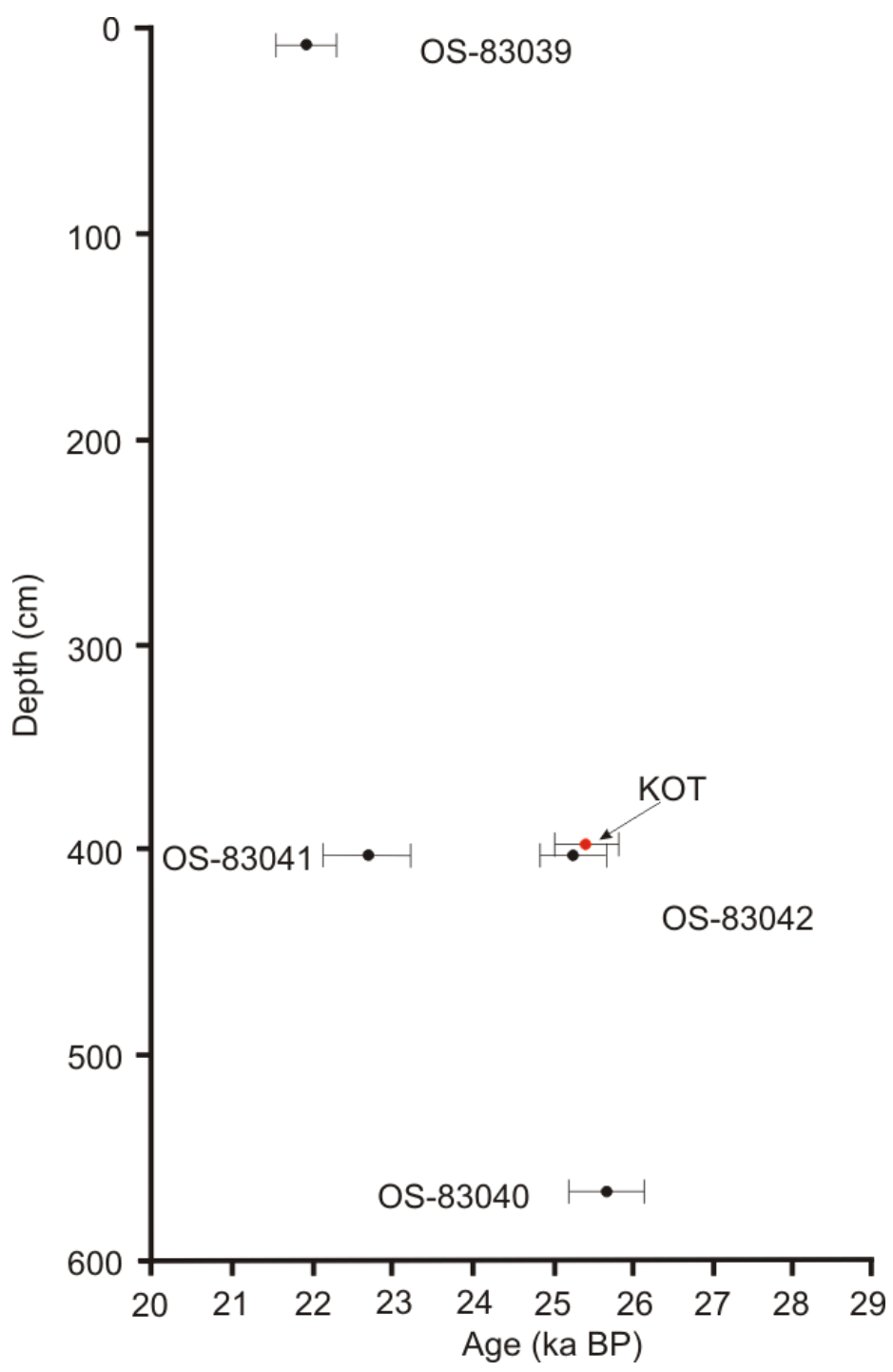

Figure 6.9: Age models for section 2, using calibrated ages and including the error bars for each age. The KOT age is also included on the diagram. 


\subsubsection{Section 1}

The radiocarbon chronology of terrace 1 is derived from two bulk sediment samples produced by Marra and Thackray (2010) and one bulk sample of the 10$60 \mu \mathrm{m}$ fraction (Figure 6.10). This shows that the period of valley/channel between 18.9-20.5 ka suggesting $279 \mathrm{~cm}$ of material was deposited over 1.5-2.0 ka. All three ages lie in stratigraphic order, however the upper two age errors overlap and therefore both samples produce similar ages and may be representative of rapid deposition at the site.

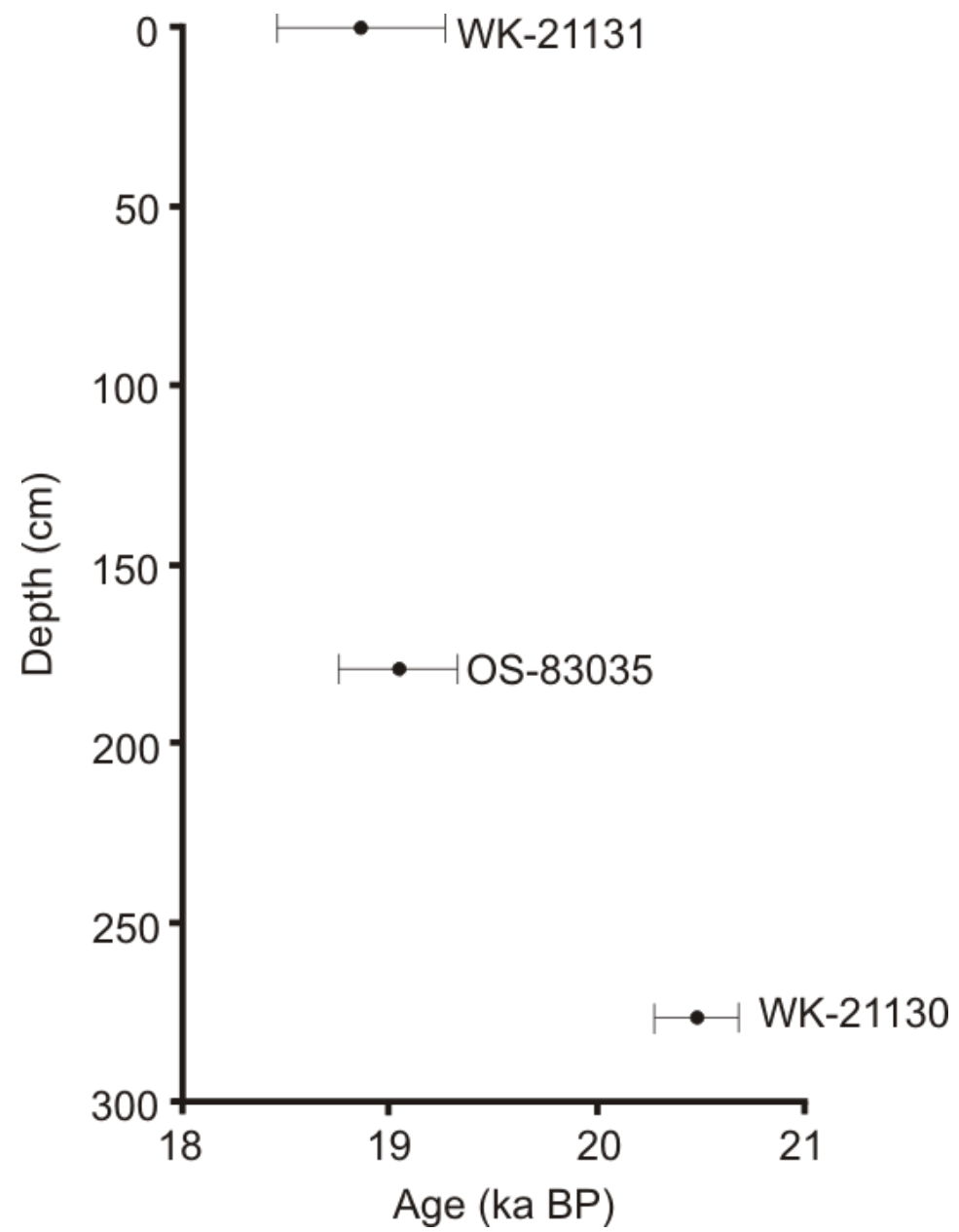

Figure 6.10: Age model for section 1, using calibrated ages and including the error bars for each age 


\subsection{Results}

The results are split into two sections. Firstly the pollen analysis is described (Figure 6.11-6.13) followed by the results of the temperature reconstructions for each section which are also presented in Figure 6.11-6.13. These figures include only the main pollen types, see appendix $\mathrm{E}$ for the whole pollen data set.

\subsubsection{Pollen analysis}

The pollen diagram for Howard Valley is shown in three figures (Figure 6.11-6.13). Each riser stratigraphy and chronology is summarised alongside the diagram. The sampling strategy used in Howard Valley was adjusted due to the nature of sediment deposition at the site. Firstly comparison with the beetle results of Marra and Thackray (2010) dictated the location of sampling. However, a good representation from the organic units identified in each sequence was needed. Therefore samples from each organic unit identified in the stratigraphy were analysed. The pollen results will be described in chronological sequence beginning with the oldest section.

\subsubsection{Section 3: Terrace riser 3 and core (37.7- 28.5 ka) (Figure 6.11)}

Section 3 consists of 12 pollen samples, four from the core and another eight from the exposed riser section. The top two assemblages of the core overlap the base of the riser and provide an opportunity to link the two sections together. The base of the core is dominated by the shrub component, with the small tree Phyllocladus at $38 \%$. The shrubs Asteraceae and Coprosma, and tall tree taxa Fuscospora and Halocarpus are present at $10 \%$ with minor abundance of Nothofagus menziesii. Poaceae $<40 \mu \mathrm{m}$ has the second highest abundance of $19 \%$.

The abundance of Poaceae $<40 \mu \mathrm{m}$ consistently increases up core peaking at $38 \%$ at the top. Conversely, Phyllocladus consistency decreases from $38 \%$ at the core base to $14 \%$ at the core top. Fuscospora follows a similar pattern as Poaceae $<40$ $\mu \mathrm{m}$, although on a smaller scale, reaching a maximum abundance of $15 \%$ at the top of the core. N. menziesii abundance increases minutely to 2-3\%. The wetland taxon Cyperaceae has consistent high abundance throughout the core, ranging $39-29 \%$. 
Three organic units were analysed in the riser spanning $199-180 \mathrm{~cm}, 159-150 \mathrm{~cm}$ and $42-37 \mathrm{~cm}$ (the youngest sub-section). The unit 199-180 is dominated by herb species, particularly Poaceae $<40 \mu \mathrm{m}$ which increases up the unit from $30 \%-49 \%$. Apiaceae and Poaceae $>40 \mu \mathrm{m}$ are present in significant abundance of c. $10 \%$ each. This unit contains a significant amount of shrub species, particularly Phyllocladus which reaches a maximum abundance of $21 \%$. To a lesser extent Asteraceae is present with a percentage of only $3 \%-6 \%$. A limited tree flora presence is in the record with Fuscospora spanning $8 \%-12 \%$ and Halocarpus only reaching $2 \%$. The wetland taxon, Cyperaceae, reaches its highest abundance in this unit, increasing from $16 \%$ to $21 \%$ by the top of this unit.

Poaceae $<40 \mu \mathrm{m}$ continues to dominate the pollen assemblage between $160-150$ $\mathrm{cm}$, ranging $47 \%-57 \%$ and Poaceae $>40 \mu \mathrm{m}$ also increases to $12 \%$. The total shrub component decreases with Phyllocladus ranging between $7 \%-17 \%$. Asteraceae, Fuscospora and Cyperaceae remain at similar percentages as the previous organic unit. Poaceae $<40 \mu \mathrm{m}$ reaches its maximum abundance $(67 \%)$ at the $43 \mathrm{~cm}$ but subsequently declines to only $33 \%$ at the top of this unit $(37 \mathrm{~cm})$. Apiaceae increases from $5 \%$ to $21 \%$ and Phyllocladus from $9 \%$ to $20 \%$. A small increase in the tree taxa Fuscospora and Halocarpus coincides with the increase in the shrub component. Cyperaceae remains at a similar abundance to the previous zone. 


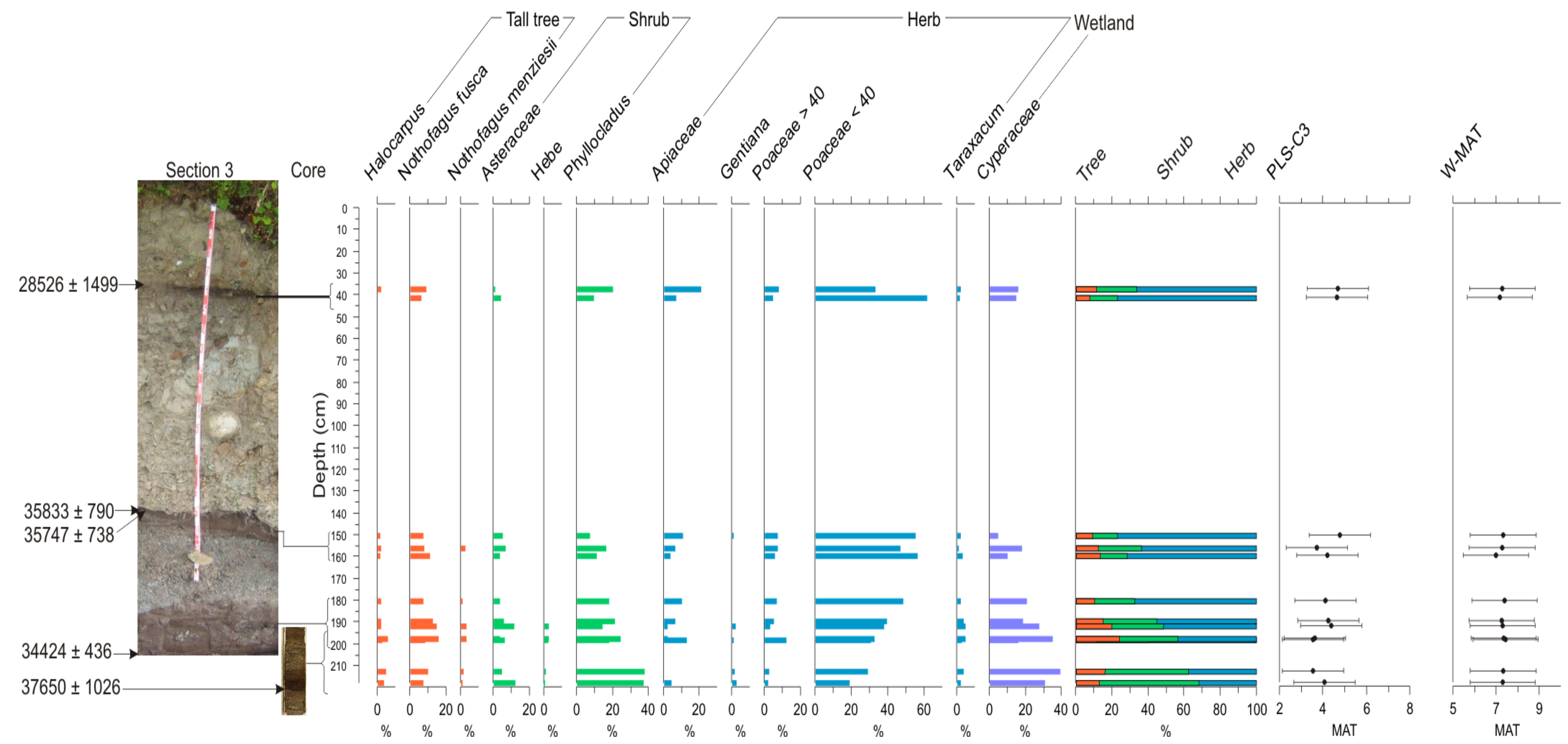

Figure 6.11: Howard valley section 3 pollen percentage diagram, including core stratigraphy, summary diagram, and pollen-climate reconstructions. Radiocarbon dates are summarised in Table 6.1 . 


\subsubsection{Section 2: Terrace riser 2 and core (26.2-21.9 ka) (Figure 6.12)}

Section 2 comprises one large river terrace riser spanning nearly $5 \mathrm{~m}$ and a core $69 \mathrm{~cm}$ long. However, only the organic layers were analysed, producing 13 samples covering the whole section. Although a large amount of sediment accumulation between the organic sections occurred, the vegetation composition remained similar throughout the section and therefore the number of samples appears to be sufficiently representative.

The two core samples are dominated by Poaceae $<40 \mu \mathrm{m}$ with an abundance of $51 \%$ and $47 \%$. The herb taxon Taraxacum has a $12 \%$ abundance and Apiaceae $7 \%$. Taraxacum decreases to trace amount at the top of the core. The shrub component is dominated by Asteraceae (4\%) and Phyllocladus which decreases from $17 \%$ to $2 \%$. Fuscospora remains between $11 \%-16 \%$. A large increase in the wetland taxon Cyperaceae occurs up the core (from 10\% to $24 \%$ ).

The base of the riser, section 2c, is again dominated by Poaceae $<40 \mu \mathrm{m}$, spanning $48 \%-45 \%$ between $430-390 \mathrm{~cm}$. Apiaceae remains at a similar abundance as in the core. Likewise Fuscospora, Asteraceae, Phyllocladus and Cyperaceae have similar percentage as the last sample in the core. At 381 and $371 \mathrm{~cm}$, Poaceae $<40 \mu \mathrm{m}$ decreases dramatically to only $27 \%$ and $22 \%$, respectively. Apiaceae becomes the dominant taxon reaching $34 \%$ and $29 \%$, respectively. Fuscospora, Phyllocladus and Cyperaceae decrease in abundance. Conversely, Asteraceae increases to a maximum 18\%. The top three samples of riser section $2 \mathrm{c}$ shows a gradual increase in Poaceae from $36 \%$ to $46 \%$ at the expense of Apiaceae, which declines from 23\% to $8 \%$. As the depth decreases the abundance of Phyllocladus and Fuscospora increases and to a lesser extent so does Hebe and Taraxacum. Conversely the proportion of Asteraceae decreases up the sequence. Cyperaceae reaches a peak abundance of $55 \%$ at $358 \mathrm{~cm}$ but subsequently decreases to $32 \%$ at the top of this section.

The top of the riser, section $2 a$, consists of three samples taken from two organic zones. The section is dominated by Poaceae < $40 \mu \mathrm{m}$ ranging 42-52\%. Apiaceae shows a continued decrease from $15 \%$ to $6 \%$. Asteraceae, Phyllocladus and Fuscospora all show a similar pattern whereby the percentage increases from c. 
$7 \%$ or below, at the base of section $2 \mathrm{a}$, to $10 \%$ in the middle sample before reducing to a similar abundance as in the first sample, at the top of the section. Cyperaceae shows a continued increase up the section from 33 to $57 \%$. 


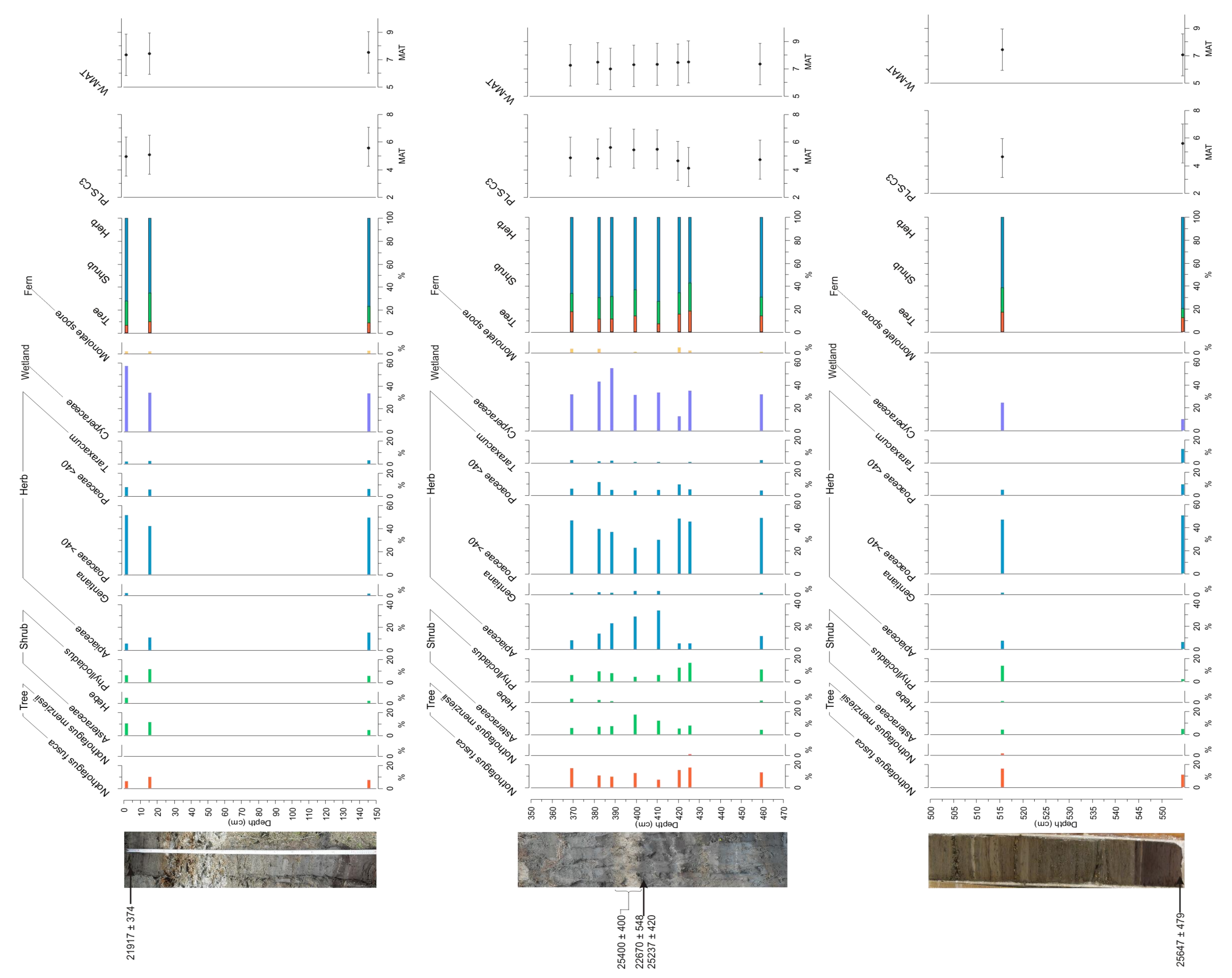

Figure 6.12: Howard Valley section 2 pollen percentage diagram, including core stratigraphy, summary diagram and pollen-climate reconstructions. Radiocarbon dates are summarised in Table 6.1. 


\subsubsection{Section 1: Terrace riser 1 (20.5-18.9 ka) (Figure 6.13)}

Section 1 is the youngest terrace and contains eight organic zones, each of which were sampled and analysed. Throughout the section Poaceae $<40 \mu \mathrm{m}$, Asteraceae and Poaceae $>40 \mu \mathrm{m}$ are the three dominant taxa and are consistently present throughout. Poaceae is the dominant taxon at the base of the sequence with $47 \%$ reducing to $30 \%$ at $250 \mathrm{~cm}$. Conversely Asteraceae has a small abundance of only $6 \%$ at the riser base but increases to $31 \%$, becoming codominant at $250 \mathrm{~cm}$. Apiaceae has a percentage range of $14-26 \%$ at the riser base and Cyperaceae increases from $43 \%$ to a maximum $83 \%$ at $255 \mathrm{~cm}$ and then reduces to $65 \%$ at $250 \mathrm{~cm}$.

From $244-74 \mathrm{~cm}$ Poaceae $<40 \mu \mathrm{m}$ is the dominant taxon ranging $40-62 \%$. Overall, Apiaceae abundance increase, but ranges between $10-30 \%$, whereas Asteraceae decreases in overall abundance to $5-15 \%$ with the majority of samples contain less than 9\%. Phyllocladus remains between $4-7 \%$ and Fuscospora oscillates between $1-8 \%$. Cyperaceae abundance is highly variable in this section ranging $21-65 \%$.

From $70-0 \mathrm{~cm}$ the pollen assemblage becomes increasingly variable with large changes in taxa percentages occurring throughout this section. Poaceae varies between 20\%-51\%, Asteraceae 6\%-33\% and Apiaceae 17\%-47\%. The other land pollen, such as Fuscospora and Phyllocladus, remain at a consistent, but low abundance in this uppermost section. Cyperaceae shows a similar erratic pattern as Poaceae, ranging $24 \%-61 \%$. 


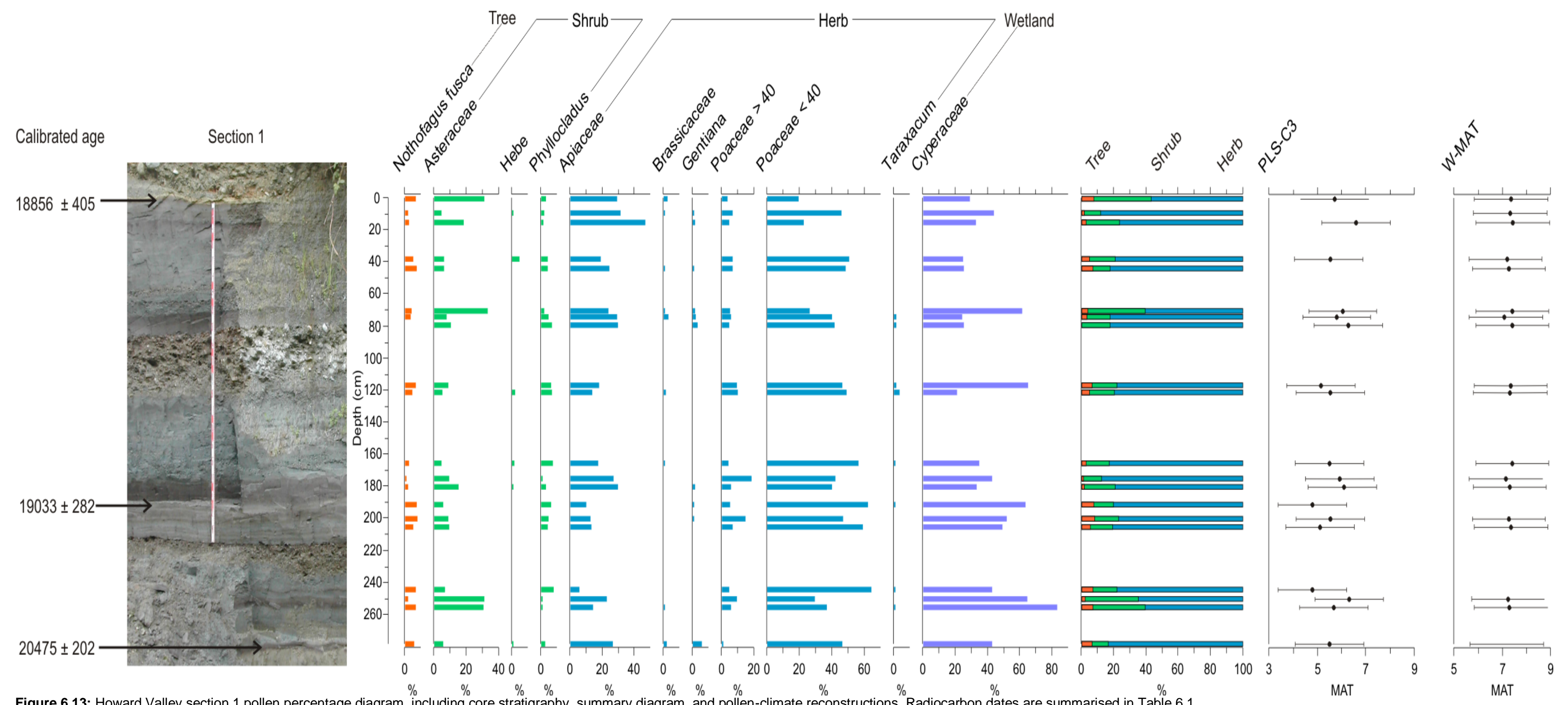




\subsubsection{Temperature reconstructions}

The pollen diagrams (figures 6.11-6.13) also present the modelled MAT reconstructions produced by PLS-C3 and W-MAT (refer to section 3.2.7). W-MAT reconstructs warmer MAT (between $1-2{ }^{\circ} \mathrm{C}$ ) than PLS-C3 for all three sections. In Section 3 (fig 6.11) the PLS-C3 model predicts a MAT ranging $3.5-4.8^{\circ} \mathrm{C}$. Initially MAT values oscillate between $3.5-4{ }^{\circ} \mathrm{C}$ and then increase to $4.7{ }^{\circ} \mathrm{C}$ at $150 \mathrm{~cm}$. MAT values remains steady around $4.7{ }^{\circ} \mathrm{C}$ for the remainder of the section analysed. W-MAT reconstructs a considerably smaller MAT range, between 7-7.4 ${ }^{\circ} \mathrm{C}$, showing little change in temperature throughout the section. Section 2 (fig 6.12) shows a limited MAT range for both models. The PLS-C3 model initial predicts a decline in MAT from $5.6{ }^{\circ} \mathrm{C}$ to $4.6{ }^{\circ} \mathrm{C}$ by $430 \mathrm{~cm}$, returning to $5.6{ }^{\circ} \mathrm{C}$ at $388 \mathrm{~cm}$. A second decline in MAT reaches $4.8^{\circ} \mathrm{C}$ at $382 \mathrm{~cm}$ which is followed by a steady increase in MAT reaching a maximum of $5.7^{\circ} \mathrm{C}$ at $145 \mathrm{~cm}$. Temperatures decrease at the top of this section reducing to $5{ }^{\circ} \mathrm{C}$ in the uppermost sample. Like the previous section, W-MAT predicts a small temperature range between 7.1-7.4 ${ }^{\circ} \mathrm{C}$ throughout the section.

For section 1 (fig 6.12), the PLS-C3 model gives an initial increase in MAT from $5.5^{\circ} \mathrm{C}$ at $279 \mathrm{~cm}$ to $6.3^{\circ} \mathrm{C}$ at $151 \mathrm{~cm}$. Temperatures then reduce to a minimum 4.8 ${ }^{\circ} \mathrm{C}$. This is followed by an overall increasing temperature trend up section, reaching a peak of $6.6{ }^{\circ} \mathrm{C}$ at $15.5 \mathrm{~cm}$, decreasing slightly to $6.3^{\circ} \mathrm{C}$ at the top of this section. The W-MAT model reconstructs a small temperature range between 7.1$7.4{ }^{\circ} \mathrm{C}$ showing little change in temperature throughout the section. Overall, the pattern of MAT reconstructed by PLS-C3 suggests MATs were warmest during the period when the youngest terrace was formed and coldest at the time the oldest terrace was formed. In contrast the W-MAT indicates MAT remained at a near consistent temperature (between $7-7.4{ }^{\circ} \mathrm{C}$ ) throughout the period spanning 37.718.9 ka. 


\subsection{Discussion}

This section interprets the pollen record produced for Howard Valley. This will be separated into pre-LGCP and LGCP time periods, based upon the chronology discussed in Section 6.4 and the timing of the LGCP as ascribed by the NZ-I CES (Alloway et al, 2007). An inferred vegetation community followed by a climate reconstruction will be produced for each period. The timing and pattern of vegetation change and inferred climatic change will be put in context with palaeoenvironmental records from other New Zealand sites and elsewhere in the Southern Hemisphere.

\subsubsection{Pre-LGCP: Section 3 (37.7- $28.5 \mathrm{ka})$}

The base of the core is dominated by the shrub Phyllocladus combined with a large abundance of Poaceae and Cyperaceae and moderate abundance of Fuscospora pollen. There are three species of Phyllocladus in New Zealand, two lowland forms and one; P. alpinus, a montane/sub-alpine species (Wardle, 1969; McQueen, 1992) although it is also found in the lowland forest in the Westland region (Patel, 1968). The pollen assemblage in the core represents a montane/sub-alpine vegetation community and $P$. alpinus is prevalent in the region today. It is therefore assumed the Phyllocladus pollen in the samples represent $P$. alpinus. In the contemporary environment of the Nelson Lake National Park, $P$. alpinus shrub sparsely covers large areas above the treeline (Wardle, 1965) and the contemporary treeline is characterised by a sharp transition from Nothofagus solandri var cliffortiodes sub-alpine forest to Chionochloa grassland (Wardle, 1965). The combination of Fuscospora, Poaceae and Phyllocladus could lead to an assumption that the site was representative of a sub-alpine/alpine treeline environment. However, the small but significant abundance of $N$. menziesii would suggest otherwise.

N. menziesii is a montane beech species which in the Nelson Lake National Park is the dominant forest tree between 900-1100 m.a.s.I. The $N$. menziesii pollen abundance is low at the site, reaching only $1 \%$ at the core base and a maximum $3 \%$ at the top of the core. At first glance this could indicate that $N$. menziesii is not prevalent in the landscape. However, Moar (1970) studied the modern pollen rain 
at Top House and St Arnaud, both located in the Nelson Lakes National Park. The sites studied were located within a mixed Nothofagus forest but the pollen rain at both sites recorded only $3 \% N$. menziesii and suggests this species is severely underrepresented in the pollen rain due to its poor ability to disperse. Therefore the $1-3 \% N$. menziesii in the pollen record would probably be representative of a large $N$. menziesii population in the region and suggest the region was not representative of the sub-alpine/alpine treeline limit.

Wardle (1965; 1969; 1991) reports Phyllocladus alpinus growing in poorly drained, boggy areas or in wet hollows at elevations below 1000 m.a.s.I, in Nothofagus fusca and $N$. solandri forest. In these environments Coprosma parviflora and $P$. alpinus form a shrub layer whilst $C$. depressa, sedges and ferns cover the hollow floor (Wardle, 1965). The large abundance of Cyperaceae suggests the site is waterlogged and represents a wetland habitat. Combined with the $P$. alpinus and small abundance of Halocarpus, which can also grow in waterlogged environments (Wardle, 1977), indicates that at $37.7 \mathrm{ka}$ the area was characterised by mixed montane beech forest comprising $N$. menziesii and Fuscospora, with wetland habitats located near the rivers, which were dominated by $P$. alpinus shrub and sedges. A decreased sample depth in the core and riser corresponds with a decrease in $P$. alpinus and Cyperaceae abundance and an increase in Fuscospora, Poaceae and to a considerably lesser extent $N$. menziesii. This vegetation pattern probably represents a drying of the site causing a decline in sedges and other wetland vegetation whilst providing an increase habitat suitable for beech and grass which expanded into the site. Poaceae is the dominant vegetation type in the record between 37.7-34.4 ka.

Unit 4, the top organic layer in the riser, is void of $N$. menziesii and contains only a small abundance of Fuscospora. The shrub component is small but Phyllocladus remains the most abundant shrub taxon in a Poaceae dominant vegetation community. The Phyllocladus abundance is not combined with a large Cyperaceae abundance and suggests the area was not as waterlogged as the period spanning 37.7-34.4 ka. Rather, the pollen assemblages suggest a Phyllocladus shrub/grassland mosaic. As mentioned above, the contemporary timberline, east of the Southern Alps, is characterised by a sharp transition from Nothofagus 
solandri var. cliffortiodes-dominated sub-alpine forest to Chionochloa grassland. Patches of shrubland comprising Phyllocladus alpinus, Hebe, Coprosma, Dracophyllum uniflorum, $D$. pronum and Podocarpus nivalis grow at this transition point (Wardle, 1965). This community is consistent with the pollen assemblage at the top of the terrace riser and indicates the site is representative of a subalpine/alpine community at, or near to, the timberline. The pollen assemblage contains significant amounts of Apiaceae, alpine herb taxa and a comparatively increased amount of tussock grass pollen compared to the underlying organic units and again supports an alpine/sub-alpine/tree limit environment.

The pollen assemblage at the top of the riser also contains trace amounts of broadleaved/podocarp species, including Weinmannia racemosa, Dacrydium cupressinum and Prumnopitys. These taxa typically occur at lower altitudes than the beech forest in the region today and can be located in scattered groves within the beech forest up to 650 m.a.s.l. The trace amounts of these podocarp and broadleaved species and their limited distribution in the modern landscape suggests the nearest podocarp/broadleaved forest to the site would have been close to the present sea level (McLea, 1996) and the pollen grains were transported to the site as opposed to growing in the area.

\subsubsection{Pre-LGCP: Climate reconstruction}

The pollen assemblage at the base of the core is representative of a boggy wetland hollow surrounded by a mixed beech forest containing Fuscospora and $N$. menziesii. In the Nelson Lake National Park today $N$. menziesii is the dominant tree taxon between $900-1100$ m.a.s.l. As the site is located at c. 500 m.a.s.l today this implies between 37.7-34.4 ka $N$. menziesii was 400-600 $\mathrm{m}$ below its current preferred elevation. By using the environmental lapse rate (ELR) of $0.5^{\circ} \mathrm{C} / 100 \mathrm{~m}$, an estimated minimum $2{ }^{\circ} \mathrm{C}$ and maximum $3^{\circ} \mathrm{C}$ MAT depression occurred at the site, suggesting that although warmer than the LGCP, climates during late MIS3 were cooler than at present.

A vegetation transition from montane beech forest between $37.7-34.4$ ka to subalpine/alpine dominated vegetation is represented at the top of section 3 . The 
exact timing of this change was not recorded due to the fragmentary nature of sediment deposition. The top of the section is dominated by Poaceae and the cold tolerant Phyllocladus and other elements of the sub-alpine/alpine zone. Phyllocladus is restricted in the contemporary environment to the $N$. solandri tree limit, between 1100-1400 m.a.s.l. This suggests that climate was considerably cooler than present day by $28.5 \mathrm{ka}$, which depressed the treeline down to $500 \mathrm{~m}$. By using the same ELR as above, a MAT depression of $3-4.5^{\circ} \mathrm{C}$ is estimated to have caused a 600-900 m lowering of the treeline. This suggests temperatures were getting progressively colder leading into the LGCP.

\subsubsection{LGCP: Section 2 and 1 vegetation interpretation (26.2- $18.9 \mathrm{ka})$}

The dominant vegetation types throughout section 2 and 1 are grassland and herb communities, indicating alpine-dominated vegetation, which is located above the treeline in the contemporary landscape (Wardle 1965). A similar vegetation composition has been reported from various other sites in the region which span the LGCP (Moar, 1980; Mabin, 1983; McLea, 1996). The low pollen abundance of podocarps; Halocarpus, Phyllocladus, and Fuscospora and trace amounts of $N$. menziesii indicates that there were tree refugia in the region.

Significant amounts of Asteracaeae remain present in the landscape throughout section 2 and 1, and may be indicative of a shrub element but the prominence of grass and other herb taxa suggest the Asteraceae is more likely to represent herb forms. Moar (1970) carried out a pollen spectra study from a high altitude site (1700 m.a.s.I) between Lake Rotoroa and Lake Rotoiti. The following herb taxa were present in the pollen rain: Asteraceae taxa (incl. Abrotanella sp, Celmisia sessiliflora and Craspedia uniflora), the Apiaceae Anistoma aromatic, Coprosma pumila, Gaultheria depressa and Poaceae taxa (incl. Chiononchloa australis, C. pallens and Hierochloe). The alpine vegetation composition described by Moar (1970) was very similar to the taxa forming the pollen assemblage at the site indicating the regional vegetation during $26.2-18.9 \mathrm{ka}$ is dominated by alpine flora. This would also suggest the Asteraceae in the record represents herb forms of the taxa. 
Overall the pollen assemblage shows little change in composition between sections 1 and 2 which are both consistently dominated by Poaceae and other alpine herb taxa including Hebe, Apiaceae, Brassicaeae, Gentiana and Asteraceae, all indicative of very cold climates. However, Fuscospora, varies in abundance between the two sections ranging $18-10 \%$ in section 2 and $8-1 \%$ in section 1. Coinciding with the Fuscospora decline in section 1 is an increase in herb abundance during the LGM. The relatively high abundance of Fuscospora in section 2 could suggest that beech forest is at or near the site and that the treeline limit was close by. However, the lower abundance of Fuscospora in section 1 suggests beech forest declined in the region at that time. Fuscospora pollen can be transported over extremely large distances, which would be made easier in open landscapes dominated by herb taxa, as the pollen assemblage in the record suggest. During the LGCP, other sites in the Westland region, which are suspected to have been beech free, consistently contained up to c. $10 \%$ Fuscospora pollen abundance (Vandergoes and Fitzsimons, 2003; Newnham et al, 2007a; Lake Mudgie). Modern pollen rain studies have found Fuscospora pollen to be the most widely dispersed mainland pollen type and it is even found in remote islands including the Antipodes $770 \mathrm{~km}$ away from New Zealand (Moar, 1967, 1970; Dodson, 1978; Mildenhall 1976). The abundance of Fuscospora at different sites and the sites' distance from source appear not to share a relationship (Moar, 1969; 1970) although vegetation cover does appear to play a role. A pollen rain study in central Canterbury Plains, which is $60 \mathrm{~km}$ downwind from $N$. fusca forest, found $21 \%$ Fuscospora pollen in exposed shrubland but only $7 \%$ in dense shrubland (Myers, 1973). This illustrates the importance of an open low-lying vegetation community in promoting Fuscospora dispersal. Considering the pollen assemblage is dominated by alpine herb and grasses the Fuscospora pollen probably came from lower altitude refugia and was blown up to the site. Section 1 has significantly lower abundance than section 2 suggesting the period between ca 20.5- 18.9 ka experienced harsher and colder conditions were causing the beech forest to migrate to more favourable conditions at lower altitudes. 


\subsubsection{LGCP: Climate reconstruction}

The pollen composition changed little between sections 2 and 1 apart from the changes in Fuscospora abundance that is significantly lower during the LGM. This suggests climatic conditions between 26.2-21.9 ka were not as cold as the conditions experienced in the region during the later LGM. The fragmentary nature of the record does not reveal conditions during the period preceding 26.2-21.9 ka, but the pollen assemblage is similar to that at the top of section 3 and suggests similar conditions were recorded in both section. However, the reduction in subalpine treeline taxa such as Phyllocladus and increase in alpine herb taxa suggest the site was not at the treeline during 26.2-21.9 ka.

In the contemporary landscape, the alpine zone is located, at $>1400$ m.a.s.l in the Nelson Lake National Park. By using the standard ELR of $0.5{ }^{\circ} \mathrm{C} / 100 \mathrm{~m}$ (Burrows, 1977), a minimum of $4.5^{\circ} \mathrm{C}$ cooling is needed to reduce the alpine zone from 1400 m.a.s.I to 500 m.a.s.I Therefore the climate during the LGCP including the LGM was at least $4.5^{\circ} \mathrm{C}$ colder than at present, reducing the MAT at Lake Rotoiti to $\mathrm{C}$. $3.5^{\circ} \mathrm{C}$, similar to the current average winter temperature of $4{ }^{\circ} \mathrm{C}$ (New Zealand National Climate Centre, 2010). Cyperaceae, indicative of poorly drained, boggy and wetland areas, are consistently present in both terrace risers with a large abundance throughout section 2 and 1 . The site therefore remained intermittently waterlogged between 26.2-18.9 ka. This does not necessarily indicate a precipitation signal but rather periods of poor drainage at the site caused by damming and subsequent backponding.

\subsubsection{Quantitative pollen/climate reconstructions}

The pattern of MAT change predicted differs between the two models (see section 8.2.4) and with the above estimated pattern of climate change using ELR and the vegetation record. The pattern of MAT predicted by the W-MAT model suggests temperature remained relatively unchanged throughout the period spanning 37.7$18.9 \mathrm{ka}$. The model estimated the MAT to be $1.4-2{ }^{\circ} \mathrm{C}$ cooler than present which during some periods is significantly lower than that estimated by the ELR (see sections 6.6.5 and 8.2.4). The pattern of MAT change predicted by the PLS-C3 model suggests temperatures got progressively warmer with the reconstruction 
and that MIS 3 was colder at Howard Valley than during the LGM. The pattern of climate change reconstructed by both models is strikingly different to that inferred from the vegetation record and using the ELR which suggest MAT were at least $1.6{ }^{\circ} \mathrm{C}$ warmer during the late MIS 3 than during the LGM. Records from elsewhere in New Zealand also support the MAT pattern as estimated by the ELR and inferred from the vegetation record (e.g. Alloway et al, 2007; Newnham et al, 2007) in contrast to the modelled results. Therefore, the pattern of MAT change reconstructed by both models seems unrealistic. The causes of the different reconstructions are likely to be attributed to the limitations of the quantitative methods and are discussed in detail in Section 8.2.4. 


\subsubsection{Discussion summary}

\begin{tabular}{|c|c|c|}
\hline Pollen assemblage zone & Vegetation reconstruction & Climatic reconstruction \\
\hline $\begin{array}{l}\text { Howard Valley sections } 2 \text { and } 1 \\
(20.5-18.9 \mathrm{ka})\end{array}$ & $\begin{array}{l}\text { Alpine vegetation dominated by } \\
\text { grassland and herb field } \\
\text { species. Fuscospora abundance } \\
\text { declined suggesting beech } \\
\text { forest moved further away from } \\
\text { the site to more favourable } \\
\text { conditions. }\end{array}$ & $\begin{array}{l}\text { Extreme cold environment } \\
\text { with a minimum } 4.5^{\circ} \mathrm{C} \\
\text { cooling experienced at the } \\
\text { site. }\end{array}$ \\
\hline $\begin{array}{l}\text { Howard Valley section } 2 \\
(26.2-21.9 \mathrm{ka})\end{array}$ & $\begin{array}{l}\text { Alpine vegetation dominated by } \\
\text { grassland and herb field } \\
\text { species. Fuscospora pollen } \\
\text { suggests the site was at or near } \\
\text { the upper limit of the beech } \\
\text { treeline. }\end{array}$ & $\begin{array}{l}\text { Colder climates than that } \\
\text { experienced at the site } \\
\text { today, estimated between } \\
3-4.5^{\circ} \mathrm{C} \text { colder. The } \\
\text { section indicates a } \\
\text { progressive cooling at the } \\
\text { site. }\end{array}$ \\
\hline $\begin{array}{l}\text { Howard Valley section } 3 \\
(28.5 \mathrm{ka})\end{array}$ & $\begin{array}{l}\text { Transition from mixed beech } \\
\text { forest with wetland groves, to an } \\
\text { alpine/sub-alpine grassland } \\
\text { dominated community at or near } \\
\text { the treeline. }\end{array}$ & $\begin{array}{l}\text { Colder climates than that } \\
\text { experienced at the site } \\
\text { today, estimated between } \\
3-4.5^{\circ} \mathrm{C} \text { colder. The } \\
\text { section indicates a } \\
\text { progressive cooling at the } \\
\text { site. }\end{array}$ \\
\hline $\begin{array}{l}\text { Howard Valley section } 3 \\
(37.7-37.4 / 34.4 \mathrm{ka})\end{array}$ & $\begin{array}{l}\text { Wetland community dominated } \\
\text { by sedges and Phyllocladus } \\
\text { alpinus shrub which is } \\
\text { surrounded by a mixed } \\
\text { Fuscospora and } N \text {. menziesii } \\
\text { beech forest. }\end{array}$ & $\begin{array}{l}\text { Cooler climates than is } \\
\text { experienced at the site } \\
\text { today estimated between } \\
2-3^{\circ} \mathrm{C} \text { colder. }\end{array}$ \\
\hline
\end{tabular}

Table 6.2: A summary table of the vegetation and climate reconstruction for Howard Valley pollen assemblage for section 1-3.

\subsubsection{Summary discussion for pre-LGCP (section 3)}

Howard Valley is a unique site in the region as it is one of a handful of sites which produces a terrestrial record extending back into MIS 3 . MIS 3 is the milder interval spanning 51-24 ka and interrupts the two glacial periods of MIS 4 and MIS 2. The vegetation reconstruction at the site between $37.7-34.4 \mathrm{ka}$ is a Fuscospora 
and N. menziesii beech forest containing Phyllocladus alpinus and Cyperaceaedominated wetland areas along the main river margins and up the side creeks and tributary streams. At the same sample locations used for this study, Marra and Thackray (2010) found abundant $N$. menziesii leaves and beetles associated with forest and forest litter habitats and confirm the pollen based vegetation reconstruction. As mentioned earlier, a modern pollen rain study by Moar (1970) found only $3 \% N$. menziesii pollen in an area containing a large $N$. menziesii population and suggest this species is underrepresented in the pollen record. The abundant $N$. menziesii leaves at this also show that $N$. menziesii is underrepresented in the palaeorecord and highlights the significant importance of the low abundance of this species when reconstructing past vegetation and climates. Therefore at this site the pollen, beetle and plant macrofossil records complement each other and indicate the importance of a multiproxy approach.

$N$. menziesii forest in the region today is limited to $900-1100$ m.a.s.l and suggests that this species was 400-600 m lower during MIS 3 than its current altitudinal limit. This represents a temperature depression of $2-3{ }^{\circ} \mathrm{C}$ cooler than present, indicating MIS 3 in New Zealand was cooler than present day but not as cold as during the LGCP (see Section 6.6.2). Marra et al (2009) reported beetle and plant macrofossil evidence form Taranaki during late MIS 3, indicating that taxa which are now restricted to the cooler north South Island were able to grow at the site during MIS 3. This evidence supports the findings at Howard Valley. Likewise the pollen record from Okarito, in south Westland is described as having milder climates during late MIS 3 than during the LGCP but experienced progressive moderate cooling represented by a sequence of minor grass peaks (Newnham et al, 2007a). In central North Island McGlone and Topping (1983) estimated temperatures were up to $3{ }^{\circ} \mathrm{C}$ cooler than that experienced in the region today, which corresponds with the MAT depression implied by the elevation of $N$. menziesii growth at Howard Valley site during 37.7-34.4 ka. It is therefore reasonable to estimate MAT would have been around 6.6-5.4 ${ }^{\circ} \mathrm{C}$ in the region, based upon a $2-3^{\circ} \mathrm{C}$ reduction from the contemporary MAT of $9{ }^{\circ} \mathrm{C}$ observed from Lake Rotoiti, during MIS 3. 
$N$. menziesii disappears from the record by $28.5 \mathrm{ka}$ when the vegetation composition is dominated by grass and alpine/sub-alpine vegetation communities demonstrating significant cooling had already commence. An estimated temperature depression of $3-4.5{ }^{\circ} \mathrm{C}$ suggests climates were becoming less favourable for $N$. menziesii growth in the region. The plant macrofossil record in Marra and Thackray (2010) also indicates a decline in $N$. menziesii leaf abundance up the riser profile, again, corresponding with the pollen evidence of climate deterioration and migration of trees from the site probably to more suitable conditions at lower elevations. The temperature depression and pollen assemblage is similar to that experienced during the LGCP (see Section 6.6.3).

The onset of the LGCP, according to the NZ-I CES, began between 29-28 ka, the timing of which corresponds with the timing of deposition of unit 4 in section 3 . However, due to the record being fragmentary, a precise age for the onset of the LGCP cannot be estimated. At $28.5 \mathrm{ka}$ in Howard Valley herb taxa, particularly grass taxa, were already dominating the vegetation community. This may suggest cooling in the region began earlier, leading to alpine dominated flora becoming established in the region by $28.5 \mathrm{ka}$. Alloway et al (1992) and Nelson et al (1993) recorded a peak in aerosol quartz accumulations, which are indicative of increased glacial activity, occurring round 34.4 ka. Likewise, Suggate and Almond (2005) aged a glacial advance in the Westland region also beginning at $34.4 \mathrm{ka}$. An earlier onset of climate deterioration at the site is therefore feasible and would explain the large transition from montane mixed beech forest to alpine/sub-alpine grassland shrub mosaic. However, due to the fragmentary record of the site, firm conclusions cannot be made.

\subsubsection{Summary discussion for the LGCP}

Marra and Thackray (2010) concluded that the dominant vegetation type throughout the LGCP was grassland with trees and shrubs becoming scarce or absent in the youngest sediments spanning 18.9-20.5 ka. The pollen record shows a similar pattern with sections 2 and 1 dominated by grass and herb taxa indicative of the alpine zone. However the abundance of Fuscospora pollen ranged 18-10\% in section 2 and only $8.1 \%$ in section 1 suggesting a decrease in Fuscospora in the region and a two step cooling. The pollen assemblage in section 2 is similar to 
that recorded in unit 4 of section 3 and appears to be a continuation of this vegetation community and inferred climate. Section 2 spans 26.2-21.9 ka and corresponds with the LGCP milder and more variable climate. The pollen record from Okarito is characterised by a decline in herb taxa and an increase in tree and shrub abundance marking a mild climate amelioration. At Okarito this milder interval is bounded by two grass peaks, the older representing the onset of the LGCP and the latter the LGM (Vandergoes et al, 2005; Newnham et al, 2007a). At Howard Valley, a change from very cold conditions during the early LGCP to a milder period of the LGCP was not recorded. Instead the pollen record spanning 28.5-21.9 ka suggest conditions were cold with MAT ranging $3-4.5{ }^{\circ} \mathrm{C}$ colder than today. Whether conditions got even harsher between the top of section 3 and the bottom of section 2 is unknown.

Evidence from the plant macrofossil and beetle analysis by Marra and Thackray (2010) concluded that between 26.5-20.7 ka the site was a mixed podocarp beech forest. However, the plant macrofossils contained mainly grass remains and include tussock material. Also, the Podocarpus leaves found in the samples could not be accurately identified but were assumed to be Podocarpus hallii which spans from the lowland to the sub-alpine zone (Poole and Adam, 1963). Marra and Thackray (2010) suggest the mixed forest community is of a similar composition to sub-alpine scrub located at the altitudinal tree limit in the modern environment (Wardle, 1980). The pollen evidence concurs with this conclusion. Grass pollen dominated the assemblage, combined with herb, Fuscospora and Phyllocladus alpinus pollen representative of the contemporary subalpine/alpine treeline limit (Wardle, 1980). However the original use of forest to describe this vegetation community by Marra and Thackray (2010) is misleading and this is a disparity between the interpretations. In this instance, to prevent misinterpretation and confusion, a accurate and description classification of the vegetation community, opposed to a vague and ambiguous classification such as forest, should be used instead. McGlone et al (2011) have argued that the difference in interpretation of beetle and pollen records can also be attributed to the vocabulary used and the different definitions of particular words such as forest. It is important that the same vocabulary is used consistently between different proxies. 
The deposition of section 1 occurred during the LGM period of major ice advance in the region. Suggate (1965) estimated the ice extent reached 650 m.a.s.l at Lake Rotoiti and 450 m.a.s.I at Lake Rotoroa during the LGM. Howard Valley, located between the two was therefore glaciated in the upper valley but the project site, which is located at 500 m.a.s.l, would have been ice free. The pollen record shows an increase in herb taxa and a decline in Fuscospora, suggesting the migration of beech and a lowering of the treeline in the region. Again the pollen record corresponds with Marra and Thackray (2010) record where shrubs and forest become absent from the record, indicative of extreme cold environments in the region. The trace amounts of $N$. menziesii suggest there is probably a significant presence of this tree in LGM refugia in the region.

In the contemporary environment, the winter snowline has a large influence on forest growth (Wardle, 1965). Soons (1979) estimated the snowline limit during the LGM along a transect located $42^{\circ} \mathrm{S}, 12 \mathrm{~km}$ south of Lake Rotoroa. She concluded that the snowline lowered from east to west and a maximum overall snowline lowering of $800-850 \mathrm{~m}$. In the Nelson Lakes National Park this would have caused a lowering of the snowline from its contemporary position of 1400 m.a.s.l (Wardle, 1965) down to 550-600 m.a.s.I which is close to the Howard Valley site elevation. In the Westland region today forest can grow near to the ice margin and it could be possible that this occurred during the last glacial (Gage, 1945). However, New Zealand shrub and tree taxa are comparatively cold intolerant when compared to Northern Hemisphere continental taxa, and so it is unlikely that these species would grow above the snowline and also cope with periodic extreme cold events, however long these lasted (Sakai and Wardle, 1978). Although, technically, trees could grow in areas up to 650 m.a.s.I, the extreme climate may have limited their growth to areas of more favourable and unexposed conditions. McLea (1996) concluded that considering glaciers did extend below the treeline in some areas in south-east Nelson, 500 m.a.s.I serves as an approximation for the upper limit of trees. At 500 m.a.s.I, the Howard Valley site is located on the edge of the treeline during the LGM. However the pollen beetle and plant macrofossil records evidence suggests that trees were located near to the site but the site itself was forest free. 
Wardle (1973) suggested that the altitudinal treeline is controlled by mean summer temperatures. Temperatures reaching an average $10{ }^{\circ} \mathrm{C}$ during the warmest months are therefore related to treeline (Wardle, 1965, 1985; Wardle and Campbell, 1976). Summer temperatures are a critical component for $N$. fusca growth as the growing season needs to be long enough to enable the seedlings to harden before the onset of colder weather (Wardle, 1973). The mean annual summer temperature in the region at 600 m.a.s.I is $14{ }^{\circ} \mathrm{C}$ (Lake Rotoiti; New Zealand National Climate Centre, 2010). The inferred MAT depression based upon the pollen evidence at the site was $4.5^{\circ} \mathrm{C}$. However, the elevation reached by the alpine vegetation advancing down the valley is unknown and the temperature depression could well be lower. McGlone et al (1993) estimated the maximum temperature depression during the $L G M$ was $5{ }^{\circ} \mathrm{C}$, similar to that estimated from the pollen record here, which if subtracted from the contemporary average summer temperature, would place Howard Valley at or very near to the possible limit of tree growth during the LGM. However, it is also important to note that temperature is not the only climatic factor influencing forest growth. It is believed that the LGM also experienced an increase in windiness, frost and reduced precipitation, all of which can limit tree growth (McGlone et al, 2010).

\subsubsection{Conclusion}

Howard Valley uniquely provides a vegetation record spanning from 37.7-18.9 ka. This site indicates that climate during the later stages of MIS 3 in the Nelson region was considerably cooler than current conditions, but milder than during the LGCP. Nevertheless it appears that climate deterioration had already started by $28.5 \mathrm{ka}$ with the region experiencing cold temperatures and alpine dominated vegetation. The onset of the vegetation transition to sub-alpine/alpine vegetation and cooling was not captured in the record. However, significant change had occurred between the two periods of organic accumulation and possibly suggests an earlier onset of the LGCP than in the NZ-I-CES (Alloway et al, 2007). The vegetation record confirms that temperatures during late MIS 3 were cooler than present, possibly $2-3{ }^{\circ} \mathrm{C}$ colder. The transition into alpine/sub-alpine dominated taxa at 28.5 ka suggest conditions at Howard Valley were significantly colder than today with similar temperatures as that experienced during the LGM. 
The LGCP was recorded in section 2 and 1 (spanning 26.2-18.9 ka). The vegetation record indicates the region experienced a period of severe cold with temperatures of at least $3-4.5{ }^{\circ} \mathrm{C}$ cooler than at present. The organic section analysed suggests a two step cooling with temperatures possibly milder between 26.2-21.9 ka before the harsh LGM conditions followed. The pollen record produced by this study corresponds closely to others in the region which covers the same time period, including the beetle record produced by Marra and Thackray (2010).

Contrary to findings elsewhere in New Zealand (e.g. Burge and Shulmeister 2007b) the pollen and beetle record are in close agreement throughout the record. The low pollen counts of $N$. menziesii mask the species importance in the environment which has been supported by both the beetle and plant macrofossil analysis in Marra and Thackray (2010) and emphasises the importance of using a multiproxy approach when producing vegetation and inferred climate reconstructions. 


\section{Chapter 7: Forks Lagoon}

The final site investigated in this project is Forks Lagoon, a shallow lake located in the Mackenzie Basin, central Canterbury (Figure 7.1). This upland plateau lies to the east of the Southern Alps, and, climatically, forms a contrasting site to the previous three sites already discussed. During the Quaternary the area was extensively glaciated, however, geological evidence indicates that Forks Lagoon is located outside the LGM ice margin. Sediment accumulation at the site therefore continued beyond the LGM and throughout the entire LGCP. Due to the dry climate and high altitude of the region, a continuous record extending beyond the LGM is exceptionally rare and makes this an important location. However, the site has its limitations. The dry land pollen counts do not produce statistically significant counts and therefore cannot produce detailed vegetation or inferred climate reconstruction. Also, initially it was thought the section analysed spanned the entire 30-8 ka period. However, after dating, the record was found to only span 31.4-17.2 ka. However, the aquatic macrophyte taxa produced abundant grains, which have proved to be important climate indicators.

Due to the low dryland pollen counts the structure of this chapter will be different to the other three. PCA is not included in the chapter as it was deemed not to provide any useful information due to the low pollen counts. An estimated temperature and treeline depression for the period using ELR was also not carried out as an accurate estimation of both would not be possible. Instead the emphasis in the chapter will be upon the macrophyte pollen concentration. The sedimentology and quantitative pollen/temperature reconstruction will also be discussed.

\subsection{Regional description}

The Mackenzie Basin is bounded to the north and west by the Southern Alps; to the east by the Two Thumb, Rokesby, Dalgery and Kirkliston ranges; and to the south by the Ohau and Waitaki Rivers. The Grampien Mountains jut into the Mackenzie Basin from the Kirkliston and Dalgery ranges. The geomorphology of the basin is dominated by glacial landforms. Extending from the Main Divide and 
considerably southwards of Lakes Tekapo and Pukaki are extensive moraines. The moraines are made up of till and gravels. Beyond the moraines lie an extensive outwash plain that has been dissected by rivers and streams. The material deposited on the plains is well graded greywacke gravels (Mildenhall, 2001).

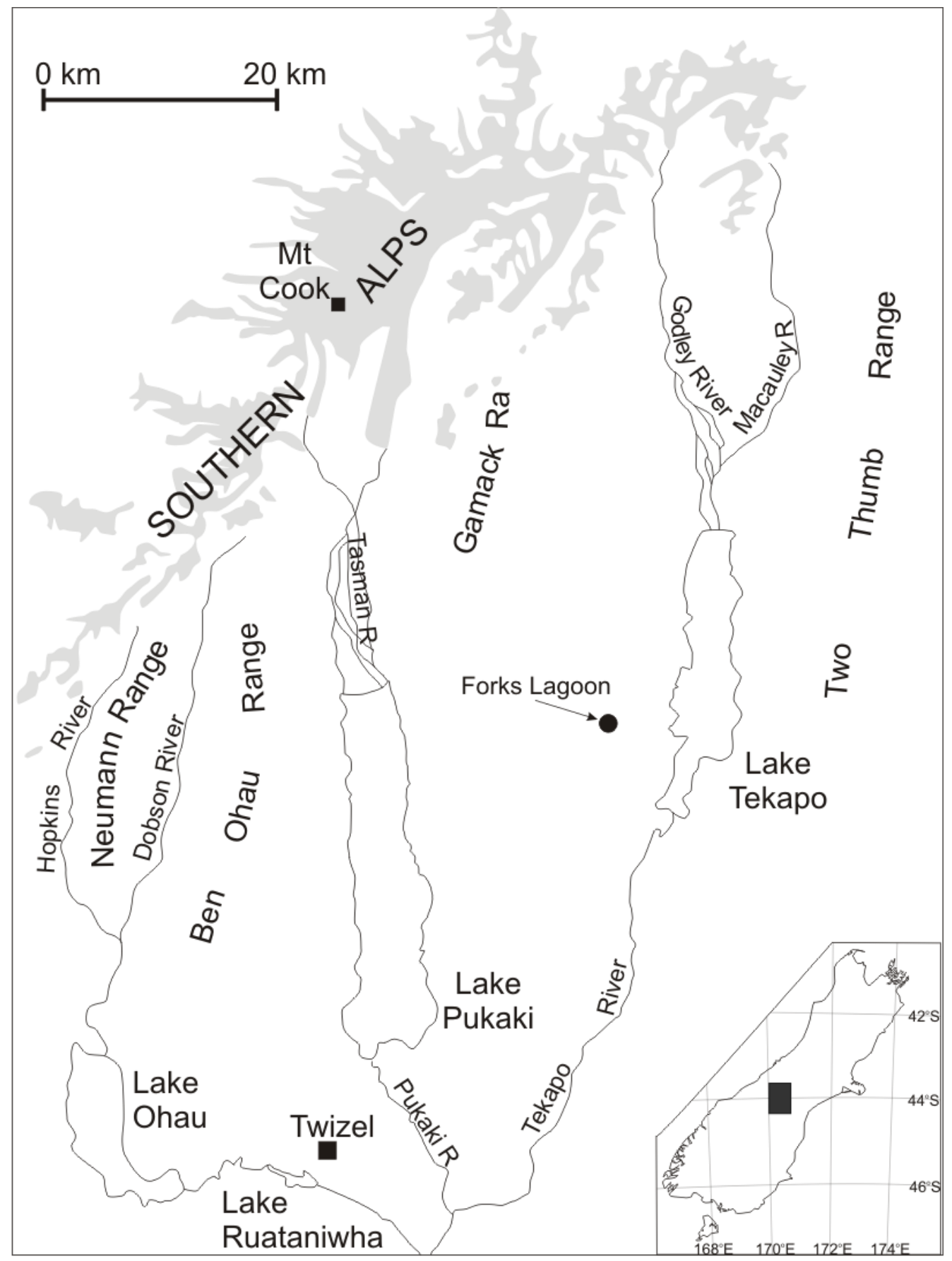

Figure 7.1: Location map of Forks Lagoon. 


\subsubsection{Climate}

Mackenzie Basin is located in the interior region of New Zealand and is surrounded on all sides by mountains ranges which cause a rain shadow affect and an important influence on the precipitation in the region. This region has low mean annual precipitation averaging ca. $600 \mathrm{~mm} / \mathrm{yr}$ and can experience regular water deficits and periodic severe drought, producing a fire prone landscape. Mean annual temperature is $8.8^{\circ} \mathrm{C}$, however, there is a large seasonal difference ranging from an average $14.5{ }^{\circ} \mathrm{C}$ during the summer to $2.6{ }^{\circ} \mathrm{C}$ during winter. Extreme temperatures events also occur in the region with temperatures reaching up to $31^{\circ} \mathrm{C}$ and down to $-15^{\circ} \mathrm{C}$ (New Zealand National Climate Centre, 2010). This area is also susceptible to the dry north-westerly (föhn) winds which increase the level of evapotranspiration, however, the prevailing wind direction is westerly. The climate in the Mackenzie Basin is vastly different to Westland (refer to Section 4.1). The Mackenzie Basin lies on the boundary between East South Island (ESI) and West South Island (WSI) climate regimes with the study site, Forks Lagoon, situated in the ESI (Lorrey pers comm). This site therefore responds differently to the prevailing synoptic conditions compared to the Westland region. During Zonal regimes, maximum and minimum temperatures are above normal, and precipitation is below normal. In Blocking regimes, maximum temperature is above normal, minimum temperature is below normal and so is precipitation. Finally, during Trough regimes maximum and minimum temperatures are below normal and precipitation is above normal (Renwick, 2011). Therefore, Forks Lagoon would receive most of its rainfall during periods dominated by the Trough regimes (see Section 2.3 for more detail).

\subsubsection{Vegetation}

Human activity has nearly totally transformed the original vegetation cover of the region. Any natural vegetation cover is scattered and restricted to small, and possibly atypical, remnants. Tussock grassland dominates the vegetation and is dominated by Chionochloa rubra and Festuca novae-zealandiae, a short tussock grass. Podocarp shrubland is dominated by Halocarpus bidwilli and includes a number of other shrubs including Phyllocladus alpinus, small leaved Coprosma spp, Aristotelia fruticosa, Melicytus alpinus, and other species. The region also 
contains a few scattered stands of Nothofagus solandri var. cliffortiodes. However, the majority of the vegetation has been modified by human activity that it is dominated by grassland which is utilised for farming. Many non-native species have also been introduced and thrive in the environment (McGlone and Moar, 1998).

\subsection{Site specific description}

Forks Lagoon ( $\left.170^{\circ} 22^{\prime} 56.9^{\prime \prime} \mathrm{E}, 43^{\circ} 56^{\prime} 35.5^{\prime \prime} \mathrm{S}\right)$ is a small lake located in the Tekapo Military zone, lying between Lake Pukaki and Lake Tekapo. The lake is impounded by a lateral moraine that is assumed to pre-date the LGM (see Figure 7.2). There is no evidence of groundwater or surface water input to the lake, suggesting the lake is predominantly rainwater fed and therefore sensitive to changes in precipitation. It is evident that lake levels fluctuate, with a dry lake basin and an ephemeral outlet stream south of the lake indicating lake levels have been higher in the past. As there is no overland source of water into the lake. The ephemeral stream (Figure 7.3) controls the maximum lake depth. 


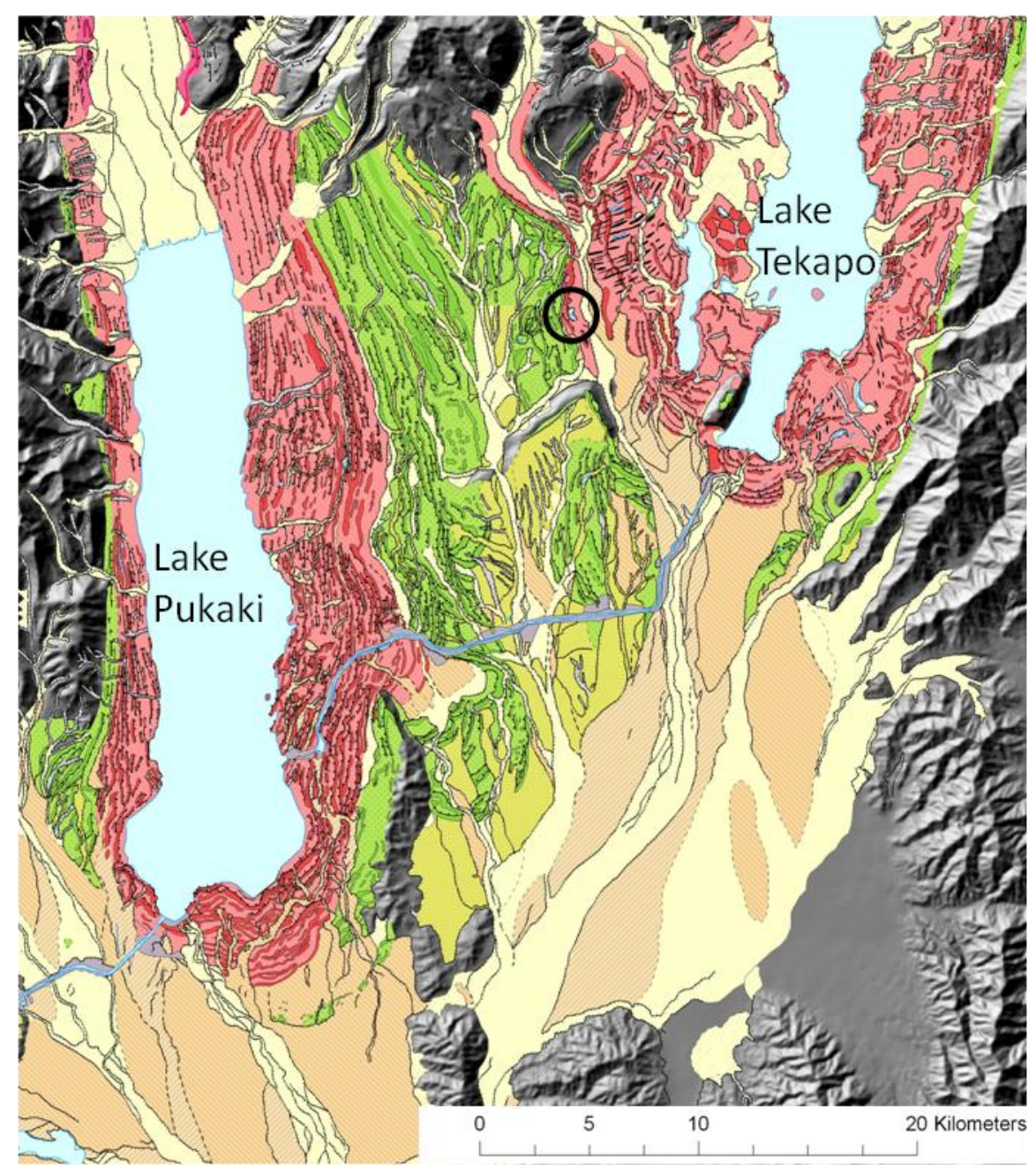

Figure 7.2: Map showing the location of moraines in relation to Forks Lagoon (circle). The red marks the location of LGM moraines and green are deposits older than the LGM. Forks Lagoon is located within a red area suggesting the moraine it lies within is an LGM moraine. However, subsequent work in the area, combined with the KOT in the core confirms the bounding moraine was deposited significantly before the LGM (Barrell et al, unpublished).

The lake today contains two basins (Figure 7.4). The first basin at the southern end of the site is currently dry. The second basin forms a shallow lake reaching a maximum current depth of $40 \mathrm{~cm}$. The lake itself is heavily dominated by macrophytic freshwater plants, particularly Isoetes alpinus. There is a lake edge effect caused by wind-induced waves where the stones bounding the lake are free of vegetation. Limosella sp forms a mat covering the stones on the lake edge. Interspersed between the stones, above the wave effect, are a number of herb taxa, the majority of which are non-native. These include Brassicaceae, Polygonum spp, Senecio jacobaea and Taraxacum officianale. The lake is surrounded by Poa dominated tussock grassland that is characteristic of this region (Figure 7.4). 


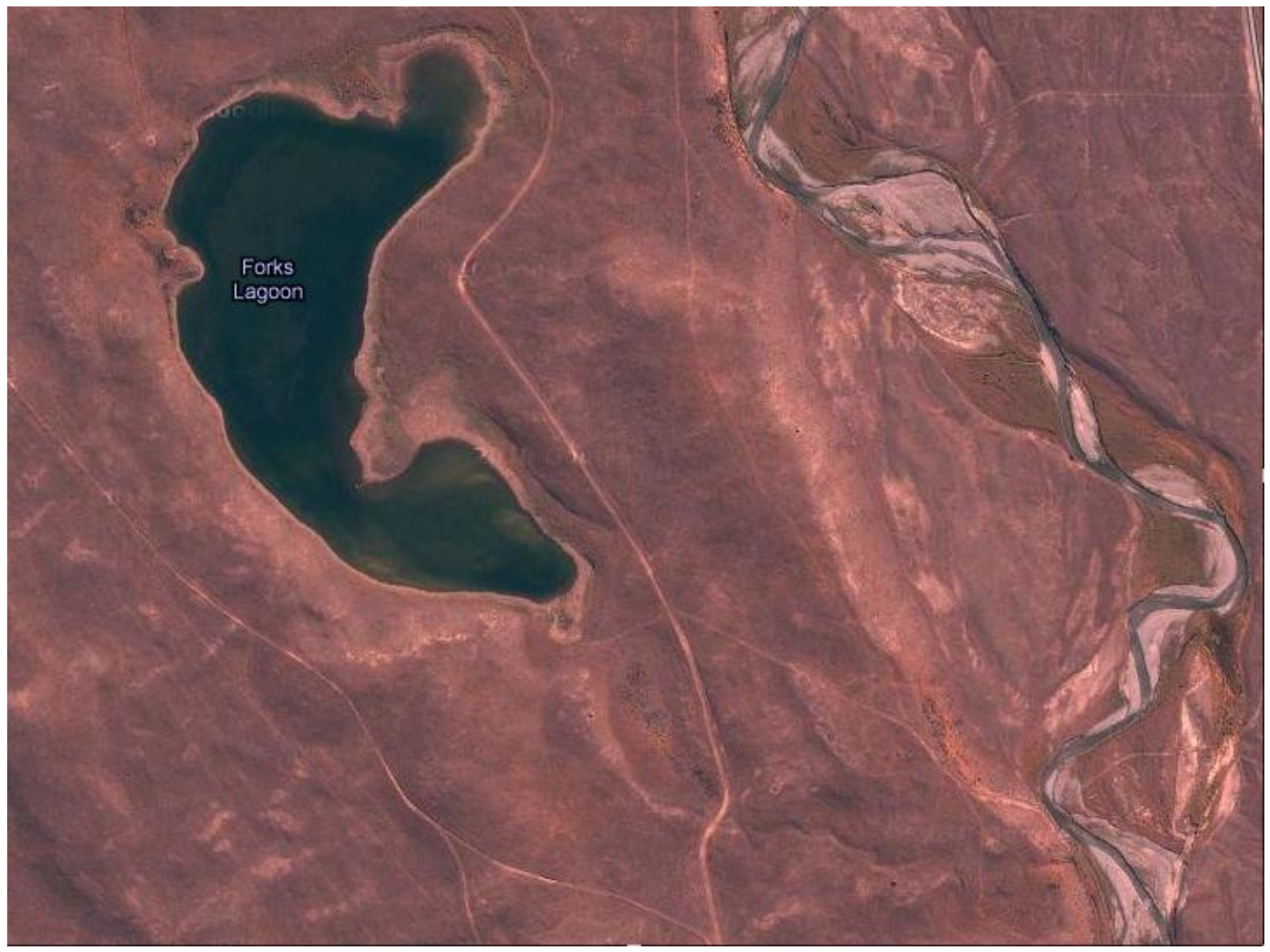

Figure 7.3: Aerial photographic image of Forks Lagoon showing the location of the ephemeral stream at the southern end of the Lagoon. Source: Google Earth.

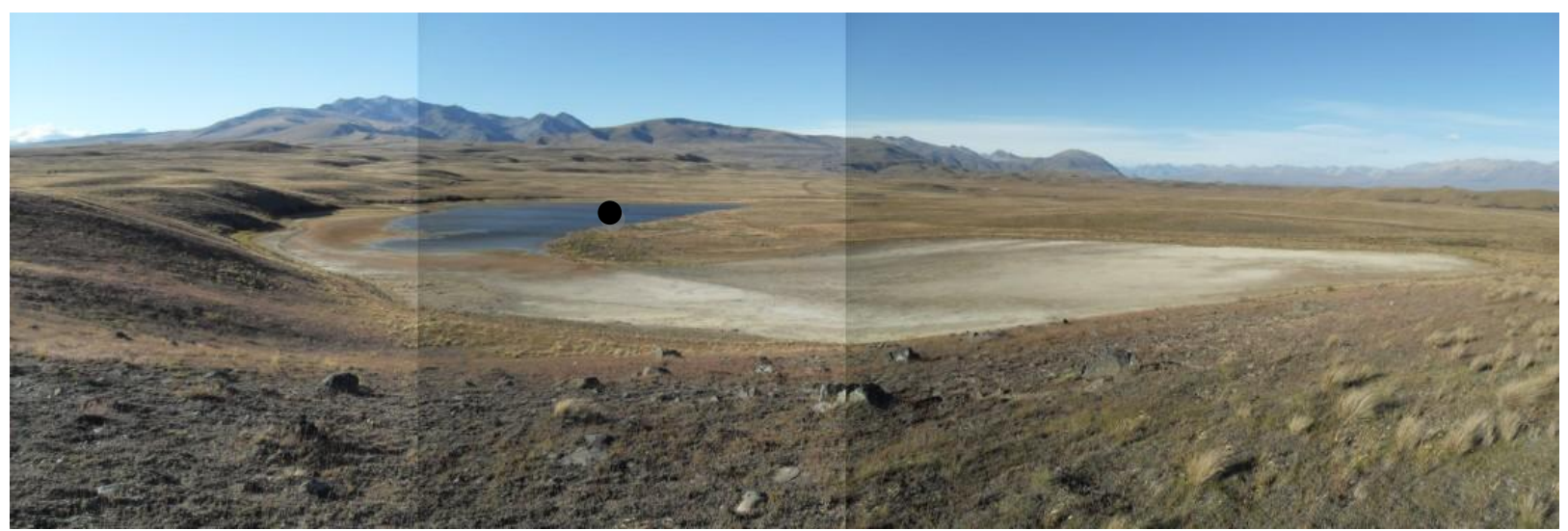

Figure 7.4: Image of Forks Lagoon taken from the south-west/ looking north-east. The black circle illustrates the core location. 


\subsection{Stratigraphy}

The core site was located in the centre of the northern end of the lake, which is the deepest part. Two cores were recovered, the first core, 0901, was taken on the lake bed surface, and the second, 0903, began $50 \mathrm{~cm}$ below the lake bed surface. The method for coring is described in Section 3.1. A maximum of $8 \mathrm{~m}$ of sediment was cored without reaching the base of the deposit. The description of the stratigraphy is shown in Figure 7.5, and includes only the sections analysed for pollen and sediment analysis. Due to the overlap between the two cores and the distinctive stratigraphy which could be correlated between cores, a continuous analysis down the core could be produced.

Sections from each core were combined to produce a continuous record spanning $206-418 \mathrm{~cm}$. This section of the core consists of silts throughout. The main variation down the core is the sediment colour which changes distinctively and abruptly from light grey to brown and provides distinct colour units. Figure 7.5 shows a detailed core description which is summarised below on a continuous depth scale.

206-245 cm: Brown silts which contain alternating light brown, brown and dark brown bands, usually $2-3 \mathrm{~cm}$ thick, although some are thicker. A grey band interrupts the organic bands between $234-238 \mathrm{~cm}$.

245-252 cm: Grey silt layer.

252-302.5 cm: Alternating thick $(10-30 \mathrm{~cm})$ bands of grey-brown to dark brown silts. The sediment is fibrous between $254-296 \mathrm{~cm}$.

302.5-357.5 cm: Grey silts containing cm-thick brown organic bands towards the top of the section. A pinky yellow sand layer interrupts the grey silts between 344$346 \mathrm{~cm}$. Visual and geochemical analysis confirms this sand to be the KOT layer (see appendix g).

357.5-366 cm: Light brown silts.

366-373.5 cm: Grey silts.

373.5-384 cm: Brown silts which contain alternating light brown, brown and dark brown bands ranging $3-5 \mathrm{~cm}$ thick.

384-400 cm: Grey silt. 
400-418 cm: Brown slits with alternating light brown, brown and dark brown silts.

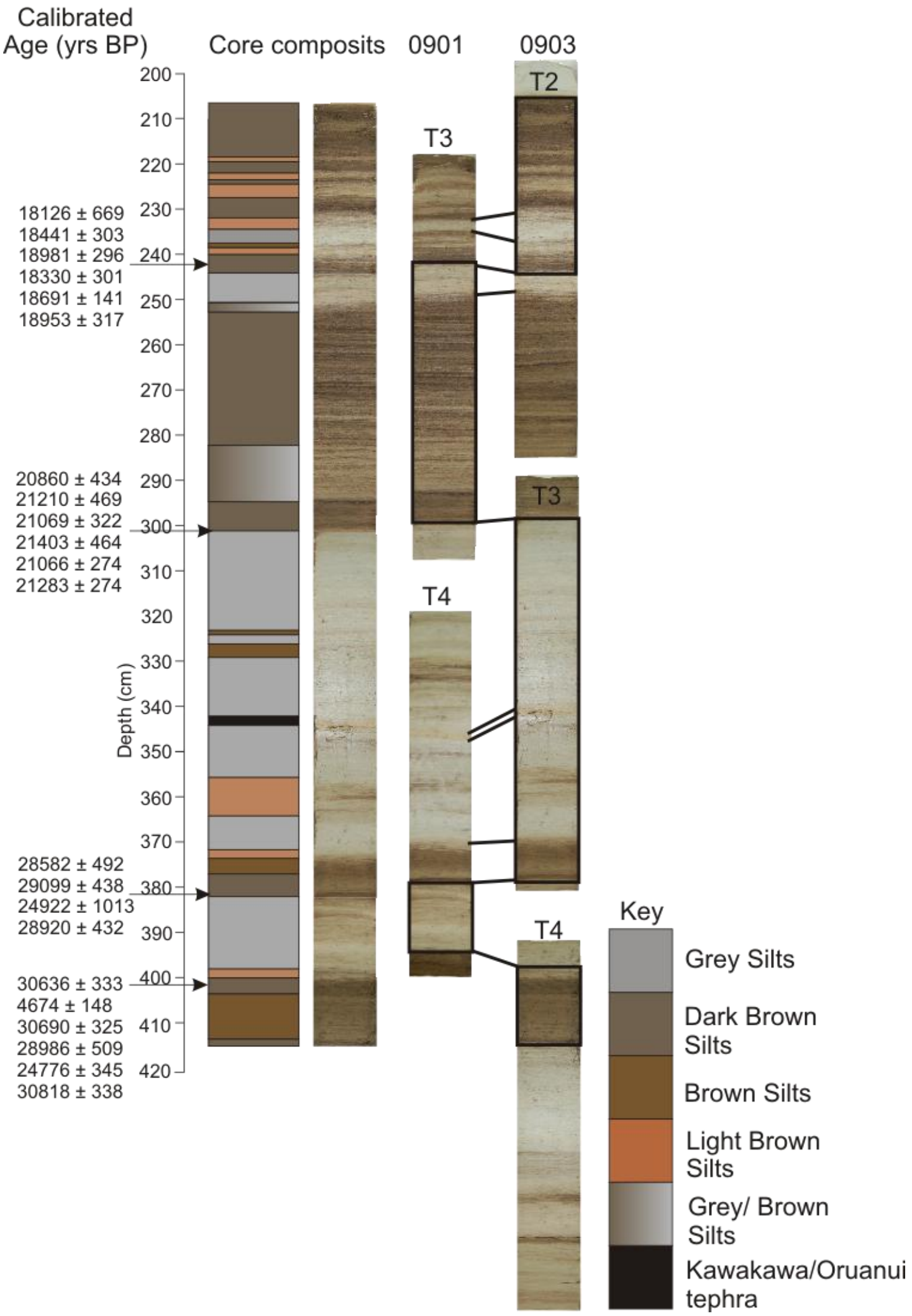

Figure 7.5: Stratigraphy cores analysed for this project with calibrated age and tie point. The black boxes on 0901 and 0903 mark the areas used to produce the continuous core image. 


\subsection{Chronology}

The radiocarbon chronology for the site was produced using bulk sediment and plant macrofossil samples. A few ages are also derived from macrospores of the aquatic macrophyte Isoetes. The results of the radiocarbon dating are displayed in Table 7.1. Two to three organic fractions were seperated for each sample using different size fractions or material to establish the age. The collection of ages from the two samples was combined to age one horizon depth. In general the ages lie in stratigraphic order. The younger ages from the horizons $242-243 \mathrm{~cm}(0903 \mathrm{~T} 2$ 42-42.5, 42.5-43 cm) and 300-302 cm (0903 T3 7-8, 8-9 cm) form tight clusters. However the older ages show greater variability and will be discussed below.

Six AMS ages were collected for horizon 401-403 cm (0901 T4 76.5-77, 78.5-79 $\mathrm{cm}$ ), the base of the section analysed. A cluster of three ages lie between 30.8$30.6 \mathrm{ka}$, collectively providing the oldest ages in the core. Three samples from the same horizon, OS-76549, OS-76895, OS-76551, produce younger ages of $28.9 \mathrm{ka}$ $24.9 \mathrm{ka}$ and $4.7 \mathrm{ka}$. Likewise, the higher horizon 380-381 cm (0903 T3 86-86.5, 86.5-87 cm) contain three ages clustering between 28.5-29.1 $\mathrm{ka}$ and one significantly younger age, sample OS-77227, of $24.9 \mathrm{ka}$. Both the horizons lie below the KOT layer which has an established age of 25.4 (Vandergoes et al, 2011). The younger ages from these deeper horizons therefore appear to be too young and therefore excluded from the age-depth model (Figure 7.6). The age range 28.5-29.1 ka for 380-381 cm appears to be more realistic. The cluster 30.8$30.6 \mathrm{ka}$ at $401-403 \mathrm{~cm}$ appear to fit well stratigraphically, however, the younger age, $28.9 \mathrm{ka}$, is similar to the above dated horizon and therefore appears to lie out of stratigraphic order.

Each of these samples giving anonymously younger ages used sedge or plant fragments from the coarser $>90 \mu \mathrm{m}$ fraction and suggest the plant macrofossils were more prone to contamination by younger carbon. The younger ages from the horizons $242-243 \mathrm{~cm}$ and $300-302 \mathrm{~cm}$ also have samples which date plant fragments but the ages produced from these samples were similar to those using other material to date. All the samples were processed using the same method. If contamination occurred during the preparation process then it would be expected 
that all the samples would produce younger ages. The larger material appears to be more susceptible to contamination in situ, whereas the smaller material, a large proportion of the organic portion is probably made up from pollen, will be less prone to contamination (see Section 3.5). The samples in the deeper horizons produced older ages and therefore even small amounts of contamination can have a large influence on the age. As the larger fraction consistently produced younger ages, it was decided not to use these ages for the age-depth model in Figure 7.6.

Figure 7.6 is the age-depth model developed for Forks Lagoon using simple linear interpolation and is discussed in the following. The ages which have not been included in the models are also shown on the figure, the exception being OS76863. As discussed above, this sample produce a significantly young age and therefore was not added to the figure. The model includes the revised age of the KOT layer of $25.4 \mathrm{ka}$ (Vandergoes et al, 2011). The initial sediment accumulation rate is $1 \mathrm{~cm} / 84$ years between $402-380 \mathrm{~cm}$ changing to $1 \mathrm{~cm} / 96$ years between $380 \mathrm{~cm}$ to the tephra layer at $344 \mathrm{~cm}$. From $344-301 \mathrm{~cm}$ the accumulation rate remains similar to before with a rate of $1 \mathrm{~cm} / 101$ years. It then doubles in pace to $1 \mathrm{~cm} / 42$ years. There is no visual evidence in the stratigraphy of the site drying out suggesting continuous deposition of sediment occurred throughout the sections analysed. 


\begin{tabular}{|c|c|c|c|c|c|c|}
\hline Sample & $\begin{array}{l}\text { Overall } \\
\text { depth }(\mathrm{cm})\end{array}$ & Fraction & ${ }^{14} \mathrm{C}$ age $\mathrm{BP}$ & $\begin{array}{l}\delta^{13} \mathrm{C} \\
\%\end{array}$ & $\begin{array}{l}\text { Reference } \\
\text { code }\end{array}$ & $\begin{array}{l}\text { Calibrated } \\
\text { age BP (2 } \\
\text { sigma) }\end{array}$ \\
\hline 0903 T2 42-42.5 & $242-242.5$ & $>90^{+}$ & $14950 \pm 300$ & -17.46 & OS-76936 & $18126 \pm 669$ \\
\hline 0903 T2 42-42.5 & $242-242.5$ & $>90^{+}$ & $15300 \pm 70$ & -15.32 & OS-76768 & $18441 \pm 303$ \\
\hline 0903 T2 42-42.5 & $242-242.5$ & $90-10^{* \star *}$ & $15750 \pm 70$ & -15.87 & OS-76861 & $18981 \pm 296$ \\
\hline 0903 T2 42.5-43 & $242.5-243$ & $>90^{+}$ & $15150 \pm 100$ & -18.12 & OS-76556 & $18330 \pm 301$ \\
\hline 0903 T2 42.5-43 & $242.5-243$ & $>90^{+}$ & $15450 \pm 55$ & -16.32 & OS-76769 & $18691 \pm 141$ \\
\hline 0903 T2 42.5-43 & $242.5-243$ & $90-10^{\star \star *}$ & $15700 \pm 75$ & -15.42 & OS-76770 & $18953 \pm 317$ \\
\hline 0903 T3 7-8 & $301-302$ & $>90^{*}$ & $17500 \pm 100$ & -16.23 & OS-76631 & $20860 \pm 434$ \\
\hline 0903 T3 7-8 & 301-302 & $>90^{* *}$ & $17800 \pm 80$ & -19.04 & OS-76597 & $21066 \pm 469$ \\
\hline 0903 T3 7-8 & $301-302$ & $90-10^{* * *}$ & $17800 \pm 65$ & -17.09 & OS76763 & $21210 \pm 322$ \\
\hline 0903 Т3 8-9 & $302-303$ & $>90^{*}$ & $17800 \pm 75$ & -18.46 & OS-76764 & $21069 \pm 464$ \\
\hline 0903 T3 8-9 & $302-303$ & $>90^{* *}$ & $17950 \pm 80$ & -19.8 & OS-76765 & $21403 \pm 274$ \\
\hline 0903 Т3 8-9 & $302-303$ & $90-10^{\star * *}$ & $17850 \pm 70$ & -17.27 & OS-77120 & $21283 \pm 274$ \\
\hline 0903 T3 86-86.5 & $380-380.5$ & $>90^{++}$ & $23800 \pm 110$ & -13.98 & OS-76598 & $28582 \pm 492$ \\
\hline 0903 T3 86-86.5 & $380-380.5$ & $90-10^{* \star *}$ & $24400 \pm 110$ & -16.42 & OS-76766 & $29099 \pm 438$ \\
\hline 0903 T3 86.5-87 & $380.5-381$ & $>90^{++}$ & $20800 \pm 390$ & -15.94 & OS-77227 & $\begin{array}{ll}24922 & \pm \\
1013\end{array}$ \\
\hline 0903 Т3 86.5-87 & $380.5-381$ & $10-90^{\star \star \star}$ & $24100 \pm 130$ & -16.36 & OS-76767 & $28920 \pm 432$ \\
\hline 0901 T4 78.5-79 & $408.5-409$ & $>90^{+}$ & $25800 \pm 160$ & -21.18 & OS-76553 & $30636 \pm 333$ \\
\hline 0901 T4 78.5-79 & $408.5-409$ & $>90^{+}$ & $4120 \pm 40$ & -16.71 & OS-76549 & $4674 \pm 148$ \\
\hline 0901 T4 78.5-79 & $408.5-409$ & $90-10^{* \star *}$ & $25900 \pm 150$ & -16.55 & OS-76860 & $30690 \pm 325$ \\
\hline 0901 T4 76.5-77 & $406.5-407$ & $>90^{+}$ & $24200 \pm 230$ & -25 & OS-76895 & $28986 \pm 509$ \\
\hline 0901 T4 76.5-77 & $406.5-407$ & $>90^{+}$ & $20800 \pm 120$ & -19.39 & OS-76551 & $24776 \pm 345$ \\
\hline 0901 T4 76.5-77 & $406.5-407$ & $90-10^{* * *}$ & $26100 \pm 130$ & -15.72 & OS-76863 & $30818 \pm 338$ \\
\hline
\end{tabular}

Table 7.1: Radiocarbon age details for Forks Lagoon. Ages were calibrated using the online OxCal program. ${ }^{*}$ Isoetes spores and fine organics, ${ }^{* *}$ bulk fine organics, ${ }^{* * *}$ organic sediments, +bulk plant fragments, ++ bulk sedge fragments. 


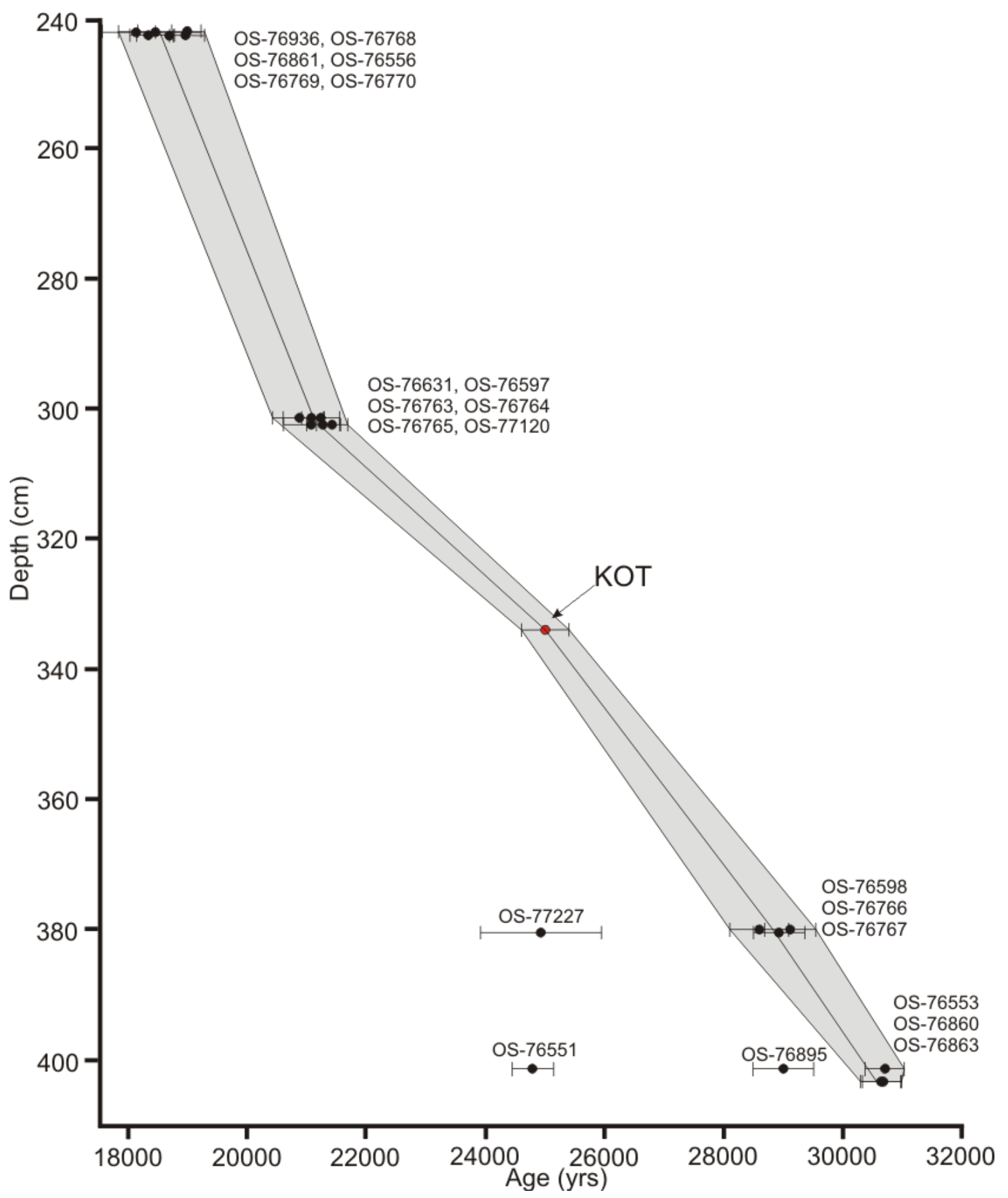

Figure 7.6: Age-depth model using calibrated radiocarbon ages for Forks Lagoon. The red dot is the KOT age estimated by Vandergoes et al (2011). Sample OS-76549 was excluded from the figure because of its apparent young age. 


\subsection{Results}

\subsubsection{Pollen stratigraphy}

The pollen results are described in two sections. Firstly the percentage data are described, and includes all taxa counted (See Appendix F for raw data). Secondly, counts from the pollen concentrates for the aquatic and total dry land pollen are presented. The Isoetes count in all samples is high and therefore the percentage data masks any important abundance changes in the other aquatic taxa. The total dry land pollen concentrates were also calculated to assess whether these related to core colour changes and/or LOI. The percentage and concentration data are presented in Figures 7.7 and 7.8. For each figure the radiocarbon ages are summarised alongside the diagram. The LOI, particle size and a summary of the core colour changes is also added to both figures. The sedimentology will be described in Section 7.5.2 and 7.5.3. The quantitative temperature reconstructions are also added to Figure 7.7 and are described in Section 7.5.4.

For the pollen analysis a $10 \mathrm{~cm}$ sampling strategy spanning $241-401 \mathrm{~cm}$ was used. To produce statistically robust data it is general practice to count a minimum of 250 dry land pollen grains for each sample. However, at Forks Lagoon a count reaching 250 grains for any sample was not possible. A maximum 97 grains were counted for one sample whilst the majority of the slides did not exceed 40 grains and one slide only contained 10 dry land pollen grains. A statistically robust dry land pollen count was not achieved and therefore a reliable vegetation and climate reconstruction cannot be achieved. However there is abundant aquatic pollen. It was therefore decided to continue with the dry land pollen analysis but focus on the aquatic pollen for climatic interpretations. The dry land pollen will therefore only produce a broad context of vegetation in the region with the counts being insufficient to go into any further detail.

The sample preparation used on this site was the same method used on the other sites (refer to Section 3.2) and produced very clean slides. The pollen grains that were present were in good condition and tended not to be obscured allowing any visible dry land pollen to be identified relatively unambiguously. However, the over abundance of Isoetes slowed the process of counting down considerably. To 
speed the process up only one traverse of Isoetes was counted. The exotic Lycopodium count for one transect was also conducted allowing for the concentrations of Isoetes and its percentage for the whole slide to be calculated.

\subsubsection{FL1: 411-395 cm (c. 31.5-c. 30.1yrs)}

The bottom few samples are dominated by herb taxa, in particular Poaceae $<40$ $\mu \mathrm{m}$ combined with low amount of Asteraceae and other herb taxa. Tree taxa occurred at low abundance and include Halocarpus, Fuscospora, N. menziesii. However, the low pollen counts overemphasise the tree abundance as only 1 grain was counted for each taxon. The wetland taxa are dominated by Isoetes.

\subsubsection{FL2: $395-250 \mathrm{~cm}$ (c. 30.1-c. 18.9yrs)}

This zone is dominated by herb taxa, with Poaceae $<40 \mu \mathrm{m}$ the dominant taxa throughout the zone. The herb component represents $100 \%$ of the TDP at $250 \mathrm{~cm}$. Persistent but low abundances of Apiaceae, Chenopodiaceae Gentiana, and Poaceae $>40 \mu \mathrm{m}$ have been derived. A significant but again low shrub component is dominated by Asteraceae and Hebe. Only trace amounts of tree taxa are present in the pollen assemblage. Isoetes continues to dominate the wetland taxa, an unknown grain, called Type A, possibly aquatic algae, is present in significant abundance, particularly between $370-310 \mathrm{~cm}$.

\subsubsection{FL3: $250-209 \mathrm{~cm}$ (c. 18.9 - c. $17.2 \mathrm{yrs}$ )}

Herb taxa is still the dominant vegetation component and Poaceae $<40 \mu \mathrm{m}$ the dominant taxon. This zone shows a small increase to low abundance in Griselinia, Myrsine and Coprosma and a small abundance of Meterosideros. Isoetes remains the dominant aquatic but a significant increase in Myriophyllum abundance occurs up the core, peaking in the topmost sample. 

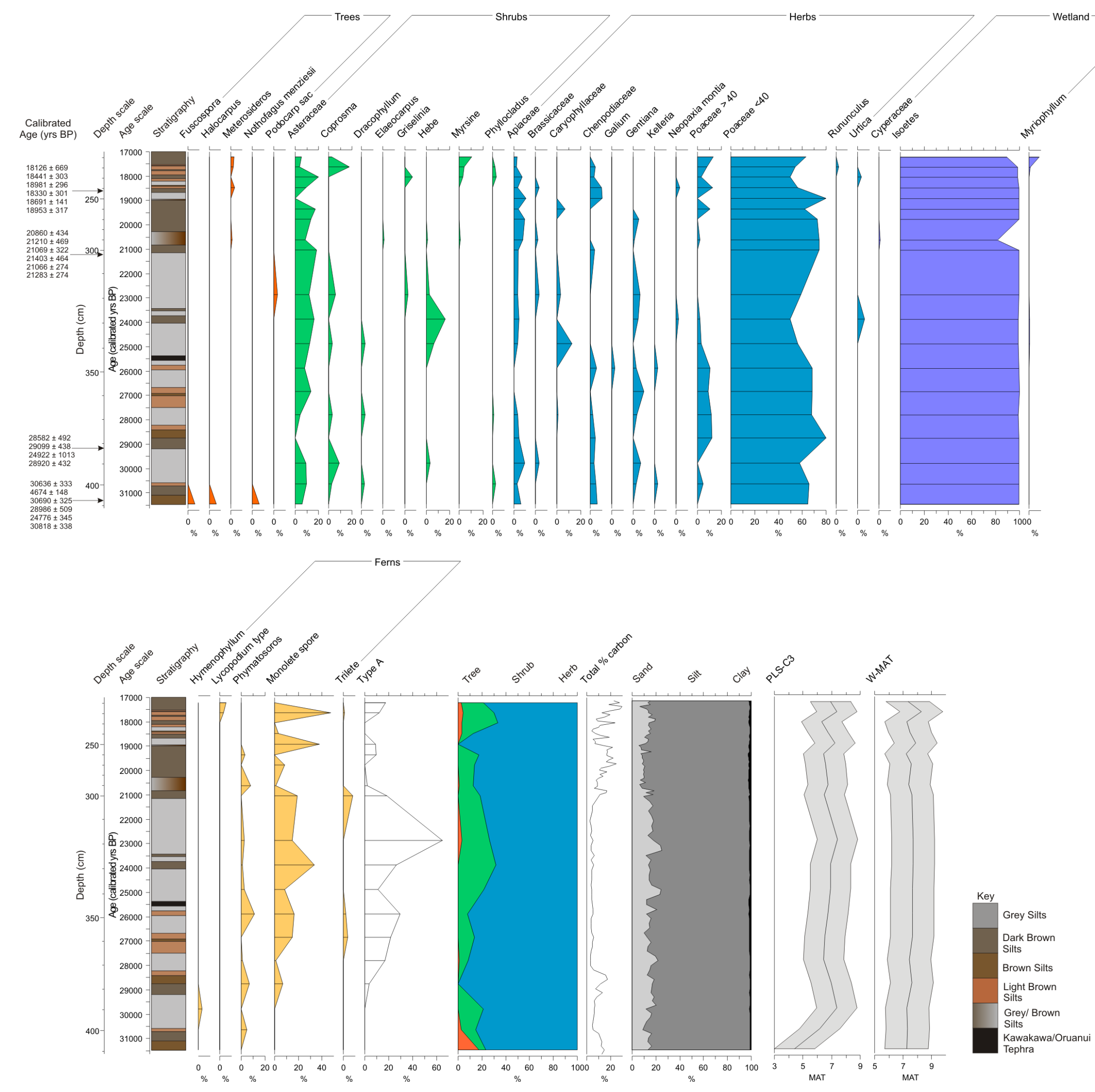

Figure 7.7: Relative percentage pollen diagram of Forks Lagoon with the core colour stratigraphy and sediment analysis added to the figure. 


\subsubsection{Pollen concentrations}

The pollen concentration data illustrate firstly the low concentrations of TDP present in the core and, secondly, the extremely high abundance of Isoetes, which is an order of magnitude greater than any other taxa counted. This is significant, as the large Isoetes concentrations mask the changes in other aquatic taxa, in particular Myriophyllum which at this site provides an important palaeoclimatical signal which would otherwise become unnoticed in the percentage data. At the base of the core to $369 \mathrm{~cm}$ the total dry land pollen abundance consistently increases reaching a peak of $255 \times 10^{3}$ grains $/ \mathrm{cc}$ at $349 \mathrm{~cm}$. The abundance then decreases down to a low concentration at $319 \mathrm{~cm}$ followed by second smaller peak at $290 \mathrm{~cm}$. Again this is followed by very low pollen concentration which increases towards the top of the core and plateauing between 95-105 $\times 10^{3}$ grains/cc between 229-209 cm.

Although consistently present, the concentrations of Isoetes are variable. The bottom $60 \mathrm{~cm}$ contains very high concentrations with an overall increasing, stepwise trend peaking with $36 \times 10^{5}$ grains $/ \mathrm{cc}$ at $351 \mathrm{~cm}$. This is followed by a decrease in concentration to $8 \times 10^{5}$ grains $/ \mathrm{cc}$ at $321 \mathrm{~cm}$. A small increase to $10 \mathrm{x}$ $10^{5}$ occurs at $301 \mathrm{~cm}$ which is again followed by a decrease to only $2 \times 10^{5}$ grains/cc, the lowest concentration in the record, at $291 \mathrm{~cm}$. In the top $70 \mathrm{~cm}$ the Isoetes concentration oscillates between high and low concentrations with the low concentrations getting progressively lower up the core with the topmost sample only receiving $4 \times 10^{5}$ grains/cc.

In contrast to Isoetes, Myriophyllum has a much lower concentration and is more sporadic in appearance. Myriophyllum is absent from the record until $381 \mathrm{~cm}$ where it has very low concentrations until $350 \mathrm{~cm}$ where it rises to a peak of $15 \mathrm{x}$ $10^{3}$ grains $/ \mathrm{cc}$ at $341 \mathrm{~cm}$ and then decreases back to trace amounts at $321 \mathrm{~cm}$. Another small peak at $301 \mathrm{~cm}$ occurs with Myriophyllum again disappearing from the record. At $251 \mathrm{~cm}$ a rapid increase in concentrations occur peaking with $55 \mathrm{x}$ $10^{3}$ grains/cc at the top of the core. 


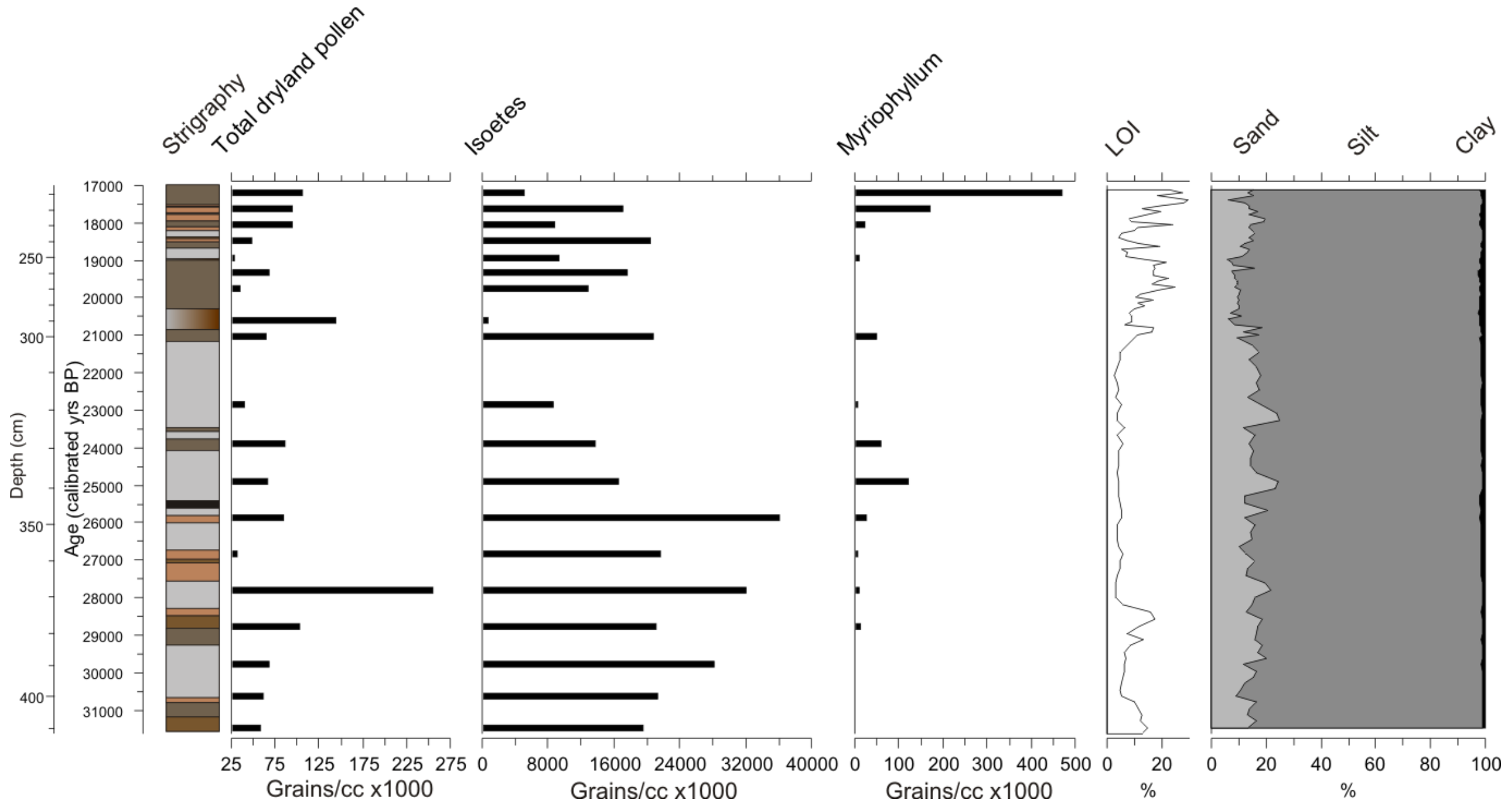

Figure 7.8: Pollen concentrations of the two aquatic taxa and total dry land pollen. Total carbon content and particle size is added for comparison between the results. 


\subsubsection{Particle Size Analysis (PSA)}

Sampling for PSA occurred at a $2 \mathrm{~cm}$ resolution and a sample width of $0.5 \mathrm{~cm}$ thick. Sampling began at $209 \mathrm{~cm}$ and continued down through the core to $411 \mathrm{~cm}$ covering the section of pollen analysis.

Throughout this section the silt fraction was the most dominant particle size, mostly ranging between $80-90 \%$. The percentage of clay also remained constant, ranging $1-2 \%$. However, the sand abundance and consequently changes in the $\%$ of silt abundance varies up the core ranging from $10 \%$ to nearly $20 \%$.

\subsubsection{LOI}

As with the PSA, sampling of LOI analysis occurred every $2 \mathrm{~cm}$ from 209.5 to $411.5 \mathrm{~cm}$. The pattern of carbon content is variable and fluctuates throughout the section analysed, and remains consistently below $30 \%$.

The base of the core, the bottom $38 \mathrm{~cm}$, contains two peaks in carbon content at $403.5-411.5 \mathrm{~cm}$ and $375.5-385.5 \mathrm{~cm}$, ranging $10-14 \%$ and $7-17.5 \%$ respectively. Much lower carbon content occurs between the two peaks, ranging only $2.8-6 \%$. After $375.5 \mathrm{~cm}$ the carbon content again declines to a range of $2.8-6 \%$ and remains stable at these low percentages up through the core until $246.5 \mathrm{~cm}$, after which a more variable carbon content ranging between $4-30 \%$ is evident. However, the majority of samples in this top $40 \mathrm{~cm}$ contain $>10 \%$ carbon and the general trend is a continued increase in LOI. The top $15 \mathrm{~cm}$ receive the highest carbon abundance pattern.

Figure 7.9 compares the location for the organic and inorganic bands in the core with the total carbon content. A consistent pattern is evident where maximum \% carbon occurs with brown or dark brown bands. Conversely, the sections of the core with minimum carbon abundances occur when the core bands are grey. This confirms that the addition of organic material is the cause of the brown sediment colour. 


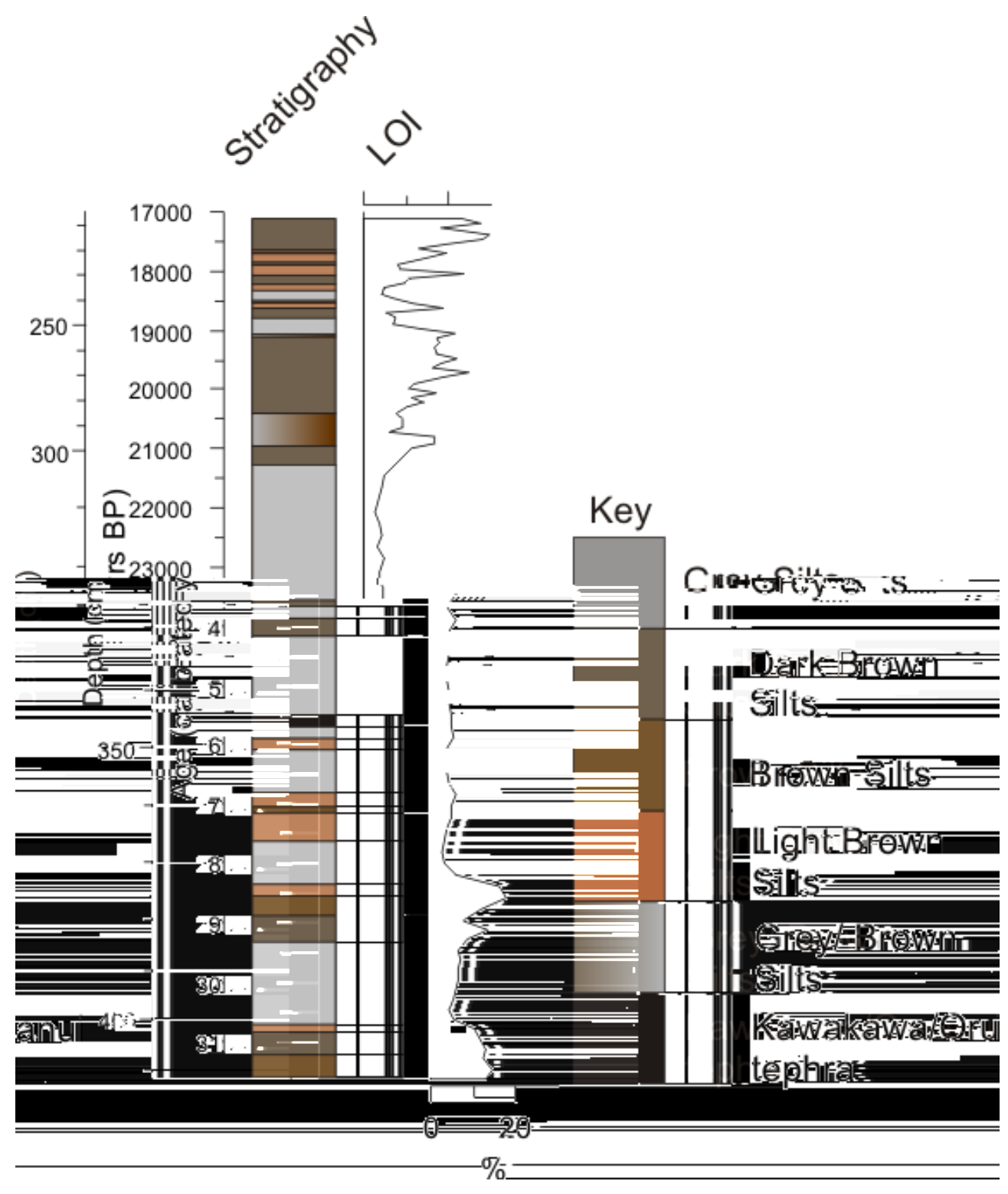

Figure 7.9: A simplified core description showing the location of the colour bands and their relationship with the total \% organic carbon.

\subsubsection{Temperature reconstruction}

Figure 7.7 contains the predicted MAT reconstruction from PLS-C3 and W-MAT. The PSL-C3 model reconstructs an initial increase in MAT from $4.4{ }^{\circ} \mathrm{C}$ at $31.5 \mathrm{ka}$ to $7.4{ }^{\circ} \mathrm{C}$ by $29.8 \mathrm{ka}$. Throughout the rest of the core MAT remains between 6.4$7.4{ }^{\circ} \mathrm{C}$ and averages $6.8{ }^{\circ} \mathrm{C}$ throughout the section analysed. The W-MAT reconstruction shows a small MAT range from $7.1-7.7^{\circ} \mathrm{C}$ recorded for the majority of the core except at $17.2 \mathrm{ka}$ where a maximum MAT of $8.3^{\circ} \mathrm{C}$ is shown. The average MAT predicted by the W-MAT model is $7.5^{\circ} \mathrm{C}$. 


\subsection{Discussion}

This section interprets the pollen and sedimentological results described in the previous section. As aforementioned the dry land pollen can only produce a limited vegetation reconstruction which is discussed first. The aquatic macrophyte and sediment analysis will follow and will be discussed in more detail.

The vegetation in the Mackenzie Basin has been heavily modified by human activity. Today, grassland is the dominant vegetation type in the region with Chionochloa (tall tussocks) sparse but consistently present in the region. Naturally these tall tussocks are restricted to the alpine zone, however in the Mackenzie basin their altitudinal extent has lowered, due to the lack of forest in the lower regions, (Molloy et al, 1963; McGlone and Moar, 1998; McGlone, 2001b; Espie and Barrett, 2006). Therefore contemporary vegetation composition and species relationship with various environmental variables, although insightful, may be misleading for interpreting native palaeo-vegetation communities. To produce a broad regional vegetation context a combination of modern vegetation studies and palaeo-records from the central Canterbury region, and neighbouring areas, will be used to produce a tentative vegetation reconstruction for Forks Lagoon during the LGCP.

\subsubsection{Vegetation reconstruction}

Throughout the 31.4-17.2 ka period the dry land pollen count is exceptionally low indicating a sparsely vegetated region. The pollen that is present is dominated by small tussock and grass taxa, coexisting with tall tussock and other herb taxa. This vegetation assemblage is indicative of alpine grassland/herbfield community. The modern alpine vegetation community in the Mount Cook National Park is dominated by Chionochloa oreophilia, C. pallens, C. crassiuscula, Rytidosperma setifolium and Poa colensoi (Wardle, 1991). It is likely that these species were prevalent in the region during the LGCP. The shrub taxa Asteraceae, Coprosma and Hebe all have low abundances in the pollen record. These taxa also grow in herb forms which are more prevalent in alpine regions. The dominance of grass and herb taxa would suggest that these 'shrub' taxa represent herb forms. 
The top section analysed, 18.9-17.2 ka, contains an increase in Myrsine, a subalpine shrub taxon along with an increase in Coprosma, Griselinia and a small abundance of Meterosideros. McGlone and Moar (1998) recorded a vegetation composition from grassland dominated vegetation and bare ground to grassCoprosma-Myrsine shrubland marking the end of the LGM. This may suggest that the Forks Lagoon record is experiencing climate amelioration at this time. However, the low counts cannot allow for any firm conclusions on climate change at this time.

Overall the DLP is indicative of an open, sparsely vegetated landscape. Any vegetation that is present represents cold-tolerant alpine community vegetation. Based upon this limited information the regional climate was harsh and cold, although this is a tentative conclusion. The modelled temperature reconstructions appear to underestimate the MAT depression with both models estimating temperatures only $1-2{ }^{\circ} \mathrm{C}$ cooler than at present. These modelled results will be discussed further in Section 8.2.4.

\subsubsection{Aquatic macrophyte and sediment records}

Isoetes spores are consistently present in the record with high concentrations indicating that the site was a lake environment throughout the LGCP. There are two species of Isoetes in New Zealand Lakes (Mason, 1975). These are Isoetes alpinus common in montane lakes and I. kirkii, which is more prevalent in lakes at lower altitudes (Brown, 1975). Due to the elevation of the site, it is assumed that the Isoetes spores are I. alpinus. This species can live in a water depth ranging from only 0.1 to a maximum of $4.5 \mathrm{~m}$ and cannot tolerate lake environments were silting is occurring (Brown, 1975). Therefore, Forks Lagoon sustained a water body, albeit shallow, between c. 31.4 - c. $17.2 \mathrm{ka}$.

Myriophyllum is also present in the record although its appearance is comparatively more sporadic and is not continuously present in the record. New Zealand contains five native species of Myriophyllum, but only two which can grow in sub-alpine lakes and tarns; $M$. pendunctulatum and $M$. tryphyllum. In the modern environment $M$. pendunctulatum is observed to prefer boggy/peaty or 
stony substrates along lake margins (Mason, 1975). The pollen grains from this plant are described by Moar (1993) as being tetra-hexaporate, but dominantly pentaporate $(76 \%)$ and sometimes have a varrucate pattern on the exine surface. M. tryphyllum is observed to grow in mid-depth lake zone on sand-sandy silt substrate (Mason, 1975). The pollen morphology ranges triporate-hexoporate with $64 \%$ of grains observed being tetraporate (Moar, 1993). The Myriophyllum grains observed at Forks Lagoon are dominantly tetraporate, with some triporate grains. The exine surface contains no verrucate pattern. The substrate of the core based upon the particle size analysis is a sandy silt. Therefore it is assumed that the Myriophyllum pollen at Forks Lagoon is M. tryphyllum a mid-water depth species.

A modern aquatic plant survey was produced for Lake Alexandrina, located in the Mackenzie Basin c. $2.5 \mathrm{~km}$ east of Forks Lagoon providing a modern analogue to apply on the macrophyte record. In this lake $M$. tryphyllum is restricted to the water depths 2-6 m located in the mid-water depth zone. I. alpinus was restricted to 0.7$4 \mathrm{~m}$ water depth and recognised as a shallow water species (Ward and Talbot, 1984). Other records also show a similar categorisation of $I$. alpinus and $M$. tryphyllum suggesting this water depth pattern is consistent in New Zealand (Brown, 1975). It can therefore be assumed that when M. tryphyllum is present in the macrophyte record, lake levels are deeper compared to periods without $M$. tryphyllum.

Forks Lagoon is a rain fed lake, with precipitation being the only input of water to the lake. As discussed earlier, consistent and high abundance of Isoetes indicates that a lake was continuously present at the site throughout the LGCP. The presence of $M$. tryphyllum is indicative of deeper water levels and therefore potentially periods of increased precipitation. $M$. tryphyllum occurs in the core between 28.7-23 ka although the core only contains significantly high concentrations between 26-24 ka, at 21 ka and 18.9-17.2 ka with the maximum abundance and concentration occurring at the top of the core. This suggests an increase in precipitation in east South Island occurred during the NZ-I CES assigned LGCP milder interval and at the end of the LGM. This will be discussed further in Section 7.6.3. 
The total percent carbon in the record remains low throughout the section analysed, and particularly during the earlier part of the LGCP (Figure 7.9). This confirms a low vegetation biomass in and around the lake as suggested by the TDP record. However, there are distinct fluctuations in LOI which relate closely to core colour changes where increased carbon relates to brown silts and low carbon corresponds with grey silts. The cause for the carbon content changes is not clear. However, two periods of increase M. tryphyllum at $21 \mathrm{ka}$ and between 18.9-17.2 ka corresponds with periods of increased carbon content and suggesting a possible relationship between the two proxies. The increase in $M$. tryphyllum concentrations may represent an increase in plant abundance and therefore an increased input of organic material. The maximum carbon content coincides with the increase in $M$. tryphyllum between 18.9-17.2 ka and also coincides with evidence of shrub increase, possibly confirming climate amelioration had started by $18.9 \mathrm{ka}$. However, the pattern of increased organic content and appearance of M. tryphyllum is not consistent, suggesting other actors are influencing carbon content at the site.

The addition of inorganic material to the site is most probably aeolian derived. The particle size analysis suggests the composition of particles remained relatively unchanged, however, the amount of material reaching the site over certain periods may have changed. Suggate and Almond is (2005) research on loess deposition in the Westland region recognised periods of increased organic content coinciding with glacial retreat. One explanation for this is a reduction in source material and therefore a relative decrease in inorganic sediment and increase in the proportion of organic material. The periods of increased organic content in the Forks Lagoon record may represent periods of reduced wind power to transport the material to the site. This suggests that prior to the start of the LGCP and at the end of the LGM the area was less windy, or there was less source material than during the LGCP, including the milder interval. However, if there is less inorganic material entering the site we would also expect a decrease in sediment accumulation rate which, based upon the available chronology does not seem to occur (see Figure 7.6 and Section 7.4). The cause of the changing carbon is therefore not clearly understood and requires more investigation. 


\subsubsection{Summary discussion}

\begin{tabular}{|c|c|c|}
\hline Core depth interval & Vegetation interpretation & Climate interpretation \\
\hline $\begin{array}{l}\text { FL3 } 250-209 \mathrm{~cm} \\
\text { (c. } 18.9-17.2 \mathrm{ka})\end{array}$ & $\begin{array}{l}\text { Alpine grass and herb taxa } \\
\text { dominate the landscape. } \\
\text { Possible expansion of sub- } \\
\text { alpine/ montane shrubs into the } \\
\text { lowland areas. A lake was } \\
\text { continually present. }\end{array}$ & $\begin{array}{l}\text { Very cold but possibly } \\
\text { beginning to warm. Increase in } \\
\text { precipitation which possibly } \\
\text { continues to increase up the } \\
\text { section. }\end{array}$ \\
\hline $\begin{array}{l}\text { FL2 } 395-250 \mathrm{~cm} \\
\text { (c. } 30.1-\text { c. } 18.9 \mathrm{ka} \text { ) }\end{array}$ & $\begin{array}{l}\text { Alpine grass and herb taxa } \\
\text { dominate the landscape. } \\
\text { Vegetation is sparse in the } \\
\text { environment. A lake was } \\
\text { continually present. }\end{array}$ & $\begin{array}{l}\text { Very cold and harsh } \\
\text { environment. Precipitation } \\
\text { fluctuated throughout the } \\
\text { period. It is possibly increasing } \\
\text { between } 26-24 \text { ka and at } 21 \text { ka } \\
\text { and drier between these } \\
\text { periods. }\end{array}$ \\
\hline $\begin{array}{l}\text { FL1 } 411-395 \mathrm{~cm} \\
\text { (c. } 31.4-\text { c. } 30.1 \mathrm{ka})\end{array}$ & $\begin{array}{l}\text { Alpine grass and herb taxa } \\
\text { dominate the landscape. Very } \\
\text { sparse and open vegetation. A } \\
\text { lake was continually present. }\end{array}$ & $\begin{array}{l}\text { Very cold and harsh } \\
\text { environment with relatively low } \\
\text { precipitation. }\end{array}$ \\
\hline
\end{tabular}

Table 7.2: Summary table of the vegetation and climate reconstructions for Forks Lagoon.

For the period spanning 31.4-17.2 $\mathrm{ka}$ the vegetation remained dominated by alpine herb/grassland with very little, if any, shrub and tree taxa present in the local and regional landscape, indicating a, very cold harsh environments. Drost et al (2007) modelled and simulated climates during the LGM in New Zealand. The results indicate that $\mathrm{ESI}$, including inland Canterbury, had a MAT $4{ }^{\circ} \mathrm{C}$ colder than at present and increased seasonality in temperature, with most cooling during the winter months. The model also predicts an increase in the number and intensity of southerlies, which bring cold polar air into the region, adding to the already harsh conditions that are expected to have been endured. This modelled climate scenario of eastern South Island is supported by the sparse vegetation cover and evidence of hardy cold-tolerant taxa in the pollen record. The limited evidence suggests that the cold conditions started before the LGCP as defined by the NZ-I 
CES, indicating cold conditions were experienced at the site 3-4 ka earlier than the CES.

\subsubsection{Aquatic plant record}

Macrophytes have consistently been used as an open water body indicator and a lake-level change indicator in palaeorecords from around the world (e.g. Grosjean et al, 2001; Vandergoes et al, 2005; Newnham et al, 2007a). However, unlike these other sites, Forks Lagoon is unique as it is possible to interpret the changes in macrophyte abundance from the site as a precipitation signal. This is possible at Forks Lagoon for two main reasons. Firstly Isoetes spores are always present with a high abundance in the core, suggesting a shallow lake was consistently present at the site throughout the period analysed. Therefore, when $M$. tryphyllum is present in the core the only interpretation is that lake level increased and when it is not present then lake level has decreased. Secondly, unlike the majority of the lake and wetland palaoerecord sites, Forks Lagoon is solely rain fed and appears to be a sensitive site to precipitation changes due to its small basin size and low rainfall amount in this area of New Zealand. Therefore, the macrophyte record at Forks Lagoon can be assumed to represent lake level changes caused primarily by precipitation changes.

The onset of the LGCP, pre $26 \mathrm{ka}$, is characterised by drier conditions. Between 26-24 ka and at $21 \mathrm{ka}$, the period spanning the LGCP milder interval is wetter. The wetter periods are interrupted by a period of drier climate spanning 24-21 ka. The third period of increased precipitation, between 18.9-17.2 ka, corresponds with a large increase in \% carbon content and an increase in Myrsine, indicating possible climate amelioration and wetter conditions coinciding with the end of the LGM and Termination I. The NZ-I CES ages Termination I between 19-18 ka and again corresponds closely with the period of wetter climate at the site.

When the timing of $M$. tryphyllum appearance is compared to other records from across New Zealand, the following pattern is observed (see Figure 8.5). Suggate and Almond (2005) reported moraine and loess deposition representing periods of ice advance in northern Westland region that coincide with periods of low or absent $M$. tryphyllum and inferred drier conditions. Similarly, peak grass 
abundance in the Okarito grass curve record by Newnham et al (2007a) and peaks in aeolian quartz dust (Alloway et al, 1992) both indicative of colder climates, correspond with periods without $M$. tryphyllum. Conversely, periods of reduced grass abundance (Newnham et al, 2007a), reduced aeolian quartz accumulation (Alloway et al, 1992) and periods where moraines and loess deposition is not evident in the landscape (Suggate and Almond, 2005), all of which suggest milder climates, coincide with periods of increased precipitation in Forks Lagoon and the surrounding area. The macrophyte record therefore suggests drier conditions in the region prevailed during periods of ice advance whilst the regional climate became wetter during ice retreat in New Zealand.

However, it is important to note that the age of the KOT layer used in the Forks Lagoon record is younger than that used by Alloway et al (1992), Suggate and Almond (2005) and Newnham et al (2007a). Therefore, the records need to be stratigraphically, not chronologically, compared during the deposition of the KOT layer. Despite this age difference, the stratigraphic comparisons produce the same conclusions as described above. Grass abundance decreases in the Okarito record (Newnham et al, 2007a) and M. tryphyllum concentrations increase at Forks Lagoon, just prior to, and continuing after, the KOT layer and both coinciding with the LGCP milder interval. This again supports a wetter climate at Forks Lagoon coinciding with warmer conditions and reduced glacial activity.

\subsubsection{Low pollen counts and lack of tree/shrub pollen}

Throughout the Forks Lagoon sequence the TDP abundance and concentration is extremely low. The abundance and preservation of the aquatic pollen taxa show preservation is not a primary factor in low pollen counts. The land pollen which is present in the record is primarily grass and other herb species, indicating the vegetation cover throughout the analysed section was alpine/grassland communities.

Modern pollen rain studies from alpine areas show the pollen spectra to be dominated by pollen derived from forest located downslope. In these situations alpine grasslands tend to have relatively low representation in the pollen rain (Pocknall, 1982; Moar, 1980; Horrocks and Odgen, 1994). McGlone (2001b) 
attributes this partially to the relatively small pollen source area of the upland regions compared to the surrounding lowlands. However, during the LGCP the upland vegetation would have significantly expanded, increasing the pollen source area. Therefore the pollen source area cannot be the sole factor for the low pollen counts at this site. McGlone (2001b) also notes that there is lower pollen production in the cool sub-alpine/alpine climates. If the vegetation community is dominated by alpine herbs and grasses, the pollen production will possibly be low and with little pollen being produced the amount deposited would also be low, equating to smaller counts. The prevailing wind direction today, and likely to have been throughout the LGCP, is north-westerly. Wind is a large transporter of pollen to a site but north-west of the site lies the Southern Alps mountain ranges. Therefore wind would have firstly come from the glaciated, vegetation free mountain ranges and then over sparsely vegetated land in the periglacial environments. Under these circumstances only sparse local and extra-local vegetation would grow in this harsh environment which perhaps again help explain the low volumes of dry land pollen in the sequence.

To summarise, a number of factors including low pollen production, relatively small pollen catchment and the prevailing wind blowing any available pollen away from the site would have contributed to the low pollen counts in the samples. The volume and composition of dry land pollen at Forks Lagoon is consistent with cold dry conditions in the Mackenzie Basin throughout the LGCP.

\subsection{Conclusion}

Forks Lagoon is a unique site in the region as it is the only one of a few records that extends the LGCP in the interior South Island area. Unfortunately the TDP counts were low throughout the section analysed and a statistically robust count was not achieved. However, this in itself provides some insight into the palaeoenvironment at the site between c. 31.4-17.2 ka. There is a significantly larger abundance of macrophytes, in particular Isoetes and M. tryphyllum which, due to the site's morphology and hydrology, can be used as a precipitation signal. However, the conclusions made for this chapter are tentative and Section 9.2 will suggest the future work needed to develop the record. 
The TDP throughout the record is sparse and dominated by alpine grassland suggesting very cold conditions were felt at the site from c. 31.4-17.2 ka. This also suggest that the LGCP began at least 4000 yrs prior to the NZ-I CES timing of this event and suggest an adjustment for the timing of this event may be needed. The core base from 31.4-26 $\mathrm{ka}$ is a period of drier climate. The LGCP 'milder' interval can be separated into two periods of wetter climates spanning 26-24 ka and at 21 $\mathrm{ka}$, which are interrupted by a period of drier climate. The timing of this drier period corresponds with evidence from other records around New Zealand of glacial advance and a period of cooling. The period 21-18.9 ka is also characterised by drier conditions in the region which is followed by wetter conditions again from 18.9-17.2 ka. This late wet period is combined with an increase in organic carbon content suggesting increase vegetation biomass and the appearance and increase in the shrub Myrsine and other sub-alpine/montane taxa. This possibly indicates the onset of Termination 1 and the end of the LGM in the region. 


\section{Chapter 8: Discussion}

The main aim of this project is to produce four new vegetation and inferred climate reconstructions from southern New Zealand which can be used to test the NZ-I CES and in particular the periods of uncertainty highlighted in the introduction, Section 1.2.2. In this chapter, the results and conclusions for each site are synthesised. The vegetation reconstructions used to compare and test the NZ-I CES are discussed using a time slice approach. Regional differences between sites are also discussed. The significance of the results in the context of comparable records from Antarctica and elsewhere in the mid-latitude Southern Hemisphere follows. Consideration is given to potential drivers of climate change and the changing climatic and oceanic regimes in the Southern Hemisphere. The final section considers the age of the KOT, reviews the NZ-I CES, discusses the wider implications of climate during the LGCP and the quantitative pollen-climate reconstructions. The discussion is followed by the conclusion chapter which will summarise these findings.

\subsection{Time slices}

Since the initial event stratigraphy was published the NZ-I group have subsequently met and discussed ways to develop and move the project forward. One outcome is to concentrate on time slices which are predefined in the preliminary NZ-I CES (Almond et al, 2010). It therefore seems suitable for the discussion chapter to follow a chronological time-slice approach. Unlike the NZ-I CES 30-8 ka time period, the oldest record here extends to c. $38 \mathrm{ka}$ and therefore the time slices start at this age. Figure 8.1 provides a summary of the four reconstructions compared to the preliminary NZ-I CES. It also shows the time slices which will be discussed. Subsequent sections refer back to this figure. 


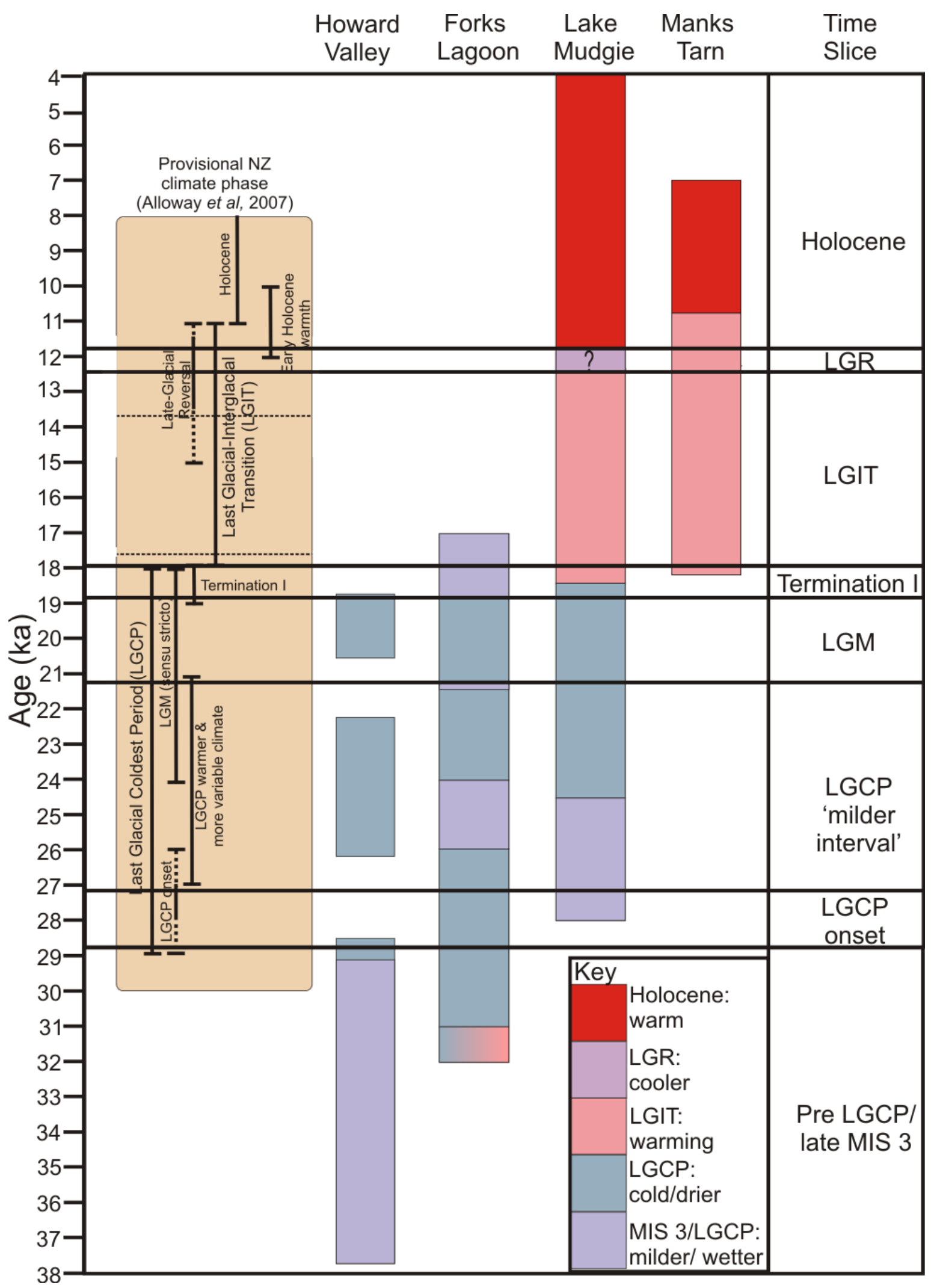

Figure 8.1: An overview of the timing of climate change recorded in the four records of this project and compared with the preliminary NZ-I CES 


\subsubsection{Late MIS 3 and an early LGCP onset}

The two oldest records, Howard Valley and Forks Lagoon, extend beyond the LGCP into the milder, although still cooler than contemporary climate, of MIS 3. The vegetation at Howard Valley between 37.7-34.4 ka is characteristic of a mixed montane Nothofagus menziesii and Fuscospora forest. The estimated treeline lowering from contemporary levels was 400-600 m, implied a MAT depression ranging $2-3{ }^{\circ} \mathrm{C}$. This corresponds with other records from New Zealand which estimate temperatures to have been $3{ }^{\circ} \mathrm{C}$ cooler than today (McGlone and Topping, 1983; Marra et al, 2009). The lowermost part of the Howard Valley sequence therefore implies onset of the LGCP was after $34.4 \mathrm{ka}$.

The Forks Lagoon record extends back to 31.4 ka, roughly 3000 years earlier than the LGCP as defined by the NZ-I CES (Alloway et al, 2007). The low dry land pollen concentrations constrain vegetation interpretations but, in combination with the low total \% carbon, suggest an open and sparsely vegetated region, and very harsh conditions. The macrophyte record suggests the period 31.4-26 ka was relatively dry compared to other periods during the LGCP. These dry conditions combined with the low pollen counts and herb dominated taxa suggest cold and harsh conditions were already established in ESI considerably earlier than the onset of the LGCP (Alloway et al, 2007). Sutherland et al (2007) present exposure ages from lateral moraines in south Westland suggesting a period of glacial advance occurred between 31.9-29.5 ka. Suggate and Almond's (2005) research on moraine and loess deposits from central Westland suggests initial cooling began $\sim 34 \mathrm{ka}$, culminating by $28 \mathrm{ka}$, again supporting an earlier start to the cold period.

The Howard Valley record provides an incomplete reconstruction with a gap between 34.4-28.5 ka. Over this period vegetation changed from mixed montane beech forest to an alpine grassland/sub-alpine treeline vegetation community. A further treeline reduction of 600-900 m represents MAT depression of 3.6-5.2 ${ }^{\circ} \mathrm{C}$ which again suggests conditions similar to those expected during the LGCP. The onset of the LGCP in the NZ-I CES is characterised by a transition from relatively milder conditions to cold e.g. increasing herb abundance at Okarito (Vandergoes et al, 2005; Newnham et al, 2007a) and a decrease in lowland podocarp relative to 
grass pollen at Pukaki (Alloway et al, 2007). The onset of the LGCP in the evidence above is characteristic of a transition from mild to colder conditions. The Howard Valley and Forks Lagoon records suggest cold and dry conditions were already established by 31.4-28.5 ka. This data is consistent with moraine evidence which suggests an earlier onset for the LGCP (e.g. Almond et al, 2001; Suggate and Almond, 2005; Sutherland et al, 2007). This indicates a need for the NZ-I to extend the temporal period included in the NZ-I project remit.

The Northern Hemispheric LGM period of extreme cold, spans 24-18 ka (Mix et al, 2001). Abundant evidence from the Southern Hemisphere points towards an extended cold period, referred to as the LGCP in this project. The LGCP includes the LGM which is the period of most extreme cold conditions and spans 21-18 ka based on the NZ-I CES. For the remainder of this discussion the LGM will refer to the New Zealand period spanning 21-18 ka unless otherwise specified. As mentioned above the NZ-I CES places the onset of the LGCP between 28-29 ka and other evidence around New Zealand, included in this project points towards an even earlier onset of cold conditions. Exposure ages from moraines in southern Chile suggest initial glacial advance began between 35-32 ka (Denton et al, 1999; Fairbanks et al 2005) whilst moraines with exposure ages of $31 \mathrm{ka}$ are found in Tasmania (Fink et al, 2000). The global sea-level curve also shows a rapid decrease in sea level between 33-30 ka (Lambeck and Chappell, 2001; Lambeck et al, 2002) coinciding with evidence of colder climates in the terrestrial records including periods of early ice sheet maximum between 33-26.5 (Clark et al, 2009).

\subsubsection{LGCP}

\subsubsection{LGCP milder interval}

This section concentrates on the LGCP mild interval which interrupts the period of cold between 27-21 ka as defined by the NZ-I CES. The onset of this milder interval was not captured in the total dry land pollen records, however, the evidence does point towards relatively less severe conditions in all three reconstructions compared to the LGM (Figure 8.1). The Howard Valley fragmentary records suggest a similar vegetation composition was present at the site between 28.5-21.9 ka and contained a higher abundance of tree taxa than 
present in the record between 20.2-18.9 ka. The Lake Mudgie vegetation reconstruction contains a relatively high shrub component compared to the samples post $23.2 \mathrm{ka}$ and suggest milder conditions at the site compared to those experienced after $23.2 \mathrm{ka}$ at Lake Mudgie and $20.2 \mathrm{ka}$ at Howard Valley, although conditions were still very cold. The Forks Lagoon aquatic macrophyte record supports a postulated increase in precipitation suggesting conditions were relatively less severe between $26-24 \mathrm{ka}$ and at $21 \mathrm{ka}$ than the drier conditions between 21-18.9 ka. The macrophyte record will be discussed in more detail below (and refer to Section 7.6). These sites suggest that the LCGP milder interval occurred sometime between $28.5-26$ ka to $21.9-21$ ka.

The milder interval in the NZ-I CES spans $27-21 \mathrm{ka}$ and is broadly consistent with the evidence presented in this project. However, the macrophyte record at Forks Lagoon shows a climatically complex milder interval. Two periods of wetter conditions occur between 26-24 ka and at 21 ka which are interrupted by a period of reduced precipitation. Evidence from loess and moraine deposits from the Westland region indicates a period of reduced glacial activity between 28-24.5 ka and 21.5-20.5 ka (Suggate and Almond, 2005). Speleothem records from north Westland region also show two $\delta^{18} \mathrm{O}$ excursions inferred to represent warmer climates during the LGCP (Hellstrom et al, 1998;). Likewise, the Okarito pollen record shows the LGCP milder interval spanning 27-21 ka but interrupted by a period of strong cooling between 25-23 ka (Newnham et al, 2007a).

The sites investigated here are located in different geographical regions of the South Island (Figure 1.2) and the pollen records from each contain different vegetation composition. The Forks Lagoon sequence (ESI) contains extremely low pollen concentrations and low carbon content, indicating a sparsely vegetated region and harsh conditions persistent through the LGCP milder interval. At Lake Mudgie, average herb abundance was $65 \%$, shrub abundance $30 \%$ and tree abundance was only $5 \%$ for the LGCP milder interval. There is a significantly larger abundance of shrubs between 26.6-23.2 ka than 21.3-18.4 ka, which is consistent with milder climates at the site during the LGCP milder interval. Finally Howard Valley contains the highest tree abundance averaging 13\%, with shrub abundance only $21 \%$ and herb abundance is $65 \%$. The $13 \%$ tree abundance 
indicates forest existed within close proximity to the site between 28.5-21.9 ka suggesting this period was milder than between 20.5-18.9 ka, the LGM. The higher abundance of trees and shrubs in Howard Valley indicates that climatic conditions were more favourable at this site than at the others. This will be expanded upon in Section 8.1.3.2.

\subsubsection{2. $L G M: 21$ to $18.9 \mathrm{ka}$}

The timing of the LGM in New Zealand, according to the NZ-I CES, occurs between 21-18 ka, although some records used in the CES suggests it extends back to $24 \mathrm{ka}$. The Lake Mudgie record shows a large decline in shrub abundance beginning at 23.2 ka which would correspond with an earlier LGM. The Forks Lagoon macrophyte record suggests drier conditions also began at $\sim 24 \mathrm{ka}$ to 18.9 ka but were interrupted by wetter conditions at 21 ka coinciding with the timing of milder climates in records elsewhere in New Zealand (Suggate and Almond, 2005; Whittaker et al, 2011) and may reflect a minor reversal in cooling (this is discussed further in Section 8.2.2). The Howard Valley vegetation record suggests that at 21.9 ka the climate in the region was milder than during the deposition of section 1 , aged 20.5-18.9 ka. Section 1 contains significantly lower tree abundance and higher herb abundance than recorded at $21.9 \mathrm{ka}$ and suggests the period of extreme cold in Howard Valley began after $21.9 \mathrm{ka}$. Therefore the three records combined suggest a climate transition from milder and wetter to colder and drier climates began $\sim 23.2 \mathrm{ka}$, but was not the period of greatest cooling. The trend in cooling is instead interrupted at $21 \mathrm{ka}$ which is then followed by a period of prolonged dry and cold climates. Evidence from the records in this project indicates the most prolonged period of harshest conditions occurred between 21 18.9 ka (Figure 8.1).

The LGM is characterised at all sites by an increased dominance of herb taxa, in particular Poaceae. Lake Mudgie contains $83 \%$ herb abundance. Howard Valley herb abundance is $\sim 10 \%$ lower, but also $10 \%$ higher than during the LGCP milder interval. Howard Valley experiences a significant decrease in average tree abundance, reducing from $13 \%$ to $5 \%$, suggesting forest had migrated further away from the site during the LGM. Only trace amounts of tree pollen was recorded in Lake Mudgie which contained a similar shrub component as Howard 
Valley. All three records suggest very harsh, cold and dry conditions whilst conditions at Howard Valley, which contained comparatively more trees and shrubs and less herbs, where not as harsh as experienced in the other sites.

The estimated MAT depressions, based upon pollen assemblages are $3.6-5.2^{\circ} \mathrm{C}$ at Howard Valley and $>5.3{ }^{\circ} \mathrm{C}$ at Lake Mudgie. Therefore, Lake Mudgie has significantly lower minimum temperatures and the largest altitudinal treeline depression of at least $1050 \mathrm{~m}$, compared to 600-900 m lowering at Howard Valley. However, it should be noted that the exceedingly low pollen concentrations and lack of woody vegetation at Forks Lagoon suggest the region also experienced very harsh conditions. Drost et al (2007) modelled a maximum MAT depression of 2.5-4 ${ }^{\circ} \mathrm{C}$ whilst Porter (1975) and Soons (1979) estimated an ELA lowering during the LGM of $800-850 \mathrm{~m}$, which is the equivalent of a $4.5{ }^{\circ} \mathrm{C}$ lowering of MAT assuming an ELR of $0.5^{\circ} \mathrm{C} / 100 \mathrm{~m}$. Ocean core records from west of the South Island estimated MAT lowering of $4-5{ }^{\circ} \mathrm{C}$ during the LGM (Pelejero et al, 2006; Barrows et al, 2007). Therefore both the proxy and simulated evidence points towards a $4-5{ }^{\circ} \mathrm{C}$ cooling during the LGM and complements the estimated temperature and treeline depressions from Howard Valley and Forks Lagoon, but not Lake Mudgie. This will be discussed further below.

McGlone and Bathgate (1983) estimated a $5{ }^{\circ} \mathrm{C}$ cooling during the LGM which would lead to an $800 \mathrm{~m}$ altitudinal lowering of vegetation zones. Based on temperature alone, montane forest would have been able to grow up to $300-400 \mathrm{~m}$ above present sea-level. It is therefore not unexpected that Forks Lagoon, located at 873 m.a.s.l, contains low dry land pollen counts indicative of an open and sparsely vegetated region, suggesting harsh conditions were experienced throughout the LGM. However, Lake Mudgie is only 140 m.a.s.l, $250 \mathrm{~m}$ below the estimated maximum elevation for montane forest growth yet the site contains a pollen assemblage resembling alpine herb and grassland. This suggests that reduced MAT was not the sole cause of tree decline in southern New Zealand. Also, the Howard Valley altitudinal location is $300 \mathrm{~m}$ above Lake Mudgie but contains relatively higher amounts of tree and shrub abundance during the LGM, which indicates a potential difference in regional vegetation and inferred climate. 
Drost et al (2007) modelled LGM climate and suggest cooling was greatest in ESI with temperatures reducing by a maximum $4{ }^{\circ} \mathrm{C}$. The modelled results predict conditions to have been coldest in ESI, however Lake Mudgie's inferred temperature depression suggest Westland experienced colder conditions than predicted. Drost et al (2007) concede that even the maximum amount of cooling predicted would not be sufficient to cause the deforestation evident in the vegetation records. The model output also suggests there was an increase in seasonality, extreme events and the occurrence and intensity of southerly wind flow over the whole of New Zealand, although particularly ESI. This airflow is capable of bringing very cold polar air to New Zealand leading to severe cold conditions. The July 1996 Southland frost can be used as a modern-analogue for this scenario. Temperatures during this event remained below freezing for over a week and reached a minimum $-15^{\circ} \mathrm{C}$. This led to a widespread mortality of indigenous vegetation (Banister, 2003). During the LGM such conditions would have been more frequent and for a longer duration which could explain the lack of tree pollen in the records and regional forest, particularly in inland ESI and exposed areas.

McGlone et al (2010) produced a compilation of LGM pollen records and found, based upon the average vegetation compositions, that New Zealand could be split into four vegetation regions: north North Island (NNI), south North Island (SNI, including north South Island), west South Island (WSI) and east South Island ESI. The tree pollen shows a north to south and west to east decline. Sites east of the Southern Alps contain the lowest tree/shrub abundance ranging 0\%-4.9\%. Conversely, grass abundance is higher in the South Island averaging $88 \%$ in WSI and $98 \%$ in ESI (McGlone et al, 2010). A similar regional variation can be seen in the three records of this project with Howard Valley, the most northern site, containing the highest tree and shrub abundance whilst Lake Mudgie (WSI) and Forks Lagoon (ESI) contain the lower tree/shrub abundances. McGlone et al (2010) suggest the main cause for the paucity of forest in ESI was an increase in southerly winds causing an increased occurrence of severe frost (McGlone et al, 1993; Drost et al, 2007). Harle et al (2004) noted that when tree dormancy is broken around late spring their tolerance to the cold is lost. A period of freezing at this time would be very effective at impeding tree growth. Cold tolerant plants grew 
from current sea-level during the LGM, providing evidence to support the occurrence of frequent cold events (McGlone et al, 2010). However, both Drost et al (2007) and McGlone et al (2010) suggest areas sheltered from these cold southerlies would still be suitable for forest growth. Howard Valley (the most northern site) and the Nelson Lakes region may be an example where pollenvegetation composition reflects relatively less harsh conditions during the LGM. Forks Lagoon, located in ESI is an exposed site located in a region which is predicted to have experienced the most severe conditions during the LGM (Drost et al, 2007; Soons, 1976) and would explain the vegetation composition and very low pollen concentrations at the site. Lake Mudgie would also have been susceptible to these hyper-cold conditions, resulting in the grass dominated pollen assemblage at this lowland site.

It is also important to comment on the method used to estimate MAT depressions at the site. The national mean annual ELR of $0.5{ }^{\circ} \mathrm{C} / 100 \mathrm{~m}$ was applied to the estimated vegetation zone depressions to estimate MAT depression. However, as mentioned in Section 3.2.6, ELR's are variable on both spatial and temporal scales. Howard Valley is located further inland, at a higher altitude and experiences lower mean annual precipitation than Lake Mudgie. Research by Meyer (1992) suggests that in drier areas the ELR is generally higher than in wetter regions. Therefore it would be expected that the ELR used for Howard Valley may be lower than one used on Lake Mudgie. This may mean the ELR used at both sites may be overestimating or underestimating MAT depressions. If possible, regional ELR would be useful but there are insufficient observational data and research on ELR. The limitations with the ELR methodology may also have some impact on the different MAT depression estimates for each site.

Estimates of precipitation from the dry land pollen records are difficult to assess as it is difficult to determine a direct relationship between vegetation assemblage and precipitation alone (Wilmshurst et al, 2007). Temperature depressions during the LGM would have had a significant influence on vegetation type at the time. However, the lack of high precipitation taxa, such as tree ferns, drought intolerant tree taxa, and a low shrub component could possibly also imply a decrease in precipitation. The Forks Lagoon macrophyte record also implies a decreased 
precipitation in the Mackenzie Basin and ESI. Therefore, all three sites point towards drier conditions in the South Island during the LGM.

\subsubsection{Global context of LGCP}

Exposure ages from moraines in Tasmania date two periods of ice advance, the earliest at $31 \mathrm{ka}$ and the second, marking the onset of the LGM, at $24 \mathrm{ka}$ (Fink et al, 2000). Vegetation reconstructions show a landscape dominated by herb and grass taxa implying a MAT $4{ }^{\circ} \mathrm{C}$ colder than today and ranging $3.7-4.2^{\circ} \mathrm{C}$ (Fletcher and Thomas, 2010). Conditions were also drier than contemporary environments, with the period of main ice advance suggested to be restricted to 20-19 ka (MacPhail, 1979). Tasmania therefore appears to show similar timings of glacial advance, vegetation composition and inferred climate as New Zealand during the LGCP. Exposure ages from the Chilean Lake District (CLD) dated glacial advance beginning late MIS 3 at 35 and 32 ka (Fairbanks et al, 2005), whilst Denton et al (1999) concluded that full glacial conditions persisted in northern CLD between 29.4-14.55 ${ }^{14} \mathrm{C}$ ka. Mean summer temperatures were reduced by $6-8{ }^{\circ} \mathrm{C}$ and equilibrium line altitudes (ELA) lowered by $1000 \mathrm{~m}$. In Laguana del Maule region snowline depression is evident after 30 ka whilst glacial advance and retreat occurred between 25.6-23.3 ka (Singer et al, 2000). In Lago Buenos Aires, Kaplan et al (2004) and Douglass et al (2006) record two ice advances at 23 and $16 \mathrm{ka}$ with the period of maximum ice advance at $23 \mathrm{ka}$ and ELA lowering by $900 \mathrm{~m}$. Also in the strait of Magellan LGM moraines were deposited between 25-17 ka (McCulloch et al, 2005; Kaplan et al, 2008). Kaplan et al (2008) concluded that a cold period, similar to the NZ-I LGCP, occurred between c. 30-16 ka in southern Patagonia, although some ages suggest ice advance occurred earlier, and a period of greatest cooling was sometime between 25-17 ka.

To summarise, in New Zealand the LGCP persisted from at least $31.4 \mathrm{ka}-18.9 \mathrm{ka}$ based upon the records used in this project. As discussed in Section 8.1.2 the onset of the cold period appears to be earlier than suggested by the NZ-I CES and is supported by a number of records both in New Zealand and elsewhere in the Southern Hemisphere (e.g. Heusser, 1981; Denton et al, 1999; Fink et al, 2000; Fairbanks et al 2005; Suggate and Almond, 2005). The LGCP is climatically complex with evidence of three drier periods from 31.5-26 ka, 24-21 ka and 21- 
18.9 ka coinciding with periods of glacial advance and increased westerly wind intensity (Alloway et al, 1992; Suggate and Almond, 2005; Newnham et al, 2007a; Anderson et al, 2009; Whittaker et al, 2011). Wetter conditions interrupted these dry periods and also mark the end of the LGM, again coinciding with periods of ice retreat and reduced westerly wind intensity (Alloway et al, 1992; Suggate and Almond, 2005; Newnham et al, 2007a; Anderson et al, 2009; Whittaker et al, 2011).

\subsubsection{Termination I (18.9-18.4 ka)}

Termination I (Figure 8.1) marks the end of the LGM and the start of climate amelioration which the NZ-I CES places between 18-19 ka. The records used in the NZ-I CES and other records from across New Zealand are broadly synchronous. Likewise the timing of Termination I in the vegetation reconstructions used in this project closely matches the NZ-I CES. At Forks Lagoon climate begins to get wetter and presumably warmer at $18.9 \mathrm{ka}$ whilst the onset of vegetation change at Lake Mudgie starts at $18.4 \mathrm{ka}$. The pattern of climate change from each site is marked by a decrease in herb abundance and an increase in the shrub and tree component. At Lake Mudgie, average herb abundance decreases by $10 \%$ whilst the shrub abundance increases to $21 \%$ and tree abundance to $4 \%$.

The Howard Valley record is different from the two above as a clear vegetation change marking the start of Termination I is not recognisable. Therefore, the calculated vegetation composition at Howard Valley was derived from averaging the top samples from section 1. Herb abundance at this site decreases by $20 \%$ and shrub abundance reaches an average 34\%. The tree component also increases to $8 \%$. However, the pollen assemblage and vegetation pattern at the time was erratic and changes significantly from one sample to the next. The large shrub component was dominated by Asteraceae which comes in both shrub and herb forms, the later being more representative of alpine/sub-alpine vegetation. The increased shrub component may not necessarily represent climatic amelioration. However the vegetation record does show a changing vegetation community suggesting an unsettled environment preventing a stable community establishing at the site. This may represent a disturbance caused by ice melt leading to flooding events causing these disturbances. Therefore, this instability 
may be linked to climate change but the age of section 1 may also be too old to capture the event which may explain the lack of a clear Termination I in the vegetation record.

Unlike the other sites, Manks Tarn provides only a postglacial vegetation reconstruction. The pollen assemblage at the core base contains little herb and grass taxa and is dominated by the shrub component by the start of sediment deposition. However, the base of this record is dated $18.1 \mathrm{ka}$, only 300 years younger than the age of the onset of Termination 1 at Lake Mudgie and given the error of ${ }^{14} \mathrm{C}$ dating the ages are broadly the same. Before shrub vegetation can establish the site first needs to be ice free, become geomorphically stable, been inhabited by primary colonisers and had soil developed, all of which would take some time. This means the area was ice free prior to $18.1 \mathrm{ka}$ and colonisation of the site, once initiated, was rapid.

The pollen assemblage at the base of the Manks Tarn record is similar to Lake Mudgie pollen zone LM1c suggesting the base of Manks Tarn pollen record marks the end of Termination I indicating the onset of deglaciation occurred not long prior to $18.1 \mathrm{ka}$.. The pattern of deglaciation at Lake Mudgie also suggests a change from herb taxa to shrub-dominated vegetation taking up to $\sim 800 \mathrm{yrs}$. This is marked by a rapid decline in grass abundance coinciding with Myrsine and Coprosma shrub increase. A range of evidence from both terrestrial and marine records from New Zealand and surrounding oceans suggests a marked climatic amelioration began sometime between 19-17.3 ka (e.g. Newnham et al, 2003; Vandergoes and Fitzsimons, 2003; Alloway et al, 2007). A similar age of Termination I is recorded in Pukaki Basin on the eastern side of the Southern Alps (Schaefer et al, 2006; Vandergoes et al, 2008; Putnam et al, 2010a). Given the errors associated with radiocarbon dating the timing of this event recorded in this project is consistent with other records from across New Zealand and corresponds with the NZ-I CES range of 18-19 ka. 


\subsubsection{Termination I: Global context}

Termination I or the start of deglaciation is recorded in a number of different proxy records spanning a range of geographic, geologic and climatic regions elsewhere in the mid-latitudes of the Southern Hemisphere. Like New Zealand's records, South America shows a broadly synchronous timing and pattern for this event. Termination I occurs $\sim 18.9-17 \mathrm{ka}$ and is marked by rapid ice retreat and vegetation response to climate amelioration (McCulloch and Davies, 2001; Moreno and León, 2003; Kaplan et al, 2004; Douglasse et al, 2006; Boës and Fagel, 2008; Kaplan et al, 2008). Further south the Antarctic ice core records suggest Termination I to have occurred sometime between 19-17 ka (Blunier et al, 1998; Petit et al, 1999; Jouzel et al, 2001; Blunier et al, 2001). Termination I is not only hemispherically synchronous but appears to be globally synchronous. Clark et al's (2009) global collation of ${ }^{14} \mathrm{C},{ }^{10} \mathrm{Be}$ and ${ }^{3} \mathrm{He}$ ages suggest the deglaciation began between 20-19 $\mathrm{ka}$ in the Northern Hemisphere and 19-18 $\mathrm{ka}$ in the southern hemisphere. Schaeffer et al (2006) also concluded a similar interhemispheric timing for deglaciation based on moraine exposure ages and suggested that the most straight forward explanation for a synchronous timing of the end of the LGM is a global rise in summer temperatures.

\subsubsection{LGIT (18.9-10.8 ka)}

The LGIT Figure 8.1) is a period characterised by climate amelioration, glacial retreat, and a change from herb and grass dominated vegetation to a gradual increase in woody vegetation both in richness and diversity. The NZ-I CES ages the period of climate amelioration as spanning 18-11.6 ka with a period of brief cooling interrupting the pattern of warming between 13.5-11.6 ka (Alloway et al, 2007). In this project, only two sites record the pattern of deglaciation, both of which are located in the Westland region (Lake Mudgie and Manks Tarn). Both records show a four stage vegetation pattern change that is related to climate warming and potentially precipitation change. Initially the onset of climate amelioration and the early stages of LGIT are dominated by Coprosma/Myrsine shrub growth, beginning at 18.4-18.1 ka. Increased warming is followed by the second vegetation stage characterised by the spread of Griselinia, Libocedrus and Pseudopanax joining the Coprosma/Myrsine shrub component, increasing 
vegetation diversity and producing a low lying broadleaved tree and shrub community at 16.3-15 ka. The increase in Griselinia may also indicate an increase in precipitation. The third phase of warming, occurring between 14.3-13.9 ka, is characterised by the increase in the montane/lowland taxon, Weinmannia. The rise of Weinmannia is greater in Manks Tarn compared to Lake Mudgie but both records suggest a continued warming and increased precipitation. The final stage of warming occurs at 13.2-12.4 ka and is characterised by a rapid increase in $D$. cupressinum dominated podocarp/hardwood forest (Figure 8.2). The vegetation composition change indicates an increase in drought intolerant taxa towards the later stages of the LGIT and continued warming throughout the LGIT. No irrefutable climatic reversals are evident in either record, although a LGR cannot be completely ruled out (the LGR will be discussed in more detail in the following section).

The pattern and timing of the vegetation change as described above (see Figure 8.2) is strikingly similar between the records and shows a strong regional pattern to climate change. The timing of vegetation change and pattern of taxa appearance is also similar to the Okarito vegetation pattern during the LGIT, except instead of Weinmannia racemosa, Metrosideros is present (Newnham et al, 2007a). These vegetation reconstructions show that once conditions are suitable, a rapid expansion of vegetation occurs and follows a specific vegetation succession. Lake Mudgie has a less well constrained chronology than Manks Tarn, but due to the same distinct vegetation patterns and abrupt transitions evident in both records it is possible to use the Manks Tarn record to better validate the timing of some vegetation transitions.

At both Manks Tarn and Lake Mudgie a sudden increase followed by a persistent abundance of Isoetes alpinus occurs between 16.3-12.4 ka and 15.6-13.2 ka, respectively. The timing is broadly synchronous between the records, suggesting conditions to promote $I$. alpinus growth were similar at each site. $I$. alpinus is an aquatic macrophyte restricted to a shallow lake level depth range of $0.4-4 \mathrm{~m}$ (Brown, 1975; see Section 7.6.2). Therefore its presence is indicative of an open water, albeit shallow, environment. Its occurrence in both records has been attributed to a lake level lowering unrelated to a direct climate influence but rather 
a process of gradual terrestrialisation of the site. This is visually evident in the Lake Mudgie core as a transition from blue-grey inorganic laminated lacustrine silts, to brown silts culminating in organic rich brown mud. The occurrence of $l$. alpinus coincides with the transition from grey inorganic silts to organic brown silts, suggesting increased organic material was entering the site and indicating terrestrialisation was occurring. However, recent research from Fletcher and Moreno (2011) uses the pattern of $I$. alpinus abundance at Okarito, south Westland region, as a precipitation signal during the LGIT. An increase in I. alpinus abundance was inferred to relate to increased precipitation. Conversely a decreased $I$. alpinus abundance is representative of drier conditions. Therefore a more rigorous discussion on $I$. alpinus appearance in the Westland sites is necessary.

As mentioned above the stratigraphic changes at Lake Mudgie clearly show a gradual transition from a lake environment to a terrestrialised boggy environment. The Manks Tarn stratigraphy is composed of homogenous brown detrital mud containing no visible evidence of sedimentological change. However, at both sites evidence in the pollen and sediment records also point towards terrestrialisation. The PCA results from both sites indicate $I$. alpinus appearance is in close relationship with Coprosma, Griselinia, Myrsine, Pseudopanax and Pseudowintera. These taxa inhabit the montane/sub-alpine zone and suggest conditions were milder than the LGCP although still colder than contemporary conditions. The presence of these taxa combined with evidence of increased total $\%$ carbon in the sediment indicates an increased organic component was entering the lake environment and contributing to sediment accumulation. The coincidence of $I$. alpinus with warmer climates may represent an indirect response to climate change whereby the increase in temperature led to greater vegetation productivity and organic material entering the lake; an additional contribution to sediment accumulation which resulted in decreased water levels.

The appearance of Leptospermum type in both records after the initial rise of $I$. alpinus also indicates a continued lake level lowering. In the contemporary environment, Leptospermum type is dominant on peat bog margins and poorly drained areas such as lake margins (Wardle, 1979). Its appearance with I. alpinus 
suggests the lake fringes were becoming increasingly terrestrialised, which would have enabled Leptospermum type to establish progressively closer to the core site. The continued high abundance of Leptospermum type after I. alpinus disappearance from the record suggests the core site no longer contained an open water body. Instead the area was fully terrestrialised but poorly drained providing suitable conditions for continued Leptospermum type growth. The pollen, sediment and stratigraphic evidence all point towards terrestrialisation causing lake levels to lower and promoting I. alpinus growth. The results do not appear to represent a precipitation signal.

Other records from the Westland region, e.g. Okarito and Gillespie Beach Road sites (see Vandergoes and Fitzsimons, 2003; Newnham et al, 2007a), also show a significant change in I. alpinus abundance during the LGIT. Okarito shows a similar stratigraphic change and I. alpinus pattern as the Lake Mudgie record with an abrupt increase of $I$. alpinus to nearly $100 \%$ at $14.2 \mathrm{ka}$ and dropping to $0 \%$ at $12 \mathrm{ka}$. This coincides with a stratigraphic transition from blue-grey silts to brown organic silt. This is followed by the sustained appearance of Empodisma, Cyperaceae and Leptospermum type, all of which are representative of peat bog/wetland environments (Wardle, 1979). The disappearance of $I$. alpinus at Okarito, at a similar timing as in Manks Tarn and Lake Mudgie, suggests there is no longer an open water body at the core location. At all these sites, therefore, lake level lowering is caused by gradual terrestrialisation of the site during the LGIT. However, Fletcher and Moreno (2011) suggest the oscillation in the I. alpinus abundance during this period represents a precipitation signal. These findings question the interpretation of Fletcher and Moreno (2011) that the $I$. alpinus oscillation at Okarito during this period represents a precipitation signal. 

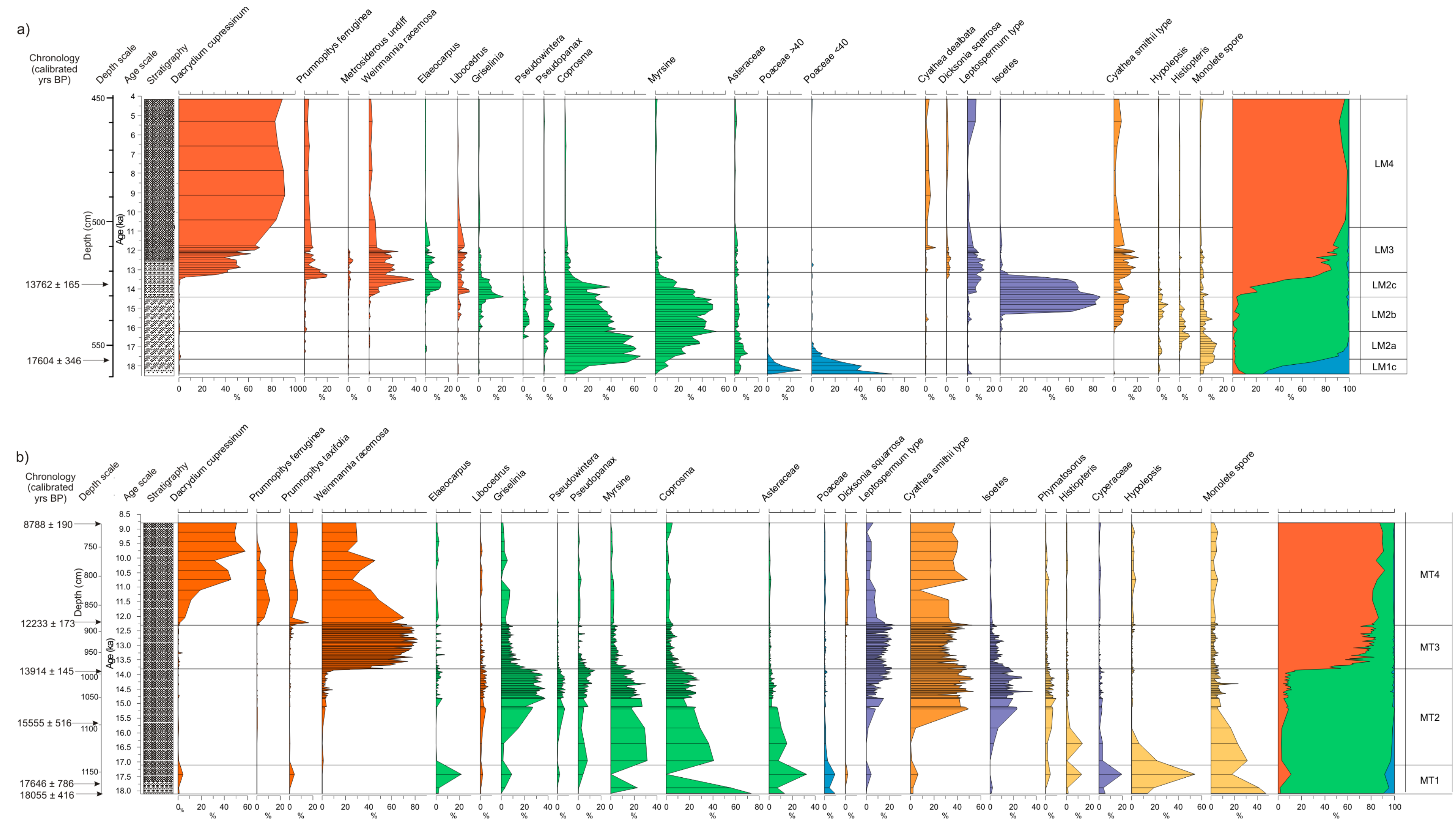

Figure 8.2: Comparison of Lake Mudgie and Manks Tarn LGIT vegetation pattern. The dry land pollen is in order of appearance followed by the wetland, tree fern and fern pollen. 


\subsubsection{Late Glacial Reversal (LGR)}

The Manks Tarn vegetation reconstruction points towards a continuous pattern of forest development and inferred temperature and precipitation increase from the start of deglaciation to the early Holocene (18.1-10.8 ka). The Lake Mudgie record indicates a minor reversal in forest development between $520-510 \mathrm{~cm}$. This is characterised by a disturbance and small decline in Dacrydium cupressinum growth combined with a minor increase in Weinmannia, Libocedrus and Elaeocarpus. These taxa were more prevalent deeper in the core, while Fuscospora, Chenopodiacae and Gonocarpus were also present in low abundance during the LGCP. A distinct lithostratigraphic change occurred at the same time, characterised by an influx of clay size particles into the site, suggesting some form of environmental disturbance in the area. The slight increase in colder tolerant taxa at the expense of $D$. cupressinum may indicate a period of minor cooling. Both models used in the transfer function suggest a cooling event is visible although the temperature depressions predicted by each model are very different. There are also a number of limitations with these models which are discussed in Section 8.2.4 and therefore these temperature reconstructions are tentative. On the basis of the Lake Mudgie chronology, this event occurred between 13.4-11.9 ka broadly coeval with other evidence of late glacial climate reversals from elsewhere in New Zealand (Newnham and Lowe, 2000; Turney et al, 2003; McGlone et al, 2004; Williams et al, 2004; Newnham et al, 2007a, Vandergoes et al, 2008; Kaplan et al, 2010).

Although the above cooling inference is plausible, coinciding with the disruption in D. cupressinum growth is a small peak in Prumnopitys ferruginea and an increase in the tree fern Cyathea smithii. Both species indicate increased precipitation and continued warming (Wardle, 1991) and are abundant in significant numbers at a similar timing in Manks Tarn. Some other records from New Zealand also show limited or no evidence of climate cooling but rather suggest there was an increase in precipitation at the time (McGlone, 1995; Singer et al, 1998; Vandergoes and Fitzsimmons, 2003). Also, a flux of coarser material is usually representative of a cooling event (Newnham et al, 2007a), whereas at Lake Mudgie, an increase in finer particles is recorded. These two scenarios: precipitation forced and temperature forced vegetation disruption will be discussed below. 
Controversial evidence for a late glacial ice advance has been suggested from the Waiho Loop Moraine, southern Westland (see Section 2.6.1.1 for more detail). Modelling climatic parameters needed to cause the Franz Josef Glacial to advance as far as the Waiho Loop, Anderson and Mackintosh (2006) estimated a $3-4.7^{\circ} \mathrm{C}$ cooling in MAT would be necessary when assuming no change in precipitation. The upper end of this temperature depression range is similar to that experienced during the LGM. This amount of cooling is not represented in proxy records which suggest a maximum of $2-3{ }^{\circ} \mathrm{C}$ cooling during this period (Newnham et al, 2007a; Vandergoes et al, 2008; Newnham et al, 2011) and a treeline depression of only 100-200 m (Newnham et al, 2007a). The small disturbance in forest development and minor increase in cool tolerant taxa at Lake Mudgie suggest only a very minor cooling would be experienced, if at all, during the LGR period and likewise does not support a $4{ }^{\circ} \mathrm{C}$ cooling.

Some records in New Zealand show little or no evidence of a cooling event occurring during the ACR/YDC interval. Instead there is some evidence to suggest an increase in precipitation occurred over New Zealand at this time caused by an increased intensity of the southern westerlies and in turn resulting in a glacial advance (Singer et al, 1998; Vandergoes and Fitzsimons, 2003; Robinson et al, 2004). Both the Lake Mudgie and Manks Tarn vegetation reconstruction point toward very wet conditions at 13.4-11.9 ka with the Lake Mudgie record suggesting the region experienced an increase in precipitation. However, Anderson and Mackintosh's (2006) model results estimates precipitation would need to increase $330-450 \%$ from current levels to induce a glacial advance reaching the Waiho Loop, assuming no temperature depression was experienced as well. This region already experiences exceptionally high precipitation and a $330-450 \%$ increase seems to be implausible.

An alternative scenario to consider is a combination of the two postulates above whereby an increase in precipitation is accompanied by a decrease in temperature. Anderson and Mackintosh (2006) showed a $3.2{ }^{\circ} \mathrm{C}$ cooling combined with a $39 \%$ increase in precipitation from existing levels would be sufficient to advance the Franz Josef Glacier to the Waiho Loop location. However this scenario still appears to be inconsistent with palaeoecological 
reconstruction. A MAT decrease of $3.2{ }^{\circ} \mathrm{C}$ would cause a $640 \mathrm{~m}$ vegetation depression. Under these conditions, at Lake Mudgie, at 143 m.a.s.I, montane forest including Weinmannia racemosa, Libocedrus bidwillii and a subcanopy of Myrsine divaricata, Griselinia lucida, G. littoralis, Pseudopanax simplex, Pseudowintera colorata, and Coprosma foetidissima (Wardle, 1977) would dominate. Although a small increase in some of these taxa are evident in the Lake Mudgie record, Dacrydium cuppressinum remains the dominant species. The upper growing limit of a D. cuppressinum dominated forest is 500 m.a.s.l, $350 \mathrm{~m}$ above the Lake Mudgie site. A maximum MAT depression, which could still produces a $D$. cuppressinum dominant vegetation community, would be $\sim 1.8{ }^{\circ} \mathrm{C}$ and is significantly lower than the Anderson and Mackintosh (2006) estimate. Instead the Lake Mudgie MAT depression is more consistent with other palaeoenvironmental reconstructions (e.g. Newnham and Lowe, 2000). However, $D$. cupressinum have reasonably well dispersed pollen and therefore a high abundance of this taxon could still be deposited in the pollen record potentially masking the true degree of cooling at the time. Vandergoes and Fitzsimons (2003) also concede that the vegetation characteristics from the lowland Westland region, which experiences high precipitation amounts, may not provide a climatically sensitive enough proxy to pick up a relatively minor short-term temperature decrease. Therefore this minor disruption in the Lake Mudgie pollen record may have underrepresented any cooling experienced in the region.

The Okarito pollen record shares a similar problem to Lake Mudgie, as it also shows a minor disturbance in the vegetation record. This was initially discounted as a cooling episode by Vandergoes and Fitzsimons (2003), but later revised by Newnham et al (2007) as representing a LGR. The original paper by Vandergoes and Fitzsimons (2003) contained results from three sites in south Westland but only Okarito showed a possible LGR, with the other two, like Manks Tarn, indicating a continuous pattern of forest development. However, elsewhere in New Zealand LGR is more clearly defined e.g. Kaipo Bog (Newnham and Lowe, 2000), Kettle Hole Bog (Turney et al, 2003), Boundary Stream (Vandergoes et al, 2008). Again, it should be noted that the lowland vegetation composition from Westland may not be sensitive enough to record a reversal, unlike the regional vegetation 
from the other sites mentioned above. From the evidence reported above the status of an LGR in Westland remains inconclusive although as discussed above the data are not inconsistent with a scenario of minor temperature depression accompanied by minor precipitation increase.

Recently, Newnham et al (2011) suggested the timing, extent and temporal length of the LGR has a latitudinal pattern. Using quantified estimates of MAT the extent of cooling could be assessed, albeit with broad errors, and the results indicating a northward decrease in cooling. Okarito, in south Westland, shows a $2{ }^{\circ} \mathrm{C}$ cooling, Kaipo bog in central North Island reconstructs a $0.5-1^{\circ} \mathrm{C}$ cooling and Pukaki, from northern North Island, estimates a maximum MAT cooling of only $0.5^{\circ} \mathrm{C}$. The timing of this cooling phase also differs from site to site with cooling occurring earlier at Okarito, beginning at $14.1 \mathrm{ka}$, and latest at Pukaki (beginning at $13 \mathrm{ka}$ ). Lake Mudgie is located near to Okarito and it can be expected that a similar pattern of cooling would be experienced at the two sites. The qualitative vegetation reconstruction for Lake Mudgie does not clearly show a climate reversal except for the possible disturbance between 13.2-11.9. The quantitative pollen-climate reconstructions propose a different conclusion however.

Lake Mudgie's quantitative pollen-climate reconstructions indicate a cooling trend between 13.2-11.9 ka, although these results are tentative. This is $1 \mathrm{ka}$ later than at Okarito, and more closely aligned with the timing of cooling at Pukaki. However, this could be a factor of the limited chronology for the Lake Mudgie record causing the temporal disparity. The Boundary Stream record located in the Mackenzie Basin, also dates the LGR between 14.2-13.2 ka, again implying the Lake Mudgie age is unexpectedly young. The extent of estimated cooling ranges $1.3-2.2^{\circ} \mathrm{C}$ for the W-MAT model and 2.1-4.8 ${ }^{\circ} \mathrm{C}$ for the PLS-C3 model, the latter appearing to be overestimating MAT depressions. The extent of cooling, particularly the W-MAT, is similar to the cooling estimated at Okarito. Lake Mudgie vegetation record, as mentioned above, also suggests an increase in precipitation occurred during the period. This also corresponds with the Anderson and Macintosh (2006) scenario of $2.2{ }^{\circ} \mathrm{C}$ cooling combined with a $39 \%$ increase in precipitation. However, it should be stressed that there are limitations with the quantitative pollen-climate models impeding firm conclusions of temperature change at the site (Section 
8.2.4). To conclude, the LGR is neither ruled out nor confirmed by the evidence presented here.

\subsubsection{LGIT global context}

Antarctic ice core records suggest a two step warming during the LGIT between $18 \mathrm{ka}$ and $14 \mathrm{ka}$. The warming pattern is interrupted by a cold reversal with lowest temperatures reached between $13.5-12.5 \mathrm{ka}$. This is followed by a second warming phase reaching Holocene conditions by $11.5 \mathrm{ka}$. An overall $9{ }^{\circ} \mathrm{C}$ temperature range from the LGM to Holocene was recorded in the Antarctic EPICA Dome C ice core record (Jouzel et al, 2001). Evidence from Australia shows a similar pattern as New Zealand, again showing a rapid response to climate amelioration. The Lake Selina record, Tasmania, shows a LGR occurring between 13.5-11.7 ka (Colhoun et al, 2010) whilst Turney et al (2004) and Muller et al (2008), report a period of wetter climate in north-eastern Australia between 13.5-12.5 ka. Both records suggest a southward migration of the ITCZ and zonal movements of mid-latitude storm tracks causing wetter conditions to be experienced in north-eastern Australia coinciding with the ACR and the Northern Hemispheric Bølling-Allerød interval. Southern Ocean marine records also suggest a cooling event occurring coincidently with the ACR (Carter et al, 2008). In New Zealand, exposure ages of moraines in ESI date a glacial advance culminating 13 ka, again coinciding with the peak period of cold in the Antarctic ice core records. It was concluded that the most likely cause for cooling at this time was the migration northwards of the subtropical front combined with an expansion of the colder Southern Ocean waters (Putnam et al, 2010b).

The pattern of deglaciation in southern South American records appears to pose similar problems of disparity between records as seen in New Zealand. As mentioned above all the records suggest an abrupt and rapid pattern of deglaciation, but there is some difference of opinion as to whether a LGR occurred in South America. Some reconstructions show a continuous trend in forest development and warming culminating at the start of the Holocene at $\sim 11.4 \mathrm{ka}$ (Ashworth and Hogansen, 1993; Haberle and Bennett, 2004; Massaferro et al, 2005). However, other records suggest a cooling period with ACR timing interrupting this pattern of climate amelioration (McCullock et al, 2005; Douglasse 
et al, 2006; Boës and Fagel, 2008). Others suggest either an intermediate ACR/YDC timing of cooling (Hajdas et al, 2003; Moreno and León, 2003; Sugden et al, 2005) or a YDC timing (Ariztegui et al, 1997; Heusser, 1998; Strelin and Malagnino, 2000). As in New Zealand, this varied timing could well be due to some sites in southern South America being climatically insensitive compared to others.

\subsubsection{Holocene}

The NZ-I CES shows a period of early Holocene warmth occurring between 11.610.8 ka (Alloway et al, 2007). Dacrydium cuppressinum in the contemporary environment dominates the warmer lowland areas. The dominance of $D$. cupressinum in the records presented here is inferred to represent temperatures that are similar to present. At Lake Mudgie, D. cupressinum becomes the dominant taxon at $11.9 \mathrm{ka}$ and at Manks Tarn, later, at $10.8 \mathrm{ka}$ (Figure 8.1), corresponding with the NZ-I CES. Similar timing of this transition has also been identified in other records: Kaipo Bog 11.5-11 ka (Newnham and Lowe, 2000), Okarito $\sim 12-11$ ka (Newnham et al, 2007a), Boundary Stream, $\sim 11.5$ ka (Vandergoes et al, 2008), Pukaki crater 11.5 ka (Sandiford et al, 2003), Kettlehole bog, Cass Basin 11.3-10.4 ka (McGlone et al, 2004). This indicates that the Holocene onset was broadly synchronous for all regions of New Zealand. The Holocene period for both records show a continued dominance of $D$. cuppressinum-dominated podocarp lowland forest, indicting warm conditions continued.

The start of the Holocene in New Zealand appears to be broadly similar throughout the Southern Hemisphere. In Tasmania rapid rainforest expansion reached a maximum during the early Holocene, $10.7 \mathrm{ka}$, and climate was even possibly 1-2 ${ }^{\circ} \mathrm{C}$ warmer than current conditions and wetter (MacPhail 1979). Likewise in South America a broadly synchronous timing of the Holocene is recorded around 11.8-10.6 ka (Moreno and León, 2003; Massaferro et al, 2005; Boés and Fagel, 2008; Unkel et al, 2008). In Antarctic records similar temperature optima occur between 11.5-9 ka (Masson et al, 2000). Walker et al (2009) dates the onset of the Holocene, based on multi-parameter annual layer counting in North Greenland Ice core Project (NGRIP) and other auxiliary records, from 
around the globe, at $11.7 \mathrm{ka}$. The global synchronicity of Holocene warming suggest direct global transfer of climatic change via changes in atmospheric greenhouse gas and water vapour concentration in the tropics (Lowell et al, 1995; Denton et al, 1999).

\subsubsection{Summary of climate change in this project}

Table 8.1 is a summary table displaying the timing of climatic events and transitions as recorded in this project and compared to the NZ-I CES. Overall the timing of climate change is broadly synchronous between sites and with the NZ-I CES. The timing of Termination I, the possible LGR at Lake Mudgie, and the start of the Holocene are particularly closely matched. However, the timing of climate change during the LGCP is more variable between the sites and the CES. The onset of the LGCP possibly begins earlier than suggested by the NZ-I group and this earlier onset is supported by other records (Section 8.1.2). This suggests an extension of the NZ-I CES timeframe is needed (Section 8.2.3.1). The period of 'milder' and more variable climate appears to be more complex than portrayed by the NZ-I group (see Section 8.2.2). The onset of the LGM is also difficult to define. The Lake Mudgie record shows cooling began 23.2 ka which corresponds with the earliest timing of this event in the CES. At Howard Valley and Forks Lagoon the LGM, marked by drier conditions at Forks Lagoon, occurred between 21-18.9 $\mathrm{ka}$, closely matching the NZ-I CES. Better chronological control and higher resolution may help to address the difficulties of pinning down the timing of climate change in this period. Also, an increase in records covering this period in New Zealand would also be useful before firm conclusions can be made on the pattern of climate change and the possible forcing factors. Section 8.2.3 will discuss the NZ-I CES in more detail.

Termination I began sometime between 18.9-18.5 ka and closely aligns with the NZ-I CES timing of 19-18 ka. The pattern of deglaciation in the two Westland sites closely matches the pattern of deglaciation in other Westland sites. Manks Tarn does not show a LGR in the record but instead a continuous pattern of climate amelioration. The qualitative evidence for Lake Mudgie suggests a possible vegetation disturbance, interrupting forest development, occurred between 13.2- 
$11.9 \mathrm{ka}$ and corresponds with the timing of the LGR in the NZ-I CES. Whether or not this is attributable to a cooling event cannot be concluded from the qualitative evidence alone. The quantitative pollen-climate transfer functions calculate a cooling trend at this time, suggesting a possible LGR occurred, but methodological limitations prevent firm conclusions from being made. The Holocene period begins between 11.9-10.8 $\mathrm{ka}$ and is characterised by $D$. cupressinum-dominated podocarp forest and conditions which are similar to the contemporary environment.

\begin{tabular}{|c|c|c|c|c|c|}
\hline Event & NZ-I CES & $\begin{array}{l}\text { Howard } \\
\text { Valley }\end{array}$ & Forks Lagoon & Lake Mudgie & Manks Tarn \\
\hline MIS 3 & - & $>39-<34$ & - & - & - \\
\hline LGCP & $29-18$ & $>28.5-18.9$ & $>31.7-19$ & - & - \\
\hline $\begin{array}{l}\text { 'milder } \\
\text { interval' }\end{array}$ & $27-21$ & $\begin{array}{ll}28.5, & 26.2- \\
22.2 & \end{array}$ & $\begin{array}{l}26-24, \\
21\end{array}$ & $>26.6-23.2$ & - \\
\hline LGM & $21-18$ & 20-18.9 & $21-19$ & 23.3-18.5 & - \\
\hline Termination I & $19-18$ & - & $19-17$ & $18.5-17.7$ & $>18.1$ \\
\hline LGIT & 18-10.6 & - & - & 17.7-11.8 & 18.1-10.8 \\
\hline LGR & $13.5-11.6$ & - & - & $13.4-11.9 ?$ & - \\
\hline Holocene & $11.6-10.8$ & - & - & 11.9 & $11.2-10.8$ \\
\hline
\end{tabular}

Table 8.1 Summary table comparing the timing of climate transitions and millennial scale events between the four project records and the NZ-I CES. All ages are ka

\subsection{Broader context}

This section expands upon the first section by discussing the broader themes touched upon above. A discussion of the age of the KOT layer will start this section followed by an assessment and critique of the NZ-I CES. This critique also considers the regional locations of sites as a factor in reconstruction of climate signals. Detailed discussion of the LGM and LGCP climate changes in this broader context will end this section. 


\subsubsection{Chronology and age models}

Chronology and age models are an integral tool used in palaeoenvironmental reconstructions, without which the timing of climate events and/or transitions and the duration of events could not be estimated. Also, comparisons between different palaeoreconstructions would prove difficult and the formulation of a climate event stratigraphy, such as the NZ-I CES, would be impossible. For this project chronology and age models have been extensively used to define the timing of climatic transitions and for comparisons to other records. However, there are important influences and limitations of chronology on age models that also have an influence on the conclusions made in this project. This includes the effect of calibrating radiocarbon years to calendar years and using mean calendar years for age models and for defining temporal boundaries of palaeoenvironmental change in reconstructions. These limitations are discussed further below.

The calibration of radiocarbon ages to calendar ages markedly decreases the age precision and increase the $2 \sigma$ age-range for each sampled dated, thereby creating greater error margins in age models. This is due firstly to inbuilt uncertainties in the available calibration models (e.g. Reimer et al 2009) and secondly to the changing ${ }^{14} \mathrm{C}$ production rate over time, that is still not fully understood (Taylor et al, 1992). During the calibration process a single mode, Gaussian structured, radiocarbon age frequently calibrates into a multi-modal calendar age which has a broader $2 \sigma$ age-range and thus reducing the age precision. This makes producing a defined age boundary for a palaeoenvironmental event/transition difficult as the event/transition can be ascribed to a broad age range. Often, and including this study, palaeoenvironmental reconstructions use mean calendar age when defining climate change boundaries, however, this leads onto a number of other limitations. The radiocarbon ages analysed in this study are all calibrated into calendar years and are initially expressed as mean calendar age with $2 \sigma$ age-range (see tables 4.x, 5.x, 6.x and 7.x). The $2 \sigma$ age-range illustrates the $95 \%$ probability that the true age of a specific sample lies somewhere within that age-range. The greater the $2 \sigma$ age-range the lower the age precision. Nevertheless, throughout the thesis the mean calendar age is expressed when reporting the timing of palaeoenvironmental change that is evident in the pollen records. This is common practice among palaeoenvironmental reconstructions, particularly when the age 
expressed has been extrapolated from an age-depth model (e.g. Alloway et al, 2007; Newnham et al, 2007; Lowe et al, 2008). However, this can give a false impression of age precision and it is important to refer to the whole $2 \sigma$ age-range, especially when making comparisons with other reconstructions. An apparent difference in timing of a climate event between records based upon mean calendar age may prove to not be so different when the whole $2 \sigma$ age-range is taken into account.

Age-depths models used in this project were created using simple linear interpolation constructed by joining the mean values of individual ages. This assumes a constant sedimentation rate between each dated horizon (refer to section 3.x for more information). However, this method also contains some inherent limitations, the most obvious being that sedimentation rates are rarely constant. However, there are other limitations regarding the chronology and the age-range of individual samples. A coherent age-depth plot, i.e. an age-depth model consisting of ages in chronological order, does not necessarily mean the calendar age of individual samples are reliable indicators of age. If the difference in mean calendar age $\pm 2 \sigma$ age-range is of sufficient magnitude between sampled horizons to not overlap, such as the majority of the Manks Tarn ages, then the model may well be valid. However, if the mean calendar age $\pm 2 \sigma$ age-range of a sample overlaps an underlying/overlying sample horizon, such as Forks Lagoon, then a reliable age-depth model is more difficult to determine (Lowe et al, 2007). In such cases using multiple samples from the same horizon to produce a number of ages can help, especially if these samples reproduce similar ages, as is the case with most duplicate ages for Forks Lagoon (refer to section 7.x for a greater discussion of the ages from Forks Lagoon). Also, using the prior knowledge that sediment accumulation occurs in chronological order and therefore samples taken up the core should produce younger ages, can also increase the validity of the model.

Despite the limitations highlighted above, the chronology and age models used form a good basis for discerning the timing of palaeoclimatic change evident in this project and for allowing broad comparisons between the project's records and published reconstructions. Future work on the chronologies at the sites used for 
this study, including an increase in the amount of radiocarbon ages at some sites and the use of Bayesian statistical approaches (refer to section 9.x), will help improve the age models.

\subsubsection{The age of the KOT layer}

Tephrostratigraphical data were used in the NZ-I CES to aid the synchronising of the records and to improve the age model. Using tephra as an age marker was particularly important in the fragmentary loess records where suitable datable material was at a minimum (Suggate and Almond, 2005). Therefore, reliable ages for these tephra layers are necessary for an accurate chronology and to accurately date the climate transitions and millennial scale events. The KOT is a key tephra marker as it lies near the beginning of the LGCP and within the LGCP milder interval. It is also the only tephra deposit in the South Island stratigraphically tying records from both the South Island and North Island sites. An accurate age for the KOT is therefore very important. However, the conflicting ages for this event have been reported, making it difficult to pinpoint a reliable age, although work has been carried out in an attempt to accomplish this (Wilson et al, 1995; Lowe et al, 2008; Vandergoes et al, 2011). In this project three records contain the KOT layer and discussion now turns to the age of this layer in connection with the pollen stratigraphy and chronology of these sites.

The radiocarbon ages produced for this project can be used to assess the compatibility of the two KOT ages of Lowe et al (2008) and Vandergoes et al (2011) with this project. Figure 8.x is a compilation of all the calibrated radiocarbon ages used in this project placed into three groups. Group 1 are the ages from samples taken stratigraphically below the KOT layer at each site. Group 2 are ages from samples taken from the sediment horizon immediately above of below the KOT layer. Group 3 are ages stratigraphically above the KOT layer.

In general, and to be expected, the samples taken above the KOT layer are younger than the accepted and revised KOT ages, and the samples below the KOT layer are older than the accepted and refined ages. However, there are some samples from the Forks Lagoon record, which are from the sediment horizons 
below the KOT layer and produce younger ages than the Lowe et al (2008) age and overlapping the Vandergoes et al (2011) ages. This has been discussed in chapter 7.4 and has been attributed to use of plant macrofossils for dating, which are more susceptible to contamination. Of the three ages dating the KOT layer directly, two produce younger mean calendar ages than those of Vandergoes et al (2011). The youngest age, SUERC-28872, from Lake Mudgie is considered to be too young $(20.8 \mathrm{ka})$. Research has shown that high rainfall regions are prone to contamination by younger organic sediments. In addition, the identification of other tephra layers in the North Island which overlay and hence post-date the KOT, also have ages which are older than the Lake Mudgie estimated age, further indicating that this age is too young (Lowe et al, 2010; See Section 3.5.2) Previous reasons for this have already been discussed in Section 4.4.1, justifying the use of the Vandergoes age of $25.4 \pm 0.4 \mathrm{ka}$ instead. Howard Valley is a site used by Vandergoes to refine the age of the KOT. In this project the horizon directly below the tephra dates this deposit as $25.2 \pm 0.4 \mathrm{ka}$ (OS-83041) and is similar to the Vandergoes age, corresponding with a younger timing for the eruption. A sample from at least $1 \mathrm{~m}$ below the tephra deposit produces an older age of $26.2 \mathrm{ka}$ which is still 1000 yrs younger than the Lowe et al (2008) age, suggesting that the KOT was deposited later than previously thought. Nevertheless, the age-range of the Howard Valley samples (OS-83041 and OS-83042) make it difficult to decide with certainty whether the Vandergoes et al (2011) age is correct. However, the stratigraphic position of the ages and the OS-83041 mean calendar age $\pm 2 \sigma$ agerange aligning more closely with the Vandergoes et al (2011) age, suggests this younger KOT age is more appropriate for this site. 


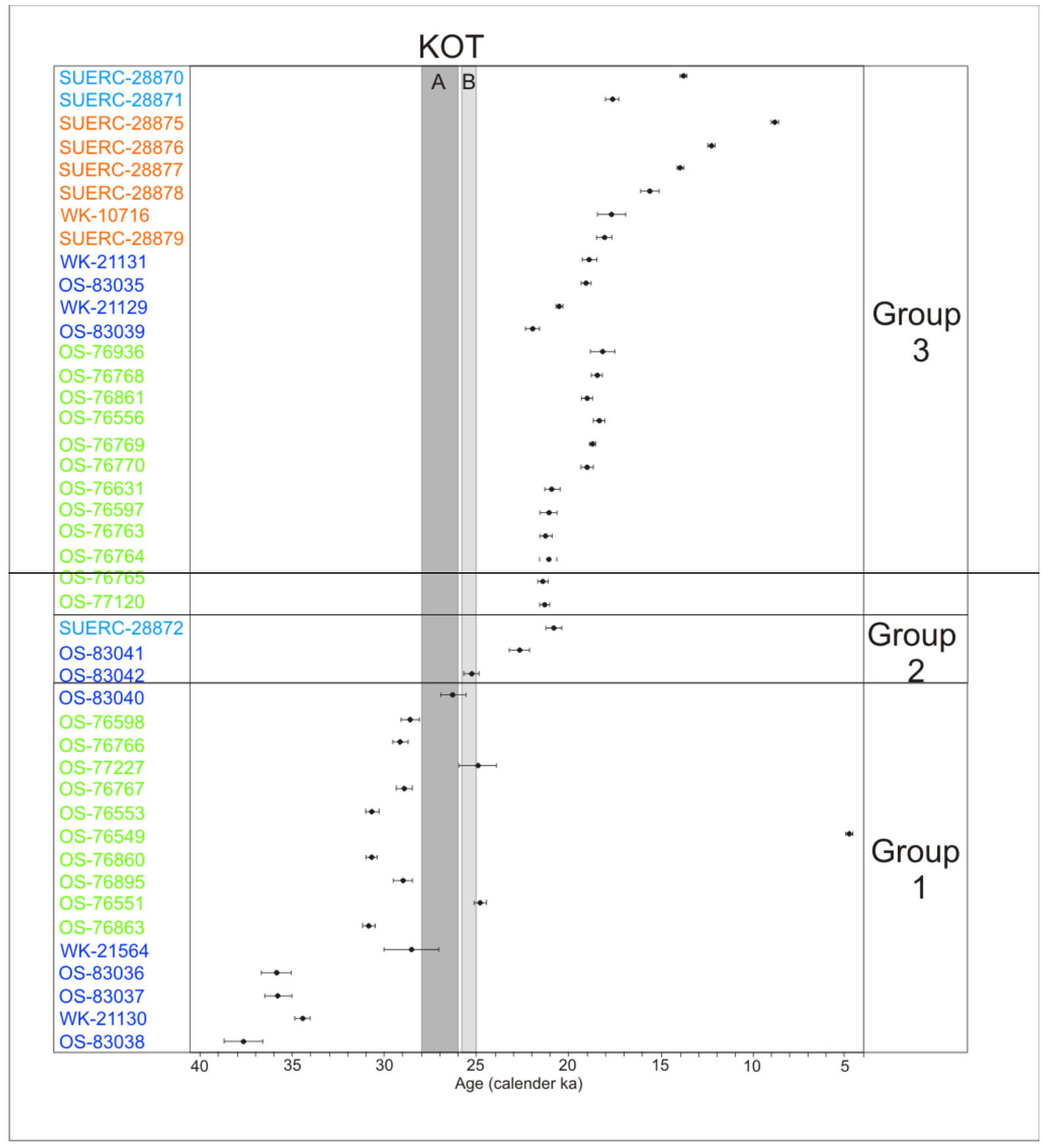

Figure 8.3: Calibrated radiocarbon ages for each site (Light blue=Lake Mudgie; Orange= Manks Tarn; Dark Blue=Howard Valley; Green=Forks Lagoon). The ages are split into three groups; Group 1 - samples taken below the KOT layer, Group 2 - samples dating the KOT layer, Group 3 - samples taken above the KOT layer. The accepted age of the KOT layer (Dark gray; Lowe et al, 2008) and the refined ages (Light gray; Vandergoes et al, 2011) are also plotted on the figure.

At Forks Lagoon the KOT layer was not directly dated, but the core chronology provides a good basis for age estimation. Figure 8.4 is a comparison of three agedepth models for Forks Lagoon. The first model is based solely on the calibrated ${ }^{14} \mathrm{C}$ ages, the second uses the Vandergoes et al (2011) age for the KOT and the third the Lowe et al (2008) age for the KOT. The extrapolated age of the tephra 
horizon in model (a) (Figure 8.4) is $\sim 24.5 \mathrm{ka}, 900$ years younger than the Vandergoes age but with overlapping errors (Figure 8.4). In comparison the Lowe et al (2008) age for the KOT does not correspond well with the sediment deposition rates. In summary the research here provides strong support for the revision of the age of the KOT. 

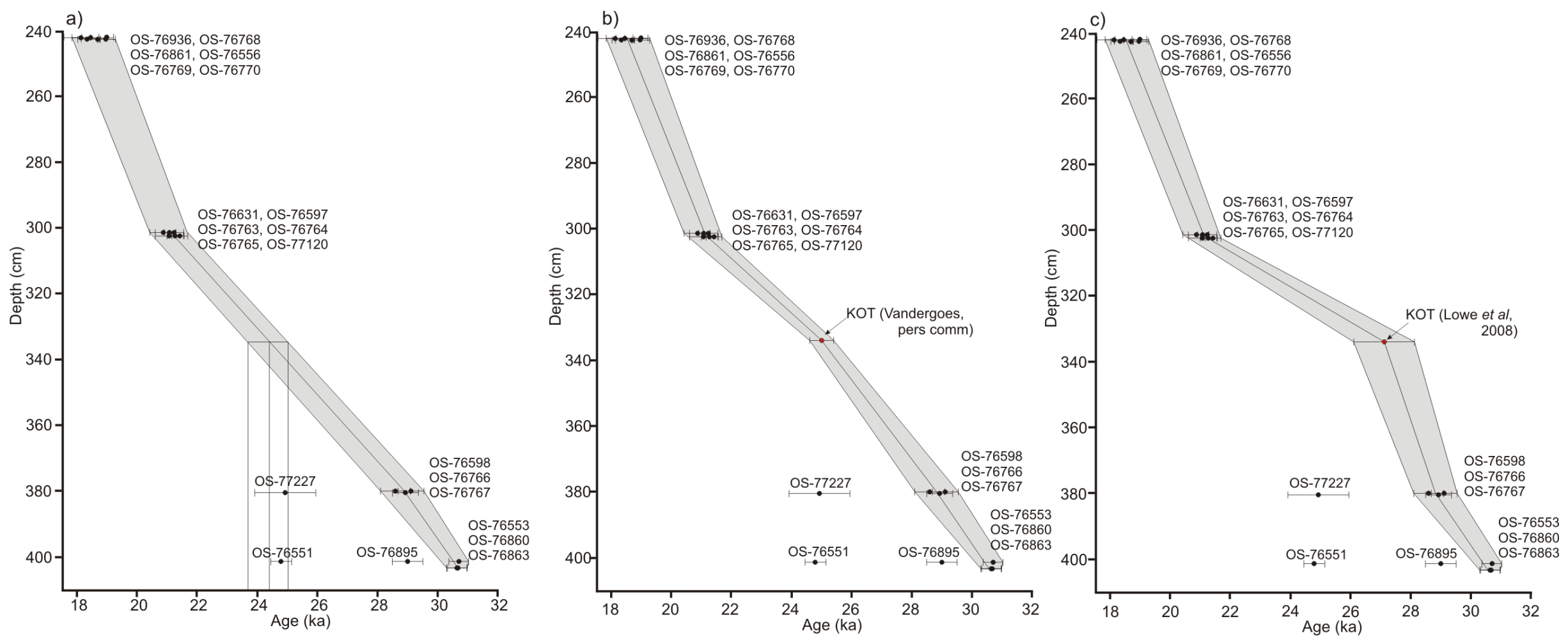

Figure 8.4: Comparison of three Forks Lagoon age-depth models using two KOT ages (b) and (c) with an age-depth model excluding the KOT tephra age (a). The extrapolated age for the tephra later in (a) is outlined by the box 


\subsubsection{Precipitation variability during the LGCP}

A range of evidence from palaeoproxy records suggests New Zealand's climate during the LGCP was dry (McGlone et al, 1993; Shulmeister et al, 2001; Whittaker et al, 2011) with an increased intensity of westerly winds (Alloway et al, 1992; Hellstrom et al, 1998; Shulmeister et al, 2004). Recent climate modelling of the LGM (21 ka) in New Zealand also points towards drier conditions over the whole of New Zealand regardless of an increased intensity of westerlies (Drost et al, 2006; Rojas et al, 2009). Whether these same conditions persisted throughout the LGCP is unclear due to the paucity of records covering this period. However, Section 7.6.3.1 suggests precipitation was variable throughout the LGCP. An understanding of the pattern of precipitation change in relation to glacial activity and temperature change can provide insight into the possible processes and forcing factors of climate change in New Zealand. The following discusses the pattern of precipitation change during the LGCP, how the pattern of precipitation relates to other evidence of climate change and tentatively suggests possible mechanisms and forcing factors of climate change in New Zealand.

The palaeoprecipitation signal from Forks Lagoon suggests three drier periods occurred between 31.4-26 ka, 24-21 ka and 21-18.9 ka. These dry periods are interrupted by two wetter periods between 26-24 ka and $21 \mathrm{ka}$. Other paleaoclimate records providing precipitation signals are not common in the South Island. An exception is a speleothem record from north-west Westland providing a sensitive precipitation record. Whittaker et al's (2011) $\delta^{13} \mathrm{C}$ speleothem record from Hollywood Cave indicates that overall MIS 2 was drier than MIS 4. However, three millennial-scale wetter periods (Figure 8.5) occurred between 30.5-29 ka, 25.5-24.2 ka and 22.6-21.4 ka, which, like the Forks Lagoon record, suggest the climate was not uniformly dry during the LGCP. The two later wetter phases recognised in Hollywood cave appear to roughly coincide with wetter periods inferred at Forks Lagoon suggesting a near synchronous pattern of wetter and drier conditions between the two regions (Figure 8.5).

Hellstrom et al (1998) provides a record of changing $\delta^{18} O$ isotopes values in meteoric water recorded in speleothems taken from Nettle Bed Cave in north-west 
Nelson. Unlike the precipitation record from Hollywood Cave, Nettle Bed Cave does not provide a precipitation signal representing wet and dry conditions. Instead a change in $\delta^{18} \mathrm{O}$ values represents a change of the source of precipitation, in this instance the Tasman Sea, which is related to oceanic fronts and atmospheric circulation changes. Hellstrom et al (1998) recognise three $\delta^{18} \mathrm{O}$ excursions between 27-25 ka, 24.5-22 ka and 20-19 ka, (Figure 7.10) which, based on a limited chronology, is broadly synchronous with the dry periods at Forks Lagoon. The $\delta^{18} \mathrm{O}$ excursions were concluded to be caused by the northward migration of the STF into the Tasman Sea (see Section 2.2.2) influencing the New Zealand temperature and $\delta^{18} \mathrm{O}$ values of the source area. The migration of STF northward is also considered to have caused stronger westerly winds in central and southern New Zealand (McGlone et al, 1993; Hellstrom et al, 1998). The evidence discussed above suggest that dry periods inferred from Forks Lagoon and Hollywood Cave are broadly synchronous with increased westerlies and vice versa during periods of wetter climates.

The timing of westerly winds intensity variations recorded at Nettle Bed Cave, and precipitation changes at Forks Lagoon and Hollywood Cave may indicate a regional response to dominant synoptic climate types. As previously mentioned in Section 2.3, in the contemporary environment Trough regimes, which are characterised by reduced westerly wind dominance, can lead to an increase in precipitation in both the ESI and WSI (Kidson, 2000; Renwick, 2011). Therefore, a dominant Trough regime could explain the increase in precipitation at both Forks Lagoon and Hollywood Cave (Whittaker et al, 2011) and the reduced westerly wind intensity (Hellstrom et al, 1998). The pattern of regional climate during a dominant Zonal regime (a regime dominated by westerly winds) causes decreased precipitation in ESI and increased precipitation in WSI (Kidson, 2000; Renwick, 2011). Decreases in precipitation at Forks Lagoon are broadly synchronous with increased westerly wind intensity from the Nettle Bed Cave record and correspond with a Zonal regime. However, under this regime the Hollywood Cave precipitation record should show an increase in precipitation opposed to a decrease. During the LGM, climate models suggest an increase in westerly wind strength would not produce wetter conditions due to cold climatic condition (Rojas et al, 2009). The cause of drier conditions 
during the LGCP at Forks Lagoon and Hollywood Cave (Whittaker et al, 2011), and period of inferred increase in westerly wind intensity, may relate to periods of very cold climate. This relationship is explored further below.

The variable pattern of climate during the LGCP is not restricted to precipitation change. The NZ-I CES places the LGCP milder interval between 27-21 ka, but again a complex pattern in temperature is evident with warmer periods between 27-24.5 and 23-22 ka (Alloway et al, 2007). At Lake Pukaki a milder interval spanning 26$24.5 \mathrm{ka}$ (Newnham et al, 2007c) closely corresponds with the wetter climate phases in Forks Lagoon and Hollywood cave (Whittaker et al, 2011). Similar climate amelioration has also been recorded at a number of other sites in New Zealand (Alloway et al, 1992; Suggate and Almond, 2005; Woodward and Shulmeister, 2007). A later period of climate amelioration is evident in Williams et al's (2010) speleothem record between 23-21.7 ka and again this is also evident in other records from New Zealand (Alloway et al, 2007; Newnham et al, 2007a) and broadly corresponds with evidence of wetter conditions at Hollywood Cave and Forks Lagoon. This suggests that wetter conditions in Forks Lagoon, and Hollywood Cave, corresponds with periods of possible glacial retreat, in north Westland (Suggate and Almond, 2005), and milder climates (e.g. Newnham et al, 2007a). Conversely, during periods of glacial advance (Suggate and Almond, 2005), and increased herb abundance representing cold environments (Newnham et al, 2007a) drier conditions occurred at Forks Lagoon. Drier periods during glacial advance corresponds with the climate modelling for the LGM (Drost et al, 2007; Rojas et al, 2009) suggesting a continuation of this relationship between cold and dry conditions into the LGCP. However, the Hollywood cave record moves away from this generalised pattern at the onset of the LGCP where evidence of cooling temperature coincides with wetter conditions, whilst dry conditions persist at Forks Lagoon. This could be a factor of the limited chronologically control at either site and/or other factors are at work influencing climate at this point of time. Better chronological control and further climate information is needed to better understand the causes of this disparity.

The paleaoclimate reconstructions mentioned above suggest the climate during the LGCP was neither uniformly dry nor cold but variable. However, due to the different 
KOT ages used between reconstructions it is important to stratigraphically compare records around this deposit, particularly between records which the chronology is dependent on the KOT age. Pukaki and its comparison to the Forks Lagoon record is an example of why stratigraphically comparing sites are important. The pollen record at Lake Pukaki was originally published by Sandiford et al (2003). In this original paper a milder period was not recognised but rather an extended cold period spanning 28-18 ka was concluded. In this record the KOT age used was $26.5 \mathrm{ka}$, although in some figures it was written as 26 ka. Newnham et al (2007c) used the same pollen record and identified a decline in grass abundance, which was ignored in the original paper. Newnham et al (2007c) suggest this grass decline represented a period of milder climate spanning 26-24.5 ka. However, the chronology uses the accepted Lowe et al (2008) age of $27.1 \pm 1 \mathrm{ka}$. The Forks Lagoon record uses the $25.4 \pm 0.4 \mathrm{ka} \mathrm{KOT}$ age. Therefore, between the three records mentioned, four different ages are used to date the same tephra. To make comparisons to either record chronologically would be incorrect and confusing. However, the KOT layer is a chronostratigraphic marker and the timing of its deposition anywhere in New Zealand, regardless of the radiocarbon age it receives, is the same. Consequently, records using different KOT ages can, and should, be stratigraphically compared. Stratigraphic comparison between records are discussed further below

At Forks Lagoon Myriophyllum tryphyllum concentrations start to increase just prior to the deposition of the KOT layer. M. tryphyllum concentrations continue to increase after the KOT deposit and then declines to nothing my 24 ka. The Okarito grass curve shows a similar pattern. Grass abundance begins to decline just prior to the KOT deposition and continues to decrease afterwards, until the start of the LGM where it increases again (Newnham et al, 2007a). In the North Island, Pukaki experiences a decline in grass abundance stratigraphically later than at Okarito. Grass abundance is still increasing around the time of the KOT deposition suggesting the climate was getting colder. However, after the KOT layer, a decline in grass abundance coinciding with the mid-LGCP occurs (Newnham et al, 2007c). Although this occurs stratigraphically later, the grass decline still coincides with the increase in $M$. tryphyllum concentrations. Therefore, even when stratigraphic comparisons between records occur, a similar conclusion can be made (see fig 8.5). 
Increased M. tryphyllum concentrations, implying wetter conditions at Forks Lagoon, coincide with a decrease in grass abundance and therefore evidence of milder climates at Okarito and Pukaki. However, it appears the onset of the milder conditions at Pukaki occurred later than at Okarito (Newnham et al, 2007a; 2007c)

The pattern of changing westerly winds intensity, the precipitation signal from both the ESI and WSI, and evidence of glacial activity suggest Zonal dominated regimes during glacial advance. Conversely, Trough regimes are dominant during glacial retreat and mild climates. However, using current synoptic conditions to explain the precipitation patterns in ESI during the LGCP may not necessarily be correct and may prove to be too simplistic. A number of potential forcing factors influencing climate change during this timeframe are possible and include; the influence of local insolation budget (Vandergoes et al, 2005), changing latitudinal position of the ITCZ (Whittaker et al, 2011), and an extended bipolar seesaw effect influencing the strength of the southern westerlies during the LGCP (Newnham et al, 2011). Although these mechanisms have been put forward more research is necessary before firm conclusions on the pattern, timing and cause of climate change in New Zealand can be established. 


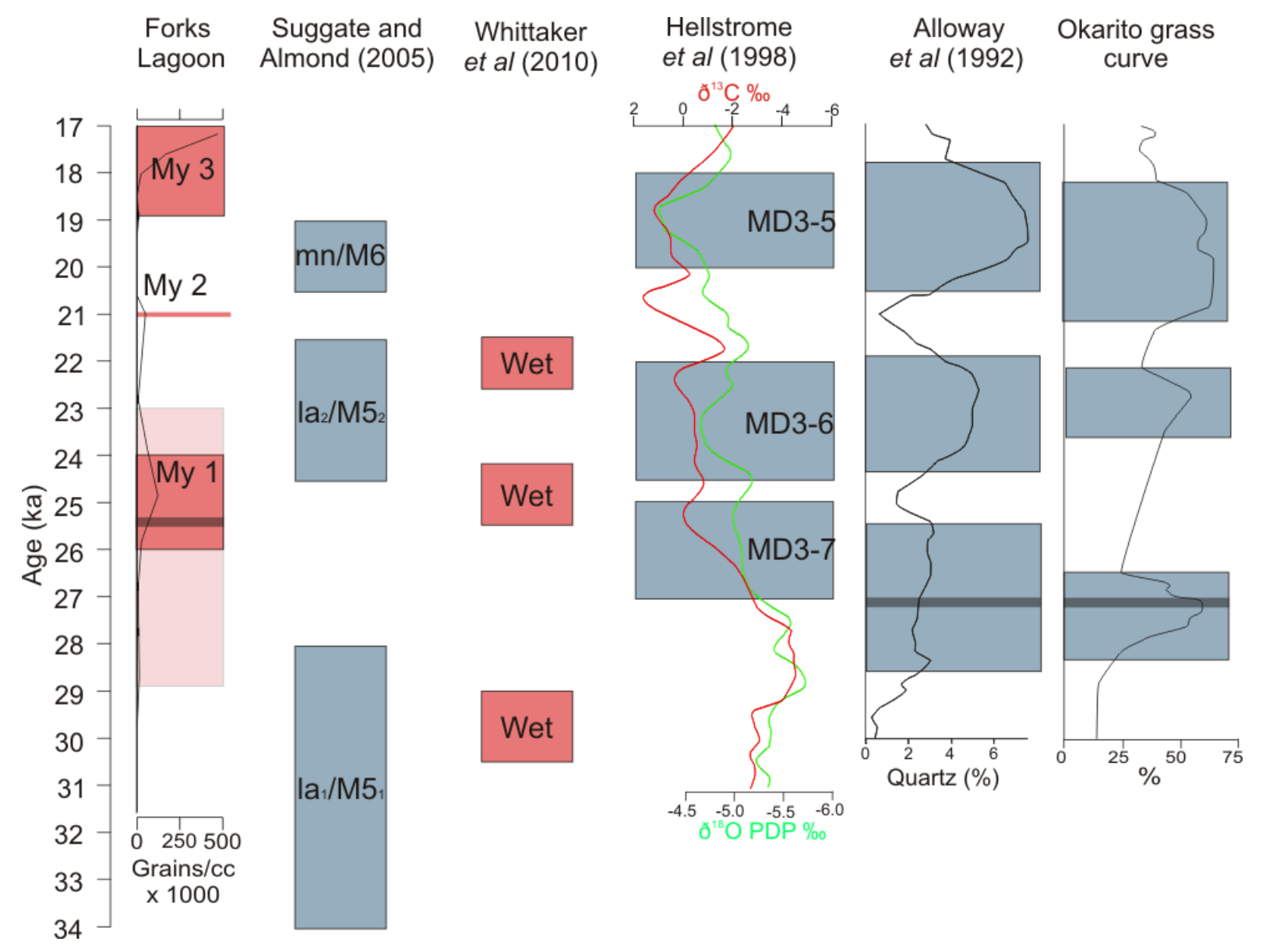

Figure 8.5: Comparison of proxy records from around New Zealand and the macrophyte record of Forks Lagoon which contains the Myriophyllum tryphyllum concentration curve. The red boxes represent periods of wetter climate. The blue boxes are period of colder climates evident in the proxy records, of glacial advance, or periods of stronger westerly wind flow. The grey line on the Forks Lagoon, Alloway et al (1992) and Okarito grass curve shows the chronological location of the KOT layer use by the different studies.

\subsubsection{NZ-I CES}

The NZ-I CES provides a good framework for the general pattern of climate change in New Zealand for the period 30-8 ka, which is needed for the processes linked to climate change to be better understood, as suggested above. Overall, large scale climate transitions occur broadly synchronously across New Zealand. However, there is greater variability in the timing of millennial scale events. Some of these differences might be attributable to poor chronological constraint, low sampling resolution, and different responses to climate change from different proxy methods used in the CES. However, addressing these limitations is an ongoing process which takes time. There are some other limitations which could be more easily and quickly resolved. The following will discuss these limitations in context of the timing and pattern of climate change represented in this project. The timing of LGCP climate 
variability is not well resolved. The previous section has already noted these limitations which also apply to the NZ-I CES and are therefore not repeated here.

\subsubsection{Temporal remit of the NZ-I CES}

The NZ-I CES not only provides a framework for the period spanning 30-8 ka but also has some influence on future research in New Zealand. In this project, sampling strategy was designed to cover the NZ-I CES timeframe. Other new research is also restricted to the NZ-I CES temporal remit (e.g. Williams et al, 2010; Augustinus et al, 2011). However, this timeframe is restrictive and prevents the addition of important evidence of patterns of climate change which may also help to ascertain potential forcing factors of climate change in New Zealand. For instance, does the upper boundary exclude important information on late glacial cooling? This example will be discussed further below.

The NZ-I CES defines the onset of the LGCP occurring between 29-28 ka. This event is characterised by an increase in herb and cold tolerant taxa and a decrease in forest taxa. This boundary therefore marks the transition from milder to colder conditions. However, this is not necessarily the case. In the Okarito pollen record this boundary lies near to the peak abundance of herb and grassland taxa suggesting significant cooling had already commenced. The 30 ka boundary used by Newnham et al (2007a) marks the onset of the LGCP near the top of a rising limb in herb abundance. In this record the 29-28 ka boundary ignores the earlier transition from mild to cold conditions which would be useful when investigating the potential climate change mechanisms. Figure 8.6 is taken from Vandergoes et al (2005) and compares the pattern of change in a number of records including the Okarito summary pollen diagram. An increase in herb taxa at the expense of tree and shrub abundance appears to begin at $\sim 35 \mathrm{ka}$. Not only does this correspond with other evidence of glacial advance in the Westland regions (see Section 8.1.2) but also with cooling in the EPICA Dome $\mathrm{C}$ ice core record and a decrease in regional summer solar insolation budget. This shows a clear link between the three records suggesting the onset of herb increase, indicative of climate cooling, corresponds with an Antarctic timing of cooling combined with a decrease in insolation budget, which 
is potentially the forcing factor of climate change in the region. This is an important aspect of climatic change that should not be ignored or excluded from the NZ-I CES.

In this project Forks Lagoon and to a certain extent Howard Valley support an earlier onset of the LGCP. Other evidence in New Zealand also points towards an earlier glacial advance which began between 35-28 ka again suggestive of an earlier onset of the cold conditions. Although the CES is restricted to 30-8 ka it would appear that a temporal extension of the NZ-I project would be useful. The North Atlantic INTIMATE group has already extended the remit to $60 \mathrm{ka}$ and recent discussions within the Australasian INTIMATE group suggest a similar development may occur. The results of this project support an extension of the temporal remit of the NZ-CES.

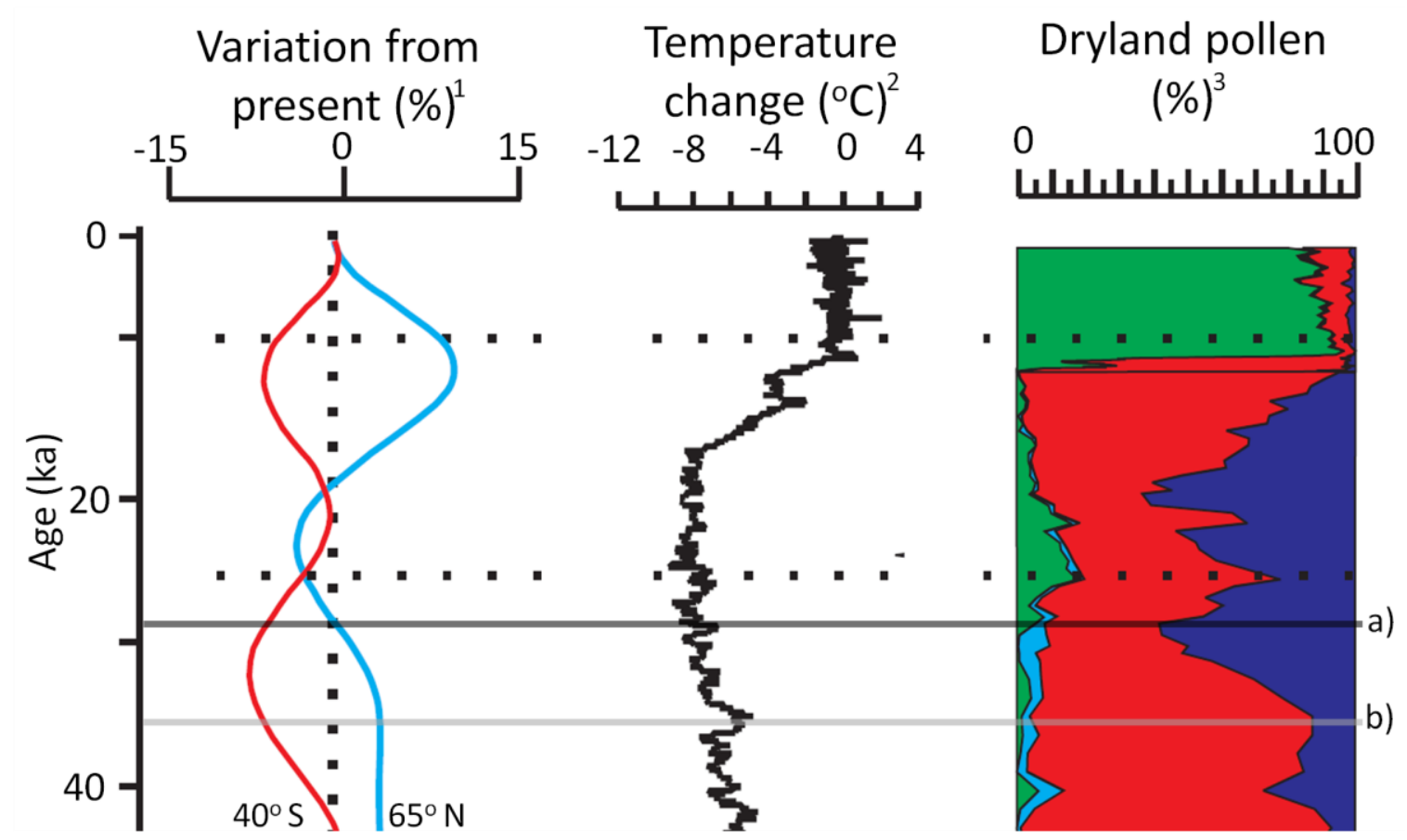

Figure 8.6: Plot of summer insolation for $40^{\circ} \mathrm{S}$ and $65^{\circ} \mathrm{N}(1)$ (Berger et al, 1991), 2) Vostock temperature curve (Petit et al, 1999), 3) Okarito pollen stratigraphy (Vandergoes et al, 2005). Figure adapted from Vandergoes et al (2005) Solid horizontal lines show a) showing the age of the onset of the LGCP used in the NZ-I CES. b) is a line drawn across the 35 ka marking where herb abundance begins to increase.

\subsubsection{Region differences in reconstructions}

The NZ-I CES combines records from the whole of New Zealand to produce a national CES. However, using records from different latitudinal locations and 
different climate regions may not be the most plausible method of creating a CES as different regions experience different climate and oceanic patterns which can influence the signal recorded in each site. McGlone et al (2010) recognised different vegetation composition between different regions of New Zealand during the LGM. The vegetation reconstructions produced in this project from the three records during the LGCP suggest that regional vegetation differences are not just restricted to the LGM but continue throughout the whole LGCP. It would also be plausible that the same regional differences would extend to the LGIT and into the Holocene.

Newnham et al (2011) have noted a latitudinal variation between records in the timing and extent of temperature depression during the LGR. Okarito, which is the most southern record used in the NZ-I CES has the earliest recognisable LGR beginning at $14.5 \mathrm{ka}$ and consisting of a $2{ }^{\circ} \mathrm{C}$ cooling, which persist for $1 \mathrm{ka}$. This cooling trend appears to be closely aligned with the ACR. Kaipo Bog, in the North Island provides evidence of a minor cooling episode between 13.6-12.6 ka and a MAT depression of $0.5-1^{\circ} \mathrm{C}$. Whilst Pukaki, the northernmost site reconstructs the smallest MAT decline of $0.5{ }^{\circ} \mathrm{C}$ commencing at $13 \mathrm{ka}$ and is the shortest cooling period estimated in the three records. Newnham et al (2011) conclude that the southernmost site follows Southern Ocean records and an ACR timing (e.g., Pahnke et al, 2003). The northernmost site shows a weak reversal that closely aligned in timing with the YDC, whereas Kaipo Bog located in an upland North Island site shows an intermediate timing overlapping both the ACR and YDC. It was postulated that the location of the ocean fronts had an influence on these climate changes with Okarito located within the spheres of the Southern Ocean, whereas Pukaki and Kaipo Bog lie equatorward of the STF (Section 2.2.2). Research by Turney et al (2003) and Carter et al (2008) in the marine realm found a similar pattern for the same time period again suggesting latitudinal variations in climate signals.

Regional climate regimes may also have an important influence on the pattern of climate change recorded at different sites in New Zealand, and could possibly explain disparities between records. As touched upon in Section 2.3 and 7.6.3.1 the South Island can be separated into three climate regions which experience different climatic responses to the same synoptic conditions. For instance in the 
contemporary environment during Zonal dominated regimes the ESI experiences drier conditions whilst the WSI experiences wetter conditions (Lorrey et al, 2007). Palaeorecords from these areas would record a different precipitation signal whilst experience the same synoptic conditions. If these regional differences were not taken into account then a different conclusion on the possible forcing factors of climate change may result. Section 8.2.2 and the pattern of precipitation and westerly wind intensity during the LGCP also points towards the importance of regional climate regimes. An understanding of each regional response to the same synoptic climate condition is important to prevent different conclusions on the main process influencing climate. Compiling a regional CES would enable comparisons between regions which may highlight this different regional response to the same synoptic conditions.

\subsubsection{NZ-I CES Summary}

The NZ-I CES provides a good start for synthesising key records from around New Zealand and producing a generalised stratigraphy. This can be used as a framework for comparisons, although there are some limitations with the scheme. Overall the timing of climate transitions and millennial scale events identified in this project occur broadly synchronously with the NZ-I CES (Table 8.1), particularly the LGM, Termination I and start of the Holocene. The records suggest an earlier onset for the LGCP and it is concluded that the temporal remit of the NZ-I project needs to extend further back in time. The limited records which extend into the LGCP and their relatively poor chronological control makes firm conclusions of the pattern of climate change in New Zealand for this period and the possible forcing factors more difficult to ascertain. However, the NZ-I CES provides a good foundation to build upon. It also highlights some periods of uncertainty, such as the timing and pattern of climate change during the LGCP milder interval and the LGR.

Since the NZ-I CES was initially produced by Alloway et al (2007), significant advances have been made which would prove useful in the CES. These advances include the production of the New Zealand pollen/climate transfer function (Wilmshurst et al, 2007), climate modelling of past New Zealand climates (Rojas et al, 
2009), broader understanding of regional climate regimes and the possible influences these had on past climates (Lorrey et al, 2007) and the improvement of existing and addition of new proxy records (e.g. Whittaker et al, 2011; Williams et al, 2010; Augustinus et al, 2011). Utilising these advances to make improvements to the NZ-I CES are important in its development. However, the limitations discussed above should also be addressed to help refine the NZ-I CES. This includes extending the remit of the NZ-I CES and taking regional differences into account when comparing climate reconstructions between sites.

\subsubsection{Quantitative pollen-climate reconstruction}

Quantitative pollen-climate modelling using the New Zealand pre-deforestation database is a notable development towards a robust quantitative method for predicting past MAT changes (Wilmshurst et al, 2007). It could also be a useful aid to define boundaries of climate change in an objective manner (refer to Section 8.2.4.2). This technique has been applied to all four pollen records in this project providing interesting and insightful MAT reconstructions. However, as noted in each site chapter (Chapter 4-7), there are discrepancies with estimated MAT depression based upon ELR. This section will discuss the benefits and limitations of the quantitative pollen-climate modelling in light of the MAT reconstruction presented in this project. Suggestions of how this effort might be advanced are included.

\subsubsection{ELR vs. the modelled MAT depression estimates}

Table 8.2 compares the estimated MAT depression of each site using the three methods: PLS-C3, W-MAT and ELR. Due to the low pollen counts at Forks Lagoon ELR estimates were not calculated. However, the pollen data were used in the climate calibration as this performed a more objective temperature reconstruction than the qualitative ELR would have. Nevertheless, it should be noted that there are limitations in using the Forks Lagoon pollen record for reconstructing past climates, due to the low pollen count. At Howard Valley the PLS-C3 model reconstruction shows MAT was progressively warming between 37.7-18.9 ka, with the youngest sediments deposited during the LGM showing the warmest climates. The W-MAT model shows no change in MAT during this period. In contrast, the estimated MAT 
using ELR predicts increased cooling with the LGM experiencing the coldest conditions. At Howard Valley and Forks Lagoon the modelled estimated LGM temperatures were lower than expected, although the PLS-C3 produces the coldest range of temperatures, which are broadly similar with the ELR estimates at Howard Valley.

The Lake Mudgie record produces a similar pattern of estimated MAT in all three methods although PLS-C3 shows the greatest disparity to ELR. The LGCP is split into two periods; a milder period between 26.6-23.2 ka and the colder LGM between 23.2-18.4 ka. Climate amelioration began at 18.4 ka with the W-MAT and ELR showing a period of warming interrupted by a slight cooling event followed by maximum MAT during the Holocene. PLS-C3 differs from the other methods because it estimates the highest temperatures occurring during the early LGIT. Temperatures slowly declined until 13.4-11.9 ka when a large temperature depression is estimated. This is followed by a period of warming although the MAT remains lower during the Holocene period than at the start of deglaciation. The Manks Tarn estimated MAT depression using ELR shows a consistent increase in temperature throughout the LGIT which is similar to the Lake Mudgie W-MAT and ELR temperature reconstructions. However, the modelled results are similar to Lake Mudgie PLS-C3 reconstructions and show MATs that are continuously declining with the largest temperature depression at $9.7 \mathrm{ka}$. This is followed by an increase in MAT with the warmest temperatures towards the top of the core. Like the Howard Valley record, both modelled results for Manks Tarns and the PLS-C3 model for Lake Mudgie do not correspond well with the inferred climate change produced in this project and from evidence elsewhere in New Zealand (see Section 8.1.5 and 8.1.5.2). This suggests the modelled results are problematic and is discussed in Sections 8.2.5.2 and 8.2.5.3. However, before the transfer function and Modern Analogue Technique can be discussed the method of ELR should first be mentioned.

As already discussed in Section 3.2.6 there are some limitations of ELRs, including temporal and spatial variation in the rate caused by a number of factors. A mean annual ELR of $0.5{ }^{\circ} \mathrm{C} / 100 \mathrm{~m}$, although a national average, may not be wholly representative of the sites in this project and may account for some discrepancies 
between the modelled results and ELR estimates. On long timescales, large changes in climatic conditions (and in particular moisture/humidity) may have a significant influence on the ELR at a site. Using a variable ELR would probably produce a more realistic MAT. However, limited knowledge of past climatic conditions makes it difficult to modify the ELR for particular periods of time. The current national average ELR could possibly be underestimating or overestimating MAT depressions during the late Quaternary. However, until suitable alternative using national annual ELRs is the best option. 


\begin{tabular}{|c|c|c|c|c|c|c|c|c|c|c|c|c|}
\hline \multirow[t]{3}{*}{ Period } & \multirow{2}{*}{\multicolumn{3}{|c|}{$\begin{array}{l}\text { Howard Valley }\left({ }^{\circ} \mathrm{C}\right) \\
\text { MAT today }\left(9^{\circ} \mathrm{C}\right)\end{array}$}} & \multirow{2}{*}{\multicolumn{3}{|c|}{$\begin{array}{l}\text { Forks Lagoon }\left({ }^{\circ} \mathrm{C}\right) \\
\text { MAT today }\left(8.8^{\circ} \mathrm{C}\right)\end{array}$}} & \multirow{2}{*}{\multicolumn{3}{|c|}{$\begin{array}{l}\text { Lake Mudgie }\left({ }^{\circ} \mathrm{C}\right) \\
\text { MAT today }\left(11.5^{\circ} \mathrm{C}\right)\end{array}$}} & \multirow{2}{*}{\multicolumn{3}{|c|}{$\begin{array}{c}\text { Manks Tarn }\left({ }^{\circ} \mathrm{C}\right) \\
\text { MAT today }\left(11.5^{\circ} \mathrm{C}\right)\end{array}$}} \\
\hline & & & & & & & & & & & & \\
\hline & PSL-C3 & W-MAT & ELR & PSL-C3 & W-MAT & ELR & PSL-C3 & W-MAT & ELR & PSL-C3 & W-MAT & ELR \\
\hline Late MIS 3 & $\begin{array}{l}4.2-5.5 \\
(5)\end{array}$ & $\begin{array}{l}1.7-1.9 \\
(1.8)\end{array}$ & $2-3$ & - & - & - & - & - & - & - & - & - \\
\hline $\begin{array}{l}\text { LGCP 'milder } \\
\text { interval' }\end{array}$ & $\begin{array}{l}3.3-4.8 \\
(4)\end{array}$ & $\begin{array}{l}1.6-2 \\
(1.7)\end{array}$ & 3-4.5 & $\begin{array}{l}1.4-4.4 \\
(2.3)\end{array}$ & $\begin{array}{l}1.3-1.5 \\
(1.4)\end{array}$ & - & $\begin{array}{l}4.5-5.6 \\
(5.2)\end{array}$ & $\begin{array}{l}3.2-4.4 \\
(3.8)\end{array}$ & $>5.3$ & - & - & - \\
\hline LGM & $\begin{array}{l}2.4-4.2 \\
(3.3)\end{array}$ & $\begin{array}{l}1.5-1.8 \\
(1.7)\end{array}$ & $3->4.5$ & $\begin{array}{l}1.6-2.4 \\
(2.1)\end{array}$ & $\begin{array}{l}1.3-1.5 \\
(1.4)\end{array}$ & - & $\begin{array}{l}5.5-6.1 \\
(5.3)\end{array}$ & $\begin{array}{l}3.8-4.2 \\
(3.6)\end{array}$ & 5.3 & - & - & - \\
\hline LGIT early & - & - & - & - & - & - & $\begin{array}{l}0.7-5.2 \\
(1.8)\end{array}$ & $\begin{array}{l}1.3-3.4 \\
(1.5)\end{array}$ & $3.3-5.3$ & $\begin{array}{l}1.3- \\
(2.3)\end{array}$ & $\begin{array}{l}1.3-2.1 \\
(1.7)\end{array}$ & $\begin{array}{l}3.4- \\
5.4\end{array}$ \\
\hline LGIT late & - & - & - & - & - & - & $\begin{array}{l}1.4-2.8 \\
(2.2)\end{array}$ & $\begin{array}{ll}1.5- & 1.9 \\
(1.7) & \end{array}$ & $2.3-3.3$ & $\begin{array}{l}2.4-3.9 \\
(3.2)\end{array}$ & $\begin{array}{l}1-2.3 \\
(2)\end{array}$ & $\begin{array}{l}2.4- \\
3.4\end{array}$ \\
\hline LGR & - & - & - & - & - & - & $\begin{array}{l}2.1-4.8 \\
(3.6)\end{array}$ & $\begin{array}{l}1.3-2.2 \\
(1.9)\end{array}$ & $?$ & $\begin{array}{l}3-4.4 \\
(3.7)\end{array}$ & $\begin{array}{l}1.2-2.1 \\
(3.7)\end{array}$ & - \\
\hline Holocene & - & - & - & - & - & - & $\begin{array}{l}1.9-3 \\
(2.3)\end{array}$ & $\begin{array}{l}0.2-1.6 \\
(0.7)\end{array}$ & $0-2.3$ & $\begin{array}{l}1.7-3.5 \\
(2.4)\end{array}$ & $\begin{array}{l}0.1-1.9 \\
(0.8)\end{array}$ & $0-2.4$ \\
\hline
\end{tabular}

Table 8.2: MAT depression range at each site inferred from the quantitative pollen/temperature model output and estimations by ELR and treeline depressions. The average MAT depression for each time frame is bracketed for the modelled results. The contemporary MAT for each site $s$ added below the site name. 


\subsubsection{Howard Valley and modelled MAT}

As mentioned previously there is a large discrepancy in the pattern of temperature change at Howard Valley between the modelled MAT and ELR estimated MAT. The qualitative methods' inferred climate change at the site is characterised by consistent cooling with the coldest conditions during the LGM. In contrast the PLS-C3 reconstruction shows the opposite pattern. Figure 8.7 shows the abundances of Phyllocladus alpinus and Fuscospora exhibit a nearly consistent inverse relationship with the PLS-C3 reconstruction, suggesting the abundance of these species has a significant influence over the predicted MAT reconstruction. In the pollen training set used in the pollen transfer functions, both Phyllocladus alpinus and Fuscospora are prevalent in colder conditions. Therefore, in the Howard Valley record when the abundance of these species declined up the sections the models inferred warming opposed to cooling, which was inferred by the vegetation reconstruction and ELR. The sparse training set for alpine vegetation could be responsible for the low predicted temperature depressions during the LGM. As the environmental gradient is not fully represented in the training set, this would limit the effectiveness of the transfer function and modern analogue technique. The dominant influence of a few taxa on the transfer function may also outweigh the influence of other taxa so that the models respond to changes of these dominant taxa as opposed to the assemblage as a whole.

Another factor which could be limiting the temperature reconstruction is the exclusion of taxa which could provide important insight to past climates in the vegetation reconstructions. This is due to the broad environmental range that some taxa represent. In this instance, Howard Valley contains a large proportion of Apiaceae, which is inferred to represent part of the alpine herbland community and is present in the youngest section at the site. However, due to the poorly modelled relationship this taxon has with temperature it is not included in the training set. Therefore a large proportion of the vegetation data cannot be applied. Better subdivision of these broad taxonomic groups to genus, subgenus or species levels, if possible, could help improve the models by enhancing the training set and providing more appropriate climate analogues than currently exist. 


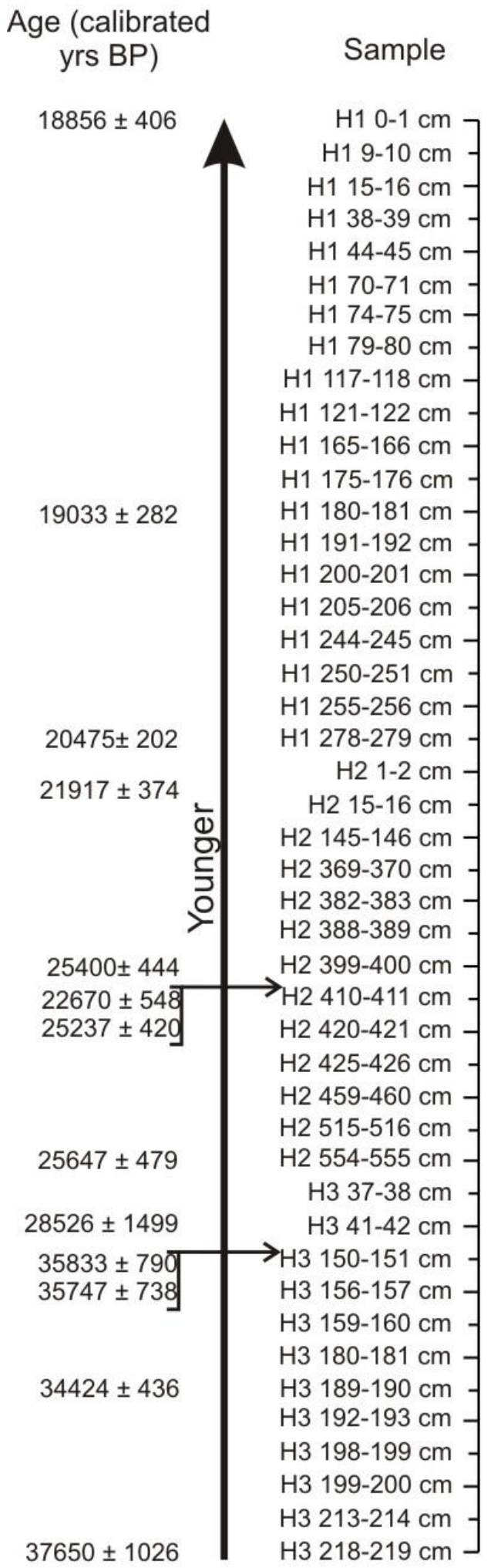

a) $\quad \mathrm{MAT}\left({ }^{\circ} \mathrm{C}\right)$

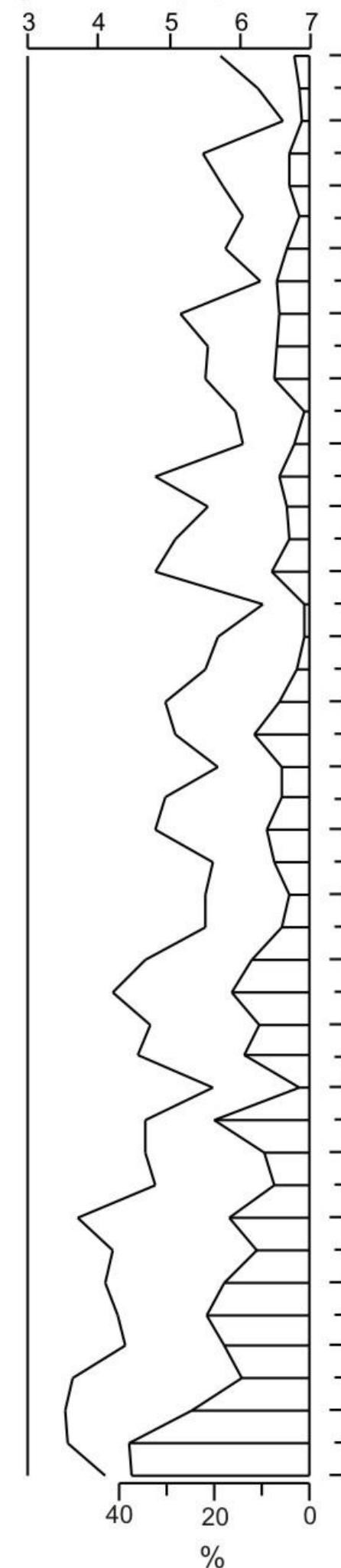

b) $\quad$ MAT $\left({ }^{\circ} \mathrm{C}\right)$

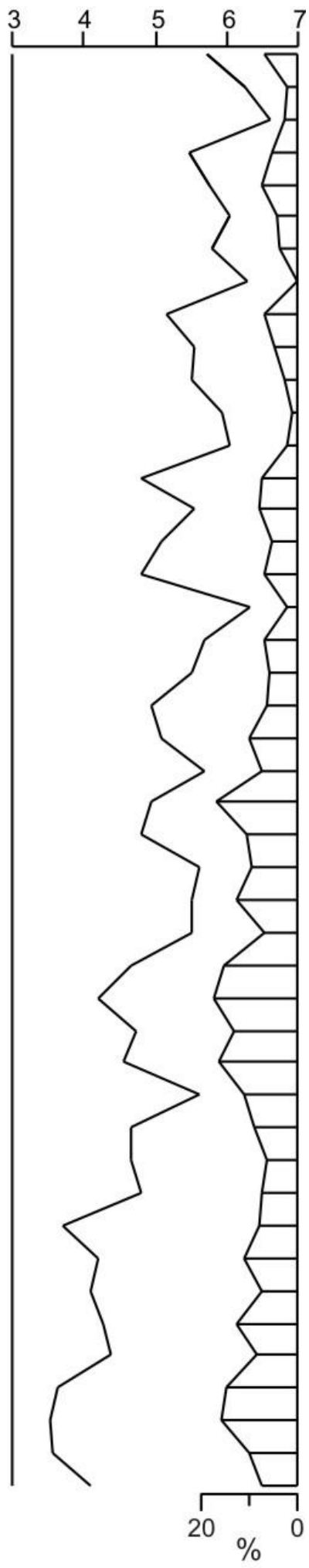

Figure 8.7: Comparison between the PLS-C3 MAT reconstruction and a) Phyllocladus alpinus and b) Fuscospora pollen abundance at Howard Valley. The samples have been placed in age order with the younger deposits at the top. The order is based upon the assumption that timing of sediment deposition is in stratigraphic order. 


\subsubsection{MAT and MAT depressions during the LGCP}

The vegetation composition of the alpine herb/grassland recorded during the LGCP and estimated temperatures from quantitative pollen/temperature reconstructions are similar between sites. However, Lake Mudgie is a lowland site and has a modern MAT of $11.5^{\circ} \mathrm{C}$ whilst Forks Lagoon and Howard Valley are at higher elevations and have lower MAT $\left(8.8{ }^{\circ} \mathrm{C}\right.$ and $9{ }^{\circ} \mathrm{C}$ respectively). When the estimated MAT for the LGCP is subtracted from the contemporary MAT at the sites, the temperature depression is less at the sites located at the higher altitudes in comparison to the lowland sites due to the former having considerably lower contemporary MAT. The training set produced by Wilmshurst et al (2007) contains sites reaching a maximum of 1540 m.a.s.l, but the cold alpine zone is still underrepresented which could lead to the MAT and therefore temperature depression during the LGCP to be underestimated.

The MAT reconstructions produced by Wilmshurst et al (2007) suggest that both models, but in particular the modern analogue technique, would overestimate the MAT of treeless periods in the records. Within the training set the only samples containing significant grassland and shrubland cover are from the south-eastern South Island. This region experiences moderate MATs, warm and dry summers and cold winters. Wilmshurst et al (2007) attributed the overestimated MAT reconstruction to the reliance of the samples from this region. This would have had greater significance on the W-MAT model, which methodologically is dependent upon the closeness of match with a set number of individual sites. A similar reason can be used to explain the overestimated MAT calculated for the LGCP in this project. A need to extend the spatial coverage of the training set is necessary before a reliable LGCP temperature reconstruction is to be achieved.

\subsubsection{LGIT in Westland}

The pattern of vegetation change and inferred temperature change using ELR suggest the LGIT was a period of near continuous climate amelioration with temperatures reaching a maximum at the beginning of the Holocene. A minor cooling episode may have occurred at Lake Mudgie between 13.4-11.9 ka but the amount of cooling cannot be quantified using ELR. This pattern of climate change is supported by a number of records from Westland and elsewhere in New Zealand (sees 
Sections 8.1.5 and 8.1.5.1). The W-MAT temperature reconstruction for Lake Mudgie also shows a similar pattern of climate change. However, the other modelled results for both Lake Mudgie and Manks Tarn reconstruct a cooling pattern from initially high temperatures at the start of the LGIT to the start of the Holocene which is followed by increasing temperatures. At Lake Mudgie, the PLS-C3 model predicts higher MAT during the early LGIT than reached in the Holocene, which is unexpected. The pattern of LGIT temperature reconstructions for both sites points to further limitation of the current models which relate to the use of taxa spanning a wide temperature gradient and the use of a national training set opposed to a regional one.

ELR reconstructions are based upon regional vegetation characteristics whilst the transfer function uses a national training set. In some cases using a nationwide training set is useful because the training set covers a wide environmental gradient, but for others it would appear a regional approach may be more appropriate. A large vegetation component in both Lake Mudgie and Manks Tarn during the early LGIT is a mixed Myrsine/Coprosma shrubland. In combination these taxa make up 60-90\% of the pollen assemblages. These taxa can grow in a wide range of habitats, from the lowland to alpine zone and in both the North and South Island of New Zealand covering a wide environmental gradient blurring the climate signal. In the Westland records the high MAT predicted at the onset of the LGIT can be attributed to the dominance of Coprosma and Myrsine. The subsequent decline in temperature during the LGIT is a factor of the decreasing abundance of these taxa up the cores. In this case the model's overestimation of MAT is largely due to applying climate envelopes for these taxa that are based on genus-level and nationwide pattern rather than on the actual species likely to be occurring in the region at the time. Regionally, Coprosma/Myrsine shrubland dominates the sub-alpine zone in the contemporary Westland environment and therefore are representative of cooler climates. Using a regional training set therefore may be helpful to reduce the wide environmental envelope that these taxa represent and thus produce a more realistic temperature reconstruction at the site. 


\subsubsection{W-MAT and PLS methodology}

Deciding which pollen-climate model is preferable for this project was difficult. The statistical parameters suggest W-MAT performs slightly better than PLS-C3 although there was not much between the two models. However, complications arise from methodological limitations discussed above and from the pattern of results presented in Chapters 4-7. The following discusses the differences in reconstruction and methodology between the two models.

For each record W-MAT consistently estimated higher MAT than PLS-C3. Wilmshurst et al (2007) noted a similar pattern for two records with modern analogue technique consistently producing $1{ }^{\circ} \mathrm{C}$ warmer MAT than the PLS during the LGIT. The authors attributed this to the underrepresentation of treeless sites in the training set. A similar explanation is proposed for this project especially for the LGCP where W-MAT appeared to consistently overestimate the MAT (Section 8.2.5.3). The WMAT method is more susceptible to poor representation of modern analogues in the training set as reliable reconstruction is dependent on close matches between modern and fossil assemblages. Instead the closest modern analogues for the fossil assemblages result in warmer estimated MAT than expected. Therefore this method is limited during the treeless periods. This evaluation indicates that more treeless sites should be added to the training set.

The PLA-C3 model is also influenced by the lack of modern pollen sites representing the alpine and treeless environments. However, this method allows species and climate data from a number of different samples that are not necessarily the closest match but infer MAT closer to the expected temperature. However, the same benefits in methodological approach for the LGCP become a hindrance during periods which contain large abundance of broad climate ranging taxa such as the Coprosma/Myrsine-dominated LGIT. The method's ability to extract climate data from the whole training set results in the inclusion of temperature data that are not representative of the environment represented by the fossil pollen assemblage. This results in warmer (LGIT at Lake Mudgie and Manks Tarn: 8.2.5.4) and colder (late MIS 3 at Howard Valley: 8.2.5.3) MAT reconstructed. Under these circumstances WMAT method restricts the climate data used to only the most closely related sites which may provide greater accuracy than PLS. 
As discussed above both the modelled results and the methods used contain limitations and the reconstructions produced should be treated carefully. Deciding upon the most appropriate model is difficult as PLS-C3 performs better during the LGCP and W-MAT performs better during the LGIT. However, the estimated MAT and calculated MAT depression are not the only important aspect of the climate reconstruction, but the pattern of change also. Based on this criterion the W-MAT performs better, particularly during the LGIT.

\subsubsection{Summary}

Despite the limitations discussed in the previous section, the pollen-climate models have provided some useful information regarding the pattern of climate change at the sites. For instance, for Lake Mudgie both models support a LGR reversal which could only be tentatively suggested using qualitative analysis. Nevertheless, the limitations (and potential solutions) which have been discussed above appear to be significant and are not only applicable to this project but to New Zealand as a whole. There is a need for better identification, including analyst consistency, to allow for other species/taxa to be incorporated in the training set and so reducing the data which is currently being ignored in the models. An increased spatial resolution of modern sites, including colder environment vegetation analogue, needs to be achieved in the training set before accurate reconstruction of LGCP, including LGM, conditions can occur. Associated with this is the use of regional training sets at sites which can refine the climate signal from the vegetation assemblage that is relative for a specific site. Again an increase in spatial resolution would be essential before regional training sets can be applied. Finally, some taxa appear to strongly influence the temperature reconstruction, such as at Howard Valley and during the LGIT in Westland. More work is needed to down-weight the influence of some taxa which may currently be distorting climate reconstructions under certain conditions, especially in regions where there is low representation of the contemporary vegetation and associated environmental variables in the training set. 


\section{Chapter 9: Conclusion and Future Work}

\subsection{Conclusions}

Pollen and sediment analysis from three regions in the South Island was undertaken to produce a vegetation and climate history for the area and test the robustness of the NZ-I CES. The project provides new data and a new precipitation proxy method; assesses the use and application of quantitative pollen-climate reconstructions; highlights the strengths and weaknesses of the NZ-I CES and suggests possible refinements.

- The pollen records contain orbital-scale and millennial-scale patterns of vegetation and climate change. The principle vegetation changes identified in the records produce similar results to studies conducted elsewhere in New Zealand. Five main vegetation and inferred climate changes are recorded between c.38-4 ka:

1. Late MIS 3 (c. 38-34 ka): at Howard Valley the vegetation is characteristic of montane Nothofagus menziesiilFuscospora forest implying a MAT depression between $2-3{ }^{\circ} \mathrm{C}$.

2. The LGCP is a period of variable climate with a two step cooling pattern evident in the pollen record and estimated in the quantitative pollen-climate reconstructions for Lake Mudgie

(a) LGCP (c.32 ka to 23-21 ka [boundary indeterminate or transitional]): vegetation is dominated by alpine grass and herbland which contains a significant abundance of tree and/or shrub taxa indicative of cold but milder climates than the LGM. MAT depression range between $5.3-3{ }^{\circ} \mathrm{C}$.

(b) LGM (23-21 ka to c.19 ka): dominated by grass and herbland taxa and containing trace amounts of tree taxa. MAT depressions range $>5.3-4.5^{\circ} \mathrm{C}$. 
3. Termination I and LGIT (18.9 ka to 11.9-10.8 ka [boundary indeterminate or transitional]): initially vegetation is dominated by Myrsine/Coprosma shrubland developing into Griselinia dominated forest followed by Weinmannia racemosa dominated montane forest. The pattern implies consistent climate amelioration and MAT depression change from $5.3-2.3^{\circ} \mathrm{C}$.

- Holocene (11.9-10.8 ka onwards): characterised by the dominance of Dacrydium cupressinum lowland forest at western sites

- A new precipitation proxy is derived from the comparative abundance of the plant marophytes Isoetes alpinus and Myriophyllum tryphyllum at Forks Lagoon, ESI. This proxy suggests that the LGCP, including the LGM, was generally drier, but is interrupted by two wetter periods between 26-24 ka and at $21 \mathrm{ka}$. These wetter periods in ESI correspond with evidence of wetter conditions in WSI, decreased westerly winds, milder conditions and decreased glacial activity. Conversely, the intervening dry period in ESI coincides with dry periods in WSI, increased intensity westerly winds, colder temperatures and increased glacial activity. The relationships imply that dry conditions relate to stadials and wet periods with interstadials.

- The patterns of climate change between western, eastern and northern South Island sites during the LGCP provide potential evidence of the influence of regional climate regimes. For example, at Forks Lagoon, evidence of drier conditions implies increased zonal flow and increased westerly wind intensity whereas evidence for wetter periods implies increased prevalence of a trough regime and reduced westerly wind intensity. In connection with regional climates, the precipitation pattern supports a northward migration of the Subtropical Front causing an increase in southern westerly wind intensity during stadials and brings colder waters around central and southern New Zealand.

- Evidence for a late glacial reversal in Westland is ambiguous. On the one hand, the pollen-vegetation reconstructions imply no major disruption to progressive climate amelioration. On the other hand, quantitative pollen- 
climate models show a MAT depression ranging 4.8-1.3 ${ }^{\circ} \mathrm{C}$ between 13.4$11.9 \mathrm{ka}$. During this interval some evidence of possible catchment disturbance is also evident at Lake Mudgie.

- Vegetation reconstructions based on pollen evidence at Howard Valley closely align with previously published vegetation interpretations based on beetle and plant macrofossil evidence. The three proxies complement one and imply a LGCP temperature depression of $3-4.5^{\circ} \mathrm{C}$ The NZ-I group uses the Kawakawa/Oruanui Tephra (KOT) age of 27.1 in the CES. However, the chronologies derived from Howard Valley and Forks Lagoon supports the younger $25.4 \mathrm{ka}$ age for the KOT. It is important to reconsider the KOT age to allow accurate comparisons between records in New Zealand and elsewhere.

- The application of the quantitative pollen-climate models produced conflicting results. Limitations in the training set and the methodology used to transfer modern environmental data to fossil data are likely to be the main reasons. The main limitations in the training set are attributed to a preponderance of taxa with climate ranges and the limited or lack of modern analogues for some of the fossil assemblages. Expanding the modern training set by the addition of more high altitude sites would improve the reconstructions produced.

- The results from this project and the NZ-I CES tend to correlate well, in particular the timing of Termination I, the possible LGR and the Holocene onset. However, there are some disparities, particularly during the LGCP including the complex climate period which is currently over simplified in the NZ-I CES. It should be noted that the disparities in the LGCP records may in part be due to different ages used for the KOT to date key boundaries or events. 


\subsection{Future work}

This section remarks on the limitations specific to this project and provides wider recommendations for future research in this field.

\subsubsection{Project specific recommendations}

- Lake Mudgie's chronology is constrained by only three AMS ages and one tephra age. The oldest AMS age appears to be too young and was excluded from the record. The stratigraphy at this site is therefore chronologically constrained by only three direct ages. It is clearly evident that more ages are required to produce a well constrained vegetation and climate reconstruction for the site.

- Statistical analysis of the chronology is needed to reduce arbitrary decisions regarding the ages. Age outliers in the datasets will be identified using sequence analysis and the OxCal program. This will refine the individual ages used in the age models.

- There are few precipitation records in New Zealand, particularly from the ESI and during the LGCP, making the Forks Lagoon marocphyte record unique. The palaeoprecipitation signal for this site could be further enhanced by increasing sampling resolution and extending the coverage beyond $31.4 \mathrm{ka}$ and into the LGIT and Holocene period. This could identify whether variations in precipitation can be identified during other key time periods such as the LGIT.

\subsubsection{Wider recommendations}

- The aim of using the quantitative pollen-climate models was to produce an objective estimate of palaeo MAT. However, limitations to the training set hinder reliable reconstructions. Improvements to the training set to provide better coverage of alpine vegetation analogues in particular are necessary to provide more robust reconstructions for cold intervals. 
- Environmental Lapse Rates (ELRs) provide a useful complementary tool to pollen-climate model reconstructions. However, these have often been applied based on generalised rates derived from large scale studies. More accurate reconstructions would be obtained from ELRs derived from the study region itself, particularly if these could be adjusted for possible changes in humidity over time.

- Analysis of modern climate emphasises the distinctive regional response to changing synoptic conditions. The research presented in this study further highlights the importance of taking a regional approach to understanding New Zealand's palaeoclimate record. 


\section{References}

Adams, R.D., 1962. Thickness of the earth's crust beneath the Campbell Plateau. New Zealand Journal of Geology and Geophysics, 5: 74-85.

Adams, J., 1980. Contemporary uplift and erosion of the Southern Alps, New Zealand: Summary. Geological Society of America Bulletin, Part 1, 91: 2-4.

Alley, R.B., 2000. The Younger Dryas cold interval as viewed from central Greenland. Quaternary Science Reviews, 19: 213-226.

Alley, R.B., 2007. Wally was right: predictive ability of the North Atlantic "conveyor belt" hypothesis for abrupt climate change. Annual Review of Earth and Planetary Sciences, 35: 241-272.

Alley, R.B., Brook, E.J., Anandakrishnan, S., 2002. A northern lead in the orbital band: north-south phasing of Ice-Age events. Quaternary Science Reviews, 21: 431-441.

Alloway, B.V., Stewart, R.B., Neall, V.E., Vucetich, C.G., 1992. Climate of the last glaciations in New Zealand, based on aerosolic quartz influx in an andesitic terrain. Quaternary Research, 38: 170-179.

Alloway, B.V., Pillans, B.J., Naish, T.R., Carter, L., Westgate, J.A., 2005. Onshore-offshore correlation of Pleistocene rhyolitic eruptions from New Zealand: Implications for TVZ eruptive history and paleoenvironmental construction. Bowen Speca Volume - Quaternary Science Reviews, 24;1601-1622

Alloway, B. V., Lowe, D.J., Barrell, D.J.A., Newnham, R.M., Almond, P.C., Augustinus, P.C., Bertler, N.A.N., Carter, L., Litchfield, N.J., McGlone, M.S., Schulmeister, J., Vandergoes, M.J., Williams, P.W., 2007. Towards a climate even stratigraphy for New Zealand over the past 30000 years (NZ-INTIMATE project). Journal of Quaternary Science, 22: 9-36.

Almond, P., 2010. The Kawakawa Tephra time-slice regional paleaoclimate reconstruction for Event $8 \mathrm{w}$ of the New Zealand Climate Event Stratigraphy. In: Proceedings of the AQUA Meeting. North Stradbroke Island, Queensland, p. 12-13.

Almond, P.C., Moar, N.T., Lian, O.B., 2001. Reinterpretation of the glacial chronology of South Westland, New Zealand. New Zealand Journal of Geology and Geophysics, 44: 1-15. 
Anderson, B., Mackintosh, A., 2006. Temperature change is the major driver of late-glacial and Holocene glacier fluctuations in New Zealand. Geology, 34: 121-124.

Anderson, R.F., Ali, S., Bradtmiller, L.I., Nielsen, S.H.H., Fleisher, M.Q., Anderson, B.E., Burckle, L.H., 2009. Wind-driven upwelling in the Southern Ocean and the deglacial rise in atmospheric $\mathrm{CO}_{2}$. Science, 323: 1443-1448.

Applegate, J.P., Lowell, T.V., Alley, R.B., 2008. Comment on "Absence of cooling in New Zealand and the Adjacent ocean during the Younger Dryas Chronozone". Science, 320: 746.

Ariztegui, D., Bianchi, M.M., Masaferro, J., Lafargue, E., Niessen, F., 1997. Interhemipheric synchrony of Late-glacial climate instability as recorded in proglacial Lake Mascardi, Argentina. Journal of Quaternary Science, 13: 333-338.

Ashworth, A.C., Hogansen, J.W., 1993. The magnitude and rapidity of the climate change marking the end of the Pleistocene in the mid-latitudes of South America. Palaeogeography, Palaeoclimatology, Palaeoecology, 101: 263-270.

Augustinus, P., D'Costa, D., Deng, Y., Hagg, J., Shane, P., 2011. A multi-proxy record of changing environments from ca. 30000 to 9000 cal. A BP: Onepoto maar palaeolake, Auckland, New Zealand. Journal of Quaternary Science, 26: 389-401.

Banister, P., 2003. Are frost hardiness rating useful predictors of frost damage in the field? A test using damage records from severe frost in South Otago and Southland, New Zealand, July 1996. New Zealand Journal of Botany, 41: 555-569.

Bard, E., Rostek, F., Ménot-Combes, G., 2004. Radiocarbon calibration beyond 20,000 ${ }^{14} \mathrm{C}$ yr BP by means of plankton foraminifera of the Iberian Margin. Quaternary Research, 61: 204-214

Barrell, D., Denton, G., Andersen, B., Lowell, T., Almond, P., Suggate, P., Hendy, C., Vandergoes, M., Newnham, R., Schlüchter, C., Preusser, F., Schäfer, J., Chinn, T., unpublished. Central South Island Glacial Geomorphology (online). Available from http;//maps.gns.cri.nz/website/csigg/ [accessed $3^{\text {rd }}$ June 2010].

Barrows, T.T., Lehman, S,J., Fifield, L.K., De Deckker, P., 2007. Absence of Cooling in New Zealand and the adjacent ocean during the younger Dryas Chronozone. Science, 318: 8688. 
Beavan, J., Tregoing, P., Bevis, M., Kato, T., Meertents, C., 2001. Motion and rigidity of the Pacific Plate and implications for plate boundary deformation. Journal of Geophysical Research, 107: doi:1029/2001JB0000282

Beer, R., Heiri, O., Tinner, W., 2007. Vegetation history, fire history and lake development recorded for 6300 years by pollen, charcoal, loss on ignition and chironomids at a small lake in southern Kyrgyzstan Alay Range, Central Asia. The Holocene, 17: 977-985.

Bennett, K.D., 1994. Confidence intervals for age estimates and deposition times in lat-Quaternary sediment sequences. The Holocene, 4: 337-348.

Bennett, K.D., Fuller, J.L., 2002. Determining the age of the mid-Holocene Tsuga Canadensis (hemlock) decline, eastern North America. The Holocene, 14: 421-429.

Berger, A., Loutre, M.F., 1991. Insolation values for the climate of the last 10 million years. Quaternary Science Reviews, 4: 297-317.

Birks, H. J. B. (1981): The use of pollen analysis in the reconstruction of past climates: a review. In: T.M.L. Wigley, M.J. Ingram and G. Farmer (eds), Climate and history. Studies in past climates and their impact of man, Cambridge University Press, Cambridge, pp. 111-138.

Birks, H.J.B., 1995. Chapter 6: Quantitative Palaeoenvironmental Reconstructions. In: Maddy, D., Brew, J.S. (eds), Statistical Modelling of Quaternary Science Data. Technical Guide, vol. 5. Quaternary Research Association, Cambridge, p. 161-254.

Birks, H.J.B., Birks, H.H., 1980. Quaternary Palaeoecology. Edward Arnold, London, p289.

Birks, H.J.B., Gordon, A.D., 1985. Numerical methods in Quaternary pollen analysis. Academic Press INC, London, p317.

Birks, H.J.B., Heiri, O., Seppa, H., Bjune, A.E., 2010. Strengths and weaknesses of quantitative climate reconstructions based on Late Quaternary biological proxies. The Open Ecology Journal, 3: 68-110

Blunier, T., Brook, E.J., 2001. Timing of millennial-scale climate change in Antarctica and Greenland during the last glacial period. Science, 291: 109-112.

Blunier, T., Chappellaz, J., Schwander, J., Dällenbach, A., Stauffer, B., Stocker, T.F., Raynaud, D., Jouzel, J., Clausen, H.B., Hammer, C.U., Johnsen, S.J., 1998. Asynchrony of Antarctica and Greenland climate change during the last glacial period. Nature, 394: 739-743. 
Boés, X., Fagel, N., 2008. Timing of the late glacial and Younger Dryas cold reversal in southern Chile varved sediments. Journal of Paleolimnology, 39: 267-281.

Bonny, A.P., 1972. A method for determining absolute pollen frequencies in lake sediments. New Phytologist, 71: 393-405.

Bos, J.A.A., van Geel, B., van der Plicht, J., Bohncke, S.J.P., 2007. Preboreal climate oscillations in Europe: Wiggle-match dating and synthesis of Dutch high-resolution multi-proxy records. Quaternary Science Reviews, 26: 1927-1950.

Brook, M.S., Brock, B.W., 2003. Valley morphology and glaciation in the Tararua Range, southern North Island, New Zealand. New Zealand Journal of Geology and Geophysics, 48: 717-724.

Brown, J.M.A.,1975. Chapter 17: Ecology of macrophytes. In: Jolly, V.H., Brown, J.M.A., (Eds) New Zealand Lakes. Auckland University Press, Auckland. pp244-262.

Burge, P.I., Shulmeister, J., 2007a. An MIS 5a to MIS 4 (or early MIS 3) environmental and climatic reconstruction from the northwest South Island, New Zealand, using beetle fossils. Journal of Quaternary Science 22: 501-516.

Burge, P.I., Shulmeister, J., 2007b. Re-envisioning the structure of last glacial vegetation in New Zealand using beetle fossils. Quaternary Research 68: 121-132.

Burrows, C.J., 1977. Late-Pleistocene and Holocene glacial episodes in the South Island, New Zealand and some climatic implications. New Zealand Geographer, 33: 34-39.

Campbell, I.B., 1986. New occurrences and distribution of Kawakawa Tephra in South Island, New Zealand. New Zealand Journal of Geology and Geophysics, 29: 425-435.

Campbell, H.J., Landis, C.A., 2003. New Zealand awash. New Zealand Geographic 2003, 6-7.

Carter, L., 2001. Currents of change. Water and Atmosphere, 9: 15-17.

Carter, L., Neil, H.L., Northcote, L., 2002. Late Quaternary ice-rafting events in the SW Pacific Ocean, off eastern New Zealand. Marine Geology, 191: 19-35.

Carter, L., Shane, P., Alloway, B., Hall, I.R., Harris, S.E., Westgate, J.A., 2003. Demise of one volcanic zone and birth of another - a 12 Ma deep ocean record of major rhyolitic eruptions from New Zealand. Geology, 31; 793-496 
Carter, L., Manighetti, B., Ganssen, G., Northcote, L., 2008. Southwest Pacific modulation of abrupt climate change during the Antarctic Cold Reversal-Younger Dryas. Palaeogeography, Palaeoclimatology, Palaeoecology, 260: 284-298.

Carter, R.M., Norris, R.J., 1976. Cainozoic history of southern New Zealand: an accord between geological observations and plate-tectonic predictions. Earth and Planetary Science Letters, 31: $85-94$

Challis, G.A., Johnston, M.R., Lauder, W.R., Suggate, R.P., 1994. Geology of the Lake Rotoroa area. Geologic Map 8. Institute of Geological and Nuclear Science, Lower Hutt, New Zealand.

Chinn, T.J., 1989. Glaciers of New Zealand: U.S. Geological Survey Professional Paper 1386-H2, $48 p$.

Clark, P.U., Dyke, A.S., Shakun, J.D., Carlson, A.E., Clark, J., Wohlfarth, B., Mitrovica, J.X., Hostetler, S.W., McCabe, A.M., 2009. The Last Glacial Maximum. Science, 325: 710-714.

Close, R.C., Moar, N.T., Tomlinson, A.I., Lowe, A.D., 1978. Aerial dispersal of biological material from Australia to New Zealand. International Journal of Biometeorology, 22: 1-19.

Colhoun, E.A., Kiernan, K., Barrows, T.T., 2010. Advances in Quaternary studies in Tasmania. In: Bishop, P., Pillans, B., (eds), Australian Landscapes. Geological Society, London, Special Publications, 346: 165-183.

Cook, E.R., Buckley, B.M., Palmer, J.G., Fenwick, P., Peterson, M.J., Boswijk, G., Fowler, A., 2006. Millennia-long tree-ring records from Tasmania and forcing past, present and future. Journal of Quaternary Science, 25: 689-699.

Cooper, R.A., Millener, P.R., 1993. The New Zealand biota: historical background and new research. Trends in ecology and evolution, 8: 429-433.

Crundwell, M., Scott, G., Naish, T., Carter, L., 2008. Glacial-interglacial ocean climate variability from planktonic foraminifera during the Mid-Pleistocene transition in the temperate Southwest Pacific, ODP Site 1123. Palaeogeography Palaeoclimatology Palaeoecology, 260: 202-229.

Dansgaard, W., Johnsen, S.J., Clausen, H.B., Dahl-Jensen, D., Gundestrup, N., 1993. Evidence for general instability of past climate from 250-kyr ice-core record. Nature, 36: 218-220. 
DeMets, C., Gordon, R.G., Argus, D.F., Stein, S., 1994. Effects of recent revisions to the geomagnetic reversal time scale on estimates of current plate motions. Geophysical Research Letters, 21: 2191-2194.

Denton, G,H., Hendy, C.H., 1994. Younger Dryas age advance of Franz Josef Glacier in the Southern Alps of New Zealand. Science, 264: 1434-1437.

Denton, G.H., Heusser, C.J., Schüchter, C., Marchant, D.R., 1999. Interhemispheric linkage of paleaoclimate during the last glaciations. Geografiska Annaler, 81: 107-153.

Digerfeldt, G., Olsson, S., Sandgre, P., 2000. Reconstruction of lake-level changes in lake Xinias, central Greece, during the last 40000 years. Palaeogeography, Palaeoclimatology, Palaeoecology, 158: 65-82.

Dodson, J.R., 1978. A vegetation history from north-east Nelson, New Zealand. New Zealand Journal of Botany, 16: 371-378.

Douglasse, D.C., Singer, B.S., Kaplan, M.R., Mickelson, D.M., Caffee, M.W., 2006. Cosmogenic nuclide surface exposure dating of boulders on last-glacial and late-glacial moraines, Lago Buenos Aires, Argentina: interpretive strategies and paleaoclimate implications. Quaternary Geochronology, 1: 43-58.

Drost, F., Renwick, J., Bhaskaran, B., Oliver, H., McGregor, J., 2007. A simulation of New Zealand's climate during the Last Glacial Maximum. Quaternary Science Reviews, 26: 25052525.

Elderfield, H., Greaves, M., Barker, S., Hall, I.R., Tripati, A., Ferretti, P., Crowhurst, S., Booth, L., Daunt, C., 2010. A record of bottom water temperature and seawater $\delta^{18} \mathrm{O}$ for the Southern Ocean over the past $440 \mathrm{kyr}$ based on $\mathrm{Mg} / \mathrm{Ca}$ of benthic foraminiferal Uviderina spp. Quaternary Science Reviews, 29: 160-169.

EPICA Community Members, 2004. Eight glacial cycles from an Antarctic ice core. Nature, 429: 623- 628.

EPICA Community Members, 2006. One-to-one coupling of glacial climate variability in Greenland and Antarctica. Nature, 444: 195-198. 
Espie, P.R., Barrett, B.I.P., 2006. Biodiversity of indigenous tussock grassland sites in Otago, Canterbury and the central North Island of New Zealand IV. Vegetation and the effect of disturbance by agricultural development and fire. Journal of the Royal Society of New Zealand, 36: 69-82

Fairbanks, R.G., Mortlock, R.A., Chiu, T.-U., Cao, L., Kaplan, A., Guilderson, T., 2005. Marine radiocarbon calibration curve spanning 0-50,000 years B.P. based on paired ${ }^{230} \mathrm{Th} /{ }^{234} \mathrm{U} /{ }^{238} \mathrm{U}$ and ${ }^{14} \mathrm{C}$ dates on pristine corals. Quaternary Science Reviews, 24: 1781-1796.

Fink, D., McKelvey, B., Hannan, D., Newsome, D., 2000. Cold rocks, hot sands: In-situ cosmogenic applications in Australia at ANTARES. Nuclear Instruments and Methods in Physics Research, 172: 838-846.

Finkelstein, S.A., Gajewski, K., Viau, A.E., 2006. Improved resolution of pollen taxonomy allows better biogeographical interpretation of post-glacial forest development: analyses from the North American Pollen Database. Journal of Ecology, 94: 415-430.

Finsinger, W., Heir, O., Valsecchis, V., Tinner, W., Lotter, A.F., 2007. Modern pollen assemblages as climate indicators in southern Europe. Global Ecology and Biogeography,16: 567-582.

Fletcher, M.-S., Thomas, I., 2010. A quantitative Late Quaternary temperature reconstruction from western Tasmania, Australia. Quaternary Science Reviews, 29: 2351-2361.

Fletcher, M.-S., Moreno, P.I., 2011. Zonally symmetric changes in the strength and position of the Southern Westerlies drove atmospheric $\mathrm{CO}_{2}$ variations over the past 14 k.y. Geology, 39: 419-422.

Fowler, A.M., Palmer, J., Fenwick, P., 2008. An assessment of the potential for centennial-scale reconstruction o atmospheric circulation from selected New Zealand tree-ring chronologies. Palaeogeography, Palaeoclimatology, Palaeoecology, 264: 238-254.

Franklin, D.A., 1968. Biological flora of New Zealand 3. Dacrydium cupressinum Lamb. (Podocarpaceae) rimu. New Zealand Journal of Botany, 6: 493-513.

Froggatt, P.C., Lowe, D.J., 1990. A review of late Quaternary silicic and some other tephra formations from New Zealand: their stratigraphy, nomenclature, distribution, volume, and age. New Zealand Journal of Geology and Geophysics, 33: 98-109.

Gage, M., 1945. The Tertiary and Quaternary geology of Ross, Westland. Transactions of the Royal Society of New Zealand, 75: 138-159. 
Gair, H.S., 1967. Sheet 20, Mt. Cook. In: Geological Map of New Zealand (1:250,000). New Zealand Geological Survey, Wellington.

Gauch, H.G., 1982. Multivariate analysis in community ecology. Cambridge University Press, Cambridge, p 298.

Gibbard, P.L., Head, M.J., Walker, M.J.C., The Subcommission on Quaternary Stratigraphy., 2010. Formal ratification of the Quaternary system/period and the Pleistocene Series/Epoch with a base at 2.58 Ma. Journal of Quaternary Science, 25: 96-102.

Gillespie, R., Hammond, A.P., Goh, K.M., Tonkin, P.J., Lowe, D.C., Sparks, R.J., Wallace, G., 1992. AMS dating of Late Quaternary tephra at Graham's Terrace. New Zealand. Radiocarbon, 34: 21-27.

Goring, S., Lacourse, T., Pellatt, M.G., Walker, I.G., Mathewes, R.W., 2010. Are pollen-based climate models improved by combining surface samples from soil and lacustrine substrates? Review of Palaeobotany and Palynology, 162: 203-212.

Grapes, R., Rieser, U., Wang, N., 2010. Optical luminescence dating of loess section containing a critical tephra marker horizon, SW North Island of New Zealand. Quaternary Geology, 5: 164-169.

Gray, A.B., Pasternack, G.B., Watson, E.B., 2010. Hydrogen peroxide treatment effects on the particle size distribution of alluvial and marsh sediments. The Holocene, 20: 293-301.

Griffiths, G.A., McSaveney, M.J.,1983. Distribution of mean annual precipitation across some steepland regions of New Zealand. New Zealand Journal of Science, 26; 197-209.

Grimm, E.C., 1987. CONISS: A FORTRAN 77 program for stratigraphically constrained cluster analysis by the method of incremental sum of squares. Computers and Geosciences, 13: 1335.

Grootes, P.M., Stuvier, M., White, J.W.C., Johnseb, S., Jouzel, J., 1993. Comparison of oxygen isotope records from GISP2 and GRIP Greenland ice cores. Nature, 366: 552-554.

Grosjean, M., Leeuwen, J.F.N., van der Knaap, W.O., Gehy, M.A., Ammann, B., Tanner, W., Messerli, B., Núñez, L.A., Valero-Garcés, B.L., Veit, H., 2001. A $22,000{ }^{14} \mathrm{C}$ year BP sediment and pollen record of climate change from Laguna Miscanti $\left(23^{\circ} \mathrm{S}\right)$, northern Chile. Global and planetary Change, 28: 35-51. 
Haberle, S.G., Bennett, K.D., 2004. Postglacial formation and dynamics of North Patagonia Archipelago, Southern Chile. Quaternary Science Reviews, 23: 23-24.

Hajdas, I., Bonani, G., Moreno, P.I., Ariztegui, D., 2003. Precise radiocarbon dating of Late-Glacial cooling in mid-latitude South America. Quaternary Research, 59: 70-78.

Hales, T.C., Roering, J.J., 2005. Climate-controlled variations in scree production, Southern Alps, New Zealand. Geology, 33: 701-704.

Hall, I.R., McCave, I.N., Shackleton, N.J., Weedon, G.P., Harris, S.E., 2001. Intensified deep Pacific inflow and ventilation in Pleistocene glacial times. Nature, 412: 809-812.

Hammond, A.P., Goh, K.M., Tonkin, P.J., Manning, M.R., 1991. Chemical pretreatments for improving the radiocarbon dates of peats and organic silts in a gley podzol environment, Graham's Terrace, North Westland. New Zealand Journal of Geology and Geophysics, 34: 191-194.

Harle, K.J., Kershaw, A.P., Clayton, E., (2004) Patterns of vegetation change in southwest Victoria (Australia) over the last two glacial/interglacial cycles: evidence from Lake Wangoom. Proceedings of the Royal Society of Victoria, 116: 105-137.

Heiri, O., Lotter, A.F., Lemeke, G., 2001. Loss on Ignition as a method for estimating organic and carbonate content in sediments: reproducibility and comparability of results. Journal of Paleolimnology, 25: 101-110.

Hellstrom, J., McCulloch, M., Stone, J.M. 1998. A detailed 31,000-year record of climate and vegetation change from the isotope geochemistry of two New Zealand speleothems. Quaternary Research, 50: 167-178.

Herbert, T.D., Peterson, L.C., Lawrence, K.T., Liu, Z., 2010. Tropical ocean temperatures over the past 3.5 million years. Science, 328: 1530-1534.

Heusser, C.J., 1981. Palynology of the last interglacial-glacial cycle in midlatitudes of southern Chile. Quaternary Research, 4: 290-315.

Heusser, L.E., Van de Geer, G., 1994. Direct correlation of terrestrial and marine paleoclimatic records from four glacial-interglacial cycles - DSDP Site 594 southwest Pacific. Quaternary Science Reviews, 13: 273-282. 
Hormes, A., Preusser, F., Denton, G., Hajdas, I., Weiss, D., Stocker, T.F., Schlüchter, C., 2003. Radiocarbon and luminescence, dating of overbank deposits in outwash sediments of the Last Glacial Maximum in North Westland New Zealand. New Zealand Journal of Geology and Geophysics, 46: 95-106.

Horrocks, M., Ogden, J., 1994. Modern pollen spectra and vegetation of Mt Hauhungatahi, central North Island, New Zealand. Journal of Biogeography, 15: 209-220.

Horrocks, M., O'Loan, A., Wallace, R., 2010. Discontinuous late Pleistocene-Holocene pollen records from Auckland Domain, northern New Zealand. New Zealand Journal of Botany, 47: 239-247.

Houghton, B.F., Wilson, C.J.N., McWilliams, M.D., Lanphere, M.A., Weaver, S.D., Briggs, R.M., Pringle, M.S., 1995. Chronology and dynamics of a large silicic magmatic systems: central Taupo Volcanic Zone, New Zealand. Geology, 23: 13-16.

Huybers, P., 2004. Comments on 'Coupling of the hemispheres in observations and simulations of glacial climate change' by Schmittner, A., Saenko, O.A., Weaver, A.J. Quaternary Science Reviews, 21: 207-210.

Huybers, P., Wunsch, C., 2005. Obliquity pacing of the late Pleistocene glacial terminations. Nature, 434: 491-494.

Imbrie, J., Imbrie, K.P., 1979. Ice Ages: solving the mystery. The Macmillan Press, London, p. 224.

Ivy-Ochs, S., Schluchter, C., Kubik, P.W., Denton, G.H., 1999. Moraine exposure dates imply synchronous Younger Dryas glacier advances in European Alps and in the Southern Alps of New Zealand. Geografiska Annaler ,81A: 313-323.

Johnsen, S.J., Dahl-Jensen, D., Gundestrup, N., Steffensen, J.P., Clausen, H.B., Miller, H., Masson-Delmotte, V., Sveinbjörnsdottir, A.R., White, J., 2001. Oxygen isotope and palaeotemperature records from six Greenland ice-core stations: Camp Century, Dye-3, GRIP, GISP2, Renland, and NorthGRIP. Journal of Quaternary Science, 16: 299-307.

Jorgensen, S., 1967. A method of absolute pollen counting. New Phytologist, 66: 489-493.

Jouzel, J., Masson, V., Cattani, O., Falourd, S., Stievenard, M., Stenni, B., Longinelli, A., Johnsen, S.J.J., Steffenssen, J.P., Petit, J.R., Schwander, J., Souchez, R., Barkov, N.I., 2001. A new 27 ky high resolution East Antarctic climate record. Geophysical Research Letters, 28: 3199. 
Kaplan M.R., Ackert, R.P., Singer, B.S., Douglass, D.C., Kurz, M.D., 2004. Cosmogenic nuclide chronology of millennial-scale glacial advances during O-isotope stage 2 in Patagonia Geological Society of America Bulletin, 116: 308.

Kaplan, M.R., Fogwill, C.J., Sugden, D.E., Hulton, N., Kupik, P.W., Freeman, S.P.H.T., 2008. Southern Patagonian glacial chronology for the last glacial period and implications for Southern Ocean climate. Quaternary Science Reviews, 27: 284-294.

Kaplan, M.R., Schaefer, J.M., Denton, G.H., Barrell, D.J.A., Chinn, T.J.H., Putnam, A.E., Andersen, B.G., Finkel, R.C., Schwartz, R., Doughty, A.M., 2010. Glacier retreat in New Zealand during the Younger Drayas stadial. Nature, 467: 194-197.

Katz, H.R., 1979. Alpine uplift and subsidence of fore-deeps. In: Walcott, R.I., Cresswell, M.M., (Eds.), The Origin of the Southern Alps. The Royal Society of New Zealand Bulletin, 18: p. $121-130$.

Kay, P.A., Andrews, J.T., 2005. Re-evaluation of pollen-climate transfer functions in Keewatin, Northern Canada. Annals of the Association of American Geographers, 73: 550-559.

Kennett, J.P., Brunner, C.A., 1973. Antarctic Late Cenozoic glaciation: evidence for initiation of icerafting and inferred increased bottom-water activity. Geological Society of America bulletin, 84: 2043-2052.

Kidson, J.W., 2000. An analysis of New Zealand synoptic types and their use in defining weather regimes. International Journal of Climatology, 20: 299-316.

Kitamura, A., Kanoto, K., 2007. Eccentricity cycles shown by early Pleistocene planktonic foraminifers of the Omma Formation, Sea of Japan. Global and Planetary Change, 55: 273283.

Knutti, R., Flückiger, J., Stocker, T.F., Timmermann, A., 2004. Strong hemisphere coupling of glacial climate through freshwater discharge and ocean circulation. Nature, 430: 851-856.

Lambeck, K., Chappell, J., 2001. Sea level change through the last glacial cycle. Science, 292: 679-686.

Lambeck, K., Yokoyama, Y., Purcell, T., 2002. Into and out if the Last Glacial Maximum: sea-level change during Oxygen Isotope Stages 3 and 2. Quaternary Science Reviews, 21: 343-360. 
Lamy, F., Kaiser, J., Ninnemann, U., Hebblan, D., Arz, H.W., Stoner, J., 2004. Antarctic timing of surface water changes off Chile and Patagonian ice sheet response. Science 304: 19591962.

Large, M.F., Biggins, J.E., 1991. Spore atlas of New Zealand ferns and fern allies. SIR Publishing, Wellington, p.167.

Lawson, I., Frogley, M., Bryant, C., Preece, R., Tzedakis, P., 2004. The Late-glacial and Holocene environmental history of the loannina basin, north-west Greece. Quaternary Science Reviews, 23: 1599-1625.

Lee, D.E., Lee, W.G., Mortimer, N., 2001. Where and why have all the flowers gone? Depletion and turnover in New Zealand Cenozoic angiosperm flora in relation to palaeogeography and climate. Australian Journal of Botany, 49: 341-356.

Liu, Z., Cleaveland, L.C., Herbert, T.D., 2008. Early onset and origin of 100-kyr cycles in Pleistocene tropical SST records. Earth and Planetary Science Letters, 265: 703-715.

Lorrey, A., Fowler, A.M., Salinger, J., 2007. Regional climate regime classification as a qualitative tool for interpreting multi-proxy paleaoclimate data spatial patterns: A New Zealand case study. Palaeogeography, Palaeoclimatology, Palaeoecology, 253: 407-433.

Lowe, D.J., Hunt, J.B., 2001. A summary of terminology used in tephra-related studies. Les Dossier de l'Archaèo-Logis, 1: 17-22.

Lowe, D.J., Shane, P.A.R., Alloway, B.V., Newnham, R.M., 2008. Fingerprints and age models for widespread New Zealand tephra marker beds erupted since 30,000 years ago: a framework for NZ-INTIMATE. Quaternary Science Reviews, 27: 95-126.

Lowe, D.J., Wilson, C.J.N., Newnham, R.M., Hogg, A.G., 2009. Dating the Kawakawa/Oruanui eruption: Comment on "Optical luminescence dating of loess section containing a critical tephra marker horizon, SW North Island of New Zealand' by Grapes et al. Quaternary Geochronology, 5: 493-496.

Lowe, J.J., Blockley, S., Trincardi, F., Asioli, A., Cattaneo, A., Matthews, I.P., Pollard, M., Wulf, S., 2007. Age modelling of late Quaternary marine sequences in the Adriatic: Towards improved precision and accuracy using volcanic event stratigraphy. Continental Shelf Research, 27: 560-582. 
Lowell, T.V., Heusser, C.J., Andersen, B.G. Moreno, P.I., Hauser, A., Denton, G.H., Heusser, L.E., Schulchter, C., Marchant, D., 1995. Interhemispheric correlation of Late Pleistocene glacial events. Science, 269: 1541-1549.

Mabin, M.C.G., 1983. Late Otiran sedimentation and glacial chronology of Warwick Valley, south east Nelson. New Zealand Journal of Geology and Geophysics, 26: 186-195.

MacPhail,M.K., 1979. Vegetation and climate in southern Tasmania since the last glaciations. Quaternary Research, 11, 306-341.

Maher, L., 1972. Absolute pollen diagram for Redrock Lake, Boulder Country, Clorado. Quaternary Research, 2: 531-553.

Maizel, J.K., (1989) Differentiation of late Pleistocene terrace deposits outwash deposits using geomorphic criteria: Tekapo valley, South Island, New Zealand. New Zealand Journal of Geology and Geophysics, 10: 1027-1039.

Mark, A.F., Dickinson, K.J.M., Hofstede, R.G.M., 2000: Alpine vegetation, plant distribution, life forms, and environments in a perhumid New Zealand region: Oceanic and tropical high mountain affinities. Arctic, Antarctic and Alpine Research, 32: 240-254.

Marra, M.J., Leschen, R., 2004. Late Quaternary paleoecology from forest beetle communities in the Awatere Valley, South Island, New Zealand. Journal of Biogeography, 31: 571-586.

Marra, M.J., Thackray, G.D., 2010. Glacial forest refugium in Howard Valley, South Island, New Zealand. Journal of Quaternary Science, 25: 309-319.

Marra, M.J., Smith, E.G.C., Shulmeister, J., Leschen, R., 2004. Late Quaternary climate change in the Awatere Valley, South Island, New Zealand using a sine model with a maximum likelihood envelope on fossil beetle data. Quaternary Science Reviews, 23: 1637-1650.

Marra M. J., Crozier M., Goff J. 2009. Palaeoenvironment and biogeography of a late MIS 3 fossil beetle fauna from South Taranaki, New Zealand. Journal of Quaternary Science, 24: 97-107.

Martinson, D.G., Pisias, N.G., Hays, J.D., Imbrie, J., Moore, T.C., Shackleton, N.J., 1987. Age dating and the orbital theory of the ice ages: development of a high resolution - 300,000 year chronostratigraphy. Quaternary Research, 27: 1-29. 
Mason, R., 1975. Chapter 16: The Macrophytes. In: Jolly, V.H., Brown, J.M.A., (Eds) New Zealand Lakes. Auckland University Press, Auckland. pp 244-262.

Masson, V., Vimeux, F., Jouzel, J., Morgan, V.,Delmotte, M., Ciais, P., Hammer, C., Johnsen, Lipenkov, V.Y., Mosley-Thompson, E., Petit, J-R., Steig, E.J., Stievenard, M., Vaikmae, R., 2000. Holocene climate variability in Antarctica based on 11 ice-core isotope records. Quaternary Research, 54: 348-358.

Massaferra, J., Brooks, S.J., 2002. Response of chironomids to Late Glacial environmental change in the Taitao Pennisula, Southern Chile. Journal of Quaternary Science, 17: 101-111.

Massaferra, J., Brooks, S.J., Haberle, S.G., 2005. The dynamics of chironomid assemblages and vegetation during the Late Quaternary at Laguna Facil, Chronos Achipelago, Southern Chile, Quaternary Science Reviews, 24: 2510-2522.

Maunder, W.J, 1971. The climate of New Zealand- physical and dynamic features. In: Gentilli, (ed). World survey of climatology: Climates of Australia and New Zealand, V 13. Elsevier, Amsterdam, pp 213-227.

McArthur, J.L., Shepherd, M.J., 1990. Late Quaternary glaciations of Mt Ruapehu, North Island, New Zealand. Journal of the Royal Society of New Zealand, 20: 287-296.

McCaplin, J.P., 1992a. Glacial and postglacial geology near Lake Tennyson, Clarence River, New Zealand Journal of Geology and Geophysics, 35: 201-210.

McCaplin, J.P., 1992b. Glacial geology of the upper Wairau Valley, Marlborough, New Zealand. New Zealand Journal of Geology and Geophysics, 35: 211-222.

McCulloch, R.D., Davies, S.J., 2001. Late-glacial and Holocene palaeoenvironmental change in the central Strait of Magellan, southern Patagonia. Palaeogeography, Palaeoclimatology, Palaeoecology, 173: 143-173.

McCulloch, R.D., Bentley, M.J., Purves, R.S., Hulton, N.R., Sugden, D.E., Clapperton, C.M., 2000. Climatic inferences from glacial and palaeoecological evidence at the last glacial termination, southern South America. Journal of Quaternary Science, 15: 409-417.

McCulloch, R.D., Bentley, M.J., Tipping, R., Clapperton, C.M., 2005. Evidence for late-glacial ice dammed lakes in the central Strait of Magellan and Bahía Inútil, southernmost South America. Geografiska Annaler, 87A: 335-362. 
McDowell, R.M, 2008. Process and pattern in the biogeography of New Zealand. Journal of Biogeography, 35: 197-212.

McGlone, M.S., 1985. Plant biogeography and the late Cenozoic history of New Zealand. New Zealand Journal of Botany, 23: 723-749.

McGlone, M.S., 1988. New Zealand. In: Huntley, B., (ed) Vegetation history. Kluwer Academic Press, Dordrecht, 558-599.

McGlone, M.S., 1989. The Polynesian settlement of New Zealand in relation to environmental and biotic changes. New Zealand Journal of Ecology, 12: 115-129.

McGlone, M.S., 1995. Lateglacial landscape and vegetation change and the Younger Dryas climatic oscillation in New Zealand. Quaternary Science Reviews, 14: 867-881.

McGlone, M.S., 2001a. A late Quaternary pollen record from marine core P69, southeastern North Island, New Zealand. New Zealand Journal of Geology and Geophysics, 44: 69-77.

McGlone, M.S., 2001b. The origins of the indigenous grasslands of southeastern South Island in relation to pre-human woody ecosystems. New Zealand Journal of Ecology, 25: 1-15.

McGlone, M.S., Bathgate, J.L. 1983. Vegetation and climate history of the Longwood Range, South Island, New Zealand, 12000 BP to the present. New Zealand Journal of Botany, 21: 293315.

McGlone, M.S., Topping, W.W., 1983. Late Quaternary vegetation, Tongariro region, central North Island, New Zealand. New Zealand Journal of Botany, 21: 53-76.

McGlone, M.S., Basher, L.R., 1995. The deforestation of the upper Awatere catchment, inland Kaikoura range, Marlborough, South Island, New Zealand. New Zealand Journal of Ecology, 19: 53-66.

McGlone, M.S., Moar N.T., 1998. Dryland Holocene vegetation history, central Otago and the MacKenzie Basin, South Island, New Zealand. New Zealand Journal of Botany, 36: 91-111.

McGlone, M.S., Salinger, M.J., Moar, N.T., 1993. Paleovegetation studies of New Zealand's climate since the Last Glacial Maximum. In: Wright Jr, H.E., Kutzbach, J.E., Webb III, T., Ruddiman, W.F., Street-Parrott, F.A., Bartlein, P.J., (eds), Global Climates since the Last Glacial Maximum, University of Minnesota Press, Minneapolis, p. 294-317. 
McGlone, M.S., Mark, A.F., Bell, D., 1995. Late Pleistocene and Holocene vegetation history, Central Otago, South Island, New Zealand. Journal of the Royal Society of New Zealand, 25: $1-22$.

McGlone, M.S., Turney, C.S.M., Wilmshurst, J.M., 2004. Late-glacial and Holocene vegetation and climatic history of the Cass Basin, central South Island, New Zealand. Quaternary Research, 62: $267-279$.

McGlone, M.S., Duncan, R.P., Heenan, P.B., 2006. Endemism, species selection and the origin and distribution of the vascular plant flora of New Zealand. Journal of Biogeography, 28: 199-216.

McGlone, M.S., Newnham, R.M., Moar, N.T., 2010. The vegetation cover of New Zealand during the Last Glacial Maximum: Do pollen records under-represent woody vegetation? Terra Australis, 32: 49-68.

McGregor, G.R., 1981. Weathering characteristics of Late Pleistocene tills. New Zealand Journal of Geology and Geophysics, 24: 107-113.

McLea, W. L., 1996. The late-Quaternary pollen record of south-east Nelson, South Island, New Zealand. New Zealand Journal of Botany ${ }_{2} 34:$ 523-538.

McQueen, D.R., 1993. A review of interactions between naturalised woody plants and indigenous vegetation in New Zealand. Tuatara, 32: 32-55.

McSaveney, M.J., Griffiths, G.A., 1983. Distribution of mean annual precipitation across some steepland regions of New Zealand. New Zealand Journal of Science, 26: 197-209.

McSweeny, G.D., 1982. Matai/Totara flood plain forest in south Westland. New Zealand Journal of Ecology, 5: 121-128.

Mew, G, Hunt, J.L, Froggart, P.C, Eden, D.N, Jackson, R.J, 1986. An occurrence of Kawakawa Tephra from the Grey River valley, South Island, New Zealand. New Zealand Journal of Geology and Geophysics, 29: 315-322.

Meyer, H.W., 1992. Lapse rates and other variables applied to estimating peleoaltitudes from fossil floras. Palaeogeography, Palaeoclimatology, Palaeoecology, 99: 71-99.

Mildenhall, D.C., 1976. Exotic pollen rain on the Chatham Islands during the last Pleistocene. New Zealand Journal of Geology and Geophysics, 19: 327-332. 
Mildenhall, D.C, 1980. New Zealand Late Cretaceous and Cenozoic plant biogeography: a contribution. Palaeogeography, palaeoclimatology, palaeoecology. 31: 197-233.

Mildenhall, D.C., 2001. Pollen analysis of Pliocene-Pleistocene Kowai Formation (Kurow Group), Mackenzie Basin, South Canterbury, New Zealand, New Zealand Journal of Geology and Geophysics, 44: 97-104.

Mildenhall, D.C., 2003. Deep-sea record of Pliocene and Pleistocene terrestrial palynomorphs from offshore eastern New Zealand (ODP site 1123, Leg 181). New Zealand of Geology and Geophysics, 46: 343-361.

Mildenhall, D.C, Pocknall, D.T, 1983. Palaeobotanical evidence for changes in Miocene and Pliocene climates of New Zealand. In: Vogel, J.C., (ed), Late Cainozoic palaeoclimates of the Southern Hemisphere. A.A. Balkema, Rotterdam, p. 159-171.

Mildenhall, D.C., Hollis, C.J., Naish, T.R., 2004. Orbitally-influence vegetation record of the MidPleistocene Climate Transition, offshore eastern New Zealand (ODP Leg 181, Site 1123). Marine Geology, 204: 87-111.

Mix, A.C., Bard, E., Schneider, R., 2001. Environmental processes of ice age: land, oceans, glaciers (EPILOG). Quaternary Science Reviews, 20: 627-657.

Moar, N.T, 1967. Contributions to the Quaternary history of the New Zealand flora. 5. Pollen diagrams from No Man's Land bog, northern Ruahine Range. New Zealand Journal of Botany, 5: 394-399.

Moar, N.T., 1970. Recent pollen spectra from three localities in the South Island, New Zealand. New Zealand Journal of Botany, 8: 210-221.

Moar, N.T., 1971. Contributions to the Quaternary history of the New Zealand flora 6. Aranuian pollen diagrams from Canterbury, Nelson, and North Westland, South Island. New Zealand Journal of Botany, 9: 80-145.

Moar, N.T., 1973. Contributions to the Quaternary history of the New Zealand flora 7. Two Aranuian pollen diagrams from central South Island. New Zealand Journal of Botany, 11: 291-304.

Moar, N.T., 1980. Late Otiran and early Aranuian grassland in central South Island. New Zealand Journal of Ecology, 3: 4-12. 
Moar, N.T, 1993. Pollen grains of New Zealand dicotyledonous plants. Manaaki Whenua Press, Lincoln, p 200.

Moar, N.T., Suggate, R.P., 1996. Vegetation history from the Kaihinu (last) interglacial to the present, west coast, South Island, New Zealand. Quaternary Science Reviews 15: 521-547.

Moar, N.T., Suggate, R.P., Barrows, C., 2008. Environments during the Kaihinu Interglacial and Otira Glaciation, coastal north Westland, New Zealand. New Zealand Journal of Botany, 46: 49-63.

Molly, B.P.J., Burrows, C.J., Cox, J.E., Johnston, J.A., Wardle, P., 1963. Distribution of subfossil forest remains in eastern South Island, New Zealand. New Zealand Journal of Botany, 1: 6877.

Molnar, P., Atwater, T., Mammertycx, J., Smith, S.M., 1975. Magnetic anomalies, bathymetry and the tectonic evolution of the South Pacific since the late Cretaceous. Geophysical Journal of the Astronomical Society, 40: 383-420.

Moore, P.D., Webb, J.A., Collinson, M.E., 1991. Pollen analysis: second edition. Blackwell Scientific Publication, London, p. 216.

Moreno, P.I., León, A.L., 2003. Abrupt vegetation changes during the last glacial to Holocene transition in mid-latitude South America. Journal of Quaternary Science, 18: 787-800.

Muller, J., Kylander, M., Wüst, R.A.J., Weiss, D., Martinez-Cortizas, A., Legrande, A.N., Jennerjahn, T., Behling, H., Anderson, W.T., Jacobson, G., 2008. Possible evidence for wet Heinrich phases in tropical NE Australia: The Lynch's Crater deposit. Quaternary Reviews, 27: 468-475.

Myers, H,W., 1973. Lapse rates and other variables applied to estimating paleoaltitudes from fossil floras. Palaeogeography, Palaeoclimatology, Palaeoecology, 99: 71-99.

Naish, T.R., and Kamp, P.J.J., 1997. High-resolution sequence stratigraphy of $6^{\text {th }}$ order (41 ka) Plio-Pliestocene cyclothems, Wanganui Basin, New Zealand: A case for the regressive system tract. Geological Society of America Bulletin, 109: 978-999.

Naish, T.R., Abbott, S.T., Alloway, B.V., Beus, A.G., Carter, R.M., Edwards, A.R., Journeaux, T.D., Kamp, P.J.J., Pillans, B.J., Saul, G., Woolfe, K.J., 1998. Astronomical calibration of a Southern Hemisphere Plio-Pleistocene reference section, Wanganui Basin, New Zealand, Quaternary Science Reviews, 17: 695-710. 
Nelson, C.S., Cooke, P.J., 2001. History of oceanic front development in the New Zealand sector of the Southern Ocean during the Cenozoic - a synthesis. New Zealand Journal of Geology and Geophysics, 44: 535-553.

Nelson, C.S., Hendy, C.H., Jarrett, G.R., Cuthbertson, A.M., 1985. Near-synchroneity of New Zealand alpine glaciations and Northern Hemisphere continental glaciations during the past 750 ka. Nature, 318: 361-363.

Nelson, C.S., Hendy, C.H., Cuthbertson, A.M., Jarrett, G.R., 1986. Late Quaternary carbonate and isotope stratigraphy, subantarctic Site 594, southwest Pacific. In: Kennett, J.P., von der Borch, C.C., (eds), Initial reports of Deep Sea Drilling Project, pp 1425-1436. U.S Government Printing Office, Washington DC, 90: 1425-1436.

Nelson, C.S., Cooke, P.J., Hendy, C.H., Cuthbertson, A.M., 1993. Oceanographic and climatic changes over the past 160,000 years at Deep Sea Drilling Project Site 594 off southeastern New Zealand, Southwest Pacific Ocean. Paleoceanography, 8: 435-458.

Nesje, A., Bjune, A.E., Bakke, J., Olaf Dahl, S., Lie, Ø., Birks, H.J.B., 2006. Holocene palaeoclimate reconstructions at Vanndalsvatnet, western Norway, with particular reference to the 8200 cal. Yr BP event. The Holocene, 16: 717-729.

New Zealand National Climate Centre, 2001. Overview of New Zealand's Climate. (online). Available from http://www.niwa.cri.nz/edu/resources/climate/overview [accessed 10th June 2008].

New Zealand National Climate Centre, 2010. The National Climate Database. (online). Available from. http://cliflo.niwa.co.nz/ [accessed $2^{\text {nd }}$ February 2010].

Newnham, R.M., 1992. A 30000 year pollen, vegetation and climate record from Otakairangi (Hikurangi), Northland, New Zealand. Journal of Biogeography, 19: 541-554.

Newnham, R.M., Lowe, D.J., 2000. Fine-resolution pollen record of late-glacial climate reversal from New Zealand. Geology, 28: 759-762.

Newnham, R.M., Lowe, D.J., Green, J.D., 1989. Palynology, vegetation and climate of the Waikato lowlands, North Island, New Zealand, since c. 18000 years ago. Journal of the Royal Society of New Zealand, 19: 127-150.

Newnham, R.M., Lowe, D.J., Williams, P.W., 1999. Quaternary environmental change in New Zealand: a review. Progress in Physical Geography, 23: 567-610. 
Newnham, R.M., Eden, D.N., Lowe, D.J., Hendy, C.H., 2003. Rerewhakaaitu Tephra, a land-sea marker for the Last Termination in New Zealand, with implications for global climate change. Quaternary Science Reviews, 22: 289-308.

Newnham, R.M., Vandergoes, M.J., Hendy, C.H., Lowe, D.J., Preusser, F., 2007a. A terrestrial palynological record for the last two glacial cycles from southwestern New Zealand. Quaternary Science Reviews, 26: 517-535.

Newnham, R.M., Vandergoes, M.J., Garnett, M.H., Lowe, D.J., Prior, C., Almond, P.C., 2007b. Test of AMS ${ }^{14} \mathrm{C}$ dating of pollen concentrations using tephrochronology. Journal of Quaternary Science 22: 37-51.

Newnham, R.M., Lowe, D.J., Giles, T., Alloway, B.V., 2007c. Vegetation and climate of Auckland, New Zealand, since ca. 32000 cal. Yr ago: support for an extended LGM. Journal of Quaternary Science, 22: 517-534.

Nicol, A., Alloway, B.V., Tonkin, P.J., 1994. Active folding in the Waipara Region of north Canterbury, New Zealand: Implications for Quaternary deformation and landscape evolution. Tectonics, 13; 1327-1344

North Greenland Ice Core Project members, 2004. High-resolution record of Northern Hemisphere climate extending into the last interglacial period. Nature, 431: 147-151.

Norton, D.A., 1985. A multivariate technique for estimating New Zealand temperature normals. Weather and Climate, 5: 64-74.

Norton, D.A., McGlone, M.S., Wigley, T.M., 1986. Quantitative analysis of modern pollen-climate relationships in New Zealand indigenous forest. New Zealand Journal of Botany, 24: 331342.

Norton, D.A., Leathwick, J.R., 1990. The lowland vegetation pattern, south Westland, New Zealand 1. Saltwater Ecological Area. New Zealand Journal of Botany, 28: 41-51.

Ogden, J., Basher, L., McGlone, M., 1998. Fire, forest regeneration and links with early human habitation: evidence from New Zealand. Annals of Botany, 81: 687-696.

Pahnke, K., Zahn, R., 2005. Southern Hemisphere water mass conversion linked with the North Atlantic climate variability. Science, 307: 948-952. 
Pahnke, K., Zahn, R., Elderfield, H., Schulz, M., 2003. 340,000-year centennial-scale marine record of Southern Hemisphere climatic oscillation. Science, 301: 948-952.

Patel, R.N., 1968. Wood anatomy of podocarpaceae indigenous to New Zealand: 3. Phyllocladus. New Zealand Journal of Botany, 6: 3-8.

Pelejero, C., Calvo, E., Barrows, T.T., Logan, G.A., De Deckker, P., 2006. South Tasman Sea alkenone paleothermometry over the last four glacial/interglacial cycles, Marine Geology, 230: 73-86.

Petit, J.R., Jouzel. J., Raynaud, D., Barkov, N.I., Basile, I., Bender, M., Chappellaz, J., Davies, M., Delay, G., 1998. Climate and atmospheric history of the past 420,000 years from the Vostock ice core, Antarctica. Nature, 399: 29-436.

Pillans, B. J., McGlone, M.S., Palmer, A.S., Mildenhall, D., Alloway, B.V., Berger, G.W., 1993. The last glacial maximum in central and southern North Island, New Zealand: a palaeoenvironmental reconstruction using the Kawakawa Tephra formation as a chronostratigraphic marker. Palaeogeography, Palaeoclimatology, Palaeoecology, 101: 283304.

Pocknall, D.T., 1982. Modern pollen spectra from mountain localities, South Island, New Zealand. New Zealand Journal of Botany, 20: 361-371.

Pole, M, 1994. The New Zealand Flora-Entirely Long-Distance Dispersal? Journal of Biogeography, 21: 625-635.

Poole, A.L., Adam, N.M., 1964. Trees and Shrubs of New Zealand. Government Printer, Wellington, p. 256.

Porter, S.C., 1975a. Glaciation limit in New Zealand Southern Alps. Arctic and Alpine Research, 7: 33-37.

Porter, S.C., 1975b. Equilibrium-line altitudes of late Quaternary glaciers in the Southern Alps, New Zealand. Quaternary Research, 5: 27-47.

Preusser, F., Andersen, B.G., Denton, G.H., Schlüchter, C., 2005. Luminescence chronology of late Pleistocene glacial deposits in north Westland, New Zealand. Quaternary Science Reviews, 24: 2207-2227. 
Prokopenko, A.A., Khursevich, G.K., Kuzmin, M.I., Kawai, T., 2009. Productivity cycles in Lake Hovsgol, NW Mongolia, during the last $1 \mathrm{Ma}$ and the age model of the HDP-04 drill core record. Quaternary International, 205: 111-125.

Putnam, A.E., Schaefer, J.M., Barrell, D.J.A., Vandergoes, M., Denton, G.H., Kaplan, M.R., Finkel, R.C., Schwartz, R., Goering, B.M., Kelly, S.E., 2010a. In situ cosmogenic ${ }^{10}$ Be productionrate calibration from the Southern Alps, New Zealand. Quaternary Geochronology, 5: 392409.

Putnam, A.E., Denton, G.H., Schaefer, J.M., Barrell, D.J.A., Andersen, B.G., Finkel, R.C., Schwartz, R., Doughty, A.M., Kaplan, M.R., Schlüchter, C., 2010b. Glacial advance in southern middle-latitudes during the Antarctic Cold Reversal. Nature Geoscience, 3: 700704.

Rawle, A., 2011. Basic Principles of particle size analysis. (online). Available from http://www.beatop.com/Articles/Basic_principles_of_particle_size_analysis.pdf [accessed 10th June 2008].

Raymo, M.E., 1997. The timing of major climate terminations. Paleoceanography, 12: 577-585.

Reif, A., Allen, R.B., 1988. Plant communities of the steepland conifer-broadleaved harwood forest of central Westland South Island New Zealand. Phytocoenologia, 16: 145-2224.

Reimer, P. J., Baillie, M. G. L., Bard, E., Bayliss, A., Beck, J. W., Blackwell, P. G., Bronk Ramsey, C., Buck, C. E., Burr, G. S., Edwards, R. L., Friedrich, M., Grootes, P. M., Guilderson, T. P., Hajdas, I., Heaton, T. J., Hogg, A. G., Hughen, K. A., Kaiser, K. F., Kromer, B., McCormac, F. G., Manning, S. W., Reimer, R. W., Richards, D. A., Southon, J. R., Talamo, S., Turney, C. S. M., van der Plicht, J., \& Weyhenmeyer, C. E., 2009. IntCal09 and Marine09 radiocarbon age calibration curves, 0-50,000 years cal BP. Radiocarbon, 51: 1111-1150.

Renwick, J.A., (in press). Kidson's synoptic weather types and surface climate variability over New Zealand. Weather and Climate.

Robinson, L.F., Henderson, G.M., Hall, I., Matthew, I., 2004. Climate control of riverine and seawater uranium-isotope ratios. Science, 305: 851-854.

Rojas, M., Moreno, P.I., Kageyama, M., Crucifix, M., Hewitt, C., Abe-Ouchi, A., Ohgaito, R., Brady, E.C., Hope, P., 2009. The southern westerlies during the last glacial maximum in PMIP2 simulations. Climate Dynamics, 32: 525-548. 
Russell, J. L., Gnanadesikan, A., Stouffer, R.J., Toggweiler, J.R., 2006. The Southern Hemisphere westerlies in a warming World: propping open the door to the deep ocean. Journal of Climate, 19: 6382-6390.

Ryan, M.R., Dunbar, G.B., Hannah, M.J., Neil, H.L., Bostock, H., Vandergoes, M.J., 2009. A 210KA terrestrial palynomorph record from a marine sediment core, West Coast, South Island. p.183 In: Barrell, D.J.A., Tulloc, A.J (eds) Geological Society of New Zealand and New Zealand Geophysical Society Joint Annual Conference, Oamaru, 23-27 November 2009: program and abstracts. Geological Society of New Zealand miscellaneous publication 128A.

Sakai, A., Wardle, P., 1978. Freezing resistance of New Zealand trees and shrubs. New Zealand Journal of Ecology, 1: 51-61.

Salinger, M.J., 1980a. New Zealand climate: I. Precipitation patterns. Monthly Weather Reviews, 108: $1892-1904$.

Salinger, M.J., 1980b. New Zealand climate: II. Temperature patterns. Monthly Weather Review, 108: 1905-1912.

Salinger , M.J., Mullan, A.B., 1999. New Zealand climate: Temperature and precipitation variations and their links with atmospheric circulation 1930-1994. International Journal of Climatology, 19: 1049-1071.

Sandiford, A., Newnham, R.M., Alloway, B., Ogden, J., 2003. A $28000-7600$ cal yr BP pollen record of vegetation and climate change from Pukaki Crater, northern New Zealand. Palaeogeography, Palaeoclimatology, Palaeoecology, 201: 235-247.

Schaefer, J.M., Denton, G.H., Barrell, D.J.A., Ivy-Ochs, S., Kubic, P.W., Anderson, B.G., Phillips, F.M., Lowell, T.V., Schluchter, C., 2006. Mid-latitude moraines reveal near-synchronous interhemispheric termination of the Last Glacial Maximum. Science, 312, 1510-1513.

Schaefer, J.M., Denton, G.H., Kaplan, M., Putnam, A., Finkel, R.C., Barrell, D.J.A., Anderson, B.G., Schwartz, R., Mackintosh, A., Chinn, T., Schluchter, C., 2009. High-frequency Holocene glacier fluctuations in New Zealand differ from the northern signature. Science, 324: 622625.

Schmittner, A., Saenko, O.A., Weaver, A.J., 2003. Coupling of the hemispheres in observations and simulations of glacial climate change. Quaternary Science Reviews, 22: 659-671. 
Self, S., 1983. Large-scale phreatomagmatic silicic volcanism: a case study from New Zealand. Journal of Volcanology and Geothermal Research, 17: 433-469.

Shepherd M.J., Price, D.M., 1990. Thermoluminescence dating of late Quaternary dune sand, Manawatu/Horowhenua area, New Zealand: a comparison with ${ }^{14} \mathrm{C}$ age determinations. New Zealand Journal of Geology and Geophysics, 33: 535-539.

Shichi, K, Kawamuro, K, Takahara, H, Hase, Y, Maki, T, Miyoshi, N, 2007. Climate and vegegation changes around Lake Baikal during the last 350,000 years. Palaeogeography, Palaeoclimatology, Palaeoecology, 248: 357-375.

Shulmeister, J., McKay, R., Singer, C., McLea, W., 2001. Glacial geology of the Cobb Valley, northwest Nelson. New Zealand Journal of Geology and Geophysics, 44: 47-54.

Shulmeister, J., Goodwin, I., Renwick, J., Harle, K., Armand, L., McGlone, M.S., Cook, E., Dodson, J., Hesse, P.P., Mayewski, P., 2004. The Southern Hemisphere westerlies in the Australasian sector over the last glacial cycle: a synthesis. Quaternary International, 118119: 23-53.

Shulmeister, J., Fink, D., Augustinus, P.C., 2005. A cosmogenic nuclide chronology of the last glacial transition in North-West Nelson, New Zealand - new insights in Southern Hemisphere climate forcing during the last deglaciation. Earth and Planetary Science Letters, 233: 455466.

Shulmeister, J., Davies, T.R., Evans, D.J.A., Hyatt, O.M., Tovar, D.S., 2009. Catastrophic landslides, glacier behaviour and moraine formation - A view from an active plate margin. Quaternary Science Reviews, 28: 1085-1096.

Singer, C., Shulmeister, J., McLea, B., 1998. Evidence against a significant Younger Dryas cooling event in New Zealand. Science, 281: 812-814.

Singer, B., Hildreth, W., Vincze, Y., 2000. ${ }^{40} \mathrm{Ar} /{ }^{39} \mathrm{Ar}$ evidence for early deglaciation of the central Chilean Andes. Geophysical Research Letters, 27: 1663-1666.

Soons, J.M., 1979. Late Quaternary environments in the central South Island of New Zealand. New Zealand Geographer, 35: 16-23.

Soons, J.M., Barrows, C.J., 1978. Dates for Otiran deposits, including plant micro-fossils and macrofossils, from Rakaia Valley. New Zealand Journal of Geology and Geophysics, 21: 607-615. 
Soons, J.M, Selby, M.J, (eds) 1992. Landforms of New Zealand. 2nd edition, Longman, Auckland, p. 404.

Stewart, R.B., Neall, V.E., 1984. Chronology of palaeoclimatic change at the end of the last glaciation. Nature, 311: 47-48.

Stocker, T.F., 2000. Past and future reorganizations in the climate system. Quaternary Science Reviews, 19: 301-319.

Stocker, T.F., Johnsen, S.J., 2003. A minimum thermodynamic model for the bipolar seesaw. Palaeoceanography, 18: 1087.

Strelin, J.A., Malagnino, E.C., 2000. Late-Glacial history of Largo Argentino, Argentina, and age of the Puerto Bandera moraines. Quaternary Research, 54: 339-347.

Sudgen, D.E., Bentley, M.J., Fogwill, C.J., Hulton, N.R.J., McCulloch, R.D., Purves, R.S., 2005. Late-Glacial glacier events in southernmost South America: A blend of 'Northern' and 'Southern' Hemispheric climatic signals? Geografiska Annaler, 87A: 273-288.

Suggate, R.P., 1965. Late Pleistocene Geology of the northern part of the South Island, New Zealand. New Zealand Geological Survey Bulletin (new series), $N^{0} 77$. New Zealand Department of Scientific and Industrial Research, Wellington, p. 90.

Suggate, R.P., 1988. Quaternary deposition and deformation in the Buller and tributary valleys. New Zealand Geological Survey Record 25. Department of Scientific and Industrial Research, Lower Hutt, p. 51.

Suggate, R.P., 1990. Late Pliocene and Quaternary glaciations of New Zealand, Quaternary Science Review, 9: 175-197.

Suggate, R.P., Almond, P.C., 2005. The Last Glacial Maximum (LGM) in western South Island, New Zealand: implications for the global LGM and MIS 2. Quaternary Science Reviews, 24: 1923-1940.

Sun, Y., Clemans, S.C., An, Z., Yu, Z., 2005. Astronomically tuned Plio-Pleistocene benthic $\delta^{18} \mathrm{O}$ record from southern China Sea and Atlantic-Pacific comparison. Earth Planetary Science Letters, 203: 1015-1029. 
Sutherland, R., Kim, K., Zondervan, A, McSaveney, M., 2007. Orbital forcing of mid-latitude Southern Hemisphere glaciations since $100 \mathrm{ka}$ inferred from cosmogenic nuclide ages of moraine boulders from the Cascade Plateau, southwest New Zealand. Geological Society of America Bulletin, 119: 443-451.

Taylor, R.E., Kra, R., Long, A., (Eds.), 1992. Radiocarbon after four decades: An interdisciplinary perspective. Springer, New York

Teldford, R.J., Heegaard, E., Birks, H.J.B., 2004. All age-depth models are wrong: but how badly? Quaternary Science Reviews, 23: 1-5.

Ter Braak, C.J.F., 1987. The analysis of vegetation-environmental relationships by canonical correspondence analsysis. Vegetatio, 69; 69-77.

Ter Braak, C.J.F., 1995. Non-linear methods for multivariate statistical calibrartion and their use in palaeoecology: a comparison of inverse ( $k$-nearest neighbours, partial least squares and weighted averaging partial least squares) and classical approaches. Chemometrics and Intelligent Laboratory Systems, 28: 165-180.

Ter Braak, C.J.F., Juggins, S., 1993. Weighted averaging partial least squares regression (WAPLS): an improved method for reconstructing environmental variables from species assemblages. Hydrobiologia, 269/270: 485-502.

Tomezak, M., Godfrey, J.S., 1994. Regional oceanography: an introduction. Pergamon, Oxford. p. 422.

Tovar, D.S., Shulmeister, J., Davies, T.R., 2008. A landslide origin of the New Zealand's Waiho Loop Moraine. Nature Geoscience, 1: 524-526.

Turney, C.S.M., McGlone, M.S., Wilmshurst, J.M., 2003. Asynchronous climate change between New Zealand and the North Atlantic during the last deglaciation. Geology, 31: 223-226.

Turney, C.S.M., Kershaw, A.P., Clemens, S.C., Branch, N., Moss, P.T., Fifield, L.K., 2004. Millennial and orbital variations of El Niño/Southern Oscillation and high-latitude climate in the last glacial period. Nature, 428: 306-310.

Turney, C.S.M., Scourse, J., Rodbell, D., 2007. Quaternary climatic, environmental and archaeological change in Australasia. Journal of Quaternary Science, 22: 421-422. 
Uncel, I., Bjorck, S., Wohlfarth, B., 2008. Deglacial environmental change on Isla de los Estados (54.4 degrees S), southeastern Tierra del Fuego. Quaternary Science Reviews, 27: 15411554.

Vacco, D.A., Alley, R.B., Pollard, D., 2010. Glacial advance and stagnation caused by rock avalanches. Earth and Planetary Science Letters, 294: 123-130.

Vandergoes, M. J., Fitzsimons, S.J., 2003. The Last Glacial-Interglacial Transition (LGIT) in south Westland, New Zealand: paleoecological insight into mid-latitude Southern Hemisphere climate change. Quaternary Science Reviews, 22: 1461-1476.

Vandergoes, M.J, Prior, C.A, 2003. AMS Dating of Pollen Concentrates-A Methodological Study of Late Quaternary Sediments from South Westland, New Zealand. Radiocarbon, 45: 479491.

Vandergoes, M., Barrell, D., 2008. Report on proceedings of June 2008 Australasian-INTIMATE Meeting. (online). Available from. http:// www.paleoclimate.org.nz [accessed $2^{\text {nd }}$ February 2010].

Vandergoes, M. J., Newnham, R.M., Preusser, F., Hendy, C.H., Lowell, T.V., Fitsimons, S.J., Hogg, A.G., Kasper, A.U., Schlüchter, C., 2005. Regional insolation forcing of late Quaternary climate change in the Southern Hemisphere. Nature, 436: 242-245.

Vandergoes, M.J., Dieffenbacher-Krall, A.C., Newnham, R.M., Denton, G.H, Blaauw, M., 2008. Cooling and changing seasonality in the Southern Alps, New Zealand during the Antarctic Cold Reversal. Quaternary Science Reviews, 27: 589-601.

Vandergoes, M.J., Hogg, A.G., Lowe, D.J., Newnham, R.M., Denton, G.H., Barrell, D., Almond, P.C., Allan, A., Wilson, C.J., 2011. Refining the age of the Kawakawa/Oruanui tephra in New Zealand. XVIII INQUA Congress, Bern, Swizterland, $21^{\text {st }}$ to $27^{\text {th }}$ July

Veblen, T.T., Stewart, G.H., 1982. On conifer regeneration gap in New Zealand- the dynamics of Libocedrus bidwilli stands on South Island. New Zealand Journal of Botany, 70: 413-436.

Walker, M.J.C., 2005. Quaternary Dating Methods. John Wiley and Sons, Chichester, p. 286. 
Walker, M., Johnsen, S., Rasmussen, S.O., Popp, T., Steffensen, J-P., Gibbard, P., Hoek, W., Lowe, J., Andrews, J., Björk, S., Cwynar, L.C., Hughen, K., Kershaw, P., Kromer, B., Litt, T., Lowe, D.J., Nakagawa, T., Newnham, R., Schwander, J., 2009. Formal definition and dating of the GSSP (Global Stratotype Section and Point) for the base of the Holocene using the Greenland NGRIP ice core, and selected auxiliary records. Journal of Quaternary Science, 24: 3-17.

Walcott, R.I., 1984. Reconstructions of the New Zealand region for the Neogene. Palaeogeography, Palaeoclimatology, Palaeoecology, 46: 217-231.

Ward, J., Talbot, J., 1984. Distribution of aquatic macrophytes in Lake Alexandrina, New Zealand. New Zealand Journal of Marine and Freshwater Research, 75: 211-220.

Wardle, P., 1965. A comparison of alpine timber lines in New Zealand and North America. New Zealand Journal of Botany, 3: 113-135.

Wardle, P., 1969. Biological flora of New Zealand 4. Phyllocladus alpinus Hook F (Podocarpaceae) Mountain Toatoa, Celery Pine. New Zealand Journal of Botany, 7: 79-95.

Wardle,P., 1973. New Zealand timberlines. Arctic and Alpine Research, 5: A127-A135.

Wardle, P., 1974. The kahikatea (Dacrycarpus dacrydioides) forest of south Westland. Proceedings of the New Zealand Ecological Society, 21; 62-71.

Wardle, P., 1975. Vascular plants of Westland National Park (New Zealand) and neighbouring lowland and coastal areas. New Zealand Journal of Botany, 13: 487-545.

Wardle, P., 1977. Plant communities of Westland National Park (New Zealand) and neighbouring lowland and coastal areas. New Zealand Journal of Botany, 15: 323-398.

Wardle, P., 1978. Further radiocarbon dates from Westland National Park and the Omoeroa River mouth, New Zealand. New Zealand Journal of Botany, 16: 147-152.

Wardle, P., 1980. Primary succession in Westland National Park and its vicinity, New Zealand. New Zealand Journal of Botany, 18: 221-232.

Wardle, P., 1985. New Zealand Timberlines. 3. A synthesis. New Zealand Journal of Botany, 23: 263-271.

Wardle, P., 1991. Vegetation of New Zealand. Cambridge University Press, Cambridge, p. 694. 
Wardle, P., Campbell, A.D., (1976) Winter dormancy in seedlings of mountain beech (Nothofagus solandri var. cliffortiodes) near timber line. New Zealand Journal of Botany, 14: 183-186.

Warren, G., 1967. Sheet 17 Hokitika ( $1^{\text {st }}$ ed). Geological Map of New Zealand 1:250 000. New Zealand Department of Scientific and Industrial Research, Wellington.

Waters, J.M., Craw, D., 2006. Goodbye Gondwana? New Zealand biogeography, geology and the problem of circularity. Systematic Biology, 55: 351-356.

Weaver, P.P.E., Carter, L., Niel, H.A., 1998 Response of surface water masses and circulation to Late Quaternary climate change east of New Zealand. Paleoceanography, 13: 70-83.

Wells, A., Duncan, R.P., Stewart, G.H., 2001. Forest dynamics in Westland, New Zealand: the importance of large, infrequent earthquake-induced disturbance. Journal of Ecology, 89: 1006-1018.

Williams, P.W., King, D.N.T., Zhao, J-X., Collerson, K.D., 2005. Late Pleistocene to Holocene composite speleothems ${ }^{18} \mathrm{O}$ and ${ }^{13} \mathrm{C}$ chronologies from South Island, New Zealand- did a global Younger Dryas really exist? Earth and Planetary Science Letters, 230: 301-317.

Williams, P.W., Neil, H.L., Zhao., J-X., 2010. Age frequency distribution and revised stable isotope curves for New Zealand speleothems: palaeoclimatic implications. International Journal of Speleology, 39: 99-112.

Wilson, C. J. N., Switsur, V.R., Ward, A.P., 1988. A new 14C age for the Oruanui (Wairakei) eruption, New Zealand. Geology magazine, 125: 297-300.

Wilson, C.J.N., Houghton, B.F., McWilliams, M.O., Lanphere, M.A., Weaver, S.D., Briggs, R.M., 1995. Volcanic and structural evolution of Taupo Volcanic Zone, New Zealand: a review. Journal of Volcanology and Geothermal Research, 68: 1-28.

Wilmshurst, J.M., McGlone, M.S., Leathwick, J.R., Newnham, R.M., 2007. A pre-deforestation pollen-climate calibration model for New Zealand and quantitative temperature reconstructions for the past 18000 years BP. Journal of Quaternary Science, 22: 535-547.

Whittaker, T.E., Hendy, C.H., Hellstrom, J.C., 2011. Abrupt millennial-scale changes in intensity of Southern Hemisphere westerly winds during marine isotope stages 2-4. Geology, 39: 455458. 
Woodward, C.A., Shulmeister, J., 2007. New Zealand chironomids as proxies for human-induced and natural environmental change: transfer function for temperature and lake production (chlorophyll a). Journal of Paleolimnology, 36: 407-429.

Wright, I.C., McGlone, M.S., Nelson, C.S., Pilans, B.J., 1995. An integrated latest Quaternary (stage 3 to present) paleoclimatic and paleoceanographic record from offshore northern New Zealand. Quaternary Research, 44: 283-293. 


\section{Appendices}

\section{Appendix A}

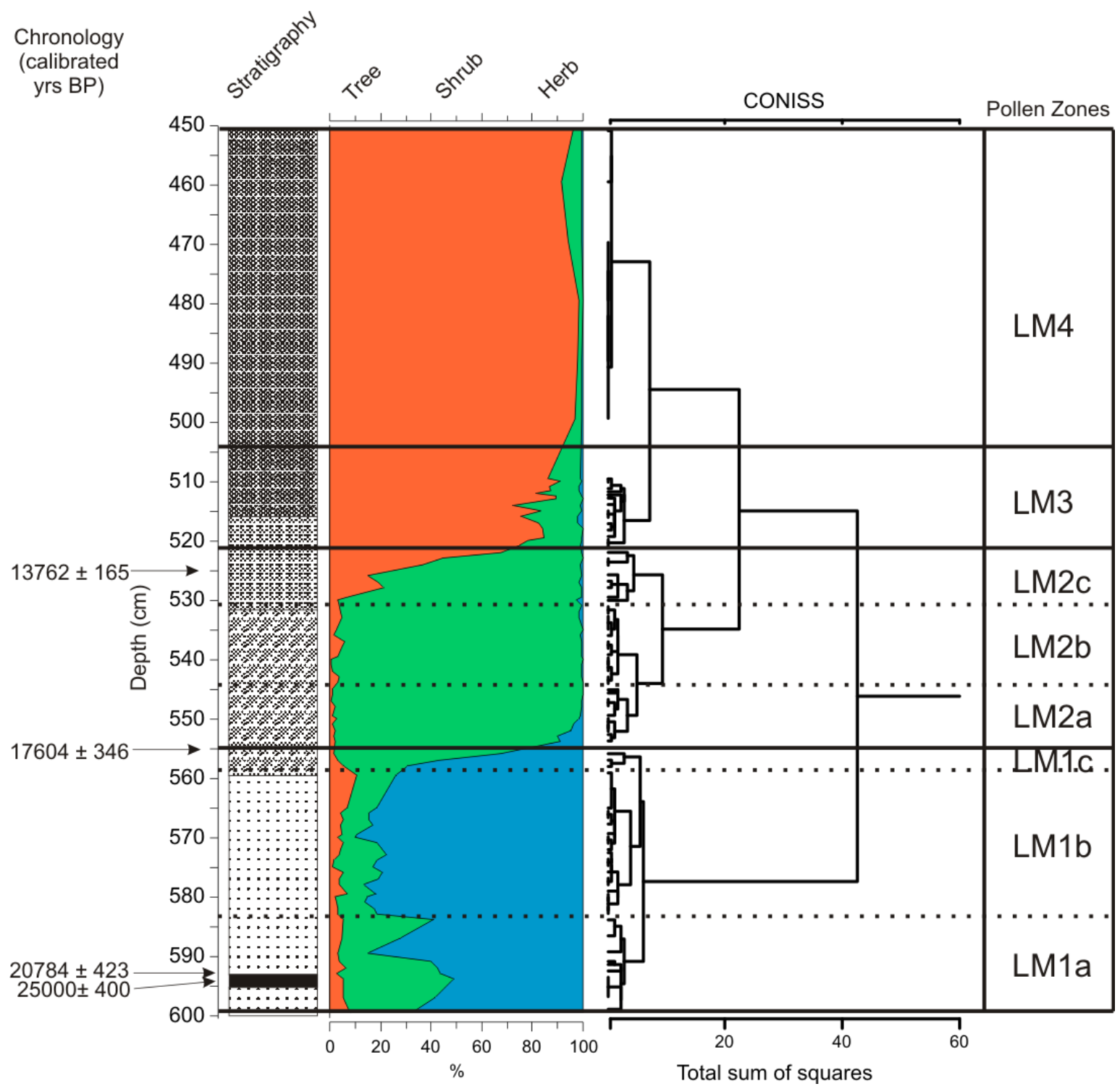

Appendix A: Lake Mudgie CONISS results on a depth scale with the sediment stratigraphy and pollen summary diagram. 


\section{Appendix B}

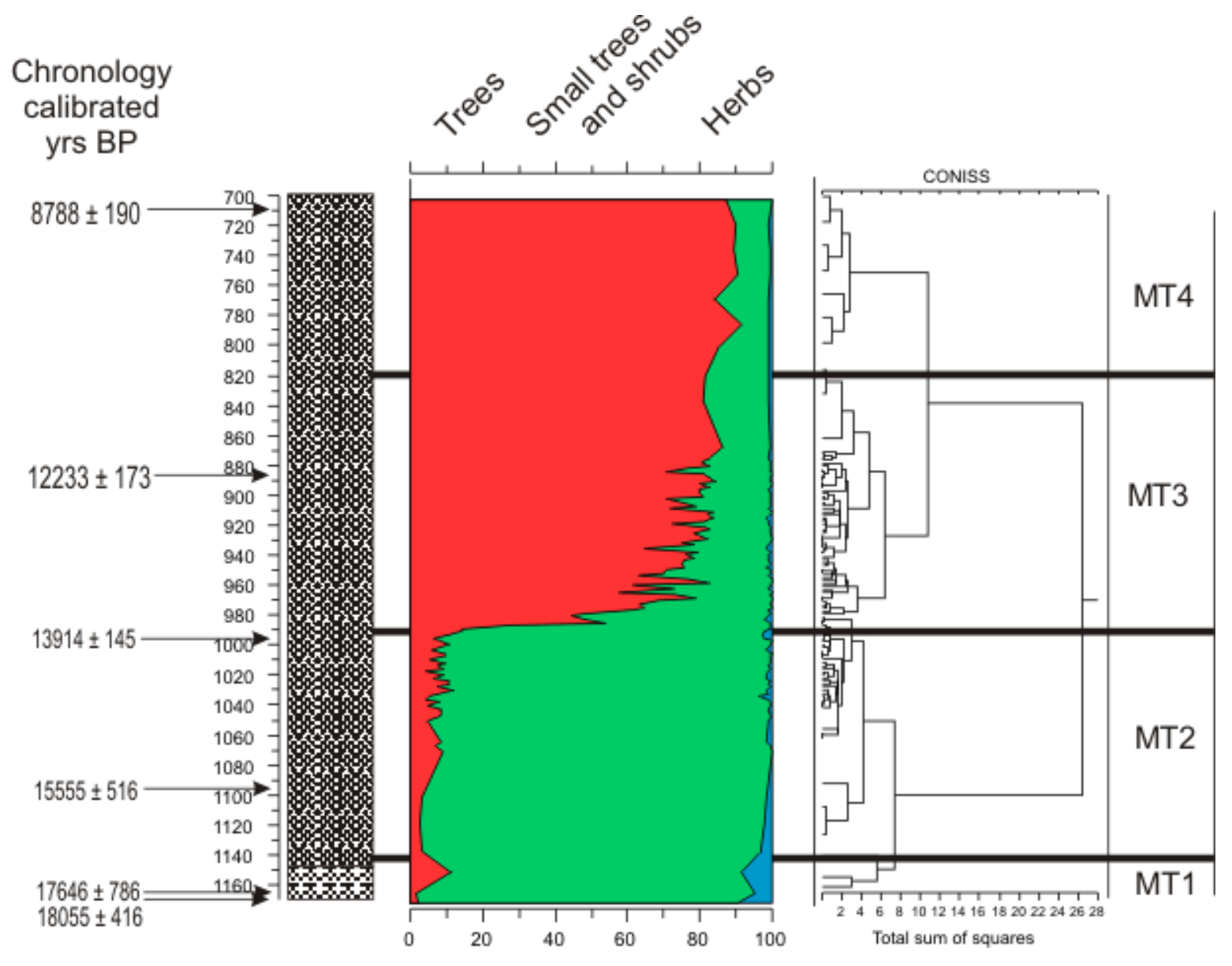

Appendix B: Manks Tarn CONISS results on a depth scale with the sediment stratigraphy and pollen summary diagram. 
Appendix G

\begin{tabular}{|c|c|c|c|c|c|c|c|c|c|c|}
\hline $\begin{array}{l}\text { Site and site } \\
\text { code }\end{array}$ & $\mathrm{SiO}_{2}$ & $\mathrm{TiO}_{2}$ & $\mathrm{Al}_{\mathrm{s}} \mathrm{O}_{3}$ & $\mathrm{FeO}$ & $\mathrm{MgO}$ & $\mathrm{CaO}$ & $\mathrm{Na}_{2} \mathrm{O}$ & $\mathrm{K}_{2} \mathrm{O}$ & $\mathrm{Cl}$ & Total \\
\hline Howard Valley & 77.4 & 0.19 & 12.6 & 1.25 & 0.14 & 1.03 & 4.03 & 3.15 & 0.22 & 95.43 \\
\hline H3/5/37-38 & 0.76 & 0.12 & 0.46 & 0.22 & 0.07 & 0.25 & 0.27 & 0.43 & 0.06 & 4.42 \\
\hline Howard Valley & 77.3 & 0.17 & 12.7 & 1.21 & 0.14 & 1.09 & 4.16 & 3.09 & 0.21 & 94.52 \\
\hline $\mathrm{H} 3 / 6 / 40-41$ & 0.33 & 0.11 & 0.19 & 0.18 & 0.04 & 0.15 & 0.28 & 0.31 & 0.06 & 1.46 \\
\hline Howard Valley & 77.6 & 0.14 & 12.6 & 1.19 & 0.14 & 1.03 & 4.05 & 3.07 & 0.22 & 94.33 \\
\hline H3/7/43-33 & 0.45 & 0.07 & 0.27 & 0.22 & 0.05 & 0.17 & 0.20 & 0.29 & 0.09 & 2.90 \\
\hline Forks Lagoon & 77.9 & 0.15 & 12.4 & 1.20 & 0.13 & 1.03 & 3.88 & 3.12 & 0.23 & 96.08 \\
\hline 0802/Т3/52 & 0.59 & 0.09 & 0.20 & 0.31 & 0.05 & 0.14 & 0.31 & 0.34 & 0.07 & 1.53 \\
\hline Forks Lagoon & 77.6 & 0.16 & 12.8 & 1.21 & 0.14 & 1.01 & 3.82 & 3.04 & 0.23 & 94.07 \\
\hline 0802/Т3/52.75 & 0.48 & 0.07 & 0.29 & 0.21 & 0.06 & 0.17 & 0.35 & 0.27 & 0.11 & 1.69 \\
\hline AT-331 & 77.4 & 0.15 & 12.6 & 1.19 & 0.14 & 1.08 & 4.06 & 3.08 & 0.21 & 94.71 \\
\hline $\begin{array}{l}\text { (ODP } \\
1123)^{\star}\end{array} \quad$ site & 0.84 & 0.07 & 0.45 & 0.25 & 0.05 & 0.17 & 0.50 & 0.33 & 0.08 & 3.98 \\
\hline \multirow[t]{2}{*}{$\mathrm{KOT}^{\star *}$} & 77.2 & 0.16 & 12.8 & 1.25 & 0.14 & 1.10 & 4.06 & 2.97 & 0.20 & 94.98 \\
\hline & 1.04 & 0.11 & 0.77 & 0.18 & 0.06 & 0.22 & 0.38 & 0.27 & 0.06 & 2.29 \\
\hline
\end{tabular}

Appendix G. Glass geochemistry of mean major element compositions for the KOT layer located in Howard Valley and Forks Lagoon. Analyses normalised to $100 \%$ before calculation of the mean in bold and \pm 2 standard deviations in weight $\%$ in italics. Total refers to the mean total of original electron probe microanalyses before normalisation. ${ }^{* *}$ KOT from Irirangi section, $10 \mathrm{~km}$ south of Waioura. *and ** data from Allan et al (2008). 
